\title{
Die Macht der Artefakte
}

Tanzkleidung und -schmuck auf

Santa Cruz, Salomonen

\author{
Dissertation \\ zur Erlangung des Doktorgrades \\ der Sozialwissenschaftlichen Fakultät \\ der Georg-August-Universität Göttingen
}

vorgelegt von

Oliver Lueb

geboren in Kaldenkirchen

Göttingen, 2018 
Erstbetreuerin:

Weitere Betreuer:
Prof. Dr. Brigitta Hauser-Schäublin

Prof. Dr. Elfriede Hermann

Prof. Dr. Klaus Schneider

21. Oktober 2016 


\section{Vorwort}

Das vorliegende Buch ist in thematischer Hinsicht eine Fortführung meiner Magisterarbeit aus dem Jahr 2008, in der ich ausgehend von ihren visuellen Erscheinungsformen, verschiedene Aspekte von Ahnendarstellung in Asmat im heute indonesischen Teil Neuguineas, untersuchte. Besonders interessierten mich schon damals Fragen danach, was die von den Schnitzern produzierten Artefakte mit den Menschen machten, ihnen bedeuteten und bei ihnen auslösten; welche Rolle die Dinge in Ritualen und im Alltagsleben einnahmen und ob sie darüber hinaus wie auch immer konstruierte Vorstellungen vom Sein und Werden veranschaulichten oder gar beeinflussten. Aufgrund der für längere Forschungsaufenthalte unzureichend stabilen politischen Situation in Papua musste ich damals akzeptieren, dass ich dort keine tiefergehenden und längeren Untersuchungen würde durchführen können. Zwangsläufig war ich für eine weitere Beschäftigung mit der Frage nach der Rolle von Artefakten für menschliches Handeln regional wieder offen, wobei mein persönliches ethnologisches Interesse dem südwestlichen Teil Ozeaniens gilt.

Bei meinem ersten, nur wenige Stunden währenden Aufenthalt als Reisebegleiter eines Kreuzfahrtschiffs auf der Insel Santa Cruz in den Salomonen im Jahr 2009 sah ich verschiedene traditionelle Tänze, bei denen mich gerade die Tanzkleidung und der -schmuck der verschiedenen Tanzgruppen erstaunte. Und zwar deshalb, weil sich ihre Ausstattung augenscheinlich von der anderer Gruppen auf Nachbarinseln zu jener Zeit so überraschend abhob: Sie bestand weitgehend aus Naturmaterialien, war ohne industriell hergestellte Farben gearbeitet und von sehr hoher handwerklicher Qualität, was anderenorts weniger der Fall war. Manche der Artefakte schienen relativ alt und intensiv getragen zu sein.

Wieder zurück in Deutschland, tat sich nach ersten Recherchen ein breites Forschungsfeld auf, da sich andeutete, dass seit den 1970er-Jahren zwar archäologische aber keine ethnologischen Untersuchungen in der Region durchgeführt worden waren, und es lediglich zu der ebenfalls zum Santa-Cruz-Archipel zählenden Insel Tikopia mehr rezente Literatur gab. Nach verschiedenen Gesprächen und Schriftwechseln erklärte sich Frau Prof. Dr. Brigitta 
Hauser-Schäublin bereit, mein Dissertationsvorhaben an der Georg-August-Universität Göttingen zu betreuen.

Im Jahr 2010 beurlaubte mich mein Arbeitgeber, das Kölner Rautenstrauch-Joest-Museum - Kulturen der Welt (RJM), für einen zweimonatigen Survey, um die Forschungsmöglichkeiten vor Ort auszuloten und die Fragestellung durch Recherchen in Museen und Archiven in Neuseeland und Australien zu konkretisieren. Nach einem zweiten Besuch als Reiseleiter im März führte ich, erneut durch das Museum beurlaubt, von Juni bis Dezember 2011 meine Feldforschung durch. In den Jahren 2012 und 2014 besuchte ich zwei weitere Male jeweils für einen halben Tag als Reiseleiter die Insel. Im Laufe dieser fünf Jahre hatte sich mit einigen Personen auf Santa Cruz ein sporadischer Brief-, E-Mail- bzw. Facebook $^{\circledR}$-Kontakt aufgebaut.

Die vorliegende Arbeit wäre nicht ohne die Hilfe und Unterstützung einiger Organisationen und zahlreicher einzelner Personen möglich gewesen. An vorderster Stelle gilt mein ganz besonderer Dank meinen engsten Gesprächspartnern Balu, Namiade, den beiden Me'esa, Yamöli und Mdewöt sowie Sade mit ihren Familien für ihr Vertrauen und ihre Bereitschaft, ihr Wissen mit mir zu teilen sowie ihre fortwährende und großzügige Gastfreundschaft vor Ort. Ohne ihre Unterstützung hätte ich keinen Zugang zu anderen Personen und den Feiern auf Ndendö erhalten - ohne sie wäre die Forschung schlichtweg unmöglich gewesen. Ebenso bedanke ich mich namentlich bei Kabi und Dawi. Nimla kale - awi!

Ich danke meiner ,Doktormutter ${ }^{6}$ Frau Prof. Dr. Hauser-Schäublin für die Annahme meines Forschungsprojektes und die anhaltende Betreuung in den vergangenen Jahren. Ebenso gilt mein Dank meiner Zweitgutachterin Frau Prof. Dr. Elfriede Hermann und meinem dritten Prüfer Herrn Prof. Dr. Klaus Schneider. Letzterer ermöglichte als Direktor des RJM in besonderem Maße die Beurlaubungen für meine Forschungsaufenthalte. Bei den Vorbereitungen, der Durchführung und Aufbereitung meiner Feldforschung standen mir zahlreiche Wissenschaftlerinnen und Wissenschaftler verschiedener Museen, Universitäten und Archive mit Rat und Tat zur Seite. Neben den Kolleginnen des Oberseminars in Göttingen sowie Jo Birks, Liz Bonshek, Grace Hutton, Sean Mallon, Fuli Pereira und Peter Sheppard danke ich vor allem Amiria Salmond für die ermutigenden und Erkenntnis bringenden Diskussionen. Zu guter Letzt gilt mein herzlichster Dank meinem Kölner Kollegen Peter Mesenhöller für seine permanente Bereitschaft, den wachsenden Text immer wieder zu lesen, zu hinterfragen und zu korrigieren.

Für die finanzielle Unterstützung meiner Feldforschungsaufenthalte danke ich namentlich der Museumsgesellschaft RJM e.V., der Dr.-Walther-Liebehenz-Stiftung und dem Institut für Ethnologie der Georg-August-Universität Göttingen (Seniorprofessur Hauser-Schäublin). Bischof George Takeli der Diözese Temotu der Anglican Church of Melanesia ermöglichte es mir, mit der Southern Cross, dem Schiff der Anglican Church of Melanesia, einige Inseln im Santa-Cruz-Archipel zu besuchen.

Soweit nicht anders aufgeführt, stammen die nachfolgenden Fotografien von mir. In meiner Arbeit verwende ich der Lesbarkeit halber für Personengruppen, etwa Zuschauer und 
Teilnehmer, die im Deutschen verwendete maskuline Form, wobei ich damit alle Gender meine. Wenn ich Personenkreise beschreibe, die genderspezifisch unterschiedliche Handlungen ausführen, etwa die Tänzerinnen und Tänzer, verwende ich das entsprechende Genus. Die vorliegende Arbeit gibt mein Verständnis, meine Sicht der Zusammenhänge in den Jahren 2009 bis 2014 wieder; Fehleinschätzungen gehen alleine zu meinen Lasten. 



\section{Inhaltsverzeichnis}

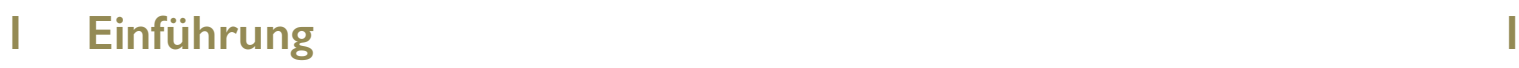

I.I Thema und Fragestellung 3

I.2 Theoretischer Rahmen 6

- Kastom - tradition - kalsa

- Renaissance des Materialisierten oder des Materiellen? 10

- Eigenständige Substanzen werden zu ,Komplizen': Akteur-NetzwerkTheorie (ANT) 13

- Handlungsmacht und Intentionen: ,Art Nexus' 17

$\begin{array}{ll}\text { I.3 Methodisches Vorgehen } 20 & 20\end{array}$

- Kontrollierter historischer Vergleich: Museums- und Archivforschung 21

- Ethnografische Feldforschung 22

I.4 Zugang zum Feld: Reiseführer, Museumsethnologe und,White Man‘ 26

I.5 Aufbau der Arbeit 28

2 Santa Cruz - Geschichte(n) und ihre Folgen 3 |

- Bevölkerung 31

- Linguistische Situation 34

- Interinsularer Handel innerhalb der Santa-Cruz-Gruppe 35

- Europäische Aneignung 37

- Missionierung und lokale Glaubensvorstellungen 40

- Wissenschaftler und ausländische Fachkräfte 44

- Jüngere Geschichte: vom Zweiten Weltkrieg zu den nationalen Unruhen 44

- Föderalismusbestrebungen der Provinz Temotu 47

3 Tanzkleidung und -schmuck als kastom-Konfigurationen 49

3.I Verwendungen des Begriffes kastom auf Ndendö 50

3.2 Historische Erläuterungen zu den kastom-Artefakten und -Tänzen 54

3.3 Aktuelle Anlässe von nelo-Tänzen 61

3.3.I "It's for the gods, our community and all about earnings" 61

3.3.2 "Reviving our culture - our heritage and our destiny“ 67

3.3.3 Messliturgie der Anglican Church of Melanesia 72

3.3.4 Politische Empfänge, Tourismus und ,Art Festivals' 73 
$\begin{array}{lll}3.4 & \text { Zwischenfazit } & 77\end{array}$

4 ,Material Histories ${ }^{6}$ der Tanzkleidung und des -schmucks 79

4.I Historische Beschreibungen und Abbildungen 80

4.2 Vier Museumssammlungen des 19. und 20. Jh. 85

4.3 Materialität der Artefakte 88

4.3.I Brustschmuck tema 88

4.3.2 Nasenschmuck nelo 97

4.3.3 Tanzschurz der Männer lepanesa 101

$\begin{array}{lll}\text { 4.3.4 Tapa } & 107\end{array}$

4.4 Zwischenfazit 116

5 Handlungs- und Wirkmacht der Artefakte in den Akteur-

Netzwerken || |9

5.IVom ,nelo-Tanz' zum, nelo-Tänzer - Akteur-Netzwerke und ihre Genese 120

5.2 Tanzkleidung und -schmuck - Entitäten des Akteur-Netzwerks, nelo-Tänzer' 147

5.2.1 Brustschmuck tema 148

5.2.2 Nasenschmuck nelo 155

5.2.3 Tanzschurz der Männer lepanesa 158

$\begin{array}{lll}5.2 .4 & \text { Tара } & 162\end{array}$

5.2.5 Schmuck aus Blättern, Blüten und Wurzeln 168

$\begin{array}{lll}\text { 5.2.6 Korallenkalk } & \text { 171 }\end{array}$

5.2.7 Wirkmacht der Tanzkleidung und des -schmucks für die Tänzer $\quad 172$

5.3 Effekte von Tanzkleidung und -schmuck im Akteur-Netzwerk, nelo-Tanz' 174

$\begin{array}{lll}\text { 5.3.I Artefakte und Tänzer } & 174\end{array}$

$\begin{array}{lll}\text { 5.3.2 } & \text { Artefakte und Publikum } & 176\end{array}$

$\begin{array}{lll}5.4 \text { Zwischenfazit } & 180\end{array}$

6 Tanzkleidung und -schmuck und ihre Hersteller | 83

6.I Tema und John Namiade 184

6.2 Nelo und Philipp Malu 190

6.3 Lepanesa und Selwyn Balu 193 
- III -

6.4 Tapa und Ena Yamöli \& Steven Mdewöt 199

6.5 Nelo-Tanzkleidung und die Graciosa Bay Nelo Association (GBNA) 203

6.6 ,Art Nexus' - Artefakte als Intentionen 208

6.7 Zwischenfazit 211

7 Zusammenfassung und Schlussfolgerungen 213

8 Verzeichnis der Quellen 219

9 Anhang - Verzeichnis der Artefakte aus den Museumssammlungen 


\section{Verzeichnis der Karten}

Seite

Karte 1: Die im Südosten der Salomonen gelegenen Santa-Gruz-Inseln.

Karte 2: Der Westen der Insel Ndendö mit der Graciosa Bay im Norden, der dort vorgelagerten Insel Temotu Neo sowie der im Süden gelegenen Nemya Bay. Ausschnitt der Karte Lata, Solomon Islands. 1016516 X715 Edition 1-SI50K ( 02007 Solomon Islands Government) mit vom mir hervorgehobenen Orten. 


\section{Verzeichnis der Abbildungen}

Abb. 1: Nelo-Tänzer anlässlich einer Aufführung für Touristen in Malo, 2009.

Abb. 2: $\quad$ Chief and Dancing Party at Nelua. John Watt Beattie, 1906, Bildausschnitt. Rautenstrauch-Joest-Museum 3951.

Abb. 3: Anonymer Tänzer in Malo, 2009.

Abb. 4: Type of native. Earrings of tortoiseshell. Breastplates of Giant Tridacna, Santa Cruz. Walter Henry Lucas (?), um 1900. Rautenstrauch-Joest-Museum 9783.

Abb. 5: Nelo-Tänzer Chief Peter Lawrence Dewa in Malo, 2009.

Abb. 6: Ben Banie mit der ersten Kopie des ,Original-nelo' von Opla, nach dem der Tanz benannt ist; Ne'ele, 2011.

Abb. 7: Modell eines Auslegerkanus mit Hai auf der Plattform zur Dekoration des Tanzplatzes; Neo, 2011.

Abb. 8: Nelo-Tänzer mit tema aus Keramik; Neo, 2011.

Abb. 9: T-Shirt aus dem Jahr 2008.

Abb. 10: Empfang mit nelo-Tänzern anlässlich der Einweihung des ,Sunrise Electrical \& Solar Skill Centre'; Venga, 2010.

Abb. 11: Auftritt einer Frauengesangsgruppe anlässlich der Einweihung; Venga, 2010. 74

Abb. 12: Auftritt einer ,Boygroup‘ anlässlich der Einweihung; Venga, 2010.

Abb. 13: Ein Kameramann zeichnet den Empfang für das nat. Fernsehen auf; Venga, 2010. 75

Abb. 14: T-Shirt, produziert anlässlich der Nominierung der Graciosa Bay Nelo Association für die Teilnahme am Festival of Pacific Arts 2012 in Honiara.

Abb. 15: Nose Ornament, Santa Cruz (COOTE 1882: 158).

Abb. 16: A Santa Cruz Islander in war dress from a description furnished by A. Lister-Kaye (EDGEPARTINGTON \& HEAPE 1890: 154).

Abb. 17: Solomon Island Natives. 2166. Kerry, Sydney. Glasplattennegativ. Fotografie von Kerry and Company. Tyrell Collection, Museum of Applied Arts and Sciences, Sydney.

Abb. 18: 405 - Headmen in a Santa Cruz Village. John Watt Beattie, 1906.

Abb. 19: Bogenschütze aus Nitendi (SPEISER, 1913: Tafel 6).

Abb. 20: Tema, H.: 18,5 cm, B.: 17,5 cm; Santa Cruz, ca. 1870; Museum of New Zealand Te Papa Tongarewa FE000734.

Abb. 21: Tema, 1. Ø ca. 18 cm; r. Ø ca. 5 cm; beide John Namiade, Luepe, 2010.

Abb. 22: Tema aus Perlmutt, Ø ca. 5 cm; Matthias Me'lekaiva, Nea, 2011. 
Abb. 23a/b: Tema aus Keramikkacheln mit Auflagen aus Kunststoff, jeweils Ø ca. 17 cm;

Hersteller unbekannt; Neo-Nemba, 2011.

Abb. 24: Versteinerte Tridacna, Nelua, 2011.

Abb. 25: Ein ,schwarzer Stein’ für unterschiedliche Schleifarbeiten; Malo, 2010.

Abb. 26: Vom abgebrochenen fossilen Tridacnastück zum tema-Rohling; Luepe, 2011. 95

Abb. 27-29: Tema, Ø ca. 5 cm; diverse Auftragsarbeiten; Philipp Malu, Monou, 2011.

Abb. 30: Kolokolo, Ø ca. 5 cm; Chief David Tate, Lavuka, Vanikoro, 2011.

Abb. 31: Kolokolo, Ø ca. 5 cm; Cleophas Makona, Lavuka, Vanikoro, 2011.

Abb. 32: Einem tema nachempfundenes Schmuckstück von der Insel Malaita, Ø ca. 17 cm; Nautilus-Shop, Honiara, 2011.

Abb. 33: Auslage mit tema-Kopien von der Insel Malaita; Ø ca. 15 und 8 cm; Museumsshop, Honiara, 2010.

Abb. 34: Nose ornament of pearl shell - wom by chiefs only (EDGE-PARTINGTON \& HEAPE 1890: 166, No. 9, retuschierter Bildausschnitt).

Abb. 35: Ein Mann aus Nitendi mit dem aus Perlmutter zierlich geschnitzten Tanznasenschmuck (SPEISER 1913: Taf. 67, Bildausschnitt). 98

Abb. 36: Nelo, B.: 11 cm; Santa Cruz, um 1900; The British Museum Oc 1944,02.1234. 98

Abb. 37: Nelo, B.: $12 \mathrm{~cm}$; Sekapulu, vermutlich Anfang 20. Jh. 98

Abb. 38: Inventarkarte: Nasenschmuck, Santa Cruz, 1914; Rautenstrauch-Joest-Museum 30562. Mit Fotografie des Schmucks aus dem Jahr 2016.

Abb. 39/40: Nelo als Nasenring, B.: 24 cm; Philipp Malu, 2011. L. Vorder- und r. Rückseite. 101

Abb. 41: Santa Cruz - Graciosa bay. [H]omme tissant une natte, village de Noelé [Ne'ele, O. L.] (Van den Broek d'Obrenan 1935: croquis no. 31 in COFFIER 2014: Planche 35). 104

Abb. 42: Lepanesa, Santa Cruz, spätes 19. Jh.; The British Museum Oc, +4970. Erworben von A. Lister-Kaye.

Abb. 43: Lepanesa. Vergrößerung aus: A Santa Cruz Islander in war dress from a description furnished by Lister-Kaye (EDGE-PARTINGTON \& HEAPE 1890:154).

Abb. 44 a: Verschiedene lepanesa; Ne'ele, 2011.

Abb. 44 b: Verschiedene lepanesa; Ne'ele, 2011.

Abb. 45: Tapa, L.: 146 cm; Santa Cruz, 1897; Rautenstrauch-Joest-Museum 3984.

Abb. 46: Tapa; Santa Cruz, 1993; Museum of New Zealand Te Papa Tongarewa FE01 1690. 110

Abb. 47/48: Mit Tapa bekleidete Frauen und Männer tanzen für Touristen; Malo, 2009. 
Abb. 51/52: Mit Tapa bekleidete Frauen und Männer tanzen für eine Politikerdelegation;

Venga, 2010.

Abb. 53: Naturels de l'âle de La Pérouse ou de Mannicolo [Vanikoro] (DILLON 1829, II: Frontispiez). 113

Abb. 54: Santa Cruz; habitant de Santa-Cruz, ile de la Reine-Charlotte, avec les narines ormis de fleurs rouges et son front [?] couvert de feuillages. P. Sellier, 1894?. Alexander Turnbull Library, Wellington, New Zealand A-340-046.

Abb. 55: Natif de Vanikoro. Les Cheveux sont enroulés dans des Bandes de tapa (DE TOLNA 1903: 268). 114

Abb. 56: Chef de Gracieuse Bay, Santa Cruz. Festetics de Tolna, 1893-1901, Bildausschnitt. Musée du Quai Branly 70.2001.19.15.1.

Abb. 57: Natifs de Vanicoro à bord du yacht Tolna. Festetics de Tolna, 1893-1901,

Bildausschnitt. Musée du Quai Branly 70.2001.19.97.

Abb. 58: 425 - School People and Others at Nimbi. John Watt Beattie, 1906, Vergrößerung.

Abb. 59/60: Die Kopfbedeckung abe, hergestellt von Matthias Me'lekaiva (1.) und von

Ben Banie (r.); Ne'ele, 2010.

Abb. 61: Die Kopfbedeckung abe, Hersteller unbekannt; Malo, 2011.

Abb. 62: Dorfmitglieder reinigen den im Jahr 2000 eröffneten nir (Tanzplatz); Ne'ele, 2011. 121

Abb. 63: Vor der Versammlung, im Vordergrund Selwyn Balu; Ne’ele, 2011.

Abb. 64: Der kastom-Kalender abu dobe; Ne'ele, 2011.

Abb. 65: Am Vorabend des Festes in Ne'ele, 2011. V. 1. n. r.: Selwyn Balu, Jerry Me’ioko, Oliver Lueb.

Abb. 66: Der ehemalige Paramount Chief Ambros hilft Steven Me'kuka beim Ankleiden. 134

Abb. 67/68: Philipp Malu und Paul Kabune bessern verschiedenen Steckschmuck aus. 134

Abb. 69: Steward Bice Me’tu lässt sich die Haare weißen. 136

Abb. 70-72: Gesichtsbemalungen. 137

Abb. 73: Steward Me'tu - noch in Bluejeans - mit einem kleinen tema narabe für den Rücken. 139

Abb. 74: Me'tu mit tema, noiatema, Armschmuck teliki, mbenia, tangalilu und maluembe. 139

Abb. 75: Simeon Me'notea aus Neo bei der parfium-Herstellung (Euodia hortensis). 139

Abb. 76: Steward Me'tu mit telengi narabe. 140

Abb. 77: Ben Banie mit telengi ndäka (Zangen des Rhinozeroskäfers). 140

Abb. 78: Alle lepanesa der an dem Tag auftretenden Tänzer hängen auf der Leine in Balus Haus.

Abb. 79: Steward Me’tu (r.) mit John Me'yirngao (1.) bei dem gemeinsamen Essen vor dem Anlegen von lepanesa und nelo.

Abb. 80: Peter Lawrence mit ,traditionellem` Gürtel. 
Abb. 81: Jerry Me’iko mit ,modernem‘ Gürtel.

Abb. 82: Brown Ite hilft Peter Lawrence Dewa beim Anlegen des lepanesa.

Abb. 83: Steward Me'tu mit Ziergürtel lemkalo (Conus-Schneckenschalengeld).

Abb. 84: Peter Lawrence Dewa mit lemkalo und altem (polynesischem) Schmuckgürtel tusemu (Glasperlen).

Abb. 85: Steward Me'tu nach dem Ankleiden, kurz vor seinem ersten nelo-Tanz.

Abb. 86: Me'tu (r.) mit seinem Vater Me'penia (Mitte) und Me'ioko (1.); Balo, 2011.

Abb. 87: Nelo-Tänzer vor dem Tanz.

Abb. 88: Die Hauptgruppe der Tänzer vor ihrem Einzug auf den Tanzplatz.

Abb. 89: Die beiden Tanzführer mit ihren abe-Kopfbedeckungen.

Abb. 90: Tema des nou nienda, 1897; Rautenstrauch-Joest-Museum 4372.

Abb. 91: Tema des nou bebla, 1897; Rautenstrauch-Joest-Museum 4373.

Abb. 92: Tema des nou nümbü, vor 1901; The British Museum Oc1944,02.1186.

Abb. 93: Tema mit Haidarstellung; John Namiade, 2014, Bildausschnitt.

Abb. 94: Wappen der Solomon Islands mit Haidarstellung.

Abb. 95: Vorderseite eines lepanesa mit dem Nalinuss-Muster ningi te’ba (leere Nussschalen); Selwyn Balu, vor 2011.

Abb. 96: Eine geöffnete Nalinuss.

Abb. 97: Querschnitt einer getrockneten Nalinusshälfte (YEN 1974: Fig. 3, Bildausschnitt). 160

Abb. 98: Lepanesa-Muster ningi ténipo (gefüllte Nuss); Venga, 2010.

Abb. 99: Tapa, L.: 219 cm; Santa Cruz, 1897; Rautenstrauch-Joest-Museum 3986.

Abb. 100: Tapa, L.: 125 cm; Santa Cruz, 1996; Auckland War Memorial Museum 55128 1996.48.2.

Abb. 101: Tapa als Hüfttuch mit ,traditionellen Rapporten‘; Steven Mdewöt, 2010.

Abb. 102: Kopfbedeckung abe mit dem traditionellen Muster ,halbe Thunfische' in der mittleren und rechten Reihe; Matthias Me'lekaiva, 2011.

Abb. 103: Kopfbedeckung abe mit dem traditionellen Muster ,Haifischzähne` und ,Sagopalme oder Nalinussbaum‘; Ben Banie, 2011.

Abb. 104: Tapaschurze; John Namiade, 2011.

Abb. 105: Beschriebene Tapa; Hersteller unbekannt; Malo, 2012.

Abb. 106: Tema mit neu entworfener Schildpattauflage; John Namiade, 2011.

Abb. 107: John Namiade vor seiner Werkstatt/seinem Verkaufsraum; Luepe, 2010. 
Abb. 110: Lirle-Entwurf aus Keramik, Kunststoff und Naturfaser; Hersteller unbekannt, 2012.188

Abb. 111: John Namiade nach einer nelo-Tanzaufführung; Honiara, 2014.

Abb. 112: Philipp Malu demonstriert das Ausfeilen eines nelo-Motivs; Monou, 2010.

Abb. 113: Telefonkarte „People of the Solomon Islands. Man of Santa Cruz, Temotu Province“; Solomon Telekom, vor 2010.

Abb. 114: Bartholomew Me'esas Neffe Philix nach einer nelo-Tanzaufführung; Honiara, 2014. 191

Abb. 115: Tema, Ø ca. 5 cm; Auftragsarbeit für die Mothers Union der Anglican Church of Melanesia; Philipp Malu, 2011.

Abb. 116: Logo der Mothers Union, 2015. 192

Abb. 117: Tema mit Vogelkopfdarstellungen, Ø ca. 15 cm; Philipp Malu, 2011.

Abb. 118: Selwyn Balu mit einem Foto seines Vaters Jonas Kepule; Ne'ele, 2010.

Abb. 119: Selwyn Balu als nelo-Tänzer in den 1990er-Jahren; Selwyn Balu. 197

Abb. 120: Selwyn Balu nach einer nelo-Tanzaufführung; Honiara, 2014. (C) GBNA 197

Abb. 121: Ena Yamöli und Steven Mdewöt mit von ihnen für einen späteren Verkauf an Touristen hergestellten Tapa vor dem Eingang des Hauses von Yamölis Vater; Nea, 2011. 200

Abb. 122: Tapa mit zentralem tema-Motiv; Steven Mdewöt, 2014.

Abb. 123/124: Steven Mdewöt nutzt eine eigens von ihm entwickelte Stempeltechnik für den Farbauftrag auf Tapa; Nea, 2010.

Abb. 125: Der Technical Advisor der GBNA, Freddy Me'esa, bei einer nelo-Tanzaufführung während des $5^{\text {th }}$ Melanesian Festivals of Arts and Culture in Port Moresby, Papua-Neuguinea, 2014. (C) GBNA

Abb. 126: GBNA-Mitglieder anlässlich der Mitgliederversammlung; Luepe, 2011.

Abb. 127: Vorstandsmitglieder der GBNA während der Mitgliederversammlung. 204

Abb. 128: Facebook ${ }^{\circledR}$-Auftritt anlässlich der Rückreise der GBNA vom $5^{\text {th }}$ Melanesian Festival of Arts and Culture in Port Moresby, Papua-Neuguinea, Juli 2014.

Abb. 129: Delegation der GBNA nach einer nelo-Tanzaufführung in Honiara auf dem Weg nach Port Moresby, Papua-Neuguinea, im Juli 2014.

Abb. 130: Die Gruppe auf dem Rückweg vom Festival während des Spendenaufrufs in Honiara im Juli 2014. John Namiade fehlt auf dem Bild.

Abb. 131: John Namiade bei dem Event.

Abb. 132: Frauen der GBNA präsentieren Federgeldrollen auf dem $5^{\text {th }}$ Melanesian Festival of Arts and Culture in Port Moresby, Papua-Neuguinea, 2014. 



\section{Einführung}

„The only reliable fact is the artefact.“ (Freddy ME’ESA 2009: 3)

„[H]ow do things stay the same as they change, and change as the stay the same?“

(Robert John FOSTER 1995: 1)

Die ethnologische Forschung Melanesiens beschäftigte sich in den 1990er-Jahren Robert FOSTER (1995: 1-16) zufolge verstärkt mit Fragen nach ,we' und ,them'. ${ }^{1}$ Dabei standen Überlegungen zu grundlegenden Unterschieden zwischen melanesischen und westlichen Vergesellschaftungsformen denen nach Ähnlichkeiten aufgrund einer geteilten Geschichte gegenüber. Seit einigen Jahren wendet sich ein Teil der Forschungen in Melanesien und Polynesien (wieder) verstärkt dem Verständnis von Dingen zu. Untersucht werden dabei Fragen u. a. danach, wie sich die Beziehungen zwischen Menschen und Dingen darstellen, wie Dinge menschliches Handeln beeinflussen, ob sie über ,Agency', im Sinne einer Art von Handlungsmacht und Wirkvermögen, verfügen und sogar nicht (nur) als Objekte, sondern (vielmehr) als Subjekte auftreten. Verschiedene Autorinnen und Autoren sprechen in der Sozial- und Kulturanthropologie in diesem Zusammenhang von einem ,material turn' oder ,material return', etwa Joshua BeLL \& Haidy GeISMAR (2009: 3), Clare HARRIS \& Michael O’HANLON (2013: 8) oder im deutschsprachigen Raum Stefanie SAMIDA et al. (2014: 1).

Mit der vorliegenden Arbeit gehe ich anhand eines ethnografischen Beispiels diesen Fragen nach und liefere damit einen Beitrag zu den Diskussionen über das Verständnis von

\footnotetext{
I Als Bezeichnungen für die kulturellen Großregionen im südlichen Pazifik verwende ich in meiner Arbeit die Begriffe „Melanesien“, „Polynesien“ und „Mikronesien“ und nicht „Remote Oceania“ oder „,Near Oceania“ wie die Grenzen zwischen den Regionen in der Archäologie gezogen werden (Roger GREEN 199l in Peter J. SHEPPARD \& Richard WALTER 2006: I), da sich viele Bewohner selber als ,Melanesier' bezeichneten und von ,Polynesiern und Mikronesiern' abgrenzten. Auch Nicholas THOMAS (2012: 22) verweist auf die rezente Nutzung dieser Begriffe durch die vielen Bevölkerungsgruppen in Ozeanien.
} 
Dingen. Anhand konkreter Artefakte - Kleidung und Schmuck eines bestimmten Tanzes auf der Insel Santa Cruz, Salomonen (vgl. Karte 1) - erörtere ich, auf welche Arten und Weisen diese Dinge erscheinen, wie sie mit den Menschen in Beziehungen treten und was sie vermitteln. Die Tanzkleidung und der -schmuck sind - so meine Hauptthese - ,mächtige Artefakte. Ich werde zeigen, dass sie über eine Handlungs- und Wirkmacht verfügen und in dem Sinne durchaus als ,Subjekte“ verstanden werden können. Ich werde ausführen, dass die Tanzkleidung und der -schmuck in substantiellen Beziehungen mit den Menschen stehen und soziokosmische Beziehungen für sie konstituieren. Dabei schaffen sie als elementare Bestandteile mit Menschen und anderen Entitäten vielfältige hybride Akteur-Netzwerke - u. a. für die Übersetzung verschiedener Traditionsrethoriken (Debatten um Tradition und rituelle Zeremonien), die ich im Rahmen der vorliegenden Arbeit als kastom-Konfigurationen definiere. ${ }^{2}$ Aufgrund ihrer Mehrdeutigkeit können die Artefakte abhängig von den jeweiligen Zielsetzungen unterschiedliche Facetten soziokosmischer Zugehörigkeiten vermitteln und diese realisieren. Kastom wird dabei nicht auf einer eher abstrakten Ebene konkret festgelegt, sondern als ein sich wandelnder und durchaus nicht unumstrittener Aushandlungsraum physisch erlebbar, den unterschiedliche Menschen/-gruppen (Tänzer, Auftraggeber, Produzenten, Zuschauer und Abnehmer) pragmatisch oder auch strategisch nutzen - ob für die Konstruktion ihrer kulturellen Zugehörigkeit im multiethnischen Nationalstaat der Salomonen oder für das Generieren von Ressourcen. Kastom wird, auf die Zukunft ausgerichtet, in der Gegenwart real. Verschiedene Akteursgruppen weiten mit den Artefakten bzw. durch sie ihre soziokosmischen Handlungsräume aus: Im Falle der Auftraggeber und Hersteller agieren die Tanzkleidung- und der -schmuck gar als Operatoren ihrer Einflusssphäre, sind Erweiterungen oder Teile der Handelnden. Ich werde aufzeigen, dass gerade die stofflichen Qualitäten der Artefakte, im Sinne von ,Essenzen`, die Basis für diese Handlungs- und Wirkmacht legen, die von den Dingen ausgeht. Nicht zuletzt verkörpert die seit rund zwei Jahrzehnten andauernde Rückbesinnung auf die natürlichen Materialien bei der Herstellung und die Verwendung der Artefakte eine wieder erstarkende kulturelle Zugehörigkeit in Santa Cruz und treibt diese gleichermaßen voran.

Mit Santa Cruz wird seit der ,Entdeckung' durch den Spanier Alvaro de Mendaña (15411595) am 7. September 1595 sowohl die im äußersten Osten der Solomon Islands gelegene Inselgruppe der Provinz Temotu als auch deren größte Insel bezeichnet, auf der die heutige Provinzhauptstadt Lata liegt. ${ }^{3}$ Die Kalksteininsel erstreckt sich über ungefähr 45 km in Ost-

\footnotetext{
${ }^{2}$ Kastom ist der Salomonen-Pidgin-Begriff, der generell im Alltagsgebrauch auf den englischen Terminus custom referiert. Zu den ethnologischen Debatten um das kastom-Konzept vgl. nachfolgend Kap. I.2, S. 7-10. Zum Salomonen-Pidgin (im Folgenden Pijin) vgl. Kap. 2, S. 35.

${ }^{3}$ Zu der Inselgruppe werden zudem im Süden die beiden Inseln Vanikoro und Utupua, im Osten die beiden Inseln Tikopia und Anuta, die nördlich gelegenen Reef und Duff Islands sowie die unbewohnte Vulkaninsel Tinakula gezählt. Die Provinz nimmt mit rund 150.000 km² ungefähr die doppelte Fläche von Österreich ein, wobei weniger als ein Prozent $\left(926 \mathrm{~km}^{2}\right)$ reine Landfläche ist, was etwas mehr als der Fläche Berlins entspricht. Nach dem zuletzt publizierten Zensus lebten im Jahr 2009 rund 21.400 Menschen in der Provinz Temotu, ungefähr vier Prozent der Solomon Islander (SOLOMON ISLAND GOVERNMENT 20 I I). Neben Santa Cruz wird die Hauptinsel
} 
West- und 25 km in Nord-Süd-Richtung. Ihre höchste Erhebung misst $550 \mathrm{~m}$ ü. d. M. Bis auf die Küstenstreifen, die teilweise aus Sand, zum größten Teil aber aus abgestorbenem Korallenriffdach bestehen und nur zum Teil mit Mangrovenwald, Pandanus- und Kokospalmen bewachsen sind, ist die Insel mit dichter Vegetation bedeckt. Auf Meereshöhe wachsen mitunter Sagopalmen, im Inselinneren befinden sich tropischer Regenwald und die Gärten der Bewohner.

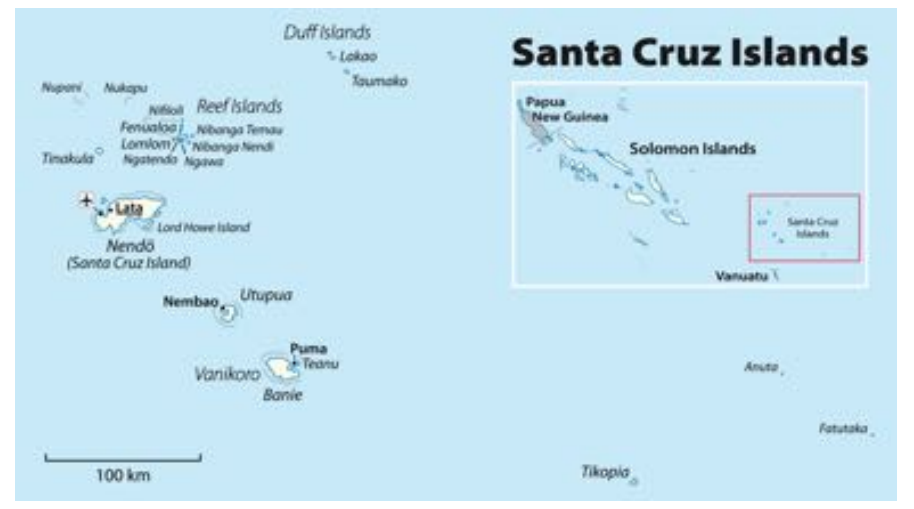

Karte 1: Die im Südosten der Salomonen gelegenen Santa-Cruz-Inseln. ${ }^{4}$

\section{I.I Thema und Fragestellung}

Während meines ersten Besuchs des Ortes Malo auf Ndendö (vgl. Karte 2, S. 22) als Reisebegleiter im Jahr 2009 wurde ich Zuschauer einiger traditioneller Tänze, die verschiedene Gruppen für die Touristen aufführten. Einer der vorgetragenen Tänze wurde nach dem Nasenschmuck nelo benannt (vgl. Abb. 1 und Abb. 5). Nach Aussagen des Moderators der Aufführungen, John Me'alue, war er der traditionelle Tanz in Santa Cruz. ${ }^{5}$ Als Grundausstattung eines nelo-Tänzers führte Me'alue zwei Schmuck- und ein Kleidungsstück auf: tema

u. a. auch Nendö, Ndende, Ndeni, Nendr oder Nitendi (Gerd KoCH 197I: II, diverse Regierungsunterlagen) sowie Inemi, Nambakena, New Guernsey oder Lord Egmont's Island (Ashley WILSON 2009: 35) genannt. Zur Zeit meines Aufenthaltes war der Name Ndendö m. E. die lokal gängige Bezeichnung. Um Verwechslungen zu vermeiden, verwende ich in meiner Arbeit die Namen Ndendö für die Insel und Santa Cruz für die Inselgruppe. ${ }^{4}$ Maximilian Dörrbecker (Chumwa) (CC BY-SA 2.0 [http://creativecommons.org/licenses/by-sa/2.0]), via Wikimedia Commons: https:/en.wikipedia.org/wiki/Santa_Cruz_Islands\#/media/File:Map_of_the_Santa_Cruz_Islands_(Solomon _Islands).png, letzter Zugriff am 26.5.2016.

${ }_{5}^{5}$ Neben diesem wurden während meiner Aufenthalte vereinzelt noch lokale Tänze wie der napa- oder lirle-Tanz und seit 2010 auch ein neuer Tanz zur Musik von Bamboo-Bands aufgeführt, die sich an vielen Orten der Solomon Islands zunehmender Beliebtheit erfreute. Laut Aussagen der Tänzer in Malo führten nur noch sie den napa-Tanz auf, bei dem Tanzkeulen zum Einsatz kamen, wie sie sich in vielen Museumssammlungen befinden. Sie waren zu Ende des 19. Jh. angeblich allerorts anzutreffen (Wilhelm FoY 1916: 227 und KOCH 1971: 178-180) und wurden noch im Jahr 1976 genutzt (William DAVENPORT 2005: 48-49), was auf eine weitere Verbreitung schließen lässt. De facto sah ich auf Ndendö die einzigen napa-Keulen in Malo. Dort konnte mir allerdings niemand mehr etwas über die Bedeutung der Formen und Bemalungen sagen. Sie wurden lediglich von Bildern kopiert, die ,ein Ausländer" Ende der 1990er-Jahre nach Malo gebracht hatte (Shadrack Sade, I4.1 I.20 I I). Die in Noipe lebenden Ambros Me'naa und Ataban Tropa (ehemaliger und 20ll amtierender Paramount Chief, Schwiegervater und -sohn) erklärten mir später viele Designs von Tanzkeulen auf Fotografien aus Museumssammlungen, die ich als Stimuli zu den Gesprächen mitgebracht hatte (6./7.10.201 I; vgl. Anm. 29). Sie berichteten, dass in ihrem Dorf aber keine Tanzkeulen mehr hergestellt würden. Zur Stellung von Chiefs auf Ndendö vgl. Kap. 2, S. 33. 
(Anhänger aus Muschelscheibe, oftmals mit Schildpattauflage), nelo (Nasenschmuck aus Perlmutt) und lepanesa (Tanzschurz aus Bananenbast). Als wichtiges Material stellte er zudem Tapa (Rindenbaststoff) heraus, aus dem Kopfbedeckungen und weitere Tanzschurze gefertigt wurden. ${ }^{6}$ Die gesamte Ausstattung hatte einen Geldwert von rund 8.000 SalomonenDollar (SBD; entsprach 2011 ca. 800 Euro), was ungefähr dem doppelten Monatsgehalt eines Angestellten im öffentlichen Dienst gleich kam (ME'ESA 2011: 2).7

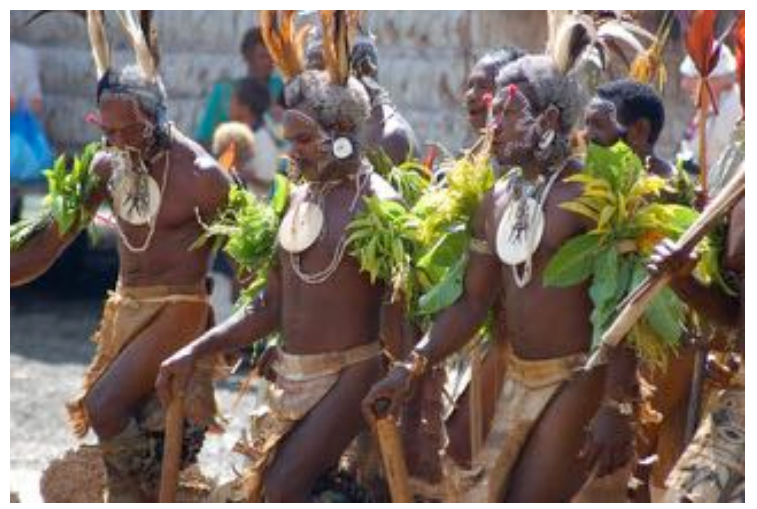

Abb. 1: Nelo-Tänzer anlässlich einer Aufführung für Touristen in Malo, 2009.

Wie ich nach meiner Rückkehr bei einer ersten Recherche herausfand, waren manche dieser Artefakte bereits im ausgehenden 19. Jh. in Museumssammlungen gelangt, so dass ich sie für einen physischen, historischen Vergleich mit aktuellen Artfakten würde nutzen können. ${ }^{8}$ Bei der Untersuchung frühester Fotografien zeigte sich eine vermeintliche Kontinuität (vgl. Abb. 2-5) der Kleidung, was zwar ihre, Originalität ${ }^{6}$ bestätigte, jedoch die Fragen nach den Gründen dafür und nach einem aktuellen Umgang mit den Artefakten offen ließ. Warum war die Situation auf Ndendö augenscheinlich so anders? Wurden die Artefakte auch zu nicht touristischen Anlässen genutzt?

Zudem stellte sich heraus, dass seit den 1970er-Jahren auf Ndendö keine ethnografischen Forschungen mehr durchgeführt worden waren und somit eine zeitliche Forschungslücke bestand. Durch eine eigene Feldforschung sollte es möglich sein, diese zu schließen und zunächst den Fragen nachzugehen, wie sich die Situation dieser vier Artefaktegruppen historisch und aktuell darstellte, und wie die mit ihnen handelnden Personen die Historie der Artefakte sahen.

\footnotetext{
${ }^{6}$ Die drei aufgeführten Bezeichnungen sind Natügu-sprachliche Begriffe, die größtenteils von den Bewohnern der Nordküste Ndendös verwendet werden. Natügu stellt auf Ndendö die dominierende indigene Sprache dar (vgl. Kap. 2, S. 34). Wenn nicht anders gekennzeichnet, handelt es sich bei den indigenen Bezeichnungen um NatüguBegriffe. Die Bezeichnung Tapa wurde generisch verwendet und stammt ursprünglich aus Polynesien.

7 Für das Jahr 2014 vgl. die Gehaltsskalen der Vereinten Nationen http://www.un.org/Depts/OHRM/salaries_ allowances/salaries/solomon.htm, für das Jahr 2015 vgl. University of the South Pacific http://www.usp.ac.fj/ index.php?id=salary_scales, letzter_Zugriff jeweils am 16.5.2016.

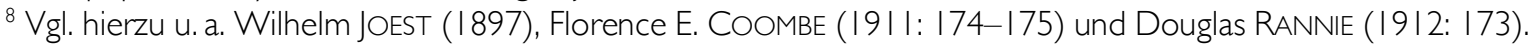
Hingegen spielte das rote Federgeld tevau, für das die Inselgruppe in Fachkreisen bekannt ist, zwar in den Berichten der älteren Männer noch eine wichtige, in deren Handlungen während meiner Aufenthalte jedoch nur noch eine untergeordnete Rolle, vgl. u. a. Harry Geoffrey BEASLEY (1936), DAVENPORT ( 1962), KOCH ( I97I) oder Liz BONSHEK (2009). Zu den Gründen der abnehmenden Bedeutung des roten Federgelds vgl. Salomé SAMOU (20 I 4).
} 

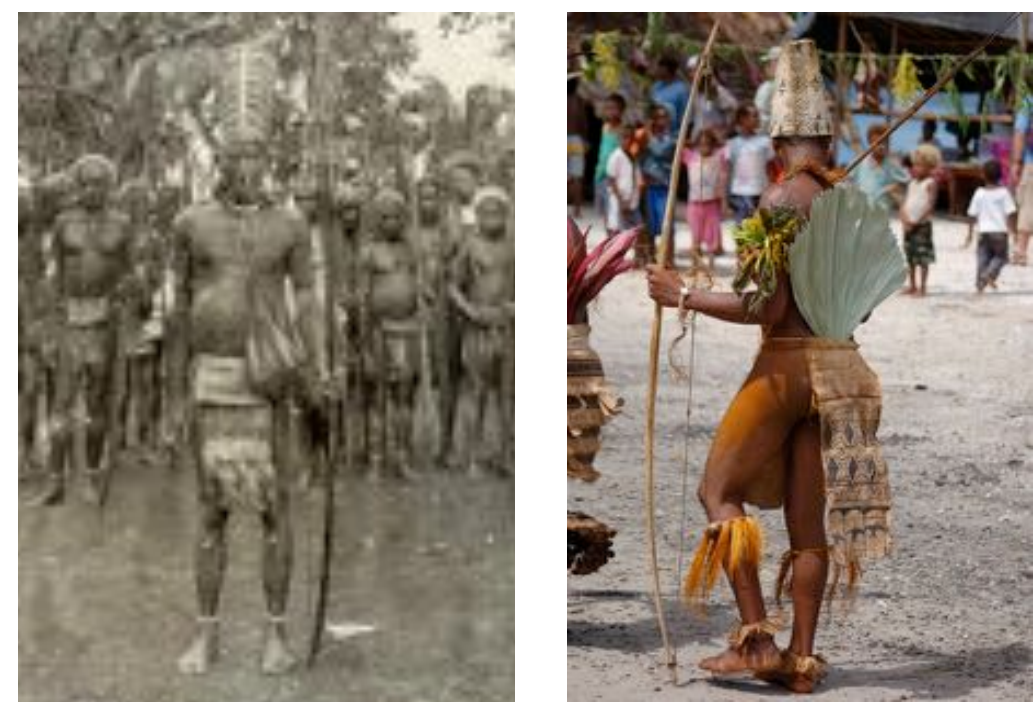

Abb. 2: Chief and Dancing Party at Nelua. John Watt Beattie, 1906, Bildausschnitt. RautenstrauchJoest-Museum 3951.

Abb. 3: Anonymer Tänzer in Malo, 2009.
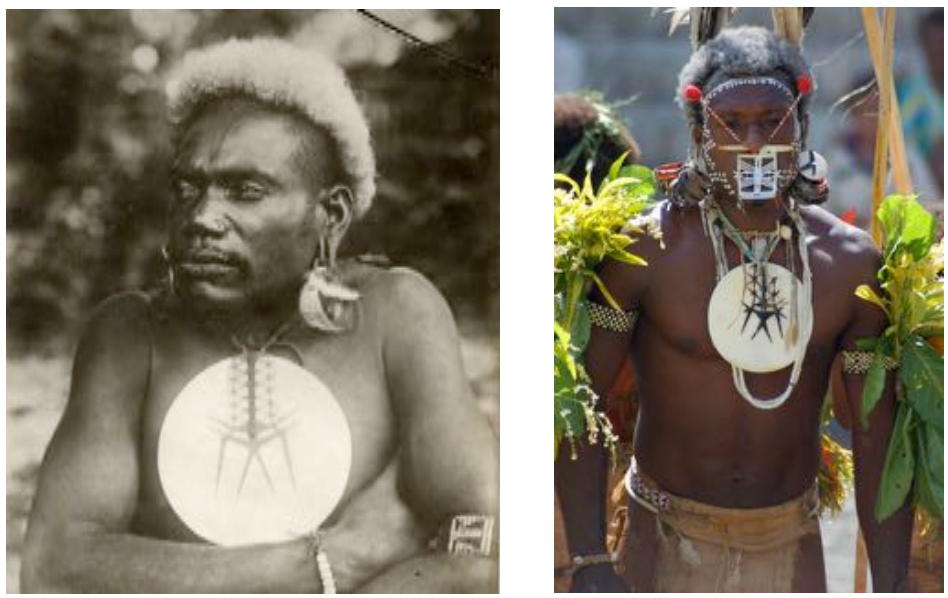

Abb. 4: Type of native. Earrings of tortoiseshell. Breastplates of Giant Tridacna, Santa Cruz. Walter Henry Lucas (?), um 1900. Rautenstrauch-Joest-Museum 9783.

Abb. 5: Nelo-Tänzer Chief Peter Lawrence Dewa in Malo, 2009.

Während meiner Forschungsaufenthalte nahm ich an mehreren nelo-Tanzaufführungen teil und stellte fest, dass diese sowohl für Außenstehende, wie ich es etwa anlässlich des Besuchs von Touristen selbst erlebt hatte, als auch für traditionelle, lokale Anlässe aufgeführt wurden. Letztere fanden in komplexen Zusammenhängen langjähriger, reziproker Tauschbeziehungen statt und wandten sich an lokale Gottheiten und spirituelle Wesen oder wurden an hohen kirchlichen Feiertagen in Messfeiern auch für den christlichen Gott aufgeführt. Ebenso verkauften einige Hersteller der Tanzkleidung und des -schmucks ihre Produkte an verschiedene Personenkreise inner- und außerhalb Ndendös. Es schien, dass dieselben Artefakte sehr unterschiedliche Inhalte in Szene setzen bzw. vermitteln konnten. In den Gesprächen vor 
Ort tauchten dabei immer wieder die im Pijin (Salomonen-Pidgin) gebräuchlichen Begriffe kastom, tradition und/oder kalsa auf. ${ }^{9}$ Mitunter diskutierten die Männer in öffentlichen Runden, was kastom entsprach und was nicht, wer an bestimmten Dingen kastom-Rechte hatte und wer nicht. In Einzelgesprächen zu den Artefakten ergaben sich auch Fragen nach der eigenen kulturellen Zugehörigkeit und danach, wie diese beibehalten bzw. wieder aktiviert werden konnte. Somit ergab sich eine weitere Fragestellung, nämlich wie diese Begrifflichkeiten auf Ndendö verstanden, konstruiert und eingesetzt wurden - hierzu lagen ebenfalls noch keine Ausarbeitungen vor.

Mit dem Fortschreiten meiner Feldforschung auf Ndendö erkannte ich, dass mein ursprünglicher Fokus auf Fragen nach der Historie der Artefakte, nach den Verwendungsanlässen und Bedeutungen der Tanzkleidung und des -schmucks dem Wesen der Artefakte nicht gerecht wurde. Dies war vor allem meiner Unkenntnis der Heterogenität der Verwendungen und der Komplexität der Artefakte selber geschuldet. Ging ich anfangs noch von einem eher passiven Verständnis der Artefakte als bedeutungsaufgeladen und repräsentativ aus, erlebte ich vor Ort, dass die Dinge zu verschiedenen Anlässen unterschiedliche Inhalte vermittelten, dass sie Gefühle und Stimmungen, Vorstellungen oder Erinnerungen hervorriefen, also aktiv etwas bewirkten. In ihnen kristallisierten sich soziokosmische Beziehungen. Daher traten nunmehr Fragen in den Vordergrund, wie die Artefakte in welche Beziehungen zu den Menschen traten, warum sie dazu in der Lage waren und welche Handlungsräume sich daraus konkret für einzelne Personen/-gruppen ergaben. Zu diesen auch in der Ethnologie Melanesiens diskutierten Fragen soll die vorliegende Arbeit einen Betrag leisten.

\section{I.2 Theoretischer Rahmen}

Im Fokus dieser Arbeit stehen Kleidung und Schmuck eines Tanzes auf der Insel Ndendö, ihre Beziehungen zu den Menschen, was die Artefakte etwa sozial und kulturell bedeuten, was sie sind, bewirken - und nicht zuletzt, wie sie ethnologisch verstanden werden können.

\footnotetext{
${ }^{9}$ In der Transkription der drei Begriffe folge ich Lamont LINDSTROM und Geoffrey M. WHITE (I994: 3). In der Einführung zu ihrem Buch über die Entwicklung von Kulturpolitik(en) in Melanesien definieren sie Kultur - wie Anfang der 1990er-Jahre in der Ethnologie nicht unüblich - als ein System mehr oder weniger geteilten, mehr oder weniger bewussten Wissens und Verständnisses, mit dem Menschen ihr Zusammenleben organisieren. Kastom und tradition beschreiben den Herausgebern zufolge hingegen Kulturbereiche, die offensichtlich werden: Kastom beziehe sich auf alle Kulturbereiche und Praktiken, über die Menschen sprechen und die sie als identitätsstiftend erachten und mit denen sie sich von ihren Nachbarn abgrenzen. Wohingegen tradition auf eine Teilgruppe von kastom verweise, die explizit aus der Vergangenheit von den Ahnen überliefert wurde. Die Autoren weisen zudem darauf hin, dass Menschen mitunter zwar um den Wandel grundlegender kastom-Praktiken wissen, diesen aber ignorieren und argumentieren, dass ihr kastom durchaus traditionell sei (1994: 3-5). Als entsprechendes Beispiel von Ndendö kann ich hier den Umgang mit der Kleidung von Frauen aufführen: Frauen beschreiben das Tragen von Shorts unter Röcken für Mädchen als kastom und tradition, wissend, dass diese Kleidung erst in den letzten Jahrzehnten eingeführt wurde und die von den Missionaren zuvor eingeführten lavalava-Baumwollwickeltücher ersetzte. Wobei auch Letztere nach Aussagen meiner Informantinnen kastom und tradition waren. Im nachfolgenden Kap. I.2, S. 7-10, stelle ich den aktuellen Stand der wissenschaftlichen Diskussion um die Begriffe und deren Verwendung in meiner Arbeit dar.
} 
Was sie vor Ort ausstrahlten bzw. zu welchen Anlässen sie in Erscheinung traten, beschrieben meine Gewährsleute allgemein als kastom, tradition und/oder kalsa. Die hinter den Begrifflichkeiten stehenden Konzepte scheinen aufgrund ihres teilweise parallelen Auftretens einerseits eng miteinander verwoben, andererseits jedoch nicht eindeutig voneinander differenziert zu sein. Bevor ich mich den eigentlichen theoretischen Grundlagen der vorliegenden Arbeit zuwende (ethnologische Perspektiven auf die Dinge und das gemeinsame Wirken von Menschen und Dingen im Besonderen), ist daher zunächst eine ethnologische Annäherung an diese Begrifflichkeiten notwendig.

\section{- Kastom-tradition-kalsa}

Den Beginn ethnologischer Debatten um Traditionsrhetoriken (Debatten um Tradition und rituelle Zeremonien) sowie deren Konstruktionen und Nutzen sahen Lamont Lindstrom und Geoffrey M. White als Gastherausgeber der Anthropological Forum-Sonderausgabe Custom Today in der im Jahr 1982 von Roger M. Keesing und Bob Tonkinson editierten MankindSonderausgabe Reinventing Traditional Culture: The Politics of Kastom in Island Melanesia (LINDSTROM \& White 1993: 468-470). Zu der Zeit, als Reinventing Traditional Culture erschien, arbeiteten Eric Hobsbawm und Terence Ranger an ihrer Publikation The Invention of Tradition (1983). Während Letztere auf das Vereinnahmen von traditionellen Rhetoriken durch Staaten mit dem Ziel der Autoritätslegitimation fokussierten, untersuchten Keesing und Tonkinson vor allem auf lokaler Ebene - regional vergleichend - damals neuaufkommende Diskurse um Tradition bzw. kastom, die im Umfeld von Dekolonisierung, Unabhängigkeitswerdung und Nation Building melanesischer Inselnationen als indigenes Konzept, als vielgestaltige Traditionsrhetoriken von Ethnologen wahrgenommen wurden. WHITE \& HVIDING (2015: 8) zufolge attestieren seitdem Wissenschaftler in der Ethnologie, den Geschichtswissenschaften und verwandten Disziplinen Debatten um kulturelle Traditionen sowohl auf nationalstaatlicher als auch auf lokaler Ebene eine zunehmende Relevanz.

In ihrer Einführung zu Custom Today legen LinDSTROM \& WHITE (1993: 468-470) ein besonderes Augenmerk auf die durch den Vergleich der regional gewonnenen Erkenntnisse, dass kastom (wie ihnen zufolge auch ,Kultur') nicht gegeben sei, sondern in Netzwerken (im Sinne sozialer Netzwerke) und Machtsystemen aktiv und kontinuierlich konstruiert werde, als Diskurs verstanden werde und sich vielfältig darstellen könne. ${ }^{10}$ Damit gehen sie über die seinerzeit von HOBSBAWM \& RANGER (1983: 1-2) entwickelte Auffassung hinaus, Tradition zu sehen als ,,a set of practices, normally governed by overtly or tacitly accepted rules and a ritual or symbolic nature, which seek to inculcate certain values and norms of behavior by repetition, which automatically implies continuity with the past. In fact, where possible, they normally attempt to establish continuity with a suitable historic past." White und Lindstrom erweitern damit maßgeblich das Verständnis von kastom über diesen im Wesentlichen auf eine Kontinuität mit der Vergangenheit verpflichteten Traditionsbegriff im Sinne von

\footnotetext{
10 White spricht in seinem eigenen Beitrag von ,"multivocal and multivalent inflections of custom" (WHITE 1993: 475).
} 
Hobwsbawm und Ranger um Tonkinsons (1993: 599; 2000) Sicht, demzufolge Tradition als Ressource konzeptioniert und von bestimmten (nicht allen) Mitgliedern einer Gruppe strategisch eingesetzt wird (oder auch nicht). KEESING (1993: 588-589) bekräftigt in seinem Nachwort zu den Beiträgen von Custom Today vor allem die wachsende Erkenntnis sowie die zunehmende Tendenz zu analysieren, dass und wie kastom-Diskurse mit Bezug auf die Vergangenheit vor allem in der Gegenwart verankert und auf die Zukunft hin ausgerichtet und im Falle von Unterdrückungen auch als Oppositionen konstruiert sind.

Ungeachtet der akademischen Debatten, die im Umfeld der zuvor genannten und weiterer Publikationen in den frühen 1990er-Jahren geführten wurden - und deren Zurückweisungen durch indigene Vertreter, die das konstruktivistische Verständnis von, invented traditions ${ }^{6}$ durch Ethnologen als neokolonial politisch werteten und entsprechend ablehnten, wobei das Verständnis von ,erfunden' zwischen Polen von Neukreation und Unwahrheit bis zu kultureller Kreativität und Ausdruck historischen Wandels variierten - entstand Knut M. RiO und Edvard Hviding (2011: 9) zufolge zunehmend ein Verständnis um die Verwobenheit von globalen Prozessen und heruntergebrochenen indigenen Perspektiven und Lebenswelten. ${ }^{11}$ Für die Autoren war das Konzept kastom „undoubtedly of the most importance, coined as it was by indigenous populations themselves so as to accommodate and appropriate colonialist visions of ,culture' and ,tradition“" (ebd., Hervorhebungen im Orig.). Graeme WERE (2015: 200) stellt heraus, dass kastom-Praktiken darüber hinaus auch politisch motivierte Antworten auf die Moderne sein können. Unabhängig davon, ob kastom als indigene Antwort auf koloniale Konfrontation (WHITE 1993: 476) und Moderne oder als eigenständiges indigenes Konzept verstanden wird, bezeichnet der Begriff auf abstrakter Ebene ein Konzept, das zum einen lokale Praktiken als Verdinglichung einer eigenen Kultur und zum anderen als ein Repertoire lokaler und nationaler Traditionen umschreibt (FOSTER 1992: 284) bzw. auf lokaler Ebene als Praxis und indigene Kategorie gleichermaßen verstanden werden muss (Ton ОтTO 1992).

\footnotetext{
"' Zu Beginn der Debatte kritisierten maßgeblich Richard HANDLER und Jocelyn LINNEKIN (1984), dass Hobbsbawms Traditionsverständnis dem landläufigen Terminus entspräche, ,Tradition' die interne Übergabe von ,cultural traits' (Kulturgrundeigenschaften) durch die Zeiten sei, woraus resultiere, dass temporäre Kontinuität die bestimmende Charakteristik von sozialer Identität sei. Dies bedeute ebenfalls, dass ,cultural traits' wie natürliche Objekte begrenzt, eigenständig und objektiv wahmehmbar seien. In dem Augenblick, in dem sie so verstanden werden und als alt oder neu, als traditionell oder modern charakterisiert werden, handele es sich weniger um eine Deskription als vielmehr um eine Interpretation. Daher müsse das Konzept von der westlichen Sicht losgelöst werden, könne ,Tradition' nicht länger auf den Kern vererbter ,cultural traits' referieren, sondern müsse als symbolische Konstruktion verstanden werden. Demnach könne ,Tradition' nicht im Sinne von Beschränktheit, Gegebenheit oder Essenz verstanden werden. Das Konzept beziehe sich vielmehr auf einen interpretativen Prozess, der sowohl Kontinuität als auch Diskontinuität verkörpere. ,Tradition' sei ein symbolischer Prozess, der vergangenen Symbolismus voraussetze und diesen kreativ reinterpretiere. Mit anderen Worten: ,Tradition' sei keine begrenzbare Wesenheit, aus abgegrenzten Bestandteilen aufgebaut, sondern ein Prozess von Interpretation, der die Bedeutung in der Gegenwart durch die Referenzbildung zu der Vergangenheit beimesse. Zur weiteren wissenschaftstheoretischen Debatte um The Invention of Tradition vgl. insbesondere die im Jahr 1992 von Margaret JOLLY und Nicholas THOMAS herausgegebene Oceania-Sonderausgabe The Politics of Tradition in the Pacific sowie Charles L. BRIGGS Beitrag aus dem Jahr 1996: The Politics of Discursive Authority in Research on the ,Invention of Tradition:
} 
Im Unterschied zu einem RIO \& HVIDING (2011: 10) zufolge in Teilen Melanesiens eher essentialistischen Kulturverständnisses (kalja) - mit Fokus auf Identität, Einheit sowie ewig eigene und unübertragbare Eigenschaften einer Unterscheidbarkeit - kann kastom ihrer Aussage nach auch als ,exchangeable, relational and partible intellectual property“ (ebd.) auf konkreter Ebene wie etwas behandelt werden, das ge-/verliehen, zerstört und verloren gegangen, aber auch eingetauscht oder anderweitig erworben wird. Auch Steffen DALSGAARD \& Ton Отто (2011) beschreiben traditionelle Praktiken im Spannungsfeld zwischen kastam als austauschbarem geistigem Eigentum und kalsa oder kulturellem Erbe als unveräußerlichem Eigentum. ${ }^{12}$ Ihrer Beobachtung nach stellt sich erst seit geraumer Zeit eine Trennung zwischen den Begriffen ein, etwa in der Manus-Provinz in Papua-Neuguinea (2011: 144). WERE (2015: 200) zufolge können diese traditionellen Praktiken (und Wertesysteme) - er bezeichnet sie als kastom activities - verändert, neuinterpretiert oder inhaltlich neu aufgeladen, idealisiert und erweitert eingesetzt werden. Nach seiner Erkenntnis mögen die Menschen ihr Leben zwar kastom-entsprechend leben, jedoch reflektieren sie dies, evaluieren und modifizieren, diskutieren und streiten darüber; wobei die Aushandlungsprozesse zunehmend politisieren. ${ }^{13}$ So stellt sich kastom (Tradition) als ein umstrittenes Feld dar, auf dem unterschiedlich positionierte Gruppen ihre partikulären symbolischen Formen und Inhalte voranbringen (TONKINSON 2000: 169). Kastom als derart verstandene Tradition eröffnet aus Sicht OTTOS (2011: 171) ,,a discursive or symbolic space for articulating intentions and interpretations, in other words for acting out agency“"

Insbesondere diese handlungsorientierte Sichtweise von kastom und Tradition möchte ich für den Umgang mit den hier untersuchten Artefakten zugrunde legen. Inwieweit traditionelle Tanzkleidung und -schmuck als Ressourcen zum Erreichen partikulärer, persönlicher oder kollektiver Ziele dienten und dazu beitrugen, kulturelle Inhalte voranzubringen und Intentionen und Interpretationen unterschiedlich positionierter Gruppen zu artikulieren (im Sinne von ausdrücken und konstruieren), und welche diese letztlich waren, soll in Kapitel 3 untersucht werden. Ebenso wird dort zu betrachten sein, ob aus indigener Perspektive Anzeichen für eine möglicherweise inhaltlich unterschiedliche Zuordnung traditioneller Praktiken zu kastom und kalja auszumachen sind, wie etwa im Falle des zuvor aufgeführten Beispiels aus der Manus-Provinz (vgl. DALSGAARD \& OTTO 2011). Meine weitere Ausführung kann nicht der Rekonstruktion einer historischen Genese von kastom-Praktiken in Santa Cruz dienen, da dies nicht Fokus meiner Forschung war (jedoch vielleicht in einem nächsten Schritt sinnvoll wäre), sondern sie wird aufzeigen, wie meine Gewährsleute (und die Tanzkleidung und der -schmuck) kastom in sehr unterschiedlichen Konfigurationen im Sinne von Aushandlungsräumen schufen, um teilweise als Einzelpersonen und teilweise als Gruppen

\footnotetext{
12 Diese beiden Transkriptionen der Begriffe kastom und kalsa entsprechen dem in der Manus-Provinz gesprochenem Papua-Neuguinea Tok Pisin.

13 Waren ehemals Debatten im Umfeld von Christianisierung, Dekolonisierung und Unabhängigkeitswerdung verankert, werden diese zunehmend durch solche um Nation Building und Teilhabe an Globalisierungsprozessen abgelöst (RANGER 2005: 335).
} 
durchaus heterodoxe Ziele und Inhalte gleichermaßen in wirtschaftlichen, umweltbezogenen, religiösen, sozialen und nicht zuletzt politischen Dimensionen zu realisieren.

\section{- Renaissance des Materialisierten oder des Materiellen?}

Mit dem eingangs erwähnten ,material turn' in der Ethnologie kann wissenschaftstheoretisch betrachtet die Tendenz umrissen werden, die mit der Begründung der akademischen Ethnologie eingetretene Trennung von ethnologischer und archäologischer Forschung zu Artefakten in Museen als ,Materielle Kultur ${ }^{6}$ von einer universitären Forschung zu sozial- und kulturanthropologischen Themen - und einer damit einhergehenden Abwendung vom Materiellen - wieder aufzuheben. Die nachfolgende Darstellung ist ein kurzer Überblick und stellt nur einen Auszug mehr oder weniger aktueller Positionen dar, ohne Anspruch auf Vollständigkeit zu erheben. Ziel meiner Darstellung ist es, grundlegende Positionen zu skizzieren und den von mir ausgewählten theoretischen Ansätzen einen Rahmen zu geben.

Unter der Bezeichnung, Materielle Kultur' werden abhängig von den jeweiligen inhaltlichen Nuancen im Allgemeinen verschiedene Konzepte subsumiert. In der englischsprachigen Literatur sind es Begriffe wie object, thing, artefact, goods, commodities; im Deutschen tauchen entsprechend auf Objekt, Ding, Artefakt, Gut, Ware, aber auch Gegenstand, Sache, Werk oder Zeug. Die Möglichkeit von Transformationen zwischen diesen verschiedenen „Zuständen` im Rahmen ihrer Zirkulation thematisierte Arjun APPADURAI (1986) in dem Sammelband The social life of things. The commodities in cultural perspective. Durch dieses neue Verständnis wurden die Dinge zu „dynamic, processual entities entangled in historical and cross-cultural webs of socialty and significance“"(Liana CHUA \& Amiria SALMOND 2012: 131; vgl. auch Brigitta HAUSER-SCHÄUBLIN 2012: 76-79).

Diskutiert werden heute unterschiedliche Verständnismöglichkeiten von ,Materieller Kultur', etwa von und in den Handlungen mit ihr, ihre Rolle für die Identität der Menschen und für die Konstitution von Gruppen, für die Konstruktion von Wissen oder für Verständnisse der Welt(-Ordnung) (vgl. etwa Hans Peter HAHN 2005; Ian WOODWARD 2007; CHUA \& SALMOND 2012; HAHN 2015). Überlegungen zur ,Natur der Dinge‘, zur ,materiellen Welt', führen zwangsläufig zu der grundlegenden Frage, ob sie etwa eine ,Materialisierung ${ }^{6}$ von Vorstellungen bzw. Konzeptionen darstellen und damit eine nachgelagerte Rolle im menschlichen Denken und Handeln einnehmen oder eben nicht - und was sie in dem Fall bedeuten, wie sie dann verstanden werden können (vgl. Ulla JOHANSEN 1992 und die anschließende Diskussion in der Zeitschrift für Ethnologie 118; BELL \& GEISMAR 2009). Letztlich geht es um die Frage, ob eine Abgrenzung zwischen materieller und immaterieller Kultur (auch wenn diese miteinander verbunden sind), ein daraus resultierender Dualismus von Geistigem und Materiellem, von ,Subjekt ${ }^{\star}$ und ,Objekt ${ }^{\star}$ zielführend, gar richtig oder falsch ist. Gerade in den nelo-Tänzen gab es aber keine derartige Trennung. Die Tänzer bildeten mit ihrer Kleidung und mit ihrem Schmuck eine Einheit, die ohne den jeweils ,Anderen“ unmöglich gewesen wäre.

Die Suche nach möglichen Bedeutungen von Artefakten/Dingen folgt dem Verständnis, nach dem ,Materielle Kultur' als eine Vergegenständlichung von Vorstellungen einer Person 
oder Gesellschaft im Sinne einer Repräsentation gesehen wird. Als denkbare Analyseebenen ergeben sich Hans Peter HAHN (2005) zufolge zwei sich durchaus ergänzende Perspektiven: Zum einen könne Bedeutung im Sinne von Zusammenhängen von Strukturen und Sinn, zwischen Dingen und Menschen oder zwischen den Dingen, im semiotischen bzw. strukturalistischen Sinne Dinge als Träger von Bedeutung (Ian HODDER 1989) oder analog zu Text (TILlEY 1990) verstanden werden. ${ }^{14}$ Durchaus ergänzend sieht Hahn eine andere Bedeutung der Dinge im Sinne einer subjektiven Wahrnehmung und Erfahrung, als eine Ableitung von subjektiver Relevanz der Dinge (Mihali Csikszentminalyi \& Eugène RochBerGHOLTON 1981). Im Unterschied zu den nachfolgenden Positionen verbleiben die von Hahn verfassten Artikel meist auf der Ebene der Bedeutung von ,Materieller Kultur und deren Kontextabhängigkeit. Dieser theoretische Zugang zu den Dingen entspricht dem von mir zuvor als „passiv“ bezeichneten Verständnis der Artefakte, als bedeutungsaufgeladen und repräsentativ, und kann nicht erklären, wie Artefakte aus sich heraus zu verschiedenen Anlässen unterschiedliche Inhalte vermitteln, Gefühle und Stimmungen, Vorstellungen oder Erinnerungen hervorrufen, also aktiv etwas bewirken.

Unter dem Dach ,Material Culture Studies ${ }^{6}$ (MCS) verbergen sich unterschiedliche Positionen. Vereinfacht dargestellt bezeichnet es eine Richtung, die vorrangig auf die Materialität von Dingen fokussiert und jede weitere theoretische oder methodische Verortung ablehnt. Hierzu zählen insbesondere das seit 1996 veröffentlichte Fournal of Material Culture (Miller \& TiLley 1996) sowie als ihr bekanntester Vertreter Daniel MiLler (1987; 1998), der durch ethnografische Arbeiten zu Konsum bekannt wurde. Die MCS verstehen sich wie auch die Akteur-Netzwerk-Theorie (ANT, vgl. weiter unten) als Korrektiv zu einer anthropozentrischen Sozialtheorie, die in ,Materieller Kultur ${ }^{6}$ ausschließlich Vergegenständlichungen von Subjekten, sozialen Beziehungen oder einer Gesellschaft sieht. Den Vertretern geht es u. a. darum, die Art und Weise zu verstehen, auf welche die Dinge den menschlichen Körper einengen, ausdehnen oder begrenzen und welche Signifikanz, Bedeutung und Macht ihnen bei der Konstituierung sozialer Beziehungen zukommen (TILLEY et al. 2006: 4). CHUA \& SALMOND (2012: 135) zufolge ist ,Materielle Kultur' nach Miller kein äußerlicher Aspekt, sondern bestimmt kulturelle Bedeutungen und soziale Ordnungen wesentlich mit, ist also unabdingbar konstitutiv. Der Prozess der Objektivierung kreiert simultan Subjekte und Objekte - als wechselseitige Konstrukte gehen sie aus dem jeweils Anderen hervor. Miller plädiert für eine weniger philosophische und mehr ethnografisch basierte Sichtweise aus dem Blickwinkel der Menschen, die die Dinge nutzen. Nach Meinung von Haidy GeISMAR (2011: 213) zeigt Miller insbesondere, wie Menschen Alltagsgegenstände nutzen, um über ihre alltäglichen Erfahrungen hinausgehen zu können und um durch sie die in seiner Sicht universalen menschlichen Erfahrungen, etwa Verlust, Trennung von Bezugspersonen, Tod, Trauer, soziale Angst und Liebe, zu vermitteln. Dabei stellt MiLLER

\footnotetext{
${ }^{14}$ Im deutschsprachigen Bereich publiziert vorrangig Hans Peter Hahn zu ,Materieller Kultur', vgl. etwa DERS. 2005 und 2015 und als Mitherausgeber eines entsprechenden Handbuchs (SAMIDA et al. 20 I4).
} 
(1987) Geismar zufolge ,the mutual constitution of persons and things“ heraus und entwickelte (2005) eine Theorie der Materialität „as immanent to sociality“, bis er zuletzt (2008 und 2009) postulierte, dass Menschen sich mit ihren Besitztümern darstellen, d. h. machen (GEISMAR 2011: 213). BELL \& GEISMAR (2009: 4) plädieren daher für einen Blick, der die Wechselbeziehungen von Menschen und Dingen in den Vordergrund stellt, der sie ,as both creative processes and as products of these complex entanglements" positioniert. Dabei weisen sie darauf hin, dass Konzepte, Überzeugungen oder Sehnsüchte zunächst Gestalt annehmen, bevor sie für eine gesellschaftliche Verwendung permanent gewandelt werden (2009: 5-6). Mit anderen Worten: Die Ideen müssen erst vergegenständlicht werden. Hierdurch erhalten die Objekte eine soziale Bedeutung und werden Teil sozialer Handlungen (2009: 19). Auch wenn dieses Verständnis von Dingen eine wechselseitige Konstitution von Personen und Dingen im Sinne einer dialektischen Beziehung attestiert, verbleibt diese auf einem Dualismus von Geistigem und Materiellem und gesteht den Dingen als solchen keine eigene Daseinsberechtigung zu: Vor dem Ding/Artefakt kommt stets die Idee. So sehe ich auch diese Ansätze für den Zugang zu meinem Datenmaterial als noch unzureichend. Die Frage nach der Art und Weise, wie aus Männern und der Tanzkleidung und dem -schmuck Einheiten wurden, und wie dieselben Artefakte auch losgelöst von den Tänzen zu unterschiedlichen Anlässen verschiedene Reaktionen hervorriefen, kann ich weiterhin noch nicht zufriedenstellend darstellen.

Andere ,Schulen“ verfolgen das Ziel, gerade diesen Dualismus aufzuheben und den Dingen eine mehr oder weniger gleichberechtigte Rolle in Beziehung zum menschlichen Handeln zuzuweisen, was einige Autoren als ,agentive turn' bezeichnen (CHUA \& SALMOND 2012: 132). Statt Artefakte/Dinge als Metaphern, Symbole, Texte, Vergegenständlichungen und Repräsentationen zu verstehen, beschäftigen sie sich mit Fragenstellungen, wie z. B. was können Dinge tun, was passiert im Prozess der Wahrnehmung von Dingen, wie wird das Handeln mit Dingen verstanden, welche Erkenntnispotentiale werden im Zusammenwirken von Menschen und Dingen freigesetzt, welche Handlungsfähigkeit und -macht kann von den Dingen ausgehen, letztlich was bewirken die Dinge. Vertreter dieser gedanklichen Ausrichtung verfolgen dabei die Frage, wie die Artefakte/Dinge soziale Handlung ermöglichen, anstatt diese als passive Empfänger menschlichen Denkens und Handelns zu betrachten. Die historische Gleichsetzung von Personen mit Subjekten und Dingen mit Objekten soll aufgehoben werden - und mit ihr die Konzeption von Artefakten als „bounded, material and inanimate entities, categorically distinct from intentional subject-persons" (CHUA \& SALMOND 2012: 132). In diesem Zusammenhang wird ein vormals an die Intentionalität des Subjekts gebundener Handlungsbegriff erweitert: ,[... [ Dinge handeln nicht allein, sie sind Mitspieler, Beteiligte, sind Handlungsträger neben anderen, erweitern diese, ergänzen, übersetzen, stabilisieren sie. Dabei werden sie oft Teil von praktischen Netzwerken, Assoziationen, die durch ihre Verknüpfung von Menschen und Dingen Ergebnisse hervorbringen, die es ohne dieses Zusammenspiel nicht gäbe.“ (Karl H. HÖRNING 2015: 172) Mit diesem hand- 
lungsorientierten Verständnis sollte es möglich werden, die vielseitigen ,Auftritte` der Artefakte darzustellen. Daniel MiLler (2005: 1 1) zufolge sind die beiden aktuell einflussreichsten Ansätze zu einem handlungsorientierten Verständnis von Artefakten/Dingen zum einen die Akteur-Netzwerk-Theorie (John LAW 1992; Michel CaLlon 2006 und Bruno LaTOuR 2005, 2008, 2010, 2014) und zum anderen ALFRED GeLLS Art and Agency (1998). ${ }^{15}$ Im Folgenden stelle ich die für die Untersuchung meiner Daten hilfreichen analytischen Perspektiven dieser beiden Theorien vor, die sich aber hinsichtlich ihres konkreten Verständnisses zu der Handlungs-und Wirkmacht hinsichtlich der Quelle der Handlungsintention unterscheiden. Diese sehen die Vertreter der ANT als auch Gell bei den Menschen, wobei Erstere sie konkret in den Übersetzungsmomenten bei der Genese und Ausprägung von Netzwerken verteilt verorten und Letzterer sie den Produzenten und Empfängern und nur nachgelagert (sekundär) den Kunstwerken attestiert, wie ich zeigen werde.

- Eigenständige Substanzen werden zu ,Komplizen': Akteur-NetzwerkTheorie (ANT)

„[W]hen an agent is introduced into the world, its disposition (or its competence, its substance, its essence - the word does not matter too much) is always connected with its action (or its performances, or its actualities, its attributes, its properties - here again the word does not matter).“ (LATOUR 2014: 21, Hervorhebungen im Orig.)

„You have to show what it does if you wish to say what it is. “ (2014: 16)

Die ANT betrachtet ,das Soziale‘ als einen Pfad von Assoziationen zwischen heterogenen Elementen. Sie versteht in dem gemeinsamen Handeln von menschlichen und nicht menschlichen Entitäten die Basis aller Beziehungen (LATOuR 2005: 5, 71). Statt Subjekte und Objekte, Soziales und Materielles, Natur oder Kultur als eigene Sphären zu betrachten, fokussiert die ANT Hybridität und Netzwerke, in denen einzelne Elemente (Aktanten) zusammenkommen. LATOUR (2010: 1, 8) sieht den Begriff ,Netzwerk ${ }^{6}$ als eine Metapher, mittels derer soziotechnische Assemblagen und Handlungen (das Werk) menschlicher und nicht menschlicher Hybriden abgebildet werden. Das Netzwerk wandelt zuvor ,eigenständige Substanzen', die aufgrund ihrer Eigenschaften wichtig für das Netzwerk sind, in ,Alliierte‘ oder ,Komplizen` des Netzwerkes, um sich selbst zu erhalten. So werden aus Objekten konkrete Entitäten und die Substanzen ,from a matter of fact to a matter of concerns" transformiert (2010: 5) und Handlungen umverteilt (2010: 2) und umgekehrt (2010: 5, 7). ${ }^{16}$ Ein

\footnotetext{
15 Michel Callon, Bruno Latour und John Law gelten als Begründer der Akteur-Netzwerk-Theorie (vgl. André BELLIGER \& David J. KRIEGER 2006: 577).

${ }^{16}$ Aus Gründen der Klarheit werde ich im Folgenden die Akteur-Netzwerke, die sich im Rahmen meiner Analyse darstellten, als solche mit einfachen An- und Ausführungszeichen kenntlich machen. Diese Netzwerke unterscheiden sich von den in der Umgangssprache als Netzwerke bezeichnete Verbindungen von Menschen (persönliche oder soziale Netzwerke) oder rein technischen Apparaturen (Computernetzwerke). Es sind soziotechnische Verbindungen, die gemeinsam etwas umwandeln und als neue Einheit schaffen.
} 
Netzwerk nach diesem Ansatz entspricht nicht einem sozialen Netzwerk im herkömmlichem Sinne, das informelle soziale Interaktionen oder lose Selbstorganisationen beschreibt. Im ANT-Verständnis liegt der Fokus auf, -werk', den Umwandlungen und Umverteilungen von Handlungen. Die in derartigen Netzwerken agierenden Entitäten bezeichnet Latour gleichermaßen als Agenten, Akteure oder Aktanten (2010: 5). Um sie definieren zu können, müssen die Attribute im Netzwerk analysiert werden: ,,an actor is nothing but a network, except that a network is nothing but actors" (ebd.). ${ }^{17}$ Da Latour den Akteur nicht als ursprüngliche Quelle von Handlungen, sondern durch Entitäten beeinflusst oder gar transformiert versteht, ist die eigentliche Handlungs- und Wirkmacht in diesen zu suchen und darzustellen (2005: 52, 60). Sie ist zwischen den menschlichen und nicht menschlichen Entitäten verteilt. Menschliche Intention, Handeln und Materialität existieren zusammen, sie können nicht voneinander getrennt werden (CHUA \& SALMOND 2012: 132). Diese komplementäre Betrachtung erachte ich für ein Verständnis der Artefakte im vorliegenden Fall als zielführend. Zum einen ermöglicht sie den Blick auf die Dinge in der Aufführung, wenn ich diese etwa als Akteur-Netzwerk ,nelo-Tanz' betrachte, in dem verschiedene Agenten/Akteure/Aktanten - Latour verwendet diese Begriffe synonym - zusammentreffen, um gemeinsam etwas Neues zu schaffen, wobei die Handlungs- und Wirkmacht auf alle Entitäten verteilt ist. Damit erlaubt sie, die Tanzkleidung und den -schmuck als einzelne Entitäten zu betrachten, ihre Attribute/Essenzen (Substanzen) zu untersuchen und sie wiederum als eigene Netzwerke zu verstehen. Wenn ich konsequent weiterginge, müsste ich diese wieder nach ihren Agenten untersuchen, die sich wiederum als neue Netzwerke darstellen. Damit stellt sich die konsequente Verfolgung dieses Akteur-Netzwerk-Konzeptes als in der Praxis äußerst schwierig, wenn nicht gar unmöglich dar, weil sich hinter jedem Aktanten fast immer wieder ein Netzwerk öffnet, womit eine Analyse unmöglich wird.

Marilyn STRATHERN (1996: 523) weist in ihrer Kritik an der ANT u. a. zu Recht auf diese Schwierigkeit hin und schlägt vor, die Netze zwecks Analyse ,abzuschneiden'bzw. ein weiteres Ausdehnen zu unterbinden. Als Ansatzpunkt schlägt sie vor: „[]f we take certain kinds of networks as socially expanded hybrids then we can take hybrids as condensed networks. That condensation works as a summation or stop." (ebd.) Meines Erachtens bezeichnet LAW (1992: 384-385) mit dem Konzept der ,Punktualisierung' genau diese Vorstellung einer Kondensation eines Netzwerkes. Dem Autor zufolge kann eine neue Entität (in meinem Fall die des nelo-Tänzers oder der Tanzkleidung und des -schmucks) nicht nur als Netzwerk heterogener Beziehungen, sondern auch als deren Effekt verstanden werden. Er führt weiter aus, dass das vermeintliche Auftreten einer Einheit mit dem Verschwinden eines Netzwerks (in der Wahrnehmung) als ein Prozess von Vereinfachung einhergeht. Grundsätzlich seien alle Phänomene Effekte oder Produkte eines heterogenen Netzwerks. In der Praxis könnten

\footnotetext{
17 Als Beispiel führt er aus der Physik den ,Welle-Teilchen-Dualismus' auf, der besagt, dass Materie je nach Betrachtung als Teilchen (ANT: Akteur) oder als Welle (ANT: Netzwerk) erklärt werden kann und dass eine komplementäre Beschreibung als angemessen präferiert wird (LATOUR 20I0: 5, http://www.spektrum.de/lexikon/ physik/welle-teilchen-dualismus/ I 5525, letzter Zugriff am 18.5.20 I6).
} 
die endlosen Verästelungen und Auswirkungen eines Netzwerkes aber kaum bewältigt, die Komplexität eines Netzwerks kaum erkannt werden. Wenn ein Netzwerk als eine Einheit agiere, verschwinde es in der menschlichen Wahrnehmung und werde durch die konkrete Handlung und einen vermeintlich einfach wahrzunehmenden Urheber ersetzt, im vorliegenden Fall die nelo-Tänzer als auch ihre Kleidung und ihr Schmuck. Zeitgleich erlösche der Entstehungsweg, in dem der Effekt generiert wurde; er sei nicht länger sichtbar oder relevant. Diese Prozesse der Vereinfachung bezeichnen Law zufolge Akteur-Netzwerk-Theoretiker als „punctualizations“ (ebd.). Für die weiteren Analysen verstehe ich die nelo-Tänzer und die Artefakte als Punktualisierung in diesem Sinne. ${ }^{18}$ Die nelo-Tänzer führen konkrete Handlungen - etwa den Tanz - aus, durch die die eigentlichen, sie konstituierenden AkteurNetzwerke in unserer Wahrnehmung ersetzt werden und die agierenden Tänzer als vermeintlich einfach wahrzunehmende Urheber erscheinen. Die Artefakte treten für einen bestimmten Anlass in Erscheinung und vermitteln etwa bestimmte mehr oder weniger klar erkennbare kastom-Aspekte, werden nur verkürzt von uns wahrgenommen. Dennoch sind und bleiben die nelo-Tänzer als auch die Artefakte ,nur' Effekte bzw. Kondensate ihrer jeweiligen heterogenen Akteur-Netzwerke. Akteur-Netzwerke zwecks ihrer Analyse entlang dieser Kondensationspunkte oder Punktualisierungen einzugrenzen, also dort für die Analyse ,herauszuschneiden', wo sie sichtbar werden, erachte ich für meine Arbeit daher als zielführend. Aus diesem Grund analysiere ich die ,nelo-Tänzer im Folgenden grundsätzlich komplementär als a. Entitäten des Akteur-Netzwerks ,nelo-Tanz‘ und b. eigene Akteur-Netzwerke. In Letzteren spielen die im Fokus meiner Untersuchung stehenden ,Artefakte' eine sichtbare Rolle, warum ich sie anschließend ebenfalls komplementär als a. Entitäten des Akteur-Netzwerkes ,nelo-Tänzer' und b. eigene Netzwerke analysieren werde.

Die verschiedenen Akteur-Netzwerke ,nelo-Tanz', die ich während meiner Aufenthalte ausmachen konnte, füge ich zwecks Analyse ihren zugrunde liegenden Anlässen entsprechend als Gruppen von kastom-Konfigurationen zusammen (Kap. 3). Das Einbinden der Akteure mit besonderem Fokus auf die nelo-Tänzer und die Artefakte untersuche ich bei dem Entstehen eines konkreten Akteur-Netzwerkes (,nelo-Tanz für Jonas Kepule‘ in Kap. 5). Bei der Darstellung des Entstehungsprozesses orientiere ich mich an CALLONS (2006) Beschreibung von Machtverhältnissen bei der Domestikation von Kammmuscheln und Fischern der St. Brieuc-Bucht in Frankreich. Der Autor bezeichnet die Akteur-Netzwerk-Theorie dabei auch als „Soziologie der Übersetzung““ (2006: 135). In seiner Beschreibung zeigt er, wie Akteure ihren gegenseitigen Handlungsspielraum und die ihnen zur Verfügung stehenden Wahlmöglichkeiten festlegen, woraus die Fähigkeit bestimmter Akteure erwächst, andere zu einer Kooperation zu bringen, und wie letztlich dadurch ein heterogenes Akteur-Netzwerk entsteht (2006: 135-136). Unter ,Übersetzung' versteht CALLON einen Prozess von verschiedenen Phasen, in denen Akteure ihre Identitäten, ihre Möglichkeiten zu Handeln sowie ihre

\footnotetext{
${ }^{18}$ Die Vorstellung eines, auf den Punkt gebrachten' und in einer vereinfachten Wahmehmung als Einheit betrachteten agierenden Akteur-Netzwerks - hier ,nelo-Tänzer' - entspricht m. E. auch dem Personenkonzept des ,Dividuums" in der New Melanesian Ethnography; vgl. Anm. 24.
} 
Handlungsspielräume aushandeln und abgrenzen, und in dessen Verlauf es zu Verschiebungen und Umwandlungen von Zielen und Interessen kommt (2006: 146, 168). ${ }^{19}$,Übersetzung beschreibt demnach einen „Mechanismus, durch den die soziale und die natürliche Welt fortschreitend Form annehmen. Das Resultat ist eine Situation, in der bestimmte Entitäten andere kontrollieren." (2006: 170) In diesem Prozess macht CALLON vier ,Momente" aus, in denen die Akteure „sich selbst und ihre Definition der Situation auf andere [...] übertragen“ (2006: 135). Callon (2006: 135, 146-164) bezeichnet sie mit „Problematisierung“ (Akteure versuchen andere davon zu überzeugen, sich für deren Belange unentbehrlich zu machen, Schaffen eines geteilten Problembewusstseins), „Interessement“ (Akteure weisen anderen Akteure Rollen zu und fixieren sie darauf, Verbündete zu suchen und Allianzen zu schmieden), „Enrolment“ (Akteure definieren ihre Rolle und setzen sich zueinander in Beziehung) und „Mobilisierung“ (Akteure wählen Sprecher unterschiedlicher Gruppierungen aus und stellen deren Repräsentationsfähigkeit sicher) und weist darauf hin, dass sie sich in der Realität überschneiden können (vgl. auch BELLIGER \& KRIEGER 2006: 40-41). In meiner Darstellung der Entstehung eines nelo-Tanzes (Kap. 5.1) bezeichne ich sie als Übersetzungsmomente eins bis vier.

Tanzkleidung und -schmuck komplementär als Entitäten in den Akteur-Netzwerken ,neloTänzer' und als eigene Netzwerke zu verstehen, erfordert zunächst, ihren Beitrag bei dem Werden eines nelo-Tänzers zu untersuchen (Kap. 5.1 und Kap 5.2). Sie darüber hinaus als eigene Akteur-Netzwerke zu untersuchen bedeutet grundsätzlich, sie allumfassend zu betrachten. Während meiner Erhebung bin ich auf ihre Attribute und Essenzen sowie deren Wertschätzung durch andere Beteiligte eingegangen (Kap. 4 und Kap 5.2) und habe die Personen befragt, die sie herstellen (Kap. 6). Für eine weiterführende Beschreibung aller beteiligten Entitäten an diesen Akteur-Netzwerken, wie es für eine dichte Beschreibung im Sinne der ANT notwendig wäre (LATOUR 2004: 69-70), habe ich aber aufgrund des Fokus auf Kleidung und Schmuck nicht in zufriedenstellendem Maße Daten erhoben und kann diese folglich hier nicht leisten. Ebenso würde eine entsprechende Darstellung den Rahmen dieser Arbeit, wie weiter oben dargelegt, sprengen, so dass ich bei dem ,Schnitt ${ }^{6}$ verbleibe und dort ,stoppe', wo die Artefakte in der Öffentlichkeit auftraten. In einem nächsten Schritt wäre hier wieder anzusetzen und die jeweiligen Akteur-Netzwerke, etwa das Gewinnen der Rohstoffe im Einzelnen, das Weiterleben der Artefakte nach den Tänzen oder dem Verkauf

\footnotetext{
19 In der Einführung ihres Handbuchs zur Akteur-Netzwerk-Theorie stellen BELLIGER \& KRIEGER (2006: 37-43) die Performanz der ,Übersetzung' als konstituierende Größe beim Entstehen eines neuen Akteur-Netzwerks heraus: „Die Gesamtheit der Übersetzungsbemühungen eines Akteurs macht sein Handlungsprogramm aus. Das durch Übersetzung entstandene Handlungsprogramm verändert die beteiligten menschlichen und nicht menschlichen [sic] Akteure und Vermittler. Sie nehmen Identitäten, Funktionen und Rollen ein, die sie alleine nicht erfüllen könnten. Dies weist darauf hin, dass Akteure auch Akteur-Netzwerke sind. Akteure sind komplex. Übersetzung schafft nicht nur Akteur-Netzwerke, sondern hybride bzw. heterogene Akteure." (2006: 42) Zum zentralen Begriff der Übersetzung in der ANT vgl. auch LAW (1992: 380, 385-389) und LATOUR (2005: 64-65; 2006: 198-199; 20 I0: 5). Madeleine AKRICH \& Bruno LATOUR (2006: 400-40I) führen vier unterschiedliche Möglichkeiten von Verschiebungen auf: aktorial (zwischen Akteuren), räumlich, zeitlich und materiell (das Ausdrucksmittel wandelt sich um).
} 
oder nach deren Zerstörung zu untersuchen. Lediglich ein Teilaspekt davon, nämlich der Wandel zu Sammlungs- oder Museumsobjekten findet sich in Kapitel 4.

\section{- Handlungsmacht und Intentionen: ,Art Nexus ${ }^{6}$}

„For many scholars, and indeed in much common-sense thinking about art, it is axiomatic that art is a matter of meaning and communication. This book suggests that it is instead about doing." (THOMAS 1998: ix, Hervorhebung im Orig.)

Wie gerade dargelegt, traten die Tanzkleidung und der -schmuck auch außerhalb der Akteur-Netzwerke ,nelo-Tanz ${ }^{6}$ und ,nelo-Tänzer zu weiteren Anlässen auf, wurden etwa von ihren Produzenten losgelöst vom nelo-Tanz als kastom- oder traditionelle Artefakte verkauft. Unabhängig davon, dass einige Artefakte ihre Hersteller, Käufer und nicht zuletzt mich mit ihren ästhetischen Qualitäten ansprachen und motivierten, sich intensiver mit ihnen zu beschäftigen - sprich wie sie auf uns wirkten, stellten sie für die Produzenten konkrete Handlungsräume dar, etwa Einkommensmöglichkeiten, soziale Anerkennung oder das Fortführen von Tätigkeiten der Elterngeneration. Sie waren für sie Mittel, um mit anderen in Beziehung zu treten. Grundsätzlich wäre diese von den Herstellern ausgehende Intention in Bezug auf die Artefakte durch die ANT erklärbar, nämlich dann, wenn man den Hersteller als eigenes Akteur-Netzwerk mit eigenen Übersetzungsmomenten versteht. Da mir zu den möglichen Aktanten dieser Netzwerke aber nur in unzureichendem Maße Informationen vorliegen, kann ich die Theorie/Methode zur systematischen Analyse an dieser Stelle nicht nutzen.

Dennoch möchte ich die Interaktion zwischen den Artefakten, Auftraggebern, Herstellern und Abnehmern beleuchten, da ich hier weitere Handlungs- und Wirkmacht von Artefakten vermute. Dazu greife ich für diese Fragestellung auf die zweite von MILLER (2005: 11) genannte handlungsorientierte ethnologische Theorie zurück, die ihm zufolge hilfreiche analytische Perspektiven bietet.

In seinem posthum erschienenen Buch Art and Agency entwickelt Alfred Gell eine „Anthropological Theory of Visual Art" und arbeitet darin verschiedene Formen und Stufen von Handlungsmacht und Wirkvermögen von Personen (ihren Produzenten und Empfängern) und Kunstwerken heraus (GELL 1998) - trennt also zwischen ,Subjekt' und ,Objekt ${ }^{6}{ }^{20}$ Statt auf einzelne Bedeutungen von Kunstwerken/Artefakten (z. B. als Zeichen) zu fokussieren, schlägt er andererseits vor zu betrachten, wie Objekte und Personen innerhalb ihrer sozialen

\footnotetext{
${ }^{20}$ Ich halte es für folgerichtig, Gells Kunstanthropologie auch für die hier untersuchten Tanzkleidungs- und -schmuckstücke (insbesondere die historischen Artefakte) anzuwenden, da Gell unter Kunstwerken sichtbare indices (also keine verbalen oder musikalischen Formen, obwohl diese meist nicht voneinander zu trennen sind, wie er einräumt) versteht, die reale, physische Dinge sind, einzigartig und identifizierbar, und etwas im Betrachter auslösen (GELL 1998: 13). Sofern sie diese Kriterien erfüllen, ,,we have no a priori means of distinguishing ,artefacts' from ,works of art"' (Gell 1996 zitiert in GELL 1998: 16). Dass die Tanzkleidung und der -schmuck diese Kriterien erfüllen, erörtere ich hinreichend in Kap. 5.
} 
Beziehungen auf ihre Milieus und gegenseitig auf sich wirken - spricht also beiden eine Wirkmacht zu, grenzt Dinge von Menschen mit Bezug auf diese Fragestellung als nicht ab. ${ }^{21}$ In seiner, wie er explizit hervorhebt, sozial- (und nicht geistes-)wissenschaftlich verorteten Kunstanthropologie theoretisiert GELL keine ästhetischen Prinzipien verschiedener Kulturen, sondern ,the mobilization of aesthetic principles (or something like them) in the course of social interaction“ (1998: 4). Ihm zufolge bestehen die menschlichen Reaktionen auf Kunstwerke weniger in ästhetischen Gefühlen als in sozialen emotionalen Antworten wie etwa Ehrfurcht, Faszination, Begierde oder Angst (1998: 6). Nach Gell ist Kunst keine Kommunikation von symbolischer Bedeutung, keine visuelle Sprache, sondern umfasst ,agency, intention, causation, result, and transformation" (ebd., Hervorhebungen im Orig.). Er versteht Kunst ,as a system of action, intended to change the world rather than encode symbolic propositions about it“" (ebd.). In Abgrenzung zu einem semiotischen Ansatz sei ihm zufolge dieser handlungszentrierte Zugang zu Kunst wissenschaftstheoretisch inhärent anthropologisch, weil mit ihm eine praktische, mediatorische Funktion von Kunstobjekten im sozialen Prozess einhergehe und keine Interpretation von Objekten verfolge, so als seien sie Text (ebd.).

In einem Analyserahmen sozialer Handlungsmöglichkeiten, den er ,Art Nexus ${ }^{6}$ nennt, zeigt er verschiedene Beziehungen auf, die eben diese Veränderungen bezwecken, statt symbolische Aussagen darüber kodieren. Innerhalb dieses spezifischen Analyserahmens sieht er (wie die ANT) Personen und Artefakte als äquivalent, die synonym untersucht werden können. Methodisch regt er an, bei den Objekten die Eigenheiten der Charakteristika herauszuarbeiten und hervorzuheben (GELL 2009: 210). Gell betrachtet die Person als mit einer Intention handelnden Kraft, weshalb er sie als ,primary agent' bezeichnet und als Initiator von Handlungen sieht; sie kann die ,secondary agency ${ }^{6}$ von Artefakten aktivieren (GELL 1998: 17, 21). An anderer Stelle führt er allgemein gehaltener aus, dass Agency ,a global characteristic of the world of people and things in which we live, rather than [...] an attribute of the human psyche, exclusively“ sei (1998: 20) oder dass etwa Kunstobjekte wie Personen angesehen werden sollten (1998: 9) oder Objekten Agency innewohnt (1998: 17). ${ }^{22}$ Dem Autor zufolge laufen Handlungs- und Wirkmacht und Intention zusammen, in ,a culturally prescribed framework for thinking about causation, when what happens is (in some vague sense) supposed to be intended in advance by some person-agent or thing-agent. Whenever an event is believed to happen because of an ,intention' lodged in the person or thing which initiates the causal sequence, that is an instance of ,agency" (ebd., Hervorhebungen im Orig., Kursivierungen O. L.). Unter einem sozialen Agenten versteht er dementsprechend eine Person und/oder ein Artefakt, ,who/which are seen as initiating causal sequences of a particular type, that is, events caused by acts of mind, or will or intention, rather than the

\footnotetext{
21 Zu Kritik an Gells Verständnis der Subjekt-Objekt-Beziehung vgl. etwa James LEACH (2007).

22 Liana CHUA \& Mark ELLIOT (20I 3: I-4) legen dar, wie mannigfaltig die Verständnismöglichkeiten von Gells Art and Agency sind. Georgina BORN zufolge scheint es, ,,that we all have our own Alfred Gell - that he is a multiplicty; and that Art and Agency is a multiplicity [... ." (2013: I30, Hervorhebung im Orig.)
} 
mere concatenation of physical events“ (1998: 16). Gell zufolge können Artefakte wie Menschen über eine social agency verfügen. Diese sei aber immer relational als Index (im Sinne von Ergebnis und/oder Instrument) menschlicher Interaktion zu verstehen. ${ }^{23}$ Aufgrund dessen beschreibt er Kunstwerke als ,,secondary agents" in conjunction with certain specific (human) associates“" (1998: 17). Gell zufolge verfügen Menschen ihrerseits über eine ,distributed personhood', deren Handlungs- und Wirkmacht nicht nur in ihren Körpern, sondern (simultan) an unterschiedlichen Orten und zu unterschiedlichen Zeiten zum Ausdruck kommen kann und zwar (zu großen Teilen) über Artefakte (1998: 21, 137-143).24. „I describe artefacts as ,social agents ${ }^{6}$ not because I wish to promulgate a form of material-culture mysticism, but only in view of the fact that objectification in artefact-form is how social agency manifests and realizes itself, via the proliferation of fragments of ,primary ${ }^{6}$ intentional agents in their ,secondary' artefactual forms“ (Gell 1998: 21). Für meine ursprüngliche Fragestellung nach der Bedeutung von Tanzkleidung und -schmuck - und an dieser Stelle konkret nach einer mögliche Handlungs- und Wirkmacht - scheint mir die Frage, ob deren Agency primär oder sekundär angelegt ist, also ein ,entweder ... oder ${ }^{6}$ weniger zielführend zu sein, als herauszuheben, dass auch Artefakte über eine soziale Agency verfügen. Aktuelle Debatten um Agency hinterfragen etwa die Richtigkeit oder Notwendigkeit einer meist grundlegenden Dichotomisierung von Subjekt und Objekt und schlagen ein ,sowohl ... als auch vor, ein Agency-Konzept, nachdem sich diese situationsabhängig konfiguriert und dynamisch wandelt (vgl. Rachel MORGAIN \& John P. TAYLOR 2015). ${ }^{25}$

Alfred Gells Kunstanthropologie ist grundsätzlich relational, setzt Menschen und Kunst/Artefakte - menschliche wie nicht menschliche Aktanten - wie auch die ANT zueinander in Beziehung. Im theoretischen Konzept des ,Art Nexus ${ }^{6}$ diskutiert Gell Artefakte als

23 ",T]he index must be seen as the outcome, and/or the instrument of ,social agency"' (Gell 1998: 16).

24 Als Beispiel führt Gell Pol-Pots-Soldaten auf, die durch das Legen von Minen nicht nur dort Handlungsmacht ausübten, wo sich ihr Körper befand (1998: 2 I). Sein Konzept der ,distributed person' bezieht Gell auf die von STRATHERN (1988) und Roy WAGNER (199 I) beschriebenen melanesischen Personenkonzepte des "Dividuums' bzw. der ,fractal personhood'. Ihrem Verständnis zufolge stellt sich die Beziehung von Person und Individuum in Melanesien im Vergleich zu anderen Regionen distinkt dar: So definiert sich eine Person nicht als losgelöstes Individuum, sondern durch ihre Beziehungen zu anderen; sie ist ein Verbund von Beziehungen zu einer Vielzahl von Personen (FOSTER 1995: 9). Mark MOSKO (2002: 93) bezeichnet nach STRATHERN (1988) die melanesische Person als ,Dividuum', als ein zusammengesetztes Wesen, dessen Teile andere Personen in früheren Beziehungen und Transaktionen begründet haben. Auf Ndendö brachten etwa viele Familienangehörige des Bräutigams den notwendigen Brautpreis zusammen. Daraus entstanden Rechte und Pflichten, die in ,namesake-Beziehungen' mündeten; zu namesake vgl. Kap. 2, S. 33-34. Bedingt würde ich im kastom-Umfeld daher auf Ndendö auch von dividualen Personenkonzepten sprechen, allerdings nicht ausschließlich. In vielen Alltagssituation wie auch bei der Herstellung von Artefakten schienen mir Frauen und Männer sehr selbstbestimmt und individuell zu agieren. Meines Erachtens ist dies heute eher ein ,sowohl ... als auch'.

${ }_{25}$ Mit dem mir vorliegenden Datenmaterial kann ich zugrunde liegende Seinsvorstellungen - an dieser Stelle grundlegende Verständnisse von ,Subjekt' und ,Objekt' sowie ihren Beziehungen - meiner Gewährsleute nicht ausreichend darstellen, da meine Fragestellungen zum Zeitpunkt meiner Feldforschung nicht darauf abzielten. Hingegen kann ich aufzeigen, welche sozialen und kulturellen Verbindungen einzelner Personen und Artefakte sich auf Ndendö darstellten, was ich hinsichtlich der Beziehungen der Artefakte zu den Tänzem und dem Publikum in Kap. 5.3 und für die der Artefakte und Hersteller in Kap. 6.6 analysiere. 
Verbindungsglieder sozialer Beziehungen (die ANT sieht sozio-technische Beziehungen) - insbesondere der zwischen Herstellern und Rezipienten - und untersucht, welche Effekte die Artefakte haben, wie sie Intentionen verkörpern, über Agency verfügen und sie in sozialen Beziehungen Resultate erzielen, in denen sie eingebettet sind (LEACH 2007: 171). Daher werde ich Gells ,Art Nexus'-Konzept am Ende von Kapitel 6 nutzen und die Verbindungen der Produzenten zu ihren Arbeiten und zu deren Abnehmern systematisch untersuchen.

Die beiden handlungsorientierten Ansätze Akteur-Netzwerk-Theorie und Art Nexus spannen den theoretischen Rahmen meiner Arbeit, um die vielfältigen, vielgestaltigen, mehrstimmigen und teilweise sich widersprechenden Facetten des Zusammenwirkens von Menschen und kastom-Artefakten im Falle des nelo-Tanzes auf Ndendö grundsätzlich darstellen zu können. Der ANT zufolge kann ich beschreiben, wie Aktanten (menschliche und nicht menschliche) in bestimmten Konfigurationen von Akteur-Netzwerken zusammenkommen und gemeinsam Inhalte übersetzen und umsetzen. Nach Gells Verständnis kann ich analysieren, wie Agency zwischen Menschen und Artefakten verteilt, ihnen zugeschrieben und aus ihnen abgeleitet werden kann, und welche sozialen Effekte sie jeweils evozieren und welche Beziehungen sie konstituieren.

\section{I.3 Methodisches Vorgehen}

Im Laufe der Forschungsabschnitte verwendete ich verschiedene Methoden, wobei ich mein grundsätzliches Vorgehen an der ,Grounded Theory‘ (Anselm STRAuss \& Juliet CORBIN 1996; BARNEY G. GLASER \& Anselm STRAUSS 2008) und an den Bedeutungszuschreibungen meiner Informanten sowie an den sich wandelnden Perspektiven der orientierte. FOSTER (1995: 4-5) stellt in seiner Konzeption der ,New Melanesian Anthropology ${ }^{6}$ heraus, dass sowohl ein historischer als auch ein ethnografischer Zugang notwendig seien, um den sozialen und kulturellen Wandel verstehen zu können, in dem Menschen (in Melanesien) handeln bzw. diesen herbeiführen. Dem Ethno-Archäologen und Material-Culture-Studies-Vertreter Dan Hicks zufolge kann es aber zur umfassenden Analyse der Dinge nicht bei einer ausschließlichen Betrachtung der sich wandelnden sozialen Verwendungen und Bedeutungen bleiben. Er fordert wie andere Vertreter der MCS eine Betrachtung der Lebensgeschichten der Materialien mit besonderem Fokus auf die stofflichen Dimensionen von Artefakten (HICKS 2010: 69, 85).

In der Kombination verschiedener Vergleichsmethoden (dem kontrollierten historischen Vergleich der Artefakte selber und dem Vergleich der Ergebnisse einer ethnografischen Feldforschung und Ethnohistorie) komme ich diesen vorgenannten Forderungen bei der Datenerhebung nach. Nach Archiv- und Museumsrecherchen in Brisbane, Wellington, Auckland und Honiara und der Vorstudie auf Ndendö standen zu Beginn der Feldforschung lediglich vier Artefaktegruppen und als Forschungsort die Graciosa Bay auf Ndendö fest. Unverändert bestimmte die grundlegende Frage, warum sich die Tanzkleidung und der Schmuck augenscheinlich nicht verändert hatten und zu welchen Anlässen sie in Erschei- 
nung traten, die Richtung meiner Untersuchung. Durch die Beobachtungen und informellen Befragungen kristallisierten sich während meines Feldforschungsaufenthaltes eine Vielzahl unterschiedlicher Auftritte der vier Artefaktegruppen sowie Zugänge und Zugangsbeschränkungen zu verschiedenen Personen(kreisen) heraus. In zunehmendem Maße ,folgte ich konkreten Artefakten, Herstellern und einigen Tänze(r)n und rückte diese schließlich in den Mittelpunkt meiner Beschreibung. Mit diesem Vorgehen versuche ich gleichermaßen „to follow the actors themselves“ (LATOUR 2005: 12, 68) und „to think through things because our informants do" (Amiria HeNARE [Salmond] et al. 2007b: 20).

Eine Herausforderung in der Analyse und der späteren Verschriftlichung ergab sich aus der Komplexität, des endlosen ,ineinander Verwoben seins ${ }^{6}$ der vielen Akteur-Netzwerke sowie aus der ,Fremdheit ' des Materials und der manchmal für mich nicht nachvollziehbaren - weil in meinen Augen teilweise heterodoxen - Aussagen und Handlungen Einzelner. Zwei Perspektiven halfen mir beim Zugang der vorliegenden Rohdaten. Zum einen ließ mich die Beschäftigung mit der Publikation Thinking Through Things (HENARE et al. 2007a) für möglicherweise andere Ontologien offen werden, in denen Artefakte/Dinge vielleicht unterschiedlich verortet/wahrgenommen werden. Martin Holbraad, einem der Mitherausgeber von Thinking Through Things, zufolge, ist es dazu notwendig, ein ,Ding ${ }^{6}$ als ein Konzept zu verstehen, das ontologisch eigenständig und kulturabhängig ist. Um es zu verstehen, muss es mit ethnografischen Daten ,gefüllt' werden, was die Autoren als rekursive Methode bezeichnen (HenARE et al. 2007b: 15, 20-22). Wichtig sei es, die Dinge so mit ihren Eigenschaften wahrzunehmen, wie sie im Feld erscheinen (CHUA \& SALMOND 2012: 137), was ganz dem Verständnis der ANT folgt, indem Dinge als Akteur-Netzwerke verschiedener Aktanten verstanden werden, die ihre eigenen Essenzen einbringen. Zum anderen gab mir die Lektüre Marilyn StRATHERns (1979, 1990 und 2013) Anregungen, wie ich mich mir fremden Sichtweisen ansatzweise nähern konnte.

- Kontrollierter historischer Vergleich: Museums- und Archivforschung Zur Vorbereitung meines insgesamt siebenwöchigen Survey im Jahr 2010 sichtete ich die Santa-Cruz-Sammlungen des British Museum in London und des Rautenstrauch-Joest-Museum in Köln. Erstere entstand als Folge der anglikanischen Mission (ab 1852) und der britischen Kolonialphase (1893-1978), Letztere geht auf den Aufenthalt des deutschen Ethnologen und Reisenden Wilhelm Joest (1852-1897) zurück, der sich bereits im Jahr 1897 vier Monate auf Ndendö aufgehalten und dort gesammelt hatte. Während des Surveys besuchte ich die Sammlungen des Museum of New Zealand Te Papa Tongarewa in Wellington und des Auckland War Memorial Museum, da dort ebenfalls im Umfeld der anglikanischen Missionierung und britischen Kolonialisierung Artefakte zusammengetragen worden waren. ${ }^{26}$ Für archäologische Fragestellungen sprach ich mit Peter Sheppard, Assoc. Prof. am Dept. of

\footnotetext{
${ }^{26}$ Kurzdarstellungen der Sammlungen finden sich in Kap. 4.2, die Ergebnisse des Vergleichs der Artefakte sind in den Kap. 4.3.1. bis 4.3.4 und alle Artefakte der Untersuchung im Anhang aufgeführt.
} 
Anthropology der University of Auckland, der sich insbesondere mit der Besiedlung des Pazifiks und den Lapita-Kulturen beschäftigt. Früheste historische Aufzeichnungen aus der britischen Kolonialzeit recherchierte ich in den Special Collections der University of Auckland Library, die das Western Pacific Archive (WPA) mit den Aufzeichnungen der von 1877 bis 1973 in Fiji ansässigen Western Pacific High Commission (WPHC) von dort übernommen hatte. Weiterführende Literaturrecherchen zur Geschichte und Ethnologie der Santa-CruzInseln führte ich u. a. in den Bibliotheken der University of Auckland, der Victoria University of Wellington und der University of Queensland sowie in der National Library of New Zealand Te Puna Mātauranga o Aotearoa und in der State Library of Queensland durch.

\section{- Ethnografische Feldforschung}

Meine Forschung bezieht sich im Wesentlichen auf die Hauptinsel Ndendö, wobei ich hauptsächlich im Nordwesten der Insel in den Dörfern entlang der Graciosa Bay, in den Dörfern Malo und Neo auf der nordwestlich vorgelagerten Insel Temotu Neo sowie dem Dorf Nea an der südwestlich gelegenen Nemya Bay gearbeitet habe (vgl. Karte 2). Ich habe den Ort Malo in den Jahren 2009 bis 2014 viermal jeweils für einige Stunden als Begleiter von Kreuzfahrten besucht sowie im Jahr 2010 drei Wochen im Rahmen einer Vorstudie und im Jahr 2011 fünf Monate für meine eigentliche Feldforschung in Santa Cruz, mit nur zwei Wochen Ausnahme auf Ndendö, gelebt.

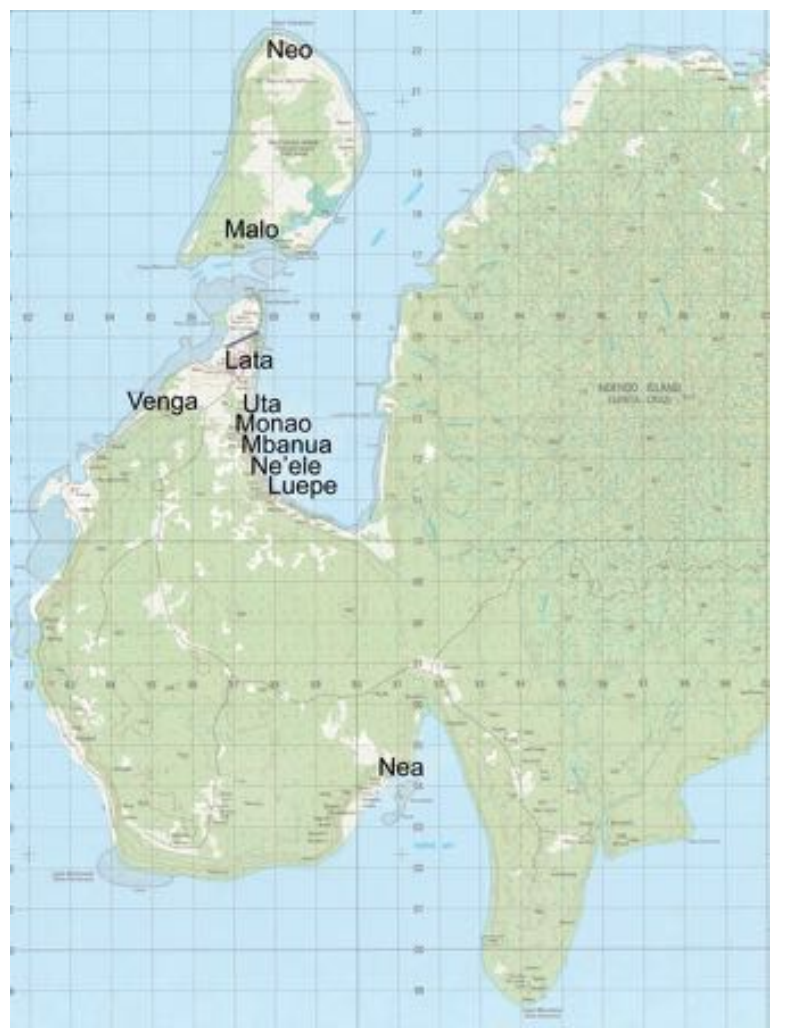

Karte 2: Der Westen der Insel Ndendö mit der Graciosa Bay im Norden, der dort vorgelagerten Insel Temotu Neo sowie der im Süden gelegenen Nemya Bay. Ausschnitt der Karte Lata, Solomon Islands. 1016516 X715 Edition 1-SI50K (C) 2007 Solomon Islands Government) mit vom mir hervorgehobenen Orten.

Vor der eigentlichen Forschung von Juli bis Dezember 2011 auf Ndendö verbrachte ich eine Woche in Honiara, um die offizielle Genehmigung meiner Forschung zu erhalten, die ich 
letztlich aber erst eine Woche vor meiner Abreise von den Salomonen im Dezember 2011 in Händen hielt. Die Wartezeit nutzte ich zum Auffrischen der Kontakte aus dem Vorjahr sowie für Besuche und Gespräche im Nationalmuseum, im angegliederten Museumsshop und in Souvenirgeschäften. Ich traf mehrere Male Terry Brown, den ehemaligen Bischof der Diözese Malaita der Anglican Church of Melanesia, und sammelte Unterlagen zum Erlernen von Pijin.

Meine ,Basisstation` auf Ndendö unterhielt ich in Lata, einem in den 1980er-Jahren gegründeten Verwaltungszentrum der Provinz Temotu mit im Jahr 2010 rund 2.000 Bewohnern. Der Verwaltungssitz wurde von meinen Gewährsleuten nicht als ,echtes ${ }^{6}$ Dorf bezeichnet, da er weder über einen Tanzplatz (nir) noch über ein Männerhaus (madeı) verfügte. Ich wohnte in dem privat geführten Gästehaus ,Rotary Lodge', das neben der Landepiste der Insel rund zehn Minuten Fußweg entfernt von Lata lag, in dem auch weitere Ausländer und Mitarbeiter nationaler, staatlicher und kirchlicher Organisationen regelmäßig übernachteten. Im Provinzregierungsgebäude in Lata hatte ich die Möglichkeit, via Internet mit meiner Familie und Freunden zu kommunizieren, solange es Strom gab und eine Verbindung existierte. Eine zweite Internetverbindung bot die Mona-School in der Graciosa Bay. Von meiner Unterkunft aus benötigte ich rund eine Stunde Fußweg bis zur Mitte der Graciosa Bay und eine halbe Stunde bis zum westlichen Ende der Bucht, um von dort aus mit einem Einbaum nach Malo auf der vorgelagerten Insel Temotu Neo übergesetzt zu werden. Wollte ich Personen in weiter entfernt gelegenen Dörfer besuchen, musste ich entsprechend der Verbindungsmöglichkeiten einen Pick-up oder ein Aluminium-Boot - immer mit Fahrern organisieren. Wenn möglich, wohnte ich während Festen oder längeren Dokumentationen bei Gastfamilien in Luepe/Ne'ele, Neo und Nea.

Eine Woche begleitete ich die MV Southern Cross durch die Provinz Temotu und konnte so persönliche Eindrücke von den Inseln Vanikoro, Utupua, Tikopia, den Duff und Reef Islands sammeln. Eine Woche verbrachte ich auf Nandelli (Pigeon Island), Reef Islands. Die meisten meiner Gewährsleute konnte ich über Mobiltelefon erreichen. Sie konnten ihre Telefone bei privaten Besitzern einer Solarzelle in ihren Dörfern aufladen, in der TelekomNiederlassung an eine Steckdose anschließen, einem Beamten oder Polizisten zum Aufladen mit ins Büro geben oder gegen Bezahlung in den wenigen Läden in Lata mit Energie versorgen. Allerdings war das auf Lata örtlich begrenzte Stromnetz nicht sehr zuverlässig und die Telefonkarten für viele zu teuer, so dass von Zeit zu Zeit keine Kommunikation über Mobiltelefon oder Internet möglich war.

Schon während des Empfang durch eine Delegation der Graciosa Bay Nelo Association (GBNA) informierte mich Selwyn Balu aus Ne'ele, mein späterer engster Gewährsmann, über ein großes Gedenkfest (alue), das er im Namen seiner und weiterer Familien in seinem Dorf anlässlich des Todestages seines Vaters vorbereitete. ${ }^{27}$ Wie er es darstellte, hatte er das

\footnotetext{
${ }^{27}$ Diese Vereinigung zur professionellen Unterstützung des bekanntesten lokalen kastom dans (traditioneller Tanz) ,nelo dans' war erst kurz vor meiner Ankunft gegründet worden vgl. Kap. 6.5; zum Gedenkfest alue vgl. Kap. 3.3.I.
} 
Datum so gelegt, dass ich die letzten Vorbereitungen und das Fest intensiv begleiten und dokumentieren konnte bzw. sollte. Durch dieses Fest kam ich mit den meisten nelo-Tänzern der Insel in Kontakt und traf in den Folgemonaten viele von ihnen wieder. Es zeigte sich, dass die Produzenten der Tanzkleidung und des -schmucks, die ich bereits während des Surveys kennengelernt hatte, die einzigen waren, die diese Artefakte in für mich wahrnehmbaren Umfang herstellten. Ebenso ergab sich, dass ich mich geografisch betrachtet auf die Orte Mbanua, Ne'ele und Luepe in der Graciosa Bay, auf Malo auf Temotu Neo und auf Nea im Südwesten der Insel konzentrieren würde, wenn ich die wesentlichen Kleidungs- und Schmuckstücke des nelo-Tanzes berücksichtigen wollte. Der Ort Venga wurde sehr häufig als Zentrum für die Produktion der napa-Tanzkeulen erwähnt. ${ }^{28} \mathrm{Da}$ sich aber dort niemand fand, der sich mit mir über die Tänze und Artefakte intensiver austauschen wollte oder konnte, und der napa-Tanz auf keinem der von mir besuchten Feste getanzt wurde, besuchte ich Venga nur zweimal. Aus ähnlichen Gründen verzichtete ich auf die Berücksichtigung des früheren Zentrums der Federgeld-Herstellung, Noipe, und beließ es bei dem einen Besuch des Vorjahres.

Mit der Fokussierung auf die Artefakte nelo, tema und lepanesa sowie Tapa als Material für die Kopfbedeckungen abe, Wickeltücher und Schurze traten meine späteren Hauptinformanten in den Vordergrund, die mich während der Feldforschung zu den Tanzfesten begleiteten, zu weiteren Interviewpartnern führten und oftmals als Übersetzer tätig wurden. Während meiner gesamten Zeit im Santa-Cruz-Archipel sprach ich Englisch und meine Gesprächspartner Englisch, Pïin oder lokale Sprachen. Im Falle Natügus übersetzten Selwyn Balu, John Namiade, Freddy Me'esa, Jerry Me'ioko, Shadrack Sade oder Bartholomew Me'esa und im Falle Nalögos Ena Yamöli ins Englische oder Pijin, sofern mich einer von ihnen begleitete. War ich völlig allein, verständigte ich mich in Pijin, wobei ich nur wenige Worte selber sprach, jedoch nach einiger Zeit das Meiste verstand. Ich führte größtenteils narrative, themenzentrierte und biografische Einzelinterviews durch. Bei anderen Befragungen mit ,Spezialisten` und in Gesprächsrunden mit Dorfältesten setzte ich zur Spezifizierung der Fragestellungen bzw. zur Visualisierung einiger Beispiele Kopien historischer Publikationen mit Abbildungen sowie von mir aufgenommene Fotografien historischer Artefakte aus Museumssammlungen ein. ${ }^{29}$ Insbesondere Aufsätze aus der Zeitschrift Ethnologica (GRAEBNER 1909 und SPEISER 1916) sowie Gerd KoGHS (1971) Publikation Materielle Kultur der Santa-

\footnotetext{
${ }^{28}$ Erste Berichte zu diesen kanuförmigen Tanzkeulen, ihrer schwarz-rot-weißen Bemalungen und Fransenanhänge sowie ihrem häufigen Vorkommen finden sich bei Albert Hastings Markham (|84|-19|8), britischer Offizier der Royal Navy (MARKHAM I872: 240), bzw. Douglas Rannie (1860-1915), schottischer Agent der britischen Krone für die Rekrutierung von Arbeitskräften für Queensland (RANNIE 1912: 174). Allerdings fehlen detaillierte Beschreibungen zum konkreten Einsatz oder deren Bedeutung. Wilhelm Foy, deutscher Ethnologe und erster Direktor des Rautenstrauch-Joest-Museum (FoY 1916), und Felix Speiser (1880-1949), Schweizer Ethnologe (SPEISER 19I5), spekulieren über den Symbolgehalt der Formen und Ornamente. Auch Gilles BOUNOURE (2004) verbleibt auf formal-ästhetischer Analyseebene.

${ }^{29}$ Konkret nutzte ich Auszüge aus Fritz Robert GrAEBNeR (1909), William Halse Rivers RIVERS (19|4), SPEISER (1915 und 1916), FOY (1916), BEASLEY (1939) und KOCH (197I) sowie ethnografische Filme von KOCH (1972
} 
Cruz-Inseln unter besonderer Berücksichtigung der Riff-Inseln erwiesen sich als sehr ergiebige Vorlagen für die Einzel- oder Gruppengespräche. Diese visuellen Medien dienten auch bei Gruppendiskussionen und persönlichen Gesprächen der inhaltlichen Bestimmung, historischen Einordnung und Klärung lokaler Verständnisse sowie auch der generellen Einschätzung vorhandenen Wissens bei unterschiedlichen Bevölkerungsgruppen auf Ndendö. ${ }^{30}$ Im Anschluss an ein Interview transkribierte ich die digitalen Aufnahmen sofort, um zeitnah Unklarheiten lösen zu können. Parallel wertete ich die Ergebnisse aus, identifizierte Informationslücken und suchte weitere Gesprächspartner, um die Informationen - wenn möglich - zu vervollständigen.

Darüber hinaus waren KoCHS Filme (1972 a-e) von unerwartet großer Hilfe. Sie wurden nicht nur mit Blick auf den historischen Vergleich zum Bindeglied zwischen den ersten Dokumentationen des ausgehenden 19. bzw. frühen 20. Jh. und meinen eigenen Untersuchungen. Vor allem setzten sie mich mit den Menschen vor Ort in Beziehung, eröffneten mir einen persönlichen Zugang, da einige meiner Gesprächspartner unter den fotografierten und gefilmten Akteuren Verwandte identifizierten und daher einen direkten Bezug zu meiner Arbeit und den Artefakten herstellten. Während der gesamten Zeit wurde ich immer wieder gebeten, an den Wochenenden in die Dörfer zu kommen und einzelnen Großfamilien die Filme vorzuführen.

Gegen Ende meiner Forschung bestanden nur unsichere Flug- und Fährverbindungen nach Honiara, so dass ich eine Woche früher als ursprünglich geplant abreiste, um meinen Rückflug nach Deutschland rechtzeitig antreten zu können. Ich verbrachte daher knapp zwei Wochen in Honiara und nutzte die Zeit für Gespräche mit dort lebenden Verwandten meiner Gewährsleute aus Ndendö, dem Aufarbeiten meiner Feldnotizen, Objektrecherchen im Nationalmuseum, administrativen Gänge bezüglich meiner Forschungs- und Ausreiseerlaubnis sowie dem Versenden der erworbenen Artefakte für das Rautenstrauch-Joest-Museum.

a-e). Zu den Vorteilen einer als Photo- bzw. Video-elicitation bezeichneten Forschungsstrategie der Visuellen Anthropologie vgl. Marcus BANKS (200 I: 88-89) und Douglas HARPER (2000 und 2002).

30 In den Gruppendiskussionen zu kastom (vgl. Kap. 3.I) und Einzelinterviews zur Ikonografie der Artefakte diskutierte ich mit meinen Informanten Fotos von Objekten aus dem Rautenstrauch-Joest-Museum und dem Auckland War Memorial Museum. 


\section{I.4 Zugang zum Feld: Reiseführer, Museumsethnologe und, White Man'31}

„Ngupe neni mirniable

na vao pe matirtuki e

nua mirtangi eesa

ngupe neni mimiable."

(Alfred Dawi, 19.10.2011)32
„Opfer von Pfeilen an einem fremden Ort; mitten in der Menschenmenge weißer Mann, völlig alleine im Krieg; Opfer von Pfeilen an einem fremden Ort.“ (Übersetzung O. L.)

Der Umstand, dass ich schon vor meinem Survey 2010 zweimal als Begleiter von Kreuzfahrttouristen auf Ndendö gewesen war, hatte in der Vorbereitungszeit meiner Feldforschungsaufenthalte bereits einen sporadischen E-Mail-Verkehr ermöglicht, erstes Vertrauen zu mir aufgebaut, aber auch Erwartungen mir gegenüber geschürt. So wurde ich am Ankunftstag meiner Feldforschung 2011 an der Landepiste in Lata von einer Delegation der Graciosa Bay Nelo Association (GBNA) offiziell empfangen. Ein kleines Kernteam meiner Partner vor Ort begleitete mich ständig und nahm meine Fragetechniken für sich selber auf, um parallel zu mir eigene Befragungen der ältesten Dorfbewohner und teilweise auch -bewohnerinnen zu historischen Kulturpraktiken anzuwenden. Am Abend vor meiner Abreise von Ndendö lud mich der Vorstand der GBNA zu einem Abschlussgespräch ein und bat mich, mit der Association eine schriftliche Vereinbarung über eine langfristige Zusammenarbeit zur Überlieferung von kastom abzuschließen.

Die Forschungssituation auf Ndendö wurde von Beginn an durch meine ersten Kurzaufenthalte als Reiseführer im April 2009 und 2010 sowie einem für April 2012 geplanten erneuten Besuch mit einem Kreuzfahrtschiff geprägt. Viele Personen erinnerten mich im Laufe meines Surveys 2010 und der Feldforschung 2011 immer wieder daran, dass ich als Touristiker ,Wohlstand' oder zumindest Einkünfte (Pijin: earnings) für am Tourismus beteiligte Personen bringen würde. Die offizielle Forschungsgenehmigung des Ministry of Education and Human Resource Development 2011 legitimierte mich, grundsätzlich an Festen teilnehmen und Fotos bzw. Filme aufnehmen zu dürfen. ${ }^{33}$ Andere Gewährsleute stellten wiederum meine Arbeit für ein deutsches Museum oder meine Absicht, ein Buch über ,ihre

\footnotetext{
3! Letzterer war der gängige Begriff, mit dem mich manche der Personen bezeichneten, die meinen Namen nicht kannten. Einige Male wurde ich von Kindern auch als ,RAMSI' gerufen, wenn sie mich zum ersten Mal sahen (als generische Bezeichnung für einen Soldaten der internationalen Friedenstruppe Regional Assistance Mission to Solomon Islands, die seit dem Jahr 2003 in den Salomonen stationiert sind, vgl. http://www.ramsi.org/about-ramsi/, letzter Zugriff am 30.5.2016). Auch Alfred Dawi nutzte die Bezeichnung,weißer Mann' in seinen Liedern über mich, vgl. Anm. 32.

32 Dieses kastom-Lied für einen nelo-Tanz dichtete Alfred Dawi neben einem weiteren anlässlich des nachfolgend vorgestellten ,ersten Vorfalls', vgl. Anm. 143. Zu einem weiteren Lied vgl. Anm. 146.

33 Tatsächlich erhielt ich diese erst einige Tage, bevor ich die Solomon Islands wieder verließ. ,Offizielle' Genehmigungen schienen als Legitimationsgrundlage gerade im Bereich ,traditionelle' Artefakte und Tänze sehr wichtig zu sein, da ich immer wieder danach gefragt wurde. Als schriftliche Legitimation vor Ort konnte ich Teile meines Antrags um die Forschungsgenehmigung, Empfehlungsschreiben des Rautenstrauch-joest-Museum und der Universität Göttingen sowie eine Bestätigung bzw. Erlaubnis mehrerer Chiefs und Dorfältester von Ndendö mit offiziellem Stempel der Provinzregierung nutzen.
} 
Kultur zu schreiben, in den Vordergrund. Es gab mehrere Situationen, in denen ich als ,weitgereister Tourismus- und Kulturexperte ' Tipps für die Aus- und Weiterbildung der Kinder oder für den Ausbau von Dörfern geben sollte. Als Reiseführer und Museumsethnologe verfügte ich über ein für manche Personen interessantes, internationales Netzwerk und erbrachte in ihren Augen eine hohe Glaubwürdigkeit als ,Kulturexperte‘. So machten mich Personen auf Dorf- und Provinzregierungsebene zu ihrem Ansprechpartner und Sprachrohr für ,kastom ${ }^{6}$ und ,earnings'. Darüber hinaus reglementierte mein ,Gender-Profil' (HAUSERSCHÄUBLIN 2002: 85) als weißer, deutscher, katholischer Mittvierziger, unverheiratet und in einem ethnologischen Museum angestellt, meinen Zugang zur Männergesellschaft, zu ,Spezialisten`sowie Schulklassen.

Um unabhängig von familiären Kontakten in mehreren Dörfern arbeiten zu können, wohnte ich, wie bereits erwähnt, alleine in Lata. Dies erwies sich als sehr sinnvoll, da mein Zimmer im Verlauf meines Aufenthaltes als privater Raum außerhalb des ansonsten recht öffentlich zugänglichen Lebens auf Ndendö akzeptiert wurde und nicht nur für mich einen Rückzugsort bot. Nicht selten erhielt ich Besuch auf einen Instantkaffee oder Tee. Ich erfuhr von verschiedenen Männern ,als erster Weißer geheime Informationen', die ich nicht preisgeben durfte. Gleichermaßen war ich Anlaufpunkt für viele Schnitzer und Tapa-Produzenten, die sich ein zusätzliches Einkommen durch mich versprachen. In dem Gästehaus in Lata wohnte parallel zu mir ein ,weißes ${ }^{6}$ Ehepaar, das für das United Nations Development Programme (UNDP) bzw. für World Vision, eine katholische Nichtregierungsorganisation, arbeitete. Dadurch wurde ich teilweise mit ihm zusammen als externe Einheit wahrgenommen und mir ein direkter Kontakt zur Provinzregierung zugeschrieben, was Vor-, aber auch Nachteile beim Zugang zu Menschen und Informationen mit sich brachte.

Aber weder meine offizielle Forschungsgenehmigung noch diese vermeintliche Unabhängigkeit verhinderten, dass ich gleich zweimal Kristallisationspunkt von Familienauseinandersetzungen wurde:

Der erste Vorfall ereignete sich während des Tanzfestes in Ne'ele, zu dem ich zwecks Aufzeichnung der Festvorbereitungen und der Tänze explizit eingeladen worden war - dies jedoch, wie sich in deren Verlauf herausstellte, nur von einem Teil einer größeren Familie. Das Oberhaupt des anderen Teils war gegen meine Anwesenheit und ignorierte meine, offizielle‘ Genehmigung sowie die Einladung der restlichen Familie und weiterer Familienführer des Dorfes. Er griff mich sogar körperlich an und setzte das Gerücht in die Welt, dass ich seinem Gegenspieler eine Million SBD (entsprach 2011 ca. 100.000 Euro) für meine Teilnahme, die Informationen zu Hintergründen und Praktiken rund um das Fest sowie letztlich für das Recht, Foto- und Filmaufnahmen tätigen zu können, gezahlt hätte. Zur Klärung der Angelegenheit wurde ich eine Woche später zu einer Vollversammlung der Familienrepräsentanten in das Dorf gebeten. In deren Verlauf entschuldigte sich einer der Chiefs im Namen aller und verpflichtete den ,Aufrührer ${ }^{6}$ über einen Boten, mich nicht weiter zu behelligen und seinen Verwandten als den von allen gewählten Hauptverantwortlichen bei dem 
Arrangieren von Festen agieren zu lassen. Von dem Abend an bis zu meiner Abreise entschuldigten sich immer wieder Personen auch aus anderen Dörfern für das in Ne'ele Passierte. Der Dichter Alfred Dawi aus Malo und der später verstorbene Wilson Kabi aus Luepe schrieben neue kastom songs über den Vorfall, wodurch ich Teil der lokalen Geschichte wurde (vgl. Anm. 32 und 143). Dieses Ereignis verdeutlichte zum einen, wie hoch das Wissen um die Feste und die Rechte an ihnen auf Ndendö eingeschätzt wurden, und dass sie ökonomische Relevanz hatten. Zum anderen zeigte sich, dass öffentlich debattiert wurde, wer dazu legitimiert war, ,traditionelle Feste' zu organisieren.

Der zweite Vorfall ereignete sich während eines mit mehreren Mitgliedern einer Familie angesetzten Gesprächtermins zum Thema Tapa-Herstellung, zu dem der wichtigste Teilnehmer nicht erschien. Wie sich am späten Abend und an den folgenden Tagen herausstellte, wollte der Mann nicht mit mir in Gegenwart seines tabu (hier im Sinne von Schwager) sprechen, der in seinen Augen die Designs seiner Familie unrechtmäßig nutzte, um sich zu bereichern. Der Beschuldigte vertraute mir wiederum an, wie unzuverlässig und unverantwortungsvoll sein Schwager lebte, da er keine Aufgaben für die Dorfgemeinschaft übernähme. Bis zu meiner Abreise beschwerten sich beide immer wieder bei mir über den jeweils Anderen und werteten einander ab. Die persönlich Leidtragende war wohl die Schwester bzw. die Ehefrau, die zwischen ihnen stand. Auch gab es eine Auseinandersetzung um Rechte an ,traditionellen Sachen': zum einen am Nutzungsrecht der Clandesigns und zum anderen in Form der normativen Erwartungshaltung, welche Aufgaben ein ,guter Mann` ,traditionell' in seinem Dorf erfüllen musste. ${ }^{34}$ Beide Parteien wollten mich für ihre Positionen gewinnen. Von dem Ehepaar wurde ich kurz vor Ende meiner Forschung öffentlich ,adoptiert'.

Die Ergebnisse meiner Feldforschung spiegeln folglich - neben meiner Sichtweise - eher die Perspektiven männlicher Experten und politischer sowie kirchlicher Eliten, und diese nur in Bezug auf die Hauptinsel Ndendö, wider. Hinsichtlich meiner Fragestellung schien dies vertretbar zu sein, da diese nach genau diejenigen Personenkreise waren, die heute mit den Artefakten als Agenten/Akteure/Aktanten in den heterogenen Akteur-Netzwerken agieren, Inhalte transformieren, Agency verteilen und Effekte hervorrufen.

\section{I.5 Aufbau der Arbeit}

„[Y]ou have ,to follow the actors themselves', that is try to catch up with their often wild innovations in order to learn from them what the collective existence has become in their hands, which methods they have elaborated to make it fit together, which accounts could best define the new associations that they have been forced to establish." (LATOUR 2005: 12, Hervorhebung im Orig.)

\footnotetext{
${ }^{34}$ Zu der Auseinandersetzung um die Rechte an den Tapa-Mustern vgl. Kap. 5.2.4 und 6.4.
} 
„FFollow the actors', becomes, ,Follow the actors in their weaving through things they have added to social skills so as to render more durable the constantly shifting interactions'." (2005: 68, Hervorhebungen im Orig.)

Dem theoretischen und methodologischen Ansatz und den Rahmenbedingungen meiner Arbeit folgend werde ich die Artefakte komplementär als konstituierende Entitäten in den Akteur-Netzwerken ,nelo-Tanz und nelo-Tänzer ${ }^{6}$ und als eigene Akteur-Netzwerke verstehen und die Analyse der recherchierten und erhobenen Informationen entlang ihres Erscheinens, ihrer Beziehungen und Handlungsräume strukturieren. Ziel ist es, die Tanzkleidung und den -schmuck aus möglichst vielen Perspektiven zu betrachten. Den Sichtweisen meiner Informanten zufolge ergibt sich dabei zunächst ein Fokus auf die zugrunde liegenden kommunalen Anlässe respektive Ziele des nelo-Tanzes, in bzw. zu denen die Artefakte erschienen, gefolgt von den auftretenden nelo-Tänzern, deren Bestandteil die Artefakte waren, vor den wechselnden Publika und zu guter Letzt eine Analyse der über den Tanz hinaus agierenden Hersteller der Tanzkleidung und des -schmucks.

So entsteht mit meiner Arbeit ein weiteres Akteur-Netzwerk, in dem u. a. indigene Sichtweisen, mein Verständnis und teilweise Nicht-Verstehen von ihnen, das ,Wirken“ vieler Entitäten vor Ort und über Internet und Briefe, wissenschaftliche Theorien, ethnologische Methoden sowie fachliche Revisionsgespräche im Laufe des Verfassens meiner Arbeit zusammenkamen und Inhalte ,übersetzten‘. An manchen Stellen sind Querverweise auf andere Netzwerke oder Effekte notwendig, die die Aktanten schufen. Meines Erachtens wird dies den gleichzeitigen und vielfältigen Erscheinungsweisen der Artefakte und Personen am ehesten gerecht. Manche der Anmerkungen ,driften' zwischen den Kapiteln, wobei sich an unterschiedlichen Stellen netzwerkspezifisch durchaus andere Inhalte von, Perspektiven auf oder Beziehungen zu Aktanten ergeben können, wobei sich teilweise Dopplungen nicht vermeiden lassen. Um diese jedoch so gering wie möglich zu halten, habe ich auch hier Querverweise eingesetzt.

Zur besseren Einordnung der Inhalte werde ich zunächst auf die historischen Hintergründe und Bezugssysteme in Santa Cruz eingehen (Kap. 2). Zu welchen Anlässen die Kleidung und der Schmuck in der Vergangenheit und während meiner Aufenthalte auftraten und welche verschiedenen Aspekte von kastom/tradition/kalsa sie in den jeweiligen Konfigurationen vermittelten, zeige ich in Kapitel 3. Anschließend richte ich in Kapitel 4 den Blick auf die ,Materialgeschichten“ der von mir untersuchten Artefakte. Hier werde ich der Frage nachgehen, wie sich insbesondere die Materialiäten im zeitlichen Verlauf darstellen. Die Kapitel 2 bis 4 legen somit die Grundlage für den eigentlichen Hauptteil der Arbeit, die Kapitel 5 und 6.

In Kapitel 5 werde ich in einem konkreten Fall die miteinander verbundenen Netzwerkprozesse trennen, den Verbund auflösen. Von einer für einen Verstorbenen veranstalteten Gedenkfeier mit nelo-Tanzaufführung ausgehend, werde ich zunächst den Anlass dieses ei- 
nen Tanzes vorstellen und als Entstehen eines Akteur-Netzwerkes beschreiben. AnschlieBend rücke ich das Ankleiden eines Tänzers in den Fokus meiner Betrachtung - als Genese eines neuen Akteur-Netzwerkes ,nelo-Tänzers' und komplementär als eigene, neue heterogene Entität (Kap. 5.1). Danach werde ich die Substanzen (,Essenzen`) der einzelnen Kleidungsund Schmuckstücke in der neuen Einheit des nelo-Tänzers beleuchten. Ich werde die Fragen erörtern, was die Dinge ausmacht, und welche Verbindungen die Männer aus ihnen herleiten (Kap. 5.2). Abschließend für die Betrachtung der Artefakte als Aktanten in diesem AkteurNetzwerk werde ich den substantiellen Beziehungen zwischen ihnen und den Tänzern mit Blick auf das Publikum während der Tanzaufführung nachgehen (Kap. 5.3). Ich werde die Effekte herausarbeiten, für die die Aktanten dieses konkrete Akteur-Netzwerk ,nelo-Tanz' geschaffen hatten.

Da die Tanzkleidung und der -schmuck auch außerhalb der Tänze als Entitäten und eigene Akteur-Netzwerke auftraten - nämlich, wenn sie den Besitzer wechselten, hier: von den Herstellern verkauft wurden - werde ich in Kapitel 6 die Artefakte nicht als substantiellen Teil der Entität nelo-Tänzer, sondern Gell zufolge als ,Verlängerung ihrer Hersteller betrachten und die in den Artefakten inneliegende Handlungs- und Wirkmacht herausarbeiten.

In Kapitel 7 werde ich die wesentlichen Erkenntnisse zusammenführen. 


\section{Santa Cruz - Geschichte(n) und ihre Folgen}

Im Folgenden werde ich der ,New Melanesian Anthropology ${ }^{\complement}$ zufolge (FOsTER 1995: 4-5) auf die Rahmenbedingungen eingehen, die für eine Einordnung der Aussagen und Handlungen meiner Gewährsleute als auch anderer Akteure hilfreich sind. Dabei spannt sich der Bogen von der Besiedlungsgeschichte mit ihren überregionalen (sozialen) Beziehungen über die europäische Aneignung und Missionierung, die Förderung eines nationalen Zusammengehörigkeitsgefühls des unabhängigen Staates der Solomon Islands mit der Spätfolge ethnischer Spannungen hin zur geplanten Föderalisierung des Staates und der Rückbesinnung auf die kulturelle Nähe von Santa Cruz zu Ni-Vanuatu.

\section{- Bevölkerung}

Vor rund 3000 Jahren erreichten erste Siedler der ,Lapita-Kultur ${ }^{6}$ die Santa-Cruz-Inseln (Alec RuKIA 1989: 4). Da bisher keine archäologischen Funde von Lapita-Keramiken aus den West- und Zentralsolomonen vorliegen und sich weder mitels DNA- noch Sprachanalysen ein Bezug zur Bevölkerung dieses Teils der Salomonen herstellen ließ, kann davon ausgegangen werden, dass die Besiedlung direkt vom Bismarck-Archipel, Papua-Neuguinea, aus erfolgte. ${ }^{35}$ Eine enge Verwandtschaft zu heutigen Bevölkerungsgruppen in Ni-Vanuatu, Fiji und Neukaledonien gilt dagegen als gesichert (SHEPPARD \& WALTER 2006). Einigen Mythen meiner Gewährsleute zufolge waren die melanesischen Santa-Cruz-Bewohner Nachfahren von ersten Menschen, die vor langer Zeit an einigen Stellen an der Küste aus Erdlöchern der Insel entstiegen waren und die nou (Natügu für Clans) begründet hatten.

Die europäische Einflussnahme ab Mitte des 19. Jh. führte dem anglikanischen Missionar W. C. O’Ferrall zufolge, der von 1897-1904 auf Ndendö lebte, zu einem massiven Bevölke-

\footnotetext{
${ }^{35}$ Der anglikanische Missionar und Anthropologe Robert Henry Codrington ( 1830-1922) attestierte schon früh: "The Santa Cruz people do not seem to be closely connected with the Solomon islanders." (CODRINGTON I89I: 69) Zum Stand der archäologischen Forschung zur Besiedlung des Santa-Cruz-Archipels vgl. DOHERTY (2007).
} 
rungsrückgang, den er im Wesentlichen auf eine Grippe- sowie eine Ruhrepedemie zurückführte. Er befürchtete, dass die Bevölkerung in den folgenden 20 Jahren aussterbe, falls nichts getan werde (O'FerRALl 1922: 67-68). Der Schweizer Ethnologe Felix Speiser verbrachte im Jahr 1912 sechs Wochen auf Ndendö. Gemäß seiner Aussage war um das Jahr 1910 die Hälfte aller Dörfer auf Ndendö ausgestorben (SPEISER 1924: 333). Im Jahr 2009 lebten 21.000 Menschen in der Provinz Temotu, was vier Prozent der Gesamtbevölkerung der Solomon Islands entsprach, und davon 11.580 Personen auf Ndendö. ${ }^{36}$ Durchschnittlich wohnten zwischen 100 bis 300 Einwohnern in den Dörfern, die größtenteils an der Küste lagen. Im Norden und Osten von Ndendö, auf der nördlich vorgelagerten Insel Temotu Neo sowie in der Nähe der Provinzhauptstadt Lata befanden sich einige rein polynesische Siedlungen, bei denen es sich laut meinen Informanten in der Regel um Einwanderer von der polynesischen Enklave Tikopia und nur selten von der polynesischen Insel Anuta handelte.

Im Jahr 2009 standen 19 Prozent der Bevölkerung Ndendös im Alter von 15-59 Jahren in einem bezahlten Arbeitsverhältnis, wovon rund ein Drittel Frauen waren (SOLOMON IsLANDS GOVERNMENT 2011). In der Regel waren dies Mitarbeiterinnen und Mitarbeiter der Regierung oder regierungsnaher Organisationen, Kirchen, Nichtregierungsorganisationen oder Angestellte in Geschäften. Fast jeder Einwohner ist altersunabhängig an der Bewirtschaftung der Familiengärten und/oder im Haushalt beteiligt, wobei Arbeit, Arbeitszeit und -aufwand sehr stark in den Familien variieren. Surplus-Anbau und -Fischerei ermöglichen manchen Familien zusätzliches Einkommen (oftmals durch Verkauf der Produkte gegen Geld). Auf allen Inseln wird Kopra produziert und in die Hauptstadt Honiara verkauft. Manche Menschen beschäftigen sich mit der Produktion von Artefakten und deren Verkauf. Ebenso wird, wenngleich selten, mit Kulturdarbietungen an Touristen in Luewa und Malo Einkommen generiert. Schiffsbesatzungen, die in der Provinzhauptstadt einklarieren müssen, kaufen mitunter Artefakte von Produzenten aus der Graciosa Bay. ${ }^{37}$

Die wichtigste soziale Einheit in Santa Cruz war und ist bis heute die Großfamilie. Sie sicherte in der Vergangenheit weitgehend das Überleben, den wirtschaftlichen Wohlstand, die soziale Stabilität und die Beziehungen zu den Ahnen und der Umwelt. Heute pflegen die Familien regionale Geschäftsbeziehungen und sind über Repräsentanten größtenteils in die

\footnotetext{
${ }^{36}$ Nach dem 2009 durchgeführten Zensus war die Bevölkerung in der Provinz Temotu von 1970 bis 2009 um plus 135 Prozent im Vergleich zu plus 222 Prozent im Landesdurchschnitt gewachsen (SOLOMON ISLANDS GOVERNMENT 20I I). Administrativ organisiert in sechs ward (Gliederungseinheiten unterhalb der Provinz) lebten auf Ndendö in Venga/Nemba 947, in Lata 2.335, in Graciosa Bay 1.264, in Nea/Noole 1.770, in Nordost-SantaCruz I.843, in Nanggu/Lord Howe I.863 und im eigenen ward Temotu Neo I.558 Personen.

${ }^{37}$ Im Jahr 201 I konnten internationale Schiffe über drei Provinzen der Solomon Islands offiziell in das Land einreisen. Neben der Landeshauptstadt Honiara konnte dies über die ,Western Province' oder die Provinz Temotu erfolgen. In den beiden letzteren Fällen konnte es passieren, dass am Tag der Einreise keine Zoll- oder Quarantäne-Beamten anwesend waren. So mussten die Schiffe oftmals einige Tage vor Ort ankern, bevor sie weiterreisen durften. Im Falle Ndendös lagen die Schiffe in der Graciosa Bay, so dass alle Bewohner entlang der Bucht sahen, wann Ausländer ein-/ausreisen wollten. Meistens waren die Schiffsbesatzungen am Kauf von Artefakten interessiert. Während meines fünfmonatigen Aufenthaltes lagen höchstens zehn Segelyachten vor Anker, deren Besatzungen aber stets Artefakte erwarben.
} 
politischen Abläufe der Provinz- und Nationalregierung einbezogen. Die Familienmitglieder bezeichnen ihre Großfamilie als Clan (Pijin, auch: laen, Natügu: nou), der über die Provinz bis hin nach Honiara reicht, wo oftmals Verwandte als Arbeitsmigranten oder Schüler leben. Ebenso ziehen Personen aufgrund von Heirat oder Arbeit auch in andere Provinzen des Landes. Abhängig von der Situation oder Zielsetzung (etwa Wohn- und Landnutzungsrechte, Fischfang oder Gestaltungsmustern) leiten die Menschen ihre Zugehörigkeit kognatisch bzw. ambilinear über ihre mütterliche oder väterliche Gruppe her. In der Provinz Temotu existieren zahlreiche Clans. In jedem Dorf leben mehrere zusammen, wobei jeder Clan als politisch unabhängige Einheit innerhalb einer Dorfgemeinschaft verstanden wird. Das Dorf selber wird im Sinne eines selbständigen Stadtstaates gesehen und Bezug zur griechischen Polis hergestellt (Ataban TrOPA 2009: 2-9).

Den mehr oder weniger autonomen clanbasierten Gemeinschaften stehen meist männliche Anführer vor, die ihren individuellen Status durch persönlichen Gewinn und Einsatz von Wohlstand erzielen. Sogenannte bonie-Positionen werden meist nicht vererbt und nach wie vor durch zeremoniellen Tausch und das Ausrichten von Festen erlangt. Die Bezeichnung bonie setzt sich aus den Natügu-Worten bo (top) und nie (tongue of flame) zusammen. Letztere ist ein Zeichen für das Anzünden der vielen Erdöfen bei einem Fest und steht als Metapher für wohlhabende Männer, die sich mit ihren Ressourcen um das Wohlergehen der Gemeinschaft kümmern, etwa durch die Beteiligung an Brautpreiszahlungen, wodurch sie oftmals mehrfacher namesake (Pijin-Bezeichnung für Namenspatron, vgl. nächster Absatz) werden (John Me'alue, 15.10.2011). Auch stellen bonie Schweine, Haifisch oder Geld für die Durchführung oder Ausstattung von Festen zur Verfügung. Ein bonie ist aber nicht zwangsläufig mit einem Chief gleichzusetzen, der zumeist gewählt als Sprecher, Repräsentant und Schlichter eine Dorfgemeinschaft politisch führt. Als Chiefs wurden auf Ndendö ausschließlich Männer gewählt. Nicht selten wurde nach dem Rücktritt oder Tod eines Chiefs einer seiner Söhne oder Schwiegersöhne als Nachfolger gewählt. Mehrere Chiefs eines ward (vgl. Anm. 36) wählten einen Paramount Chief. Vom bonie wird auch die Bezeichnung opla abgegrenzt, die nur auf den höheren Wohlstand einer Person hinweist, nicht aber auf deren soziale Bedeutung für die Gemeinschaften (vgl. Anm. 83).

Für das Aufwachsen von Kindern nehmen sogenannte namesake auf Ndendö eine gesonderte Stellung ein. Durch ihre Beteiligung am Brautpreis erwerben die Männer nach absteigender Höhe des von ihnen beigesteuerten Teils zum Brautpreis schon vor möglichen Geburten späterer Kinder das Recht, diesen der Reihe ihres Beitrages folgend Namen zu geben. Werden es Mädchen, geben die Ehefrauen der jeweiligen Männer den Kindern ihren Namen. Das Erstgeborene wird von dem Ehepaar ,benannt', das am meisten zum Brautpreis zugesteuert hat, die den zweithöchsten Beitrag geleistet haben geben dem Zweitgeborenen den Namen usw. Bei den Namen handelt es sich um ,kastom-Namen', die in der Regel eine spezifische Eigenschaft der Namengebenden in der lokalen Sprache beschreiben. Etwa Me'tu - Mann mit den Schmerzen (vgl. Anm. 158). Dieser kastom-Name kann sich im Laufe eines Lebens ändern, wenn etwa andere Männer mehr Geld oder Waren zum Aufwachsen 
des Kindes beisteuern oder früheren namesake folgen, wenn diese frühzeitig verstarben. Einen christlichen Namen erhalten die Kinder bei der Taufe. Somit setzten sich die Namen aus zwei Teilen zusammen, wobei der christliche wie in unserem Sprachgebrauch als Vor- und der kastom- als Nachname genutzt wird: etwa John Namiade, Selwyn Balu. Der respektive die Namensgebende übernimmt die Pflicht, ihre/n namesake lebenslang zu unterstützen und etwa die Initiationsfeiern auszurichten. Dieses namesake-System ist für das neue Brautpaar Garant für die Sozialisation eines ihrer ungeborenen Kinder. Somit war das spätere Kind nicht nur Kind seiner biologischen Eltern, sondern stand schon vor seiner Geburt in einer lebenslangen namesake-Beziehung zu einem anderen Menschen, dessen Namen es tragen würde. Ein bonie hatte im Laufe seines Lebens zu vielen Brautpreisen beigetragen, so dass sein kastom-Name bzw. der seiner Ehefrau entsprechend häufig vorkam. ${ }^{38}$

Ein bewusstes zur Schau stellen von den vorgenannten herausgehobenen Positionen ist eher selten und unerwünscht. Gewählte politische und kulturelle Führer (etwa Chiefs, Paramount Chiefs, Obleute und Mitglieder des Village Executive Government) sowie Inhaber öffentlicher Ämter agieren in der Regel in einer bonie-Art und -Weise insbesondere bei der Verteilung von Wohlstand an Familienmitglieder und Unterstützer.

Über die Großfamilie und soziale Verflechtungen hinaus sieht man sich zudem in Abgrenzung zu anderen größeren Gruppen seiner wantok (Pijin für das englische one talk - einer Sprachegruppe zugehörig) verpflichtet. So sind auf Ndendö letztlich drei soziale BezugsgröBen relevant: die der (erweiterten) Familie, des Clans und der wantok.

\section{- Linguistische Situation}

Auf Ndendö gibt es die drei Sprachen Natügu (im Norden und Nordwesten), Nalögo (im Süden und Südwesten) sowie Nagu (im Südosten) (BOERGER 2007; BOERGER \& ZIMMERMAN 2012). Natügu wird auch von Sprechern der beiden anderen Sprachgruppen verstanden und teilweise gesprochen. Bis heute ist nicht abschließend geklärt, ob die linguistischen Wurzeln austronesisch oder voraustronesisch sind (Moira Winifrid DOHERTY 2007: 74-78). Es gibt verschiedene Erklärungsmodelle, warum es auf den Santa-Cruz-Inseln zu einer Vermischung dieser beiden großen Sprachfamilien kam. Die Klärung, welchen Ursprung die Sprachen haben, steht jedoch noch aus (SHEPPARD \& WALTER 2006: 66; DOHERTy 2007: 81-84). Seit 1987 führt die amerikanische Linguistin Brenda Boerger (Summer Institute of Linguistics/SIL International) Forschungen zu Santa-Cruz-Sprachen durch. Sie entwickelte mit einem Sprachteam, das aus Vertreterinnen und Vertretern verschiedener Dörfer zusammengesetzt war, eine neue, eigens für Natügu entwickelte Orthografie (BOERGER 2007, 2009 und BOERGER \& ZIMMERMAN 2012). Gemeinsam veröffentlichten sie erste Wörter- und Textbücher, zuletzt 2008 das Neue Testament mit Psalmen und dem Buch Ruth. Diese Transkription des gesprochenen Wortes hat sich bis heute auf Ndendö nicht

${ }^{38}$ Zur Bedeutung der namesake vgl. auch SAMOU 20 I4: 16. 
völlig durchgesetzt: Während z. B. die Provinzregierung und die Anglican Church of Melanesia Boergers Schreibweise zeitweise folgten, lehnten einigen Informanten aus der Graciosa Bay diese ab und präferierten eine ältere Transkription mit Umlauten, die $\mathrm{u}$. a. auf den Linguisten Stephen Adolphe Wurm (1922-2001) zurückgeht. ${ }^{39}$ Da die Sichtweisen variierten, war es mir nicht immer möglich, eine einzige von allen akzeptierte Schreibweise zu finden. Manchmal wurde mir der Umlaut [ö] mit [ir] (entsprechend dem englischen ,Sir ${ }^{6}$ ) buchstabiert, so dass ich in solchen konkreten Fällen den entsprechenden Wünschen nachkam. Für meine Arbeit verwende ich die Transkription mit Umlauten.

Aufgrund der langen Austausch- und Migrationsgeschichte innerhalb der Santa-CruzInseln sind fast alle Sprachen der Inselgruppe auf Ndendö anzutreffen. Neben ihrer jeweiligen lokalen Sprache sprechen heute nahezu alle Bewohner der Provinz Temotu als Lingua Franca Solomon Pijin, das sich in Vokabular und Grammatik von Tok Pisin in Papua Neuguinea und Bislama in Ni-Vanuatu unterscheidet. ${ }^{40}$ Mit Beginn der britischen Besatzung wurde Englisch eingeführt, mit der Unabhängigkeit der Solomon Islands 1978 dieses zur Amtssprache erklärt und nachfolgend in den Schulen unterrichtet, so dass es heute von der Altersgruppe bis Mitte vierzig Jahre verstanden und meist auch gesprochen wird. In der Regel beherrschten meine Gesprächspartner mindestens zwei Sprachen - ihre Lokalsprache und Pijin - und oftmals zusätzlich Englisch. ${ }^{41}$ Ich wurde gebeten, Englisch zu sprechen und Pijin als Antworten zu akzeptieren, falls mein Gegenüber nicht Englisch sprach. Bisher liegen weder ein offizielles Wörterbuch für Natügu und Nalögo noch für Solomon Pïin vor, so dass es für viele Begriffe sich wandelnde Transkriptionen gibt. Ich habe versucht, meine Transkriptionen abzusichern, indem ich bei relevanten Begriffen mehrere Sichtweisen einholte und mich für die jeweilige Mehrheitsversion entschied. Für die Pijin-Begriffe orientiere ich mich an dem von der Regierung der Solomon Islands verabschiedeten Leitfaden Wei Fo Raetem Olketa Wod Long Pijin (Gerry BeIMERs 2008).

\section{- Interinsularer Handel innerhalb der Santa-Gruz-Gruppe}

Vermutlich aufgrund der begrenzten Ressourcen auf vielen Inseln waren und sind die Bewohner der Santa-Cruz-Inseln aktive interinsulare Händler. Neben regelmäßigen, geplanten Tauschbeziehungen mit dem Bismarck-Archipel, die fremde Güter wie z. B. Keramiken und

\footnotetext{
${ }^{39}$ Persönliche Gespräche mit John Me'alue und Freddy Me'esa.

${ }^{40}$ In den 1980er- und 1990er-Jahren setzte sich Pijin als lokale Verkehrssprache in der Santa-Cruz-Gruppe durch (Brenda H. BOeRger \& Gabrielle ZIMMERMAN 20 I2: I 16). In der Zeit von 1976 bis 1999 verzehnfachte sich die Anzahl der Pijin-Sprechenden in der Provinz Temotu (BOeRger 2007: I29; BOeRger \& ZIMMERMAN 20 I2: I I51 16). Das Pijin Basisvokabular hat eine größere Ähnlichkeit zu Standard-Englisch als zu Tok Pisin aus PapuaNeuguinea; die Sprachverständlichkeit mit Bislama aus Ni-Vanuatu ist recht hoch, vgl. http://www.ethnologue.com/ language/pis, letzter Zugriff am 16.2.2013.

${ }^{41}$ Laut Zensus 2009 sprachen in Temotu 66,I Prozent der über 5-jährigen Englisch. 53,8 Prozent sprachen Pijin, 36 Prozent eine lokale und 36 Prozent eine andere Sprache (SOLOMON ISLANDS GOVERNMENT 20 I I: I). Allerdings variierte auf lokaler Ebene die Beurteilung sehr darüber, was als ,Englisch' und was als ,Pijin' bezeichnet wurde.
} 
Obsidian einbrachten, kam es auch zu ungeplanten Kontakten mit anderen Inseln. ${ }^{42}$ Aufgrund ungünstiger Witterungs- und Strömungsbedingungen wurden immer wieder Boote aus und auf Nachbarinseln verdriftet. ${ }^{43}$ Überregionale regelmäßige Beziehungen existierten zudem zwischen den Santa-Cruz-Inseln und den im Südwesten gelegenen Banks und Torres Islands von Ni-Vanuatu (KOLSHUS 2013: 321-322). Eigenen Legenden nach reisten übernatürliche Wesen sogar zu den nordwestlich gelegenen polynesischen Inseln Sikaiana (270 Meilen) und Ontong Java (500 Meilen). Über einen Austausch mit der polynesischen Enklave Tikopia liegen bereits für die Zeit vor 1828 Aufzeichnungen vor. Selbst Einflüsse aus den weiter entfernten polynesischen Inselstaaten Samoa und Tonga gelten als gesichert. Von Beziehungen zu den Westsalomonen gibt es dagegen keine Berichte (DAVENPORT 1964a; DOHERTY 2007: 102-105).

Davenport schildert das bis in die 1930er-Jahre hinein existierende ausgefeilte Handelssystem innerhalb der Inselgruppe: Von den südlich gelegenen Inseln Vanikoro und Utupa wurden gegen Muschelscheiben und Stoffe rote Federn nach Ndendö getauscht, die dort für die Herstellung des gleichnamigen Geldes benötigt wurden. Das Federgeld war lokal essentieller Bestandteil des Brautpreises und diente zudem als Kompensationszahlungsmittel bei der Befriedung verfeindeter Parteien. Es wurde aber auch zusammen mit anderen Handwerksprodukten, Holz und Lebensmitteln weiter nach Norden zu den Reef Islands gegen Schildkröten und Kokosnussschnüre sowie Frauen - als Ehefrauen oder Konkubinen für Männerhauseinheiten - und Navigatoren gehandelt. Das Federgeld wurde sogar bis in die Duff Islands gegen Frauen und die hochseetüchtigen Boote te puke zum Tausch eingesetzt. Trotz Umsetzung der administrativen Kontrolle durch die Briten nach dem Zweiten Weltkrieg, mit der offiziell der Frauenhandel auf den Reef und Duff Inseln verboten wurde, bestand das System noch einige Zeit weiter. Das Verbot wurde zunächst ignoriert, da die beiden nördlichen Inselgruppen über keine anderen Tauschmittel verfügten. Erst mit dem Aufkommen von Lohnarbeit, von ausländischen Importwaren sowie letztlich der Integration in die globale Geldwirtschaft in Form der australischen Währung entstand eine ernsthafte Konkurrenzsituation zu dem roten Federgeld, das zunehmend weniger nachgefragt und demzufolge auch weniger produziert wurde. Im weiteren historischen Verlauf wurde das Federgeld ökonomisch obsolet (DAVENPORT 1962 und 1969). 2011 war das Handelssystem nicht mehr existent: Federgeld und te puke waren durch Geld, Konsumgüter und westliche Technik ersetzt worden. Nach meinen Beobachtungen und nach Aussagen vieler Informanten orientierten sich die Bedürfnisse der meisten Menschen am Warenangebot der Landeshauptstadt Honiara.

\footnotetext{
42 Von dem überregionalen Handel mit dem Bismarck-Archipel zeugt etwa eine Malanggan-Maske aus Neuirland, die mit Tapa aus Santa Cruz bezogen wurde und sich heute in der Sammlung des Musée du Quai Branly in Paris befindet (http://collections.quaibranly.fr/\#eca06085-I4af-4564-b984-9 I 8faa393472, letzter Zugriff am I.9.20 I 4). Bereits MARKHAM (I872: 242-243) berichtete von dem Austausch und der Heterogenität melanesischer und polynesischer Gruppen in der Region.

${ }^{43}$ CODRINGTON ( 189 I: 346) berichtet von diesen Ereignissen, bei denen Santa Cruzer bis nach Malaita und Ulawa drifteten, wo sie als Notdürftige aufgenommen wurden und bleiben oder wieder abreisen konnten.
} 
Die Bewohner der beiden polynesischen Enklaven Tikopia und Anuta nahmen weitgehend nicht am diesem interinsularen Austausch teil. Lediglich zwischen Tikopia und den südlichen Inseln Vanikoro und Utupua ist Handel mit Kurkuma und Kava belegt (Dumont d'Urville in DAVENPORT 1968a: 241). Thorgeir Kolshus (2013: 321-322) attestiert Verbindungen von Tikopia zu den 200 Kilometer entfernten Banks- und Torres-Inseln im heutigen Vanuatu.

\section{- Europäische Aneignung}

Moira Doherty gibt für den Zeitraum 1595 bis 1935 einen umfassenden historischen Überblick über Kontakte und Austausch zwischen Europäern und der Bevölkerung der SantaCruz-Inseln (DOHERTY 2007: 526-564). ${ }^{44}$ Daher verzichte ich an dieser Stelle auf eine ausführliche Darstellung der frühen Geschichte und konzentriere mich im Nachfolgenden auf die Zeit vom Beginn der Kolonialisierung und Missionierung bis heute.

Nach der ,Entdeckung' 1595 und dem missglückten Versuch, auf Ndendö eine florierende Kolonie zu gründen, verlor die spanische Krone das Interesse an der Inselgruppe, bis fast zwei Jahrhunderte später Engländer und Franzosen im 18. und 19. Jh. den Pazifik zu erforschen begannen. ${ }^{45}$ Die Santa-Cruz-Inseln wurden im 19. Jh. nur selten von Walfängern angefahren, da die Region abseits der großen Walfängerrouten lag. ${ }^{46}$ Erst zum Ende des 19. Jh. verdichteten sich die Berichte über Beziehungen zu den Bewohnern des Archipels durch die zunehmende Präsenz der späteren Kolonialmächte England, Deutschland und Frankreich. Zum einen tauschten Schiffsbesatzungen und Händler u. a. Eisenringe, -klingen und -nägel, Stoffe, Tabak, Glasperlen und Angelhaken gegen Seegurken, Kokosnussöl, Schildpatt und Perlmutt ein, und zum anderen wurden ab 1870 sogenannte Blackbirding-Fahrten zur (il)legalen Rekrutierung von Arbeitskräften für Plantagen in Vanuatu und Queensland (Australien) durchgeführt. ${ }^{47}$ Manche der ,angeworbenen' Arbeiter kehrten Jahre später zurück und brachten Güter und Berichte mit (GREAT Britain. Foreign AND COMMONwEALTH OFFICE 1974: 131-132). Für den Zeitraum 1871-1906 wurden für Queensland 573 Arbeiter aus der Provinz Temotu rekrutiert (Charles PRICE \& Elizabeth BAKER 1976: Taf. 1 zitiert in Clive MoORE 2009: 29), wovon in der ersten Dekade nur wenige nach Santa Cruz zurückkehrten (Actaeon Edward C. FORREST 1894). Nach RANNIE (1912: 170, 176) war die

\footnotetext{
${ }^{44}$ Siehe hierzu auch Henry B. GUPPY ( 887: 246-27I) oder MARKHAM ( 872), die einen sehr ausführlichen historischen Überblick der Aufzeichnungen bis ungefähr 1860 geben.

${ }^{45}$ Für die Santa-Cruz-Inseln sind zu nennen: 1767 Carteret, 1788 La Pérouse (Verlust von zwei Schiffen vor Vanikoro, wodurch eine größere Menge an Eisen und anderen Gütern in den lokalen Warenkreis gelangte und in den Folgejahren Suchtrupps aus Europa in die Region entsendet wurden), I793 D'Entrecasteaux, I823 Duperrey, 1826/7 Dillon, 1827 Jules Sébastian César Dumont D'Urville, 1828 de Tromelin, 1863 de Rienzi.

${ }^{46}$ Judith A. BENNETT ( 1987: 350-352) führt zehn Kontakte auf. Als früheste Aufzeichnung eines Handels zwischen einer Schiffscrew und der Bevölkerung in Santa Cruz führt sie das Jahr 1833 auf (1987: Appendix 3).

${ }^{47}$ CODRINGTON ( 89 |: 3 |4) ist über den schnell verlaufenen Einfluss erster Handelskontakte erstaunt: Bis rund zehn Jahre vor seinen Aufzeichnungen war die Inselgruppe so gut wie nicht von Europäern besucht worden, und Mitte der 1880 er-Jahre waren Werkzeuge aus Stein und Muschel weitestgehend verschwunden und durch Eisenwerkzeuge ersetzt worden.
} 
Inselgruppe nicht so stark von der illegalen Arbeiterrekrutierung betroffen; die meisten Männer stammten von den Reef und Duff Islands. Aufgrund der gewaltsamen Entführungen verstärkten sich die Feindseligkeiten gegenüber den Fremden, in deren Zusammenhang 1871 Bischof Patteson auf Nukapu und 1875 Commodore Goodenough in der Carlisle Bay im Norden von Ndendö ermordert wurden (Robert William ROBSON 1950: 407; GREAT Britain. Foreign AND Commonwealth OfFICE 1974: 132). ${ }^{48}$ Seit spätestens 1886 war die britische Krone bemüht, zwischen den Schiffsbesatzungen und der lokalen Bevölkerung friedliche Beziehungen aufzubauen. ${ }^{49}$ Am 16. Juli 1892 untersagte die britische Krone die Anwerbung von Arbeitern von den Pazifischen Inseln gänzlich und überwachte die Einhaltung des Verbots seit 1896 durch die ständige Präsenz eines Resident Commissioner mit Sitz in Tulagi (Florida Islands oder Nggela Group). ${ }^{50}$ Am 18. August 1898 wurden die SantaCruz-Gruppe und die Reef Islands sowie am 1. Oktober 1898 die Insel Anuta, die Duff Islands und Temotu Island in das British Solomon Islands Protectorate (BSIP) eingegliedert (OFFice Of THE High COMMISSIONER FOR THE Western PACIFIC 1898a und 1898b). Um die Kolonie wirtschaftlich erschließen zu können und Investitionen in Plantagen und Handelsniederlassungen abzusichern, musste die Sicherheit im BSIP für Beamte und Siedler gewährleistet werden. Zuallererst wurden Kopfjagd und Kriege unterbunden. Die Vernichtung von Kriegskanus, das Verbot von interinsularem Sklavenhandel sowie die allgemeine Befriedung der Inseln bzw. Gruppen untereinander unterwanderten die Autoritäten der lokalen Führer. Dafür beteiligte der aufkommende Handel mit Kopra und Perlmutt die Dorfbewohner am globalen Waren- bzw. Geldkreislauf, was den Wandel der sozialen Strukturen in den Dörfern weiter vorantrieb (Sir Baddely Devesi 1992: 13; FRAENKEL 2004: 26-27).

$\mathrm{Zu}$ dieser Zeit lebten nur wenige ausländische Händler auf den Santa-Cruz-Inseln, von denen A. E. C. Forrest (früherer Laienmissionar und späterer Händler) großen Einfluss auf die europäische Erschließung der Inselgruppe hatte. ${ }^{51}$ Bei ihm verbrachte Wilhelm Joest von

\footnotetext{
48 Inwieweit Pattesons Tod ausschließlich in diesem Zusammenhang verstanden werden muss oder ob noch andere Interpretationen des Vorfalls möglich sind, erörtere ich im nachfolgenden Kap. Missionierung und lokale Glaubensvorstellungen.

49 Sailing Orders von Rear-Admiral Tryon an Captain Clayton, H. M. S. Diamond, 17. September 1886: ,It is desirable you should call at Santa Cruz with the object of confirming friendly relations with the natives [...]" (HIGH COMMISSION FOR WESTERN PACIFIC ISLANDS I 886)

${ }^{50}$ Queensland 1895: Enclosure in No. 26, Schriftverkehr zwischen dem Office of the High Commissioner for the Western Pacific und dem Resident Commissioner, British Solomon Islands Protectorate: ,,[...] on the subject off illegal recruiting of native labourers from the Santa Cruz Group [...]" (HIGH COMMISSION FOR WESTERN PACIFIC ISLANDS 1898-1903, Despatches no. 397, 4II und 710). Der Resident Commissioner unterstand dem High Commissioner for the Western Pacific in Fiji. Ihm unterstand ein District Commissioner, assistiert von ein bis zwei District Officern. Diese zentrale Form der Verwaltung wurde bis 1942 aufrechterhalten. Die indigene Bevölkerung hatte keinerlei Partizipationsmöglichkeit, und ihre Bedürfnisse wurden nicht berücksichtigt: ,_[...] [1]hey were subject to a govemment that was not responsible to them." (Sam ALASIA 1989: I4I)

${ }^{51}$ Forrest scheint einer der wichtigsten Europäer in der Geschichte von Santa Cruz gewesen zu sein. Er kam I 887 als Laienmissionar nach Santa Cruz und war der erste Europäer, der die lokale Sprache erlernte. Noch meine Informanten berichteten, dass er alleine im Kanu zu den Reef Islands paddelte und lernte, Haie auf traditionelle lokale Weise zu fangen. Er wurde von den Bewohnern Me'buano (lässt sich am ehesten übersetzen mit: HaifischMann) genannt. Er gründete die erste Schule auf Ndendö und befriedete verfeindete Kriegsparteien. Über ihn
} 
August bis November 1897 vier Monate an der Nordküste von Ndendö, bevor er erkrankte und verstarb (JOEST 1897; Arthur BAESSLER 1900: 368-403). Während der europäischen Vorherrschaft auf Ndendö gab es nur eine einzige Plantage: Von 1904 bis 1920 betrieb die Firma Lever Bros. unter der Leitung von Matthew, einem Engländer, eine Kokosnussplantage und einen Handelsladen in der Graciosa Bay (ROBSON 1950: 407). SPEISER (1916 und 1924) lebte während seines sechswöchigen Aufenthaltes im Jahr 1912 bei dem Engländer. Japanische Schiffsbesatzungen, französische Händler aus Vanuatu, dem ehemaligen französischen Protektoratsgebiet Nouvelles-Hébrides, sowie der englische Kapitän Fred Jones betrieben in den Santa-Cruz-Inseln sporadischen Handel mit Seegurken (Holothuroidea), Trochusschnecken (Trochus niloticus), Turbanschnecken (Turbo marmoratus), Kopra und Holz. Zu Beginn des 20. Jh. gelangten immer wieder Informationen nach Australien und Europa, dass es nach wie vor zu Übergriffen der lokalen Bevölkerung mit dem Ziel kam, die Fremden zu vertreiben (DOHERTY 2007: 526-564). „The Solomons gained the reputation of being the most dangerous place in the Pacific." (GREAT BRITAIN. Foreign AND COMMONwEALTH OFFICE 1974: 131) Infolgedessen blieb das europäische Interesse an einem intensiven Austausch weiterhin verhalten.

Der Archipel gelangte erst 1923 mit der Eröffnung eines Verwaltungspostens auf Vanikoro zur Sicherung des Holzschlages auf dieser Insel allmählich unter die Administration der Briten. ${ }^{52}$ Während jener Zeit ging die Bevölkerung weiter zurück. Die Fremden schleppten neue Krankheiten ein, etwa Masern, Keuchhusten Windpocken und Tuberkulose, denen die Bewohner schutzlos ausgesetzt waren (DAVENPORT 1969: 160; YEN 1976: 205).

Während des Zweiten Weltkriegs fanden in den Salomonen schwere Kämpfe zwischen Japanern und Amerikanern statt, wobei es in der Santa-Cruz-Gruppe allerdings nur vor den Reef Islands zu einem Gefecht mit nachhaltigen Auswirkungen kam. ${ }^{53}$ Die Bewohner der

wurden traditionelle Kriegsgesänge gedichtet, die bis heute bei Tänzen gesungen werden, ihn damit ehren und seine außergewöhnlichen Fähigkeiten darstellen. Aber Forrest war nicht unumstritten, da sich an seiner Person nach Aussagen der Bewohner von Nelua, wo er die Kirche, die Schule und später auch seine Handelsstation unterhielt, die zwei Clans der Siedlung entzweiten, was zur Auflösung des, alten' Nelua führte. Die heutigen Bewohner des ,neuen' Nelua (Nachfahren der Rückkehrer einer der beiden Clans) sind sich nicht sicher, ob sich der Streit um sexuelle Vergehen gegenüber weiblichen oder männlichen Jugendlichen entfachte (persönliche Kommentare). Aufgrund der Vorkommnisse wurde Forrest 1896 oder 1897 aus der Kirche entlassen und blieb zunächst als Händler auf Ndendö. 190I oder 1904 wurde er auf Weisung des High Commisioners Woodford festgenommen und nach Sydney gebracht, von wo aus er auf die Torres Islands floh und auf Loh Island außerhalb des Zugriffs der britischen Krone eine Handelsstation eröffnete. Als emeut eine Verfolgung drohte, vergiftete er sich 1908 (Charles Morris WOODFORD I898; Robert AlDRICH 2003: 246-275, DAVENPORT 2005: 8-9; Charles MONTGOMERY 2006: Kap. 20.). Siehe auch nachfolgend Missionierung und lokale Glaubensvorstellungen.

52 Auf Vanikoro befand sich eines der Postzentren des BSIP ebenso wie die Timber Company, die sogar eine eigene Funkstation unterhielt (BRITISH SOLOMON ISLANDS 1931: 5, 8; BENNETT 1987: 210). Aber auch während dieser Zeit waren nie mehr als ein Dutzend Europäer auf der Insel (DAVENPORT 1968a: 210).

${ }^{53}$ Vor Vanikoro ankerte 1942 ein amerikanischer Zerstörer, der wahrscheinlich versehentlich von alliierten Bombern angegriffen wurde (DAVENPORT 1968a: 21I). In den Reef Islands unterhielten die US-Amerikaner einen Beobachtungsposten, bei dem zeitweise Wasserflugzeuge landeten und vereinzelt Marineschiffe ankerten. Hier kam es am 26. Oktober 1942 zur Schlacht von Santa Cruz zwischen Amerikanem und Japanern, bei der beide Kriegsparteien Flugzeugträger verloren. Die Japaner bombardierten den Posten. Ein japanisches U-Boot lief auf 
übrigen Inseln wussten zwar von den Geschehnissen, machten aber weitgehend keine persönlichen Erfahrungen mit dem Krieg. Während dieser Zeit war die gesamte Inselgruppe isoliert und erneut ohne europäische administrative Kontrolle (DAVENPORT 1964a: 60). Aufgrund dessen erfolgte letztendlich der unmittelbare Zugriff der Kolonialmacht erst nach dem Zweiten Weltkrieg (ROBSON 1950: 407; DAVENPORT 1962: 95; BENNETT 1987: 271 ).

1959 etablierte der Brite Thomas Hepworth als erster Europäer einen regelmäßigen Kopra-Handel in den Santa-Cruz-Inseln und pachtete mit seiner Frau in den Reef Islands eine kleine Insel, auf der seine Familie bis heute lebt. Ross Hepworth, einer der beiden Söhne, wurde 1997 zum Präsident der Provinz Temotu gewählt (Lucy IRVINE 2000).

\title{
- Missionierung und lokale Glaubensvorstellungen
}

Auch die Missionierungsversuche setzten im Vergleich zu Nachbarregionen recht spät ein und wurden immer wieder unterbrochen. Der Laienmissionar Forrest schrieb am 5. November 1894 an den High Commissioner of the South Pacific:

\begin{abstract}
„The Melanesian Mission started work in the Group in 1864 when two members of the staff were killed in the main island, for sometimes there was no opening. In 1871 work [unleserlich] was again stopped when Bishop Patteson was killed with Mr. Atkin. [...] We have established friendly relations all through the Reef Islands, the Duff Group + have made an opening at [unleserlich]. All over the mainland we have gained a strong hold on the people. There are many villages asking for schools the only reason we do not start them, is, that we have no teachers at our disposal at present. If these people were [...] looked after, I believe a great future is before them." (FORREST 1894, Transkription O. L.)
\end{abstract}

Begonnen hatte die Missionierungsgeschichte - ausgehend von Auckland in Neuseeland laut O'Ferrall bereits im Jahr 1852 mit einer ersten Sichtung der Inselgruppe durch Bischof Selwyn von der Anglican Church of Melanesia auf seiner Fahrt mit der MV Southern Cross sowie seinem ersten Besuch auf verschiedenen Inseln der Provinz Temotu vier Jahre später zusammen mit Rev. John Coleridge Patteson (O'FerRALl 1908; Ruth Miriam Ross 1983: 7-15). ${ }^{54}$ Patteson, seit einem Jahr erster Bischof von Melanesien, besuchte 1862 mehrere Dörfer auf Ndendö und stieß zunächst auf positive Resonanz seitens der Bevölkerung. Es folgten vier erfolglose Versuche (1864 sogar mit zwei Todesfällen), auf Ndendö nachhaltige Kontakte aufzubauen. Als Folge des gewaltsamen Todes von Bischof Patteson 1871 auf der

\footnotetext{
Grund, und die sich rettende Mannschaft wurde aus der Luft mit Maschinengewehren beschossen. Das austretende Öl des U-Boots verseuchte auf Jahre hinaus die Riffe in der Mohawk Bay. Tonnen von Treibgut der gesunkenen Schiffe verschmutzten die Küsten. Viele Bewohner flüchteten von den Küsten, um in ihren Gärten zu leben (DAVENPORT 1969: I6l; http://www.uss-homet.org/history/wwii/santa_cruz. shtml, letzter Zugriff am 5.9.20 I4).

${ }^{54}$ Laut Dokumentation der Melanesian Mission begann die von O'Ferrall dargestellte Missionierung der SantaCruz-Gruppe ab 1857 (THE MELANESIAN MISSION 1880).
} 
zu den Reef Islands zählenden Insel Nukapu wurde die Missionierung zunächst wieder eingestellt (FORREST 1894; O'FERRAL 1908). ${ }^{55}$

1878 gelang es seinem Nachfolger Bischof John Selwyn durch einen Zufall zwei Opfer einer verdrifteten Bootsfahrt in die Santa-Cruz-Gruppe zurückzubringen - woraufhin die Bevölkerung Vertrauen zu den Missionaren fasste und sich anschließend der Christianisierung öffnete (O'FERRAL 1908).

Die Missionierung begann in Leluovu an der Nordküste von Ndendö (THE MELANESIAN MisSION 1880: 885). Von dort oder von Nelua aus, wo Forrest angeblich lebte, wurde der Hauptsitz der Mission an die Ostküste der der Graciosa Bay vorgelagerten kleinen Insel Te Motu verlegt, bevor er anschließend wieder zurück auf die Hauptinsel Ndendö an einen Ort namens Namu an der Graciosa Bay wechselte (BAESSLER 1900: 370; O'FERRAL 1908 und persönliches Gespräch mit Jerry Me'ioko, einem suspendierten Priester der Anglican Church of Melanesia). Im Jahr 2011 befanden sich der Verwaltungssitz der Diözese Temotu in Lata, das Diocesan Headquarter in Luova, ein Priesterseminar in Luesalo an der Graciosa Bay sowie einige Schulen mit Internaten an der Nordküste von Ndendö. Im Jahr 1999 gehörten 86 Prozent der Bevölkerung der Provinz Temotu der Anglican Church of Melanesia an (Statistics Office, Solomon Islands Government in FraenkeL 2004: Table 2.1). 2011 traf ich in der Provinzhauptstadt Lata auf nur wenige Vertreter der Sieben-Tage-Adventisten, Zeugen Jehovas, Katholiken und Bahai'i.

O'Ferrall berichtete zu indigenen Glaubensvorstellungen und deren Ausübung, dass in allen Siedlungen maduka (Geisterhäuser) vorzufinden waren, in denen aus Holz geschnitzten Figuren Speisen oder,Geld' als Opfer gebracht wurden, um sie für eigene Unternehmungen als Unterstützer zu gewinnen. Diese Figuren hatten zoo- und anthropomorphe Formen. Manche wurden als Verkörperungen von Ahnen betrachtet. Diese waren bekannt dafür, dass sie zu Lebzeiten besondere Fähigkeiten gehabt hatten, besonders stark oder wohlhabend

\footnotetext{
${ }^{55}$ Laut Interpretation der Anglican Church of Melanesia waren die Feindseligkeiten als Vergeltungsakte für die Arbeiterrekrutierungen in der Region zu verstehen (O'FERRALL 1908 und persönliches Gespräch mit Vicar General Patteson). Auch RANNIE (1912: 18-19) berichtet von dem Vorfall, der sich angeblich ereignete, weil sich vor dem Besuch des Bischofs der Kapitän eines Blackbirder-Schiffs als Geistlicher verkleidet, Männer von Nukapu auf sein Schiff gelockt und entführt hatte. Montgomery beschreibt die Zusammenhänge differenzierter: Die Bewohner der Santa-Cruz-Inseln sahen keinen Unterschied zwischen der Aufnahme von Kindern für die Missionsschule auf die MV Southern Cross und der Aufnahme von Arbeitern für entlegene Plantagen. Trotz vieler Warnungen brach Patteson, der unter den Folgen des Vorfalls von 1864 psychisch litt, auf, um die Santa-Cruz-Gruppe zu missionieren. Nach seiner Ankunft auf Nukapu wurde er aufgrund der Unkenntnis formaler Regeln getötet: Er hatte dem falschen chief zum falschen Zeitpunkt Geschenke überreicht. Sein Leichnam wurde weder geköpft, geschweige denn verzehrt (was von anderen Zwischenfällen berichtet worden war), sondern seinem Status gemäß in Matten gehüllt, bevor der Leichnam von Rev. Atkin zurückgeholt wurde. Ebenso wurde der Täter von seiner Heimatinsel Nukapu verbannt und später sogar von einem chief auf Ndendö erschossen. Da diese Details aber weniger der christlichen Märtyrergeschichte im viktorianischen England dienten, die ,offizielle' Version vielmehr der politischen Agenda der Briten gegen das Blackbirding half, wurden einige Fakten unterschlagen. Forrest wurde die Geschichte später seitens der Bewohner berichtet, sodass er als erster die gesamte Geschichte erfuhr (MONTGOMERY 2006: Kap. 20); vgl. auch Leslie FuguI \& Simeon BUTU 1989: 87.
} 
gewesen waren. Da sie verstorben waren, konnte man nun deren Geist (ghost) um Unterstützung anrufen. Es gab gute und böse, menschliche und nicht menschliche, männliche und weibliche, erwachsene und Kinder-dukna, die mitunter als Glücksbringer auf Reisen mitgeführt wurden (O'FERRALL 1908). ${ }^{56}$ Manche Lebenden erhielten von den ,Geistern' einen bevorzugten Kontakt, so dass sie über besondere Beziehungen zu diesen bzw. Macht über diese verfügten und als meduka bezeichnet wurden (O'FERRALL 1908; Codrington in GRAEBNER 1909: 148-149). Solche Menschen konnten von anderen gebeten werden, für eigene Belange einen Zugang zu diesen,Geistern' zu schaffen. O'Ferrall beschrieb darüber hinaus weder weitere Praktiken der Glaubensausübung noch benannte er Bezüge zu den lokalen Tänzen. Auch in allen anderen mir vorliegenden historischen Berichten sind keine Aussagen hierzu auffindbar. ${ }^{57}$

In zunehmendem Maße ließen sich die Bewohner taufen, engagierten sich in den Kirchen und schickten ihre Kinder auf die Missionsschulen. Infolgedessen gaben sie die maduka und dukna-Darstellungen - zumindest auf den für Außenstehende wahrnehmbaren Ebenen weitgehend auf. Koch attestierte als ein Ergebnis seiner Forschung Ende der 1960er-Jahre: „Über die traditionellen Glaubensvorstellungen in diesem Archipel sind wir nicht voll informiert. [...] [U]nd infolge der weitgehenden Christianisierung ist in der Gegenwart eine umfassende Studie zu diesem Thema kaum noch möglich.“ (КоCH 1971: 175)

Trotz Christianisierung waren zur Zeit meiner Forschungsaufenthalte bestimmte Aspekte früherer Glaubensvorstellungen weiterhin vorhanden: Der amtierende Bischof der Anglican Church of Melanesia, George Angus Takeli aus Ulawa, berichtete mir, dass die Bewohner Santa Cruz' teilweise Magie (Pijin: magic) noch als Todesursache ansahen. Ebenso wies er daraufhin, dass mitunter die Abwesenheit von Dorfbewohnern oder Angehörigen bei Trauerfeiern als Indiz für deren Mitschuld am Tod der oder des Verstorbenen verstanden werde (George Takeli, 1.8.2011). Bei zwei Todesfällen während meines Aufenthaltes 2011 wurde

\footnotetext{
56 In der frühen Literatur erwähnt CODRINGTON (| 89|: 70) die Bezeichnung duka [sic.] als lokale Beschreibung für ghost und vergleicht sie mit dem in den Florida-Inseln gebräuchlichen Begriff paluduka für ,Geisterbefragung' und der Bezeichnung dukduk für ,Geister' in Neubritannien. Der Geist eines zu Lebzeiten angesehenen Verstorbenen konnte duka werden, auch wenn er Jahre später in Vergessenheit geriet (I89 I: 139, 264). Duka wurden auch als Talisman mit auf Seefahrten genommen ( 89 I: 20I). Ob es sich dabei letztlich um spirits oder ghosts handelte, konnte Codrington abschließend nicht feststellen. Als spirit bezeichnete er ein Wesen, das einer höheren Ordnung als der Mensch angehört, während ein ghost der körperlose Geist eines Menschen sei (|89|: I2 |-122). Joyce GILLETT (1939) zufolge repräsentierten die duka den Geist oder die Seele einer/eines Verstorbenen, die/der zu Lebzeiten ein hohes Ansehen genossen hatte. Für die 1960er-Jahre beschreibt KoCH (I97I: 14) die Vorstellungen von Schutzgöttern oder Göttern sowie von Kulturheroen, Kobolden und übelwollenden Geistern. 201 I wurde mir der Begriff dukna meistens mit devil umschrieben, wobei mir zwei Informanten erklärten, dass es früher eher gods gewesen seien, die erst durch die Missionare, verteufelt' wurden. Zu Herkunft, Mythen, Verkörperung und Verehrung der dukna vgl. DAVENPORT (2005), dem zufolge dukna niemals aus den menschlichen Seelen oder Toten hervorgehen konnten und eher im Sinne von deities und supranatural beeings verstanden wurden (2005: I, 37). Heute bezeichnen meine Informanten mit dem Begriff dukna lokale Gottheiten, wie einen Meeresgott oder eine Gottheit des Windes oder Feuers. Ahnen stellten keine dukna dar, und mit dem Begriff spirits wurden mir etwa Nixen oder Kobolde benannt. Alle gab es in weiblichen und männlichen Formen. $57 \mathrm{Vgl}$. insbesondere Joest bei BAESSLER (1900: 388-390); GRAEBNER (1909: 147-155) und SPEISER (I924: $34 \mid-342)$.
} 
ich Zeuge von derartigen Interpretationen durch meine Gewährsleute. Im ersten Fall verdächtigten zwei Söhne einen entfernten Familienangehörigen, durch die Platzierung giftiger magischer Pfeile im Wohnhaus des Vaters dessen Krankheit ausgelöst zu haben, der er wenig später erlag. Bestätigt wurde dies durch ein weibliches Medium in Honiara, das sehen konnte, wo die Pfeile versteckt worden waren, woraufhin der älteste Sohn das Wohnhaus des Vaters abriss und seine Mutter zu sich ins Haus aufnahm. Als Motiv für die Tat vermutete er den Neid eines Verwandten auf den wirtschaftlichen Erfolg seiner Familie. Im zweiten Fall handelte es sich um die Ermordung eines Kindes im Südosten von Ndendö. Die Tat verstand einer meiner Gewährsleute als Opfer eines, Wild Man` an dessen dukna im Zusammenhang mit einem bekannten Landdisput zwischen zwei Familien in der Region. ${ }^{58}$ Bei einem mehrtägigen Aufenthalt in Nemba anlässlich der Schließung eines Tanzplatzes wurde mir ,empfohlen', mich im Dunkeln alleine nicht zu weit vom Junggesellenhaus zu entfernen, da ,Wild Men' unterwegs sein könnten, die mir vielleicht Böses wollten. Ich sollte besser direkt vor der Hütte urinieren oder jemanden wecken, der mich zum weiter entfernten Toilettenabschnitt am Riff begleiten würde. ,Fliegende Feuer‘ am Himmel wären dukna auf ihrem Weg zum Vulkan Tinakula. ${ }^{59}$

Einige Gesprächspartner gewährten mir Einblicke in ihr Verständnis von und ihren Umgang mit den ,alten' Gottheiten (deity, dukna). Demnach hatte jede Region in der Santa-CruzGruppe, jedes Dorf und jeder Clan eigene dukna, die sowohl um das Wohl der Gemeinschaft als auch jedes Einzelnen angesprochen werden konnten. Dies konnte über einen Priester (pagan priest, medukna) erfolgen, der den/die dukna an einem geheimen Ort auf dem kastomLand seines Clans (nou) ehrte (TROPA 2009: 8). In der Öffentlichkeit konnte einer/einem dukna durch das gemeinsame Ausrichten von Festen gedient werden, die sich im Rahmen eines Zyklus über 10-15 Jahre ausdehnen konnten. Durch gemeinschaftliches Essen, die Verteilung von Schweinefleisch, Hai- oder Thunfisch sowie das Aufführen des nelo-Tanzes ehrten die Initiatoren ihre/ihren dukna einerseits allgemein und baten sie/ihn andererseits konkret um Vergebung für begangene Fehler, um Heilung von Schwerkranken, um Unterstützung bei Auseinandersetzungen mit anderen Clans oder Dörfern oder bei wirtschaftlichen Aktivitäten. Abbildungen oder Figuren wurden mir keine gezeigt, ebenso gab es angeblich keine maduka mehr. Aber mir wurden Zeichen beschrieben, die auf eine Anwesenheit von dukna hinwiesen, und Plätze gezeigt, an denen sie verweilten. Mit verschiedenen Informanten ging ich mehrmals auf dem ,napa-trail', dem Weg, über den die dukna die Seelen der Verstorbenen in das Totenreich Nadap, einen imaginären Ort nördlich der höchsten Erhebung von Ndendö, begleiten. An diesem Ort lebten die Ahnenseelen und die dukna gemeinsam zusammen. Menschen, die den Zug der Seelen kreuzten, würden zu Tode kommen, wenn sie nicht rechtzeitig auswichen. Von einer kleinen, vor der Küste bei Venga liegenden

\footnotetext{
${ }^{58}$ SOLOMON TIMES ( 15.9 .20 I I) und pers. Kommentar eines Informanten, der für diese Aussagen anonym bleiben möchte.

59 Inwieweit es tatsächlich um meinen ,Schutz' oder eher um eine Kontrolle über mich ging, vermag ich nicht zu beurteilen.
} 
Insel, über die der ,napa-trail verlief, durfte ich keine Fotos aufnehmen. Auf die Frage, wie die dukna in Relation zu dem christlichen Gott stehen, wurde mir meistens geantwortet, dass es beide gäbe: die lokalen dukna und den christlichen Gott. Ein Informant interpretierte die dukna als ,gefallene Engel'.

Dies verdeutlicht, wie flexibel meine Gewährsleute die indigenen und christlichen Glaubensvorstellungen miteinander vereinbarten. Auch nach meinen Beobachtungen 2010 und 2011 waren die Menschen regelmäßige Kirchgänger und zelebrierten parallel ,alte‘ Glaubensüberzeugungen: Namensgebungen, Trauungen und auch Beerdigungen wurden nach kastom und nach christlichem Verständnis zelebriert. Nelo-Tänzer traten zu besonderen Anlässen wie z. B. zu Weihnachten und Ostern oder bei Priesterweihen in christlichen Gottesdiensten auf und sangen in Natügu und als kastom-Lieder umgeschrieben etwa das Kyrie oder Gloria (vgl. Kap. 3.3.3). Ein Informant bezeichnete seine Kosmologie als ,holistisch “ und verstand die Welt als Einheit von Materie und Geist, von Mensch und Gott.

In verschiedenen Zusammenhängen erlebte ich unterschiedlichen Umgang mit den dukna und dem christlichen Gott. Nach meiner Beobachtung bezogen sich meine Gesprächspartner nun anlassbezogen auf die kastom-Vorstellungen oder auf den christlichen Gott in synkretistischer Art und Weise. ${ }^{60}$

\section{- Wissenschaftler und ausländische Fachkräfte}

Neben wenigen Archäologen, Ethnologen und Linguisten, die ich mit ihren Kontakten zur Bevölkerung Ndendös und ihren Forschungen an den entsprechenden Stellen meiner Arbeit berücksichtige, hielten sich nach der Unabhängigkeit der Salomonen wenige ausländische Ärzte und Mitarbeiter von Nichtregierungsorganisationen zur Unterstützung beim Aufbau der Provinz in Temotu auf. Von ihnen erinnerten meine Gewährsleute meist deren Vornamen und Berufe und nur manchmal auch die Nationalitäten. Lediglich der Neuseeländer Ashley WILSON (2009) publizierte über seine Erfahrungen aus den Jahren 1997-1999, in denen er als Freiwillige einer neuseeländischen Hilfsorganisation eine Kokosnussölproduktion in Lata aufbauen sollte. Auch seine Darstellungen fließen in meine Arbeit ein.

\section{- Jüngere Geschichte: vom Zweiten Weltkrieg zu den nationalen Unruhen}

Unter den eingreifenden Änderungen der sozialen Organisation der lokalen Bevölkerung nach dem Zweiten Weltkrieg waren zunächst Befriedung und Sesshaftwerdung sowie die Einführung von Schulen und medizinischer Grundversorgung zu beobachten. Unter der Native Administration Regulation von 1947 wurde das arbeitsfreie Wochenende, ein Gebot zur Tierhaltung in Gattern sowie ein Dorfreinigungstag in den Solomon Islands eingeführt

\footnotetext{
60 Bei den alue-Festen in Neo/Nemba wurde der Katechet des Dorfes gebeten, bei den Vorbereitungsmalzeiten zu beten und später auch den Tanzplatz zu weihen, um die „,bösen Geister" zu vertreiben; zu alue-Festen vgl. Kap. 3.3. I. Am Eingang von Nea befand sich ein kleiner Steinzirkel mit einem heiligen Stein in der Mitte und von Pflanzen verdeckt, der mit weißer Magie die mögliche schwarze Magie von Fremden neutralisieren sollte. Auch den Brüdern der Melanesian Brotherhood wurden übernatürliche Kräften zugeschrieben (MONTGOMERY 2006: Kap. 19, The Brothers and their Miracles).
} 
(Lawrence FoAnaOTA 1989: 70). Die britische Administration importierte neue Materialien zum Hausbau, regte an, die Wohnhäuser auf Pfosten zu bauen, und verlagerte die Kochstätten aus den Wohnhäusern in separate Kochhäuser. Da Wehr- und Schutzanlagen obsolet wurden, änderten sich die Haus- und Dorfanlagen nachhaltig. Die traditionellen Dorforganisationsstrukturen von Männerhäusern, Wohneinheiten und Tanzplätzen lösten sich auf (DAVENPORT 1969: 165-173). ${ }^{61}$ Koch betrachtete seinen dreimonatigen Aufenthalt 1966/67 als ,vermutlich [...] letzte Gelegenheit, die materielle Kultur dieser Inseln am Ort zu erfassen“, da die Inselgruppe in zunehmenden Maße verkehrstechnisch an die Hauptstadt angebunden wurde, was zu einem stetig steigenden Import externer Waren und Ideen führte (KOCH 1971: 5).

Im Jahr 1964 wurden mit dem Local Government Act lokale Councils ins Leben gerufen, dessen Umsetzung aber nur unzureichend war und zu keiner Machtverlagerung von Honiara zurück an die lokalen Chiefs führte (Jaap TIMMER 2008: 195). Ab 1968 sollte das zentralisierte europäische System modifiziert werden, da es zum einen dem ,Melanesian style of decision making' nicht gerecht wurde und zum anderen unzureichend an die indigene Bevölkerung vermittelt worden war und demzufolge für alle unbefriedigend gelebt wurde. ${ }^{62}$ Nach einem 1970 fehlgeschlagenen Versuch, ein Governing Council direkt zu wählen, erfolgten 1973 Neuwahlen. ${ }^{63}$ Zum ersten Mal traten in den Solomon Islands zwei Parteien gegeneinander mit dem Ziel an, ein Council of Ministers sowie den ersten Chief Minister der Solomon Islands zu stellen. Unter dem Sieger Solomon Mamaloni begannen 1974 die Verhandlungen zur Unabhängigkeit der Solomon Islands. Er wurde aber bei der nächsten Wahl 1976 nicht wiedergewählt, so dass sein Nachfolger Peter Kenilorea das Land am 7. Juli 1978 in die Unabhängigkeit führte. Die neue Verfassung sah abermals keine Eigenständigkeit der größeren Inseln/Inselgruppen im Sinne eines föderalistischen Staatenverbundes vor.

\footnotetext{
${ }^{61}$ Bis zur Einflussnahme der britischen Verwaltung errichtete die Bevölkerung auf Ndendö fortwährend neue Siedlungen und verließ sie wieder, wobei sie teilweise nicht direkt an den Küsten siedelten. Archäologische Untersuchungen belegen die Inlandbesiedlung zur Zeit der spanischen ,Entdeckung' im I6. Jh. (Douglas Ernest YEN 1974: 22I). Erst als keine Gefahr mehr von Übergriffen von Nachbargruppen drohte, errichteten die Menschen dauerhafte Siedlungen direkt am Meer, abseits der mit Moskitos verseuchten Wälder. Dort war in der Regel die Trinkwasserversorgung einfacher, die hygienischen Verhältnisse besser und das Klima erträglicher (persönliche Kommentare auf der Wanderung zu dem in diesem Zusammenhang aufgegebenem Dorf Dei am I4.I I.20 I I). ${ }^{62}$ Als , melanesischen Weg' bezeichnet AlASIA ( 1989: 144) Verhandlungen, bei denen eine Gruppe von Menschen zusammensitzt, das Problem erörtert und gemeinsam einen Konsens herbeiführt, der von allen akzeptiert werden kann; weniger eine formale Debatte, die durch eine Abstimmung zu einem Entschluss führt. „Disputes were defined and addressed within an elaborate complex of kinship, status and social relations. [...] Notions of reciprocity and equivalence were crucial [...]. Such approaches typically entailed a strong element of bargaining and compromise, in contrast to ,win-or-lose' adjudication under Western common law." (Sinclair Dinnen et al. zitiert in MOORE 2004: 28-29, Hervorhebung im Orig.)

${ }^{63}$ Dieses Council sollte eine eigenentwickelte Regierungsform darstellen und durch einen Konsensmodus Entscheidungen treffen, um keine Aufspaltungen in einer bereits ungleichen Nation voranzutreiben, wie es für ein Parteiensystem analog zum Westminster-Modell befürchtet wurde (DEVISI I992: 3).
} 
In der Folgezeit wurden erste Separationsforderungen laut, u. a. auch in der Provinz Temotu. ${ }^{64}$ Die Bewohner organisierten auf lokaler Ebene ihre Gemeinschaften und Ressourcen weiterhin in der Art und Weise, wie sie es für angemessen erachteten und modifizierten Neuerungen so, dass sie ihnen Nutzen brachten. Gleichzeitig änderten sie aufgrund der Christianisierung und von außen geprägten staatlichen Erziehung die Vorstellungen über Führungsstile und gender-Beziehungen (ebd.). Was ursprünglich von außen eingeführt worden war, adaptierte die Bevölkerung in weiten Teilen und verstand es genauso als kastom wie eine formal tradierte Kontinuität ,alter' Kulturpraktiken (FRAENKEL 2004: 12). Die Forderungen nach mehr politischer Autonomie einzelner Inseln führten 1984 zum Erlass des Provincial Government Act, der die Verantwortlichkeiten zumindest für Agrar-, Erziehungsund Gesundheitspolitik in die Hände einer auf Provinzebene gewählten Provincial Assembly und eines Executive Committee legte (ALASIA 1989: 149). Im Jahr 1987 empfahl ein Constitutional Review Committee eine föderalistische Verfassung für die Solomon Islands, die mehr Macht in die bis dahin als Provinzen organisierten Inselregionen geben und vor allem vor Ort eine Kontrolle zum Ressourcenzugang, über traditionelles Landrecht sowie die damit verbundenen ökonomischen Entwicklungsmöglichkeiten garantieren sollte (TIMMER 2008: 196).

Im Zuge der britischen Entwicklungspolitik, die sich auf Guadalcanal und die Western Solomons konzentrierte und die bevölkerungsreichste Insel Malaita nicht berücksichtigte, zogen immer mehr Menschen von Malaita nach Guadalcanal (MOORE 2004: 35). Die Hauptstadt Honiara wurde in zunehmendem Maße von Malaitern bevölkert, und es kam vermehrt zu sozialen und rechtlichen Auseinandersetzungen über Gewohnheitsrecht und andere Formen von Landnutzung und -besitz (AMNESTy INTERNATIONAL 2000). Die Solomon Islands waren in den 1990er-Jahren mit einem rapiden sozialen, demografischen und ökonomischen Wandel konfrontiert. Die Kombination von geringer wirtschaftlicher Entwicklung und einer stark wachsenden Bevölkerung führte zu einer entwurzelten und unterbeschäftigten Generation, die wenig an die existierende Ordnung glaubte (FRAENKEL 2004: 10). Von 1998 an wurden Honiara (bzw. Guadalcanal) sowie Malaita immer wieder Austragungsort ethnischer Spannungen, zunächst zwischen den Bevölkerungsgruppen der beiden größten Inseln Malaita und Guadalcanal. ${ }^{65}$ Diese mündeten im Juni 2000 im Sturz der Regierung und lösten in der Landeshauptstadt bürgerkriegsähnliche Zustände aus. Nahezu alle Ausländer wurden aus den Solomon Islands evakuiert, die meisten Solomon Islander, die

\footnotetext{
${ }^{64}$ Mamaloni schrieb später dazu: „,We have delayed too long in effecting fundamental reforms in accord with the aspirations of the masses, reforms in terms of government and socio-economic system [...]. Public statements have already proven that Choiseul, Rennel/Bellona, Guadalcanal, Temotu but to mention a few, want to retain their own original ,island nation' or entity status." (MAMALONI 1992: 17-18, Hervorhebung im Orig.)

${ }^{65}$ Zu den Hintergründen der sogenannten tensions von 1998 bis 2003 siehe insbesondere Jon FRAENKEL (2004) und für den Zeitraum bis 2006 Sinclair DINNEN \& Stewart FIRTH (2008). Die Spannungen gingen auf die I940erund 1950er-Jahre zurück, in denen Malaiter für die US-Armee in Honiara gearbeitet hatten und dortgeblieben waren.
} 
nicht aus Honiara stammten, verließen die Hauptstadt und gingen in ihre Heimatdörfer zurück, da es in Honiara weder Sicherheit noch ausreichend Nahrungsmittel gab (MOORE 2004: 12, 17).

Darunter waren auch Migranten aus Santa Cruz, die in der Hauptstadt arbeiteten oder ihrer Ausbildung nachgingen. Die Rückkehrer brachten in den Augen mancher der in Santa Cruz Verbliebenen ungewohnte und teilweise nicht kastom-konforme Verhaltensweisen mit. Dazu zählten etwa Kleidungsstile, lautes Verhalten in den Dörfern nach Einbruch der Dunkelheit, Ernährungsgewohnheiten, Trinken von Alkohol und sinkender Respekt vor den Dorfältesten (persönliche Gespräche u. a. mit Bischof Takeli, Tom Olu, Chief Rockson Tungale).

Unmittelbar nach der Unterzeichnung des, Townsville Peace Agreement' am 15. Oktober 2000 durch die beiden verfeindeten Parteien Malaita Eagle Force und Isatabu Freedom Movement stellten die Gegner die feindlichen Handlungen ein. Dennoch führten die folgenden drei Jahre zu einem nahezu vollkommenen Zusammenbruch des politischen und wirtschaftlichen Systems des Nationalstaates (2004: 20).

\section{- Föderalismusbestrebungen der Provinz Temotu}

Eine wichtige Friedensinitiative sahen die Provinzregierungen zunächst in ihrer eigenen politischen Stärkung. ${ }^{66}$ Die Verfassung sollte in Richtung einer föderalistischen Struktur verändert werden. Dazu vereinbarten die Premiers auf der Provincial Premiers' Conference, die Nationalregierung mit einer Verfassungsänderung zu beauftragen mit dem Ziel, die bisherigen Provinzen in Länder mit eigenen Verfassungen zu überführen. ${ }^{67}$ Es wurde eine State Government Task Force eingerichtet, die eine neue Verfassung erarbeiten sollte. ${ }^{68}$ Die große Herausforderung bestand darin, zum einen die traditionellen Führungssysteme auf lokaler Ebene mit der nationalen Regierung zu verbinden und zum anderen parallel die Variationen politischer Strukturen zwischen den Inseln zu berücksichtigen ${ }^{69}$. Ab Mai 2002 überprüfte ein Projektteam des United Nations Development Programme (UNDP) den Reformprozess sowie mögliche soziale, ökonomische, strukturelle und administrative Auswirkungen von Dezentralisierung und Föderalismus in den Solomon Islands. Es unterstützte die Regierung bei den Entwicklungsvorbereitungen eines dezentralen Regierungsmodells sowie bei öffentlichen Anhörungen und dem Zusammenführen eines ersten Verfassungsentwurfes. ${ }^{70} \mathrm{Ab} 2003$ wurden landesweit Beratungen mit lokalen Führern und Provinzregierungen durchgeführt.

\footnotetext{
${ }^{66}$ Zum Entwicklungsprozess einer föderalistischen Verfassung der Solomonen vgl. auch Katy LE RoY (20I I : 26-37).

${ }^{67}$ Kerninhalt der Premiers-Konferenz in Buala, Provinz Isabel, am 17.1 I.2000; vgl. http://www.austlii.edu.au/au/ joumals/AltLaw]I/2002/78.html, letzter Zugriff am 23.9.20 I2. Ebenso wurden durch diese Initiative die Abspaltungsforderungen der Provinzen Temotu, Makira/Ulawa und Rennell/Bellona abgemildert.

${ }^{68}$ Constitutional Reform Unit (o. J., vermutlich Anfang 2008).

${ }^{69}$ Die unterschiedlichen Paramount-, Village- und Clan-Chief-Strukturen wie auch die Frage nach einer Integration von Frauen in politische Führungspositionen wurde diskutiert (SOLOMON ISLANDS CONSTITUTIONAL REFORM PROJECTS 2003, Workshop Paper 5).

70 CONSTitutional ReForm Unit (o. J., vermutlich Anfang 2008).
} 
In einem offiziellen Schreiben verwies der Premier der Provinz Temotu darauf, dass alleine für seine Provinz fünf Regionen mit eigenen Kulturen existierten, die bis zu diesem Zeitpunkt nur unvollständig berücksichtigt worden waren: Nende, Pele (Reef Islands), Duffs und Outliers, Utupua und Vanikoro sowie Tikopia und Anuta (Schreiben des Premiers Hon. Johnson Levela an den UNDP Project Coordinator vom 24.2.2003). Durch die in ihren Augen weiterhin unzureichende Berücksichtigung lokaler kultureller Diversität drohte die Provinz Temotu verstärkt mit der Abspaltung von den Solomon Islands (TEMOTU PROVINCIAL SubMission 2003). In dieser Eingabe formulierte die Provinzregierung, auf welcher Ebene (national oder Provinz) die einzelnen Politikfelder anzusiedeln waren. Nach dem ersten Entwurf einer föderalistischen Verfassung folgten weitere Anhörungen und Überarbeitungen des Entwurfes. In den folgenden Jahren entwickelten die Provinzen Vorschläge, wie welche Politikbereiche auf Bundes- und Landesebene verteilt werden sollten. Da die Politiker dies über ,melanesische Entscheidungsfindungsprozesse' (vgl. Anm. 62) herbeiführen wollten, dauerte der Prozess zur Zeit meiner Aufenthalte noch an. Der aktuelle Stand der in den Jahren 2007-2009 erarbeiteten Vorschläge findet sich bei TROPA (2009), einem amtierenden Paramount Chief und Mitglied des Nationalparlaments. Aus ihm wird ersichtlich, wie stark das Ideal für die Provinz Temotu an der Vergangenheit orientiert ist. Die ,Macher favorisieren demnach eine im Laufe von tausenden Jahren entwickelte, partizipative, direkte Demokratieform, die Gott für die traditionelle Gesellschaft Ndendös kreiert hat (2009: 3).

Der Prozess war während meiner Feldforschung weiterhin nicht abgeschlossen und bildete einen wesentlichen Hintergrund, vor dem die Bereitschaft der Bevölkerung auf breiter Basis für eine kulturelle Rückbesinnung u. a. auf den nelo-Tanz und die damit verbundenen Artefakte gesehen werden kann. 


\section{Tanzkleidung und -schmuck als kastom-Konfigurationen}

Im folgenden Kapitel werde ich unterschiedliche Anlässe, zu denen die Tanzkleidung und der -schmuck auftraten, und verschiedene Perspektiven auf sie herausarbeiten. Primär waren kastom-Tänze Anlass für das Erscheinen der Tanzkleidung und des -schmucks. Aber in einigen anderen Fällen traf ich auch außerhalb von Tanzaufführungen auf die Artefakte - nämlich dann, wenn sie an Nicht-Tänzer, Einheimische wie auch Besucher, als Repräsentationen einer alten, distinkten Santa-Cruz-Kultur bzw. als Santa-Cruz-kastom veräußert oder seitens der Kirche oder der Regierung verschenkt wurden. Unter einem Anlass verstehe ich hier die Intention einer Inszenierung eines Tanzes oder im Falle des Verkaufs die Intention der Verund Kaufenden, kastom zu artikulieren, im Sinne von konstruieren und ausdrücken. Damit folge ich dem Netzwerkverständnis der ANT, demzufolge Akteur-Netzwerke zur Lösung spezifischer Problemstellungen aufgebaut werden (CALLON 2006: 135, 146-164; vgl. Kap. 1.2). Die letztlich umgesetzten Inszenierungen der Tänze bzw. Verkäufe der Artefakte zeigen spezifische Konfigurationen der jeweiligen Netzwerke zu dem Zeitpunkt, an dem die ,Arbeitsleistung' der Akteur-Netzwerke als Artikulation von kastom in Beziehung zum Außen öffentlich und mit ihnen auch die Tanzkleidung und der -schmuck sichtbar werden. Aus diesem Grund trägt dieses Kapitel die Überschrift Tanzkleidung und -schmuck als kastom-Konfigurationen.

Zuerst werde ich analysieren, wie meine Gewährsleute und andere Personenkreise, die nicht männliche Erwachsene waren und nicht in mehr oder weniger direktem Zusammenhang zu den Tänzen oder Artefakten standen, kastom bzw. kalsa auf Ndendö im Allgemeinen und auf den nelo-Tanz und die damit verbundenen Artefakte im Besonderen sahen (Kap.3.1). Daran anschließend werde ich historische Quellen betrachten (Kap. 3.2), um eine Vergleichsmöglichkeit zu den Anlässen zu erhalten, zu denen die Tanzkleidung und der -schmuck auf Ndendö während meiner Aufenthalte konkret in Erscheinung traten und wie die Artefakte in diese eingebunden waren. Dabei geht es mir nicht darum herauszufinden, ob Anlässe ,originär` oder ,genuin` sind, sondern vielmehr, wie sie sich möglicherweise 
gewandelt haben und wie sie von der lokalen Bevölkerung kommentiert werden. Da die beteiligten Aktanten und die Problemstellungen bzw. Ziele bei den rezenten Aufführungen variierten, ergaben sich zwar unterschiedliche spezifische Konfigurationen für das grundlegende Verständnis der Artefakte, aber es ist letztlich weniger relevant, welcher Tänzer und welcher Schmuck im Einzelfall erschienen. Wichtiger hingegen scheinen mir die Beweggründe der Aufführungen als Analysekategorien zu sein, so dass ich eine Einteilung in vier Anlassgruppen vorschlage (Kap. 3.3).

\section{I Verwendungen des Begriffes kastom auf Ndendö}

Die Begriffe kastom, kalsa und tradition wurden auf Ndendö flexibel und oftmals nicht eindeutig verwendet, was die in Kapitel 1.2 erläuterten Darstellungen zum ethnologischen Verständnis des Umgangs mit den Begrifflichkeiten in Melanesien wiederspiegelt. Die Menschen diskutierten nicht nur, was kastom zur Zeit meiner Aufenthalte oder in der weiter zurückliegenden Vergangenheit war, sondern auch, ob die Handlungen Anderer kastom entsprachen oder ob kastom in aktuellen Angelegenheiten relevant oder anwendbar war. Tom Olu zufolge stellten kastom and kalsa eine Art normativen Rahmen, der nach Sicht Ataban Tropas Teil eines Ganzen (von Gott gegebenem, wobei er hier den christlichen Gott meinte) war:

„Well, this island belongs to kastom, belongs to kalsa. And, you know, kalsa and kastom have all the right to question, what is coming into this island. [...] If we lose kalsa, kastom is out of place. Then you have nothing to question, then this island is going to become ruined and spoiled.“ (Tom Alfred Olu, 8.11.2011)

„When God created me, everything was there: land, climate, kastom and government system. I am complete, the system is there. My father told me for example not to play with girls because they were tabu. Kastom must be put into constitutional law." (Ataban Tropa, 6.10.2011)

Konkrete Situationen, die ich neben den Aufführungen von nelo-Tänzen in Verbindung zu kastom erlebte, waren u. a. Praktiken bei einer Hochzeitszeremonie; Wertzuschreibungen, materielle Bestandteile und in die Zukunft gerichtete Pflichten bei zwei Brautpreisverhandlungen wie etwa die Namensgebung Neugeborener; Gastgeschenke der Anglican Church of Melanesia und der Provinzregierung; halböffentliche Diskussionen um Landnutzungsrechte, Gartenbau und Tourismusförderung sowie allgemeine Kleidungsvorschriften, Regeln zum 
Umgang von Frauen und Männern oder Obligationen aus reziproken Beziehungen zwischen verschieden Familien/Clans. ${ }^{71}$ Die Verwobenheit mit der Vergangenheit, die Relevanz dieses Wissens um kastom und Zeremonien auch für das heutige Zusammenleben beschrieb Freddy Me'esa:

\begin{abstract}
„My father was a kastom man, somebody, who built up his wealth on kalsa [...]. He was one of the last big men of Santa Cruz. In a way he was [...] a wealthy man in tradition. [...] My father inherited that from his father, Harper Lvao. Keeping the kalsa is a part of our growing up. When my grandfather was still alive, I saw that people from around Graciosa Bay, even Santa Cruz, came to visit him, to talk with him, talk about kastom [...]. He was a source of knowledge for kastom and special ceremonies. The way he conducted ceremonies is still well known, like bride price and other things.“ (Freddy Me'esa, 21.7.2011)
\end{abstract}

In Auseinandersetzungen um die Anwesenheit von mir und anderen Nicht-Einheimischen bei alue-Festen oder bei öffentlichen Diskussionen zur Akzeptanz meiner durch das nationale Erziehungsministerium ausgestellten Forschungsgenehmigung - manche Personen vermuteten ein eher wirtschaftliches Interesse meinerseits bei der Erhebung von ,lokalem Wissen - bezogen sich gegensätzliche Parteien gleichermaßen auf kastom. Auch wurden Dorfmitglieder beschuldigt, kastom kommerzialisiert zu haben. ${ }^{72} \mathrm{Zu}$ einem positiven wirtschaftlichen Aspekt von kastom-Artefakten führte Freddy Me'esa weiter aus:

„Nelo-dance, our traditional dance, in Santa Cruz is unique. And there are others like napa, and lele and tepepa-dance. They are all unique because our costums are traditionally made [...]. One thing we know as well is that these traditional artifacts have become tourist attractions in our area. So well, on one side it's like a commercial thing that we, you know, earn income with.“ (Freddy Me’esa, 21.7.2011)

Um nicht ausschließlich die Sichtweisen von mit nelo-Tänzen und Artefakten beschäftigten Männern zu erhalten, suchte ich nach Möglichkeiten, mit Frauen und Jugendlichen zu sprechen. Mich interessierte, wie junge Menschen zu kastom stehen und dies mit ihrem Leben, das sie als Schüler auch weg von Zuhause führten, in Einklag brachten. Hierbei stieß ich schon bei der Anbahnung auf sehr präsente kastom-Regeln: Ich durfte nicht mit heiratsfähi-

\footnotetext{
${ }^{71}$ An vielen Stellen in dieser Arbeit finden sich Hinweise zum Umgang mit kastom. Vgl. insbesondere zum namesake-Konzept (Kap. 2, S 33-34, Anm. 24 und 38), zur Unterstützung bei der Vorbereitung von Festen (Anm. I49), und zu den außerhalb der nationalen Rechtssprechung agierenden ,Wild Men' (Anm. 154).

72 Zur negativen Auslegung kommerzieller Aktivitäten mit kastom vgl. auch Tom Olus Kommentaren zur Verkleinerung der tema und zu den Aktivitäten von Wilson Kabi (Anm. 96). Ebenso verstehe ich meinen ,Vorfall', bei dem mir zu Last gelegt wurde, ich hätte an einem nelo-Tanz als Zuschauer teilgenommen und unerlaubt Fotografien und Aufzeichnungen angefertigt; vgl. Kap. I.4.
} 
gen Frauen alleine zusammen sein, musste Gespräche mit älteren Jugendlichen nach Geschlechtern getrennt durchführen und durfte die älteren Schülerinnen nur in Anwesenheit eines Lehrers befragen. ${ }^{73}$ In den Gesprächen zeigte sich, dass der Begriff Tradition tendenziell im Sinne einer alten, aussterbenden Lebensweise verstanden wurde, als Art und Weise, wie die (alten) Menschen in ihren Dörfern lebten, etwa im Erdofen kochten und miteinander kommunizierten (mittels Schneckenhorn oder Trommeln sowie nicht schriftlich fixiertes Vermitteln). Ebenso wurden der Einsatz von Federgeld beim Brautpreis, bestimmte Formen von Gartenarbeit und Fischfangmethoden, der Gebrauch von Steinäxten oder kastom-Tänze als traditionsverbunden erlebt. Tradition war ,something, what has been done by our ancestors in former times, what old people do, something which does not exist any longer". Ein Schüler aus No'ole an der Südküste Ndendös erwähnte, dass sein Dorf die lokale Sprache und damit seine Identität und Kultur verliere. Auch wenn sie sich nicht direkt mit den Traditionen der Alten identifizieren konnten, schien kastom als Regelwerk wahrgenommen zu werden, das von allen - auch ihnen selber - beachtet wurde/werden musste. Sie stimmten darüber ein, dass Kinder initiiert werden und Mädchen Shorts unter den Röcken tragen mussten, Mädchen keine Männerhäuser betreten und nicht vor Jungen/Männern gehen durften, dass Eltern Hochzeiten arrangierten konnten - wobei auch Liebeshochzeiten vorkamen - und Brautpreise verhandeln mussten. Einige Schüler erwähnten ,kastom-Häuser', in denen traditionelle Artefakte aufbewahrt wurden, und nannten als Beispiel ein Haus in Mbanua in der Graciosa Bay. ${ }^{74}$ Was die Schülerinnen und Schüler weitaus mehr interessierte, waren Kleidung aus der Hauptstadt, Mobiltelefone und Musik wie Hip-Hop oder Reggae sowie eine gute Ausbildung und ein gut bezahlter Beruf.

In allen Gruppendiskussionen zeigte sich zudem, dass alte Artefakte, die aktuell nicht mehr verwendet wurden, auch nicht erkannt wurden. Die nur noch in sehr wenigen Dörfern genutzten Tanzkeulen napa ba wurden ausschließlich von Kindern aus den Dörfern Malo und Nonia erkannt, die sie bei einem napa-Tanz im Jahr 2008 auf der Lata Trade Show gesehen hatten. Bei dem Tanzschurz lepanesa diskutierten die Befragten darüber, ob dieser aus Tapa oder Bananenbast hergestellt wäre. Die Mehrzahl entschied sich für Tapa (was falsch war). Ihrer Meinung nach wurden Tanzschürze von Frauen und Männern im Rahmen von kastom-Tänzen, von Frauen bei kastom-Heiratszeremonien oder von älteren Frauen getragen. Ich selber hatte in Lata eine einzige Frau gesehen, die Tapa im Alltag trug. Alle

\footnotetext{
${ }^{73}$ Insgesamt führte ich vier Gruppendiskussionen mit Schülerinnen und Schülern im Alter von elf bis 2 I Jahren durch. Für den 31. Oktober und I. November 20II hatte ich jeweils acht nach Geschlechtern getrennte Schülerinnen und Schüler der Form-4-Klasse der Secondary School Lata in den Besprechungsraum des bischöflichen Verwaltungsgebäudes in Lata eingeladen. Dies war der einzige öffentliche große Raum, der mir in Lata zugänglich war. Am 8. November sprach ich mit 13 Schulkindern der Grade-6-Klasse der Kati Primary School sowie am I I. November mit rund 40 Schülerinnen und Schülern der Form- I- und 2-Klassen der Mona Secondary School, in den jeweiligen Schulen in der Graciosa Bay.

${ }^{74}$ Dieses Haus war für Ndendö recht ungewöhnlich, da es einen sechseckigen Grundriss hatte und mit Bretten aus Farnholz verkleidet war. Letzteres zeichnete meinen Gewährsleuten zufolge ursprünglich die Männerhäuser aus. In diesem kastom-Haus bewahrte Paul Fisheryoung Kebunes Familie historische Artefakte auf.
} 
erkannten den tema-Brustschmuck, wobei einige bezüglich des Namens unsicher waren, ob er tema oder nelo genannt wurde. Zwei Jungen hingegen gaben sogar den Namen mabu für die Schildpattauflage wieder. Alle kannten deren Verwendung durch nelo-Tänzer, und einige erwähnten zusätzlich die frühere Schutzfunktion der tema für Krieger. Ebenso war die kleinere Variante dieses Brustschmucks bekannt, von der viele wussten, dass sie in der Graciosa Bay gekauft werden konnte, wobei sie deren Preis als zu hoch und daher für sich als unerschwinglich einstuften. Die Schülerinnen und Schüler waren sich darin einig, dass temaBrustschmuck als traditionelles Artefakt relevant war, das exklusiv (zu) den Menschen in Santa Cruz gehörte und diese Beziehung symbolisierte. Die verkleinerte Variante bezeichneten manche als ,fashion', und einige ältere Jugendliche bezeichneten sie eher abwertend als ,money making - this has nothing to do with our culture'.

Mit Ausnahme eines einzigen Schülers hatten alle übrigen während verschiedener Feste mit viel Spaß auf den Tanzplätzen getanzt. Die meisten von ihnen waren in die Vorbereitungen der Feste involviert. Die Jungen mussten beim Fischfang und beim Öffnen und Raspeln der Kokosnüsse helfen, die Mädchen beim Kochen und bei der Kokosmilchgewinnung. Beide Geschlechter unterstützten ihre Familien beim Sammeln von Feuerholz. Anlässe für die Feste waren den meisten nicht bekannt. Nur die Schülerinnen und Schüler der Mona Secondary School stellten Zusammenhänge zu gemeinsamen Essen, Initiationsfeiern sowie zum traditionellen Abschlussfest alue dar: „Some devils are there, to get rid of them, kind of worship, protecting the people, peace making. “75

Wie sich zeigte, kannten die Kinder und Jugendlichen ausschließlich diejenigen Artefakte, die die nelo-Tänzer im Kontext der kastom-Feste oder sogenannter ,Kunst- und Kultur-Shows' als Ausdruck von Tradition, im Sinne einer kollektiven Verbindung mit der Vergangenheit und einer kulturellen Zugehörigkeit aktiv nutzten. Eine besondere Stellung nahmen dabei die tema ein, die Jugendliche und Erwachsene, Frauen wie Männer in der verkleinerten Variante als ,fashion' und Symbol einer kulturellen Zugehörigkeit zu Santa Cruz gleichermaßen trugen, sofern sie für sie erschwinglich waren. Die Jugendlichen erlebten kastom in Form von Verhaltensrichtlinien als Teil ihres persönlichen Alltags, wohingegen sie Tradition bei ihren Großeltern verorteten und tendenziell als etwas Aussterbendes sahen.

Kastom stellte sich auf Ndendö als ein durchaus umstrittenes Feld dar, auf dem unterschiedlich positionierte Gruppen ihre partikulären symbolischen Formen und Inhalte auf die Zukunft gerichtet voranbrachten. Kastom-Wissen und -praktiken waren in ihren vielfältigen Erscheinungsweisen keine ,einfach nur ${ }^{6}$ aus der Vergangenheit überlieferte oder wieder aufgeputzte ,alte Hüte', sondern vielmehr zeit-, raum, ziel- und zielgruppenabhängige, strategisch genutzte und auf die Zukunft gerichtete Ressourcen - Repertoires an Wissen, Wertzuschreibungen und Legitimationen und mit ihnen verbundene Handlungsstränge. Innerhalb eines Handlungsstrangs (im Sinne der ANT eines Akteur-Netzwerks) schien kastom - wenn

${ }^{75}$ Zu dem Abschlussfest alue vgl. Kap. 3.3.1. 
auch nicht unumstritten - in sich kongruent (im Sinne der ANT eine Entität) zu sein. ${ }^{76}$ In unterschiedlichen Akteur-Netzwerken konnten konkrete kastom-Inhalte für Außenstehende mitunter heterodox erscheinen. ${ }^{77}$ Für das Verständnis von kastom auf Ndendö schlage ich vor, den Komplex als offenen, nicht eindeutig festgelegten Aushandlungsraum zu verstehen, der abhängig von den Machtverhältnissen zugunsten oder zulasten von Personen/-gruppen situationsabhängig und auf die Zukunft gerichtet Richtlinien vorgibt und von ihnen aktiv genutzt wird. So kann kastom neben alten auch durchaus neue kulturelle Aspekte bezeichnen, etwa dass Frauen unter den Röcken Shorts tragen sollten, dass der sonntägliche Gang zum christlichen Gottesdienst mehr oder weniger verpflichtend ist, dass ein Gebet an den christlichen Gott am Ende eines Festzyklus für dukna durchaus erwünscht ist oder dass verkleinerte tema von manchen als kastom-Artefakte angesehen werden und von manchen eben nicht.

Im weiteren Verlauf der Arbeit wird sich zeigen, dass auf Ndendö mitunter dieselben Artefakte, Menschen und Tänze zu unterschiedlichen Zeiten in unterschiedlichen AkteurNetzwerken verschiedene kastom-Konfigurationen schufen, und dass Artefakte und meine Gewährsleute als Aktanten zwischen verschiedenen Akteur-Netzwerken hin- und hergingen (nach ANT-Terminologie ,drifteten') und verschiedene Inhalte, übersetzten'. Wie sie in einem ganz konkreten Fall zusammenkamen, zu ,Komplizen‘ wurden (vgl. Kap. 1.2), zusammenwirkten und ein heterogenes Akteur-Netzwerk bildeten - nämlich einen nelo-Tanz als Gedenkfeier für einen Verstorbenen ausrichteten - werde ich in Kapitel 5 vorstellen und untersuchen.

\subsection{Historische Erläuterungen zu den kastom-Artefakten und -Tänzen}

In der frühen Literatur finden sich neben den reinen Beschreibungen der Artefakte (vgl. Kap. 4.1) nur wenige Berichte über deren Verwendung. Dass die Menschen auf Ndendö Artefakte gegen europäische Waren einhandelten, belegte als erster Jacques Julien Houtou de Labillardière (1755-1834), Naturwissenschaftler und Teilnehmer der Suche nach La Perouse unter D'Entrecasteaux (DE LABILLARDIÈRE 1800: 261). In seiner Ausführung bleibt offen, ob er unter „,commodities“ auch Kleidung und Schmuck verstand. James Cumming DEWAR (1892: 246, 49) erwähnt als erster konkret Tanzkleidung und -schmuck als Handelsgut. Knapp zehn Jahre später berichtet Graham Officer (1867-1909), ein vom Victoria Museum in Melbourne beauftragter Sammler, dass die Artefakte - darunter auch Tanzkeulen - seinem Erachten nach bereits für den Verkauf hergestellt wurden. Über seinen zweistündigen Besuch auf Ndendö am 13. August 1901 schreibt er in seinem Tagebuch:

„About 100 canoes came off the steamer. All of outriggers type. Natives bringing large quantaties of bows and arrows for sale, as well as mats, model canoes, bag,

\footnotetext{
76 Zum Entstehen von Akteur-Netzwerken und ihrem möglichen Erscheinen als Entität, als Punktualisierung einer verkürzten Wahrnehmung vgl. S. 14-I5.

${ }_{77}$ Als Beispiele dazu verweise ich auf die in Kap. I.4 skizzierten Familienauseinandersetzungen, die sich an meiner Person verdichteten.
} 
dancing clubs etc. Bought some bows and arrows, some mats but most of the things the natives brought off are obviously made for sale and of no value to a museum. Mats here are made on looms and of very nice workmanship. [...] Natives eager to trade as usual asking exorbitant prices. Many wore large rings of tortoise shell in the septa of their noses and a large circular plate of pearl shell with a turtle shell ornament on it around their necks. They are light coloured and some had their hair coloured with lime.“ (Rhys RICHARDS 2013: 122)

MARKHAM (1872: 239) berichtete als erster über die Tänze und deren weite Verbreitung, die sie begleitende traurige Musik mit ,vortrefflichem Takt“ und über die Orte, an denen sie aufgeführt werden:

„The islanders are very fond of dancing, to the accompaniment of a plaintive air, and in admirable time. All voyagers have noticed this love of dancing. The companions of Quiros observed it, and Captain Carteret mentions having seen large numbers of people on Santa Cruz island, dancing in a ring." (MARKHAM 1872: 239)

CODRINGTON (1891: 330) zufolge besaß jeder Anführer (,great man“) in der Nähe seines Hauses einen solchen Platz, der von großen Korallenscheiben umgrenzt war. ${ }^{78}$ Ziel des Tanzes war es gemäß Codrington, möglichst exakt und laut gemeinsam mit den Füßen auf den Boden zu stampfen. J. GIRIEUd \& H. HERRENSGHMIDT (1898: 197) erwähnen einen narpoTanz in den Reef Islands, der bis zu zehn Stunden dauerte. Joest (BAESSLER 1900: 397) führt an, dass kurz vor seiner Ankunft Tänze mit Keulen stattgefunden hatten. Des Weiteren berichtet er von ,Peitschentänzen` und dem gemeinsamen Tanzen von Frauen und Männern, wobei erstere geduckt tanzen mussten. Auch O'FERRAL (1908) beschreibt, dass Frauen alleine oder zusammen mit Männern tanzten und sich dabei gebückt auf Händen und Füßen bewegten. Ihm zufolge wurden die Tänze auf runden Tanzplätzen bei Vollmond im Umfeld eines mehrere Tage währenden Festes aufgeführt und dauerten von Sonnenuntergang bis -aufgang. Insbesondere die Tänzer achteten peinlich genau auf ihr Aussehen, wie ,, a young English girl for her first ball“" (ebd.). Es gab verschiedene Tänze mit unterschiedlicher Ausstattung und Gesängen in Strophenform. COOMBE (1911: 174, 177-178) berichtet neben einer ausgeprägten Fähigkeit der Insulaner, beim Handel zu Feilschen, von Tänzen im Zusammenhang mit aufwendigen Festen anlässlich von Passageriten. SPEISER erwähnt den Tanzplatz in der Beschreibung der Dorfarchitektur und den Tanz lediglich im Zusammenhang mit den Tanzkeulen (1916: 177, 209). In seiner Analyse der Santa-Cruz-Tanzkeulen aus der Sammlung des Rautenstrauch-Joest-Museum untersucht FOY (1916) die Formensprache dieser Artefakte und die Ikonografie ihrer Bemalung, geht aber nicht auf deren Ge-

${ }^{78}$ Zur Bedeutung der Tanzplätze vgl. insbesondere Kap. 3.3.I, Anm. 86, 88, 89 sowie Abb. 62 und Anm. I 44. 
brauch in den Tänzen ein. Ebenso widmet sich BEASLEY (1939) ausschließlich der Gestaltung und Symbolik der, Tamar (tema) und verzichtet auf die Darstellung möglicher Nutzungsumfelder. In den folgenden 30 Jahren erscheinen meinen Recherchen zufolge keine weiteren Publikationen zur Tanzkleidung auf den Santa-Cruz-Inseln.

In der jüngeren Literatur analysierte Davenport in den 1960er Jahren als einziger ausführlich Mythologie, Lieder und Anlässe der Tänze im Archipel - im Gegensatz zu KoCH (1971: 96-131 und 1972e), der die Materialität der Objekte sowie die Techniken des Ankleidens und des Tanzes in den Vordergrund stellte. Von der Insel Utupua berichtet DAVENPORT über einen napa-Tanz mit Tanzkeulen, der anlässlich der Reifefeiern von Jugendlichen aufgeführt wurde. Die Tänze gehörten einzelnen Tänzern, die für ihre Aufführungen bezahlt wurden (1968a: 242). Für die Insel Vanikoro führt er neben verschiedenen, dem napa-Tanz ähnlichen Performances, zwei weitere Tänze auf, zu denen aufwendige Maskenkostüme getragen wurden. Auch dort besaßen die Tänzer einzelne Tänze, für deren Aufführungen sie bezahlt werden mussten (1968a: 267-274). In den Duff Islands wurden DAVENPORT (1968b: 180-187) zufolge zwei Serien von Reiferiten für Heranwachsende durchgeführt, in deren Verlauf neben großen Essen und Lebensmitteldistributionen in den Dörfern teilweise auch Tänze durchgeführt werden mussten. ${ }^{79}$ Den Bewohnern der Main Reef Islands attestiert DAVENPORT (1969: 197-213) die höchste Anzahl von Festen und zeigt auf, dass neben den bereits dargestellten Anlässen weitere nicht minder wichtig waren. ${ }^{80}$ Durch die Finanzierung und Organisation lokaler Feste konnten die Veranstalter ihren sozialen Status ausbauen, ihr Prestige akkumulieren und ihre Einflussmöglichkeit bzw. Macht erhöhen. Neben der Steigerung des sozialen Status für einen Einzelnen festigten die Essen in Verbindung mit einer reziproken Erwartungshaltung auch die sozialen Beziehungen innerhalb der Gemeinschaft, meist zwischen den Clans eines Ehepaares. ${ }^{81}$ Um die Feste noch größer gestalten zu können, legten verschiedene Familien Anlässe wie z. B. das Durchstechen der Ohrläppchen ihrer Kinder zusammen und feierten gemeinsam (1969: 200-201). DAVENPORT (1969: 203-213) beschreibt ausführlich ein besonderes Initiationsfest (segūaū), das alle jungen Männer und

\footnotetext{
${ }^{79}$ Die erste Serie von Essensfesten zelebrierte die Ankunft eines zukünftigen Mitglieds der Gemeinschaft (von der Schwangerschaft der Mutter bis zum ersten Haarschnitt des Kindes). Im Laufe der zweiten Serie wurden verschiedene Stationen in der Sozialisation eines Kindes bis zum vollwertigen Mitglied der Gemeinschaft gefeiert (vom Durchstechen der Ohrläppchen, des Septums und der Nasenflügel bis zum ersten Anlegen der Erwachsenenkleidung). Daneben gab es noch weitere einzelne Anlässe für gemeinschaftliches Essen wie der erste Fang eines Hais durch einen Jugendlichen, das gemeinsame Wehklagen bei der Trauer um eine Person sowie der ein bis zwei Jahre spätere Abschluss der Trauerzeit (DAVENPORT 1968b: 180-187).

80 Aufgrund ihrer Lage und Bevölkerungsstruktur sowie der indigenen Sicht folgend unterteilt DAVENPORT (I 969 : 152-153) die Reef Islands in zwei Regionen: Die östlichen Inseln sind größer, höher und liegen eng zusammen, wohingegen die westlichen Inseln kleiner, niedriger und weiter verstreut liegen. Er bezeichnet die erste Gruppe Main und die zweite Outer Reef Islands. Auch in der Besiedlung zeigen sich Unterschiede: Während die Main Islands (außer Nifiloli) von Personen bewohnt sind, die die Sprachen von Ndendö sprechen, leben auf den Outer Islands (und Nifiloli) Polynesisch sprechende Gruppen. Ebenso entsprechen ihre Phänotypen eher melanesischen bzw. polynesischen Wurzeln, wobei sich die Bevölkerungsgruppen bis in die 1960er-Jahre durchaus vermischt hatten.

81 Zu den komplexen reziproken Tauschbeziehungen siehe DAVENPORT I968a: 213.
} 
auch Töchter sehr wohlhabender Familien durchlaufen mussten. Dieses Fest wurde letztmalig um 1940 in den Main Reef Islands durchgeführt und war seiner Meinung nach in der Vergangenheit sehr wahrscheinlich auch auf Ndendö ausgerichtet worden (1969: 212-213). Lediglich in seiner posthum erschienenen Publikation weist DAVENPORT (2005: 39-54) auf den Zusammenhang von Tänzen, Festen und Verehrung der lokalen dukna auf Ndendö hin. Er gibt Einblicke in den Ablauf einiger Feste, erläutert die Anlässe von ,Eröffnungs- und Schließungszeremonien`von Tanzplätzen und geht Überlieferung und Wandel der Mythen in Luepe, Mbanua, Napir und Malo nach. DAVEnPORT (2005: 42-43) stellt eine Funktion der Tänzer und ihrer Kleidung besonders heraus: Die nelo-Tänzer stellten dukna dar bzw. ahmten diese nach. Ihm zufolge konnten nur gutaussehende und wohl geformte Männer Tänzer werden, da sie Nächte ohne Schlaf ertragen und viele Stunden durchtanzen und -singen mussten; ihre Kleidung und Schmuck waren Kopien der Tanzausstattung der dukna. Laut Aussagen meiner Gewährsleute repräsentierten die Tänzer keine dukna, sondern kopierten lediglich ihren Tanz. Ob sich das Verständnis in den vergangenen 50 Jahre tendenziell geändert hat und wo Tänzer und Publikum die Grenze zogen, kann ich aufgrund unzureichender Quellenlage nicht klären.

Den Festezyklus auf Ndendö, dessen Dreh- und Angelpunkt während meiner Aufenthalte der nelo-Tanz darstellte und wie ich ihn auch erlebt habe, interpretiert Davenport für die 1960er- und 1970er-Jahre wie folgt:

\begin{abstract}
„An important secular and sociological aspect of commencing a public dance series is the reciprocity that enters into the effort. Whenever a community sends out an invitation to another community to attend a song and dance event of this kind, an acceptance entails an obligation to reciprocate in like manner at some future date. [...] The results are reciprocal networks throughout the island, touching the lives of everyone, even the dukna. This thick social and ritual interrelationships, together with economic trade and exchange, traditionally enmeshed all Nendö communities into a kind of polity that had neither social class nor hereditary chiefs or other public officials.“ (DAVENPORT 2005: 40, Hervorhebung im Orig.) ${ }^{82}$
\end{abstract}

\footnotetext{
${ }^{82}$ In seiner Herleitung melanesischer Eigenheiten bei der Bildung und Wiederherstellung sozialer Beziehungen und Identitäten verweist FOSTER (1995: 16-17) auf die Rolle von Produktions- und Tauschpraktiken. Er identifiziert zwei unterschiedlich ausgeprägte Formen von Reziprozität. Er grenzt reziprokes Handeln im Modus ,,multiplication“ (Zuwachsaustausch zum Ausbau sozialer Beziehungen) von „,replication“ (identischer Austausch zur Erhaltung von sozialen Beziehungen) ab. Bei erst genanntem gehen kastom- und bisnis-Praktiken eher zusammen, da kastom-Objekte und ,moderne' Objekte wie Geld und industriell hergestellten Konsumartikeln parallel eingesetzt werden (1995: 18, 233-248). Die Produktions- und Austauschpraktiken auf Ndendö habe ich sehr deutlich im Sinne eines multiplikativen Modus erlebt. DAVENPORT (1969: 216-219) berichtet von einer Art ökonomischen Wettstreit (kūonivala), bei dem eine Männerhausorganisation einen Gegner statt zu einem Krieg mit Waffen zu einem reziproken Tausch herausforderte, der in der Regel zum wirtschaftlichen Ruin einer Partei führte.
} 
Aufgrund der ehemals nicht schriftlich fixierten Wissensüberlieferung auf Ndendö liegen keine indigenen schriftlichen Aufzeichnungen zur Verwendung der Tanzkleidung und des -schmucks vor. Alle Informanten verbanden sie rückblickend als kastom- oder traditionelle Artefakte unmittelbar in Verbindung mit dem nelo-Tanz. Gemäß dem von der Salomoneninsel Ulawa stammenden und amtierenden Bischof der Anglican Church of Melanesia in der Diözese Temotu, George Takeli, wurden Tänze im Santa-Cruz-Archipel kontinuierlich und regelmäßig durchgeführt. Einen möglichen Grund für die in seinen Augen abnehmende Häufigkeit in der jüngeren Vergangenheit sah er in den hohen Kosten für die mit den Tänzen verbundenen Feste:

„These kastom dances happen almost in every month or season of the year. They are periodic celebrations. So, they [the people, O. L.] are putting a lot of important goods, like canned food, piles of rice along with the normal traditional food. So to host that kind of ceremony today is quite expensive. That's why it may affect it having regularly now.“ (Bischof George Takeli, 1.8.2011)

Bischof George nannte zahlreiche Anlässe für die Feste, die seiner Meinung nach in erster Linie neue Beziehungen herstellen oder nach Krisenzeiten existierende wiederherstellen sollten wie z. B. Initiation, Heirat, Krieg, Frieden, Tod oder allgemein Aussöhnung zwischen verfeindeten Parteien. Der frühere Paramount Chief Ambros aus Nonia verwies auf schlechte Ernten oder Krankheitsepidemien als weitere Gründe (7.10.2011). Bischof George Takeli verstand die Feste und die mit ihnen verbundenen Tänze als eine gelebte und lebendige Kommunikationspraxis und als einen Teil von Kompensationsleistungen zur Beilegung von Auseinandersetzungen oder Verpflichtungen:

„The dance is the closing ceremony. It's a way of saying, Thank you' to those, who come. They [the people, O. L.] don't say it through words. They say through that particular dance that the ceremony, the mourning ceremony is finished. In some of these cultures you don't say ,Thank you'. ,Thank you' doesn't make any sense to anybody. You don't shake hands. Shake hands doesn't mean anything for anybody at all. We don't say ,Thank you'. They live, Thank you'. Even if somebody says sorry, this is especially important in reconciliation. You don't just say sorry. Nobody will understand you. You don't say ,Sorry', you must live ,Sorry', you must act out that ,Sorry'. So, in reconciliation $[\ldots]$ you involve them in the whole ceremony, by asking them to come, by eating together with them, and by dancing together with them. That's how you say, Thank you'. [...] That's the thing, that's, what it means. It's not a hidden practice, it's just the way they communicate. “ (Bischof George Takeli, 1.8.2011)

Auch nach Aussage meiner Gesprächspartner in der Graciosa Bay gab es nelo-Tänze, solange sie sich erinnern konnten, und es würde sie auch in der Zukunft geben. Freddy Me'esa führte 
dies auf die Herkunft des Tanzes und die bestehenden Beziehungen zu den lokalen dukna zurück:

„Nelo-dance is originated from a belief in Graciosa-Bay. In former times a person was taken by the gods to their place. The spirit of the person lives on. That god claimed that some people had committed a sin against him, and therefore a nelo-dance had to be made for him. That's why we keep maintaining it.“ (Freddy Me'esa, 21.7.2011)

Wie mir - zusammen mit vielen männlichen Jugendlichen und Kindern als Publikum - in einer später für mich einberufenen Zusammenkunft von einigen der ältesten Männer in Nep erzählt wurde, ging der Ursprung des nelo-Tanzes sowie der entsprechenden Kleidung und des Schmucks auf eine Begebenheit zu Beginn des 20. Jahrhunderts - man sagte vor vier Generationen - zurück:

Der dukna Melake hatte einen leiblichen Sohn mit dem Namen Menopulu und einen ,adoptierten‘ Menschensohn mit dem Namen Opla, den er von dessen Eltern entführt hatte. ${ }^{83}$ Oplas Mutter stammte aus Uta, sein Vater aus Mabu. Eines Tages gab es ein großes dukna-Fest in Nadabu (im Norden von Ndendö gelegen), dem Ort, in dem die dukna und die Seelen der Verstorbenen leben. Opla wollte unbedingt zu dem Fest. Sein Adoptivvater und alle anderen dukna waren dagegen, da Opla ein Mensch war. Opla wollte aber so gerne dort hin und bettelte förmlich darum, bis Melake nachgab. Er schärfte Oplas älterem Bruder Menoplu jedoch ein, dass Opla nichts anrühren, annehmen, geschweige denn Essen zu sich nehmen dürfte, da die Dinge nur für dukna und nicht für Menschen seien. Auf dem Fest wurden nelo- und die beiden napa-Tänze napa naoli (Bambus) und napa ba (Keulen) getanzt. Opla war von der Aura des nelo-Tanzes begeistert und wollte diesen Tanz mit all seinen Dingen und Inhalten haben. Der Anführer der nelo-Tänzer hörte, wie Opla dies zu seinem Bruder sagte, und fragte Menopulu, was Opla wolle. Menopulu wiederholte den Wunsch seines Bruders. Der Tanzführer willigte ein und teilte mit, die dukna würden alles zu Oplas Vaterhaus bringen. Im Folgenden wurden das Tritornshorn, mit dessen Ton der Tanz beginnt, ein Hund, ein Schwein und die gesamte Tanzkleidung nach Mabu gebracht, nur das nelo fehlte.

Melake arrangierte ein neues Tanzfest auf der Vulkaninsel Tinakula, zu dem alle dukna kamen. Sein Sohn Menopulu wollte, dass alle dukna von dort weiter nach Naleani (einer ehemaligen Siedlung auf Temotu Neo) und anschließend direkt am nächsten Morgen weiter nach Notapir (heute Manaputi) auf Ndendö gingen, um dort

\footnotetext{
${ }^{83}$ Opla war in der Vergangenheit eine Bezeichnung für Wohlstand, Reichtum oder auch für Personen, die überdurchschnittlich viel darüber verfügten und für ihre Großzügigkeit und Mildtätigkeit bekannt waren - mitunter wurden diese auch bonie genannt (zum Begriff bonie vgl. S. 33). Heute bedeutet Opla auch Geld. Obla hingegen bezeichnet junge Männer.
} 
zu tanzen. Die anderen dukna weigerten sich zunächst, da jeder Tanz einen ganzen Tag und eine Nacht dauerte und drei Tage hintereinander zu viel für sie gewesen wären. Aber später willigten sie ein. Auf seinem Weg von Naleani nach Notapir paddelte Menopulu durch die raue See. Als er kurz vor Note Kemate (Riffküstenspitze südlich von Venga) war, fiel sein nelo vom Kanu ins Meer und sank sofort zu Boden. Menopulu tauchte nicht danach und fuhr weiter. Ein Mann namens Mei aus Mbanua (Vorfahr vor vier Generationen von Charles Newes, dem ersten Premier Minister der Temotu Province) paddelte auf dem Nachhauseweg von seiner Gartenarbeit an der Stelle vorbei und sah ein Glitzern am Meeresboden. Er tauchte danach und nahm das nelo mit nach Hause, nicht wissend, was es war. In der Nacht erschien ihm Opla in voller Tanzkleidung, der es von ihm zurückforderte. Mei verstand, dass es ein Nasenschmuck sein müsse, den er gefunden hatte, und wollte ihn Opla nicht zurückgeben. Zur damaligen Zeit rannten die Schweine noch frei durch die Siedlungen, und ein Schwein trat auf das nelo, so dass ein Stück abbrach. Mei brachte das nelo zu Sekapulu, dem besten Schnitzer des Dorfes, um es nachmachen zu lassen.

(Zusammenführung und Übersetzung eines ,Story Telling' mit Männern im Männerhaus von Nep O. L., 27.7.2011, vgl. Abb. 6 und 37) $)^{84}$

Diese erste nelo-Kopie befand sich aktuell in Charles Newes Besitz. Er verlieh sie an Tänzer etwa an Ben Banie (s. Abb. 6) sowie an den nelo-Produzenten Phillip Malu als Vorlage für dessen Fertigung. ${ }^{85}$

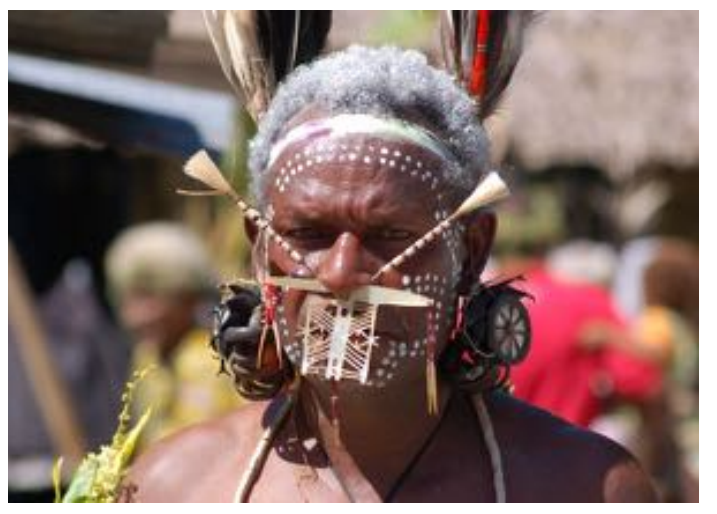

Abb. 6: Ben Banie mit der ersten Kopie des ,Original-nelo ${ }^{6}$ von Opla, nach dem der Tanz benannt ist; Ne'ele, 2011.

Den frühsten Aufzeichnungen zufolge wurden Teile der Tanzkleidung und des -schmucks im Austausch mit europäischen Gebrauchsgegenständen zur Ware und ab dem späten 19. Jh. als solche produziert. Aus derselben Zeit liegt eine erste Information vor, die einen

\footnotetext{
${ }^{84}$ Mit ,Story Telling' bezeichneten meine Gewährsleute eine Art öffentlichen Unterricht, während dessen die ältesten Männer ihr Wissen austauschten und sich auf eine gemeinsame Sicht einigten. Die hier aufgeführte Geschichte hörte ich während meiner Aufenthalte 2010 und $201 \mathrm{I}$ auch in leicht abgewandelten Variationen. Eine weitere Version findet sich bei DAVENPORT (2005: 92-94).

${ }^{85}$ Zu diesem nelo sowie den Arbeiten von Phillip Malu siehe auch Kap. 4.3.2 und Kap. 6.2.
} 
direkten Bezug der Artefakte zu Tänzen herstellt. In den Quellen ab dem frühen 20. Jh. finden Tänze und deren Anlässe - konkret Passageriten - losgelöst von den Artefakten Erwähnung. Ausführlichere Hinweise tauchen in der Literatur erst ab den 1960er-Jahren auf. Tänze wurden demnach auch zur Akkumulation von Prestige, sozialem Status und Einflussmöglichkeiten veranstaltet, dienten der Verehrung lokaler Gottheiten, der Abwendung von Krisen sowie der Kompensation von politischen Auseinandersetzungen und sozialen Verpflichtungen. Ich kann also von einer kontinuierlichen Ausübung der Tänze bis mindestens in die 1960er-Jahre ausgehen.

Laut Aussage des nicht aus Santa Cruz stammenden Bischofs der Anglican Church of Melanesia ging die Anzahl der Tänze aktuell aufgrund der steigenden Kosten für neu verwendete, importierte Lebensmittel zurück. Meine Gewährsleute auf Ndendö betonten die kontinuierliche Fortführung der Tanzfeste und legten weniger Fokus auf die Anzahl der Feste. Ich selber erlebte eine Gedenkfeier für einen Verstorbenen sowie eine große SchlieBungszeremonie eines Tanzplatzes (vgl. Kap. 3.3.1) innerhalb eines halben Jahres und hörte von zwei Festen, die etwa ein Jahr später stattfinden sollten - was weit entfernt von der Regelmäßigkeit ist, die Bischof Georg für die Vergangenheit beschrieb.

\subsection{Aktuelle Anlässe von nelo-Tänzen}

Den Aussagen meiner Informanten und meinen Beobachtungen zufolge traten die Tanzkleidung und der -schmuck aktuell in nelo-Tänzen auf kastom-Festen, christlichen Gottesdiensten und auf Aufführungen vor politischen Delegationen des Nationalstaats und Touristen sowie auf nationalen und internationalen ,Kunst- und Kulturfestivals ${ }^{6}$ in Erscheinung. Darüber hinaus verkauften die Produzenten der Artefakte ihre Produkte auf Ndendö an die lokale Bevölkerung, an Regierungs- und Kirchenvertreter sowie an Touristen und außerhalb der Insel an den Museumsshop in Honiara. Da diese Verkäufe außerhalb des Akteur-Netzwerkes ,nelo-Tanz' in eigenen Netzwerken stattfanden und die Artefakte primär mit den Herstellern und nicht den Tänzern zusammenwirkten, werde ich diese Anlässe nach den Untersuchungen zu den Artefakten und ihrem Erscheinen in einem konkreten Tanz in Kapitel 5 separat in Kapitel 6 untersuchen.

\subsection{1 "It's for the gods, our community and all about earnings"}

Nach Sicht meiner Gesprächspartner waren Feste mit nelo-Tanz fester Bestandteil und Ausdruck ihres kastom. Diese Feierlichkeiten bezeichneten sie aktuell im Allgemeinen in Englisch/Pïin als feastings und im Besonderen als cleansing ritual (Natügu: alue). ${ }^{86}$ John Me'alue

\footnotetext{
${ }^{86}$ Früher wurden nelo-Tänze auch aus anderen Gründen veranstaltet. In der Vergangenheit kam es mitunter vor, dass Tänzer eines anderen Dorfes den Tanzplatz (Natügu: nir) raubten. Dies passierte, wenn in einem Dorf bestimmte Nahrungsmittel knapp wurden oder bekannt war, dass ein anderes Dorf über eine besonders große Menge dieser Nahrungsmittel verfügte. In solchen Fällen führte eine Gruppe in der Nacht unangemeldet neloTänze auf dem nir des anderen Dorfes auf und erwartete als Gegenleistung prompte Bewirtung und Bezahlung mit den begehrten Nahrungsmitteln. Dies war in der Vergangenheit besonders für die Frauen des geraubten nir äußerst schwierig, da sie mitten in der Nacht in ihre teilweise sehr entlegenen Gärten gehen mussten, um die
} 
(15.10.2011) erläuterte die Bedeutung von alue zum einen mit ,Sünde` und zum anderen mit „Sehen`, wobei dies im Sinne von ,Sieh, was wir für dich tun' verstanden werden sollte und sich an bestimmte dukna wendete. Den Abschluss eines Reinigungs- bzw. Heilungsrituals bezeichneten meine Gewährsleute in Pijin als closing ceremony. Ein einzelner Festzyklus konnte sich über mehrere Jahre (manchmal über 20 Jahre) erstrecken und einem oder mehreren dukna gewidmet ein. Auslöser für einen solchen Zyklus konnten eine allgemeine Ehrung der dukna in Verbindung mit einer konkreten auf die Zukunft gerichteten Bitte um Unterstützung, eine Gegenleistung für bereits erfolgten Schutz oder auch eine Wiedergutmachung für getanes Unrecht sein. Wenn die dukna von den Menschen einen Zyklus einforderten, teilten sie dies den Menschen mit, indem sie einzelnen Dorfbewohnern im Traum erschienen oder sich in Naturphänomenen, -katastrophen, Epidemien oder anderen nicht erklärbaren Ereignissen zu Erkennen gaben. Die einzelnen Feste dauerten in der Vergangenheit bis zu einer Woche, aktuell dauern sie zumeist ein bis zwei Tage. Einzelne Männer, die ihr Einkommen oder ihren sozialen Status erhöhen wollten, oder Familien(verbände) oder Dorfgemeinschaften, die bestimmte Anliegen hatten, organisierten die Feste und initiierten die damit verbundenen komplexen Tauschbeziehungen (Freddy Me'esa, Selwyn Balu und John Namiade, 21.7.2011; Selwyn Balu, 28.7.2011). ${ }^{87}$

Den Kern dieser Feste bildete seit jeher nach Aussage meiner Informanten der von den dukna entlehnte nelo-Tanz. Der Aussagen einiger Männer zufolge wurde er früher von einem napa-Tanz eingeleitet, wobei die Praxis und das Wissen darum aber derzeit, ruhten'. Der neloTanz wurde ausschließlich auf dem besonders hergerichteten Tanzplatz (Pijin: dance circle, Natügu: nir) aufgeführt, wozu dieser zunächst gebaut und mit einem eigenen ersten Fest inklusive nelo-Tanz und großem Essen für Tänzer und Gäste eingeweiht wurde. ${ }^{88}$ Damit war der Tanzplatz ,eröffnet'. In der Folgezeit konnten die ausrichtenden Familien zu besonderen Anlässen wie zum Jahrgedächtnis eines verstorbenen Familienmitglieds, zur Initiation, in Kriegs- oder Krisenzeiten, zur Einführung neuer nelo-Tänzer oder zur Wiedereinführung von nelo-Tänzern nach einer Trauerphase fortlaufend Feste (Tänze und Essen) auf dem nir geben. In den Ruhezeiten zwischen den Festen verwilderte ein geöffneter Tanzplatz und diente unterschiedlichen profanen Zwecken (vgl. Anm. 144). Der Tanzplatz konnte auch ,verliehen' werden, wozu eine andere Gruppe signalisieren musste, dass sie den Tanzplatz nutzen wollte. Im Gegenzug für die Ehrung der eigenen dukna durch die Gäste mussten die Besitzer des nir alle Tänzer und Gäste bewirten und die Tänzer bezahlen. Wenn die dukna

Nahrungsmittel für die Bewirtung der Tänzer zu besorgen (Freddy Me'esa, Selwyn Balu und John Namiade, 21.7.2011).

${ }^{87}$ Einkommen konnte mit der Organisation eines Festes generiert werden, da das Tauschsystem auf Ndendö im Modus eines Zuwachsaustauschs angelegt ist; vgl. Anm. 82.

${ }^{88}$ Für die Errichtung eines Tanzplatzes wurden große Vertiefungen in den Boden gegraben und nicht mehr seetüchtige Kanus mit der Unterseite nach oben in diese gelegt. Die Löcher wurden mehrmals aufgefült und der Boden festgetreten. Dadurch entstand eine Art Resonanzkörper, der das Aufstampfen während des Tanzes akustisch dumpf verstärkte (vgl. Boerger 2009: 106). Die erste Erwähnung eines Tanzplatzes in Vanikoro findet sich bei D'URVILLE ( I 833: 327), und einen Tanzplatz auf Ndendö beschreibt CODRINGTON ( 89 |: 333). 
nach einigen Festen signalisierten, dass sie ausreichend geehrt worden waren oder die Menschen ausreichend gesühnt hatten, stand das ,Schließen“ des Tanzplatzes (Natügu: nir ba’pe, Tanzplatz, der erloschen/tot ist) an. ${ }^{89}$ Das opulente Abschlussfest stellte den aufwendigsten Teil des Zyklus dar, da der Tanzplatz besonders geschmückt wurde und möglichst viele Tänzer organisiert und bezahlt werden mussten. Für dieses Fest mussten darüber hinaus die ausführenden Familien dem/den dukna zu Ehren Schweine schlachten, nach festgelegten Regeln Teile des Fleisches den dukna opfern, zu anderen madei-(Männerhaus-)Organisationen bringen und den größten Teil in einem gemeinschaftlichen Essen verzehren. Dadurch waren alle informiert, dass der nir geschlossen wurde und die Familien ausreichend Kompensation geleistet hatten - die Familien waren ,erlöst' (Freddy Me'esa, Selwyn Balu und John Namiade, 21.7.2011; Selwyn Balu, 28.7.2011; Selwyn Balu und Freddy Me'esa, 5.8.2011).

Vom 29. August bis zum 1. September 2011 hatte ich die Möglichkeit, in Neo einem solchen Abschlussfest beizuwohnen. Neo bezeichnete eigentlich zwei auf Temotu Neo liegende Nachbardörfer, von dem eines auch Nemba genannt wurde. Obwohl ich die beiden Dörfer aufgrund ihrer Entfernung von rund 500 Metern voneinander als getrennte Einheiten wahrnahm, gehörten ihre Familien zueinander und sahen sich daher als ein Dorf. Wie Andy Me'take (28.10.2011) berichtete, war Nemba das Ursprungsdorf, das zu Zeiten seines Großvaters zugunsten des neuen Neos verlassen worden war. Er selber war Ende der 1980erJahre mit seiner Familie wieder zurückgezogen. Meiner Schätzung nach lebten etwa jeweils 200 bis 300 Einwohner in den beiden Dörfern. ${ }^{90}$ Neo verfügte laut Selwyn Balu über vier oder fünf ,geschlossene ‘ Tanzplätze. In einem war er initiiert worden, und in einem anderen hatte er als nelo-Tänzer sein Debüt gegeben (Selwyn Balu, 23.8.2011). Von den ursprünglich zehn Männerhäusern in Neo existierte noch eines. Nemba verfügte über einen nir und ein madei. Erster stellte den örtlichen Mittelpunkt des Festes dar, letztes diente den Männern als Zentrum ihrer Vorbereitungen. An der Nordostgrenze Nembas hatten die Bewohner eine Mauer aus Korallenblöcken sowie einen fast zwei Meter hohen Zaun aus dünnen Baumstämmen errichtet, um dort die für das Abschlussfest notwendigen Schweine einzupferchen. Die Familien hatten mit Unterstützung ihrer jeweiligen Netzwerke insgesamt rund 100 Tiere zusammengebracht. Zum Garen der Schweine hoben die Familien im Dorf jeweils zwischen einem und vier Erdöfen aus. Insgesamt zählte ich rund 20 Öfen. Das Fest war Andy Me'takes Aussage nach unter seiner Leitung seiner und drei weiterer Familien organisiert worden. Es stellte den Abschluss eines sieben Jahre andauernden Zeitraums dar, in dem die vier Familien in loser Abfolge Feste ausrichteten. Der Grund für den alue-Zyklus in Nemba stellte Me'take wie folgt dar:

\footnotetext{
${ }^{89}$ Im Jahr 20I I verfügten nur noch wenige Dörfer auf Ndendö über einen, geöffneten' Tanzplatz, wohingegen in allen bewohnten und verlassenen Dörfern der Insel, geschlossene' Plätze zu sehen waren. Die Natügu-Erklärung gab John Me'alue am 15.10.201 I.

90 Beide Dorfnamen gibt es noch weitere Male auf Ndendö. Im Folgenden verwende ich abweichend von der Praxis, beide Dörfer mit dem gleichen Namen zu bezeichnen, das alte Neo mit Nemba und das neue mit Neo.
} 
In den 1990er-Jahren war Barnabas Nepnwë an Mundkrebs erkrankt, was einige Familienmitglieder als ein Zeichen gedeutet hatten, dass ihr dukna einen Festzyklus zu seinen Ehren einforderte. Zusätzlich war es im Jahr 2000 zwischen den Dörfern Malo und Nemba zu Auseinandersetzungen über Landnutzungsrechte gekommen. In deren Verlauf hatten die Bewohner Nembas an der von ihnen eingeforderten Grenze Kokospalmen gepflanzt und den Bewohnern Malos angedroht, Nembas $d u^{-}$ kna würden dafür Sorge tragen, dass diejenigen Personen sterben müssten, die die Palmen entfernten. In der Folge erlag Barnabas Nepnwë seiner Erkrankung. Die Familie folgerte, dass sein Tod ein klares Zeichen ihrer dukna war. Nembas Einwohner hatten die Unterstützung ihrer dukna eingefordert und den Nachbarn in Malo damit gedroht. Es war offensichtlich, dass die dukna folglich ihren Tribut einforderten. Vier Familien einigten sich, als Kompensation für den geleisteten Schutz gegenüber Malo, zur Vorbeugung weiterer Krankheiten und zur Ehrung der dukna einen Festzyklus auszurichten. Diese vier Familien hatten im Jahr 2004 den Tanzplatz in Nemba wiedereröffnet. Den Namen einer der dukna erinnerte Andy Me'take nicht (oder wollte ihn nicht aussprechen). Er beschrieb sie als weibliches Wesen, mit nur einer Brust, die im Wald lebte. Bei dem anderen dukna handelte es sich um Manda, eine männliche Nixe. Nach ihm war auch der Tanzplatz benannt worden: nir Manda. Me'take erinnerte nicht, wie viele Feste seit der Eröffnung des Tanzplatzes ausgerichtet worden waren. Er berichtete von der Anfrage eines Dorfes, auf dem Platz zur Ehrung der dukna zu tanzen und als Gegenleistung Thunfisch zu erhalten. Nemba hatte eine gute Saison im Fischfang, und Personen aus dem anderen Dorf hatten eine Palme auf Nembas Tanzplatz errichtet, woraus ersichtlich wurde, dass andere Tänzer den nir ,leihen' wollten. Im Folgejahr ,liehen' Tänzer aus Nemba den Tanzplatz von Noipe in der Erwartung, Taro zu erhalten, den Noipe in dem Jahr im Überfluss hatte. (Andy Me’take, 28.10.2011)

Am Vortag des Festes hatten sich einige Männer der beiden Dörfer Neo und Nemba in Nembas madei zur gemeinsamen Arbeit versammelt. Sie stellten Artefakte aus Rippen und Blättern der Pandanuspalme zur Dekoration des Tanzplatzes her, die sie später an eine quer über den Tanzplatz gespannte Liane hingen. Sie schnitzten Modelle ihrer jeweiligen Arbeitsgeräte, die sie zum Einkommenserwerb benötigten. Ich erkannte traditionelle Geräte wie Rasseln zum Haifischfang, Paddel zum Kanufahren, Kurkuma-Rollen und zahlreiche Rollen von Federgeld sowie neuere Arbeitsgeräte wie ein Kanu mit Außenbordmotor für den Fischfang, einen Ofen zum Trocknen von Kopra oder Buschmesser (vgl. Abb. 7). Der Lehrer Simeon Me'noyea aus Neo, der mir als Übersetzer während meines Aufenthaltes in Nemba zur Seite gestellt worden war, erläuterte, dass diese Modelle die Einnahmemöglichkeiten der Familien der beiden Dörfer für die Zukunft sichern sollten: „It's all about earnings.“ 

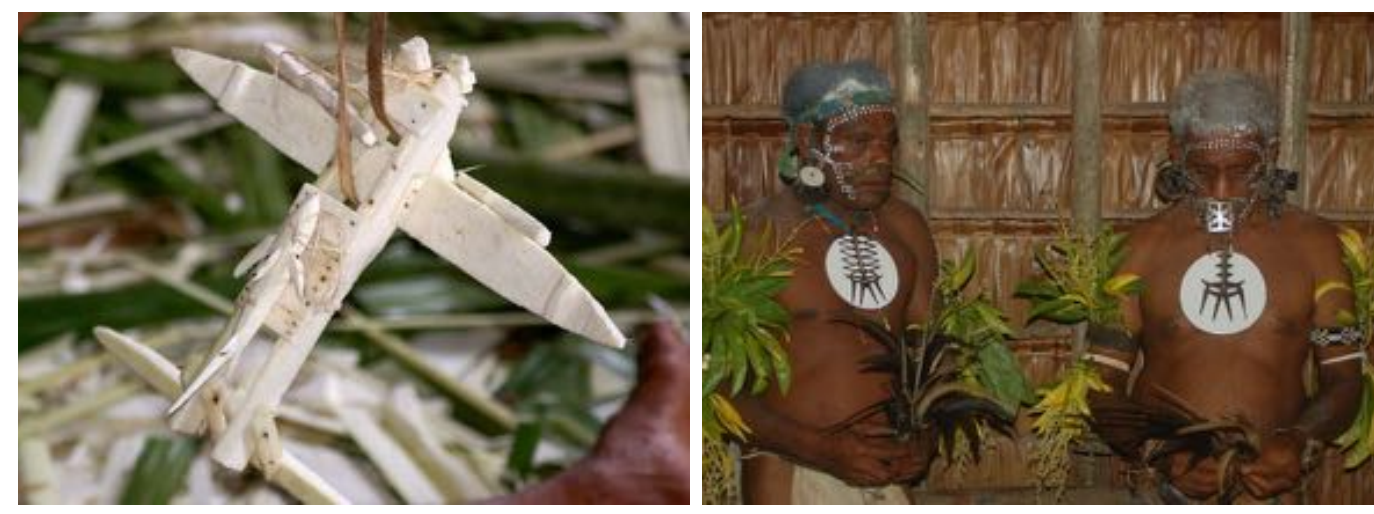

Abb. 7: Modell eines Auslegerkanus mit Hai auf der Plattform zur Dekoration des Tanzplatzes; Neo, 2011.

Abb. 8: Nelo-Tänzer mit tema aus Keramik; Neo, 2011.

Im Morgengrauen nach dem Fest wurden die Dekorationen in eine geflochtene Matte gerollt und geheim‘ im Meer versenkt, um sie dem Meeres-dukna Mebok zu übergeben, damit er im Zuge des lokalen Tauschsystems mehr zurückgeben würde. (Simeon Me'noyea, 29.8.2011)

Am eigentlichen Festtag traten nach dem Eröffnungssegen des Katecheten Simon Peter Dewa 14 nelo-Tänzer auf, die zum größten Teil aus Neo-Nemba, Malo und Dörfern entlang der Graciosa Bay stammten. Ihre Kleidung und ihr Schmuck waren hinsichtlich der Materialien sehr gemischt. Ich erkannte zum einen Tänzer des früheren Festes, bei dem ich ihr Ankleiden dokumentiert hatte (vgl. Kap. 5.1). Ihre Artefakte waren vorwiegend aus traditionellen Materialien hergestellt. Zum anderen sah ich aber auch mir unbekannte Tänzer, von denen wenige tema aus Keramik oder lepanesa aus Kunstfasern trugen (vgl. Abb. 8; Kap. 4.3.1 und Kap. 4.3.3). Die 14 nelo-Tänzer tanzten später von Sonnenuntergang bis Sonnenaufgang, nur unterbrochen von drei festgelegten Essenspausen. Nach dem Tanz wurde ein zweites Mal Schweinefleisch für andere madei-Organisationen verteilt.

Im Anschluss folgte eine seit einigen Jahren anstehende Initiationsfeier für Mädchen und Jungen. Die Initiationsfeier hieß in Natügu nertatongir und bedeutete, jemandem etwas geben, jemanden in einen neuen Lebensabschnitt bringen' (Jerry Me'ioko 22.8.2011). Bei dem Fest erhielten die Kinder/Jugendlichen ihre ersten kaleko (Pijin für ,Kleidung', wobei hier das erste ,offizielle‘ Kleidungsstück - ein bedrucktes, importiertes Wickeltuch aus Baumwolle oder Kunstfasern - gemeint war, das von manchen auch lavalava genannt wurde. ${ }^{91}$ Das Wickeltuch bekleidete bei den Männern die Hüften bis zu den Knien und bei den Frauen den Oberkörper bis zu den Knien. Die Kinder tragen heute zwar vorher bereits Alltagskleidung wie Shorts (Jungen), Röcke (Mädchen) und T-Shirts, aber noch nicht dieses ,erwachsene“ Wickeltuch, das im Jahr 2011 weitaus weniger als Alltagskleidung denn als Kleidung beim

\footnotetext{
9l Zur kulturellen Bedeutung und Geschichte dieser Stoffe in Melanesien (calico in melanesischem Pidgin) vgl. WERE (2005).
} 
Baden bzw. Waschen genutzt wurde. Kaleko waren auch zwingender Bestandteil des Brautpreises und gern gesehenes Geschenk. Bei der Initiation wurden den Initianden kleine Ringe (telengi) an Ohrläppchen und/oder Septum und/oder Nasenflügel gesteckt. Die Schildpattringe waren so gefertigt, dass die Ringe so gut wie keine Lücken hatten und dadurch ein sehr starker Druck auf die Stellen ausgeübt wurde, an denen später die Löcher entstehen sollten. Nicht wenige Kleinkinder weinten beim Anlegen der Ohrringe. Die Ringe verblieben für zwei bis vier Wochen an den Körperstellen. In diesem Zeitraum bildeten sich Fleisch und Haut angeblich so weit zurück, dass nach dem Abnehmen der Ringe die verbleibende sehr dünne und nahezu vertrocknete Hautschicht blutlos mit einem zusammengerollten Blatt durchstoßen werden konnte. Anschließend wurden Schmuckohrringe oder -stecker angebracht und im Nasenbereich kleine Röhrchen (aus Holz oder Bambustriebe) eingesetzt, um das Zuwachsen der Nasenflügel oder des Septums zu verhindern, wobei auf dem Fest bei nur einem Jugendlichen die Nasenflügel und bei niemandem das Septum durchstoßen wurde. Die Initiationsfeiern fanden 2011 in der Regel nach dem Abschluss einer SchlieBungszeremonie eines nir statt, wenn für diese sowieso bereits große Mengen an Schweinefleischgaben erforderlich waren. Nach kastom waren die Initiationen aber nicht zwingend daran gebunden. Es waren eher wirtschaftliche Überlegungen, da weniger Schweine aufgezogen und getauscht werden mussten, wenn die Initiation mit einem Fest zusammenfiel (Selwyn Balu 17.10.2011). Wenn ein nertatongir separat stattfand, wurde es von einem Gastgeber (Pijin: host, nicht mit einem bonie, opla oder namesake zu verwechseln; vgl. Kap. 2, S. 33-34 und Anm. 83) veranstaltet, der durch den mit der Organisation und Durchführung verbundenen Tausch von Schweinefleisch (heute mitunter gegen Geld) wirtschaftlich reicher und damit sozial anerkannter wurde (Shadrack Sade, 31.8.2011).

Nach der rund einstündigen Prozedur, die nach meiner Wahrnehmung keiner festgelegten Struktur folgte und an vielen Kindern und Jugendlichen parallel und nacheinander von verschiedenen Männern durchgeführt wurde, verließen alle Teilnehmer den Tanzplatz - er war nun geschlossen bzw. tot. Die auf dem Tanzplatz verbliebenen Essensreste und Matten lagen durcheinander offen herum und sollten an Ort und Stelle verrotten. In wenigen Wochen wäre der Platz mit Vegetation überwuchert, wie mir gesagt wurde.

Eine erste kastom-Konfiguration, in der die nelo-Tanzartefakte und -Tänzer gleichermaßen auftraten, stellen folglich die alue-Feste dar. Hierbei handelt es sich um traditionelle Anlässe, die laut Aussagen meiner Gewährsleute seit Generationen Auslöser für die Tänze/Artefakte waren. Diese Feste wurden aus vielerlei Gründen ausgerichtet und verfolgten durchaus unterschiedliche Ziele. Grundsätzlich standen sie im Zusammenhang mit dem Aufbau, Unterhalt und Lösen von Beziehungen und folgten dem lokalen Konzept eines Zuwachsaustauschs (vgl. Anm. 82). In der Vergangenheit konnten dies spirituelle Beziehungen zu den dukna, kosmische zur Umwelt, politische und ökonomische zu anderen Männerhausgemeinschaften oder soziale innerhalb der eigenen Gruppe sein. Als konkrete aktuelle nelo-Tanzanlässe führten meine Gesprächspartner für diese kastom-Konfiguration den Beistand von dukna in Fragen um Landnutzungsrechte sowie bei Ernte und Fischfang, bei dem Schutz vor Unwettern- 
und Naturkatastrophen sowie die wirtschaftlich sinnvolle Verbindung zu den Initiationsfeiern auf.

\subsection{2 "Reviving our culture - our heritage and our destiny"}

Diese Botschaft trugen im Jahr 2008 T-Shirts, die anlässlich einer einwöchigen ,Agricultural and Cultural Trade Show' (eine Art Präsentation lokaler Produkte und Aufführungen im weitesten Sinne) in Lata und einer parallel dort stattfindenden Konferenz der Provincial Premiers der Solomon Islands hergestellt worden waren (vgl. Abb. 9). Der Name der Veranstaltung verdeutlicht recht gut, wie ,Kultur ${ }^{6}$ von der damaligen Provinzregierung gesehen wurde, nämlich als konkret abgegrenztes Produkt, das sogar gehandelt, d. h. veräußert werden kann (vgl. Kap. 3.1). ${ }^{92}$

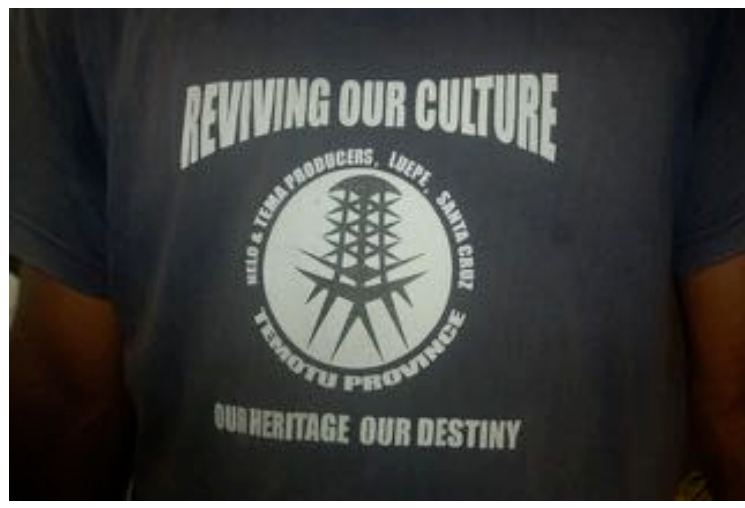

Abb. 9: T-Shirt aus dem Jahr 2008.

John Namiade hatte nach eigener Aussage im Vorfeld der Schau die Idee, ein T-Shirt mit einem tema-Design und dem Veranstaltungs-Claim als Präsent für die Teilnehmer der Premierminister-Konferenz aufzulegen. Dies hatte der dem damaligen Premier der Provinz Temotu, John Patteson Oti, vorgeschlagen und von ihm die Finanzierung für die Produktion von 150 T-Shirts zugesichert bekommen. Nachdem diese innerhalb einer Woche verteilt bzw. verkauft worden waren, hatte Namiade weitere 100 Stück auf eigene Rechnung in Honiara herstellen lassen - auch diese waren bereits kurze Zeit nach ihrem Eintreffen auf Ndendö vergriffen. Die T-Shirts waren auf großes Interesse bei der Bevölkerung gestoßen: Sie symbolisierten eine Bewegung zur Wiederbelebung traditioneller Artefakte, die lokale Politiker und Zivilakteure einige Zeit vorher in der Provinz Temotu angestoßen hatten (John Namiade, 21.9.2011).

Alfred Tom Olu zufolge - 1992 bis 2002 als Kultur- und Tourismusminister Mitglied der Temotu-Provinzregierung -, ging die Initiative dieser kulturellen Revitalisierung auf den damaligen Premierminister der Provinz Temotu, Father Sir John Ini Lapli, Knight Grand

\footnotetext{
92 Lt. WILSON (2009: 162-163) gab es in Lata mindestens seit dem Jahr 1998 ,Agricultural Trade Shows', auf denen zum einen neue landwirtschaftliche Produkte (1999 waren es Honig, Ziegenfleisch und Reis) und zum anderen auch ,Kultur' in Form von Chorgesängen und Tänzen beworben werden sollten. Ziel war, die Bevölkerung auf neue Einkommensmöglichkeiten aufmerksam zu machen. WHITE (20I5: 73) führt für die Solomon Islands allgemein auf, dass in der Zeit zwischen der Unabhängigkeitserklärung (1978) und dem Ende der Tensions (2003) gerade auf lokaler Ebene traditionelle kulturelle Praktiken aktiv durch die Provinzregierungen unterstützt wurden.
} 
Cross of the Most Distinguished Order of Saint Michael and Saint George (GCMG), zurück, der während seiner Amtszeit die politische, ökonomische und kulturelle Eigenständigkeit Temotus stärken wollte. ${ }^{93}$ Olus Aussagen zufolge hatte Lapli Ende der 1970er-Jahre am St John's Theological College in Auckland, Neuseeland, Theologie studiert. Er vermutete, dass Sir John dort die Revitalisierungsbemühungen der Maori-Kultur erlebt hatte, wodurch der spätere Premierminister für die Relevanz traditioneller, indigener Kultur sensibilisiert worden war und dies nach dessen Rückkehr nach Santa Cruz auf politischer Ebene thematisiert hatte. Nach seinem Amtsantritt ließ Sir John im Jahr 1994/5 in der Provinzhauptstadt Lata ein madei nach traditionellem Vorbild bauen - in dessen Zentrum hing sogar ein vollständiger Satz Federgeld - und mit dem Segen des damaligen anglikanischen Bischofs der Temotu-Diözese Lazarus Monano eröffnen. Das Haus diente zum einen für Empfänge von Regierungsgästen, zum anderen als Schlafplatz für Besucher von anderen Inseln des SantaCruz-Archipels. An das madei angeschlossen befand sich ein abschließbarer Nebenraum, in dem traditionelle Artefakte aufbewahrt und ausgestellt wurden. Unter Lapli initiierte die Provinzregierung von 1994/5 bis 2002 darüber hinaus jährlich den ,Temotu Cultural Festival Day', an dem sich die Bewohner des Archipels präsentieren und wirtschaftlich und kulturell austauschen sollten. ${ }^{94}$ Ebenso setzte sich seine Regierung für einen von der Landeshauptstadt Honiara eigenständigen wirtschaftlichen Ausbau der Provinz ein und gründete 1993 die Temotu Development Authority (TDA), deren erster Manager 1995 der neuseeländische Volontär Barry Skudder wurde (WILSON 2009: 15). Laut mehrerer Aussagen setzte dieser sich ebenfalls für die Wiederbelebung der Herstellung traditioneller Artefakte ein. Nach Ablauf von zwei Legislaturperioden wurde Laplis Regierung abgewählt. Die Nachfolgeregierung unter Premier Patteson Oti fuhr als Folge der bürgerkriegsähnlichen Zustände auf Guadalcanal und Malaita notgedrungen die politische Unterstützung für die kulturelle Revitalisierung zurück, wodurch das madei an Relevanz verlor und letztlich verfiel (Tom Olu, 8.11.2011).

Innerhalb der acht Jahre unter Sir John Ini Laplis Regierung aber war die Bewegung so weit von der zumeist älteren Bevölkerung aufgenommen worden, dass nunmehr Akteure auf Dorfebene die Revitalisierung weiter vorantrieben. So warb neben anderen auch Tom Olu

\footnotetext{
93 Auch in der Zusammenlegung der beiden Ressorts Kultur und Tourismus zeigt sich die ökonomische Lesart von ,Kultur' im Sinne eines Wirtschaftsfaktors. Reverend Father Sir John Ini Lapli (geb. 1955) wurde am 21.01. 1999 von Königin Elizabeth II. zum GCMG geschlagen, nachdem er für die Legislaturperiode 1999-2004 zum GovernorGeneral der Solomon Islands gewählt worden war (http://pidp.org/archive/2003/May/05-02- I7.htm, letzter Zugriff am 17.7.20 14). Zur Rolle Sir John Laplis vgl. auch Roger EAST \& Richard J. THOMAS (2003: 473-475) und WILSON (2009). Leider war es mir 20 I I während meines gesamten Aufenthaltes in Santa Cruz trotz mehrmaliger Versuche nicht möglich, ihn für ein Interview zu gewinnen. Ich hatte Sir John Lapli während meines Surveys im Jahr 201 I in Honiara gesprochen, als mir seine Relevanz für die Wiederbelebung noch nicht bekannt war. Andere Ausländer von Nichtregierungsorganisationen bestätigten meine Situation, dass er auch nach ihrer Sicht Ausländern nur ungem für Gespräche zur Verfügung stand.

${ }_{94}$ WHITE (20I5: 73) beschreibt den Zeitraum von der Unabhängigkeit der Salomonen bis zum Ende der Unruhen im Jahr 2003 als ,,period of active exploration and production of cultural activities in rural locales", in dem vielerorts ähnliche Projekte wie in Santa Cruz umgesetzt wurden. Ihm zufolge erinnerten sie die lokale Bevölkerung in politisch, ökonomisch und sozial unsicheren Zeiten an die Werte ihrer indigenen Praktiken (20l5: 74-75).
} 
- dann als Privatperson mit eigenem Geld - für seine Vorhaben, die jüngere Generation in kastom-Liedern zu unterweisen, ihnen die traditionellen Tänze näher zu bringen und die Artefakte mit traditionellen Materialien herzustellen. ${ }^{95}$ Hierzu suchte er Kontakt zu Dorfältesten (Männern wie auch Frauen) und befragte sie nach ihrem kastom-Wissen, konkret über Tänze und die Organisation von Festen. Er motivierte Schullehrer und fand schließlich in Wilson Kabi - einem lokal anerkannten Tänzer, Chief und Produzenten verschiedener Artefakte - einen großen Unterstützer, den er und weitere Personen teilweise aus eigenen Mitteln dafür bezahlten. ${ }^{96}$

Unter dem Motto „reviving madei“ verstand Tom Olu ein weit gefächertes Aufgabenspektrum: Sicherung des Wissens über 1. aussterbende, traditionelle' Praktiken und Materialien: Fischfangmethoden, Einbaumkanus, Häuser, Federgeld, Taschen und Körbe, Rindenbast, Tänze und Musik sowie Geld; 2. orale Weitergabe von Wissen: Genealogien, kastom-Geschichten, traditionelle Geschichten der Ethnogenese, Mythologie, traditionelle Heirat(szeremonien) und Regierungssysteme; 3. archäologische und historische Arbeiten wie Dokumentation aller historischer Stätten und ,traditioneller' Landnutzungsgrenzen, Forschungen zu den Materialien und 4. Sichtung des im Ausland vorhandenen ethnografischen Materials: Sammlung alter Quellen zur Sicherung für die Zukunft. Tom Olus Vater hatte mit Roger Green und William Davenport zusammengearbeitet. Er selber kannte Mick Pendergrast und hatte einige Texte von Davenport gelesen (Tom Olu, 8.11.2011).

Die zuvor beschriebenen ersten Schritte einer kulturellen Reaktivierungsbewegung stießen gemäß Aussagen meiner Informanten in der Folgezeit auf immer mehr Befürworter. In den Dörfern entlang der Graciosa Bay, im ihr gegenüberliegenden Ort Malo und an Ndendös Südküste in Neo hatten sich vorwiegend Männer zwischen 30 bis 50 Jahren zu Gruppen formiert, um die Revitalisierung zu unterstützen und von ihr zu profitieren. Sie gründeten Gruppen, um bestimmte Tänze und Artefakte wiederzubeleben bzw. die Herstellung Letzterer wieder in natürliche Materialien zurückzuführen, um den ,Fremdeinwirkungen` und ,Auflöseerscheinungen` der 1980er- und 1990er-Jahre entgegenzuwirken. ${ }^{97}$

\footnotetext{
95 Zu den jeweiligen Auswirkungen dieser politisch vorangetriebenen kulturellen Revitalisierung auf die einzelnen Artefakte vgl. nachfolgend Kap. 4.

${ }^{96}$ Im Gespräch mit Olu zeigte sich sein ambivalentes Verhältnis zu Wilson Kabi, den er einerseits für das Tradieren von kastom-Liedern an Jüngere schätzte und zeitweise von der Regierung bezahlen ließ. Andererseits missfiel Olu Kabis Verkauf von Artefakten an Fremde: „He destroyed our kalsa“. Wilson Kabi wäre in erster Linie ein Vermarkter gewesen, der traditionelle tabu nicht beachtet und „,seine Kultur ausverkauft" hätte, womit er meinte, dass Kabi sehr geschäftstüchtig immer wieder alte Artefakte an den Meistbietenden verkauft hätte. Als anderes Beispiel führte Olu Kabis Produktion der tema auf: Traditionell waren diese ausnahmslos dem Krieg und den kastom-Tänzen vorbehalten und durften nur von Männern getragen werden. In der Folgezeit hatte Kabi die tema zudem an jeden verkauft, der sie haben wollte, und diese so verkleinert, dass sie Olus Meinung nach zu reiner Dekoration verkommen waren, alltagstauglich wurden und nun auch von Frauen getragen wurden. (Tom Olu, 8. I I.20 II) Letzteres bestätigte sich im August 20 I I, als Bischof George bei Philipp Malu I00 verkleinerte tema mit einem spezifischen Mothers-Union-Design im Santa-Cruz-Stil als Souvenir für die Teilnehmerinnen einer Kirchensynode in Lata bestellte (vgl. Abb. 27-29 und Kap. 6.2). Zu Wilson Kabi vgl. Kap. 4.3.I und Kap. 6.I.

${ }_{97} \mathrm{Zu}$ den jeweiligen Auswirkungen auf die Artefakte vgl. nachfolgend Kap. 4, zu einer Organisation vgl. Kap. 6.5.
} 
„What we wanted to revive was the making of the costumes, because in the 80s and 90s not so many people made the costumes. So, when we organized a nelo-dance in those days, we saw some people wearing what we call lavalava. They just adopted the pattern, it was not traditional anymore. But nowadays, when people like Selwyn, who makes the clothes, and John, who makes the tema, that's the traditional way of doing it again. As I said in the 80 s and 90 s we were sort of losing that making of traditional artefacts. “ (Freddy Me'esa, 21.7.2011)

Selwyn Balu (16.11.2011) zufolge wurde im Jahr 2011 die Graciosa Bay Nelo Association in erster Linie zur besseren Zusammenarbeit der Hersteller und gemeinsamen Vermarktung ihrer Produkte gegründet. Früher hätte jeder für sich gearbeitet und nicht gewusst, was sein Nachbar gemacht hätte. Nun würden die Produzenten versuchen, sich abzusprechen, teilweise eine gemeinsame Preisgestaltung umzusetzen und sich gegenseitig bei Touristen oder anderen Interessierten weiterzuempfehlen. Freddy Me'esa sah insbesondere in der Herausstellung der Einzigartigkeit von Tänzen und Materialien die Möglichkeit, die lokale „Kultur zu erhalten, sie an die nächste Generation weiterzugeben und gleichzeitig mit den Artefakten und Tänzen im Tourismus Einkünfte zu generieren (vgl. auch das Zitat auf S. 51):

„[...] On the other side it's really to revive it as it was in the former days. I think, that's the best way of preserving the kalsa. [...] We also train our young people in our traditional ways of reviving and making them. And we also show to the world, that we inherited a unique way of living from our grandfathers. We want to tell the World, that's how we are. Like as I said, that most of our artifacts are unique from the rest of Solomon Islands. Like in our nelo dance [...] I guess, we are the only one in the world, that uses banana fibres for that type of traditional clothes. [...] and every other artfact on a nelo-dancer or costume is traditionally made from different things. So, we in Santa Cruz, Ndende, we make use of the resources in the sea, the land and even the bush. So, most of the things are traditional materials." (Freddy Me'esa, 21.7.2011)

John Namiade (9.11.2011) sah in der Wiederaufnahme der Herstellung, traditioneller Artefakte und dem steigenden öffentlichen Interesse an ihnen den eigentlichen Wendepunkt in der Rückbesinnung auf die eigene ,Kultur ${ }^{6}$. Eine andere, fast gegenläufige Einschätzung zu den Revitalisierungsbemühungen der Hersteller der Nordküste entlang der Graciosa Bay hörte ich an der Südküste Ndendös. Der Tapa-Produzent Steven Mdewöt plante nach eigenen Aussagen als eine Art Gegenbewegung zu den Aktivitäten in der Graciosa Bay die Gründung einer eigenen Nelo Association. Sein Ziel lag ihm zufolge weniger im vermehrten Absatz von ,traditionell‘ hergestellten Artefakten, als ,to show the full kalsa with it's history and their stories" (Steven Mdewöt, 21.10.2011). Denn im Unterschied zur Bevölkerung der Nordküste wären die Designs der von ihnen produzierten Artefakte nicht nur Dekoration, 
sondern trügen tiefe Bedeutungen, die nach wie vor von Generation zu Generation weitergegeben werden müssten. Ihm zufolge hatten die Bewohner der Graciosa Bay die Artefakte und Tänze von, der anderen Seite' (also seiner Seite) gekauft und durch Imitation zwar die Herstellung und den Umgang, nicht aber deren Bedeutungen gelernt. Mdewöt war nach eigener Darstellung als potentielles Mitglied vom Vorstand der Graciosa Bay Nelo Association angesprochen worden, hatte eine Mitgliedschaft aber abgelehnt. ${ }^{98}$

Als eine weitere kastom-Konfiguration für den Auftritt der Artefakte stellt sich die in den 1990er-Jahren zunächst politisch motivierte Revitalisierung ,traditioneller ${ }^{6}$ Artefakte in Verbindung mit lokalen Tänzen, Gesängen und Geschichtserzählungen dar. Auch hierbei handelt es sich um lokale Anlässe und Netzwerke, bei denen die Artefakte aber noch mehr im Mittelpunkt stehen als bei den zuvor vorgestellten traditionellen alue-Festen. Wie sich zeigte, hatten sich für diese bewusste und gesteuerte kastom-Auslegung zunächst wenige Politiker und nachfolgend in zunehmendem Maße Privatpersonen auf Dorfebene - Tänzer und Hersteller der Artefakte - gegen ein ,Vergessen“ tradierter Herstellungstechniken und Artefakte gestellt. Durch die Inklusion gerade der ältesten Bevölkerungsgruppen versuchten die Initiatoren, das Wissen zu erheben und zu sichern. Sie entschieden sich bei der Materialwahl der Kleidungs- und Schmuckstücke bewusst gegen die Aufnahme ,moderner` Werkstoffe und Farben und eine Rückkehr zu den natürlichen Materialien. ${ }^{99}$ Parallel entstand mit der Wiederbelebung eines Gefühls kultureller Einzigartigkeit etwa im Falle der tema auch eine neue Variante, die in zunehmendem Maße auch von Personen getragen wurde, denen dies dem kastom entsprechend vorenthalten war, nämlich Nicht-Kriegern und -Chiefs sowie Frauen. Dies widerspricht den geäußerten Zielen eines „preserving our kalsa“ (Freddy Me'esa, 21.7.2011) und ist in dieser indigenen Sicht eben keine Fortschreibung von kastom. Es ist ein gutes Beispiel für die Ambivalenz des Revitalisierungsprojektes, genau so, wie es Me'esa (s. o.) äußerte, wonach das Vorhaben einerseits eine Einkommensmöglichkeit sei und gleichzeitig die Rückbesinnung auf die traditionellen Materialien unterstützte. Es lässt die Vielseitigkeit von kastom erahnen und zeigt, dass verschiedene Netzwerke gleichzeitig existieren können. An dieser Stelle möchte ich die These formulieren, dass diese kastom-Konfiguration eine pragmatische ist, sich nicht zwingend als ein geschlossenes System darstellt und die Intention stärker auf eine distinkte kulturelle Zugehörigkeit ausgerichtet ist.

\footnotetext{
98 Dass auch seine Sicht nicht unumstritten war, zeigte sich in Kommentaren seines Schwagers, der nämlich die Rechte an den Designs in seiner eigenen Familie, also inklusive seiner Schwester, der Ehefrau Mdewöts, aber eben nicht bei Mdewöt selber verankert sah; vgl. S. 28 und Kap. 6.4.

${ }_{99}$ Wie sich diese Verläufe bei den jeweiligen Artefakten darstellten, zeige ich nachfolgend in Kap. 4.
} 


\subsubsection{Messliturgie der Anglican Church of Melanesia}

Im Verlauf der Christianisierung hatte die anglikanische Kirche in Santa Cruz kastom-Tänze als lokal relevante kulturelle Ausdrucksformen in ihre lokale Liturgie aufgenommen. ${ }^{100} \mathrm{Ne}$ ben der Übersetzung des Neuen Testaments in Natügu wurden seit geraumer Zeit an Festtagen wie z. B. zu Ostern und Weihnachten sowie zu besondern Anlässen wie Weihen kirchlicher Amtsträger auch Tänze in die Gottesdienste einbezogen. ${ }^{101}$ So wurden nelo-Tänzer eingeladen, das Gloria und Kyrie als in ,alte' Sprache und in Strophenform umgewandelte kastom-Lieder zu singen (Freddy Me'esa, 21.7.2011; Bischof George, 1.8.2011). Für den Gebrauch in der Kirche waren dazu Teile kirchlicher Liedtexte in Natügu übersetzt, in passende Strophenform umgewandelt und seitdem von den Tänzern gesungen worden (Selwyn Balu und John Namiade, 20.10.2011). Die Bedeutungen einzelner Wörter waren nur noch den ältesten kastom-Dichtern wie Alfred Dawi aus Malo oder Wilson Kabi aus Luepe bekannt. Gemäß Dawi war es elementar wichtig, die passenden Worte zu finden, um eine bestimmte Stimmung im Lied hervorzurufen. Viele der Zuhörer konnten zwar einzelne Worte nicht mehr übersetzen, verstanden aber den Sinn der Strophen und fühlten die bezweckten Emotionen (Alfred Dawi, 19.10.2011). Aus klerikaler Perspektive stellten die Tänze nach Aussage Bischof Georges eine Art performative Danksagung an den christlichen Gott dar, bei der das für Santa Cruz traditionelle Verständnis, nicht ,Danke` zu sagen, sondern in einem gemeinschaftlichen Tanz (oder Essen) zu vermitteln, d. h. auszuführen, zum Ausdruck kommt (vgl. Zitat S. 58):

„People dance certain parts of the liturgy, of the prayer, like the Gloria, where the thanks giving service[s]. Like the procession for the gospel, the reading of the word of god, like the offering of the wafer, people dance and carry it forward. [...] Even in the beginning of the service there is a procession, that's a dance in itself. A procession, that goes up and the whole service will be a ceremonial dancing service. And then it comes back to the eating, and then it ends with other ceremonial dances as well. So, it's quite a celebration. But in all, what they are saying is: Thank you [God]." (Bischof George Takeli, 1.8.2011)

\footnotetext{
100 Bei WILSON (2009: I5I, I59) finden sich Fotografien von Tänzern auf Priesterweihen auf Ndendö. Nach dem Zweiten Vatikanischen Konzil 1962-1965 waren die römisch-katholischen Priester und Missionare weltweit aufgefordert, lokale Ausdrucksformen in die Messliturgie aufzunehmen; vgl. „Dekret über die Missionstätigkeit der Kirche Ad Gentes' (http://mww.vatican.va/archive/hist_councils/ii_vatican_council/documents/vatii_decree_1965 I 207 _ad-gentes_ge.html, letzter_Zugriff am 18.7.20 I4). Als Beispiel dieser neuen Form der Missionierung in Melanesien habe ich selber christliche Einflüsse auf Ahnendarstellungen der Asmat an der Südküste Papuas, Indonesien, an anderer Stelle untersucht (Oliver LUEB 2008: 39-4I). Ob die Aufnahme lokaler Ausdrucksformen in der Liturgie auch in Missionierung der Anglican Church of Melanesia zentral vorgegeben war, konnte ich nicht ermitteln.

${ }^{101}$ Die bereits erwähnte Linguistin Brenda Borger hatte in Zusammenarbeit vor allem mit Simon Me'ambö und Rich Bukari die Übersetzung geleistet (Simon Me'ambö, 24. I 0.20I I); vgl. Kap. 2, S. 34-35. Im Jahr 2008 war unter der Leitung von Sir John Ini Lapli die Übersetzung des Neuen Testaments, der Psalmen und des Buchs Ruth veröffentlicht worden.
} 
Aus weiteren Aussagen Bischof Georges schließe ich, dass er dabei nicht zwischen unterschiedlichen lokalen Tänzen unterschied und sogar den als lokal distinkten Trauertanz tepape als ein und dasselbe ansah (ebd.). Freddy Me'esa verwies allerdings auf einen Unterschied zwischen den Tänzen im Rahmen der Messen und den traditionellen nelo-Tänzen:

„We tried to kind of christianise the dancing. Instead of worshiping devils [dukna, O. L.] with the [nelo-]costume, we tried to worship God. Those ones [dances] mostly respond, like Sanctus, Kyrie eleison to priests, as incense burning. [...] We believe those are to glorify God. [...] But people change believes in places. That one may worship God really, but in nelo[-dance] they worship Opla, dancing with the same costume. [...] We dance [nelo] from Monday to Friday - Saturday and Sunday we want praying in the church.“ (Freddy Me'esa, 21.7.2011)

Als weitere kastom-Konfiguration stellt sich der Tanz der nelo-Tänzer während christlicher Gottesdienste dar. Hier zeigt sich, dass die Interpretationen der Inhalte zwischen den Beteiligten variieren. Auf der einen Seite sehe ich den Bischof der Diözese, der zwar Solomon Islander war, aber nicht aus Santa Cruz stammte und die Tänze allgemein als zeremonielle Tänze oder kastom-Tänze als traditionelle Danksagung bezeichnete. Auf der anderen Seite äußerte Freddy Me'esa eindeutig Unterschiede zwischen den Tänzen mit nelo-Tanzkleidung in der Kirche und außerhalb der christlichen Verwendung. Er legte aber nicht dar, ob Kirchgänge etwa kastom seien oder nicht. Immerhin äußerte er, dass man am Samstag und Sonntag in der Kirche betete. Für die Artefakte hatte dies aber keine Auswirkung, sie wurden zu beiden Anlässen gleichermaßen getragen.

\subsubsection{Politische Empfänge, Tourismus und ,Art Festivals'}

An dieser Stelle fasse ich drei unterschiedliche Anlässe zusammen, da diese sich darin glichen, dass der nelo-Tanz und die -artefakte als kastom im Sinne einer ,traditionellen SantaCruz-Kultur' gegenüber anderen, nicht aus Temotu stammenden Zuschauern dargestellt wurden. Da mir keine Informationen darüber vorliegen, ob in der Vergangenheit nelo-Tänze zu Empfängen von sozial höher gestellten Personen veranstaltet wurden, sondern ausschließlich in reziproken Beziehungen relevant waren (vgl. Kap. 3.3.1), sehe ich hier auch den Empfang nationaler Politiker richtig verortet. Waren die in Kapitel 3.3.2 beschriebenen ,Temotu Province Agriculture Trade Shows' und die späteren ,Agricultural \& Cultural Trade Shows ${ }^{6}$ lokale Repräsentationen im Rahmen der Revitalisierungsbewegungen der vergangenen 20 Jahre, so stellten sich die nachfolgenden Anlässe auch national bzw. international dar.

- Politische Empfänge

Während meiner Forschungsaufenthalte 2010/11 nutzten die jeweils amtierenden Provinzregierungen den nelo-Tanz als Rahmenprogramm bei einigen ,offiziellen' Anlässen: Am 1. Juni 2010 etwa empfingen nelo-Tänzer in dem madei von Venga eine Delegation nationaler Politiker zur Einweihung des ,Sunrise Electrical \& Solar Skill Centre' (vgl. Abb. 10 und 
Abb. 11), bevor die Gastgeber einen nelo-Tanz zur Demonstration von ,traditionellem, einzigartigem Santa-Cruz-kastom ${ }^{6}$ aufführen ließen (Bartholomew Me'esa, 1.6.2010). Im Anschluss führten die nelo-Tänzer die Ehrengäste in einer Art Prozession zu dem Haus, vor dem weitere Reden gehalten und Gesänge vorgetragen wurden. Zu einer Gesangsgruppe zählten ältere in Tapa gekleidete Frauen, die das zuvor inszenierte Bild einer ,traditionellen Kultur ${ }^{6}$ weiter bestätigten, aber auch eine Art Boygroup, die mit technischer Verstärkung Solomon Island-Popmusik präsentierten (vgl. Abb. 12). Auch der Ort der Präsentation zeigte ein anderes Bild von Ndendö, mit bunten Plastikstühlen, Luftballons und bedruckten Tischdecken, was in meinen Augen ebenso kastom war, aber nicht als solcher benannt wurde. ${ }^{102}$ Zur Dokumentation dieses Empfangs und der Eröffnung des Schulungszentrums war eigens eine Filmcrew eines Fernsehsenders aus Honiara angereist (vgl. Abb. 13). Für den Empfang einer Delegation aus Vanuatu im Frühjahr 2012 anlässlich der Unterzeichnung eines Wirtschaftsabkommens zwischen der Provinz Temotu und dem Nachbarstaat Vanuatu plante die Provinzregierung im November 2011 eine offizielle Begrüßung mit nelo-Tanz in Monou, wozu die Bewohner des Dorfes bereits begonnen hatten, ein madei zu bauen (Philipp Malu, $10.11 .2011) \cdot{ }^{103}$
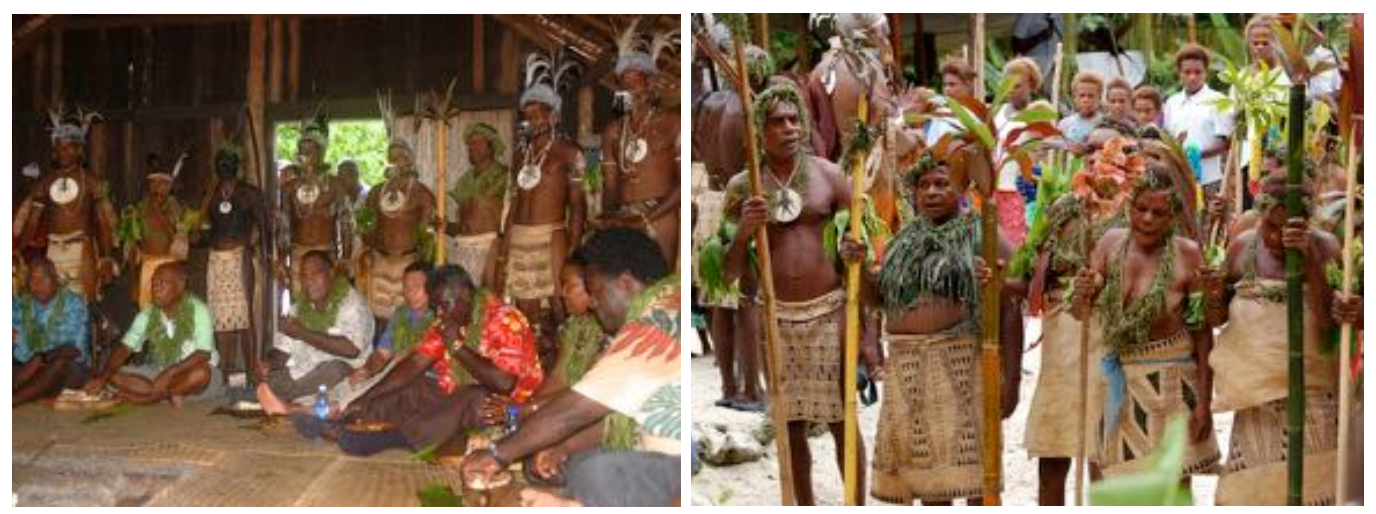

Abb. 10: Empfang mit nelo-Tänzern anlässlich der Einweihung des ,Sunrise Electrical \& Solar Skill Centre'; Venga, 2010.

Abb. 11: Auftritt einer Frauengesangsgruppe anlässlich der Einweihung; Venga, 2010.

\footnotetext{
102 Mich erinnerte die Gleichzeitigkeit von ,Santa-Cruz-kastom und etwas anderem an eine Hochzeitsfeier, an der ich teilnehmen durfte. Dort wurde die Braut zuerst nach ,Santa-Cruz-kastom' gekleidet, dem Bräutigam vorgestellt und an den Strand geführt, um einem Meeresgott zu opfern. Anschließend kehrte sie nochmals in das elterliche Haus zurück und wurde nach ,Malaita-kastom' als Braut gekleidet, um dann in das Haus der Eltem des Bräutigams einzuziehen. Das Paar hatte noch kein eigenes Haus gebaut. Mir wurde es als sehr wichtig dargestellt, dass die Braut, deren Mutter in Nordmalaita geboren war, auch dem kastom ihrer Mutter entsprechend als ,Braut aus Malaita' inszeniert wurde (Mary l'nepa und Nicolas Ngonyir, 27.8.20 I I).

${ }^{103}$ An diesem Ort war bereits im Jahr 1959 Prinz Philipp, Duke of Edinburgh, als Repräsentant der damaligen Kolonialmacht Großbritannien an Land gegangen und offiziell begrüßt worden. Dies stellten meine Gewährsleute als Grund heraus, warum die Delegation in Monou und nirgendwo anders empfangen werden sollte. Am 25.8.20 II hatten die Tourismusminister der beiden Länder eine Absichtserklärung unterzeichnet und planten einen offiziellen Besuch um Ende desselben Jahres (SOLOMON TIMES 20I2).
} 

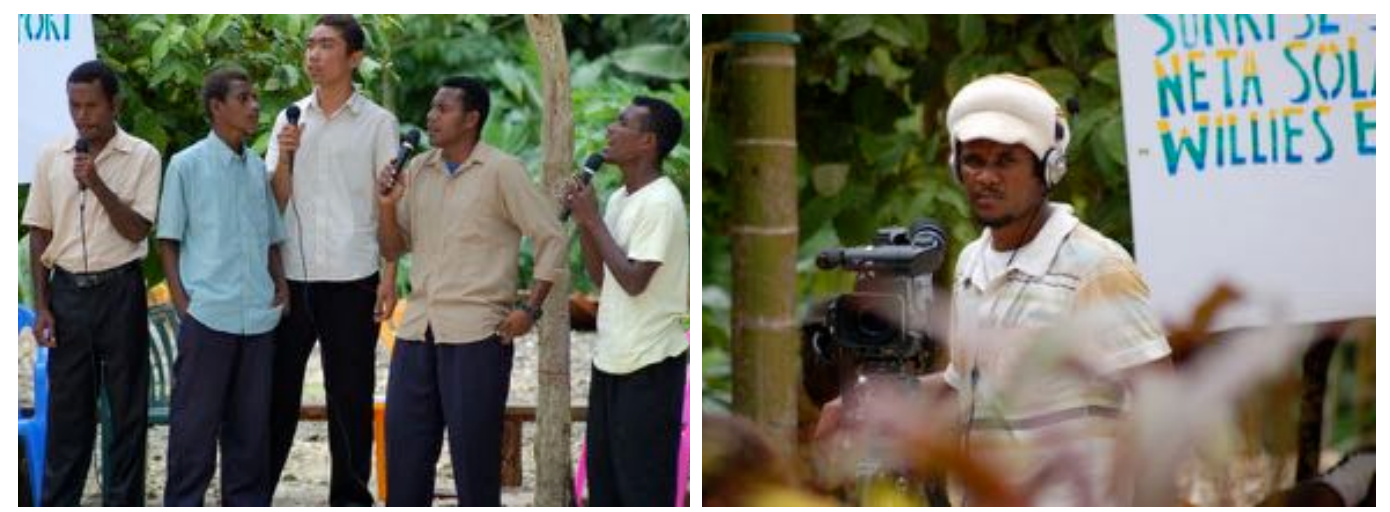

Abb. 12: Auftritt einer ,Boygroup' anlässlich der Einweihung; Venga, 2010.

Abb. 13: Ein Kameramann zeichnet den Empfang für das nationale Fernsehen auf; Venga, 2010.

- $\quad$ Touristische Empfänge

Im Laufe meiner Besuche als Touristenbegleiter hatte ich mehrere Tanzvorführungen in Malo erlebt, dem einzigen Dorf Ndendös, das zu der Zeit aktiv in den Kreuzfahrttourismus eingebunden war (vgl. Abb. 1, 47-52, 133-134). Seit dem Ende der tensions in der Landeshauptstadt im Jahr 2003 hatten den Aussagen einiger Bewohner Malos zufolge etwa ein bis zwei Kreuzfahrtschiffe pro Jahr Malo besucht, wobei jeweils 100 bis 300 Touristen ins Dorf kamen. Für die Besucher präsentierte eine napa-Tanzgruppe aus Malo ihre Tänze, gefolgt von einem nelo-Tanz mit Männern auch aus anderen Dörfern Ndendös. Ein Repräsentant Malos gab dem Publikum einige Hintergründe zu den Tänzen und der Beschaffenheit der Tanzkleidung, etwa Tapa, Bananenbast und Muscheln.

Nach den Vorführungen konnten die Touristen einige der von den Ausrichtern als ,traditionelle Arbeitstechniken' bezeichneten Praktiken und Handarbeiten kennenlernen wie z. B. Kochen mit heißen Steinen, Tapa-Schlagen, Flechten von Matten aus Kokospalmwedeln oder Knüpfen von Schleudern für die Vogeljagd. Parallel boten einige Produzenten ihre Artefakte zum Verkauf an wie bemalte Tapa, tema, nelo, gewobene Taschen aus Bananenbast, geflochtene Taschen aus Pandanusblatt, oder Muscheln- und Schneckenschalen, Lapita-Keramikscherben oder Relikte aus dem Zweiten Weltkrieg. ${ }^{104}$ Manche Touristen fotografierten oder filmten die Hersteller mit deren Familien. Erkundigten sich die Käufer nach dem Hintergrund und den Funktionen der Artefakte, erläuterten die Verkäufer ihre Ware soweit die sprachlichen Fähigkeiten auf beiden Seiten ausreichten. Auf diese Art gelangten einige Artefakte - teilweise mit dazugehörigen Geschichten - und mit ihnen Namen und Abbildungen ihrer Hersteller ins Ausland.

${ }^{104}$ Zu Lapita und dem Zweiten Weltkrieg vgl. Kap. 2. 
- Art Festivals

Auch in der Landeshauptstadt Honiara waren in den vergangenen 20 Jahren Feste ausgerichtet worden, in deren Verlauf Vertreter einzelner Provinzen (so auch Temotu) ihre lokalen Tänze aufführten, z. B. anlässlich des zehnten Unabhängigkeitstages der Solomon Islands am 7.7.1988 (Michael MG Coy 2006: 118) oder zehn Jahre später im Juli 1998 (WILSON 2009: 191). In den Jahren 2012 und 2014 präsentierte die Graciosa Bay Nelo Association auch außerhalb Ndendös nelo-Tänze (vgl. Kap. 6.5). Die Gruppe hatte sich erfolgreich um eine Teilnahme am Festival of Pacific Arts 2012 in Honiara beworben. Aufgrund dessen hatte sie nach Aussage von John Namiade ein T-Shirt produziert, das ich am 13. April 2012 bei einem kurzen Besuch als Reisebegleiter von ihm erhielt (vgl. Abb. 14). Bei einem Vergleich mit dem T-Shirt aus dem Jahre 2008 (vgl. Abb. 9) fällt auf, dass die ,Produzenten der traditionellen Santa-Cruz-Artefakte' nun ein nelo als Symbol für ihre Organisation gewählt hatten - was zwar der Bezeichnung der Association entsprach, gleichzeitig aber zu dem Identitätssymbol der Bevölkerung Temotus, nämlich dem tema, in Konkurrenz stand. Bei meinem letzten touristischen Besuch am 27. März 2014 informierte mich Namiade, dass die Graciosa Bay Nelo Association für das im Juni 2014 geplante $5^{\text {th }}$ Melanesian Festival of Arts and Culture in Port Moresby, Papua-Neuguinea, ausgewählt worden war, um als eine Gruppe von mehreren die Solomon Islands zu repräsentieren.

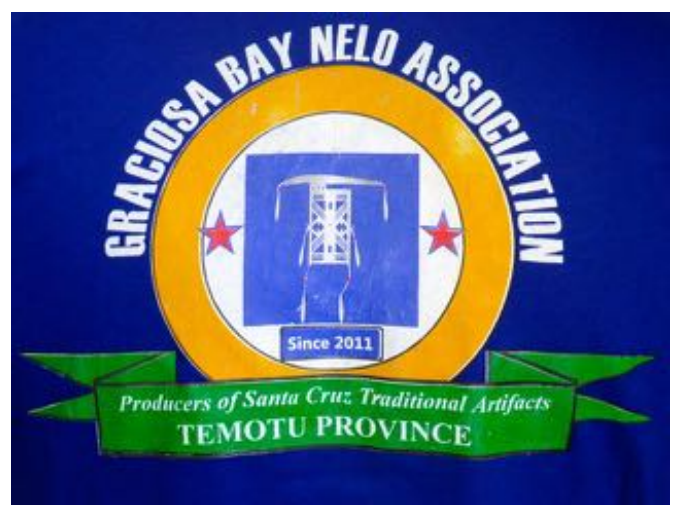

Abb. 14: T-Shirt, produziert anlässlich der Nominierung der Graciosa Bay Nelo Association für die Teilnahme am Festival of Pacific Arts 2012 in Honiara.

Mit den an dieser Stelle zusammengeführten kastom-Konfigurationen traten die nelo-Tänzer mit der Tanzkleidung und dem -schmuck zu sehr unterschiedlichen und durch Außenstehende verursachte Anlässe in Erscheinung. Das Zielpublikum stammte nicht aus Ndendö, wobei zu den politischen und touristischen Empfängen viele Zuschauer aus Ndendö anwesend waren. Die Intention der jeweiligen Inszenierungen war aber dieselbe, nämlich vermeintlich ,authentische ${ }^{6}$ kastom-Tänze als Ausdruck einer ,alten und kontinuierlich fortgeführten Tradition` zu präsentieren. In diesen Aufführungen (bzw. Rekonstruktionen) sah ich in erster Linie das, was m. E. im Rahmen der Revitalisierungsbewegungen aktiviert werden sollte: eine vermeintlich lokal geprägte, einzigartige, ,traditionelle Kultur ${ }^{6}$ mit einem feststehenden, in sich geschlossenen und sich von anderen Nachbarinseln abgrenzenden Kern - etwas Imaginäres, das vermeintlich schon immer so existierte und sich nicht geändert hatte. 
Tatsächlich war aber das Präsentierte, das Ergebnis eines rund 20 Jahre jungen Prozesses, der auf historische Vorlagen zurückgriff, wie ich im nachfolgenden Kapitel 4 für die einzelnen von mir untersuchten Artefaktegruppen detailliert zeigen werde. Dieses essentialistische Verständnis der Begriffe wiederspricht der tatsächlich gelebten Praxis sich wandelnder kastomInhalte. Sie verkörperte eher ein starres, rein auf die Vergangenheit bezogenes und für dörfliche Strukturen idealisiertes ästhetisches Bild von ,kastom - tradition - kalsa ${ }^{6}$, wie es meine Gewährsleute mit den Artefakten zu inszenieren versuchten.

\subsection{Zwischenfazit}

Wie sich zeigte, traten die Tanzkleidung und der -schmuck zu sehr unterschiedlichen Anlässen auf - meist zusammen mit den Tänzern im nelo-Tanz. In den jeweiligen Inszenierungen unterschieden sich die Artefakte hinsichtlich ihrer Ästhetik kaum. Hingegen verfolgten die Ausrichtenden u. a. mit den Tänzen vielfältige Intentionen, etwa als zu erbringende Leistung in soziokosmischen Tauschbeziehungen, als Repräsentation einer distinkt erlebten kulturellen Zugehörigkeit oder als Anknüpfungspunkt zu einer globalisierten Wirtschaft. Hierzu setzten sie kastom-Aspekte flexibel zusammen. In meinen Augen belegt Freddy Me'esas Aussage zum nelo-Tanz in Messfeiern dieses eher pragmatische Verständnis (vgl. S. 73). Für ihn stellte es keinen Gegensatz dar, wenn der nelo-Tanz sowohl im alue-Fest als auch im christlichen Gottesdienst erschien - einmal war es so und ein anderes Mal war es eben anders. Die Parallelität von unterschiedlichen Ausdrucksformen lokaler ,Tradition' wie im Fall politischer Empfänge zeigte eine weitere Form möglicher lokaler Zusammensetzungen von kastom. In diesem Sinne möchte ich dafür plädieren, die vielfältigen und oftmals gleichzeitigen Auftritte der Artefakte auf Ndendö als intentionale kastom-Konfigurationen zu verstehen. In diesen unterschiedlichen Zusammensetzungen von, Tradition` und ,Kultur ' treten dieselben Artefakte zu verschiedenen Anlässen in Erscheinung und tragen dazu bei, bestimmte wechselnde Inhalte zu inszenieren, ohne dass sie ihre Funktion verlieren, Träger und Vermittler einer wie auch immer erlebten Geschichte zu sein. Diese Eigenschaft der Artefakte, immer wieder andere Inhalte zu vermitteln und hervorzurufen, stellt besonders die Fähigkeit dieser Aktanten dar, zwischen verschiedenen Akteur-Netzwerken zu ,driften' und verschiedene Anliegen zu ,übersetzen`. So treten die Artefakte als Tanzkleidung und -schmuck in verschiedenen Akteur-Netzwerken in Erscheinung - von traditionellen, lokalen alue-Festen und christlichen Gottesdiensten über profane Politikerempfänge und Touristenbesuche bis hin zu internationalen Kunst- und Kulturshows - und vermitteln gleichermaßen soziokosmische Beziehungen, kulturelle Zugehörigkeiten und Abgrenzungen sowie Teilhabe an einer globalisierten Welt. 



\section{4 ,Material Histories` der Tanzkleidung und des -schmucks}

Den Begriff der „Material Histories' führt der Ethno-Archäologe und Mitherausgeber des Oxford Handbook of Material Culture Studies Dan Hicks in seiner Darstellung der wissenschaftstheoretischen Entwicklung der ,Material Culture Studies' ein (HICKS 2010: 82). Ihm zufolge umfassen ,Materialgeschichten“ in der historischen Archäologie nicht nur ein Verständnis von sich wandelnden sozialen Verwendungen und Bedeutungen, sondern auch die Betrachtung der ,Lebensgeschichten` von Artefakten. Nach Meinung von Hicks werden diese in ethnologischen Analysen vernachlässigt, da diese auf die Beziehungen der Menschen zu den Dingen fokussieren (2010: 69, 85). Insbesondere die stofflichen Dimensionen von Artefakten, ihre komplexe Beschaffenheit und ihr Wandel im zeitlichen Verlauf bieten sich als Untersuchungsfelder für ,Materialgeschichten` an (2010: 75). Bestimmte physikalische oder funktionale Eigenschaften können Auswirkungen darauf haben, wie Dinge von Menschen verstanden werden und im Leben der Menschen operieren (Gell 1996 in HicKs 2010: 74). Dabei kann die Wirkungskraft der Artefakte von verschiedenen Faktoren ihrer Materialien abhängen, wie etwa von der Stofflichkeit (z. B. Beschaffenheit, Geruch/Geschmack, Härte oder Haltbarkeit, Gewicht), der Herstellung (z. B. Zusammensetzung, Oberflächenstruktur, Verfügbarkeit) und ihrer jeweiligen ,Materialgeschichte'. MiLleR (2005: 3, zitiert in Hicks 2010: 75) bezeichnet diese Wirksamkeit als „,consequences of materiality“ und fordert:

„An analysis of an artefact must begin with its most obvious characteristic, which is that it exists as a physically concrete form independent of any individual's mental image of it. This may provide the key to understanding its power and significance in cultural construction. The importance of this physicality of the artefact derives from its ability thereby to act as a bridge, not only between the mental and the physical worlds, but also, more unexpectedly, between the consciousness and the unconscious.“ (MILLER 1987: 99, zitiert in HICKS 2010: 69-70) 
In diesem Kapitel nehme ich Hicks Ansatz auf und gehe den ,Lebensgeschichten' der von mir untersuchten vier Artefaktegruppen losgelöst von ihren (sozialen) Beziehungen nach. Ich beginne meine Rekonstruktion ihrer Geschichten mit einem Überblick über erste Beschreibungen und Abbildungen vom späten 18. bis zum frühen 20. Jh. In einem nächsten Schritt betrachte ich vier Museumssammlungen zu Santa-Cruz aus dem späten 19. und frühen 20. Jh. Diese historischen Informationen ergänze ich anschließend um rezente Artefakte und - vor allem für die Entwicklungen seit den 1980er-Jahren - um Aussagen relevanter Akteure. Die einzelnen Vergleiche sollen Erkenntnisse darüber liefern, ob und wenn ja, wie sich die Materialien gewandelt haben.

Die rezenten Verwendungen von und Bedeutungszuschreibungen zu den Artefakten in Santa Cruz berücksichtige ich in der Analyse heutiger Akteur-Netzwerke gesondert im nachfolgenden Kapitel 5.2, um die ,Materialgeschichten“ der Dinge eben möglichst losgelöst von „any individual's mental image“ betrachten zu können (s. o.: MILLER 1987: 99, zitiert in HICKS 2010: 69-70). Möglichen Motivationen der Hersteller gehe daher ebenfalls gesondert nach und diskutiere sie in Kapitel 6.

\section{I Historische Beschreibungen und Abbildungen}

Aufgrund der überschaubaren Anzahl von Publikationen, die die von mir untersuchten Artefakte entweder beschreiben oder darstellen, berücksichtige ich alle mir bekannten Quellen.

- Beschreibungen

Alexander Dalrymple (1737-1808), schottischer Geograf und Hauptvertreter der Theorie von der Existenz einer, Terra Australis Incognita', führte im Jahr 1770 die frühesten Berichte der spanischen Reisen und Endeckungen im Südpazifik zusammen und übersetze sie ins Englische. Ihm zufolge schrieb der portugiesische Navigator Pedro Fernandez de Quirós (1565-1614) nach seiner Rückkehr von Santa Cruz nach Manila an den spanischen Rechtsgelehrten und Kolonialbeamten Dr. Don Antonio de Morga Sánchez Garay (1559-1636) über den ersten Kontakt zu Bewohnern von Ndendö unter Alvaro Mendaña de Neyra im Jahr 1595:

„They all came naked, except their privities, which they covered with a kind of soft cloth (tolas blandas); most of them were stained with a dye, blacker than their own colour, and with others different. Their faces and bodies were marked with streaks (rayos); their arms were bound round with many turns of black rattans, and from their necks hung many strings of a kind of small beads of bone, ebony, and fishes teeth. They carried, hanging to different parts of their persons, many plates (paternas), small, and large, made of pearl shell.“ (DALRYMPLE 1770: 78, eigene Hervorhebungen)

Nach DE LABILLARDiÈRES Ausführungen (1800: 256) trugen die Männer auf Ndendö zwei Jahrhunderte später außer mehrfach um die Hüfte gebundenen Strängen und geflochtenen und mit Muscheln verzierten Armbändern keine weitere Kleidung. Die meisten von ihnen 
waren auf dem Rücken tatauiert und trugen durch Nase und Ohren Schildpattringe. Sie hatten ihr Haar mit Kalk geweißt und waren mit Pfeil und Bogen bewaffnet. Von den Bewohnern der Graciosa Bay erwarb Labillardière am 24. Mai 1793 einige Kleidungs- und Schmuckstücke:

„I remarked in their possession a necklace of glass beads, some green and others red, which appeared to me to be of English manufacture, and which they agreed to exchange. We bought from these inhabitants a piece of cloth, which gave us no very favourable idea of their industry: it was composed of coarse bark of trees, and very indifferently joined together. One of them wore, suspended upon his breast, a small circular piece of alabaster [im franz. Original: applati et taillé circulairement], which he parted with to satisfay us.“ (LABILLARDIÈrE 1800: 269, Hervorhebung O. L.)

Weitere knapp zwei Jahrhunderte später erschien Markhams Darstellung, nach der sich die Kleidung - abgesehen von der Erwähnung eines Schurzes bei Frauen und Männern - nicht wesentlich geändert hatte:

„Their dress consists of a number of tortoise-shell ear-rings, strung together, which hang from their ears down to the shoulders, and they wear one large tortoise-shell ring through their nose, which gives them a most hideous expression of countenance. Necklaces of human teeth, and armlets made from shell are constantly worn; there is also a very pretty kind of armlett worn on the fore-arm, consisting of small pieces of white shell and cocoa-nut woven together in various patterns, principally zig-zag. With the exeption of these ornaments, and a string fastened tightly round the waist, to which a small apron is secured, both men and women go perfectly naked. Breast-plates made of white shell, varying in size from five and a half to nine inches in diameter, are also worn by the chiefs of the Santa Cruz and Swallow Islands [...].“(MARKHAM 1873: 164-165)

\section{- Abbildungen}

Die erste visuelle Darstellung eines Schmuckstücks aus Santa Cruz findet sich bei Walter Coote (1865-1937), einem britischen Armeeoffizier, und zeigt ein nelo (vgl. Abb. 15), das allerdings auf dem Kopf stehend abgebildet wurde. Neben seinen eher abwertenden Beschreibungen der äußeren Erscheinung der meisten Insulaner erwähnt er junge, gutaussehende Männer als Träger eben dieser nelo. 


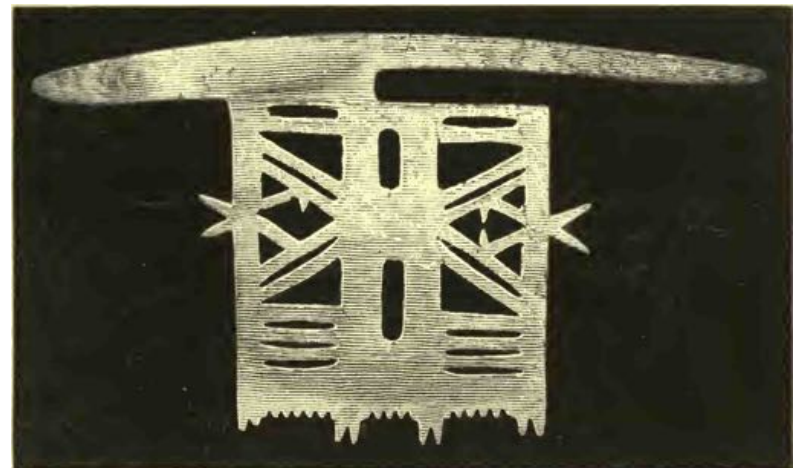

Abb. 15: Nose Ornament, Santa Cruz (COOTE 1882: 158 [im Original auf dem Kopf stehend abgebildet]).

Abb. 16: A Santa Cruz Islander in war dress from a description furnished by A. Lister-Kaye (EDGE-PARTINGTON \& HEAPE 1890: 154).

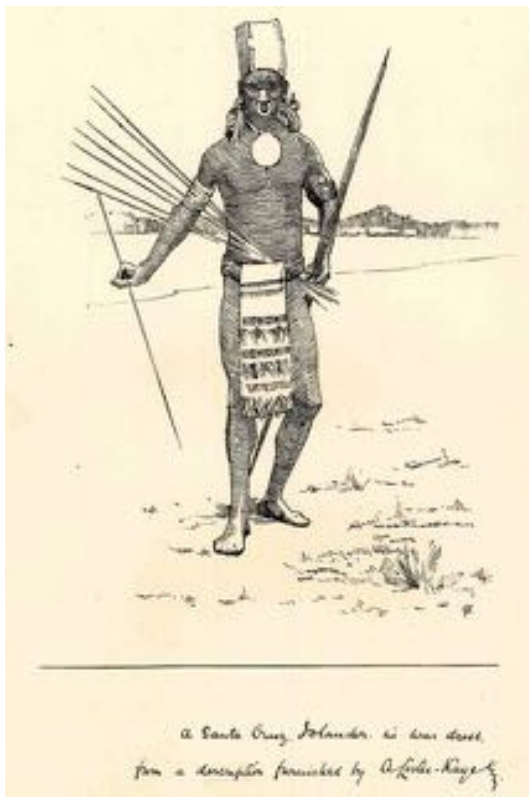

James Edge-Partington (1854-1930), britischer Sammler und ehrenamtlicher Mitarbeiter des British Museum, und der ebenfalls aus England stammende Sammler Charles Heape (1848-1926) zeigten in ihrem im Jahr 1890 ausschließlich für die private Zirkulation herausgegebenem Album die vermutlich erste In-situ-Darstellung eines „Santa Cruz Islanders in war dress" (vgl. Abb. 16). ${ }^{105}$ Diese ließen sie nach Beschreibungen des Lehrers und Laienmissionars Alan Lister-Kaye (geb. 1854, Todestag unbekannt) anfertigen, der in den Jahren 1882-84 mehrere Wochen auf Ndendö verbracht hatte. Neben Pfeilen und Bogen trägt der vermeintliche Krieger einen verzierten Schurz an einem breiten Gürtel, einen Brustschmuck, eine Kopfbedeckung, einen Nasenring, Ohrringe und verschiedene Armreifen. Ob es sich dabei tatsächlich um die Kleidung eines Kriegers handelt, kann ich aufgrund fehlender Quellen nicht bestätigen. Heute entspricht sie der repräsentativen Kleidung eines, Tanzanführers' (vgl. Abb. 89). ${ }^{106}$ Vergleicht man Markhams zuvor zitierte Beschreibung mit dieser Illustration, sind mit Ausnahme des Schurzes und der Kopfbedeckung viele Übereinstimmungen festzustellen, so dass ich sie als realistische Darstellung der Bekleidung bestimmter Männer am Ende des 19. Jh. einstufe. Neben zahlreichen weiteren Artefakten ließen James Edge-Partington \& Charles Heape zwei Tanzkeulen (1890: 155 Nr. 1 und 2), einen Webstuhl (1890: 160 Nr. 1) sowie zwei tema (1890: 162 Nr. 1 und 228 Nr. 9) illustrieren. Die Vorlagen dazu stammten aus ihren eigenen Sammlungen sowie von Kaye, Coote und Robert Codrington.

\footnotetext{
$105 \mathrm{Zu}$ James Edge-Partington, Charles Heape und deren Album vgl. Roger NEICH (2009).

${ }^{106}$ Aus anderen Bereichen Melanesiens (z. B. bei den Dani und Asmat in Westen Neuguineas) ist dokumentiert, dass sich Männer im Krieg durchaus schmückten, um ihren Status zu unterstreichen, sich durch bestimmte Schmuckstücke zu schützen, aber auch, um gefährlicher zu erscheinen oder gar Kraft und Macht zu erhalten (Beatrice VOIROL 20I I: 44, 46, I05-109).
} 
Der österreichisch-ungarische Aristokrat und Reisende Rodolphe Festetics de Tolna (1865-1933) segelte Ende des 19. Jh. acht Jahre auf seiner Privatyacht durch den Pazifik und erreichte die Santa-Cruz-Inseln im Jahr 1895. In seiner Publikation Chez les Cannibales führt er zur Kleidung der Bevölkerung auf Vanikoro auf:

„Die Männer bedecken sich mit einem Stück Tapa, das am Bauch herunterhängt; die Frauen rollen ein Stück Stoff um ihre Taille herum. Sie [die Frauen, O. L.] sind am Körper fein tatauiert. Beide Geschlechter tragen an den Ohren große Ringe aus aufgereihten Perlen oder ausgeschnittenem Schildpatt. Manchmal tragen sie Dutzende am selben Ohr, dessen Ohrläppchen mit einem Loch versehen ist, das durch das Gewicht der Ringe erweitert wurde, und wo manche ihre Pfeife aufhängen. Sie tragen am Arm, nahe am Ellenbogen, Armringe in verschiedenen Farben. Sie zeigen schöne Muster, Waben, Zickzackmuster, Sägezahnmuster oder unterbrochene Balken. Dort befestigen sie meist ihre Pfeife. Auf der Brust, wie eine Erkennungsmarke, hängt eine runde Scheibe herab [se balance], hergestellt aus einer großen Muschel, so wie eine Jakobsmuschel den Hut der alten Pilger schmückte.“ (DE TOLNA 1903: 267, Übersetzung Volkmar Suhr und O. L.)

Graham Officer, erwähnt 1901 in seiner Darstellung u. a. Nasenringe aus Schildpatt, große kreisförmige Muschelscheiben mit Schildpattauflagen, und mit Kalk geweißtes Haar (RICHARDS 2013: 119-126; vgl. S. 54-55). O'FERRALL (1908) beschreibt Kleidung/ Schmuck der Tänzer recht detailliert und führt dazu geweißtes und gebürstetes Haar, beste Schurze, Muschelarmringe, Ohrringe, große Perlmuttornamente, riechende Pflanzenbüschel, teilweise Tanzkeulen, Bogen und Pfeile sowie ein großes Palmblatt im Gürtel auf.

Bei meinen Recherchen stieß ich u. a. auf eine zwischen 1879 und 1917 aufgenommene Fotografie des australischen Fotografen Charles Henry Kerry (1857-1928), auf der eine große Gruppe Männer aus Santa Cruz abgebildet ist (vgl. Abb. 17).

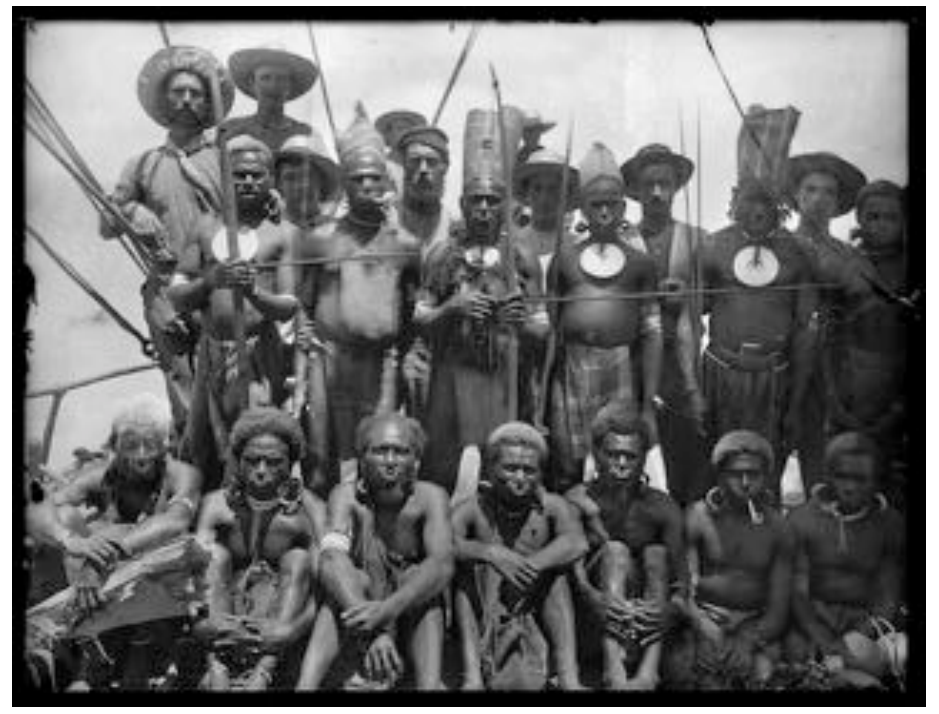

Abb. 17: Solomon Island Natives. 2166. Kerry, Sydney. Glasplattennegativ. Fotografie von Kerry and Company. Tyrell Collection, Museum of Applied Arts and Sciences, Sydney. 
Ann STEPHEN (1993: 73-74) sieht das Foto im Zusammenhang mit der Rekrutierung von Arbeitern gegen Ende des 19. Jh. Die Männer tragen in unterschiedlichen Kombinationen Kleidungs- und Schmuckstücke, die Dank der hohen Qualität der Aufnahme sehr gut erkennbar sind. So sind Schurze aus unbemalter und bemalter Tapa sowie aus Baumwolle, Brustschmuck mit und ohne Schildpattauflagen, Nasen- und Ohrringe und Armschmuck zu sehen. Gleich vier Männer tragen bemalte Kopfbedeckungen aus Tapa. Meines Erachtens tragen einige der Männer Kleidung, die Personen mit einer höheren Position vorbehalten war, und andere Männer scheinen recht alt zu sein. Daher würde ich eher nicht davon ausgehen, dass es sich bei den Fotografierten um (zukünftige) Plantagenarbeiter handelt. Ob, und falls ja, wo und unter welchen Umständen Kerry das Foto aufgenommen hat, ist leider unklar.

Erste Fotografien von Ndendö stammen etwa von de Tolna aus dem Jahr 1895, der diese im Jahr 1903 zur Illustration der Berichte seiner Kreuzfahrt durch den Pazifik nutzte (vgl. Abb. 56-57), oder wenig später von Joest aus dem Jahr 1897, von denen der deutsche Forschungsreisender und Ethnologe Baessler (1857-1907) einige zusammen mit den Joestschen Aufzeichnungen posthum veröffentlichte (vgl. BAESSLER 1900). Die am weitesten verbreiteten Fotografien aus dem frühen 20. Jh. stammen von Beattie, der im Jahr 1906 die MV Southern Cross der Melanesian Mission begleitete und am 28. September sowie am 2. und 3. November insgesamt 74 Aufnahmen rund um die Graciosa Bay erstellte (vgl. Abb. 2, 18 und 58) (BEATTIE 1906: 13-20, 51-54; BEATTIE o. J.). In den Folgejahren nutzen gleich mehrere Autoren diese zur Bebilderung ihrer eigenen Ausführungen wie O'FERRALL (1908), Graebner (1909), CoOmbe (1911), RANnie (1912), Rivers (1914) und später Beasley (1936 und 1939). SPEISER (1924 [1913]; vgl. Abb. 19) publizierte hingegen wieder mit eigenen Aufnahmen. Ab Mitte des 20. Jh. erscheinen - sofern sie Tanzkleidung und -schmuck betreffen - nur wenige Fotografien, die, mit Ausnahme von DAVENPORT (1962-1975), KOCH (1971; 1972 a-e) und WILSON (2009), nicht auf eigenen Aufenthalten in Santa Cruz basieren, sondern in erster Linie aus privaten oder Museumssammlungen veröffentlichen (z. B. Deborah B. Waite 1983 und 1987; BounOure 2004; BonsheK 2009).

Neben der reinen Erwähnung oder Abbildung von Schurzen, Kopfbedeckungen, Nasenund Ohrringen, Brustschmuck und verschiedenen Armreifen bleiben detaillierte Angaben zu den Materialitäten der einzelnen Artefakte in den frühen Quellen eher vage. Sie werden lediglich als gewebte Schurze, oder Schurze aus Tapa, Ohr- und Nasenringe aus Schildpatt, große Perlmuttornamente, Brustschmuck aus Alabaster oder Muscheln sowie Armreifen/-manschetten aus Muscheln oder Kokosnuss und Ketten mit Zähnen bestehend aufgeführt. Konkrete Informationen zu Herkunft und Herstellung der Artefakte fehlen völlig. Lediglich LABILLARDIÈRE (1800: 269) erwähnt Glasperlen, deren Herkunft er in England vermutet. Erst zum Ende des 19. Jh. berichten Missionare, Reisende und Sammler über mögliche Rohstoffe und Zusammensetzungen einzelner Artefaktegruppen. Die entsprechen- 
den Hinweise berücksichtige ich nachfolgend bei den jeweiligen Darstellungen in den Kapiteln 4.3.1-4.3.4. Zu den Herstellungsweisen bleiben die Angaben - außer denen zum Weben und zur Tapa-Herstellung - bis heute unzureichend.

\subsection{Vier Museumssammlungen des I9. und 20. Jh.}

Im Rahmen meines Surveys sichtete ich Santa Cruz-Sammlungen in Museen, um mir einen Überblick über historische Artefakte und ihre Materialitäten zu verschaffen. Ziel war auch, durch eine Gegenüberstellung mit rezenten Objekten Teile der jeweiligen ,Materialgeschichten' rekonstruieren zu können, die nicht in der vorhandenen Literatur abgedeckt waren.

Idealerweise sollten die Sammlungen möglichst weit zurückdatieren, wenn möglich gut dokumentiert und mir physisch zugänglich sein. Der in Kapitel 2 dargelegten Geschichte folgend, waren es vorwiegend englische Missionare und Kolonialbeamte sowie Händler und Reisende weiterer Länder, die sich seit Mitte des 19. Jh. in Santa Cruz aufhielten. So war es naheliegend, in Europa die Sammlung der ehemaligen Kolonialmacht England im British Museum in London einzubeziehen. Darüber hinaus eignete sich das Rautenstrauch-JoestMuseum in Köln, weil dessen Santa-Cruz-Samlung bereits im Jahr 1897 erworben und schon zu Beginn des 20. Jh. umfassend publiziert worden war (GRAEBNER 1909; FOY 1916; SPEISER 1916). In Neuseeland suchte ich während meines Surveys 2010 das Auckland War Memorial Museum und das Museum of New Zealand Te Papa Tongarewa in Wellington in der Hoffnung auf, dort Artefakte zu finden, die ursprünglich aus dem Melanesian Mission Museum in Auckland stammten. Dieses war im Jahr 1929 von der Anglican Church of Melanesia eröffnet worden und brachte Artefakte aus dem gesamten Einflussgebiet der Mission zusammen (Ross 1983: 7-15, 53-62). Die Sammlung wurde 1974 dem New Zealand Historic Places Trust übergeben, der mit Hilfe der University of Auckland die Artefakte restaurieren ließ. Aus den Salomonen stammende Artefakte wurden teilweise auf Wunsch des damaligen Archbishops of Melanesia, John Chisholm (1922-1975), in das Nationalmuseum nach Honiara überführt, teilweise verblieben sie in Auckland - wo allerdings, blieb offen (Neil Colquhoun BEGG 1983: IX). In Honiara verschwanden die Objekte größtenteils - spätestens während der tensions (pers. Kommentar Tony Heroake, Direktor des Nationalmuseums in Honiara). ${ }^{107}$ Es stellte sich allerdings heraus, dass weder in Auckland noch in Wellington größere Konvolute aus dem Missionsmuseum eingegangen waren. Das British Museum hatte im Jahr 1991 einen Teil der 1.500 Artefakte umfassenden Salomonen-Sammlung des Melanesian Mission Museum erhalten:

„From a collection of Melanesian artefacts made by the British branch of the Melanesian Mission between 1880 and 1939. In 1991 Ben Burt of the British Museum

\footnotetext{
107 Selbst der Umfang der Verluste ist unklar, da auch viele Dokumentationen verschwanden. Zu den tensions vgl. Kap. 2, S. 46-47.
} 
listed and arranged the dispersal of this collection, which had been kept by the Secretary to the Melanesian Mission in his vicarage in Henley on Thames. The Mission gave much of the collection to the National Museum of Solomon Islands, some to the British Museum and other museums, and the remainder was sold."108

Dennoch verfügen beide Häuser über Bestände aus dem ausgehenden 19. sowie frühen 20. Jh., die ich für meine Arbeit nutzen konnte.

\section{- The British Museum, London}

Die Gründung des British Museum geht auf die über 70.000 Objekte umfassende Privatsammlung des britischen Naturwissenschaftlers Sir Hans Sloane (1660-1753) zurück und beinhaltete zunächst Bücher, Manuskripte, naturwissenschaftliche Präparate, Antiquitäten und Ethnografika. Als erstes öffentlich zugängliches Nationalmuseum öffnete es im Jahr 1759 seine Pforten. ${ }^{109}$ Die Santa Cruz-Islands-Sammlung des Britsh Museum umfasst laut Datenbank 1.281 Objekte aus der Zeit von 1848 bis 2009. ${ }^{110}$ Hiervon sind 760 Objekte Fotografien oder Abbildungen, die größtenteils von Beattie aus dem Jahre 1906 sowie von Pendergrast aus den 1970er-Jahren stammen (Letztere größtenteils aus Tikopia) - so dass die Sammlung ungefähr 520 ethnografische Alltags- und Ritualgegenstände umfasst. Im Wesentlichen hatten sie Missionare der Anglican Church of Melanesia (etwa Rev. Percy Charles Wyndham Earée und Rev. Hubert S. Nind), Kolonialbeamte (Charles M. Woodford, 18521927; Thomas Edge-Partington, 1883-1920), Wissenschaftler (Sir Raymond William Firth, 1901-2002; Mick Pendergrast 1932-2010; Dorota Starzecka, geb. 1939) sowie Reisende und Sammler (Julius Lucius Brenchley, 1816-1873, und Beasley) zusammengetragen. ${ }^{11}$ Im Rahmen des ,Melanesia Project', das das Museum von 2005 bis 2010 in Zusammenarbeit mit dem Museum of Archaeology and Anthropolgy in Cambridge durchführte, gelangten zuletzt im Jahr 2009 neue Artefakte in die Sammlung. ${ }^{112}$ Für meine Untersuchung von Tanzkleidung und -schmuck waren letztlich 31 Artefakte relevant (vgl. Anhang).

\section{- Rautenstrauch-Joest-Museum, Köln}

Das Kölner Rautenstrauch-Joest-Museum - Kulturen der Welt wurde 1906 auf Basis der rund 3.500 Ethnografika umfassenden Privatsammlung von Wilhelm Joest eröffnet, der am

\footnotetext{
$108 \mathrm{Vgl}$. Objektangaben zu den Inventarnummern Oc|99|,08.1-137, http://www.britishmuseum.org/research/ collection_online/collection_object_details.aspx?objectld=484450\&partld=| \&.searchText=Oc | 99 | ,08. I \&page= |, letzter Zugriff am 26.7.2014.

109 Vgl. http://www.britishmuseum.org/about_us/the_museums_story/general_history.aspx, letzter Zugriff am 22.4.2016.

110 Vgl. http://www.britishmuseum.org/research/collection_online/search.aspx?place=9022; Suchbegriffe: Santa Cruz Islands, Oceania, Melanesia, Solomon Islands; letzter Zugriff am 2.8.20 I4.

II Zu Edge-Partington vgl. S. 82, BEASLEY (1936 und 1939) veröffentlichte Forschungsberichte zu seiner Sammlung. Pendergrast unterhielt zu verschiedenen Hersteller über längere Jahre persönliche Kontakte; vgl. Kap. 6.

112 Als ein Ergebnis des Projektes veröffentlichte das British Museum die Publikation Melanesia. Art and Encounter (Lissant BOLTON et al. 2013). Ben Burt (2013: 191-195) ging im Rahmen des Projektes u. a. der Entstehung der Solomon-Islands-Sammlung des British Museum nach.
} 
25.11.1897 auf der Rückfahrt von Ndendö nach Sydney verstorben war. ${ }^{113}$ Seine mit Eugen von Rautenstrauch verheiratete Schwester Adele schenkte die Sammlung zusammen mit dem Geld für den Bau eines Museums der Stadt Köln (Ludwig Theodor vON RAUTENSTRAUCH 2010: 6). Das Ethnologische Museum in Berlin verfügt ebenfalls über eine umfassende Sammlung Joest, die aber weitestgehend Artefakte von seinen früheren Reisen und nur wenige von seiner letzten Reise umfasst, wohingegen sich alle von ihm aufgenommenen Fotografien in Berlin befinden. Das Rautenstrauch-Joest-Museum tauschte Anfang des 20. Jh. von den ursprünglich rund 480 Santa-Cruz-Artefakten einen nicht unerheblichen Teil von etwa 160 Ethnografika mit anderen Museen als sogenannte Dubletten (pers. Auskunft Burkhard Fenner, ehemaliger Ozeanienreferent des RJM). Rechnet man weitere 90 im Verlauf der ersten Hälfte des 20. Jh. neu gesammelte Artefakte hinzu und sieht von den ungefähr 140 Pfeilen der Sammlung ab, finden sich etwa 270 Alltags- und Ritualgegenstände in der Santa-Cruz-Sammlung des Hauses, von denen 26 Untersuchungsgegenstand meiner Arbeit waren (vgl. Anhang).

\section{- Auckland War Memorial Museum Tāmaki Paenga Hira}

Die zunächst im Jahr 1852 als naturkundliches Museum angelegte Institution wandelte sich in den Folgejahren zu einem Generalmuseum und versteht sich zunehmend als Forschungsstätte. ${ }^{114}$ Mit 1.030 Objekten stellt die Santa-Cruz-Sammlung des Auckland War Museum die nominal größte der vier von mir berücksichtigten Museen dar, wobei 400 Objekte Pfeile sind (pers. Auskunft Fuli Pereira, Curator Pacific). Die Artefakte decken den Zeitraum vom Beginn des 20. Jh. bis zum Beginn des 21. Jh. ab. Die ältesten Objekte stammen aus dem Umfeld der Melanesian Mission, etwa von Arthur Henry Wedewood Burges, Kapitän des Missionsschiffs Southern Cross (gest. 1957), oder dem Melanesian Mission Trust, von James Edge-Partington, dem früheren Vorsitzenden des Auckland Museum Institutes Artur Thomas Pycroft (1875-1971) oder von Sir Frank Crossley Mappin (1884-1975), dem langjährigen Ratsmitglied des Museums. Für meine Untersuchung konnte ich auf 78 Artefakte zurückgreifen (vgl. Anhang).

\section{- Museum of New Zealand Te Papa Tongarewa, Wellington}

Die Geschichte des Museums beginnt im Jahr 1865 mit der Gründung des Colonial Museum, das 1907 in Dominion Museum und 1972 in National Museum umbenannt wurde. Im Jahr 1998 eröffnete das Museum of New Zealand Te Papa Tongarewa und führte die Sammlungen des National Museum und der National Art Gallery zusammen. ${ }^{115}$ Das Museum beherbergt heute Sammlungen zu internationaler Kunst und Geschichte, zur Naturkunde Neuseelands sowie zu Māori und anderen Pazifikkulturen. Als wichtige Teilsammlungen der beiden letztgenannten gelten etwa die Sammlungen Lord Saint Oswalds

\footnotetext{
113 Joest verbracht im Jahr I 897 vier Monate in der Graciosa Bay; vgl. S. 38 (JOEST I897; BAESSLER 1900).

$114 \mathrm{Vgl.} \mathrm{http://www.aucklandmuseum.com/collections-research/collections/about-our-collections,} \mathrm{letzter} \mathrm{Zugriff}$ am 17.4.2016.

115 Vgl. http://mww.tepapa.govt.nz/AboutUs/history/Pages/default.aspx, letzter Zugriff am 26. 10.20 I 4.
} 
Rowland Winn, ${ }^{\text {nd }}$ Baron Saint Oswald (1857-1919), die u. a. von James Cook erworbene Objekte beinhaltet, des englischen Ethnografikahändlers William Ockelford Oldman (18791949), des Dominion-Museum-Direktors Augustus Hamilton (1854-1913) und Schenkungen der Sammler Sir Arthur Hamilton Gordon (1829-1912), George Augustus Constantine Phipps $2^{\text {nd }}$ Marquess von Normanby (1819-90) und Alexander Horsburgh Turnbull (18681918). ${ }^{116}$ Die Sant-Cruz-Sammlung umfasst 256 Objekte, darunter 16 Fotografien, rund 60 Pfeile und 12 Bogen. Für meine Untersuchung standen 62 Artefakte zur Verfügung (vgl. Anhang).

\subsection{Materialität der Artefakte}

Nominal konnte ich auf knapp 200 Tanzkleidungs- und Schmuckstücken der vier Sammlungen zurückgreifen. Allerdings verfügten nur knapp 60 tema über eine Schildpattauflage, und von den als ,Schurz' deklarierten Artefakten konnte ich nur neun als mit heutigen Tanzschurzen vergleichbare lempanesa identifizieren. 19 Tapa waren in der ersten Hälfte des 20. Jh. in die Museen gelangt. In allen vier Sammlungen fand ich nur zwei nelo, was bemerkenswert ist, da gerade der Nasenschmuck als ästhetische Arbeit und Ausdruck höchster Kunstfertigkeit auf hohes Sammlerinteresse hätte stoßen müssen.

Wie ich zunächst bei einem historischen Vergleich feststellte, hatten sich die Artefakte in der Zeit von der zweiten Hälfte des 19. Jh. bis heute in unterschiedlichem Maße gewandelt: Während sich die tema und lepanesa auf den ersten Blick relativ wenig geändert hatten, stellten sich die Tapa insbesondere in der Gestaltung anders dar.

\subsection{Brustschmuck tema}

Der am häufigsten beschriebene und gesammelte Schmuck von Santa Cruz stellt zweifelsohne der Brustschmuck tema dar. Nach frühen Darstellungen eines Kriegers von Santa Cruz bei EDGE-PARTINGTON \& HEAPE (1890: 154 vgl. Abb. 16) sowie eines undekorierten (1890: 162 no.1) und eines dekorierten tema (1890: 228 no. 9) erscheinen ab 1900 erste Fotografien aus Santa Cruz - und mit ihnen Abbildungen von tema tragenden Männern. Dazu zählen Fotografien u. a. von DE TOLNA (1903: 283 Abb. 136: „Natifs de Carlisle Bay“"), Joest (BAESSLER 1900: 376 Abb. 34: „Eingeborene von Santa Cruz“) und ab dem frühen 20. Jh. von Beattie etwa bei Missionsautoren wie O'Ferrall (1908, Abb. „Headmen in a Santa Cruz Village“, Abb. „Nibi -- A New School Village“ mit Erwähnung der Artefakte tema, tapa und abe) oder CoOmbe (1911, Abb. S. 170: „The People have a Sinister Reputation“). Im historischen Fotoarchiv des Rautenstrauch-Joest-Museum befinden sich zwei Fotografien von tema tragenden Männern („Type of native. Earrings of tortoiseshell. Breastplates of Giant Tridacna“, Inv. 9783, vgl. Abb. 4, und „Type of native. Noserings of tortoiseshell. Breast-

\footnotetext{
116 Vgl. http://collections.tepapa.govt.nz/Topic/I 330, http://collections.tepapa.govt.nz/search?searchTerm=Pacific \%20Cultures\%20collection\&scope=all, letzter Zugriff jeweils am 3.4.20 I 6.
} 
plate of Giant Tridacna“, Inv. 9784), die von Walter Henry Lucas (1869-1954), einem britischen Händler und Technical Advisor der britischen Kolonialmacht, stammen und 1911 in die Sammlung gelangten. ${ }^{117}$

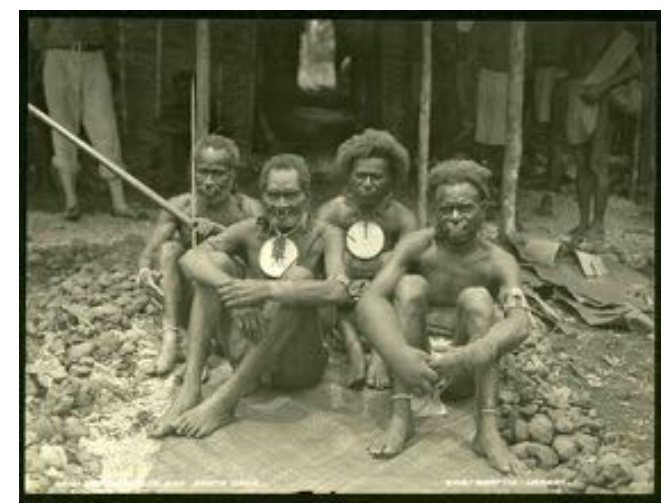

Abb. 18: 405 - Headmen in a Santa Cruz Village. John Watt Beattie, 1906. Auf dem Bild tragen zwei Chiefs tema, einmal mit und einmal ohne Schildpattauflage. Freddy Me'esa zufolge ist die zweite Person von links sein Großvater Chief Mona aus der Graciosa Bay (pers. Kommentar Freddy Me'esa).

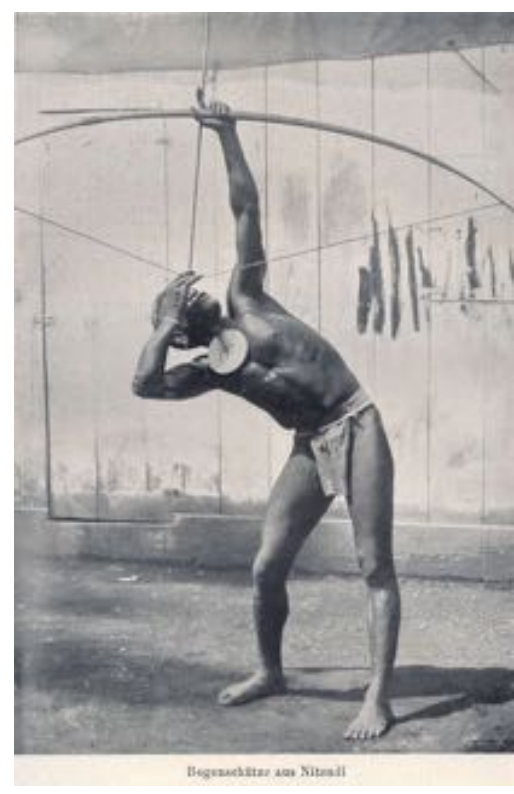

Abb. 19: Bogenschütze aus Nitendi (SPEISER, 1913: Tafel 6)

SPEISER veröffentlichte 1913 seine Publikation mit eigenen Fotografien, die u. a. auch Männer mit tema darstellen (1924 [1913]: Taf. 6: „Bogenschütze aus Nitendi“ - vgl. Abb. 19, Taf. 60: „Blick an einer Dorffront auf Nitendi entlang“ und Taf. 62: „Ansicht eines Dorfes auf Nitendi vom Meer aus").

\section{- Stofflichkeiten}

Ersten schriftlichen Hinweisen zufolge bestanden die Brustschmuckplatten aus Perlmutt (DALRYMPLE 1770 nach de Quiros 1595), Alabaster (LABILLARDIÈRE 1800) und weißer Muschel (MARKHAM 1873; vgl. Einleitung dieses Kapitels). COOTE (1882: 158) weist das Material generisch als ,,a large round shell plate“ aus. Weitere zehn Jahre später berichtet DEWAR (1892: 249) als erster über eine Kombination von Muschel und Schildpattauflage: „I also succeeded in obtaining some very handsome ornaments [...] These were made of a white shell, beautifully polished, of circular shape, and about six inches in diameter. On the front was a varied fretwork pattern in tortoise-shell.“ De Tolna liefert erste Hinweise zur Herkunft und Verarbeitung des Rohmaterials:

„Die Eingeborenen [Küstenbewohner, O. L.] kaufen das Ausgangsmaterial bei den Buschbewohnern, die sie [es] offensichtlich in ihren Bergen im fossilen Zustand finden. Sie bearbeiten das Material aber selbst. Sie schneiden es zurecht, polieren es, fügen Perlen und Schildpatt an. Wenn sie dann die runde Scheibe eine Zeit lang

\footnotetext{
117 Ob Lucas die Fotografien selber aufnahm, ist nicht sicher.
} 
getragen haben, so verkaufen sie die derart umgearbeiteten den Buschbewohnern gegen eine Frau.“ (DE TOLNA 1903: 267-268, Übersetzung Volkmar Suhr und O. L. $)^{118}$

GRAEBNER (1909: 78-79) fasst die damaligen Kenntnisse über den Brustschmuck zusammen: ,[...] dessen häufigste und bekannteste Form [ist] eine große, bis 13 1/2 cm im Durchmesser haltende Tridacnascheibe - nach F. de Tolna aus fossilen Schalen. Oft ist die Scheibe nicht weiter verziert, oft aber trägt sie eine gefällige Auflage aus dünnem Schildpatt [...].“ Auf den verschiedenen Abbildungen sowie in den Museumssammlungen (vgl. Anhang) finden sich tema mit und ohne Schildpattauflage, wobei sich die Beschaffenheit der Tridacnascheibe nicht unterscheidet. Ihre Oberfläche ist glatt, und in der Mitte der Scheiben befindet sich eine Bohrung. Hinsichtlich der Größen variieren sie von fünf bis 20 Zentimeter Durchmesser. Ab einem Durchmesser von sechs Zentimetern verfügen sie teilweise über Schildpattauflagen, wobei zwei Drittel der dekorierten Scheiben einen Durchmesser von elf bis 19 Zentimetern aufweisen. Bei manchen tema ist durch die Bohrung mehrmals eine gedrehte Schnur aus Pflanzenfasern über den Rand der Scheibe gezogen, wodurch am Scheibenrand eine Möglichkeit geschaffen wird, andere Schnüre oder auch Bänder, etwa aus Baumwolle, einzufädeln, mit denen der Brustschmuck am Hals getragen werden kann. Befindet sich auf dem tema eine Schildpattauflage, so ist diese mittels einer gedrehten Schnur auf die Unterlage gebunden. Dazu ist das Schildpatt ebenfalls an einer Stelle durchbohrt, so dass durch die Muschelscheibe und die Perlmuttauflage mehrfach eine Schnur hindurch gezogen und um den Rand gelegt werden kann. In wenigen Ausnahmefällen sind auf die Schnüre zur Befestigung am Hals Conus-Schneckenhausscheibchen gezogen oder zusätzlich mit ihnen verzierte Schnüre angebracht.

Das älteste erhaltene tema mit Schildpattauflage der vier untersuchten Sammlungen ist Artefakt no. FE000734 des Museum of New Zealand Te Papa Tongarewa. Es wurde um das Jahr 1870 hergestellt und gelangte im Jahr 1913 in die Sammlung (vgl. Abb. 20). Die Form ist nicht völlig rund, sondern ein wenig oval. Die Auflage ist, wie zuvor beschrieben, auf der Tridacnascheibe festgebunden. Am oberen Teil der Bindung ist eine geflochtene Kordel durchgezogen. An jeden Strang ist eine kleine gedrehte Schnur mit aufgezogenen Conus-Schneckenhausscheibchen und blauer Glasperle befestigt. Schon bei Labillardière findet sich ein Hinweis auf europäische Glasperlen (vgl. Zitat S. 81). Die Schildpattauflage unterscheidet sich in ihrer Gestaltung - mit Ausnahme des sehr ähnlichen tema 7317 aus der Sammlung des Auckland Museum - von den übrigen, da sie zweimal die Schwingen abstrahierter Fregattvögel zeigt.

\footnotetext{
118 Versteinerte Riesenmuscheln habe ich oftmals an Wegen durch die Wälder der Küstenbereiche auf Santa Cruz, Vanikoro und Utupua liegen gesehen, weniger auf den ,flachen' Atollinseln der Reef Islands. Auf der Fahrt mit dem Missionsschiff Southern Cross habe ich beobachtet, wie Passagiere nach Riesenmuscheln tauchten, um sie während der späteren Fahrt zu kochen. Die Schalen der Tiere wurden anschließend ins Meer geworfen, so dass ich davon ausgehe, dass frische Schalen keinen Wert an sich im Santa-Cruz-Archipel darstellen.
} 
The British Museum verfügt seit 1944 über eine Sammlung von Beasley, zu der u. a. zehn tema gehören. Er erwarb die Artefakte im Jahr 1924 von Rev. Nind aus der Melanesischen Mission, die dieser im Jahr 1901 in Santa Cruz gesammelt hatte. In einem Artikel zeigt BEASLEY (1939) zwei tema mit und eines ohne Schildpatt sowie elf weitere Muster der Auflagen, losgelöst von der Muschelscheibe, um gezielt die Gestaltungselemente zu analysieren und Ähnlichkeiten zu vergleichbaren Artefakten aus Südostasien aufzuzeigen und kulturelle Verbindungen zwischen den Regionen herzustellen (vgl. Anhang). Einige seiner Abbildungen entsprechen tema-Abbildungen des British Museum. Die drei erhaltenen tema der Rautenstrauch-Joest-Sammlung - erworben im Jahr 1897 von Joest - ähneln in ihrer Gestaltung denjenigen von Beasley. Bei dem Vergleich der Beasley-Auflagen mit denen der Sammlung des Auckland Museum zeigen sich bei den Artefakten der Museumssammlung mit den Inventarnummern 18131, 30986.2 und 30986.3 Abweichungen in der Gestaltung. Ebenso unterscheiden sich die tema 51551 des Rautenstrauch-Joest-Museum und 53221 des Auckland Museum von den übrigen. Diese beiden Gestaltungen ähneln Brustschmuck, wie er in den Geschäften in Honiara angeboten wird. Gemäß einem Verkäufer stammten diese von der Insel Malaita (vgl. Abb. 32). Alle tema sind aus Tridacna hergestellt. Von einer einzigen Ausnahme abgesehen bestehen alle übrigen Auflagen aus Schildpatt. Nur tema 30986.2 des Auckland Museum ist mit Perlmutt belegt.

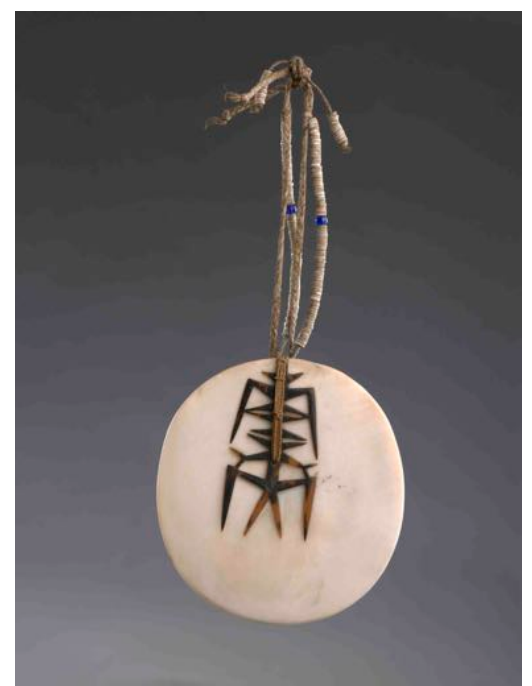

Abb. 20: Tema, H.: 18,5 cm, B.: 17,5 cm; Santa Cruz, ca. 1870; Museum of New Zealand Te Papa Tongarewa FE000734.

(C) Museum of New Zealand Te Papa Tongarewa

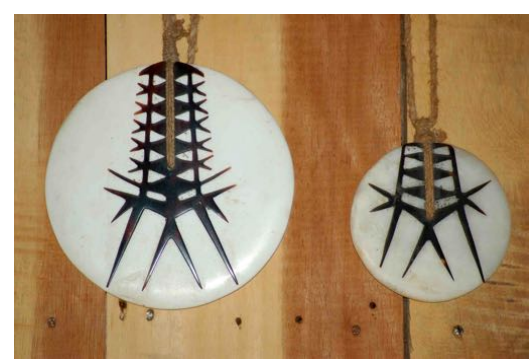

Abb. 21: Tema, 1. Ø ca. $18 \mathrm{~cm}$, r. Ø ca. $5 \mathrm{~cm}$; beide John Namiade, Luepe, 2010.

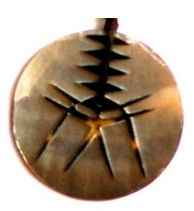

Abb. 22: Tema aus Perlmutt, Ø ca. 5 cm; Matthias Me'lekaiva, Nea, 2011.

Ein Vergleich historischer und rezenter Arbeiten zeigt eine große Ähnlichkeit hinsichtlich der Größen und Materialkombinationen. Allerdings sind heute zusätzlich zu großen tema aus Tridacna und Schildpatt kleinere Varianten in den Materialkombinationen Tridacna mit Schildpatt sowie Perlmutt von Austern mit Schildpatt oder Holz (vgl. Abb. 21 und Abb. 22) 
zu finden. Als Trageschnüre dienen gegenwärtig aus Kokosnussfasern gedrehte Kordeln und aus Kunstfasern industriell hergestellte Schnüre. Letztere beziehen die Produzenten aus Honiara (Wilson Kabi, 2.6.2010, und John Namiade, 9.11.2011). Vergleicht man die Oberflächenstrukturen der alten mit denen der neuen tema, sind die rezenten Arbeiten regelmäßiger und ihre Ränder dünner und flach auslaufender. Diese verfeinerte Machart findet sich auch in der Ausarbeitung der Auflagen. Sie laufen sehr viel dünner und spitzer als ihre Vorgänger aus. Die Elaboriertheit heutiger Arbeiten wird durch einen stärkeren Glanz unterstrichen, den die Produzenten nach eigenen Aussagen durch ein Polieren der Tridacnascheiben und Schildpattauflagen mit Muschelkalk erzielen, der beim Heraustrennen und Schleifen der tema anfällt. Einer der heutigen Produzenten vermischt den Polierstaub zusätzlich mit zerstoßenem und gebranntem Korallenkalk (Ben Banie, 12.10.2011).

Neben diesen natürlichen Materialien nutzen spätestens seit Beginn der 1980er-Jahre einige Produzenten auch industriell gefertigte Keramikfliesen als Muschelersatz und auch Gummi oder Kunststoff als Schildpattersatz. ${ }^{119}$ Diese waren vor meiner Forschung weder von Museen gesammelt noch in anderer Form außerhalb von Santa Cruz dokumentiert worden. Bei zwei Tänzern sah ich selber derart beschaffene tema (vgl. Abb. 8 und Abb. 23a, 23b). Auch Spiegelglas wurde einmal als Ersatz für eine Muschelscheibe genutzt (Selwyn Balu, 10.11.2011).

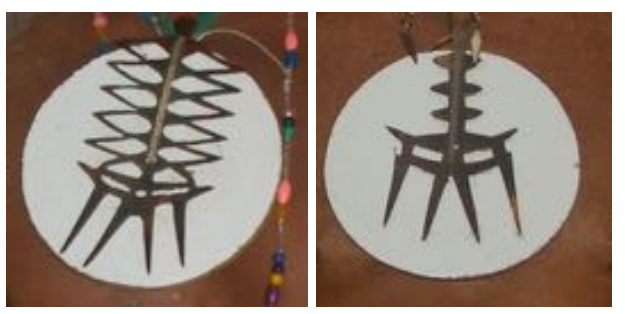

Abb. 23a und 23b: Tema aus Keramikkacheln mit Auflagen aus Kunststoff, jeweils $\varnothing$ ca. 17 cm; Hersteller unbekannt; Neo-Nemba, 2011.

- Herstellung

Manche der heute 50- bis 60-jährigen Männer erinnerten sich an Beobachtungen ihrer frühesten Kindheit und an Erzählungen ihrer Väter, nach denen in der Vergangenheit die Männer selber ihren Brustschmuck gefertigt hatten. Demnach wurden in einem ersten Schritt mit Hilfe von Steinen Blöcke von fossilen Tridacnaschalen abgeschlagen (vgl. Abb. 24). Diese Muschelblöcke wurden anschließend in monatelangen Arbeitsschritten jeweils nachts bei hellem Mondlicht außerhalb des Dorfes solange auf einem rauen Stein geschliffen, bis die gewünschte Scheibengröße und -dicke erreicht wurde (vgl. Abb. 25). Meinen Gewährsleuten zufolge mussten die Männer ihre tema außerhalb eines Dorfes schleifen, weil die Arbeit relativ laut war und die Ruhe im Dorf störte. Zum anderen befürchtete man, dass das Geräusch unerwünschte dukna anziehen und die Bewohner in Gefahr bringen könnte. Zur Unterstützung riefen die Hersteller ihre eigenen dukna an. Heute existieren zwar noch

119 Diese ,neuen' tema waren zu dieser Zeit nicht selten. So trugen etwa Davis Käeluwio aus Nemba oder auch Selwyn Balu tema aus Keramikfliesen (Philipp Malu, 10.1 I.20 I I; Selwyn Balu, 17.10.20 I I). 
einige Schleifsteine, aber das Wissen um mit ihnen in Verbindung stehende konkrete Techniken ist nicht mehr vorhanden. Ebenso musste die Frage unbeantwortet bleiben, wie in der Vergangenheit das Loch in die Mitte der tema gebohrt wurde. Zu der Herstellung der Schildpattauflagen erinnerten meine Gewährsleute, dass die Formen ehemals mittels aus Kokosnussfasern gedrehter Kordeln aus dem Schildpatt gefräst und anschließend mit gebranntem Korallenkalk poliert worden waren. (Stephen Mdewöt, 21.10.2011, und John Me'alue $4.11 .2011)$
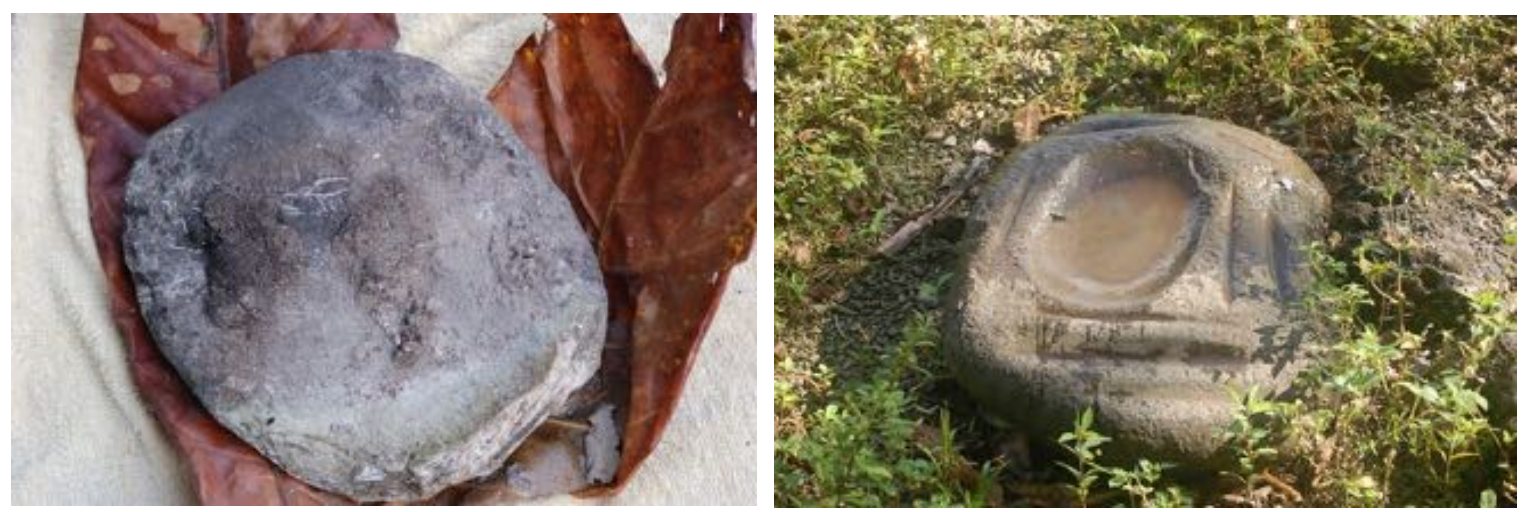

Abb. 24: Versteinerte Tridacna; Nelua, 2011.

Abb. 25: Ein ,schwarzer Stein' für unterschiedliche Schleifarbeiten; Malo, 2010.

- Heutige Verarbeitung

Meinen Informanten zufolge gab es in den 1980er-Jahren auf Ndendö nur wenige noch vollständig erhaltene tema. Die meisten Schmuckstücke waren verkauft worden oder ihre Schildpattauflagen zum Teil abgebrochen. Niemand widmete sich der zeitintensiven Herstellung. (Wilson Kabi 2.6.2010; Selwyn Balu 17.10.2011; Hudson Me’tea 11.11.2011). Da nelo-Tänzer kontinuierlich - wenn auch mit abnehmender Häufigkeit - nelo-Tänze aufführten, wurden weiterhin tema benötigt. Man vermutete, dass mit dem steigenden Kontakt zur Landeshauptstadt Honiara jemand auf die Keramikkacheln, die für den Bau ,moderner ${ }^{6}$ Häuser nach Honiara importiert wurden, aufmerksam geworden sei und sie als Alternative für den Rohstoff der Tridacna angesehen haben muss. Das Material war relativ leicht erhältlich, bereits dünn genug und vermutlich einfach in eine Runde Form zu bringen und zu durchbohren. Zudem war es auf einer Seite hochglänzend (Selwyn Balu 17.10.2011). Wer genau diese Person war, ist nicht mehr bekannt. Nach Philippe Malu (10.11.2011) gehörte neben anderen Me'punie aus Monou in den 1980er-Jahren zu den tema-Produzenten, die mit dem neuen Material arbeiteten. Im Jahr 2000 stellte John Namiade zufolge (5.9.201 1) auch James Telewi aus Nembu tema aus Keramik mit Leder- oder Gummiauflage her. Zwar war die Herstellung mit dem neuen Material einfacher als mit dem traditionellen, jedoch gestaltete sich dessen Lagerung schwieriger, da die Keramik leichter sprang. Dennoch nutzen einige Tänzer die Keramikkacheln bis heute (vgl. Kap. 3.3.1). 
Einen anderen Weg der Herstellung schlug Wilson Kabi aus Luepe ein, dessen Vater in den 1980er-Jahren zu früh verstorben war, um sein Wissen um die traditionelle tema-Produktion vorher an seinen Sohn weitergeben zu können. Kabi war stattdessen von seinem Schwiegervater Walter Me'esa, einem nelo-Tänzer, im Tanz und in der Fertigung von nelo unterwiesen worden, jedoch nicht in der Herstellung von tema. ${ }^{120}$ Da Kabi zu seinen neloTänzen zwar ein eigenes tema, aber keines aus Keramik tragen wollte, musste er sich seiner Aussage zufolge dessen Fertigung selber aneignen, was ihm nach vielen erfolglosen Versuchen - unter Einsatz von traditionellen Werkzeugen wie Steinklingen und ,schwarzen Steinen' - letztlich gelang (Wilson Kabi, 2.6.2010).

Meinen Informanten zufolge lag Ende der 1980er-Jahre der Niederländer Dieter Ludwig mit seinem Segelboot in der Graciosa Bay und war auf der Suche nach ,typischen“ Artefakten erfolglos geblieben. Hudson Me’tea aus Venga war einer seiner Ansprechpartner. In einem Gespräch über ,typische Artefakte' hatte Me'tea als Grund für das geringe Angebot an tema das Fehlen von Werkzeugen angeführt, woraufhin Ludwig zusagte, im folgenden Jahr wiederzukommen und Werkzeuge mitzubringen. Im Jahr 1989 oder 1990 übergab Ludwig Eisensägen und -feilen sowie ein Buch mit Abbildungen für die Herstellung von tema an Me'tea. In den folgenden 15 Jahren fertigte Me'tea rund 30 große tema und war zudem auf die Idee gekommen, verkleinerte tema zu produzieren, da sie weniger aufwendig in der Herstellung und leichter verkäuflich waren. Im Jahr 2005 wurde ihm eine Anstellung in Lata angeboten, woraufhin er die tema-Produktion einstellte und seine Werkzeuge an Wilson Kabi übergab. (Hudson Me'tea, 11.11.2011)

Ludwig besuchte in den Jahren 2001 bis 2004 jährlich die Graciosa Bay und hatte währenddessen einen Kontakt zu Kabi aufgebaut und ihn regelmäßig mit neuen Werkzeugen (Sägeblätter für Laubsägen und Feilen aus Eisen) versorgt (Dieter Ludwig, 5.2.2015). Wie Kabi es darstellte, versetzten ihn die neuen Sägen und Feilen in die Lage, in zunehmendem Maße in sehr viel kürzerer Zeit Scheiben aus der Tridacnaschale zu schneiden und Auflagen aus Schildpatt zu sägen. Benötigte er zuvor für die Produktion eines tema rund fünf Monate, so gelang ihm dies durch den Einsatz der neuen Werkzeuge in nur zwei Wochen. Kabi wurde in zunehmendem Maße von anderen Tänzern gebeten, für sie wieder tema aus Tridacna und Schildpatt herzustellen. Als Vorlagen für die Auflagen nutzte er Me'teas Abbildungen und neue, die er in den Folgejahren von dem deutschen Ethnologen Frank Reiter erhielt - so auch Kochs Publikation von 1971.

Parallel dazu hatte, von der lokalen Provinzregierung ausgehend, in den späten 1990erJahren eine kulturelle Rückbesinnung eingesetzt, die insbesondere eine Renaissance ,traditioneller, lokaler Materialien und überlieferter Praktiken und Werte verfolgte (vgl. Kap. 3.3.2). Dazu zählte auch die nelo-Tanzkleidung und der -schmuck.

120 Zwei Abbildungen von Walter Me'esa finden sich bei KOCH (197I: Taf. 4 zweite Person von oben und Taf. I5 mittlerer nelo-Tänzer). 
Kabis Sohn John Namiade begann in den 2000er-Jahren sich das Basiswissen zur temaHerstellung von seinem Vater Wilson Kabi anzueignen. Im Jahr 2005 stieg Namiade endgültig in die Herstellung ein und übernahm zunehmend Aufträge von seinem Vater. Im Jahr 2007 erhielt Namiade von der Provinzregierung einen Generator und Bargeld für eine Sägeund Schleifmaschine, mit deren Hilfe er, soweit er Absatzmöglichkeiten sieht, bis heute tema produziert. Seit dem Tod seines Vaters Kabi im August 2011 ist Namiade, soweit ich es beobachten konnte, der bekannteste tema-Produzent der Insel. ${ }^{121}$

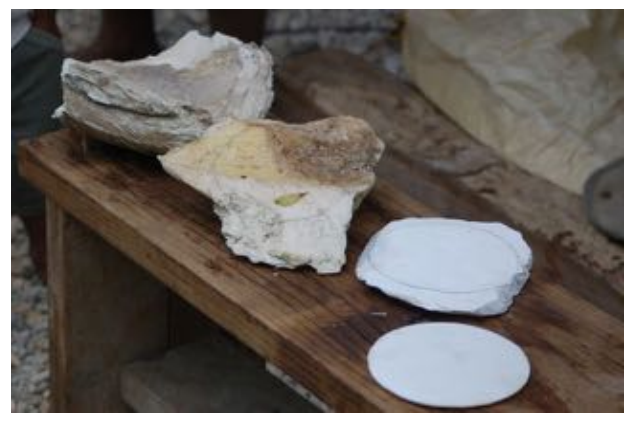

Abb. 26: Vom abgebrochenen fossilen Tridacnastück zum tema-Rohling; Luepe, 2011.

Neben John Namiade stellten auf Ndendö im Jahr 2011 noch weitere Personen tema her, etwa Ben Banie und Hugo Me'kio aus Luepa, Philipp Malu aus Monou und Matthias Me'lekaiva aus Neo - wenn auch nicht in demselben Maße wie er (Selwyn Balu, 13.10.2011). Damit stellte die Graciosa Bay zur Zeit meiner Feldforschung das Zentrum der tema-Produktion auf Ndendö und in Santa Cruz dar. Von den zuvor genannten Personen trat insbesondere Philipp Malu in Erscheinung. ${ }^{122}$ Malu hatte nach eigener Darstellung erstmals im Jahr 1994 von Wilson Kabi Werkzeuge zur Produktion von tema erhalten. Seitdem fertigte er von Zeit zu Zeit immer wieder als Auftragsarbeiten die kleine tema-Variante in höheren Stückzahlen, etwa für die Royal Solomon Islands Police oder für die Melanesische Kirche (vgl. Abb. 27-29). Im November 2011 erreichte ihn eine Anfrage einer in Honiara tätigen Firma aus Papua-Neuguinea, die für einen Firmenevent 300 kleine tema erwerben wollten (Philipp Malu, 10.11.2011).
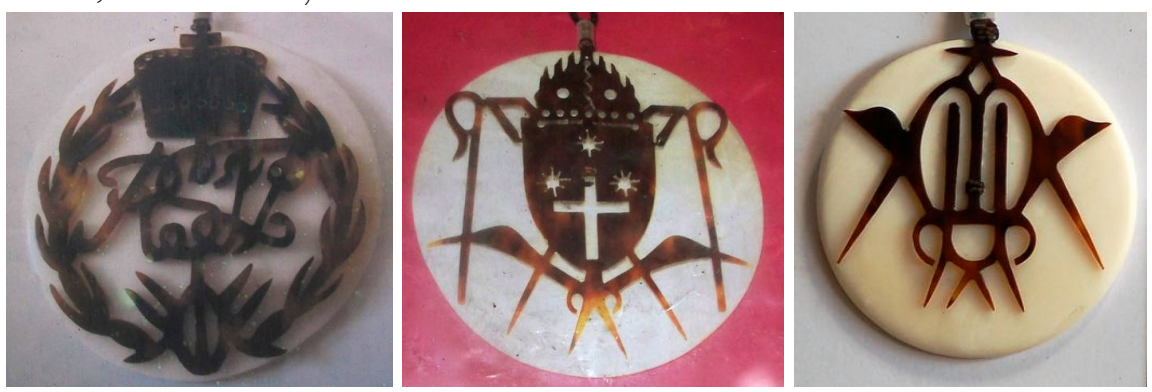

Abb. 27-29: Tema, Ø ca. 5 cm; diverse Auftragsarbeiten; Philipp Malu, Monou, 2011.

V. l. n. r.: Royal Solomon Islands Police (vor 2000), Anglican Church of Melanesia (vor 2009), Mothers Union der Anglican Church of Melanesia (2011).

$121 \mathrm{Zu}$ dem tema-Produzenten John Namiade vgl. weiter Kap. 3.3.2 und insbesondere Kap. 6.I.

$122 \mathrm{Zu}$ Philipp Malu und seiner Bedeutung als nelo-Produzent vgl. nachfolgende Kap. 4.3.2 und 6.2. 
Auch auf der Insel Vanikoro wurden im Jahr 2011 - wenn auch in kleinerem Umfang - tema (lokal: kolokolo) hergestellt: Chief David Tate aus Lavuka hatte in den 2000er-Jahren von dem bereits erwähnten Wilson Kabi, einem Freund seines Vaters, Sägeblätter und Feilen aus Metall erhalten und sich die Fertigung selber angeeignet (vgl. Abb. 30). Mittlerweile hatte er sein Können mit seinem Bruder Cleophas Makona geteilt (vgl. Abb. 32). Wie Tate berichtete, hatte er von einer Gruppe französischer Wissenschaftler, die sich im Jahr 1999 zu Untersuchungen bezüglich des Verbleibs der verschollenen La Pérouse-Expeditionsschiffe auf Vanikoro aufgehalten hatte, Abbildungen von tema erhalten. (David Tate, 7.9.2011)
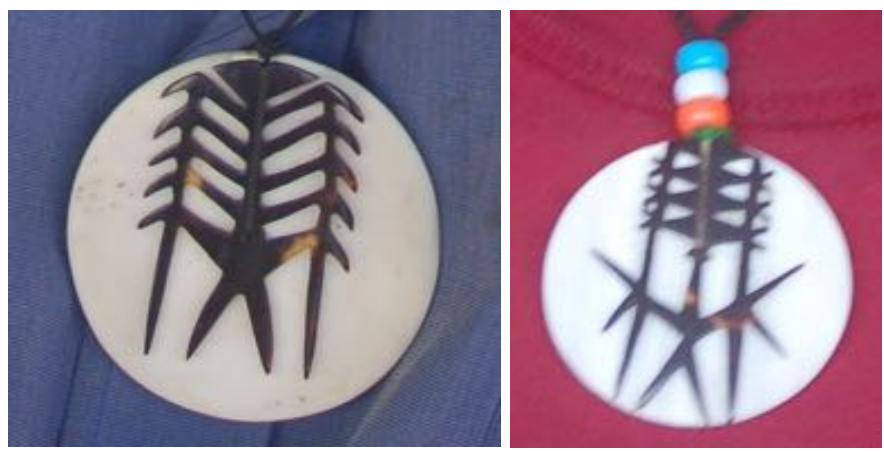

Abb. 30: Kolokolo, Ø ca. 5 cm; Chief David Tate, Lavuka, Vanikoro, 2011. Das Motiv entspricht dem des tema Nr. 18131 des Auckland War Memorial Museum.

Abb. 31: Kolokolo, Ø ca. 5 cm; Gleophas Makona, Lavuka, Vanikoro, 2011.

Neben den zuvor dargestellten tema aus Santa Gruz traf ich in verschiedenen Geschäften und im Museumsshop des Nationalmuseums in der Hauptstadt Honiara weitere ähnliche Artefakte an. Wie mir die Verkäufer mitteilten, hatten sie diesen Schmuck von ,Fremden', etwa Produzenten von der Salomoneninsel Malaita, erworben. Diese fertigten mit Wissen der Händler aus ,traditionellen' Materialien ,tema ${ }^{6}$, imitierten die Originale aus Santa Cruz und boten sie in der Landeshauptstadt Honiara an (vgl. Abb. 32 und Abb. 33).
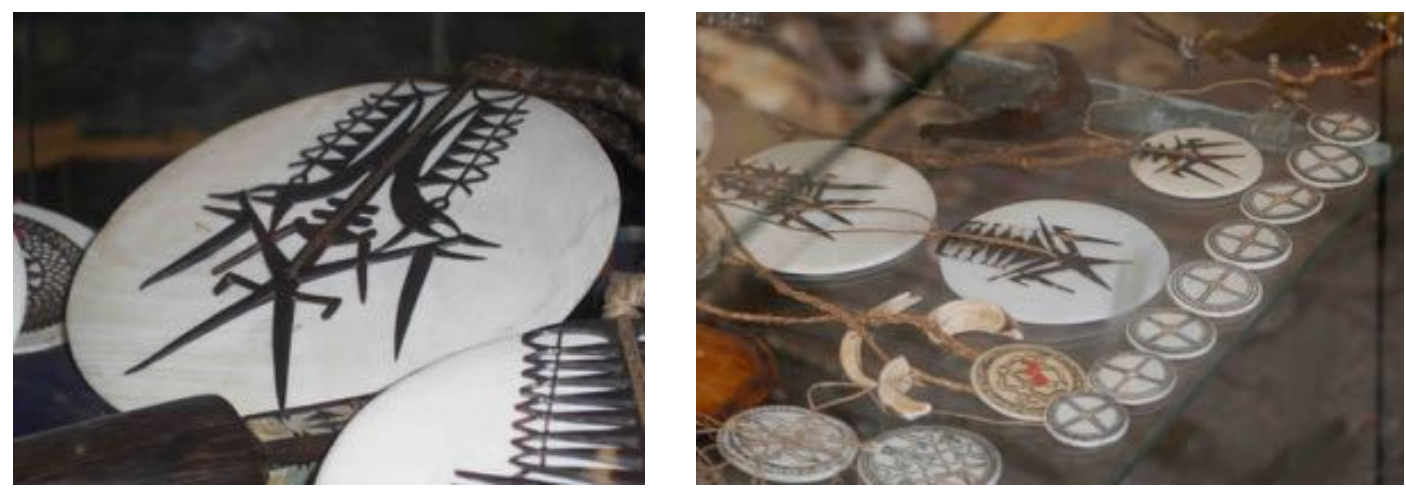

Abb. 32: Einem tema nachempfundenes Schmuckstück von der Insel Malaita, Ø ca. 17 cm; Nautilus-Shop, Honiara, 2011.

Abb. 33: Auslage mit tema-Kopien von der Insel Malaita, Ø ca. 15 und $8 \mathrm{~cm}$; Museumsshop, Honiara, 2010. 
- Materialgeschichte

Die Produktion der aus natürlichen Materialien gefertigten tema auf Ndendö hatte bis in die 1990er-Jahre abgenommen und war fast zum Erliegen gekommen. Damit einhergehend verringerte sich zunehmend der Bestand der tema auf der Insel. Engpassfaktor waren die temaRohlinge aus Tridacna, nicht das Schildpatt, das kontinuierlich verwendet wurde. Wobei dies nicht an einer Verknappung des Rohstoffs Muschel lag, sondern vielmehr war es der für die Herstellung der Muschelscheiben notwendige, enorm hohe Arbeits- und Zeitaufwand, der die Männer davon abhielt, den Brustschmuck weiter herzustellen. In den wenigen Fällen, in denen nelo-Tänzer neue tema benötigten, hatten einige Tänzer seit den 1980er-Jahren begonnen, das traditionelle Material gegen Keramikfliesen als Rohstoff für den Brustschmuck zu ersetzen. Erst das Einführen neuer Werkzeuge und damit verbundener Herstellungstechniken - wie der Einsatz von zunächst manuell und seit dem Jahr 2007 auch elektrisch betriebener Sägen und Schleifgeräten - ermöglichte interessierten Männern durch eine weniger zeit- und arbeitsintensive Herstellung die Wiederaufnahme der lokalen tema-Produktion. Zudem hatte zunächst ein Hersteller begonnen, eine stark verkleinerte Variante zu produzieren. Der Erfolg motivierte andere, ebenfalls in die Herstellung der kleinen tema einzusteigen. Der verkürzte Zeitaufwand verringerte den Preis. Dadurch wurden insbesondere die Schmuckstücke für einen erweiterten Kreis von Abnehmern bzw. Abnehmerinnen erschwinglich und wieder zunehmend bzw. erstmals interessant. Das Interesse an ihnen stieg aber auch, weil die in den späten 1990er-Jahren einsetzende kulturelle Rückbesinnung in der Provinz Temotu traditionelle Materialien und Artefakte in den Mittelpunkt lokaler Debatten rückte. Die Nachfrage wurde m. E. politisch forciert, und einige Personen erkannten die Situation und nutzen ihre Chancen, wie ich in Kapitel 6 zeigen werde.

Die heutige Präsenz der tema - ihre Materialität, ihre Designs und die Verbreitung - erweckt fälschlicherweise den Eindruck, die Materialgeschichte der tema sei kontinuierlich fortgeschrieben worden. Tatsächlich ist sie den sozialen Umbrüchen der Menschen gefolgt und hat einen großen Wandel vollzogen. Viele der heute ,traditionellen' tema sind nur wenige Jahre alt.

\subsubsection{Nasenschmuck nelo}

Obwohl das nelo als erstes Schmuckstück überhaupt aus Santa Cruz abgebildet wurde (COOTE 1882: 185, vgl. Abb. 15), findet sich der Nasenschmuck in nur zwei weiteren Publikationen der frühen Literatur (EDGE-PARTINGTON \& HeAPE 1890: 166, No. 9 und SPEISER 1924: Taf. 67): 

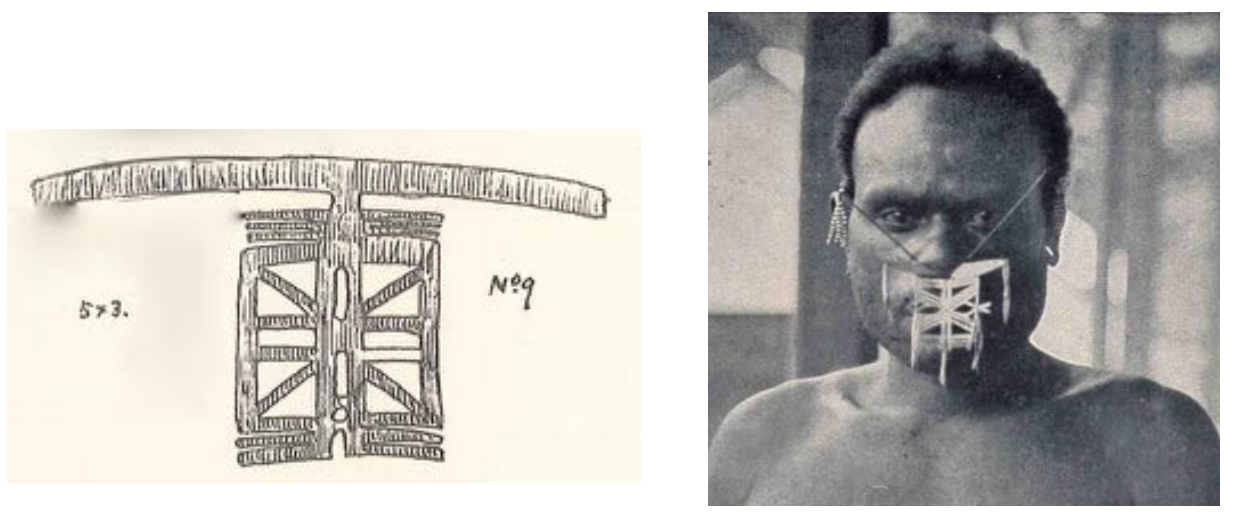

Abb. 34: Nose ormament of pearl shell - worm by chiefs only (EDGE-PARTINGTON \& HEAPE 1890: 166, No. 9, retuschierter Bildausschnitt).

Abb. 35: Ein Mann aus Nitendi mit dem aus Perlmutter zierlich geschnitzten Tanznasenschmuck (SPEISER 1913: Taf. 67, Bildausschnitt).

- Stofflichkeiten

CоOтE (1882: 159) gibt als erster Hinweise zur Beschaffenheit und beschreibt nelo als „elaborately fretted mother-of-pearl plates fastened into their noses“. Nach O' Ferall (1908) tauschen einige Männer für Tänze ihren Nasenring aus Schildpatt gegen einen großen aus Perlmutt aus. GraebNeR (1909: 76) referiert die beiden erstgenannten Quellen Coote sowie Edge-Partington \& Heape. RANNIE (1912: 174) berichtet über den Erwerb von „beautifully carved ornaments, in pearl and tortoise-shell“", wobei unklar bleibt, ob es sich dabei um Brust- oder Nasenschmuck handelt. Die geringe Anzahl der Darstellungen dieses Artefaktes spiegelt sich letztlich auch in den Sammlungen der vier Museen wieder: Lediglich das British Museum (Inv. Oc1944,02.1234, datiert um das Jahr 1900, vgl. Abb. 36) und das Rautenstrauch-Joest-Museum (Inv. 30562, gesammelt im Jahr 1912, vgl. Abb. 38) verfügen über jeweils ein nelo. Koch (1971: 118) stellt in seiner Publikation drei nelo aus den 1960er-Jahren vor.
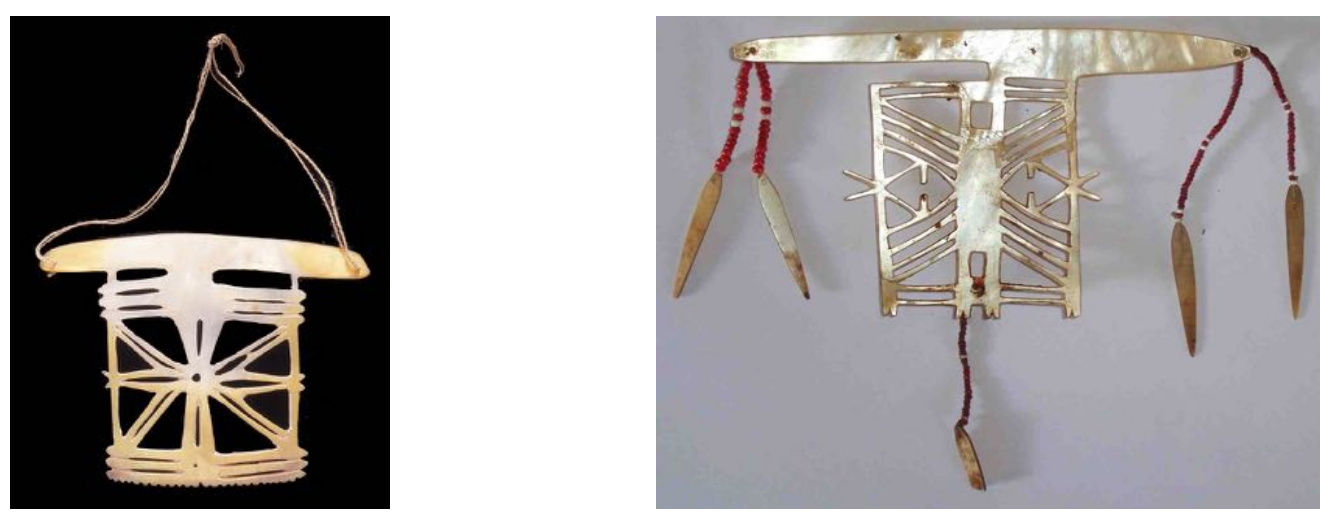

Abb. 36: Nelo, B.: 11 cm; Santa Cruz, um 1900; The British Museum Oc1944,02.1234. (C) BM

Abb. 37: Nelo, B.: $12 \mathrm{~cm}$; Sekapulu, vermutlich Anfang 20. Jh. Sie gilt als erste Kopie des nelo von Opla. Zur Geschichte, wie die Menschen in den Besitz eines nelo kamen, vgl. S. 67-68 und Abb. 6. 


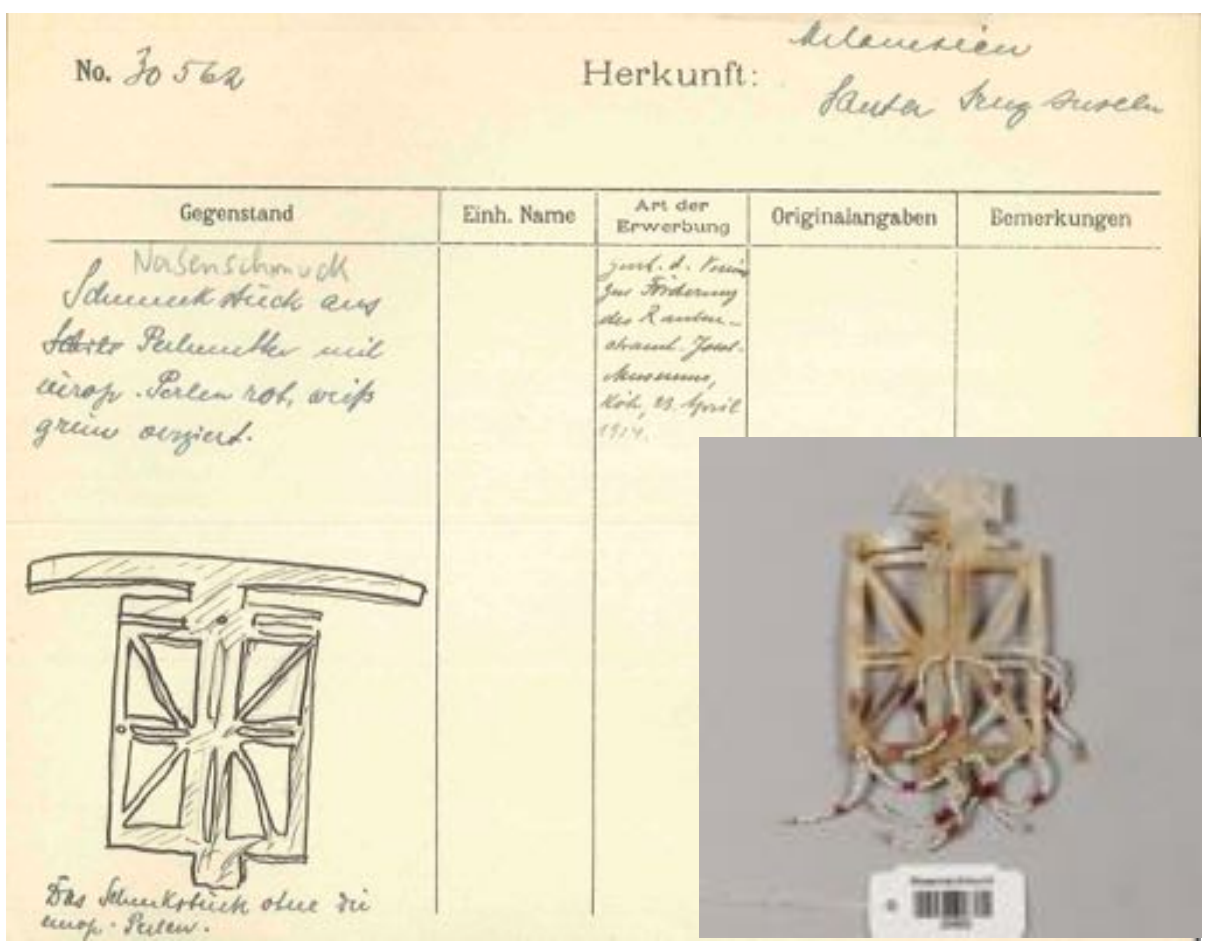

Abb. 38: Inventarkarte: Nasenschmuck, Santa Cruz, 1914; Rautenstrauch-Joest-Museum 30562. Mit Fotografie des Schmucks aus dem Jahr 2016. Die beiden oberen Stegteile sind abgebrochen und nicht mehr vorhanden. Aus der Illustration wird jedoch ersichtlich, dass es keine Verbindung des oberen Stegs mit dem unteren rechteckigen Teil gab. C RJM

Alle mir vorliegenden nelo sind aus Perlmutt gefertigt. Bei dem Nasenschmuck Oc1944,02.1234 aus der Sammlung des British Museum fallen Eigenheiten auf, die sich bei keinem anderen Nasenschmuck aus Ndendö wiederfinden. Zum einen sind keine zusätzlichen Materialien angebracht, etwa Schnüre aus Pflanzenfasern mit Schneckenschalenscheiben, Glasperlen oder Anhängern aus Schildpatt, wie in den Abbildungen 36-38 und bei KOCH (1971: 118) zu sehen. Zum anderen sind die beiden Enden des oberen Querstegs mit dem quadratischen Hauptteil verbunden, wie es ebenfalls bei keinem anderen nelo der Fall ist. In der Beschreibung zu Oc1944,02.1234 führt das British Museum auf, dass dieser Nasenschmuck vor Mund und Nase getragen und mittels einer Schnur hinter den Ohren befestigt wurde. Beasley hat das Artefakt im Jahr 1924 von Rev. Herbert J. Nind der Melanesian Mission erworben und diese Informationen zu dem Schmuck aufgeführt. Nind war im Jahr 1902 im Santa-Cruz-Archipel stationiert, wo genau, ist leider nicht ersichtlich. ${ }^{123}$ Diese Trageweise ist in keiner anderen Quelle aufgeführt. COOTE (1882: 159) beschreibt das Tragen in der Nase. Aufgrund Cootes und O'Ferralls oben aufgeführter Aussagen, Speisers Fotografie (vgl. Abb. 35) und rezenten nelo auf Ndendö spricht mehr dafür, dass das nelo in der

${ }^{123} \mathrm{Vgl.} \mathrm{http://anglicanhistory.org/oceania/cwilson/report1902.html,} \mathrm{letzter} \mathrm{Zugriff} \mathrm{am} \mathrm{23.4.2016.}$ 
britischen Sammlung untypisch für die Insel ist. Leider habe ich keine weiteren Informationen erlangen können, die zu einer sicheren Aussage führen könnten.

- Herstellung

In den Jahren 2010/11 war Philipp Malu aus Manou der einzige aktive Produzent der nelo. Gemäß seiner Aussage beherrschten zwar noch weitere Männer grundsätzlich die Fähigkeit, die aufwendigen Ajour-Arbeiten zu fertigen, diese traten aber nicht in Erscheinung. Malu erklärte, dass in der Vergangenheit die Schalen der gold- oder silberlippigen (Pinctada maxima) bzw. schwarzlippigen (Pinctada margaritifera) Perlauster an der Außenseite so lange geschliffen wurden, bis ausschließlich glänzendes Perlmutt übrigblieb. ${ }^{124}$ Anschließend wurden Löcher durch das Perlmutt getrieben - womit konnte ich leider nicht in Erfahrung bringen -, Schnüre aus Kokosnussfasern durchgezogen und diese so lange hin- und hergezogen, bis die gewünschten Formen herausgesägt waren.

- Heutige Verarbeitung

Malu hatte erstmals im Jahr 1994 erfolgreich ein tema hergestellt, was ihn nach eigener Aussage so motivierte, sich nachfolgend an die nelo-Herstellung zu wagen. ${ }^{125}$ Nachdem er anfangs durch langes Reiben der Schalen auf einem ,schwarzen Stein' das Perlmutt gewann, setzte er mittlerweile aus Australien importierte Schleifaufsätze ein, für deren Antrieb er den Generator von John Namiade auslieh (vgl. S. 113). Für das Durchstechen und Ausfeilen der Muster nutzte er ein Set verschieden starker Metallfeilen. Ein erstes Set hatte er dazu Mitte der 1990er-Jahre in Honiara bestellt. Philipp Malu war bei allen Tänzern bekannt, und wenn ein neuer Nasenschmuck benötigt wurde, war er den Aussagen der Tänzer zufolge derjenige, der mit der Herstellung beauftragt wurde. Die Größe und zum Teil auch die Art der Muster, die Malu herausarbeiten konnte, ergaben sich nach seiner Darstellung aus der natürlichen Form der jeweiligen Auster. Nach eigenen Angaben fertigte er nelo nach vier historischen Vorlagen sowie nach einem von ihm entworfenem neuen Design. Die Glasperlen, die Malu nutze, stammten von Mick Pendergrast, der ihm Ende der 1990er-Jahre eine größere Menge Perlen mitgebracht hatte. An jedem Ende der Schnüre befestigte Malu kleine flache, längliche Anhänger aus Schildpatt oder Perlmutt, die er mit Eisensägen und -feilen selber herstellte.

Ende der 2000er-Jahre wurde Malu beauftragt, ein nelo herzustellen, das nicht mehr durch das Septum gezogen werden musste (vgl. Abb. 39 und Abb. 40, S. 196 und Kap. 6.2). Malu entwickelte eine Tragetechnik, die ein Einhängen des nelo oberhalb der Oberlippenrinne an der Nasenscheidewand ermöglicht. Dazu sägte er eine kleine Einkerbung in die Mitte des oberen Querstegs und befestigte einen nach oben geöffneten Schildpattring dahinter. Der Ring verfügte am unteren Teil über einen horizontalen Querausleger, mit dem

\footnotetext{
${ }^{124}$ Schwarzlippaustern kommen It. Davenport nicht an den Küsten Ndendös vor und mussten eingehandelt werden, warum sie als besonders kostbar galten (2005: 25). Malu tauchte nach eigener Aussage selber nach den Austern, direkt in der Graciosa Bucht vor dem Strand seines Hauses.

125 Zur Biografie Philipp Malus und seinen Arbeiten vgl. Kap. 6.2.
} 
Malu den Ring durch Aussparungen im nelo einklemmte und zusätzlich mit einem Faden fixierte, wie die nachfolgenden Abbildungen verdeutlichen.
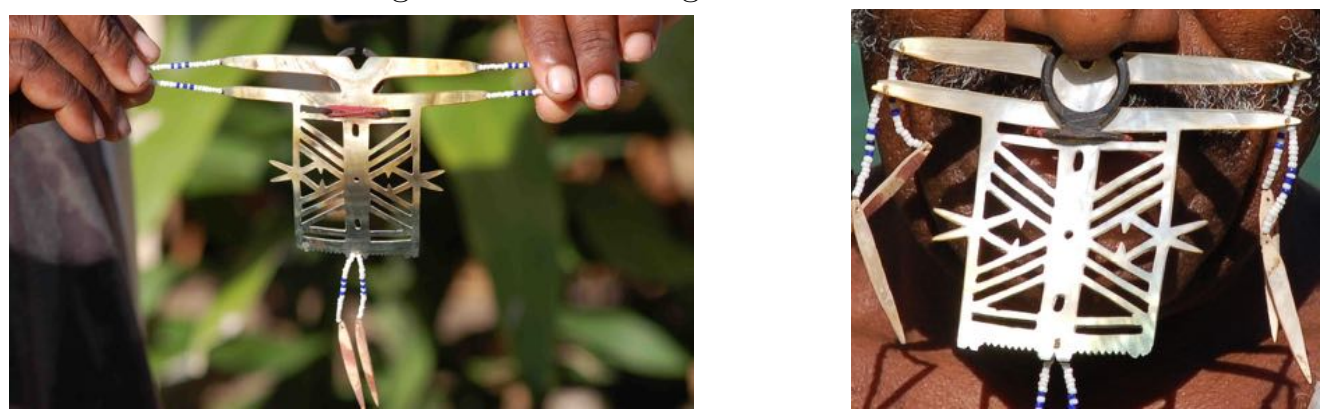

Abb. 39 und 40: Nelo als Nasenring, B.: 24 cm; Philipp Malu, 2011; 1. Vorderseite, r. Rückseite.

Dieser neue nelo-Typ weist neben den herkömmlich eingesetzten Materialien Perlmutt, auf Nylonschnur aufgezogenen Glasperlen und Schildpattanhänger Schildpatt und roten Faden als weitere Materialien auf. (Philipp Malu, 25.5.2010 und 10.11.2011)

- Materialgeschichte

Für die Materialgeschichte des Nasenschmucks nelo lässt sich beim Vergleich historischer und rezenter Arbeiten kaum ein Wandel ausmachen. Das Basismaterial Perlmutt wird kontinuierlich verarbeitet. Die ursprünglich aus natürlichen Fasern hergestellten Schnüre für die Perlen sind durch Nylon ersetzt. Ob früheste Applikationen nur aus natürlichen Materialien wie etwa Conus-Schneckenhausscheibchen oder auch immer aus schon europäischen bzw. neuseeländischen Glasperlen bestanden, kann ich aufgrund fehlender Quellen nicht abschließend ermitteln. Schildpattanhänger sind in den Abbildungen 37 und 39 durchgängig wiederzufinden. Völlig neu ist die modifizierte Grundform mit der V-förmigen Einkerbung und dem zusätzlich angebrachten Schildpattring.

Modifiziert hat sich ebenfalls die Herstellungstechnik. Wie bei der tema-Produktion greift der nelo-Produzent seit der Verfügbarkeit einer elektrisch unterstützten Schleifmaschine auf diese zurück. Die Ajour-Arbeiten führt Malu manuell mittels Eisenfeilen aus.

\subsubsection{Tanzschurz der Männer lepanesa}

Über Kleidung und Matten wird in der frühen Literatur zwar berichtet, doch sind die Aussagen eher allgemein gehalten. Sie werden oftmals als ,apron', ,waist-cloth' oder auch ,mats bezeichnet. Ob es sich dabei im Einzelnen um gewobene Textilien oder um Rindenbaststoffe, Tapa, handelt, bleibt meist offen oder wird sogar falsch aufgeführt. Hingegen stimmen die Berichte dahingehend überein, dass die Fabrikate von außergewöhnlich hoher Kunstfertigkeit zeugten. Nach DALRYMPLES Übersetzung (1770: 78) beschrieb de Quiros im Jahr 1595 die Kleidung der Bewohner von Santa Cruz allgemein als ,a kind of soft cloth“. Peter Dillon (1788-1847), Sandelholzhändler, selbsternannter Forscher und Entdecker der Wracks der La Pérouse-Expedition, erwarb einige Stücke Stoff, die seiner Vermutung nach auf einem Webstuhl hergestellt worden waren (DILLON 1829: 300). MARKHAM (1873: 164f.) 
erwähnt hinsichtlich der Machart unspezifisch „,a small apron“, der von Männern getragen wird. COоTE (1882: 158f.) berichtet über ,turmeric-coated mats [...], and some of them were perfect in taste and workmanship“. Ob tatsächlich gewobene Matten mit Kurkuma eingerieben wurden, oder es sich in Wirklichkeit um Tapa handelte, bleibt offen.

- Stofflichkeiten und Herstellung

In den frühen Berichten über die lepanesa sind die Materialität der Schurze und ihrer Herstellung im wahrsten Sinne des Wortes eng miteinander verwoben. Von Beginn an stand die Herkunft des Webstuhls im Vordergrund der Diskussionen, so dass eine Trennung zwischen Stofflichkeit und Herstellung für die historischen lepanesa nicht zielführend scheint. CoDRINGTON (1891: 20, 316) resümiert über den Webstuhl und dessen Ähnlichkeit zu Webstühlen von anderen Inseln in Mikronesien und Südostasien sowie konkret über Bananenbast als genutztem Werkstoff: „[T] he remarkable thing is that in Santa Cruz alone is found a loom with which beautiful mats are woven with the fibre of banana cultivated for the purpose; these looms are identical with those in use in the Caroline and Philippine Islands and in Borneo. “DEwAR (1892: 246) schreibt: „Their dress consisted of a waist-cloth hanging down in front.“ Später gibt er zusätzlich „tappa“ als eigenständige Position in einer Auflistung lokaler Handelsgüter an (ebd.). Bei ihm findet sich auch die erste Abbildung eines Webstuhls mit einer sich noch in der Fertigung befindlichen Matte (1892: 247). Joest (BAESSLER 1900: 376) berichtet von einem „,aus Bananenfaser hergestellten Schurz“ für Männer. In Bezug auf die Herstellungstechnik attestiert Georg Christian ThILENIUS (1902: 134) den Webarbeiten eine Ähnlichkeit mit denen der nordwestlich gelegenen Inseln von Sikaiana bis Nukuor und verweist auf ihre Funktion als „,wertvoller Tauschartikel“ gegen Tapa im Handel mit Bewohnern aus dem Inselinneren. ${ }^{126}$ O'FERRALL (1908) zeigt einen Weber bei der Arbeit und widmet sich sehr detailliert der Herkunft des Geräts und der Materialien, dem Arbeitsprozess und verschiedenen Größen der „Matten“ für Frauen und Männer:

„The Cruzians are deservedly famous for the beautiful mats and bags which they make. The fibre used in these is obtained from the succulent stem of the Banana plant; a stem is laid upon a slab of wood and beaten to a pulp with a heavy piece of wood; the vegetable matter is then scraped away and the fibre hung up to dry in the sun, it is then combed out and is ready for use. But a Cruzian does not plait his mats (like other Melanesians), he has a wonderful loom--how it comes to pass that the loom is found only at Santa Cruz in the whole of Melanesia no one can say, the nearest locality where a loom is used seems to be the Caroline Islands which are

\footnotetext{
126 Thilenius ist die einzige Quelle, die einen derartigen Tausch mit den Webarbeiten beschreibt. Rodolphe Festetics DE TOLNA (1903: 267-268) berichtet von Tauschvorgängen zwischen der Küsten- und Inlandsbevölkerung Ndendös, allerdings beziehen sich diese auf tema. SPEISER (1924: 339) zufolge wurde Tapa nicht in der Graciosa Bay hergestellt, sondern aus dem Inselinneren bezogen. Bezüglich der Tapa kann ich bestätigen, dass sie zu der Zeit meines Feldaufenthaltes aus dem Süden der Insel ,über das Landesinnere' an die Graciosa Bay gelangte.
} 
about 1,000 miles distant. The native tradition is that it was invented by a woman, but insomuch that it kept her from the less interesting and more arduous labour in the gardens, the invention was appropriated by her lord and master. Canoes, driven away by contrary weather, or impelled by the pure spirit of adventure, have travelled extraordinary distances in the Pacific, and it is possible that in this manner the loom first found its way to Santa Cruz. Its existence was remarked upon by the Spaniards in 1595, so that the puzzle is little likely to be solved now.

The fibre of a black-stemmed banana is used for working patterns in the mats and bags. Such a mat as that in the illustration would be worn by the wife or daughter of a man of high rank; a narrower mat is the men's sole dress, and is worn like an apron ,fore and aft $^{6}$, being held in position by a belt which may be made simply of a piece of bark, or plaited string or split cane, sometimes a purely ornamental belt of shell is also worn, or one of banana fibre elaborately worked." (O'FERRALL 1908: o. A., Hervorhebung im Orig.)

GRAEBNER (1909: 83) zeigt u. a. einige Frauen- und Männerschurze und bezieht sich in der Darstellung der Weberei mit Bananenbast in Santa Cruz auf die zuvor zitierten Aussagen sowie auf die Abbildung von EdGe-PARTington \& HeAPE aus dem Jahr 1890 (vgl. Abb. 16). Er beschreibt ausführlich den Aufbau der Webstühle, die unterschiedlichen Produkte, den Prozess des Webens und des Einbringens der verschiedenen Dekorationen (1909: 123-130). So wurden die schwarzen Muster „,mit Hilfe einer hölzernen Nadel [...] einzeln über dem entsprechenden Schussfaden durch das Gewebe gezogen [...]“, Faserbüschel abhängig vom Enderzeugnis eingezogen oder eingeknüpft und „Pandanusblattstreifen mit den zersplissenen Enden gleich fest eingewebt“" (1909: 124). Allerdings geht Graebner im Falle der schwarzen Fäden noch von einseitig gefärbten aus (ebd.). COOMBE (1911: 174-176) widmet sich ebenfalls ausführlich der Darstellung des Webstuhls. Sie führt explizit schwarzstämmige Bananen als Ursprung der Fäden auf (1911: 175) und lobt die Fabrikate als exquisites Handwerk mit einem Zitat des späteren Bischofs von Melanesien, Rev. Cecil Wilson: „, The garment was] spotlessly clean and squarly put on. No one can compare with him in Melanesia.“ (1911: 176) Sie verweist ebenfalls darauf, dass bereits Mendaña diese vorgefunden hatte und sie demzufolge kein Import der Spanier waren (1911: 175). Da sie für die melanesische Mission arbeitete, liegt es nahe, dass sie O'Ferralls Schrift kannte. Auch RAnNIE (1912: 174) ist von der Qualität der Schurze beeindruckt, deren Muster den Glanz von schwarzer Seide hätten: „They were the most beautiful articles of that manufacture I have ever seen among the South Sea Islanders. [...] All the designs showed great taste and ingenuity."

Neben den beiden Abbildungen von Edge-Partington \& HeAPe (1890, vgl. Abb. 16) und BeATTIE (1906, vgl. Abb. 2), die das Tragen der gewebten Schurze durch Männer dokumentieren, erscheinen nur zwei weitere Fotografien und eine Illustration, die die Herstellung dokumentieren. Sie zeigen Männern beim Weben (Beattie in O'FERRALL 1908: Abb. „Mat Making“ und SPEISER 1924 [1913]: Taf. 65 „Kuli am Webstuhl, Santa-Cruz-Inseln“, 
sowie van den Broek d'Obrenan [1935] in Christian COIFFIER 2014: Planche 34 „,croquis no. 31: Santa Cruz - Graciosa Bay, homme tissant une natte“, vgl. Abb. 41). Abbildung von mit gewobenen ,Stoffen“ bekleideten Frauen liegen mir nicht vor, obwohl O'Ferrall, wie oben aufgeführt, berichtet, dass ,Matten` sowohl von Töchtern und Frauen von Männern mit höherer Position als auch von Männern als Kleidung genutzt wurden.

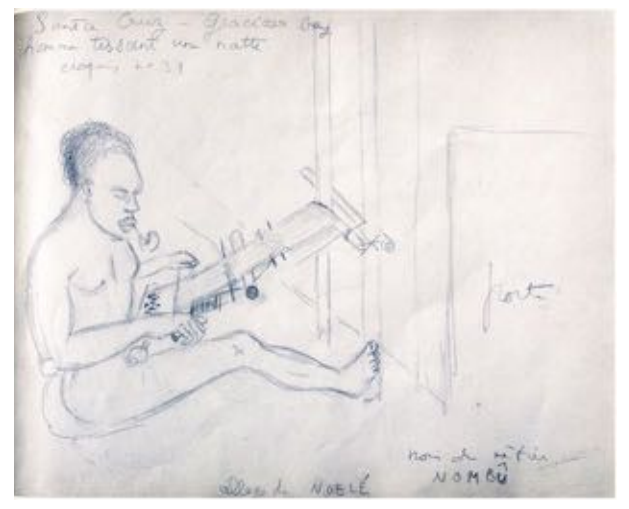
Abb. 41: Santa Cruz - Graciosa bay. $[\mathrm{H}]$ omme tissant une natte, village de Noelé [Ne'ele, O. L.]
(Van den Broek d'Obrenan 1935: croquis no. 31 in
COFFIER 2014: Planche 35).

Erst KocH (1971: Taf. 17 und Taf. 18) zeigt eine Weberin sowie ein gewebtes Hüfttuch für Frauen. Er beschreibt ausführlich das Weben, wie er es während seines Aufenthaltes erlebte (191: 98-101). Nach seiner Darstellung war das Weben eine Arbeit von Spezialisten, die ihre Fähigkeiten und ihr Wissen innerhalb der Familie weitergaben. ${ }^{127}$ Neben den In-situ-Darstellungen dokumentieren andere Abbildungen ausschließlich Artefakte in den Museumssammlungen, so etwa GRAEBNER (1909: 83, 125), SPEISER (1916: 159 Abb. 2, 161 Abb. 4) und $\operatorname{KOCH}$ (1971: Taf. 13, 14 und 18).

Der älteste in den Sammlungen der vier Museen erhaltene Männerschurz stammt vom Ende des 19. Jh. und befindet sich im British Museum (vgl. Abb. 42). Mit Ausnahme der angebrachten Pandanusblattstreifen und der Anzahl der Motivreihen ähnelt er der Darstellung bei Edge-PaRtington \& HeAPE (vgl. Abb. 43). Die mit schwarzem Bananenbast gestalteten geometrischen Muster lassen sich bis ins Detail wiedererkennen. Alle von mir gesichteten historischen und rezenten lepanesa aus Santa Cruz weisen dieselbe Anordnung der

\footnotetext{
${ }^{127}$ Dies bestätigte der Weber Selwyn Balu aus Ne'ele. Zu Selwyn Balu vgl. Kap. 5.2.3 und 6.3. Ob zur Zeit meiner Forschungsaufenthalte noch weitere Personen auf den Reef Islands mit Bananenbast arbeiteten, konnte ich nicht abschließend klären. Generalvikar Patteson Parus von den Reef Islands sprach von einem gut 80-jährigen Mann auf seiner Heimatinsel, der noch webte (26.7.20 I I). Leider hatte ich keine Möglichkeit, diesem Hinweis nachzugehen. KOCH (197I: 99) berichtet bereits zur Zeit seines Aufenthaltes über die vermeintlich letzte Weberin auf den Reef Islands. Über Weber/Weberinnen von anderen Inseln im Santa-Cruz-Archipel liegen mir weder historische noch rezente Informationen vor. In einem persönlichen Gespräch berichtete Liz Bonshek (vgl. S. 25 I), dass Selwyn Balu der letzte lebende Weber in Santa Cruz sei (5.3.20 I0). Nach Balus Aussage hatte er seine Webkenntnisse an zwei seiner Söhne weitergegeben und diese hatten ihr Wissen wiederum mit zwei von Balus Brüdern geteilt. Alle vier stellten gewebte Taschen aber keine Tanzschurze her.
} 
Dekorationen aus Pandanusblattstreifen, Faserbüscheln und schwarzem Bananenbast auf: an einem Ende drei und an dem anderen Ende vier Reihen. ${ }^{28}$

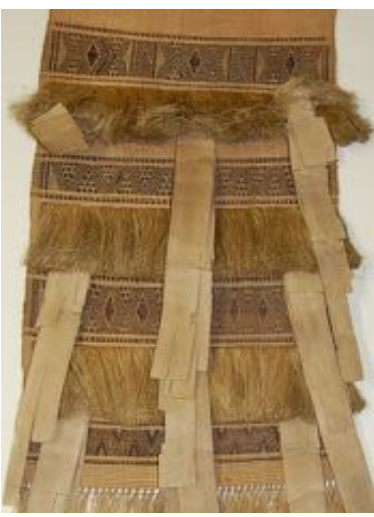

Abb. 42: Lepanesa, Santa Cruz, spätes 19. Jh.; The British Museum Oc,+4970. Erworben von A. Lister-Kaye. „Grass cloth band, with bands of pattern in black at the two ends, fringes and leaf tabs. Mat, man's dress. “ (C) BM

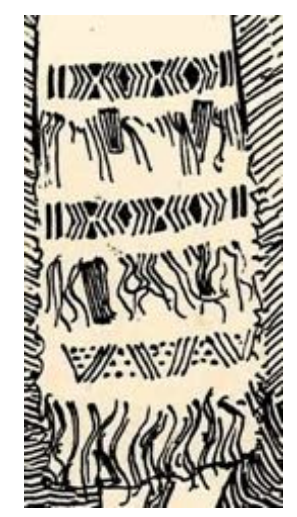

Abb. 43: Lepanesa. Vergrößerung aus: A Santa Cruz Islander in war dress from a description fumished by Lister-Kaye (EDGE-PARTINGTON \& HEAPE 1890: 154). Vgl. Abb. 16, S. 82.

- Heutige Verarbeitung

Im Gegensatz zu den historischen Berichten über die homogene Materialität der Schurze erschien auf dem Fest in Ne'ele im August 2011 eine ganze Bandbreite an Materialien, die dem Weber Selwyn Balu zufolge zu diesem Zeitpunkt in Gebrauch waren. ${ }^{129}$ Neben den bereits dargestellten traditionellen natürlichen Materialien sah ich eine Vielzahl anderer Kombinationen (vgl. Abb. 44 a und Abb. 44 b).

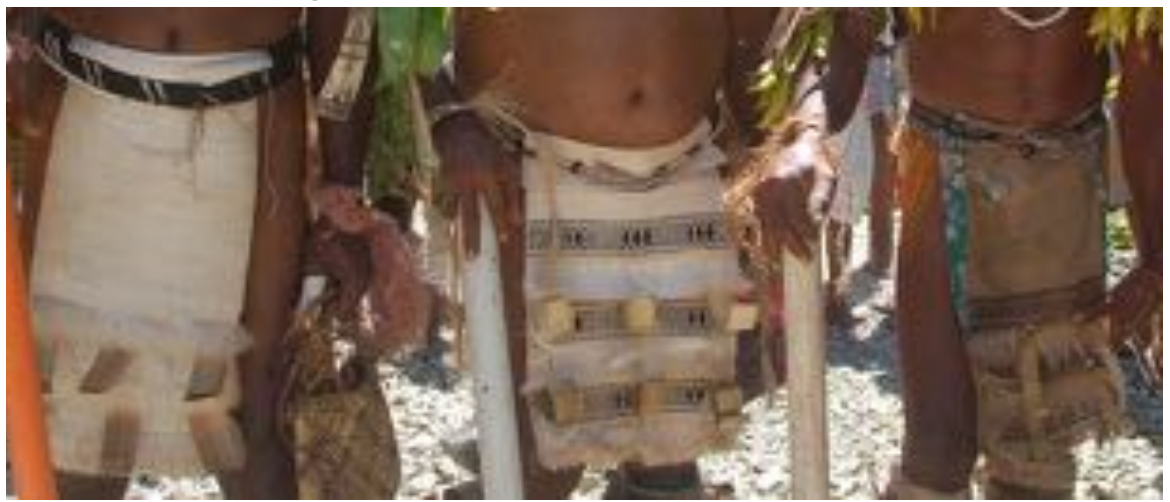

Abb. 44 a: Verschiedene lepanesa; Ne'ele, 2011. V. 1. n. r.: aus Baumwolle mit verblichener Dekoration aus schwarzem Bananenbast, Schurz aus neuem und aus altem Bananenbast mit Ausbesserungen aus buntem Baumwollstoff.

128 Die Tänzer trugen zu allen Tänzen, die ich in den Jahren 2009-2014 beobachtete, das Ende mit den drei Reihen als Vorder- und das mit den vier als Rückseite des Tanzschurzes. Es könnte also sein, dass es sich bei Abbildung in Edge-Partington \& Heape um das Vorderteil des Tanzschurzes Oc,+4970 des Brutsh Museum handelt.

${ }^{129}$ Eine ausführliche Beschreibung des Festes in Ne'ele findet sich in Kap. 5. 


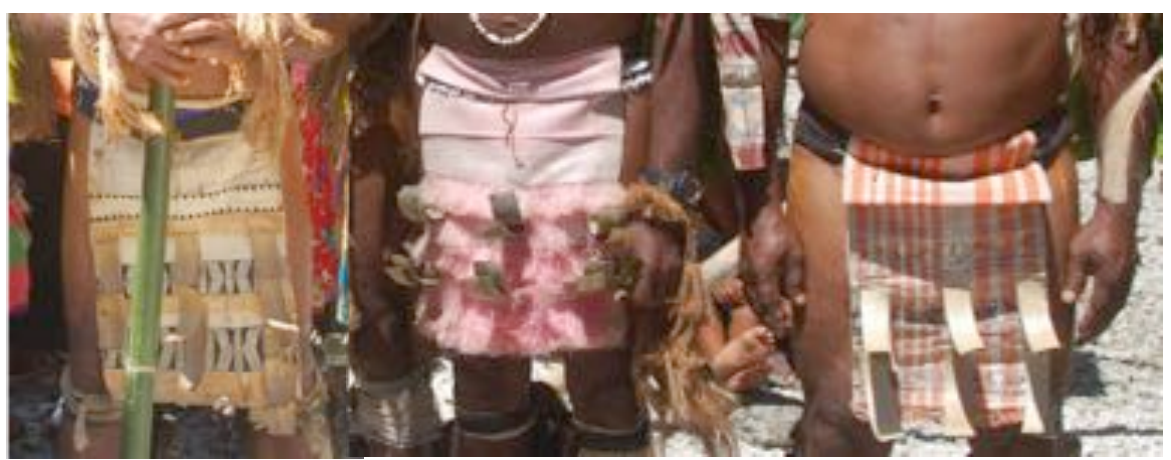

Abb. 44 b: Verschiedene lepanesa; Ne'ele, 2011. V. 1. n. r.: aus bemalter Tapa, rosé-farbenen Kunstfasern (gewonnen aus einem alten Verpackungssack) und aus Kunstfasern in gebrochenem Weiß und Orange (gewonnen aus einer gebrauchten Fußmatte). Bei den beiden letzteren sind die Muster aus schwarzem Bananenbast verblichen.

Gemäß Selwyn Balu stammten diese - mit Ausnahme des lepanesa in der Mitte der Abbildung 44 a und dem links gezeigten der Abbildung 44 b - aus den 1980er- bis 90er-Jahren, als nach der Unabhängigkeit des Landes vermehrt ,neue' Materialien über die Landeshauptstadt Honiara nach Santa Cruz gelangten. Die meisten dieser lepanesa hatte Balu zufolge sein Vater Jonas Kepule hergestellt, der auf Wunsch seiner Auftraggeber importierte Werkstoffe nutzte, wenn ihm diese zum Weben überlassen wurden. ${ }^{130}$ Dabei handelte es sich um Baumwollgarn und Kunstfasern, die Kepule durch das Auftrennen von Verpackungssäcken oder Matten gewonnen hatte. Die Tänzer favorisierten nach Selwyn Balus Erinnerungen die ,neuen` Materialien, da die Baumwolle weich war, weniger an den Oberschenkelinnenseiten scheuerte und die Kunstfasern wasser- und ungezieferresistent waren sowie über einen dauerhaft schönen Glanz verfügten. Nur die Fasern der eingezogenen Muster bestanden durchgehend aus schwarzem Bananenbast.

Selwyn Balu hatte das Weben von seinem Vater erlernt und war seit dessen Tod im Jahr 2006 nach vielen Aussagen der einzige Weber von lepanesa auf Ndendö, vermutlich sogar im gesamten Santa-Cruz-Archipel. ${ }^{131}$ Dazu nutzte er ein Trennstab-Webgerät, um aus hellem Bananenbast (Natügu: birpi = Banane) eine Art Leinenbindung herzustellen. Die Faserbüschel und Pandanusblattstreifen knüpfte er während des Prozesses ein. Als zusätzliche Dekoration zog er später mit einer flachen hölzernen Nadel dünne Streifen der schwarzstämmigen Banane (Natügu: birpi pa = schwarze Banane) in das fertige Gewebe ein. Seine vom Vater erlernte Art zu Weben deckt sich weitgehend mit der weiter oben aufgeführten historischen Beschreibung. Für die Herstellung des hellen Bananenbasts bevorzugte er möglichst lange Staudenstämme der Bananen, da ihre Länge die maximale Länge der Baststreifen vorgab. Je länger diese waren, desto weniger musste er die bei der Verlängerung der Baststreifen

130 Zur Rolle von Jonas Kepule bei der Überlieferung des Webens siehe Kap. 5.2.3.

131 Zur Einschätzung dieser Aussage vgl. Anm. 127 Zu Selwyn Balu vgl. insbesondere Kap. 6.3. 
entstehenden Knoten beim Weben berücksichtigen, damit man diese später im fertigen Tanzschurz nicht sah (Selwyn Balu, 17.10. und 3.11.2011).

Gemäß eigener Aussage hatte Balu einige dieser alten, mit ,neuen` Materialien gewebten Tanzschurze schon zu Ausbesserungsarbeiten erhalten. In den meisten Fällen waren es abgerissene Verzierungen oder Einziehmuster, die er erneuerte. So wie er es mir darstellte, unterstützte er von Beginn an die Rückbesinnung auf, traditionelle' Artefakte und Werkstoffe und setzte sich intensiv für die Verwendung der natürlichen Materialien bei den Tanzschurzen ein. ${ }^{132}$ Er hatte in den 1990er-Jahren Mick Pendegrast kennengelernt, der ihn bis zu seinem Tod im Jahr 2010 mehrere Male besuchte, ihn mit Informationen zu Sammlungsbeständen aus neuseeländischen und britischen Museen versorgte und ihn immerzu motivierte, das Weben in den Mittelpunkt seiner Tätigkeit zu stellen. Selwyn Balu nannte die Tanzschurze lepanesa oder lempanesa (Selwyn Balu, 17.10.2011). ${ }^{133}$

- Materialgeschichte

Die für die Herstellung der lepanesa genutzten Materialien waren im zeitlichen Verlauf seit den ersten Berichten unterschiedlich. Das Basismaterial Bananenbast wurde kontinuierlich auf traditionellen Trennstab-Webgeräten verwendet. Für die Dekorationen wurden immer schwarzer Bananenbast, Pandanusblatt und Faserbüschel eingesetzt. Im Laufe der 1980erund 90er-Jahre kamen für das Gewebe weitere Materialien wie etwa Baumwolle und Kunstfasern hinzu. Obwohl die neuen Materialien einfacher in der Aufbewahrung waren und über einen höheren Tragekomfort verfügten, haben sie den traditionell verwendeten Bananenbast nicht verdrängt. Im Jahr 2011 gab es vermutlich nur noch eine Weberfamilie, wobei nur ein einzelner Mann Tanzschurze herstellte. Dieser Weber hatte sich der in den späten 1990erJahren beginnenden Revitalisierungsbewegung angeschlossen und unterstützte aktiv den Einsatz ausschließlich natürlicher traditioneller Werkstoffe. Dies führte zu einer Stagnation der Verbreitung ,neuer‘ Materialien und einer Zunahme von aus Bananenbast hergestellten lepanesa. Die neuesten Tanzschurze glichen im Jahr 2011 wieder den alten in den Museumssammlungen erhaltenen. Lediglich die Feinheit der Gewebe und die Anzahl der Dekore haben sich im Vergleich zu Schurzen aus dem frühen 20. Jh. verringert.

\subsubsection{Tapa}

Nach den zu Beginn dieses Kapitels erwähnten unspezifischen ,Stoff'-Beschreibungen bei DALRYMPLE (1770: 78) und MARKHAM (1873: 164-165) dokumentieren die Autoren der nachfolgenden Jahre Unterschiede bei der Tapa hinsichtlich ihrer Beschaffenheit und Funktionen. Sie berichten von unbemalten und bemalten Rindenstoffen, die die Frauen zumeist als Wickeltücher und die Männer als Schurze nutzten. Zudem gab es Tapa, die die Männer

\footnotetext{
132 So kam es ihm sehr gelegen, dass ich für die Sammlung des Rautenstrauch-Joest-Museum Beispiele der lepanesa aus Kunstfasern im Austausch gegen neue aus Bananenbast erwerben wollte. Zur kulturellen Revitalisierung vgl. Kap. 3.3.2.

$133 \mathrm{KOCH}$ (1971: 98) führt die Männerschurze von Ndendö als nesa oder napanesa auf.
} 
als Kopfbedeckung trugen. Diesen unterschiedlichen Verwendungen folgend, werde ich die Materialgeschichten von Tapa zuerst als Material für ein Umwickeln des Körpers und anschließend als eines für Kopfbedeckungen untersuchen. ${ }^{134}$

- Tapa zum Umhüllen des Körpers

Johannes Dietrich Eberhard Schmeltz \& Rudolph Krause führen zu Santa-Cruz-Tapa aus der Sammlung des damaligen Hamburger Museum Godeffroy auf: „Bastzeug, ähnlich dem in Samoa ,Tapa' genannten Stoff [...]. Auf die eine Seite Muster in schwarzer Farbe aufgemalt, Dreiecke, rautenförmige Figuren und Zickzackstreifen zu länglichen Vierecken vereinigt.“ (1881: 117, Hervorhebungen im Orig.) Ihrer Vermutung nach wurde Tapa aus dem Papiermaulbeerbaum (Broussonetia papyrifera) gewonnen, was durch den Vergleich zu Samoa naheliegend war. Nach COOTE (1882: 164) bedeckten Frauen ihre Gesichter mit „some native cloth“.

○ Stofflichkeiten

GRAEBNER (1909: 84-85) fasst die damaligen Erkenntnisse zusammen, denen zufolge die Frauen Röcke und Schultertücher aus Tapa trugen. Nach den ihm vorliegenden Informationen wurde Tapa von Frauen aus Bast des Brotfruchtbaums (Artocarpus spec.) und des Feigenbaums (Ficus spec.) hergestellt, naturbelassen, mit Kurkuma (Curcuma longa) gefärbt oder mit schwarzen Mustern bemalt (1909: 116-117). Materialanalysen für Tapa in Santa Cruz stehen noch aus. Die Tapa aus Ndendö sind steifer, dicker und härter als Tapa aus Zentralpolynesien und Hawai'i, wo sie aus Papiermaulbeerbaum gewonnen werden. Ebenso sind die Faserstrukturen gröber und die Farbvariationen dunkler. Von daher kommen Brotfruchtbaum und Feigenbaum augenscheinlich eher in Betracht. Interessanterweise berichten NeICH \& PENDERGRAST (1997: 125-126) von einer vierten Baumart, die sie als Hauptquelle der Tapa auf Ndendö ausmachten, den Upasbaum (Antiaris toxicaria). Er gehört wie die drei anderen zuvor genannten Arten zur Familie der Maulbeergewächse (Moraceae). In der Dokumentation der Sammlung des Museum of New Zealand Te Papa Tongarewa findet sich zu einer Tapa aus den späten 1990er-Jahren (FE011690, vgl. Abb. 46) der Hinweis, dass das Material wahrscheinlich nicht vom Papiermaulbeerbaum stamme.

\footnotetext{
134 Neben den zuvor dargestellten Nutzungsformen von Tapa in Form von diversen Kleidungsstücken findet sich später bei GRAEBNER (1909: I 15) und KOCH (1971: 102) auch die Verwendung von Tapa als Leichentuch. Bei der Beisetzung von Wilson Kabi am 29.8.20I I wurde sein Leichnam mit einem Baumwolltuch und nicht mit Tapa bedeckt. Nach Aussagen von Ena Yamöli und Steven Mdewöt wurde in der Vergangenheit Federgeld mit Tapa umwickelt und darin gelagert und war darüber hinaus als Tuch separater Bestandteil des Brautpreises (3.6.20 I0). Bei zwei Brautpreisverhandlungen und einer Hochzeitszeremonie, an denen ich teilnahm, nutzten die Akteure Baumwoll- statt Tapatücher für den Brautpreis bzw. die Kleidung (20. 8.20 I I und 27.8.20 I I). Bei einem kurzen Aufenthalt auf der Santa-Cruz-Insel Tikopia berichteten mir Bewohner von großen (temami) und kleinen (fakamaru) Tapa, die die Frauen herstellten. Erstere wurden von ihnen bei kastom-Tänzen getragen und darüber hinaus als Decken und Schutz vor Mücken verwendet. Letztere trugen die Männer bei kastom-Tänzen, und die Frauen bündelten und trugen Feuerholz mit ihnen (Ethel und Wilfried Ruakimanu, Teonga, Tikopia, 7.9.20 I I). NeICH \& PENDERGRAST (1997: 120) zufolge bezeichnet der Begriff te mami auf Tikopia den Upasbaum (Antiaris toxicaria), aus dem der Bast gewonnen wird.
} 
Im Gegensatz zu Graebners Feststellung, dass nur Frauen Schurze aus Tapa tragen und die Schurze der Männer aus Bananenbast gewebt waren (1909: 83), dokumentieren zu der Zeit aufgenommene Fotografien auch Männer in Tapa-Schurzen. Joest zeigt etwa eine Frau mit Kind, die Tapa als Hüftuch und Kopfbedeckung tragen, sowie einen Mann mit Lendenschurz (BAESSLER 1900: 380 Abb. XXXV). COOMBE (1911: 174) erwähnt Tapa nur am Rande, dokumentiert aber mit Beattie-Fotografien verschiedene Verwendungen von Tapa: als Wickeltuch und Kopfbedeckung für Frauen und als Tragetuch für Kinder (1911: 211, „The women-folk. Nukapu“") sowie als Schurze für Männer (1911: 170, „The people have a sinister reputation. Vanikoro“; S. 171, „The natives came paddling out to us. Santa Cruz“; S. 207 „The men-Folk. Nukapu“). SPEISER (1924: 332, 339) geht detailliert auf Tapa als Schurze für Männer und als Hüft- und Kopftücher für Frauen ein. Er berichtet von unbemalten und, ihm zufolge, mit einfachen geometrischen Mustern aus Sepia bemalten oder mit gelbem Ocker eingeriebenen Stoffen. ${ }^{135}$ Die Namen der Muster stammen seiner Ansicht nach von Vorlagen aus der Natur (SPEISER 1916: 194-199). Er zeigt gleich mehrfach Männer in Tapa-Schurzen (1916: 158, Abb.1 „Mann von vorn und von der Seite, mit Haarkalotte und gemustertem Rindenstoff-Schurz“; 1924 [1913]: Titelfoto „Bogenschütze von Nitendi, Santa-Cruz-Inseln“; Taf. 6 „Bogenschütze aus Nitendi“; Taf. 2 „Männerakt aus Nitendi“; Taf. 51 „Bogenschütze auf Santa Cruz“ und Taf. 60 „Blick an einer Dorffront auf Nitendi entlang $\left.{ }^{6}\right)$.

Bei den Fotografien fällt auf, dass die Tapa in der Regel unbemalt sind und lediglich ein einziger dekorierter, von SPEISER (1916: 158 Abb.1) abgebildeter Schurz den früh in die Sammlungen der vier Museen gelangten Schurzen ähnelt. Da ich in diesem Kapitel nicht auf die Darstellungsformen im Einzelnen eingehe - ihre Analyse findet sich in Kapitel 5.2.4 -, möchte ich lediglich zu Vergleichszwecken der Materialität als Ganzem eine historische Tapa aufführen weitere Abbildungen finden sich im Anhang).

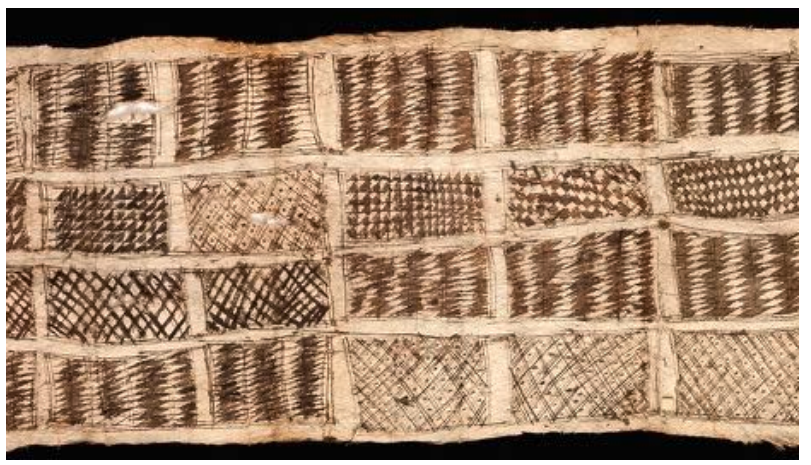

Abb. 45: Tapa, L.: 146 cm; Santa Cruz, 1897; Rautenstrauch-Joest-Museum 3984. (C) RBA, Fotograf: Wolfgang F. Meier, Bildausschnitt.

\footnotetext{
135 Ob die schwarze Farbe zu der Zeit tatsächlich aus Sepia gewonnen wurde und das gelbe Ocker mineralisch war, ist nicht mehr zu prüfen. Während meiner Aufenthalte wurde die schwarze Farbe aus Ruß und Meereswasser gemischt und die gelb-orange Farbe aus Kurkuma hergestellt.
} 


\section{○ Herstellung}

Mit der einsetzenden Missionierung im späten 19. Jh. verdrängten importierte Baumwolltücher in zunehmendem Maße Tapa als Material für Kleidung, so dass die Fertigung des Rindenstoffs an Bedeutung verlor. Die Bewohner von Ndendö gaben die Herstellung aber nicht vollständig auf, wie KoCH (1971: 102-104) Ende der 1960er-Jahre dokumentierte. Sein Film über Tapa-Herstellung (1972 e) zeigt die unterschiedlichen Arbeitsschritte der Tapa-Gewinnung auf Ndendö, weshalb man von einem fortwährenden Praxiswissen für die Herstellung unbemalter Tapa ausgehen kann. Während meines Aufenthaltes haben mir mehrfach Gesprächspartner hölzerne Tapa-Schlegel der vorigen Generation gezeigt. Ebenso erhielt ich die Information, dass Tapa vor allem von den polynesischstämmigen Frauen nach wie vor hergestellt wurde. Damit komme ich zu einem anderen Schluss als NEICH \& PENDERGRAST (1997: 125-126), denen zufolge seit den 1930er-Jahren keine Tapa mehr gefertigt worden war, bis in den 1970er-Jahren einige Schullehrer begannen, die Tapa-Herstellung im Schulunterricht als Handwerk wieder aufleben zu lassen. Die ,neuen` Tapa waren sehr viel kleiner als jene des frühen 20. Jh. und konnten demzufolge nicht mehr als Kleidung genutzt werden, wie auch in Abbildung $46 \mathrm{zu}$ sehen. Auch hinsichtlich der Gestaltung unterscheidet sich dieses wie andere Stücke aus der Zeit grundlegend von den frühen Arbeiten: Die Aufteilung in kleine Rechtecke ist durch größere Blöcke zusammengefasster, orangefarben umrandeter Rechtecke ersetzt. Lediglich einzelne Reihen mit Rauten und Dreiecken erinnern an gewobene Tanzschurze.

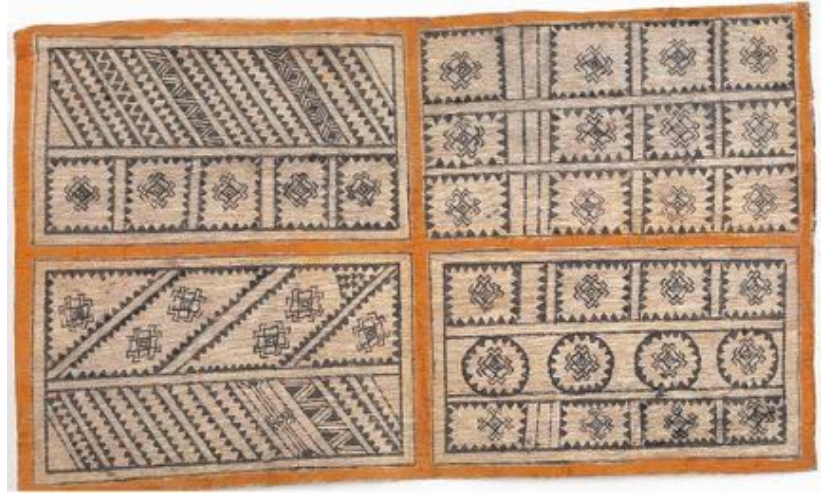

Abb. 46: Tapa; Santa Cruz, 1993; Museum of New Zealand Te Papa Tongarewa FE011690. (C) Museum of New Zealand Te Papa Tongarewa

- Heutige Verarbeitung

In den Jahren 2009-2014 nutzten Frauen und Männer Tapa in unterschiedlichen Funktionen und Gestaltungen: Bei touristischen Aufführungen trugen Frauen und Männer sie als Wickelrock bzw. als Tanzschurz. Einzelne Personen verkauften Tapa als Artefakte an Touristen (vgl. Abb. 47-52). 

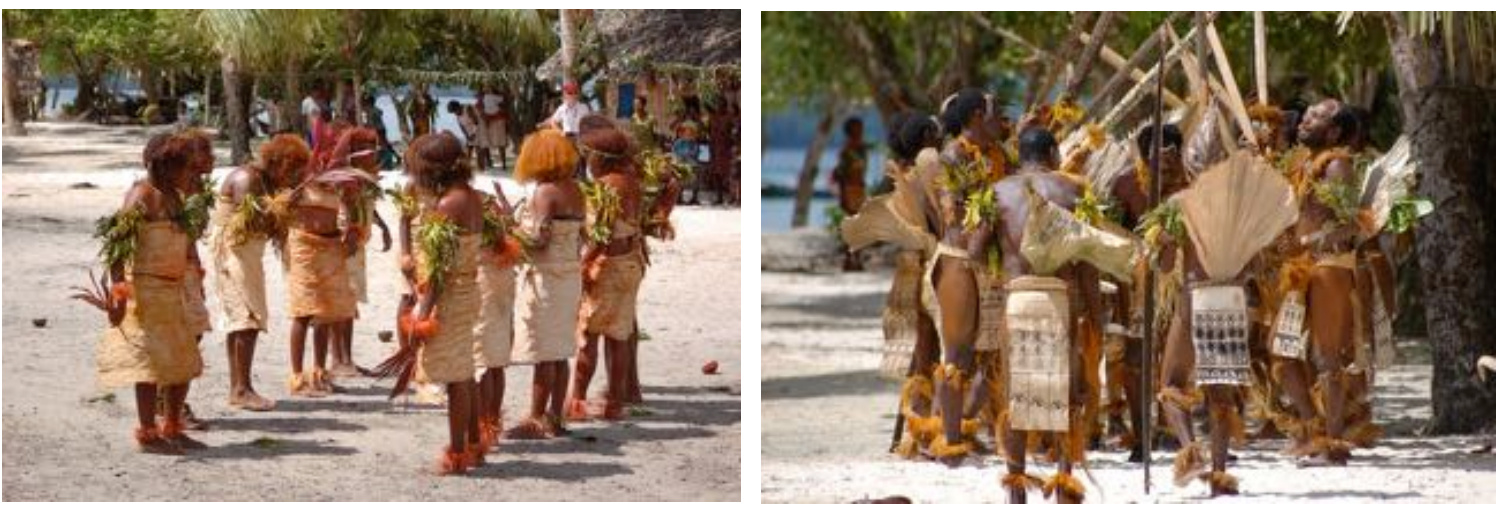

Abb. 47 und 48: Mit Tapa bekleidete Frauen und Männer tanzen für Touristen; Malo, 2009.
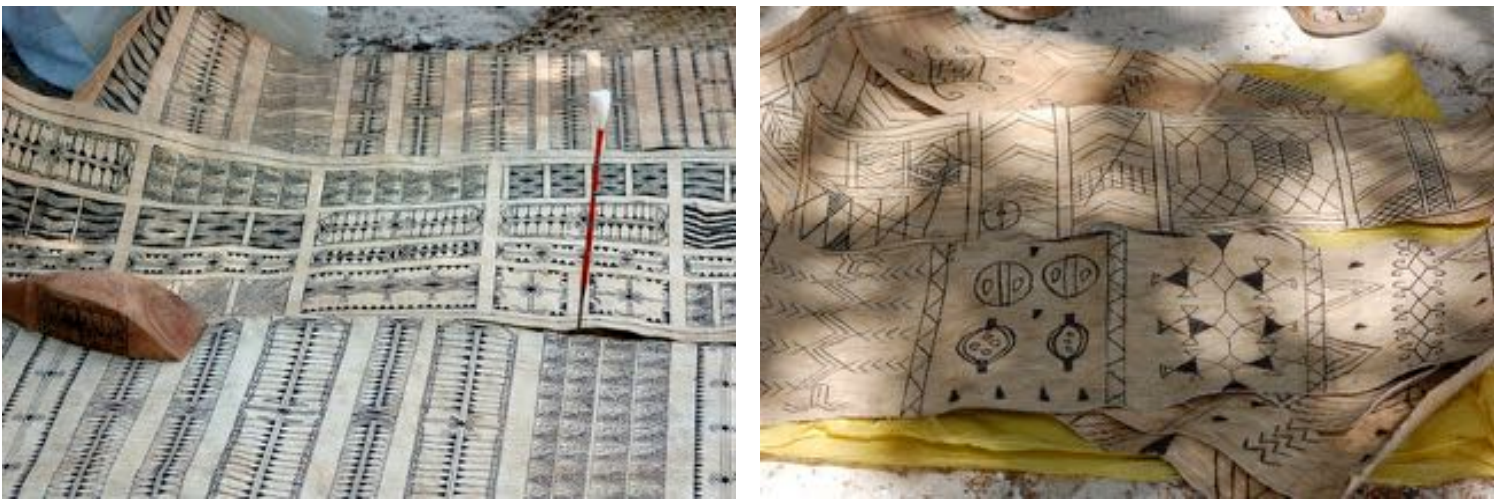

Abb. 49 und 50: Bemalte Tapa für den Verkauf an Touristen; Malo, 2009.
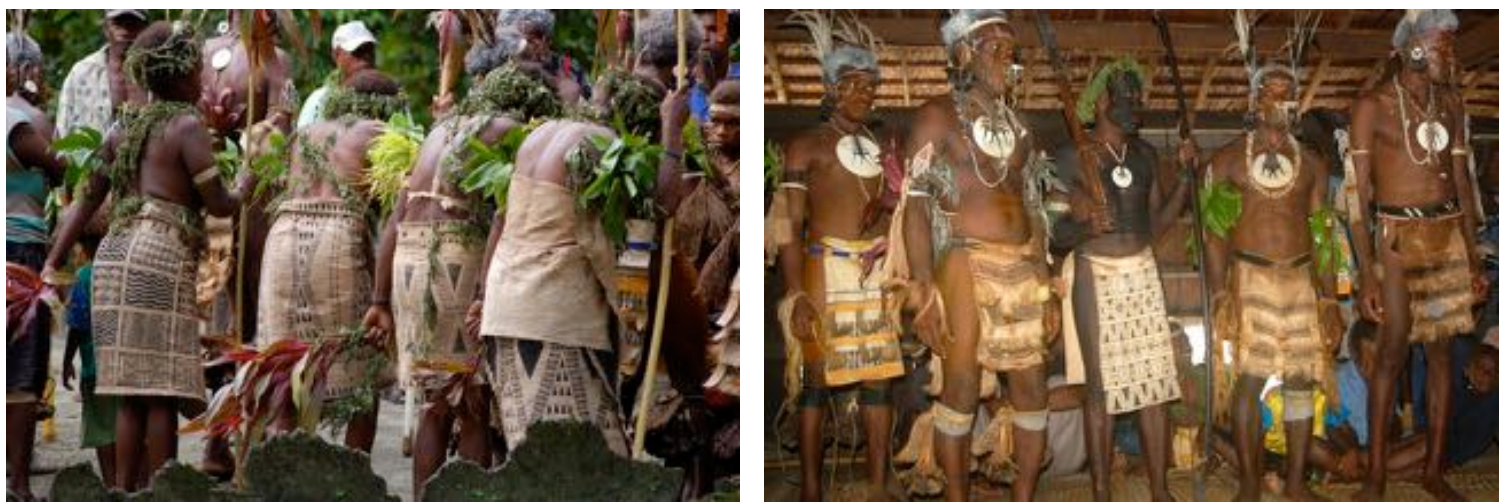

Abb. 51 und 52: Mit Tapa bekleidete Frauen und Männer tanzen für eine Politikerdelegation;

Venga, 2010.

Die hier abgebildeten Tapa geben einen guten Überblick über die in den Jahren 2009-2010 verwendeten Materialien bzw. Materialkombinationen. Die Tapa waren, wie bereits oben erwähnt, recht dick und steif, grobfaserig und gräulich bis mittelbraun. Entweder waren die Arbeiten gar nicht oder mit schwarzer Farbe bemalt. Im Falle des Tapa-lepanesa (vgl. Abb. 52 1.) wurde der Rindenbaststoff zusätzlich mit Kurkuma bestrichen und mit weiteren Materialien verziert. Dieser Schurz war der einzige aus Tapa gefertigte, den ich sah. 
Mehreren Aussagen zufolge fertigte während meiner Forschung nur eine einzige im Süden Ndendös lebende Familie in erwähnenswertem Umfang bemalte Tapa. Zu ihr gehörten u. a. die Geschwister Ena Yamöli und Matthias Me'lekaiva aus Nea sowie Yamölis Ehemann Steven Mdewöt aus No'ole. ${ }^{136}$ Für die Tapa-Herstellung verwendete das Ehepaar YamöliMdewöt Schösslinge des in Nalögo mokali oder nokali genannten Upasbaums, wobei es auch die Nutzung weiterer Maulbeergewächse, etwa des Brotfruchtbaums oder des Feigenbaums, kannte. Die Herstellungstechnik des Paares unterschied sich nur in Details von dem von Koch im Jahr 1966 dokumentierten Prozess, wobei KoGH als Rohstoffquelle einen wildwachsenden Papiermaulbeerbaum aufführt (1972a, 1971: 102-104).

In der Regel schlägt heute der Mann den Baumschössling mit einer Machte. Mit einem Messer mit Metallklinge schneiden ein Mann oder eine Frau die gesamte Rinde längs des Stamms entlang auf und lösen sie unter Zuhilfenahme eines Holzspatels vom Holzkern ab. Dann ziehen mehrere Personen gemeinsam die innere Rinde von der äußeren ab. In Kochs Film schlägt die Frau den Baum und schabt mit einem Messer die äußere Rinde ab, bevor sie die innere vom Holzstamm abzieht. Das Schlagen der Tapa ist nach wie vor Aufgabe der Frauen und erfolgt mit denselben Hilfsmitteln wie in der Vergangenheit: Auf einem Baumstamm wird die Innenrinde in feuchtem Zustand quer auf den Stamm gelegt und mit einem Holzschlegel geschlagen. Ena Yamöli hatte die Fertigung von der Schwester ihrer Mutter erlernt und schulte im Jahr 2011 ihre Nichte Irene Wendy Me'na darin. Die Beschaffenheit und Dicke des Endproduktes hängt vom Alter des Schösslings sowie der Intensität und Dauer des Schlagens ab. Nachdem die gewünschte Breite und Dicke erreicht ist, wird die Tapa im Meer gewaschen und zum Trockenen in die Sonne gehängt. Nach dem Trockenen ,bügelt ${ }^{`}$ Steven Mdewöt mit einem flachen, ebenen Brett die Tapa unter hohem Druck auf einem ebenfalls sehr flachen und ebenen Holzbrett. Nach langem Hin- und Herreiben wird die Tapa weicher und glatter. Damit ist sie für die Dekoration ausreichend vorbereitet. Die Bemalung der Tapa erfolgt dem Ehepaar zufolge damals wie heute durch die Männer. Sie verwenden dabei schwarze Farbe, die Ena Yamöli aus Ruß, den sie durch das Verbrennen von Harz des ngali nut- oder no nina-Baums (Canarium indicum) gewinnt, ausgepresstem Pflanzensaft, z. B. aus der Wurzel des monango-Baumes, und Meerwasser herstellt und verkauft. Wenn die Tapa ,wertvoller` sein soll, nutzen die Männer als gelbe Farbe Kurkuma, das sie

\footnotetext{
${ }^{136}$ Vereinzelt traf ich auf Ndendö auch andere Produzenten an: Isaac Me'satu aus Nemboi, dem Nachbarort von Nea, bot mir von ihm bemalte Tapa zum Verkauf an. Deren Gestaltung wich völlig von den von Mdewöt und den Tänzem aus Malo bemalten ab; sie glich denen in Abb. 50. Der rund 80-jährige Me'satu stellte neben Tapa auch Federgeldstäbe (noiapu) her. Er hatte von seiner Mutter l'pengu, die ebenfalls in Nemboi lebte, das TapaSchlagen erlernt. Seine beiden Schwestem sowie sein verstorbener Bruder beherrschten dies nicht. Er hatte das Tapa-Schlagen einem seiner Söhne beigebracht, der aber nun in Honiara lebte und keine Tapa mehr herstellte (Isaac Me'satu, 9.I I.20 I I). In Lata sah ich eine unbemalte Tapa, die zum Trocknen aufgehängt war. Laut Aussagen meiner Informanten fertigen aus Tikopia stammende und auf Ndendö lebende Frauen zuweilen unbemalte Tapa. Die napa-Tänzer aus Malo erwarben bei Bedarf unbemalte Tapa von Frauen aus den polynesischen Enklaven der Ndendö vorgelagerten Insel Temotu Neo und bemalten diese selber (Shadrack Sade, |4.I I.20 I I, vgl. Anhang Tapa Inv. 64824 des Rautenstrauch-Joest-Museum).
} 
von der aus den Reef Islands stammenden und in Neo-Nemba lebenden Frau I'nuni kaufen. ${ }^{137}$ Steven Mdewöt trägt die Muster mit selbst geschnitzten Holzstempeln unter Zuhilfenahme eines Kunststofflineals auf, wohingegen in der Vergangenheit gemäß seiner Aussage freihändig gemalt wurde. Mdewöt hatte diese Technik selber entwickelt, um die Muster akkurater aufzutragen, was er als Qualitätsmerkmal seiner Arbeit definierte und durch die Akzeptanz seiner Abnehmer bestätigt sah (Ena Yamöli und Steven Mdewöt, 3.6.2010, 25.10.2011). ${ }^{138}$

- Tapa als Kopfbedeckung

Als frühester Autor erwähnt DILLON (1829) diese Tapa-Verwendung mit der Bezeichnung „caps of the paper-cloth“ und illustriert gleich zwei Männer mit einer derartigen Kopfbedeckung im Titelbild des Einbands seiner Publikation (vgl. Abb. 53). Auf der Abbildung von PARTINGTON \& HeAPE (1890: 154, vgl. Abb. 16) trägt der ,Krieger ${ }^{6}$ eine ungemusterte Kopfbedeckung. SELLIER (1894?) porträtiert einen Mann von Santa Cruz, der eine Kopfbedeckung am Hinterkopf trägt (vgl. Abb. 54). Auch DE TOLNAS' Fotografien aus den Jahren 1893-1901 zeigen Männer mit Kopfbedeckungen: Abbildung 55 zeigt einen ungemusterten abe aus Vanikoro während Abbildungen 56 und 57 gemusterte aus der Graciosa Bay in Ndendö darstellen. Die ersten drei Darstellungen gleichen in auffallendem Maße zwei Darstellung von van den Broek d'Obrenan, die sie im Jahr 1935 in Dondro auf der Insel Manus angefertigt hatte (COIFFIER 2014: Abb. 85). Die Gestaltung der beiden letzteren erinnert an die der Tapa der Wickeltücher bzw. Tanzschurze aus dem ausgehenden 19./frühen 20. Jh. (vgl. Abb. 45 oder Anhang). In ihrer Form ähnelt sie einer anderen Illustration, die van den Broek d'Obrenan in Batussi auf Manus angefertigt hatte (COIFFIER 2014: Abb. 82).

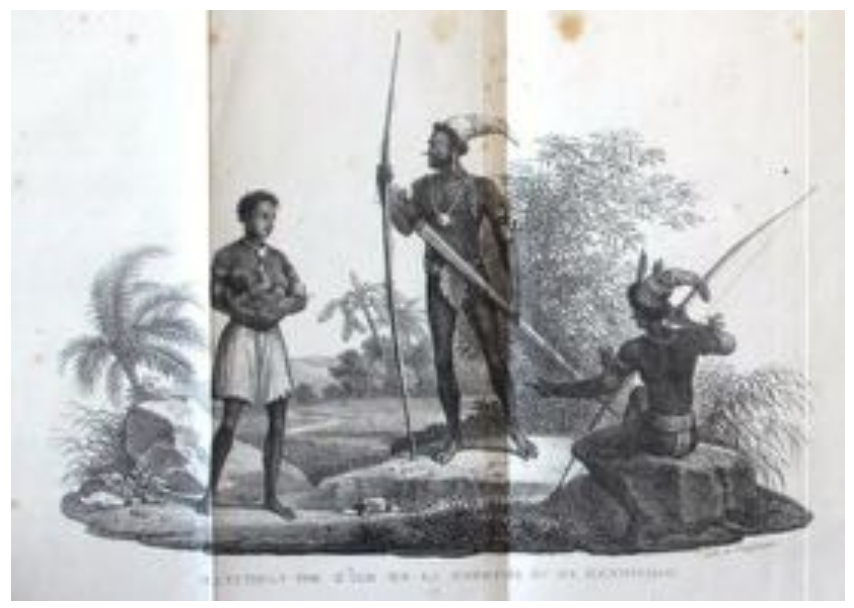

Abb. 53: Naturels de l’île de La Pérouse ou de Mannicolo [Vanikoro, O. L.] (DILLON 1829, II: Frontispiz).

137 Zur Bedeutung von Kurkuma vgl. Kap. 5.2.5.

138 Zu Steven Mdewöts Verständnis seiner Arbeit vgl. Kap. 6.4. 

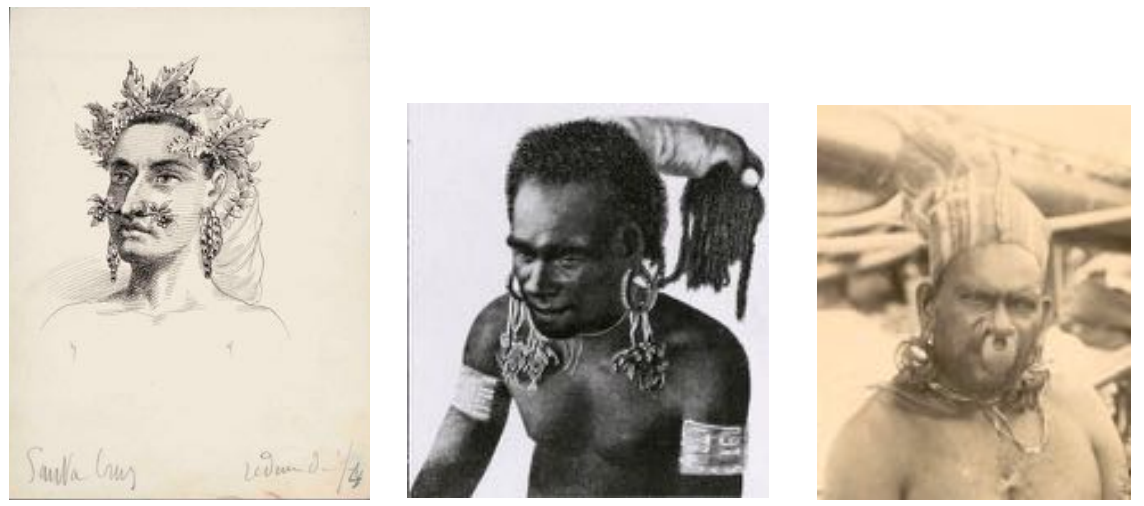

Abb. 54: Santa Cruz; habitant de Santa-Cruz, ile de la Reine-Charlotte, avec les narines ornis de fleurs rouges et son front [?] couvert de feuillages. P. Sellier, 1894?, Bildausschnitt. Alexander Turnbull Library, Wellington, New Zealand A-340-046.

Abb. 55: Natif de Vanikoro. Les Cheveux sont enroulés dans des Bandes de tapa (DE TOLNA 1903: 268).

Abb. 56: Chef de Gracieuse Bay, Santa Cruz. Festetics de Tolna, 1893-1901, Bildausschnitt. Musée du Quai Branly 70.2001.19.15.1.
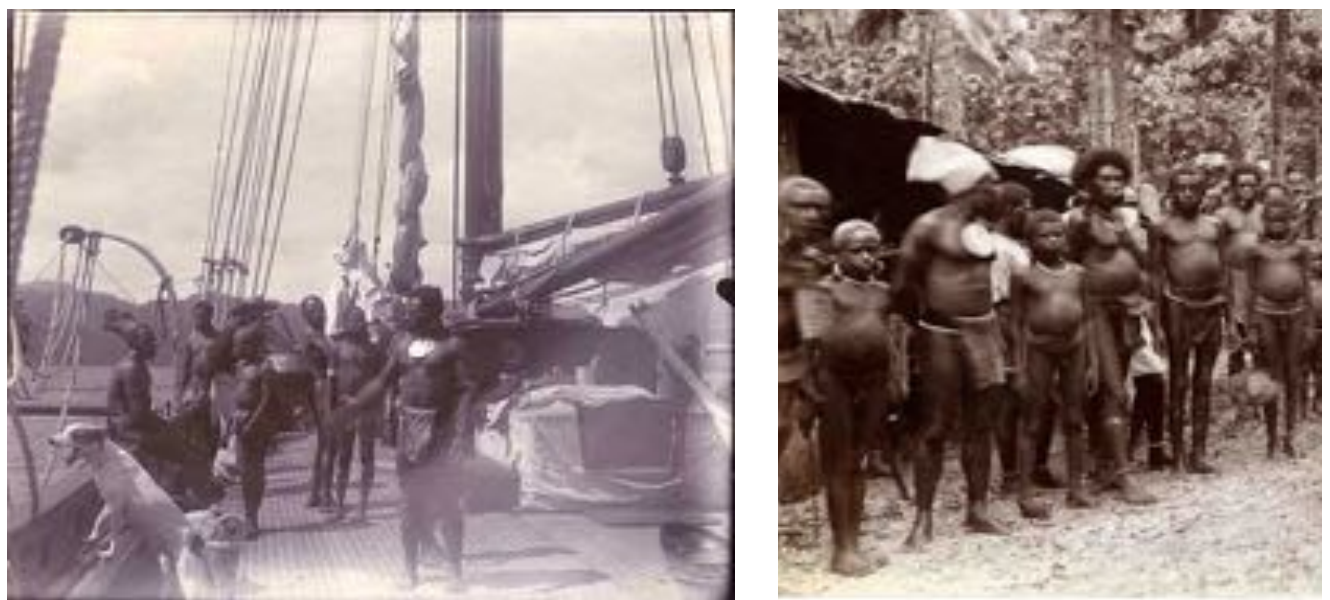

Abb. 57: Natifs de Vanicoro à bord du yacht Tolna. Festetics de Tolna, 1893-1901, Bildausschnitt. Musée du Quai Branly 70.2001.19.97. Auf der linken Seite des Fotos sind ein Mann sowie ein Jugendlicher mit Kopfbedeckung abgebildet.

Abb. 58: 425 - School People and Others at Nimbi. John Watt Beattie, 1906, Vergrößerung. Auf der linken Bildhälfte ist ein Mann mit heller Kopfbedeckung, tema und Tapa-Schurz zu sehen.

Die Fotografien Beatties (vgl. Abb. 58), Kerrys (vgl. Abb. 17) und de Tolnas (vgl. Abb. 56 und Abb. 57) und zeigen Männer mit bemalten, zylinderförmig nahezu senkrecht getragenen Kopfbedeckungen. Die Fotografien de Tolnas (vgl. Abb. 55) und Beatties (vgl. Abb. 58) zeigen einen zweiten, unbemalten Typus Kopfbedeckung, der eher denen der Abbildungen 53 und 54 ähnelt.

○ Stofflichkeiten

GRAEBNER (1909: 85) erwähnt ein „Kopftuch aambe aus Brotfruchtbast“, das Thilenius 1898 an der Nordküste von Ndendö erworben und dokumentiert hatte, beschreibt dies aber nicht 
eingehender. Des Weiteren erwähnt er den Gebrauch von meist rot gefärbter Tapa als kegelförmige Hülle für das Haupthaar der Männer auf Vanikoro, die vom Hinterkopf über den Rücken fiel (1909: 86). In den folgenden Jahren werden die Kopfbedeckungen weder erwähnt noch abgebildet: KOCH (1971) rekurriert auf die Aufsätze von GRAEBNER (1909) und SPEISER (1916), die die zuvor angegebenen Originalquellen aufführen, und erwähnt keine Arbeiten aus der Zeit seines Aufenthaltes. Auch Davenport liefert keine Hinweise über den Gebrauch von Kopfbedeckungen aus Tapa in den 1960er-Jahren. Nach DAVENPORT (2005: 19) verlor die Kopfbedeckung seit den 1930er-Jahren zunehmend an Bedeutung als Ausdruck sozialen Status, und die Männer ersetzten sie durch europäische Hüte oder Kappen (,soft brown hats with a brim“). Er berichtet von nur einem einzigen beschädigten abe, den er während seiner Feldforschungen sah.

○ Herstellung

$\mathrm{Zu}$ der traditionellen Herstellung liegen mir keine Informationen vor.

○ Heutige Verarbeitung

In den Jahren 2009-2011 trugen jedoch einige Männer auf Ndendö zu kastom-Tänzen bemalte Kopfbedeckungen, die sie als abe bezeichneten (vgl. Abb. 59-61). ${ }^{139}$ Die beiden abe auf den Abbildungen 59 und 60 werden zum nelo-Tanz getragen und ähneln den zuvor erwähnten historischen bemalten Kopfbedeckungen. Die beiden abgebildeten abe (vgl. Abb. 61) unterscheiden sich in Form und Trageweise von den zuvor beschriebenen. Sie waren kürzer und breiter und wurden um 90 Grad versetzt getragen, so dass die Motivseite nicht nach vorne, sondern zur Seite zeigte. Die Muster dieser abe finden sich auch auf manchen napaTanzkeulen, die die beiden Männer bei dem gleichnamigen Tanz trugen. Die Tänzer bemalten eigenen Aussagen zufolge ihre Tapa und Keulen selber (Shadrack Sade, 14.11.2011). Das Material ist gröber als das der beiden erstgenannten und hat eine andere Farblichkeit. $\mathrm{Zu}$ ihren Produzenten habe ich keine Aussagen.
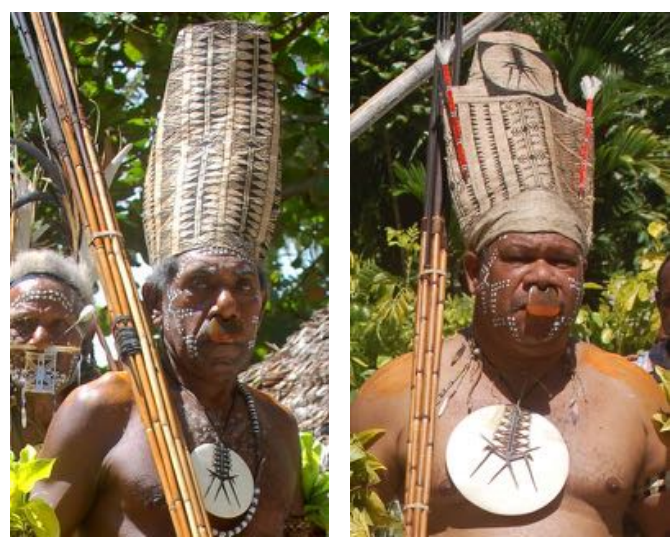

Abb. 59 und 60: Die Kopfbedeckung abe, hergestellt von Matthias Me'lekaiva (1.) und von Ben Banie (r.); Ne'ele, 2010.

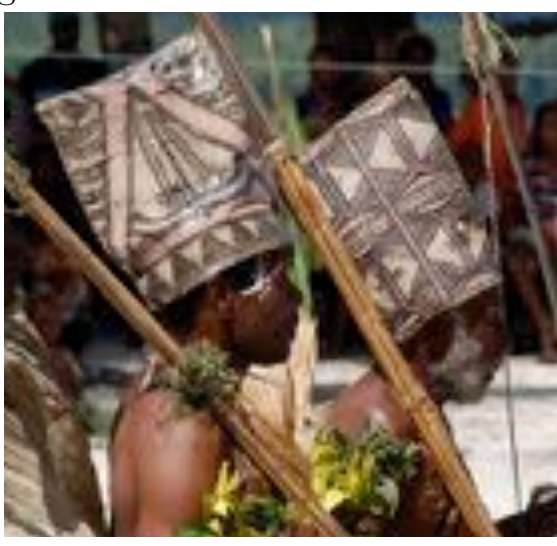

Abb. 61: Die Kopfbedeckung abe, Hersteller unbekannt; Malo, 2011.

\footnotetext{
139 Bei meinem kurzen Besuch auf Vanikoro am 6.9.201 I traf ich keine Männer mit Kopfbedeckungen aus Tapa an und erhielt auch keine Informationen dazu.
} 
Die beiden links abgebildeten abe stellten Matthias Me'lekaiva aus Nea und Ben Banie aus Luepa her. Die von Me'lekaiva gestaltete Kopfbedeckung (vgl. Abb. 59) gleicht in ihrer konischen Form mehr dem historischen abe des Anführers aus Nelua als der von Banie bemalten (vgl. Abb. 60) - er hatte den abe nach oben hin breiter genäht und mit einer Art Aufsatz zugeschnitten, auf den er zentral ein tema gemalt hatte. Me'lekaiva hatte zur Herstellung unbemalte Tapa und Farbe von seiner Schwester Ena Yamöli erhalten - Banie musste beides von ihr erwerben. Zusammengenäht und bemalt hatten die zwei Männer die abe selber.

- Materialgeschichte

Während in der Gewinnung des Rindenstoffs sowie der Farben kaum ein Wandel auszumachen ist, haben sich Technik und Art von Verarbeitung und Gestaltung geändert. Auch wenn sich aufgrund der sinkenden Nachfrage nach dem Material zunehmend weniger Frauen der Fertigung widmeten, gaben einige das Wissen weiter, so dass nach meiner Erkenntnis kontinuierlich unbemalte Tapa produziert wurde. Im Jahr 2011 stellten auf Ndendö noch zwei Frauen die zur Bemalung notwendigen Farben Schwarz und Gelb aus natürlichen Materialien her. Der Wandel ist vielmehr in der Weiterverarbeitung durch die Männer auszumachen: War das Fällen von Schösslingen und Rindenbast ehemals reine Frauenarbeit, half heute der Ehemann seiner Ehefrau bei dieser Arbeit. Nach dem eigentlichen TapaSchlagen - was nach wie vor Frauenarbeit war - glättete der Mann die frische Tapa als Vorbereitung zur Dekoration. Bei den Kopfbedeckungen abe hatten die Männer unterschiedliche, neue Formen entwickelt. Einer der wenigen produzierenden Tapa-Hersteller hatte eine für Santa Cruz völlig neue Gestaltungstechnik entwickelt - er war vom Freihandzeichnen auf eine Stempeltechnik übergegangen.

\subsection{Zwischenfazit}

Die ,Materialgeschichten“ der vier von mir untersuchten Artefaktegruppen tema, nelo, lepanesa und Tapa stellen sich bei einer ersten Betrachtung relativ kontinuierlich dar: Vergleicht man die rezenten Tanzkleidungs- und Schmuckstücke lediglich mit frühesten Aufzeichnungen, Fotografien und gesammelten Artefakten, scheinen diese nur einen geringen Wandel durchlaufen zu haben. Die Ergebnisse wirken hinsichtlich ihrer Materialität und ihres haptischen sowie visuellen Erscheinens recht ähnlich. Auch die zeitlichen Verläufe der Materialgeschichten weisen Parallelen auf: Bis in die 1970er-Jahre verloren alle traditionellen Artefakte an Bedeutung, so dass sich immer weniger Menschen für sie interessierten und die Nachfrage sank. Als Folge dessen sahen sich weniger Menschen genötigt, ihre Ressourcen für die zeitund arbeitsintensive Fertigung zu Verfügung zu stellen, was wiederum einen Verlust des Wissens um die Herstellung der Artefakte nach sich zog. Nur für die lokalen kastom-Tänze waren die Artefakte weiterhin von Bedeutung, auch wenn sich die Materialien bei manchen Schmuckstücken änderten. Letztlich sorgte sich nur noch eine kleine Gruppe Interessierter - in erster Linie die Tänzer selber - um den Erhalt sowie die Fertigung der Kleidungs- und Schmuckstücke. Mit der aufkommenden Rückbesinnung auf eine eigene Santa-Cruz-Geschichte und -Kultur erlebten seit Ende der 1990er-Jahre alle kastom-Artefakte ein steigendes 
Interesse und wurden wieder vermehrt nachgefragt und gefertigt. Da aber nur noch wenige Personen über das notwendige Wissen verfügten, beschränkte sich die ehemals in der breiten Bevölkerung verankerte Fertigung auf wenige Einzelakteure bzw. Familien, die heute für die Herstellung dieser Artefakte auf der Insel bekannt sind. Mit Ausnahme des gegenwärtigen lepanesa-Produzenten versuchten diese, die Kleidungs- und Schmuckstücke mit neuen Werkzeugen und Techniken effizienter als ihre Vorfahren herzustellen und der steigenden Nachfrage gerecht zu werden und/oder durch innovative Gestaltung weitere Verwendungsanlässe zu schaffen und neue Zielgruppen zu erschließen.

Betrachtet man den Verlauf jeder einzelnen Materialgeschichte genauer, ergeben sich weitere Unterschiede:

- Die damaligen Produzenten der tema und lepanesa ersetzten in den 1980er- und 1990er-Jahren einige natürliche Werkstoffe durch neu importierte Materialien, da diese einfacher und mit weniger Aufwand zu erhalten, resistenter gegen Feuchtigkeit und Insektenfraß oder einfach bequemer beim Tragen waren. Aber trotz dieser Vorteile ersetzten die Hersteller seit den späten 1990er-Jahren im Rahmen der Rückbesinnung auf die natürlichen Materialien die ,modernen ${ }^{6}$ wieder durch die ,alten'. Im Falle der tema verkleinerte zunächst ein Hersteller deren Größe, wodurch er vorher Nicht-Interessierte als Abnehmer gewinnen und dadurch seine Einkommensmöglichkeiten steigern konnte - was weitere Produzenten auf den Plan rief.

- $\quad$ Anders verhielt es sich bei Tapa und nelo, wo es keine Änderungen in den Roh- bzw. Werkstoffen gab. Tapa war zwar für viele Alltagsbereiche weitgehend durch importierte Baumwolle ersetzt worden, hatte aber unverändert ihre Rechtfertigung bei kastom-Tänzen behalten, da Baumwolle hier als unpassend angesehen wurde und im Falle der Kopfbedeckung abe unzureichend steif war. Da Tapa sich als Souvenir und ,originales Kunsthandwerk ${ }^{6}$ für den aufkeimenden Tourismus eignete, fertigten die wenigen Produzenten Tapa als rein ästhetisches Produkt, was sich in der Größe und Gestaltung, aber nicht in der Materialität niederschlug. Gerade der Umstand, dass sowohl der ,Stoff' als auch die Farben der Bemalung natürlich waren, stand für die Qualität der Arbeiten.

Die Nachfrage nach nelo war wahrscheinlich schon immer relativ gering, da laut meiner Gewährsleute nur sehr wenige Männer über das für das Tragen notwendige Piercing der Nasenscheidewand verfügten. Sie begründeten dies damit, dass die dafür notwendigen Initiationsfeiern zusätzliche Ressourcen erforderten, so dass es sehr kostspielig war, nelo-Tänzer zu werden. Aufgrund dieser zunächst ökonomischen und dadurch bedingten auch physischen Beschränkungen stieg die Anzahl der Tänzer nach der kulturellen Revitalisierung nicht automatisch an. Nelo waren zudem Erbstücke und wurden von der einen an die folgende Generation weitergegeben, so dass sie nur ersetzt werden mussten, wenn sie zerbrachen. Folglich konnte die Nachfrage nicht so schnell steigen wie bei den anderen drei Artefaktegruppen. Heute erarbeiten sich auch Männer in Santa Cruz, die als Kinder keine Septum-Piercings erhalten hatten, als Angestellte Wohlstand und soziale Anerkennung. Einige von ihnen wollen dennoch als nelo-Tänzer auftreten und überlegen, wie sie ein nelo ohne 
dafür notweniges Piercing tragen können. Der einzig aktive nelo-Produzent der Insel passte die Konstruktion des nelo den neuen Anforderungen an und schuf, typologisch betrachtet, ein völlig neues Artefakt, das ohne Initiationsfeierlichkeiten getragen werden konnte. Die wenigen Hersteller hatten die tema, nelo und Tapa mit den jeweiligen althergebrachten Materialien ,marktkonform' modifiziert und letztendlich erneuert - neue (spezifische) Materialformen waren aus den Bedürfnissen der Abnehmer heraus entstanden: Tema sind heute miniaturisiert und auch in Perlmutt mit Holzauflage erhältlich. Nelo existieren nun auch als Nasenringe, und Tapa wird in Bilderformaten verkauft. Lediglich die lepanesa sind (wieder nur) in althergebrachten Materialien und Gestaltungen erhältlich. Alle vier Artefaktegruppen ,übersetzen' anlassbezogen die vielfältigen sich wandelnden und mitunter divergierenden Verständnisweisen von,Santa-Cruz-Sein'. 


\section{Handlungs- und Wirkmacht der Artefakte in den Akteur- Netzwerken}

„When a force manipulates another, it does not mean that it is a cause generating effects; it can also be an occasion for other things to start acting." (LATOUR 2005: 60)

In den vorhergehenden Kapiteln habe ich rezente Erscheinungsweisen von Tanzkleidung und -schmuck in unterschiedlichen Konfigurationen des Akteur-Netzwerks ,kastom ${ }^{6}$ in der Graciosa Bay - etwa auf Festen in Dörfern, Aufführungen für Touristen oder Politiker und während Messfeiern - vorgestellt und die ,Material Histories' von vier Artefaktegruppen rekonstruiert.

In diesem Kapitel werde ich für einen konkreten Fall betrachten, auf welche Weisen spezifische Artefakte, Menschen und weitere Aktanten zueinander in Beziehung traten und wie sich dabei insbesondere die Tanzkleidung und der -schmuck darstellten. Als Ausgangspunkt meiner Untersuchung werde ich in einem ersten Schritt die Genese eines nelo-Tanzes für eine Gedenkfeier und mit ihr das Werden eines nelo-Tänzers im Sinne der Akteur-NetzwerkTheorie beschreiben (Kap. 5.1). In der anschließenden Analyse der Wirkweisen der Tanzkleidung und des -schmucks (im Sinne von Aktanten in diesen Akteur-Netzwerken) werde ich untersuchen, über welche Attribute oder ,Essenzen' die Artefakte verfügten, mittels derer sie für die Akteur-Netzwerke relevant waren (Kap. 5.2). In einem zweiten Schritt werde ich untersuchen, wie die Tänzer und das Publikum auf diese nicht menschlichen Faktoren reagierten bzw. mit ihnen agierten, und was die Artefakte auslösten (Kap. 5.3). Die sich daraus ergebenden Handlungsräume stellen die Handlungs- und Wirkmacht der Artefakte dar, die ich im Zwischenfazit kurz zusammenfassen werde (Kap. 5.4). 


\section{I Vom ,nelo-Tanz' zum ,nelo-Tänzer` - Akteur-Netzwerke und ihre Genese}

Wie in Kapitel 3 näher ausgeführt, trat die Entität ,nelo-Tanz' auf Ndendö aus sehr unterschiedlichen Anlässen in Erscheinung und war jeweils eine intentionale Konfiguration des Akteur-Netzwerks ,kastom‘. Während darin zumeist dieselben Artefakte (Tanzkleidung und -schmuck) agierten, erschienen von der jeweiligen Konfiguration abhängig andere Akteure. Wenngleich auch die Tänzer aufgrund ihrer erworbenen Ausstattungen und Fähigkeiten meist dieselben waren, variierten etwa die Auftraggeber und Zuschauer: Verwandte, Einwohner aus Santa Cruz oder anderen Provinzen der Solomon Islands, Politiker, Kirchenleute, Vertreter von Nichtregierungsorganisationen, Wissenschaftler oder Touristen. Allgemein gehaltene Aussagen einzelner Aktanten, etwa Tänzer oder Auftraggeber, sowie meine Beobachtungen ließen mich zu dem Schluss kommen, dass ein nelo-Tanz als kastomTanz abhängig von seiner Konfiguration unterschiedliche Bedeutungen haben kann (vgl. Kap. 3). Die folgende Darstellung stellt meinen Versuch dar, einen konkreten Fall im Sinne der ANT als Akteur-Netzwerk zu beschreiben und zu untersuchen, wie die Artefakte in diesem Fall in Erscheinung traten und was sie bewirkten.

\section{- Anlass und ausrichtende Familien - ein neues Akteur-Netzwerk entsteht}

Das im August 2011 in Ne'ele stattfindende Fest war seit der Eröffnung des Tanzplatzes vor elf Jahren das vierte auf diesem nir. Nach Aussagen meiner Gewährsleute war ein weiter zurückliegendes Ereignis die Ursache für diesen Festzyklus: Zwei Männer aus Ne'ele hatten in den 1970er-Jahren ein freilaufendes Schwein aus Uta (ein mittelbarer Nachbarort Ne'eles, aus dem der dukna Opla stammte) gefangen, getötet und es mit Hilfe einer Frau aus Ne'ele in einem nächsten Schritt zubereitet und anschließend gemeinsam verzehrt. Sie hatten dem Eigentümer des Schweins keine Kompensation gezahlt, woraufhin dieser von seinem dukna Opla forderte, dass „the roofs of their houses will fall down“, was bedeutete, die Anführer der Gruppe sollten sterben, womit unaufhaltsam der Untergang des gesamten Clans besiegelt werde und letztlich das Dorf aussterbe. Obwohl die beteiligten Akteure in den 1980erJahren 500 SBD als Kompensation gezahlt haben sollen, starben beide Haupttäter aus (un)erklärlichen Gründen an einer Mundkrebsart. Nachdem weitere Nachfahren der Täter in den folgenden 1980er- und 90er-Jahren an derselben Krankheit starben wurde den Familienangehörigen klar, dass sie einen Festzyklus zu Ehren Oplas durchführen mussten, um das Unrecht ihrer Väter bzw. Mutter zu sühnen und weitere Krebsfälle zu vermeiden. Letztlich waren vier Familien aus Ne'ele, Manao und Luepe beteiligt und eröffneten im Jahr 2000 in Ne'ele einen Tanzplatz (Abb. 62). 


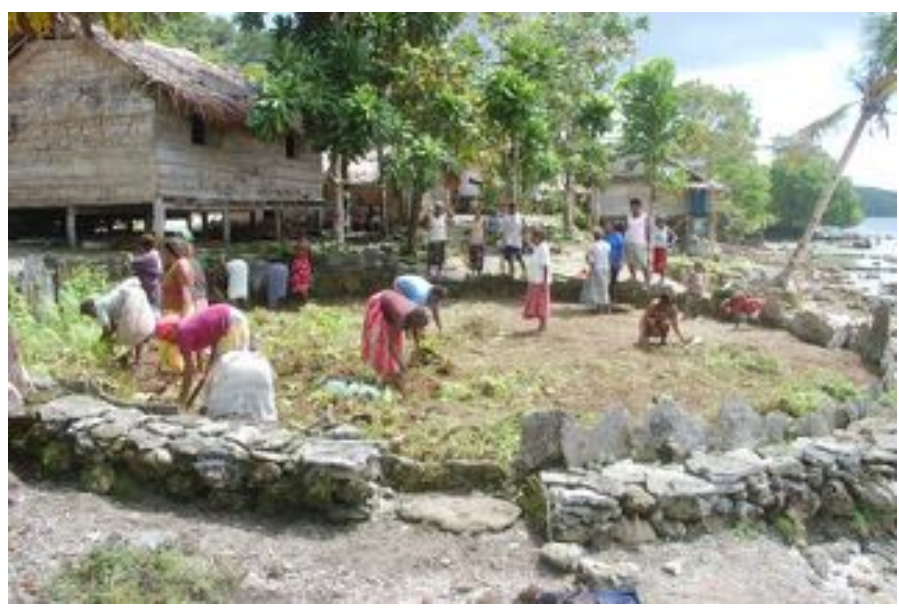

Abb. 62: Dorfmitglieder reinigen den im Jahr 2000 eröffneten nir (Tanzplatz); Ne'ele, 2011.

Nach der gemeinsamen Eröffnung des nir richteten zwei der beteiligten Familien in den Jahren 2004 und 2006 weitere Feste aus. Als Nachfahre der dritten beteiligten Familie organisierte Selwyn Balu am 7. August 2009 zu Ehren seines im Jahr 2006 verstorbenen und beigesetzten Vaters Jonas Kepule und anlässlich der Errichtung eines Kreuzes auf dessen Grab ein großes Fest. ${ }^{140}$ Ein Jahr später entschied Balu, im August 2011 erneut eine Gedenkfeier zu Ehren seines Vaters in seinem Heimatdorf Ne'ele auszurichten. Diese Entscheidung betrachte ich als Ausgangspunkt der Entstehung eines neuen Akteur-Netzwerkes, das ich nachfolgend ,nelo-Tanz für Jonas Kepule‘ nenne, und beginne an diesem Punkt mit meiner Beschreibung. Ich wähle diesen Zeitraum auch, weil er mit dem Beginn meiner Feldforschung zusammenfiel und ich daher Handlungen und Akteure verfolgen konnte und sie analog dem in Kapitel 1.2 vorgestellten Vorgehen des ANT-Vertreters CALLON zueinander in Beziehung setzen möchte.

Bei den folgenden Darstellungen und den Handlungen folge ich Selwyn Balu, den ich als Initiator dieses Festes bezeichnen möchte. Die Beschreibungen sind meine (verkürzten) Zusammenfassungen, die sich in der Realität nicht so idealtypisch Phase für Phase dargestellt haben - Callon weist darauf hin, dass sie sich überschneiden können. Mir geht es an dieser Stelle vielmehr darum, Teilprozesse einer konkreten Akteur-Netzwerk-Genese auszumachen und dadurch die Handlungsräume der heterogenen Akteure greifen und vergleichen zu können. Bei den folgenden Momenten der, Übersetzung führe ich nur wenige Beispiele auf, da eine detaillierte Ausführung den Rahmen dieser Arbeit sprengen würde. Sie sollen in erster Linie die jeweilige Phase in der Genese des Akteur-Netzwerks verdeutlichen. Da die ersten beiden Phasen bzw. ,Momente' vor meinem Eintreffen im Juli 2011 stattgefunden hatten, muss ich auf die Darstellungen meiner Gewährsleute zurückgreifen. Ich selbst traf im Übergangszeitraum der Phasen zwei und drei ein und wurde selber (unbeabsichtigt und zunächst unbewusst) Aktant in diesem Akteur-Netzwerk. ${ }^{141}$ Die vier ,Momente der

\footnotetext{
140 Zur Bedeutung von Jonas Kepule für die Herstellung der lepanesa vgl. Kap. 4.3.3 und insbesondere Kap. 6.3.

141 Schon am Tage meiner Ankunft, am 16.7.20 I I, berichtete mir Selwyn Balu von dem geplanten Gedenkfest für seinen Vater, das er für wenige Wochen später angesetzt habe und das ich unbedingt dokumentiere solle.
} 
Übersetzung` können sich mit Blick auf den Initiator Selwyn Balu wie folgt beschreiben lassen:

Übersetzungsmoment eins: Gemäß seiner Aussage hatte Selwyn Balu für sich akzeptiert, dass einer seiner Vorfahren an dem unerlaubten Schweineverzehr beteiligt gewesen war, seine Familie keine dem kastom entsprechend notwendige Kompensation geleistet hatte und daher zwingend in der Schuld des dukna stand. Der fünfte Todestag seines Vaters schien ihm ein angemessener Anlass, die enorme Vorbereitungsarbeit und die mit dem Fest verbundenen Kosten auf sich zu nehmen, um Kompensation für das begangene Unrecht seines Vorfahrens zu leisten und damit seine Familie für die Zukunft zu schützen. Er hatte über einen längeren Zeitraum in seinem relevanten sozialen Umfeld (in zahlreichen Familien- und Dorfbesprechungen) die Thematik (seine Verpflichtung, eine Gedenkfeier zu organisieren) problematisiert. Nach eigenen Aussagen war Selwyn Balu im Jahr 2006 zum Obmann seines Dorfes Ne'ele gewählt worden, um die Bewahrung der, Tradition und Kultur' sicherzustellen (pers. Kommentar 17.11.2011). Seitdem akkumulierte Selwyn Balu kastom-Wissen und wurde aufgrund dessen von den meisten Verwandten und Nachbarn geschätzt. ${ }^{142}$ Er hatte sich in seinem direkten sozialen Umfeld als unentbehrlich für diesen Bereich gemacht, woraus sich die Akzeptanz der Relevanz seines Anliegens auch für andere Aktanten ergab: Balu war ein mächtiger Akteur im Akteur-Netzwerk ,Santa-Cruz-kastom`. Innerhalb anderer Akteur-Netzwerke spielte er hingegen eine weniger relevante Rolle, etwa im ,Santa-Cruz-Tourismus', wenngleich er selber Tanzschurze für Tänzer herstellte, die zu diesen Anlässen auftraten. „Der Akteur existiert nicht außerhalb der Beziehungen, die er eingeht. Seine Identität schwankt parallel zu ihnen." (Tourraine 1974, zitiert in CALLON 2006: 152)

Übersetzungsmoment zwei: Als Mittler zwischen der Thematik/Problematik (ein Fest als Kompensation für die Fehler der Vorfahren ausrichten zu müssen und damit kastom zu akzeptieren und zu leben) und den Familienmitgliedern sowie Dorfnachbarn versuchte Selwyn Balu für seine Planung Unterstützung zu finden. Seiner Aussage zufolge organisierte er immer wieder Besprechungen und machte damit das Bewusstsein seines Problems publik, erhielt es aufrecht. Dabei nutzte Balu seine Kenntnisse der Interessen und Fähigkeiten anderer Akteure mit dem Ziel, sie als Verbündete zu gewinnen. In einer Vielzahl voneinander losgelöster Prozesse versuchte Selwyn Balu, die übrigen Aktanten auf die für sie in den Festvorbereitungen vorgesehenen Rollen vorzubereiten und zu fixieren. Laut eigener Aussagen befragte er Gleichgesinnte, ehemals befreundete Männer seines Vaters in Einzelgesprächen oder andere Dorfälteste in öffentlichen Besprechungen nach der ,richtigen' kastom-Durchführung eines Festes. Mit diesem Wissen und der erlangten Aufmerksamkeit ging er auf die Vertreter der anderen drei betroffenen Familien zu. Wenn er andere nelo-Tänze besuchte,

\footnotetext{
142 Balu musste über ein Jahr im Voraus mit ersten Planungen des Festes beginnen, um eine ausreichende Menge an Gemüse, Früchten und Schweinefleisch für die vielen Essen sicherzustellen. Auch die fristgemäße Ausbesserung und unter Umständen auch Neuproduktion von Tanzkleidung und -schmuck fiel unter seine Leitung. Zum Zusammenhang von Festen und einer Steigerung lokaler Nahrungsmittelproduktion und Spezialisierung bei der Herstellung von ,,socially valued goods in small-scale societies“ vgl. Katherine A. SPIELMANN (2002: 197).
} 
etwa bei öffentlichen Empfängen von Würdeträgern, Touristen oder in der Kirche, sprach er einige der Tänzer an, die in seinen Augen die ,richtigen' waren und informierte sie über sein geplantes Fest im darauffolgenden Jahr. Indem er so handelte, definierte er die Identitäten, Ziele und/oder Neigungen seiner Verbündeten und grenzte gleichzeitig andere aus, die ihre Identitäten auf andere Weise definieren wollten (vgl. CALLON 2006: 152, der dies als elementare Handlungen im Moment des Interessements herausstellt). So war seine Mitgliedschaft in der Graciosa Bay Nelo Association (GBNA) für ihn sehr hilfreich, da er dort mit offenen Armen empfangen wurde, als er bei einer Versammlung der Gruppe mitteilte, dass er ein Fest mit einem nelo-Tanz für seinen Vater ausrichten wollte. Das in Aussicht gestellte Fest bot allen Mitgliedern eine attraktive Möglichkeit, entweder Artefakte für den Tanz zu produzieren (und idealerweise zu verkaufen) oder als Tänzer aktiv werden (und damit Geld verdienen) zu können und damit gegenüber allen anderen Teilnehmenden die jeweiligen persönlichen Fähigkeiten demonstrieren zu können. Gleichzeitig konnte die Existenz der GBNA legitimiert werden, weil das Fest gerade für die jüngere Bevölkerung kastom in der Konfiguration eines ,traditionellen' nelo-Tanzes erlebbar machte. Ebenso waren die Vorbereitungsarbeiten willkommener Anlass, sich wieder regelmäßig zu treffen, sich teilweise von anderen, weniger attraktiven Beschäftigungen zu entschuldigen, kastom zu lernen und letztlich ein großes Fest mit gutem Essen feiern zu können. Durch die enge Anbindung an die GBNA wurden hingegen andere Hersteller gleicher Artefakte, die der Assoziation nicht angehörten, von den Vorbereitungen und den zuvor dargelegten Möglichkeiten ausgegrenzt. Letztlich war Selwyn Balu derjenige, der in dieser Phase weitestgehend vorgab, welche Akteure und Entitäten assoziiert wurden, ein System von Bündnissen konstruierten und soziale Strukturen formten (vgl. Beschreibung des Interessements bei CALLON 2006: 156).

Übersetzungsmoment drei: Nach dieser Phase des konkreten Interesseweckens und der Bildung erster Beziehungen für die Umsetzung seines Planes respektive der Lösung seines Problems versuchte Selwyn Balu die verschiedenen Rollen, die er den übrigen Akteuren angedacht hatte, zu definieren und miteinander in (Macht-)Beziehungen zu setzen. Nun musste es Balu gelingen, dass die Familienmitglieder und Dorfbewohner, die Mitglieder der GNBA und auch ich eben diese Rollen akzeptierten, mit anderen Worten, sich bei seinem Projekt ,einschrieben“ (vgl. 2006: 156-159). Dies versuchte Selwyn Balu mit diversen Strategien und Mechanismen. In erster Linie setzte er auf seine hohe Akzeptanz als Obmann in der Graciosa Bay. Ohne wahrnehmbaren Widerstand folgten seine Familienmitglieder und Dorfnachbarn seinen Empfehlungen. ${ }^{143}$ Meines Erachtens basierte die hohe Akzeptanz auf seinem Wissen über das traditionelle Weben, seiner Fähigkeit lepanesa zu weben und seinen

\footnotetext{
143 Auch der spätere Vorfall in der Nacht des Festes, bei dem ich aufgrund meiner Anwesenheit und der Tatsache, dass ich filmte, von zwei Mitgliedem der erweiterten Familie angegriffen wurde (vgl. Kap. 1.4), schmälerte nicht seine Reputation - im Gegenteil: Nach einer einige Tage später einberufenen Dorfversammlung mit öffentlicher Anhörung meiner Person wurde ein Familienvertreter zu den beiden Brüdern geschickt, um ihnen die Entscheidung der Gruppe mitzuteilen, dass ich rechtmäßig in ihrem Namen gehandelt hatte und sie mich nicht weiter
} 
Kenntnissen über den nelo-Tanz selber. Seine „Führerschaft" in diesem Bereich untermauerte er zudem durch meine Anwesenheit. Indem er mich einlud, seine Vorbereitungen und Durchführungen im privaten als auch im öffentlichen Raum zu dokumentieren, verkörperte ich als Wissenschaftler aus Deutschland die Relevanz seines Anliegens, seines Wissens und seiner Fähigkeit über Ndendö hinaus. Meine Wahrnehmung seiner sozialen und kulturellen Position innerhalb seiner Gruppen bestärkte wiederum mich, mich für seine Pläne einzusetzen und die mir zugeschriebenen Rollen als dokumentierender Ethnologe und ,Freund der Familie' anzunehmen. Es war ein nicht klar abgesprochener reziproker Tausch: Ich dokumentierte sein Fest, nahm das damit verbundene kastom-Wissen auf und schrieb ihm eine gewisse Bedeutung und Relevanz zu. Im Gegenzug unterstützte er mich bei meiner Forschung auch in anderen Teilen der Insel, bis hin zu der Erlaubnis, an dem später in Neo-Nemba ausgerichteten Abschussfest alue teilnehmen zu dürfen.

Übersetzungsmoment vier: Im letzten ,Moment der Übersetzung', bei der Genese des Akteur-Netzwerkes ,nelo-Tanz für Jonas Kepule‘, versuchte Selwyn Balu sicherzustellen, dass in seinem Sinne zuverlässige ,Sprecher' einzelne Gruppierungen repräsentierten (vgl. 2006: 159-164). Im Umfeld der Tanzorganisation hatte er etwa verschiedene ,Story Tellings` (vgl. Anm. 84) in den Dörfern organisiert, in denen er Verwandte hatte, um von den Dorfältesten in Gegenwart der übrigen Männer die ,richtigen' kastom-Praktiken zu erfahren. Bei manchen dieser Gespräche waren auch ältere Frauen anwesend. Nachfolgend lud er anerkannte Chiefs ein, beim Ankleiden der Tänzer anwesend zu sein und an seiner Stelle für die ,richtige Kleidung zu sorgen. Im Laufe der zahlreichen Besprechungen mit den Familienvertreterinnen und -vertretern hatte er die Übrigen von seinen Vorstellungen von dem Ablauf des Festes und dessen Umfang überzeugen können. Wie weiter unten aufgeführt, wollten alle ausrichtenden Familien ihren Verpflichtungen nachkommen und hatten einzelne Akteure benannt. Vertreter der GBNA hatte er motivieren können, Artefakte für das Fest herzustellen; viele ihrer dort organisierten Tänzer wollten an dem Fest teilnehmen. Nach dem und durch den Aufbau des Akteur-Netzwerkes ,nelo-Tanz für Jonas Kepule‘ war es Selwyn Balu gelungen, mit verpflichtenden Beziehungen viele Akteure miteinander in Beziehung zu bringen und Rollen festzuschreiben. Somit stand der tatsächlichen Realisation seines ursprünglich persönlichen Problems, das er erfolgreich in und mit dem Akteur-Netzwerk in ein gemeinschaftliches Ziel ,übersetzt ${ }^{6}$ hatte, nichts mehr im Wege: ,Jetzt, am Schluss der beschriebenen vier Momente, [war] ein zwingendes Akteur-Netzwerk von Beziehungen geknüpft worden.“ (2006: 164).

Mit den zuletzt aufgeführten beiden Phasen ,Enrolment' (Akzeptanz von Rollen und dem nun gemeinschaftlichen Ziel ,nelo-Tanz für Jonas Kepule als Kompensation für ein historisches Vergehen gegen kastom ) und ,Mobilisierung' (das Akteur-Netzwerk ,nelo-Tanz für Jonas

behelligten durften. Selwyn Balus und meine Darstellung wurde als die richtige und die der Brüder als die falsche bewertet. 
Kepule‘ benennt Repräsentanten) entstanden weitere neue Akteur-Netzwerke, etwa die vielfältigen,Vorbereitungsarbeiten des Festes ${ }^{6}$ oder die ,nelo-Tänzer'. Nachfolgend werde ich das Entstehen des Letzteren betrachten, da in diesem die Tanzkleidung und der -schmuck zentrale Aktanten waren. Aus diesem Grund möchte ich die letzte offizielle Besprechung von Selwyn Balu mit den Vertreterinnen und Vertretern der ausrichtenden Familien genauer darstellen. Nach meinem Verständnis stellt sie den Übergang vom Übersetzungsmoment des ,Enrolment‘ zur Mobilisierung dar.

\section{- Abstimmen der Festvorbereitungen - das Akteur-Netzwerk wächst}

Für den 17. Juli 2011 hatte Selwyn Balu die Repräsentanten der anderen drei beteiligten Familien seines Dorfes zu einer letzten Vorbesprechung in sein Haus eingeladen (Abb. 63). Wie er mir sagte, stellte er dazu in Ermangelung eines madei (Männerhauses) in Ne'ele wie gewöhnlich den öffentlichen Teil seines privaten Hauses zur Verfügung, der zugleich auch Ort seiner Webtätigkeit war. Viele noch offene Fragen mussten geklärt werden: Wer würde den seit zwei Jahren nicht mehr benutzten Tanzplatz (auch er stellt einen Aktanten bzw. ein weiteres Akteur-Netzwerk dar) reinigen und ausbessern, wer ein provisorisches Gemeinschaftshaus (erneut ein Akteur-Netzwerk) am nir bauen? ${ }^{144}$ Wer sollte die notwendigen groBen Mengen an Brennholz und Kokosnüssen für das gemeinschaftliche Kochen heranschaffen, welche Familie würde welches Essen zubereiten (zwei miteinander verwobene AkteurNetzwerke)? Detaillierte Beschreibungen dieser beiden umfassenden und miteinander verflochtenen Akteur-Netzwerke ,Kochen` und ,gemeinschaftliches Essen` mit ihren zahlreichen Menschen und nicht menschlichen Aktanten sprengen an dieser Stelle den Rahmen meiner Arbeit, da Tanzkleidung und -schmuck im Fokus stehen und ich alleine nicht bei allen Handlungen zugegen sein konnte, so dass meine Einblicke nur unvollständig sind. Aufgrund ihrer Relevanz möchte ich dennoch nicht ganz auf ihre Darstellung verzichten und führe hier nur einige Details auf: Das gemeinsame Essen beschrieb Bischof George als wichtige kulturelle Praxis in Santa Cruz, u. a. um sich öffentlich zu bedanken. Essen als Danksagung war in Santa Cruz gebräuchlicher, als den Dank in Worte zu fassen:

\footnotetext{
144 Warum auch Tanzplätze oder Häuser Aktanten sind, möchte ich am Beispiel der Tanzplätze auf Ndendö ausführen: Ein geöffneter nir schien zu keiner Zeit (nur) ein sakraler Ort zu sein. Auf mit Vegetation überwucherten Tanzplätzen sah ich Hunde und Schweine frei herumlaufen, auf einem weniger bewachsenen spielten Kinder Fußball, er war Teil des alltäglichen Lebens. Nach dem Schweineschlachten in Neo-Nemba beobachtete ich Kinder auf dem Platz beim Ballspielen mit Schweineblasen. In Nelua kultivierten die Bewohner Tabakpflanzen auf dem nir. Dennoch waren die Plätze ,Tanzplätze', und viele Erwachsene wussten sehr wohl, ob er ,geöffnet' oder ,geschlossen' war. Bei einer Begehung des Waldes um Malo/Dei auf Temotu Neo und um Nelua zeigten mir meine Gewährsleute eine Vielzahl zerfallener nir, die nach ihren Aussagen Anfang des 20. Jh. aktiv genutzt worden waren. Zu manchen erinnerten meine Begleiter Namen. Die meisten Plätze wurden nach dem Dorf bzw. Dorfteil genannt, in dem sie sich befanden. Einen nannten sie aufgrund seiner außergewöhnlichen Größe nir pumbe (Natügu für Kugelfisch) (Alfred Dawi und Chief Philipp, I4.I I.20 I I). Abhängig von der Konfiguration seines Akteur-Netzwerks wechselte der Aktant Tanzplatz mit seiner Materialität und seinen physischen Attributen seine „Essenz', seine Performanzfähigkeit. Er ,driftete' zwischen den Akteur-Netzwerken, abhängig von seinem Zustand etwa vom Ritualplatz zum fertilen Boden oder zum profanen Spielplatz. Meine Gesprächspartner nannten geschlossene Tanzplätze auch tote Tanzplätze.
} 
„But it [the ceremony, O. L.] involves eating of pigs, dancing, and shooting of arrows $[\ldots]$. Those are the ceremonies, that hold the communities together. [...] They know, what, Thank you' means. You involve them in the whole ceremony, by asking them to come, by eating together with them, and by dancing together with them. That's when you say, Thank you'. So, in all these [Santa Cruz, O. L.] cultures, you don't say ,Thank you'““ (Bischof George, 1.8.2011)

Im Akteur-Netzwerk ,Kochen' agierten Menschen mit anderen Aktanten (Tiere, Pflanzen, Kochutensilien, Brennholz, Wasser, Techniken, Wissen etc.) und schufen an speziell dafür hergerichteten Orten (ebenfalls Aktanten) für eine gewisse Zeit eine soziale Gemeinschaft. Darüber hinaus - und das ist der zentrale Aspekt - ,verkörperte' das Akteur-Netzwerk, gemeinschaftliches Essen' allen Teilnehmenden die Prosperität und die erfolgreiche Kooperationsfähigkeit der ausrichtenden Familien/Assoziationen. Es signalisierte, dass Familien, Frauen, Kinder, Männer und nicht menschliche Aktanten (etwa Tiere, Pflanzen, Boden, Klima sowie Ahnen, Gott, dukna oder Spirits) über einen längeren Zeitraum auf einen festgelegten Zeitpunkt zielgerichtet unter Leitung zusammengearbeitet hatten: von Opfergaben und Gedenken an Ahnen und übernatürliche Kräfte, vom Anlegen der Gärten durch die Männer, dem Pflanzen und Ernten von Yams, Taro und Süßkartoffeln durch die Frauen und Männer, von der Aufzucht von Schweinen durch die Frauen, dem Sammeln von Kokosnüssen und Brennholz durch die Frauen und Kinder, über das Fertigen, Zusammentragen und Reinigen von Koch- und Essschalen, dem Fangen der Fische durch die Männer bis hin zum gemeinschaftlichen Kochen und Servieren durch die Frauen innerhalb der Familienorganisationen. Auf die Zukunft gerichtet, erwarteten die Ausrichtenden von ihren Gästen, als Gegenleistung von diesen zu einem späteren Zeitpunkt eingeladen zu werden und eröffneten damit zukünftige Beziehungen zu anderen Familien und Dörfern (John Me'alue, 15.10.2011). So bildeten die beiden Akteur-Netzwerke ,Kochen` und ,gemeinschaftliches Essen` Möglichkeiten, Assoziationen aufrechtzuerhalten und auf die Zukunft gerichtet aufzubauen. Die zunächst undifferenzierte Praxis der Assoziation wurde als soziale Notwendigkeit erlebbar gemacht, geteilt und in zukünftige Handlungen überführt.

Mit Blick auf den nelo-Tanz stellten sich hauptsächlich folgende Fragen: Welche nelo-Tänzer (als Akteur-Netzwerk werde ich es weiter unten ausführlich beschreiben) sollten eingeladen, von welchen ,Kriegern' beschützt und in welcher Höhe bezahlt werden, und welche Tanzanführer würden die Tänzer in welcher Folge auf den Tanzplatz führen? ${ }^{145}$ Welche

\footnotetext{
145 Im Jahr 20 I I gab es auf Ndendö meinen Beobachtungen zufolge weniger als 40 aktive nelo-Tänzer, die allerorts bekannt waren. Sie lebten über die ganze Insel (und darüber hinaus) verteilt und wurden von den ausrichtenden Familien zum Tanzen bei den unterschiedlichen Anlässen engagiert. Gefragt wurden zuerst mit der Familie in Beziehung stehende Tänzer und erst danach ,lose' Bekannte. Nach DAVENPORT (1969: 208 Anm. 26) wurden bis in die 1960er-Jahre nur junge Männer Tänzer. Ältere Männer entsprachen nicht mehr dem Ideal eines gutaussehenden, wohlproportionierten und muskulösen Mannes (vgl. Anm. I58). Im Jahr 20I I jedoch war der Großteil der Tänzer über 40 Jahre alt. In der Regel engagierte eine Familie einen Tänzer, um in ihrem Namen zu tanzen. In der Vergangenheit erfolgte die Bezahlung in erster Linie mit Schweinfleisch, im Jahr 20I I erhielten die Tänzer
} 
kastom-Handlungen sollte die Mutter eines Debütanten bei dessen Auftritt ausführen? Wer sollte ansonsten noch aktiv mittanzen? Selwyn Balu insistierte, dass die Frauen an ihre, richtige' (nach vorne geneigte) kastom-Tanzhaltung zu denken hatten. Welche Familie sollte in welcher Reihenfolge welche Speisen anbieten? Welche Gäste sollten geladen werden, und welche Besucher wurden erwartet? Ebenso wurden die Themen der kastom-Lieder für die Tänze besprochen. ${ }^{146}$ Die Teilnehmer entschieden, zum ersten Mal seit sehr langer Zeit wieder ein Fest mit einem Schießwettbewerb zu eröffnen. ${ }^{147}$
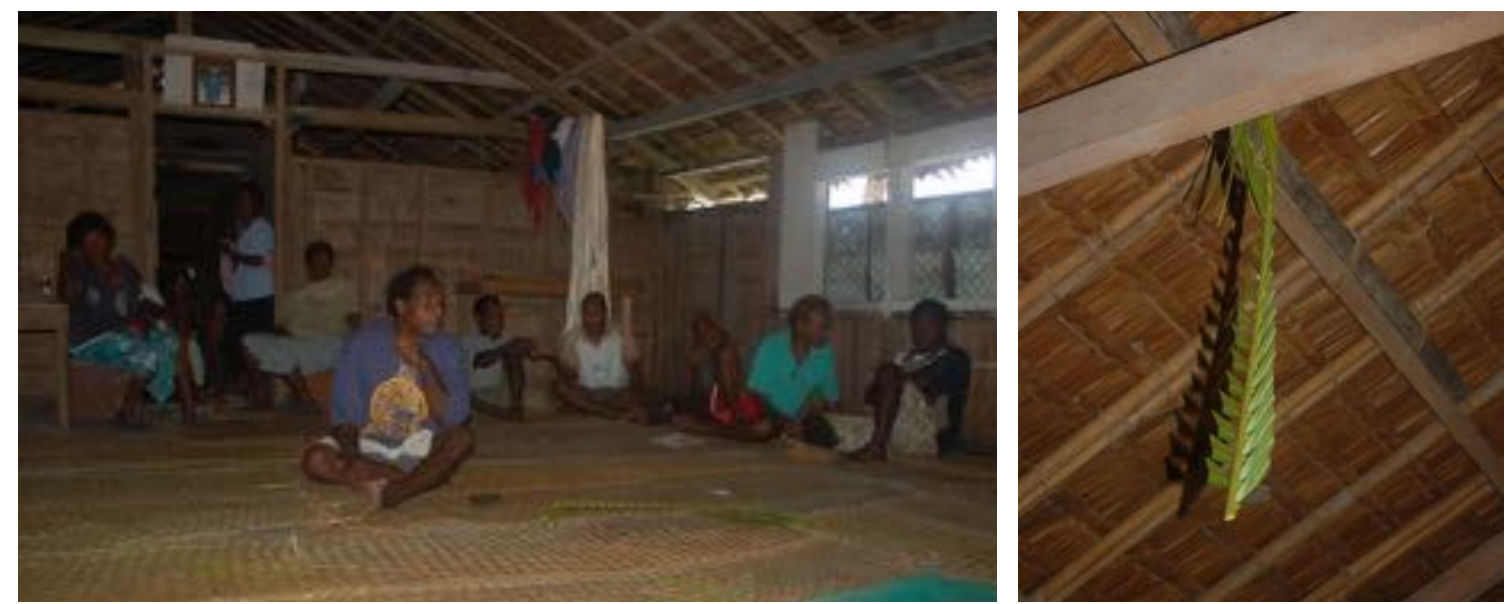

Abb. 63: Vor der Versammlung, im Vordergrund Selwyn Balu; Ne'ele, 2011.

Abb. 64: Der kastom-Kalender abu dobe; Ne'ele, 2011.

Zum Abschluss der Besprechung ließ Selwyn Balu erstmals wieder einen kastom-Kalender (Natügu: abu dobe, ,der Tag ist festgelegt') in seiner Hütte aufhängen: Von dem Zeitpunkt an

zusätzlich Bargeld. Für das Fest in Ne'ele wurden pro Tänzer zwischen 100-200 SBD (entsprach im Jahr 20 I I ca. 10-20 Euro) veranschlagt. Hatte ein Tänzer kein komplettes Tanzkleidungsset, trug der Auftraggeber zusätzlich die anfallenden ,Leihgebühren:

146 Zur Auswahl standen u. a. Lieder, die historische Ereignisse umrissen, Männlichkeit und Tapferkeit in Form von Kriegsliedern besangen, Geschichten der dukna wiedergaben oder auch die Beziehungen von Männern und Frauen thematisierten. Zu Aufbau und Art der Gesänge vgl. DAVENPORT (1975). Sie waren Bestandteil der oralen Geschichtserzählung. Auch über ,meinen Vorfall' (vgl. Kap. I.4 und Anm. I43) verfasste direkt nach dem Ereignis der Dichter Alfred Dawi zwei Liedtexte: Zum ersten vgl. Zitat zu Beginn des Kap. I.4. Das zweite lautete: „,Mitten in Menschenmenge; dem Krieg entkommen; Weißer Mann nimmt es [den Angriff, O. L.] als Einzelkämpfer; Mitten in Menschenmenge" (Alfred Dawi, 19.10.2011)

147 Nelo-Tänzer sowie die sie beschützenden ,Krieger' würden versuchen, mit Pfeil und Bogen eine ca. 50 Meter vom Strand entfernt im Meer aufgestellte Bananenstaude dreimal hintereinander zu treffen. Wenn dies gelang, könnte das Fest beginnen. Tatsächlich traf später niemand dreimal hintereinander. Viele Männer konnten kaum mit den traditionell gefertigten Bögen und Pfeilen umgehen, was mehrere Male zum Gelächter im Publikum führte. Nach einer guten Stunde beendete Selwyn Balu den Wettbewerb und wies die Teilnehmer an, zum Tanzplatz zu ziehen. Die sogenannten Krieger begleiteten in der Nacht die Tänzer, um sie vor den dukna zu schützen, für die das Fest ausgerichtet wurde. Anderenfalls könnte es passieren, dass sich diese in Menschenform unter die Feiernden mischten und die nelo-Tänzer gefährdeten. Zudem war es in der Vergangenheit immer wieder auf Festen zu Auseinandersetzungen zwischen Gruppen gekommen, die durch die Krieger beigelegt wurden (Freddy Me'esa, 21.7.201 I). 
sollte jeden Morgen ein Blatt von der Rippe eines kupierten Palmwedels entfernt werden, so dass die verbleibende Anzahl der Blätter die Tage bis zum Fest signalisierte (s. Abb. 64).

Dieses Fest sollte das letzte sein, bevor die vier beteiligten Familien den nir in Ne'ele im Oktober 2012 mit einer Closing Ceremony unter der kastom-Leitung von Selwyn Balu schlieBen wollten. Beim Abschlussfest wollte Balu die Kinder seiner Schwägerin Veronica (die Zwillingsschwester seiner Ehefrau Miriam I'ambuk) initiieren lassen. ${ }^{148}$ Dazu müsste er den Mann bezahlen, der den Kindern die Ohrringe anlegt, die Personen, die die für die Festessen notwendigen Schweine züchten, die Nahrungsmittel anpflanzen und zubereiten, das Feuerholz beschaffen und die für die Essenzubereitung benötigten Erdöfen ausheben. Selwyn Balu betrachtete dies u. a. als Gegenleistung dafür, dass die Schwester seiner Ehefrau diese während des gesamten Festzyklus in den vergangenen elf Jahren bei deren Arbeit unterstützt, selber gekocht und in ihrem eigenen Garten Gemüse und Obst angebaut hatte. ${ }^{149}$

\section{- Erste Männer treffen ein - das ,Setting ${ }^{6}$}

In der ANT-Terminologie bezeichnet ,Setting ${ }^{6}$ die Konstellation von Menschen und nicht menschlichen Aktanten, bei denen Kompetenzen und Performanzen verteilt sind (AKRICH \& LATOUR 2006: 399) sowie das eigentliche Objekt der Analyse, ,das von einem (soziologischen) Beobachter als Gegenstand der Forschung ,konstruiert' wird“ (BELLIGER \& KRIEGER 2006: 44). Die folgenden Darstellungen des Vorabends und des eigentlichen Ankleidens sind in diesem Sinne meine Rekonstruktionen der Ereignisse bzw. Abläufe, meine (ethnologische) Konstruktion eines ,ANT-Setting،. Da ich alleine im Feld war und keine Assistenz hatte, war ich vollends damit beschäftigt, möglichst umfassend zu fotografieren und zu filmen und stichpunktartig möglichst direkt Kommentare oder Beobachtungen festzuhalten. An den Tagen

\footnotetext{
$148 \mathrm{Zu}$ Inhalten und Ablauf der Initiationsfeiern (nertatongir) vgl. S. 65-66.

149 Es war nicht unüblich, sich für die während eines gesamten Festzyklus zusätzlich anfallenden Garten- und Kocharbeiten Unterstützung aus der eigenen oder einer anderen Familie zu sichem. Grundsätzlich konnte dazu jede Frau bzw. Familie angefragt werden. Balu hatte seiner Aussage nach die Zwillingsschwester seiner Ehefrau gefragt, damit die beiden Schwestern mehr Zeit miteinander verbringen und, wie sie es von Kind auf gewohnt waren, zusammenarbeiten konnten. Von diesem Arrangement war auch der Ehemann der Schwägerin betroffen, da er seiner Frau bei der zusätzlichen Gartenarbeit helfen musste. Diese eingegangene Beziehung verpflichtete die beiden ,Vertragspartner' über den Tod hinaus. Würde die Schwägerin vor Abschluss des Zyklus sterben, müsste eine ihrer Töchter die Arbeitsleistung erbringen. Würde Balu vorzeitig sterben, müsste einer seiner Söhne die erbrachte Leistung bezahlen. Er hatte seinen Erstgeborenen Walter Kola bereits damit vertraut gemacht. Wurde die Beziehung eingegangen, mussten beide Familien während des gesamten Festzyklus ihre Leistungen erbringen: Anbauen/Kochen und dafür Entgelten. Die Beziehung wurde durch eine erste ,Zahlung' eröffnet, wozu Balu seiner Schwägerin im Jahr 2000 nach der Eröffnung des Tanzplatzes in Ne'ele I 50 SBD (entsprach im Jahr 20 I I ca. I5 Euro), einen kaleko sowie sämtliches in seinem Haus übriggebliebenes Festessen gegeben hatte. Von dem Zeitpunkt an musste die Schwägerin für jedes folgende Fest Gemüse und Obst anbauen und Essen zubereiten. Beendet wurde die Beziehung durch eine Abschlusszahlung, die ebenfalls in der Öffentlichkeit erfolgte. Entweder übergab der auftraggebende Mann oder dessen Ehefrau der zuarbeitenden Frau den Lohn. Balu plante, bei der Schließung des Tanzplatzes 2012 in Ne'ele der Familie seiner Schwägerin zusätzlich ein halbes Schwein zu geben. Er würde auch seiner Frau l'ambuk bei der Schließung des Tanzplatzes einen Lohn geben, weil sie nicht aus Ne'ele stammte, aber für den nir in Ne'ele gearbeitet hatte. Falls er vorher sterben würde, müsste sein ältester Sohn seine eigene Mutter bezahlen. Dieser kastom war Balu von seinem Vater Kepule überliefert worden (Selwyn Balu, 17.10.2011).
} 
nach dem Fest überprüfte und vervollständigte ich meine Aufzeichnungen in Gesprächen mit Selwyn Balu, Jerry Me'ioko und John Namiade sowie weiteren Teilnehmern. So konnte ich meine Feldtagebucheinträge vom 12./13. August 2011 mit Hintergrundinformationen ergänzen. Gab mir nur eine einzelne Person die jeweilige Information, werde ich diese benennen, sofern diese nicht ausdrücklich auf Anonymität bestand.

Aufgrund der Beliebtheit Selwyn Balus und seines Vaters sowie ihrer beider Ansehen als nelo-Tänzer und kastom-Obmänner hatten 26 Männer, davon 24 als Tänzer und zwei als Tanzanführer, ihre Teilnahme an der Gedenkfeier zugesagt - laut Selwyn Balu so viele wie nie zuvor. ${ }^{150}$ Dabei handelte es sich um ,gewöhnliche` Männer, die im alläglichen Leben keinen Sonderstatus genossen. Die Akteure waren, wie sich später herausstellte, im Alter zwischen Ende 20 und 75 Jahren und zwischen einem und rund $360 \mathrm{Mal}$ als nelo-Tänzer aufgetreten. ${ }^{151} \mathrm{Zu}$ ihnen zählte u. a. Walter Kola. Er stammte aus Ne'ele und war der namesake von Selwyn Balus Erstgeborenem. Kola war in der Graciosa Bay gesellschaftlich hoch angesehen, da er zu dem Zeitpunkt als Acting Police Commissioner of the Royal Solomon Islands Police Force arbeitete und mit seiner Kernfamilie in Honiara lebte. Auch er war Nachfahre einer der als Auslöser des Festzyklus geltenden Personen. Sein Vater war vor einem Jahr verstorben, und während der einjährigen, durch kastom festgelegten Trauerzeit durfte er nicht als nelo-Tänzer auftreten. Mit dieser Feier wurde Kola wie drei weitere Tänzer, die ebenfalls ihre Trauerzeit beendet hatten, wieder in den Kreis der aktiven Tänzer aufgenommen. Deshalb war er extra aus der Landeshauptstadt angereist. Zudem sollte ein neuer nelo-Tänzer aufgenommen werden: der 29-jährige Steward Bice Me'tu aus Pala, einem am östlichen Ende der Graciosa Bay gelegenen Dorf. ${ }^{152}$ Sein Vater Martin Me'penia war selber noch aktiver nelo-Tänzer und galt als bonie der Graciosa-Bay-Dörfer Balo, Nepa und Pala. ${ }^{153}$ Er wollte nun den Tanz an seinen Sohn Me'tu weitergeben. Der erfahrenste und berühmteste Tänzer unter ihnen war Wilson Kabi aus Luepe, der in den Orten entlang der Graciosa Bay sein kastom-Wissen weitergegeben und Jugendliche darin unterwiesen hatte. ${ }^{154}$

\footnotetext{
150 Zu anderen Festen kamen durchschnittlich zwölf bis 16 Tänzer. Die Anzahl der Tänzer sollte immer gerade sein, damit jeweils zwei Tänzer als Paar auf den nir ziehen, zusammen tanzen und sich gegenseitig beschützen konnten, insbesondere, wenn sie sich außerhalb des Tanzplatzes bewegten. Unter anderem sollte vermieden werden, dass sich dukna in Menschenform unter sie mischten und die Tanzenden gefährdeten. Dies war eine weitere Schutzmaßnahme neben den ,Kriegem', die die Tänzer während der gesamten Festdauer auf Schritt und Tritt begleiteten.

151 An dieser Stelle bedanke ich mich ausdrücklich bei John Namiade für die Unterstützung bei der Erhebung dieser Daten. Namiade befragte am Morgen des 12. Augusts alle Tänzer und ,Krieger', damit ich mich ganz der Dokumentation des Ankleidens widmen konnte. Ohne seine Hilfe hätte ich keine vollständige Liste aller anwesenden Tänzer und Krieger des Tanzes erhalten.

152 Zu Steward Bice Me'tu und seinem Vater Martin Me'penia vgl. Anm. I 58. Me'penia war vielfacher namesake, u. a. von Jerry Me'ioko. Da Me'penia die Schwester von Me'ikos Vaters geheiratet hatte, wurde er dessen tabu, den Me'iko auch als Vater bezeichnete (Gespräche mit Me'ioko am 22.8.20 I I in Lata und mit Me'tu, Me'ioko und Me'penia am 13.9.201 I in Balo).

153 Zum Begriff bonie vgl. S. 33.

154 Wilson Kabi verstarb wenige Tage später am 27. August 201 I im Alter von 63 Jahren im Lata Hospital. Nach Aussagen eines Informanten, der anonym bleiben möchte, erlag er den Wirkungen von magischen Pfeilen eines ,Wild Man', die dieser in Kabis Wohnhaus platziert hatte. Angeblich war der Täter auf dessen wirtschaftlichen
} 
Am Vorabend des Festes waren in Ne'ele noch in vielen Häusern die Essensvorbereitungen im Gange, als die ersten mit Plastiktüten und Rucksäcken bepackten Männer aus entfernter gelegenen Dörfern eintrafen. Sie wären am folgenden Morgen zu spät zum Ankleiden für den nelo-Tanz angekommen.

[...] Kurz zuvor hatte Selwyn Balu doch noch einen Hai von seinem Tabu Andy Ata aus Neo erhalten. Tagsüber hatte er mich mehrfach darauf hingewiesen, dass er bereits vor Tagen bei ihm zwei bis drei Haie für die Verpflegung seiner, wichtigsten` Gäste bestellt hatte. Immer wieder hatte Andy ihn vertröstet und das schlechte Wetter dafür verantwortlich gemacht, dass er nicht zum Haifang aufs Meer hatte fahren können. Zwei Jahre zuvor, versichert Selwyn mir stolz, hätte er seinen Gästen 14 Haie reichen können. Er hatte mich mittags ausdrücklich gebeten, Andy und seinen Fang zu fotografieren, sobald diese einträfen. Leider komme ich zu spät in Selwyns Küche - ich wollte die Zubereitung eines Taro-Puddings in einer anderen Kochhütte bis zum Ende dokumentieren - und kann nur noch den bereits zerlegten Hai in einer Aluschüssel fotografieren: Die Fischstücke schwimmen im Blut, und die glasigen Augen des toten Hais starren mich an. Wir gehen ins Haus.

Inzwischen ist es dunkel geworden. Erwartungsvoll, sichtlich ermüdet, aber dennoch voller Tatendrang pausiert Selwyn Balu, Betelnuss kauend, im öffentlich zugänglichen Aufenthaltsraum seines Hauses. Er sagt, er hätte die beiden letzten Nächte nicht geschlafen, da er noch Tanzschurze ausbessern und einen neuen fertig stellen musste. Neben ihm sitzen John Namiade und Jerry Me’ioko. Ich setze mich zu ihnen. Ich bin ziemlich fertig. Mein T-Shirt klebt völlig durchgeschwitzt an Brust und Rücken, und mein Nacken brennt von der Sonne, die den ganzen Tag geschienen hat. Beim Filmen, Fotografieren und Befragen hatte ich sie total vergessen, so dass ich einmal mehr einen mittelprächtigen Sonnenbrand habe. Nachdem es in den vergangenen Tagen immer wieder sintflutartig geregnet hatte, ist es heute überraschend trocken geblieben. Der

Erfolg und sein hohes Ansehen neidisch. Ein weibliches Medium, das mit einem Mann aus Santa Cruz verheiratet war und in Honiara lebte, selber von einer anderen Salomonen-Insel stammte und noch nie einen Fuß auf Ndendö gesetzt hatte, bestätigte den Verdacht und konnte die Verstecke der magischen Pfeile erkennen. DAVENPORT (2005: 37) berichtet von der Fähigkeit weiblicher Medien, Träume zu interpretieren, in denen sich die dukna den Menschen mitteilen wollen. Einige Wochen später riss Kabis ältester Sohn das Haus seines Vaters ab und holte seine Mutter zu sich ins Haus. Manche ,Wild Men' waren nach Aussage meines Informanten innerhalb der Dörfer auf Ndendö namentlich bekannt. Sie lebten außerhalb gesellschaftlicher Normen und standen in Kontakt zu den dukna, deren übernatürliche Kräfte und Fähigkeiten sie gegen Opfergaben erhielten. Mit dem Wirken eines, Wild Man' wurde mir auch ein Mord in Nanggu - einem Dorf im äußersten Südosten Ndendös gelegen - erklärt, bei dem ein Kind geköpft worden war. Der Täter wurde lokal benannt, aber nicht der Polizei übergeben. Es wurde vermutet, dass das ,Opfer' in Zusammenhang mit einem bereits lange währenden Landdisput stand (ebenfalls anonym). Dieses Verständnis von ,Wild Men' - allägliche Männer stehen außerhalb der sozialen Gruppe und können ohne Sanktionen gegen die Normen verstoßen - steht im Gegensatz zu Vorstellungen von ,wilden', im Wald lebenden Wesen, etwa „orang utan" oder „man-bush", wie CORDINGTON (I89 I: 354-355) sie für die Region der Salomonen und Vanuatu erwähnt. Zu der Bedeutung von Wilson Kabi für die kulturelle Revitalisierung und die Artefakteherstellung auf Ndendö vgl. auch Kap. 3.3.2 und Kap. 4.3.I. 
Himmel ist jetzt wolkenlos, und eine sternenklare Vollmondnacht steht bevor. Selwyns magische „last green leaves for no rain“, so seine Worte, scheinen zu wirken. Ich hatte sie nicht zu Gesicht bekommen, aber er versichert mir lachend, dass er am Abend zuvor irgendwelche Blätter für das Ende des Regens, geopfert' hätte. Ich bin einmal mehr verunsichert, ob dem wirklich so war oder es sich um weiteres ,Story Telling“ handelte - hatte er doch tagsüber noch Zeltplanen um den Tanzplatz herum als Unterstand für das Publikum anbringen lassen. Er meinte als Sonnenschutz, aber ich vermutete eher gegen möglichen Regen.

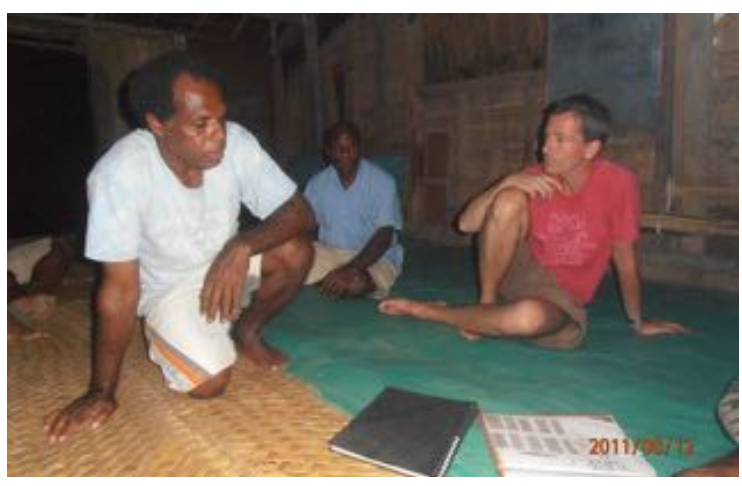

Abb. 65: Am Vorabend des Festes in Ne'ele, 2011. V. 1. n. r.: Selwyn Balu, Jerry Me'ioko, Oliver Lueb.

(C) John Namiade

Selwyns Ehefrau Miriam bringt uns zur Erfrischung Wasser und Bananen und verschwindet schnell wieder, weil sie noch lange kochen muss. Aus Ermangelung eines madei in Ne'ele stellt Selwyn den Aufenthalts- und Arbeitsraum seines Hauses zum Ankleiden der Tänzer für das anstehende Fest zur Verfügung. An der dem Meer zugewandten Längsseite des Raumes hat er eine Leine gespannt, an der die lepanesa der neloTänzer während des Ankleidens nebeneinander präsentiert werden sollen, wie er mir auf meine Nachfrage erläutert. Einige Tanzschurze, die er schon in den vergangenen Tagen ausgebessert hat, hängen bereits auf der Leine. Am Boden verstreut liegen drei Mappen mit Fotos und Kopien von Fotos früherer Feste sowie Informationen zu lepanesa aus Santa Cruz, die Selwyn im Laufe der Jahre - vor allem mit Hilfe von Mick Pendergrast - zusammengetragen hat. Immer wieder kommen Jungen in das Haus, setzen oder legen sich für eine kurze Zeit auf die grüne Kunststoffplane oder die geflochtenen Matten aus Kokospalmblättern auf den mit Korallenschutt aufgefüllten Boden des Hauses und blättern durch die Kladden. Wenn etwas interessant scheint, nehmen sie Taschenlampen zu Hilfe, da die einzige mit Batterie betriebene Lampe - die Selwyn von John geliehen hat - im großen Raum zu wenig Licht gibt. Sie diskutieren in Natügu über die vielen Abbildungen. John und Selwyn informieren mich, dass das offizielle Ankleiden der nelo-Tänzer schon vor dem Morgengrauen des nächsten Tages beginnen soll, und Selwyn daher ab jetzt erste Männer aus entfernter gelegenen Dörfern erwartet, die bei ihm die Nacht verbringen wollen. Andere werden auch bei ihren Verwandten oder Auftraggebern in Ne'ele übernachten. 
Aus einem Nachbarhaus dringen Stimmen, Gesänge und Gelächter zu uns. Selwyn erklärt mir, die Männer übten noch einmal kastom-Lieder, da das Repertoire an Liedern enorm groß und die Themen vielfältig seien. Er schlägt John und mir vor, ich solle noch solange bleiben, bis die ersten Männer kämen und könne dann mit John zu dessen Haus gehen, um dort ein paar Stunden zu schlafen. Meine Enttäuschung sieht er mir an und beruhigt mich, dass sie nur in Natügu sprechen würden und es nichts ,Wichtiges ${ }^{6}$ zu dokumentieren gäbe. John bestätigt dies und meint, er würde mich begleiten, da er noch Tanzschurze aus Tapa für ein paar Jungen bemalen müsste, die morgen mittanzen würden. Als ich mich damit abgefunden habe, betreten Brown Ite und Simon Menotea aus Neo und kurz darauf Richard Me'esa aus Manoputi Selwyns Haus. John meint, sie seien erfahrene nelo-Tänzer, hätten bestimmt schon zehn bis 40 oder gar 50 Tänze absolviert. In Rucksäcken und Plastiktüten haben sie ihre Tanzkleidung und den Schmuck mitgebracht. Erst begrüßen sie Selwyn und John, dann mich. Untereinander sprechen sie Natügu - immer, wenn es Selwyn oder John wichtig scheint, übersetzen die beiden für mich ins Englische. Manchmal sprechen sie aber auch Pïin, so dass ich Bruchstücke aufschnappe: Es geht um ihren Lohn, den sie für den Tanz erhalten sollen, die Lieder, die sie singen werden, um Tabak und Betelnuss. Nach der Begrüßung nehmen sie im Schneidersitz auf dem Boden Platz und beginnen ihr Gepäck zu öffnen. Sie wollen in aller Ruhe ihre Kleidung auf Vollständigkeit und Zustand prüfen, um zu schauen, was am nächsten Morgen noch ergänzt werden muss. Völlig fasziniert beobachte ich sie und wundere mich, wie stark die Ausstattungen der Tänzer variieren. Leise frage ich John, warum dem so sei. Er nennt verschiedene Gründe: Nicht alle Tänzer verfügten über die für das Tragen aller Schmuckstücke notwendigen Piercings, nur wenige hätten eine komplette Ausstattung geerbt und nicht jeder könnte sich die noch fehlenden, teilweise kostspieligen Schmuckstücke leisten. Nur manche der Ältesten besäßen alle notwendigen Stücke, die sie entweder schon von ihren Vätern übernommen oder von „Sponsoren“ erhalten hätten. Auf meine Rückfrage, wer denn die Sponsoren sind, nannte er allgemein namesake oder bonie. Wenn notwendig, leihen die Tänzer Fehlendes aus. Die Leihgebühr haben deren Auftraggeber zu tragen.

Die drei Männer haben ihre Tanzausstattung aufwendig verpackt: Jeder hat seinen lepanesa auf herkömmliche Weise zunächst um ein Bambusrohr und dann in ein Blatt der Fächerpalme gewickelt und schließlich in eine Plastiktüte gepackt, um ihn vor Ungeziefer und Feuchtigkeit zu schützen. Die nelo bewahren sie in Watte eingeschlagen, in Behältern aus Holz, Metall oder Kunststoff auf. Die Federn des Haarschmucks meikio stecken in Bambusröhren. In weiteren Plastiktüten befinden sich gleich mehrere Dinge: verschiedene Arten Ohrringe und Steckschmuck, die sie nach der Prüfung ausbessern oder am nächsten Morgen ausbessern lassen, ebenso wie die Beinrasseln nasepale, verschiedene Ketten und Armreifen. Simon Me'notea hat bereits vor Tagen Balu seinen lepanesa zur Ausbesserung überlassen, den er nun zurückerhält - es ist zu meiner 
Überraschung ein Tanzschurz aus Kunstfasern. Simon ist mit den von Selwyn angebrachten neuen Dekorationen aus Pandanus sichtlich zufrieden und lacht. Auf meine Frage, warum er keinen Tanzschurz aus Bananenbast trage, antwortet Simon, dass er auch lieber einen neuen, ,traditionellen' hätte, sich diesen aber (noch) nicht leisten könne. ${ }^{155}$ Die beiden Männer aus Neo berichten von einer in rund zwei Wochen stattfindenden Schließungsfeier ihres Tanzplatzes und den damit verbundenen Initiationen der Kinder und Jugendlichen, wozu über 100 Schweine geschlachtet werden und einige der Tänzer des nächsten Tages bereits engagiert sein sollen. Ich muss mich bremsen, um sie nicht mit Fragen zu löchern, da ich Selwyn gegenüber nicht den Eindruck erwecken möchte, dass mir die Schließungsfeier wichtiger sei als die Gedenkfeier seines Vaters. Von daher kommt mir Johns Hinweis sehr gelegen, dass er noch arbeiten müsse und ich ihn bitte begleiten möge. Selwyn scheint darauf gewartet zu haben und versichert mir nochmals, dass ich nichts, Wichtiges'verpassen würde. Alleine mache es für mich keinen Sinn zu bleiben, da die Männer zunehmend in Natügu sprächen und ich jemanden brauche, der mir übersetzt. Daher brechen John und ich kurz nach 10 Uhr auf. [...]

\section{- Das Anlegen der Tanzkleidung - weitere Akteur-Netzwerke entstehen}

Wie bereits zuvor ist auch die folgende Darstellung meine Rekonstruktion der vielen oftmals parallellaufenden Handlungen. Um sowohl die Vielzahl der Beziehungen bzw. Handlungen zwischen den Männern untereinander als auch zwischen ihnen und ihrer Kleidung besser greifen` zu können, beschreibe ich einen Ankleidungsprozess chronologisch, der mehr oder weniger der idealen Praxis entspricht, wie mir Selwyn Balu später versicherte. ${ }^{156}$ Im Fokus meiner Betrachtung steht dabei der junge Tanzdebütant Steward Bice Me'tu, der die Rolle und Funktion eines nelo-Tänzers von seinem Vater übernehmen wollte und darin Möglichkeiten für die eigene soziale und ökonomische Entwicklung als auch für die Artikulation seiner ,modernen` kulturellen Identität sah (pers. Kommentar).

[...] Es ist kurz vor 5 Uhr morgens, als John und ich sein Haus verlassen. Obwohl es noch stockdunkel ist, herrscht rege Betriebsamkeit entlang des Weges zu Selwyns Haus. In den separierten und für die Vorbereitungen teilweise ausgebauten Kochstellen der Häuser sehe ich viele Frauen arbeiten. Aus allen Häusern zieht beißender Qualm von den schwelenden Erdöfen in den noch immer sternenklaren Himmel. Als wir wieder bei Selwyn ankommen, schließt seine Ehefrau Miriam in ihrer Kochhütte die seit Tagen dauernden Arbeiten ab - Zeichen von Müdigkeit erkenne ich in ihrem Gesicht überraschender Weise keine - und lächelt mich an. Im Haus sind im Laufe

\footnotetext{
155 Selwyn Balu berechnete im Jahr 20II den Tänzem für einen neuen Tanzschurz 450 SBD als Fixpreis, wohingegen er sie an Fremde für bis zu I.200 SBD verkaufte. Im Jahr 20 I I entsprach dies ca. 45 bzw. I 20 Euro.

156 DAVENPORT (2005: 20-2I) und KOCH (1971: 129-130) beschreiben das Anlegen der Tanzkleidung und des Schmucks in den 1960er-/I970er-Jahren. Letzterer filmte zudem das Ankleiden (1972 e).
} 
der Nacht weitere Männer eingetroffen. Ich erkenne im Schein ihrer Taschenlampen Philipp Malu und Kennedy Olu und gehe zu ihnen. Beim Auspacken und Aufbauen meiner Kamera berichtet Philipp, dass Kennedy und er ausgewählt worden waren, die Gesichter der Tänzer mit den typischen Mustern zu bemalen. Sie besprechen gerade, mit welchem Werkzeug sie die Farbe auftragen wollen und entscheiden sich für dünne Holzstäbchen. In dem spärlich beleuchteten Haus mache ich auch Älteste aus wie z. B. den ehemaligen Paramount Chief Ambros Me'naa aus Nonia. Wie er mir sagt, wohnt er während des Festes bei seinem Freund Wilson Kabi im Nachbardorf Luepe. Ein anderer ist Alan Me'naip aus Ne'ele, ein ehemaliger nelo-Tänzer, der in den 1970erJahren mit William Davenport zusammengearbeitet hatte. ${ }^{157}$ Von Minute zu Minute passiert zunehmend mehr und weitere Männer treffen ein - nicht nur die Tänzer. Ich wünschte, ich könnte mich teilen. Philipp möchte, dass ich ihn beim Arbeiten filme, Selwyn ruft mich nach draußen, um das Färben der Haare zu dokumentieren, und einige der nelo-Tänzer, die ich schon vorher kennengelernt hatte, zeigen mir stolz ihre Schmuckstücke und möchten mit ihnen fotografiert werden. Die meisten wissen, dass ich meine Fotos auf CD brennen und einige CDs bei den Familien lassen werde - die wenigsten haben Fotos von sich als nelo-Tänzer. Einige der jungen zuschauenden Männer haben ihre Mobiltelefone mitgebracht und fotografieren ebenfalls das Ankleiden der Männer oder als ,Selfie ${ }^{6}$ sich selber neben den nelo-Tänzern. Ein wiederkehrendes Muster fällt mir auf: Die älteren Anwesenden beraten die jüngeren - etwa Philipp Malu, Kennedy Olu und Paul Fisheryoung Kabune bei der Ausbesserung der Schmuckstücke - und helfen anderen nelo-Tänzern beim Ankleiden (s. Abb. 66).
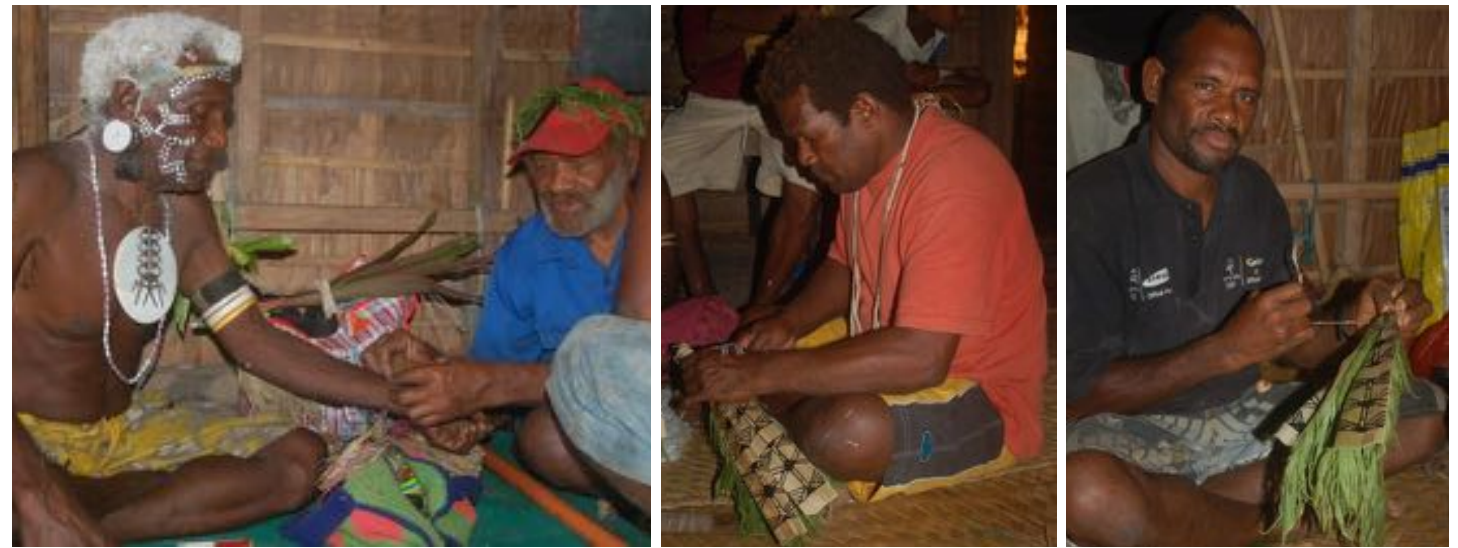

Abb. 66: Der ehemalige Paramount Chief Ambros (r.) hilft Steven Me'kuka (l.) beim Ankleiden. Noch tragen die Tänzer ihre Shorts oder kaleko, die manche zum einfacheren Umziehen um ihre Hüften gewickelt haben.

Abb. 67 und 68: Philipp Malu und Paul Kabune bessern verschiedenen Steckschmuck aus.

${ }^{157}$ Auf dem Foto des Einbands von Davenport (2005) ist er der links abgebildete Tänzer. 
Nachdem ungefähr die Hälfte der erwarteten nelo-Tänzer eingetroffen ist, erscheint gegen 8 Uhr Steward Bice Me’tu, der heute sein Debüt geben und das ,nelo-TänzerSein'von seinem Vater Martin Me'penia übernehmen will. ${ }^{158}$ Er trägt eine lange Bluejeans mit T-Shirt. Me’tu begrüßt einige Bekannte und sucht einen freien Platz im Haus um seine Taschen abzulegen. Ich folge ihm und begrüße ihn ebenfalls. Über Jerry Me'ioko, einen tabu und namesake seines Vaters, hatte ich ihn fragen lassen, ob ich sein Debüt dokumentieren dürfe, und vor dem Fest seine Einwilligung erhalten. Dennoch bin ich ein wenig gehemmt, da auch ich ,mein Debüt ${ }^{6}$ - als dokumentierender Ethnologe - bei dem Fest gebe und mich durchaus unwohl fühle, permanent mit Foto- und Filmkameras ,drauf zu halten‘. Zuhause würde ich nie so nahe an mir fremde Personen herantreten. Später beschreibt Me'tu, wie angespannt auch er war, dass er Lampenfieber hatte und sich sehr unwohl fühlte, im Mittelpunkt des Geschehens gestanden zu haben. Er kam sich im lepanesa nackt vor und schämte sich, sich vor und mit den anderen Männern umziehen zu müssen. Aber all dies schmälerte seinen späteren Stolz nicht. Er hielt die ganze Nacht durch - was nicht allen Debütanten gelang - und erfuhr in den Tagen nach dem Fest sehr viel Lob. Er wurde zu einem geachteten Mitglied seines Dorfes und Mitglied der Graciosa Bay Nelo Association. Nach eigener Aussage wollte er in den kommenden Jahren seinen Bekanntheitsgrad und seine Popularität als nelo-Tänzer weiter steigern. Ihm zufolge wurden die Tänzer als Garanten der Überlieferung der ,Kultur' angesehen und galten als „,real Santa Cruz men, [...] [who] uphold traditional norms of traditional dancing". Seine nelo-Tanzausstattung stammte von seinem Vater Me'penia, die dieser bis zu dem Tag noch selber genutzt und zudem bereits

\footnotetext{
158 Den kastom-Namen Me'tu hatte Steward Bice von James Lengi erhalten, der zwar nicht an der Brautpreiszahlung der Familie des Vaters beteiligt gewesen war, aber Stewards Initiationsfeier ausgerichtet hatte und dadurch das Recht der Namensgebung erhalten hatte. Er litt zu der Zeit an einer langwierigen Beinverletzung mit ständigen Schmerzen (Natügu: tu), so dass er seinem namesake nicht den Namen Lengi, sondern Me'tu (Mann mit den Schmerzen) gab. Me'tu, selber bereits Vater von zwei Kindern, war der Erstgeborene aus der zweiten Ehe seines Vaters Me'penia und arbeitete als Kassierer der Solarenergie-Ladestation in Balo in der Graciosa Bay. Sein Vater erachtete die beiden Söhne aus erster Ehe als ungeeignet, nelo-Tänzer zu werden, da sie in seinen Augen zu dick und wenig athletisch waren. Zudem hatten sie ihrerseits kein Interesse bekundet, von ihrem Vater den nelo-Tanz zu übemehmen. Folglich hatte Me'penia als nächsten seinen Erstgeborenen aus zweiter Ehe gefragt. Seiner Aussage zufolge war Me'tu darauf sehr stolz gewesen und hatte das Angebot sofort angenommen. Er respektierte und ehrte seinen Vater und den kastom seines Dorfes. So wie er es sah, war der nelo-Tanz von den Vorfahren weitergegeben worden und für ihn daher sehr wichtig. Me'tu betrachtete den Tanz aber auch als zukünftige Einkommensquelle. Er war ungefähr im Alter von fünf Jahren initiiert worden und verfügte dadurch grundsätzlich über alle für einen nelo-Tänzer notwendigen Piercings. Er hatte jedoch das Loch in seinem Septum unzureichend geweitet, so dass er (noch) kein nelo tragen konnte. Ab Januar 2012 wollte er dies durch das Einsetzen zunehmend dickerer Stöckchen nachholen, um bei seinem erhofften Auftritt im Rahmen des Festivals of Pacific Arts (FoPA) im Juli 2012 in Honiara ein nelo tragen zu können, falls die Graciosa Bay Nelo Association, in der er bereits Mitglied war, dort auftreten würde. Da die Löcher in seinen Nasenflügeln fast zugewachsen waren und er im Juli auch mit den Federgeldstäben noiapu auftreten wollte, plante er diese von einem verwandten Arzt im Hospital von Lata wieder vollständig öffnen zu lassen. Er hatte keine besonderen Tanzunterweisungen erhalten, sondern im Laufe der Jahre an vielen Tänzen als Zuschauer teilgenommen und durch Zuhören einige Lieder erlernt (Me'tu, Me'penia und Me'ioko, I3.9.20II).
} 
u. a. vier- oder fünfmal an Jerry Me'ioko verliehen hatte. Me'penia selber war aufgrund des frühen Todes seines Vaters bereits als Jugendlicher noch vor dem Zweiten Weltkrieg von den Ältesten seines Dorfes gebeten worden, nelo-Tänzer zu werden. Das nelo war 1951 von Simon Me'abir aus Nepa hergestellt und wie das tema bereits vom Großvater an den Vater vererbt worden. Die Ohranhänger talengi waren über 20 Jahre alt und schon mehrfach ausgebessert. Erst nach einer offiziellen Übergabezeremonie würde die Ausstattung von Me'penia in Me'tus Eigentum übergehen. Der lepanesa hingegen war ,neu' und aus Bananenbast - Me'tu hatte ihn bereits einmal im Rahmen eines Gottesdienstes, aber noch nicht zu einem kastom-Tanz getragen (Me'tu, Me'penia und Me'ioko, 13.9.2011). ${ }^{159}$

Von draußen dringen immer wieder Selwyns Aufforderungen in das Haus, die Tänzer mögen herauskommen, um sich die Haare weißen zu lassen. Damit man ihn überall hört, hat er sich ein Megafon geliehen. Me'tu zieht sein T-Shirt aus und begibt sich vor den Seiteneingang des Hauses. Einer der wechselnden Helfer nimmt sich seiner an und bittet ihn, sich vor ihn neben zwei Schüsseln zu hocken. Aus der einen Schüssel nimmt der Mann ein wenig lime (Pijin für gebrannten Korallenkalk) und zerreibt diesen zusätzlich mit Wasser aus einer weiteren Schale zwischen seinen Händen. Dann streicht er die weiße Farbe locker auf Me'tus Haare. Er wiederholt den Vorgang mehrere Male, bis dessen Haare mehr oder weniger gleichmäßig mit der Farbe bedeckt sind. Anschließend zupft er die Haare mit einem lokal gefertigten Holzkamm auf, so dass sie wieder ihr ursprüngliches Volumen erhalten (s. Abb. 69).

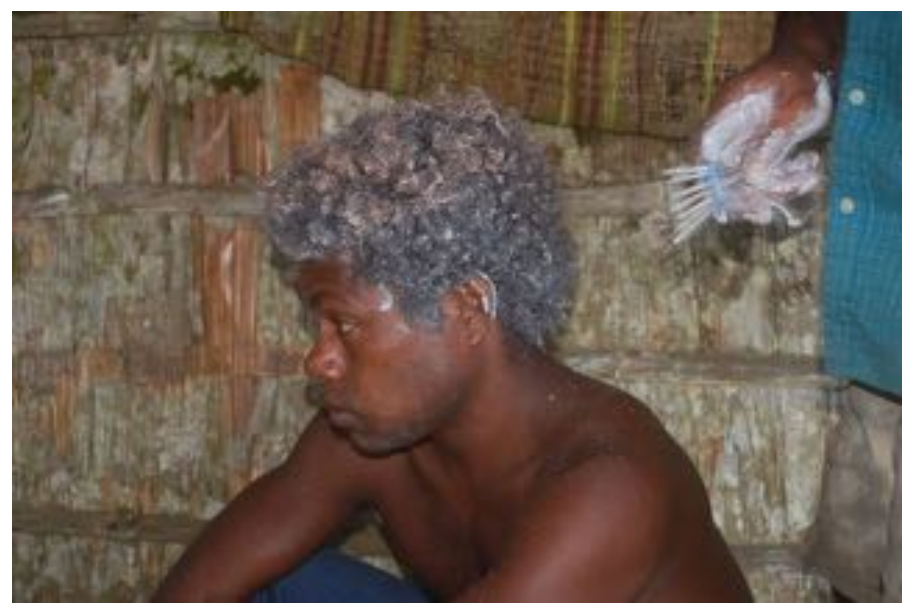

Abb. 69: Steward Bice Me'tu lässt sich die Haare weißen.

Neben Me'tu hat Chief Peter Lawrence Dewa aus Malo Platz genommen und lässt sich von einem anderen Mann parallel die Haare weißen. Der Kalk verleiht den Haaren nicht nur eine weiße Farbe, sondern macht die Frisur auch starr, so dass nach dem Trocknen der lime-Paste der Haarschmuck meioko besser in ihr halten wird. Neben der

${ }^{159}$ Zur Rolle von nelo-Tänzern bei den Gottesdiensten auf Ndendö vgl. Kap. 3.3.3. 
Vorstellung, mit der Aufmachung dukna zu kopieren, wird mir keine weitere Bedeutung der Färbung genannt. ${ }^{160}$

Nach dem Färben der Haare kehrt Me'tu ins Haus zurück und setzt sich zu Philipp Malu, um sein Gesicht bemalen zu lassen. Malu taucht ein Holzstäbchen in eine Metalldose mit industriell hergestellter weißer Farbe und trägt nach und nach zwei Reihen Tupfen auf Me'tus Gesicht auf. Das Motiv nori tema (nori: Muster, tema: Mond, vgl. Kap. 5.2.1) ist ausschließlich den Debütanten vorbehalten und unterscheidet sich in der Stirngestaltung sowie an den seitlichen Wangenpartien von dem malipo genannten Motiv der übrigen Tänzer (vgl. Abb. 70-72). Malu erläutert weiter, dass das zentrale Element an der Wange eines Ersttänzers einen Halbmond und der spitze Winkel aller Anderen einen Haizahn symbolisierte. Die in zwei Linien gepunktete Umrandung hieß dapwa me, was so viel wie ,Muster nur für Männer` bedeutete. Weitere Bedeutungen nannte er nicht. ${ }^{161}$
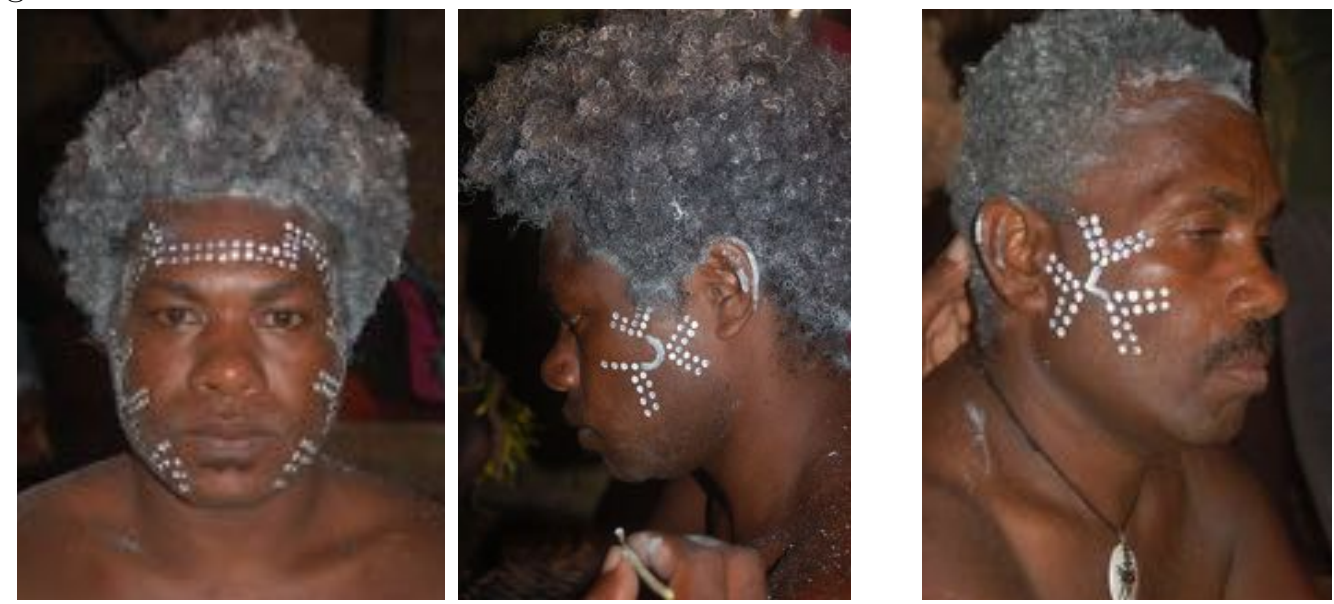

Abb. 70-72: Gesichtsbemalungen. V. 1. n. r.: Me’tu trägt das den Debütanten vorbehaltene Halbmond-Muster nori tema. Eddie Me'nangos Schläfen werden hingegen mit dem HaizahnMuster malipo, dem der etablierten Tänzer, bemalt. Er trägt hier noch ein kleines tema.

Als Me'tu fertigt ist, kehrt er zu seinem Platz zurück, wo auch Chief Dewa in der Zwischenzeit seine Kleidungs- und Schmuckstücke ausgebreitet hat. Nun erst fällt mir auf, dass jeder Zentimeter Bodens in Selwyns Haus belegt ist. Überall stehen und sitzen Männer, reden und lachen miteinander. Wenn es keine Tänzer sind, begutachten sie

\footnotetext{
160 Die Haare können geweißt, mit Ruß geschwärzt oder je zur Hälfte geweißt und geschwärzt werden. Dies lag, It. Tänzern, in ihrem eigenem Ermessen. Wichtig war angeblich, dass dies paarweise erfolgen sollte. Zu diesem Fest war dies allerdings nicht der Fall. Ein Paar musste ,gemischt' auftreten, da nur einer, Bartholomew Me'aiol, seine Haare geschwärzt hatte, wohingegen alle anderen ihre Haare weiß gefärbt trugen (Me'tu, Me'penia und Me'ioko, 13.9.20 I I). Bei den Tanzaufführungen für Touristen in Malo in den Jahren 2009 bis 20 I 4 trugen dagegen mehrere Männer schwarze oder schwarz-weiße Frisuren.

161 In der Vergangenheit wurde wie beim Haar Lime als Farbe für die Gesichtsbemalung benutzt, der sich im Laufe der Nacht infolge des Schwitzens jedoch abwusch. Heute setzen Malu und Olu die wesentlich länger haltenden Industriefarben ein, die sich während der Tänze nicht ablösen. Malu war auch zu dem Abschlussfest alue in NeoNemba gebeten worden, die Tänzer zu bemalen (Philipp Malu, 31.8.20 I I).
} 
den Schmuck und helfen den nelo-Tänzern beim Ankleiden. Selwyn läuft mit seinem Megafon durch die Menge und instruiert die Neuankommenden. Ich versuche, nicht nur Me'tu zu begleiten, sondern zumindest jeden Tänzer beim Auftragen der Gesichtsbemalung zu fotografieren, um von jedem ein Porträt zu haben und später die Namen zuordnen zu können. John Namiade fotografiert viele der von ihm gefertigten tema an den Männern, die sie tragen. Ich bekomme leichte Panik, nicht alles dokumentieren zu können und bitte ihn, die Namen aller Tänzer sowie die Anzahl der Tänze aufzuschreiben, die sie jeweils absolviert hatten. Für John scheint dies eine interessante Frage zu sein, und er macht sich sofort ans Werk. Nach einem kurzen Gespräch miteinander (in Natügu), einer Zigarette und einem Betelpfriem widmen sich Me'tu und Dewa parallel dem Anlegen ihrer Kleidungsstücke, wobei es keine festgelegte Reihenfolge zu geben scheint. Selwyn Balu ruft indessen immer wieder durch das Megafon, dass die Tänzer bis zum ersten gemeinsamen Essen gegen 10.30 Uhr das Anlegen aller Schmuckstücke am Oberkörper abgeschlossen haben müssen. Nach der Pause sollen sie ab spätestens 11.30 Uhr jeweils ihren lepanesa, ihre Beinrasseln nasepale, ihren meioko und abschließend ihren Nasenschmuck nelo und noiapu (Federgeldstäbe) anlegen. Gegen 12 Uhr mittags sollen sie zusammen mit den Kriegern vollständig angezogen vor seinem Haus zusammenkommen und zum nir ziehen.

Me'tu entnimmt daraufhin seinem Rucksack zwei Plastiktüten. In der einen befindet sich eine Kette Muschelgeld noiatema und in der anderen das tema seines Vaters bzw. Großvaters, das zusätzlich noch in ein Tuch gewickelt ist. Der Mann, der ihm zuvor noch die Haare gefärbt hatte, hilft ihm nun, tema und noiatema anzulegen. Dazu knotet er die Enden der Bänder zusammen und befestigte ein tema narabe (kleineres tema) an dem Band des großen tema auf Me'tus Rücken (s. Abb. 73). Mir erschließt sich keine eindeutige Zuordnung, wer wem zur Seite steht, da Tänzer, Krieger und auch nicht am Tanz Beteiligte unterschiedlichen Tänzern helfen. Soweit ich erkennen kann, bestehen bis auf eine Ausnahme alle tema aus Tridacnamuschel, und nur ein tema ist ohne Schildpattauflage mabu. ${ }^{162}$

Nachdem Me'tu die ersten Schmuckstücke angelegt hat, entnimmt er weiteren Tüten seines Rucksacks verschiedene Armbänder und -reifen. Auf jeden Arm streift er zuerst ein aus Lianenbast und Schneckenperlen geflochtenes Armband teliki und danach zwei Oberarmreifen mbenia aus Trochus-Seeschneckengehäuse. Nicht alle Tänzer tragen Armbänder/-reifen aus Naturmaterialien. Manche der Schmucksachen sind aus Kunststoff bzw. aus elastischen Kunstfasern gefertigt. ${ }^{163}$ Dann schiebt Me'tu an jedem Arm den Tanzschmuck tangalilu (ein Artefakt aus Holz mit Glasperlen, bemalten TapaStreifen und Bündeln getrockneter Pflanzenfasern) in die Armbänder und -reifen (vgl.

162 Charles Me'aio aus Banua trug als einziger ein tema aus Keramik. Im Gegensatz zum Fest in Ne'ele trugen auf dem Abschlussfest in Neo-Nemba mehrere nelo-Tänzer tema aus Keramik (vgl. auch Kap. 4.3. I, S. 92-93).

163 Diesen Steckschmuck hatten zuvor Malu, Kebune und Olu für die Tänzer ausgebessert, sofern diese es als nötig erachtet hatten (vgl. Abb. 67-68 und Abb. 75). 
Abb. 74). Abschließend für den Oberarmschmuck nimmt er sich zwei Büschel mit wohlriechenden Blättern und Blüten und steckt sie zu dem Tanzschmuck. ${ }^{164}$ Diesen in Pijin parfium genannten, frischen Pflanzenschmuck fertigt u. a. Simon Me'notea während des Morgens, wozu er Blätter und Blütenstände der Euodia hortensis mit Kordel zu kleinen Sträußen bindet (s. Abb. 75).
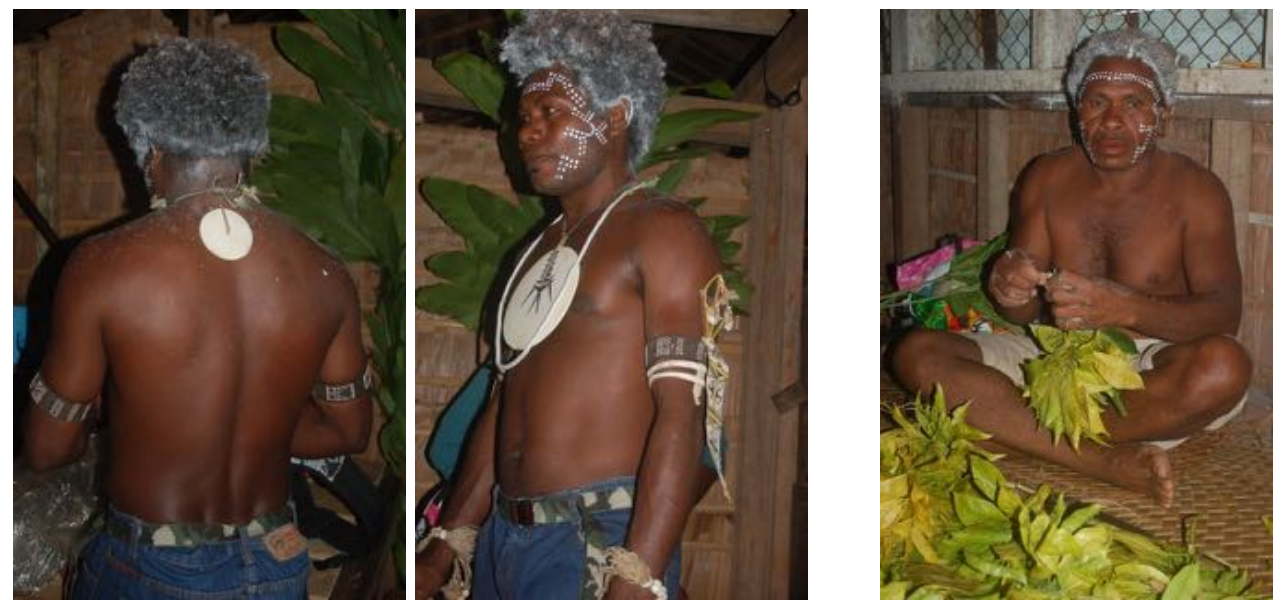

Abb. 73: Steward Me'tu - noch in Bluejeans - mit einem kleinen tema narabe für den Rücken. Abb. 74: Me'tu mit tema, noiatema, Armschmuck teliki, mbenia, tangalilu und maluembe.

Abb. 75: Simeon Me'notea aus Neo bei der parfum-Herstellung (Euodia hortensis).

Als letzten Schmuck für den Arm entnimmt Me'tu einer Plastiktüte zwei Armbänder für die Unterarme maluembe und bittet einen Helfer, ihm diese umzubinden. Nicht alle Tänzer legen diese Art Armbänder an, manche tragen stattdessen eine Armbanduhr, manche lassen ihre Handgelenke frei. Da Me'tu seinen Armschmuck nun vollständig angelegt hat, fotografiere ich ihn ein weiteres Mal. Mir ist es sehr unangenehm, immer wieder ,drauf ${ }^{\natural}$ zu halten, und ich komme mir immer wieder wie ein Fremdkörper vor. Wie ich merke, ist er mir gegenüber sehr schüchtern und spricht so gut wie gar nicht mit mir. Da ich ihn nicht in die Enge und mich nicht noch weiter in den Vordergrund drängen möchte, halte ich mich ein wenig abseits und warte mit Fragen. Jerry Me’ioko kommt von Zeit zu Zeit zu uns und beantwortet an seiner Stelle meine Frage, wofür ich ihm sehr dankbar bin. Als Nächstes lässt sich Me'tu einen schwarzen Baumwollstreifen oberhalb der Stirn am Haaransatz festbinden. An diesem Kopfband lassen sich einige nelo-Tänzer ihre telengi anbringen, damit ihre Ohren nicht das ganze Gewicht des teilweise sehr ausladenden Ohrschmucks tragen müssen. Ich mache keinen Mann mit großen Löchern in den Ohrläppchen aus, wie ich sie auf historischen Fotos gesehen hatte. Der Mehrzahl dient das Band zudem zum Fixieren des Haarschmucks

\footnotetext{
164 Manche der Tänzer trugen statt der Armbänder und -reifen aus natürlichen Materialien Nylon-Sportbänder und Reifen aus PVC. 20I I stellte u. a. der ehemalige Paramount Chief Ambros Me'naa aus Nonia (vgl. Abb. 66) teliki her; Armreifen aus Trochus-Seeschneckengehäuse produzierten Wilson Kabi und John Namiade aus Luepe sowie Ben Banie aus Ne'ele.
} 
meikio. Me'tus Ohrschmuck wird telengi narabe genannt und besteht aus sechs ineinander gesteckten Schildpattringen, einer Scheibe Tridacnamuschel im selben Durchmesser der Ringe, die mit einem grafischen Dekor aus Schildpatt belegt ist (s. Abb. 76). Ähnliche telengi anderer Tänzer unterscheiden sich im Wesentlichen im Schildpattdekor. Einen ganz anderen Typ trägt hingegen Ben Banie. Bei seinem telengi ndäka genannten Ohrschmuck wird die Tridacnascheibe mit einem Kranz aus Zangen des Rhinozeroskäfers (Oryctes rhinoceros) umrahmt. Laut Philipp Malus Aussagen ist er selber der einzige, der zu dem Zeitpunkt diese Art der telengi herstellt (vgl. Abb. 77).
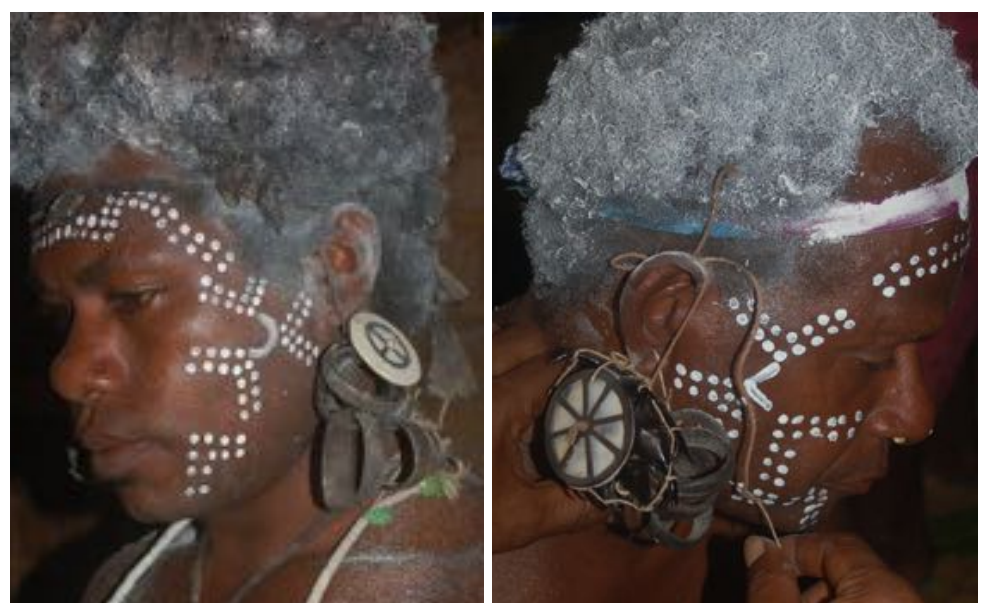

Abb. 76: Steward Me'tu mit telengi narabe.

Abb. 77: Ben Banie mit telengi ndäka (Zangen des Rhinozeroskäfers).

Wie Selwyn mir mitteilt, sind inzwischen alle Tänzer bis auf einen anwesend, dessen Absage soeben erst eintraf. Da Balus Haus nicht mehr ausreichend Platz für alle bietet, hängen die zuletzt Ankommenden ihre lepanesa im Haus an der Leine auf (s. Abb. 78) und verlassen nach den Begrüßungen wieder den Raum, um sich außen vor dem Haus auf geflochtenen Kokosblattmatten auf dem Boden niederzulassen.

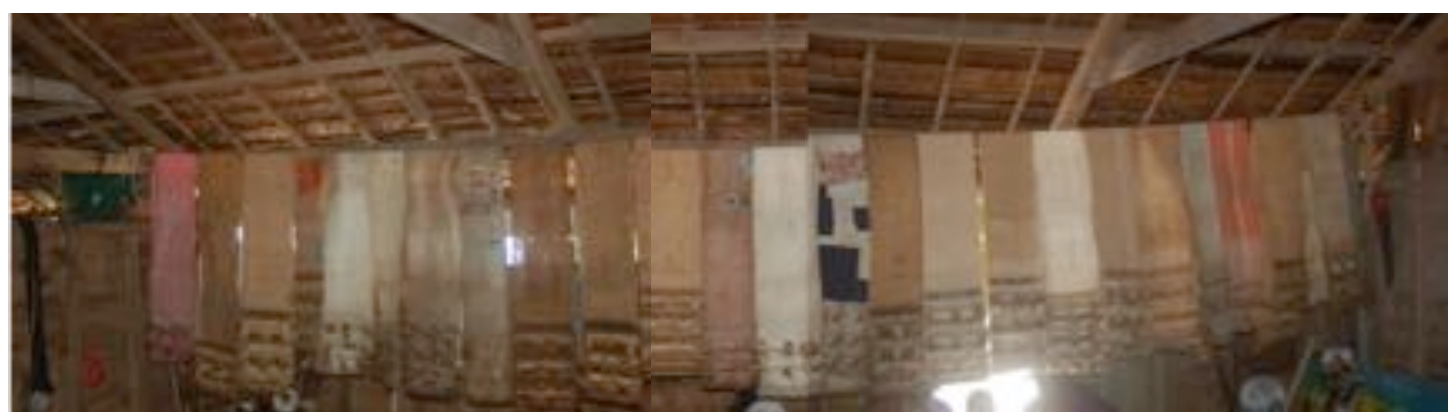

Abb. 78: Alle lepanesa der an dem Tag auftretenden Tänzer hängen auf der Leine in Balus Haus. Die unterschiedlichen Materialien und ihr Alter sind gut erkennbar.

In und vor dem Haus sitzen nun überall Männer inmitten von Rucksäcken, Plastiktüten und Körben und legen ihre Ausstattungen selber und mit Hilfe anderer an. Es ist in meinen Augen ein absolutes Durcheinander, die Männer lachen, rauchen, rufen 
sich zu oder essen, und viele Kinder rennen ständig zwischen ihnen herum und begutachten, was die Erwachsenen tun. Da die Zahl der nelo-Tänzer ,gerade' sein soll, muss für den ausgefallenen Tänzer sehr schnell ein Ersatzmann gefunden werden. ${ }^{165}$ Jerry Me'ioko hatte einen Teil seiner Ausstattung für den Tänzer mitgebracht, der nicht gekommen war. Da er auch Mitglied der Graciosa Bay Nelo Association ist, bittet Selwyn Balu ihn kurzerhand, spontan für ihn einzuspringen. Me'ioko ist über die unerwartete Wendung wenig erfreut, wie er mir unverblümt mitteilt. Er hatte sich sehr darauf gefreut, das Fest als Zuschauer begleiten zu können und nicht den restlichen Tag bis zum Morgengrauen tanzen zu müssen. Dennoch gibt er Balus Wunsch nach. Das Zusammentragen der fehlenden Kleidung und Schmuckstücke erfolgt sehr zügig. Schwierig ist lediglich, ein passendes nelo für ihn zu finden, da die Öffnung in Me’iokos Septum, seiner Aussage nach, relativ eng ist und kaum eins passt. Nachdem sich jemand bereit erklärt, sein nelo gegen ein anderes mit einem größeren Steg zu tauschen, ist eins für Me'ioko gefunden.

Die Zeit vergeht wie im Fluge. Es ist schon 10.30 Uhr, als Balu mich darauf hinweist, dass seine Ehefrau I'ambuk begonnen hat, mit ihren Helferinnen Essen für alle Tänzer, Krieger und Helfer in ihrem Haus sowie auf deren Vorplatz zu servieren. Es war das erste von vier gemeinsamen Essen der nelo-Tänzer im Laufe des Fests. Die nächsten sollten gegen 14 Uhr, 21 Uhr und am nächsten Morgen zum Abschluss nach Sonnenaufgang stattfinden. Jede der vier Gastgeberfamilien musste eines der großen Essen ausrichten, die in unmittelbarer Nähe ihrer Häuser stattfanden. In kleinen, traditionellen Holzschalen (Pijin: small kastom bowls, Natügu: lam katapo), auf Bananenblättern, in Kunststoffboxen, Aluminiumschüsseln und Blechschalen bringen sie Gemüse wie zubereitete Blätter des Königsbaums (Pïin: cabbage, Natügu: lopra), Püree (Pïin: pudding) von gebackenen Yams, Sumpf- und Trockentaro, Kochbananen und Kokosnussöl, gegarte pana (Natügu für lokale Süßkartoffelart), Taro, Yams und im Erdofen gebackene

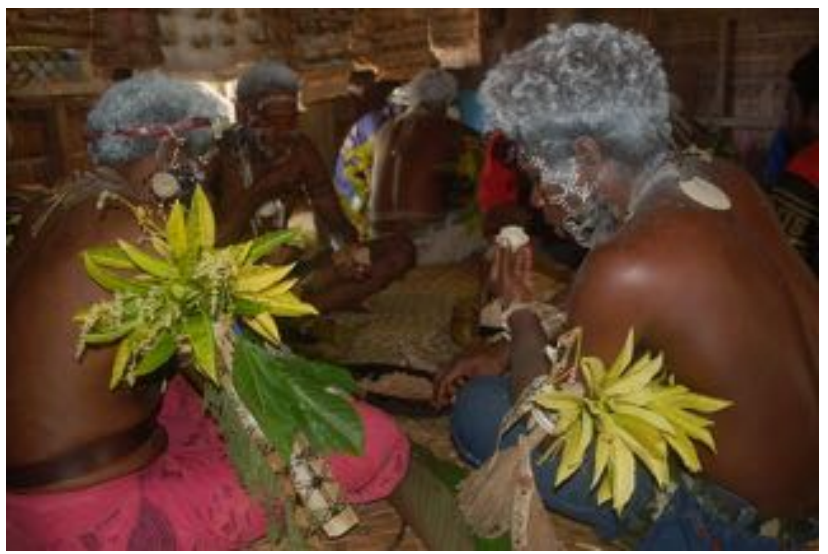

Abb. 79: Steward Me'tu (r.) mit John Me'yirngao (1.) bei dem gemeinsamen Essen vor dem Anlegen von lepanesa und nelo.

\footnotetext{
165 Aus demselben Grund wurde auch Selyn Balu später in der Nacht unerwartet zum Tänzer, da der ältere Hugo Mawe aus Menau Knieschmerzen bekam und nicht mehr tanzen konnte. Zu den möglichen Gefahren durch die dukna im Tanz vgl. Anm. 150.
} 
Thunfischstücke. ${ }^{166}$ Me'tu nimmt zusammen mit John Me'yirngao in Balus Haus Platz und erhält eine der Schalen (s. Abb. 79).

Wie vorher angekündigt, fordert Selwyn Balu nach einer guten Stunde Pause die neloTänzer auf, das Essen zu beenden und sich weiter anzukleiden. Jetzt folgt nach den Aussagen der Tänzer der wichtigste Schritt: das Anlegen der lepanesa. Me'tu steht auf, geht zur Wäscheleine mit den Tanzschurzen, nimmt den für ihn neu gefertigten Bananenbast-Tanzschurz ab und kehrt zu seinen Sachen zurück. Als Erstes legt er einen handelsüblichen Gürtel oberhalb seiner Bluejeans an. Peter Lawrence Dewa und Jerry Me'ioko haben ebenfalls ihre lepanesa abgenommen und stehen plötzlich neben uns, um sich gegenseitig beim Ankleiden zu helfen. Me'ioko trägt ebenfalls einen industriell hergestellten Gürtel, wohingegen Dewa einen ,traditionellen` Rindengürtel anlegt (vgl. Abb. 80 und Abb. 81).
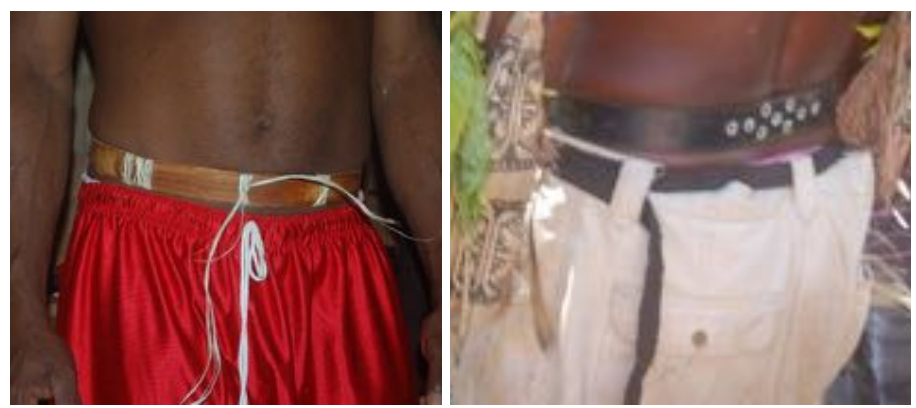

Abb. 80: Chief Peter Lawrence Dewa mit ,traditionellem` Gürtel.

Abb. 81: Jerry Me’iko mit ,modernem‘ Gürtel.

Jetzt kommt der eigentlich heikle Teil: Die Tänzer müssen sich vor dem vollständigen Anlegen der lepanesa ihrer Unterwäsche entledigen. Verunsichert schauen Me'tu und Dewa zu mir herüber, drehen sich blitzschnell einander zu und schirmen sich so gegenseitig vor den Blicken Fremder - insbesondere mir - ab. Ich kann nur andeutungsweise erkennen, dass sie zunächst ihre lepanesa vor dem Körper mit einer Falte unter den Gürtel ziehen, die dann über den Gürtel gelegt wird. Daraufhin ziehen sie ihre Hosen und Unterwäsche aus und den Schurz umgehend zwischen den Beinen hindurch und unter den Gürtel am Rücken. Ein bis zwei Helfer richten jeweils die Rückseite des lepanesa aus (vgl. Abb. 82). Mehrere Male gehen die Tänzer dabei in die Hocke, um den Tanzschurz straff zu ziehen, bis er die Genitalien bedeckt und trotzdem ausreichend Bewegungsraum bietet. Abschließend bindet Me’tu einen Stoffgürtel sowie einen lemkalo genannten Ziergürtel mit Conus-Schneckenschalengeld über seine Hüfte, mit der die Faltenüberwürfe an Vorder- und Rückseite festgezurrt werden (vgl. Abb. 83).

\footnotetext{
166 Selwyn Balu wie auch die anderen Gastgeber mussten für das Fest viele der Schalen und Schüsseln von Haushalten Verwandter und Nachbarn ausleihen.
} 

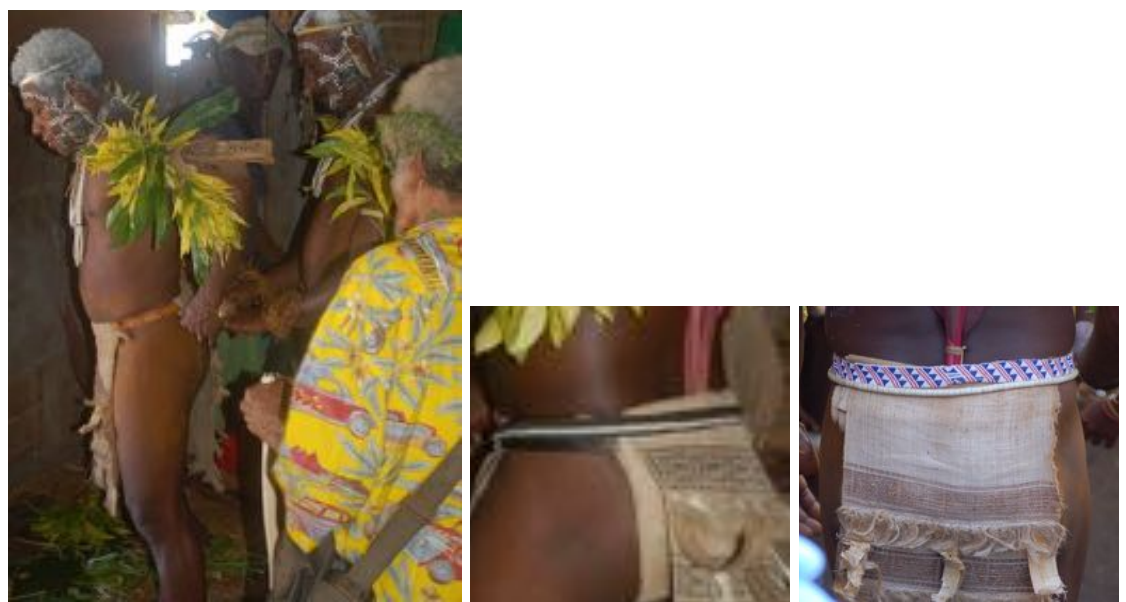

Abb. 82: Brown Ite hilft Peter Lawrence Dewa beim Anlegen des lepanesa.

Abb. 83: Steward Me'tu mit Ziergürtel lemkalo (Conus-Schneckenschalengeld).

Abb. 84: Peter Lawrence Dewa mit lemkalo und altem (polynesischem) Schmuckgürtel tusemu (Glasperlen).

Dewa legt neben dem lemkalo einen weiteren Schmuckgürtel tusemu (Natügu?) über den lepanesa, den er von seiner aus den Reef Islands stammenden polynesischen Mutter erhalten hatte (vgl. Abb. 84). ${ }^{167}$ Nun fehlt nur noch ein Bund Blätter der Ti-Pflanze (Cordyline fruticosa, Natügu: no nüngü), den sich die Tänzer am Rücken in die Gürtel einstecken lassen. ${ }^{168}$

Nach dem Anlegen des lepanesa bindet sich Me'tu die Rasseln nasepale unterhalb der Knie um seine Beine. Dabei unterlegt er die Kokosfaserkordel nicht wie viele andere nelo-Tänzer mit einem Stoff- oder Gummiband, um die Haut zu schützen. Da er aus bereits erwähnten Gründen weder nelo noch naiapo tragen kann, steckt ihm ein Helfer als letzten Schmuck ein Paar meikio (Kopfschmuck aus weißen und schwarzen Schweiffedern von Hähnen) hinter den Ohren in die Haare und fixiert sie mittels des Kopfbands.

Die Ausstattung seines Vaters ist der Beginn von Me'tus Wandel vom ,einfachen Mann` zum nelo-Tänzer. Rein äußerlich ist er nicht mehr von den etablierten Tänzern zu unterscheiden. Nun muss er die Nacht durchtanzen - sich beweisen, um tatsächlich ein geachteter nelo-Tänzer auf Ndendö zu werden.

\footnotetext{
$167 \mathrm{KOCH}$ (1971: 105) zufolge war das Tragen dieses Gürteltyps ehemals nur Frauen vorbehalten.

168 KOCH (1971: 129-130) beschreibt das Anlegen der lepanesa ein wenig anders: Nach seiner Aussage wurden die Schurze am Rücken zweifach gefaltet unter den Gürtel geschoben. Bei Peter Lawrence Dewa konnte ich eine mehrfache Faltung des Schurzes am Rücken ausmachen (vgl. Abb. 83). Bei anderen Tänzem wurde der Schurz auch nur einfach gefaltet unter dem Gürtel durchgezogen. Vielleicht steht die Anzahl der Faltungen mit der Länge des Schurzes und der Größe des Trägers in Verbindung und dient der Adjustierung der Gesamtlänge auf Kniehöhe.
} 


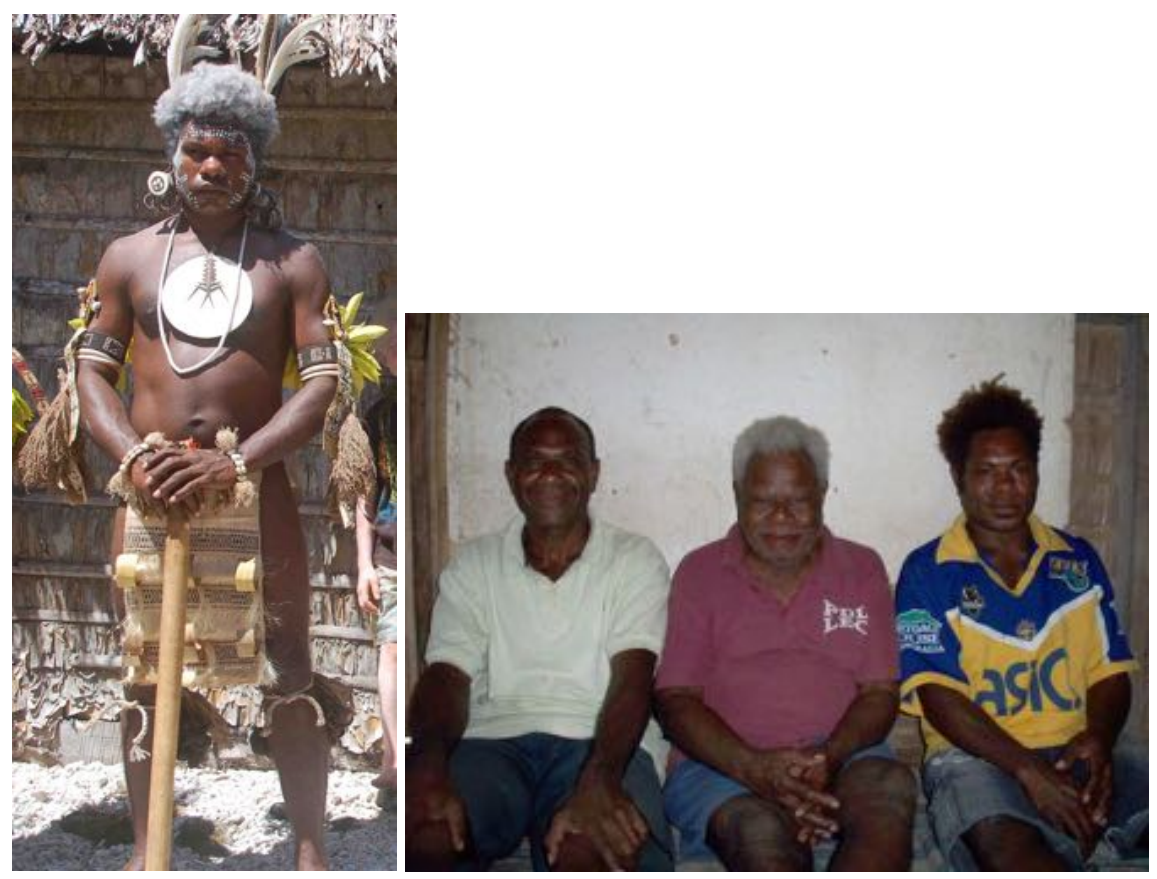

Abb. 85: Steward Me'tu nach dem Ankleiden, kurz vor seinem ersten nelo-Tanz.

Abb. 86: Me’tu (r.) mit seinem Vater Me'penia (Mitte) und Me’ioko (1.); Balo, 2011.

Für die meisten übrigen Tänzer aber steht noch aus, den Nasenschmuck noiapu und nelo anzulegen. Diejenigen, die ersteren tragen, stecken die Stäbe langsam soweit durch die Löcher ihrer Nasenflügel, bis sich deren Spitzen unterhalb der Nasenscheidewand kreuzen. Erst zuallerletzt legen sie die nelo an: Als Erstes benetzen die Tänzer mit Speichel oder Kokosnussöl den Perlmuttanhänger und die Glasperlenschnur, die an dem einzuführenden Steg befestigt sind. Dann nehmen sie den Anhänger des Stegs in die eine Hand, stecken ihn vorsichtig durch das Loch der Nasenscheidewand und ziehen ihn mit der anderen Hand langsam durch. Nach dem Anhänger folgt direkt die Schnur mit den Glasperlen und zuletzt der Steg bis zu dessen Anschlag. Bei einigen Männern scheint dies Schmerzen zu verursachen, bei anderen nicht. Manchen schießen dabei Tränen in die Augen, andere unterhalten sich dabei mit ihren Nachbarn. Nun haben auch sie ihre ,Verwandlung' vollzogen (vgl. Abb. 87 und Abb. 88).

Einige der Tänzer lassen sich von Helfern an der Hüfte sowie an den Schultern Kurkuma (Curcuma longa, Pijin: turmeric) auftragen. Laut Aussage der Tänzer soll die Farbe die Haut vor der Sonne schützen. Zudem gilt sie als Farbe der dukna und hat demzufolge auch symbolischen Wert. ${ }^{169}[\ldots]$

${ }^{169}$ Zu weiteren Bedeutungen von Kurkuma vgl. Kap. 5.2.5. 

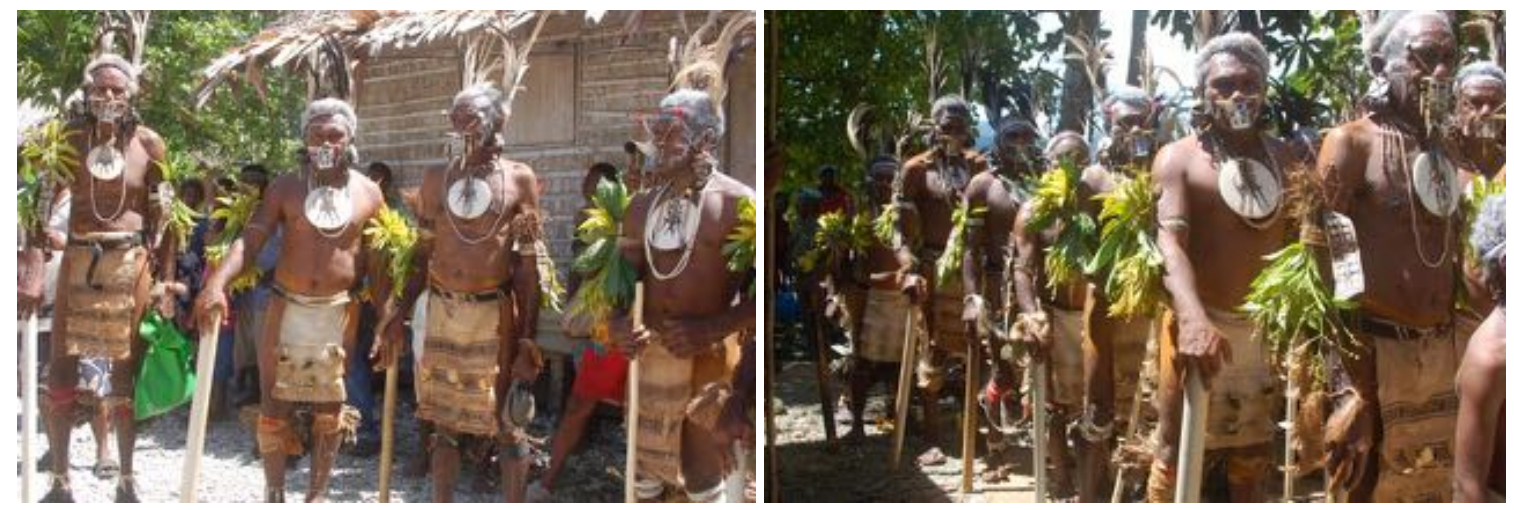

Abb. 87: Nelo-Tänzer vor dem Tanz. V. li. n. r.: Hugo Me'awe, Simeon Me'noyea, Wilson Kabi und Peter Lawrence Dewa.

Abb. 88: Die Hauptgruppe der Tänzer vor ihrem Einzug auf den Tanzplatz.

Wie auch bereits auf früheren Abbildungen von DAVENPORT (2005: 13) zu sehen, trugen vereinzelte Männer Taschen zur Aufbewahrung von Betelnuss, Kalk und Tabak (vgl. Abb. 87).

\section{- Sonderfall $a b e$}

Zu dem Tanz in Ne'ele führten zwei nach ihrem Kopfaufsatz abe benannte Anführer jeweils eine Gruppe nelo-Tänzer auf den nir (vgl. Abb. 89). Ihre Ausstattung glich größtenteils der der übrigen Tänzer, wich aber in Details davon ab: Sie trugen kein nelo, sondern einen telengi (Nasenring aus Schildpatt), Pfeil und Bogen und eben einen abe. Ihr Aussehen erinnert an die frühesten Abbildungen bzw. Fotografien (vgl. Abb. 2 und Abb. 16). Als abe konnten, eigenen Aussagen zufolge, nur wichtige Persönlichkeiten auftreten. Im Jahr 2011 waren dies zum einen Duddeley Dopue, der sowohl als recht wohlhabend als auch als kastom men bekannt und geachtet war. Er widmete sich der Überlieferung der Tanzgesänge und fertigte Artefakte, u. a. die in jedem Haushalt vorhandenen Holzschüsseln (Pijin: kastom bowl, Natügu: lam) und traditionellen Paddel, und war Mitglied der Graciosa Bay Nelo Association. Zum anderen war es der Acting Police Commissioner Walter Kola. Als Mitausrichter des Festes war letzterer verpflichtet, ein Essen für die Tänzer und die sie begleitenden Krieger zu geben und hatte aufgrund seines Amtes in Honiara dazu auch offizielle Gäste der Provinzregierung sowie einen Vertreter der Regional Assistance Mission to the Solomon Islands (RAMSI) eingeladen. ${ }^{170}$

\footnotetext{
${ }^{170}$ Für das Fest wurden ansonsten keine weiteren ,White Men' erwartet, was sich als nicht ganz zutreffend erwies, da eine am Nachmittag angekommene australisch-niederländische Schiffscrew, die auf die Zoll- und QuarantäneAbfertigung am nächsten Morgen warten musste, am Abend anwesend war. Ihre Anwesenheit erwähne ich, da neben mir später auch die Crew bezichtigt wurde, unerlaubt fotografiert und sich dadurch einen finanziellen Vorteil verschafft zu haben. Tage später diskutierten die Anführer der ausrichtenden Familien der Closing Ceremony in Neo deren Anwesenheit als Präzedenzfall für den Umgang mit unerwarteten, fremden Gästen. Als ein Ergebnis der Diskussion einigten sie sich dahingehend, dass ich Zucker als Gastgeschenk geben sollte und im Gegenzug die Erlaubnis erhielt, das Fest zu dokumentieren, wobei ich zusätzlich alle Fotos und Filme auf DVD brennen und dem Sprecher der ausführenden Familie geben sollte. Andere Ausländer würden keine Foto-/Film-
} 


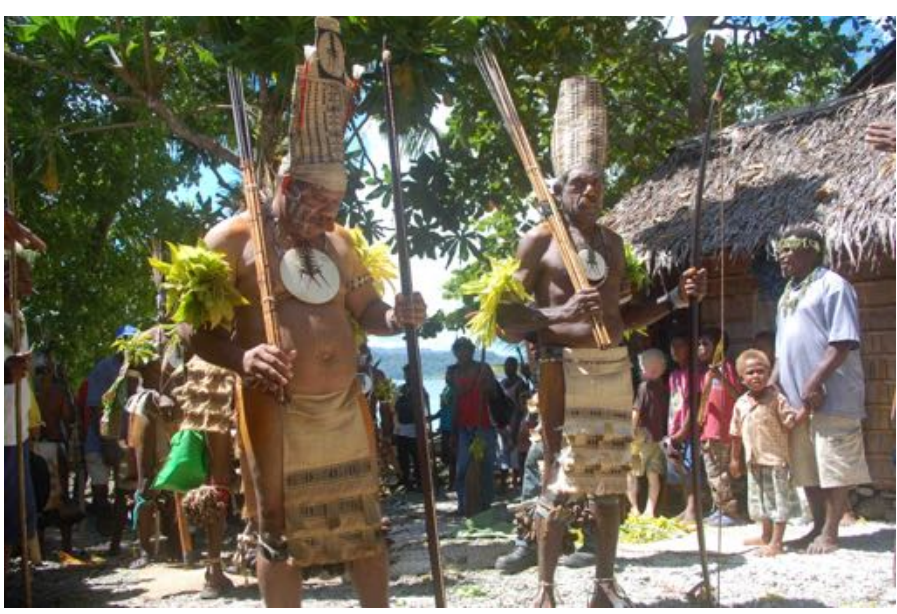

Abb. 89: Die beiden Tanzführer Acting Police Commissioner Walter Kola (1.) und Duddley Dopue (r.) mit ihren abe-Kopfbedeckungen.

Wie ist das bis hierhin Geschehene zusammenzufassen und zu verstehen?

Aus dem ursprünglich persönlichen Anliegen Selwyn Balus, mit einer Gedenkfeier für seinen Vater zugleich eine kastom-Kompensation für das Vergehen eines Vorfahren auszurichten, war ein Fest entstanden, zu dessen Gelingen viele heterogene Entitäten, vor allem ,nelo-Tänzer` beitrugen.

Mit Hilfe des von Callon entwickelten ANT-Konzeptes der ,Übersetzungsmomente (vgl. Kap. 1.2) konnte ich analysieren, wie sich aus dem konkreten Anlass der Gedenkfeier als ein zentraler Aktant das Akteur-Netzwerk ,nelo-Tanz für Jonas Kepule' entwickelte. Ich konnte damit beleuchten, wie seine konkrete Konfiguration im Verlauf seines Werdens in und mit den (Aus-)Handlungen und Aktanten, die für die Durchführung des Festes und ganz konkret des Tanzes zusammenkamen und miteinander assoziierten. Im Verlauf der verschiedenen Übersetzungsmomente hatten viele Akteure ihre Unterstützung zugesichert, ließen sich von Selwyn Balu und anderen Sprechern dieses Akteur-Netzwerkes Rollen zuweisen, folgten (weitestgehend) deren Anweisungen und aktivierten ihr Wissen und ihre Beziehungen. Als eines von mehreren für die Festvorbereitungen notwendigen heterogenen Akteur-Netzwerken wie etwa „Kochen', ,Tanzplatz' oder ,Interims-Männerhaus' traten die für den ,nelo-Tanz für Jonas Kepule` zentralen Entitäten ,nelo-Tänzer` im Sinne eigener Akteur-Netzwerke in Erscheinung.

In der konkreten Beschreibung des Ankleidens eines jungen Mannes wurde ersichtlich, wie menschliche und nicht menschliche Aktanten zusammenfanden und eine neue Entität

erlaubnis erhalten. Bei dem Fest ergab sich allerdings eine neue Herausforderung, da hier keine ,Weißen', sondern ältere Missionarsschüler von anderen Inseln zugegen waren, die aber auch nicht als, Einheimische' wahrgenommen wurden. Die Frage, in welcher Form das Fotografieren und Filmen von kastom-Festen für nicht aus Santa Cruz stammende Personen erlaubt oder verboten werden sollte, trat bis zu meiner Abreise immer wieder auf. Einerseits wollten viele Familiensprecher (etwa Selwyn Balu, Freddy Me'esa) die Insel grundsätzlich für den Tourismus öffnen und diesen sogar fördern (zum damals geplanten Abkommen der Provinz Temotu mit dem Nachbarstaat Ni-Vanuatu vgl. Solomon Times 2012), andererseits wehrten sich andere Vertreter vehement dagegen, nicht jeden einzelnen Fall selber entscheiden zu dürfen. Es wurde die allgemeine Sorge geäußert, dass ,fremde' Personen mit dem Verkauf von Aufnahmen Geld verdienen und die lokale Bevölkerung an dem daraus resultierenden Gewinn eben nicht beteiligt würde. 
schufen. Wichtig an dieser Stelle ist mir, darauf hinzuweisen, dass diese neue Entität des ,neloTänzers' aber kein aus sich heraus allein agierender Mensch, sondern ein hybrides AkteurNetzwerk, das aus vielen heterogenen ,Komplizen“ entstanden, zu dieser hybriden Einheit transformiert und als deren Effekt zu verstehen ist, ganz im Sinne Laws Darstellung des ANT-Konzepts der Punktualisierung (vgl. Kap. 1.2). Mit anderen Worten:Jeder nelo-Tänzer ist das wahrnehmbare Ergebnis eines darunterliegenden Akteur-Netzwerks, in das vielfältige Intentionen und heterogene Beziehungen vom mannigfaltigen Aktanten eingeflossen sind, durch die es sich überhaupt erst bilden konnte. Wenn ein Netzwerk als eine Einheit agiert, wie es die Männer oberflächlich betrachtet tun, besteht Law zufolge allerdings die Gefahr, dass es in der menschlichen Wahrnehmung verschwinde und durch die konkrete Handlung und einen vermeintlich einfach wahrzunehmenden Urheber - im vorliegend Fall die Tänzer - ersetzt werde. Zeitgleich erlösche in der Wahrnehmung der Entstehungsweg, in dem der Effekt generiert wurde; er sei nicht länger sichtbar oder relevant. Die nelo-Tänzer führen konkrete Handlungen - etwa den Tanz - aus, durch die die eigentlichen, sie konstituierenden Akteur-Netzwerke in unserer Wahrnehmung ersetzt werden und die agierenden Tänzer als vermeintlich einfach wahrzunehmende Urheber erscheinen (können). Dennoch sind und bleiben die nelo-Tänzer Effekte ihrer jeweiligen Akteur-Netzwerke, Ergebnisse vielfältiger Handlungen unter Anwendung von umfangreichem (kastom-)Wissen und zahlreicher heterogener Beziehungen von Menschen, Dingen und Zeit, wobei die Tanzkleidung und der -schmuck eine herausragende Position einnehmen, wie ich im Folgenden zeigen werde.

\subsection{Tanzkleidung und -schmuck - Entitäten des Akteur-Netzwerks, nelo-Tänzer ${ }^{6}$}

Wie sich bei dem zuvor geschilderten Fall des nelo-Tanzdebütanten Steward Bice Me'tu zeigte, war im Laufe des Ankleidens eine neue, heterogene Entität - ein ,Zusammenwirken“ von Menschen, Wissen, Dingen und Diskussionen um sie - entstanden: ein ,nelo-Tänzer‘. Eine Besonderheit bei der Analyse stellte der Umstand dar, dass diese Entität zunächst als eine in sich vermeintlich geschlossene Einheit erschien, weil es ein Mensch war, der tanzte, agierte und als solcher wahrgenommen wurde. Bei genauerer Betrachtung ergab sich jedoch, dass er eben keine homogene Einheit im eigentlichen Sinne, sondern ein agierendes AkteurNetzwerk war, eine Vielzahl von Aktanten, die zueinander in Beziehung traten und diese neue Entität gemeinsam bildeten. Mit und in diesem Akteur-Netzwerk ,nelo-Tänzer fügten sich menschliche und nicht menschliche Aktanten zusammen und wandelten - in ANTTerminologie ,übersetzten ${ }^{\text {- }}$ verschiedene Komponenten in eine ,Tanzfigur', d. h. in einen nelo-Tänzer, der für bestimmte Aufgaben anderer für einen festgelegten Zeitraum geschaffen wurde. Im Falle der ,nelo-Tänzer waren die Akteur-Netzwerke sehr komplex, standen teilweise mit anderen in unmittelbarer Verbindung, waren mitunter verdeckt oder spannten sich über einen längeren Zeitraum. Daher war es naheliegend, die heterogenen Akteur-Netzwerke ,nelo-Tänzer ${ }^{6}$ und deren Netzwerken (im Sinne von Arbeiten oder Transformieren) in einer verkürzten Wahrnehmung nicht als Punktualisierungen bzw. Effekte eben dieser Akteur-Netzwerke sondern als eine Einheit zu betrachten. 
Neben den Menschen, ihren Beziehungen und ihrem kastom-Wissen scheinen die von ihnen hergestellten und genutzten Artefakte sowie die von ihnen ausgewählten natürlichen Materialien weitere zentrale Aktanten in den Akteur-Netzwerken ,nelo-Tänzer und in den mit ihnen verbundenen Prozessen der ,Übersetzung ${ }^{6}$ zu sein. Denn ohne die spezifische Tanzkleidung und den -schmuck wäre eine Transformation in meinen Augen unmöglich. Latour bezweifelt sogar, dass Beziehungen aus sich heraus auf lange Zeit bestehen oder sich gar ausweiten. Dafür bedürften sie anderer, nicht menschlicher Akteure: „It's the power exerted through entities that don't sleep and associations that don't break down that allow power to last longer and expand further [...].“ (LATOUR 2005: 70) LATOUR (2014: 21) begründet dies mit den Attributen oder Eigenschaften der jeweiligen Dinge, die er als Substanzen oder Essenzen von Aktanten bezeichnet. Worin diese bei der Tanzkleidung und dem -schmuck bestehen, und ob und wenn ja, worin sich diese vielleicht von denen der menschlichen Aktanten unterscheiden, werde ich im Folgenden analysieren. Die Wirkkraft der Dinge entspringt Hicks (2010: 75) zufolge aus ihrer physischen Beschaffenheit, ihrer Materialität. Dabei nehmen Faktoren wie etwa Beständigkeit und Verfall, Herkunft, Zusammensetzung, Beschaffenheit oder Rarität der Materialien Einfluss auf die menschliche Wahrnehmung und stellen Ausgangspunkte für die Beziehungen zu den Artefakten dar. Daher werde ich auf die ,Materialgeschichten“ der vier Artefaktegruppen (vgl. Kap. 4) zurückgreifen und in diesem Kapitel die Bedeutungszuschreibungen der jeweiligen Materialgeschichten und ihre kulturellen Bezugssysteme herausstellen. Zusätzlich zu den vier in dieser Arbeit fokussierten Kleidungs- und Schmuckstücken werde ich den nicht in Museumssammlungen vorhandenen vergänglichen Pflanzenschmuck sowie Farben berücksichtigen, deren Relevanz sich insbesondere während des Ankleidens herausstellte.

Um ein möglichst breites Spektrum an Bedeutungszuschreibungen zu erhalten, beschränke ich mich in den nachfolgenden Betrachtungen einzelner Kleidungs- und Schmuckstücke nicht ausschließlich auf die Informationen, die ich im direkten Umfeld des Ankleidens der nelo-Tänzer in Ne'ele erhalten habe, sondern ergänze diese mit darüber hinausgehenden Erläuterungen meiner Gewährsleute. Dabei erhebe ich weder Anspruch auf Vollständigkeit noch auf Repräsentativität. Die wesentlichen Schlüsse ziehe ich aus den Aussagen meiner Gewährsleute sowie aus der teilnehmenden Beobachtung. Weitergehende Verständniszugänge leite ich aus älteren Quellen und aus Vergleichen mit ähnlichen Phänomenen auf Ndendö ab. Bei der daran anschließenden Betrachtung des Umgangs mit den Artefakten im nelo-Tanz greife ich auf Interviews und Gespräche zurück.

\subsection{Brustschmuck tema}

Wie in Kapitel 4.3.1 dargelegt, kam der Brustschmuck historisch in zwei Varianten vor ohne und mit Dekorauflage. Gemäß Aussagen meiner Gewährsleute setzten ihn die Männer für verschiedene Zwecke ein: Kriegern diente er als Schutz vor feindlichen Pfeilen, Chiefs dokumentierten hiermit ihre besondere Position, und für nelo-Tänzer war er obligatorischer 
Bestandteil der Tanzkleidung. Heute findet sich zudem neben den beiden traditionellen Formen eine verkleinerte Variante. Männer und insbesondere auch Frauen tragen die meist aus Tridacna und Schildpatt gefertigten Artefakte nach eigenen Aussagen als Alltagsschmuck und Ausdruck ihrer Abstammung aus Santa Cruz.

\section{$\bigcirc$ Rezentes Wissen über Bedeutungszuschreibungen}

Das Wissen über tema war zum Zeitpunkt meiner Forschung über viele Personen verteilt. Ich bin niemandem begegnet, der gleichermaßen über Materialien, Herstellung, Nutzen und Bedeutung Auskunft geben konnte oder wollte. Es stellte sich heraus, dass einzelne Personen jeweils nur Teilaspekte wiedergaben - selbst der auf Ndendö bekannteste tema-Produzent, John Namiade, der sich auf die Herstellung von Brustschmuck spezialisiert hatte, konnte mir keine umfassenden Informationen geben.

\section{○ Begrifflichkeit}

Die lokale Bezeichnung des Brustschmucks tema bedeutet verschiedenen Informanten zufolge ,Mond ${ }^{6}$ - unabhängig davon, ob er über eine Schildpattauflage verfügte oder nicht. Nach John Me'alue war die Bezeichnung dem Polynesischen entlehnt und setzte sich aus te (bestimmter Artikel) und ma (Nomen: Auge) zusammen. ${ }^{171}$ Die Schildpattauflage bezeichnete er mit mabu, was er mir als ma (Auge) und $b u$ (dunkel) im Sinne von ,das Dunkle des Auges', sprich Pupille, übersetzte (4.11.2011) Wenn ich die beiden Morpheme hingegen analog der Morphologie des malaiischen (als einer anderen malayo-polynesischen Sprache) Begriffs mata hari verbinde, was ,Auge des Tages', sprich Sonne bedeutet, ergäbe sich ,Auge der Dunkelheit', sprich Mond. Allerdings hörte ich den Begriff mabu nur von wenigen Tänzern und gar nicht von den tema-Produzenten. Während der Gruppendiskussion mit Schülerinnen und Schülern der Mona-Secondary School in der Graciosa Bay nannten gleich drei Schüler den Begriff. Ansonsten begegnete ich ihm nur noch in einem Antrag für das lokale Museum in Luepe. ${ }^{172}$ Darüber hinaus gaben mir meine Gewährsleute keine weiteren Informationen. Warum der Brustschmuck mit ,Mond' bezeichnet wurde, und ob neben der ersichtlichen Analogie eines Vollmondes und der weißen kreisrunden Tridacnascheibe noch andere Beziehungen zum Mond existierten, konnte ich nicht ermitteln. Die wenigen Erklärungsansätze werde ich unter den jeweiligen Bedeutungen der Materialattribute aufführen.

\section{- Bewertung der Rohstoffe}

Das Basismaterial für tema bildete bis in die 1960er-Jahre hinein und seit der Rückbesinnung auf traditionelle Materialien ab den späten 1990er-Jahren wieder die Schale der Tridacna in versteinerter Form, nicht frisch dem Meer entnommen (vgl. Kap. 4.3.1). Eine Erklärung

\footnotetext{
171 Laut BEASLEY (1939: 28) bezeichnete der Name tamar - als andere Transkription von tema - den Mond, unter dem die Bewohner Ndendös Beasley zufolge im frühen 20. Jh. die Ehefrau der Sonne verstanden, eine kreative Kraft, die u. a. auch die Welt erschaffen hatte.

172 Die SIL-International-Linguistin Brenda Boerger bestätigte die Bedeutung von tema als Mond, wobei sie darauf hinwies, dass dies in der Lokalsprache Natügu kein zusammengesetzter Begriff sei. Sie bestätigte weiterhin, das te im Polynesischen ein bestimmter Artikel sei und bu (resp. bü) in Natügu ,dunkel' bedeute. Zu John Me'alue vermutete sie: „,[...] his dialect is not identical to the one where I worked, but it is the same language. Mostly they have a few different words and they preserve some older, historical pronunciations." (E-Mails vom 5./6.2.20I5)
} 
für die Nutzung ausschließlich fossiler Muscheln habe ich nicht erhalten. Aufgrund der geologischen Formation der Insel Ndendö konnte man an vielen Stellen im Inselinneren versteinerte Tridacna finden, sie sind auf Ndendö keine Rarität. Der Hauptproduzent John Namiade sammelte gleich drei größere fossile Schalen, als wir nach alten, im frühen 20. Jh. aufgegebenen Tanzplätzen im Wald in der Nähe von Nelua suchten. Nach unserer Rückkehr nach Nelua wünschte Namiade Fotoaufnahmen von sich und einigen seiner Verwandten im Dorf. Wie er mir später mitteilte, wollte er mit den Fotos einerseits seine guten Beziehungen zu den Verwandten und andererseits seinen aufgrund der Clanzugehörigkeit basierenden Anspruch auf das von ihnen dort genutzte kastom-Land dokumentiert wissen. Dies schien ihm wichtig, da kurz zuvor sein Vater verstorben war und dieser nicht mehr die Verbindung zu dem Land respektive die damit verbundenen Nutzungsrechte zum Ausdruck bringen konnte. Die im Wald gesammelten Tridacna stammten von ,seinem kastom-Land, wie er sagte, und verkörperten somit seine Verbindung dorthin. Laut John Namiade übergaben ihm manche Auftraggeber eigene fossile Tridacna, damit er aus diesem Material tema für sie herstellte.

Im Gegensatz dazu erwarb John Namiade das Schildpatt für die mabu-Auflagen nach Verfügbarkeit gegen Bezahlung von Freunden seines Vaters (und nach dessen Tod als sein Nachfolger nun seinen) von der Insel Vanikoro (pers. Kommentare, 8.10.2011). Nach meiner Beobachtung werden Schildkröten im Santa-Cruz-Archipel geschätzt und nur in geringem Maße gejagt. Sie stellen weder eine bedrohte Tierart noch eine Besonderheit dar. Die Frage, warum die Auflage nach wie vor aus Schildpatt und nicht aus einem anderen natürlichen Material gewonnen wird, stellte niemand. ${ }^{173}$

Beide Materialien verfügen über eine relativ hohe Haltbarkeit. Die Tridacnascheibe war völlig und die Schildpattauflage weitestgehend gegen Ungeziefer resistent. Ebenso setzte ihnen die hohe Luftfeuchtigkeit nicht sonderlich zu. Nicht selten brach im Laufe seiner Geschichte ein Stück eines tema oder mabu ab, was aber die Wertigkeit nicht sonderlich zu verringern schien. Insbesondere die noch erhaltenen geerbten tema mit Schildpattauflagen wurden von mehreren Tänzern erkannt und ihren Besitzern und Vorbesitzern zugeordnet. Chief Peter Lawrence Dewas tema etwa hatten bereits sein Vater, sein Großvater und sein Urgroßvater getragen. Dewas Aussage zufolge verkörperte sein Brustschmuck für ihn auch die Beziehung(en) zu seinen Vorfahren und erinnerte ihn an die Verstorbenen (pers. Kommentar, 12.8.2011).

\section{○ Wirkung der Farbigkeit}

Die Tridacnaschale reflektiert recht stark das Licht, sowohl tagsüber als auch nachts. Als matt schimmernde, nahezu weiße, runde und flächigen Scheibe verkörpert das tema auf eindrucksvolle Weise den Namen gebenden Mond - je größer, desto ,einleuchtender ${ }^{6}$,erscheint ${ }^{6}$

\footnotetext{
173 Eine Interpretation des Rohstoffs Meeresschildkröte und fossiler Tridacna als Symbol für die lokale Umwelt scheint naheliegend, gründet aber nicht auf Aussagen meiner Gewährsleute. Genauso denkbar wäre ein praxisorientiertes Verständnis dahingehend, dass diese Materialien schlichtweg natürlich vorkamen und über relevante Attribute für einen gelemten Einsatz in der Schmuckherstellung verfügten.
} 
die Beziehung zum Mond. Wäre das Material glänzender, würde es vielleicht eher an die gleißende Sonne erinnern.

Auch bildet die helle Untergrundfarbe einen starken Kontrast zu dem dunklen Schildpatt der mabu-Auflagen, so dass diese gut erkennbar sind. Selbst bei wenig Licht, etwa nachts bei einem nelo-Tanz, kann man recht gut das Motiv erkennen und die Tänzer identifizieren, vorausgesetzt man weiß, wer welches tema trägt.

Bei den stark verkleinerten tema sind die Effekte stark reduziert. Die Schildpattauflage nimmt im Vergleich zu den größeren Schmuckstücken proportional sehr viel mehr von der Tridacnaoberfläche ein. Die Gestaltung der kleinen mabu stellt sich weitaus einheitlicher dar als die der ursprünglichen tema.

\section{○ Ikonografie}

Hinsichtlich der Motive der Schildpattauflagen konnte ich auf Ndendö zwei Richtungen unterscheiden: Variationen der historischen mabu und aktuelle Auftragsarbeiten mit von auBen eingeführten eigenständigen Motiven, etwa des Wappens der Royal Solomon Islands Police oder das der Anglican Church of Melanesia (vgl. Kap. 4.3.1). Letztere werde ich hier nicht weiterverfolgen, da sie in keinem Zusammenhang mit dem nelo-Tanz stehen. Interessant wäre sicherlich herauszufinden, welche Motive gerade die Polizei und die Kirche verfolgten, eine lokale kulturelle Ausdrucksform mit ihren Emblemen zu verschmelzen und was mögliche Träger dazu meinten.

Als Bedeutung der traditionellen mabu-Darstellungen auf den tema führen historische Quellen abstrahierte Fregattvögel und Haifischzähne auf, wobei diese eine Herkunft von Santa Cruz und/oder sozialen Status ausdrückten (GRAEBNER 1909: 79, SPEISER 1915: 328, BEASLEY 1939). Diese Interpretationen schienen auch im Jahr 2011 mehr oder weniger Allgemeinwissen der erwachsenen Männer gewesen zu sein. Bei den von mir befragten Kindern und jungen Erwachsenen war dieses Wissen auch vorhanden, jedoch weniger deutlich ausgeprägt (vgl. Kap. 3.1). In Einzel- oder Gruppengesprächen teilten mir vereinzelte Personen/-gruppen, die sich in unterschiedlicher Intensität mit kastom-Artefakten beschäftigten, ihr darüberhinausgehendes Wissen mit:

Während einer öffentlichen Gesprächsrunde im Männerhaus von Nep (27.7.2011) berichteten ältere Männer, dass Fregattvögel als sehr gute Jäger angesehen und bei den Fischern sehr beliebt seien, da sie auf dem offenen Meer das Vorhandensein von Fischschwärmen signalisieren. Auf den tema galten die Fregattvogel-Darstellungen im unteren Teil aller mabu als Zeichen für einen Krieger und früher auch für die Kopfjagd. In der Vergangenheit hätten daher nur gute Krieger tema mit Auflage getragen. Gemäß Aussagen einiger Mitglieder einer Familie aus Nea stellte der obere Teil der Schildpattauflage das Totem (meist Fischarten) eines nou (Clan) dar, mit dem sein Träger die Zugehörigkeit zu seinem nou ausdrückte. ${ }^{174}$

\footnotetext{
${ }^{174}$ In verschiedenen anderen Zusammenhängen, etwa Aufbringen von Brautpreis, Landnutzungsrechten oder Beziehungen zu dukna, erwähnten einige Gesprächspartner das Thema Clanzugehörigkeiten weit häufiger. Allerdings erinnerten nicht alle spontan ihre nou und mussten erst Dritte fragen. Ich habe niemanden gesprochen, der
} 

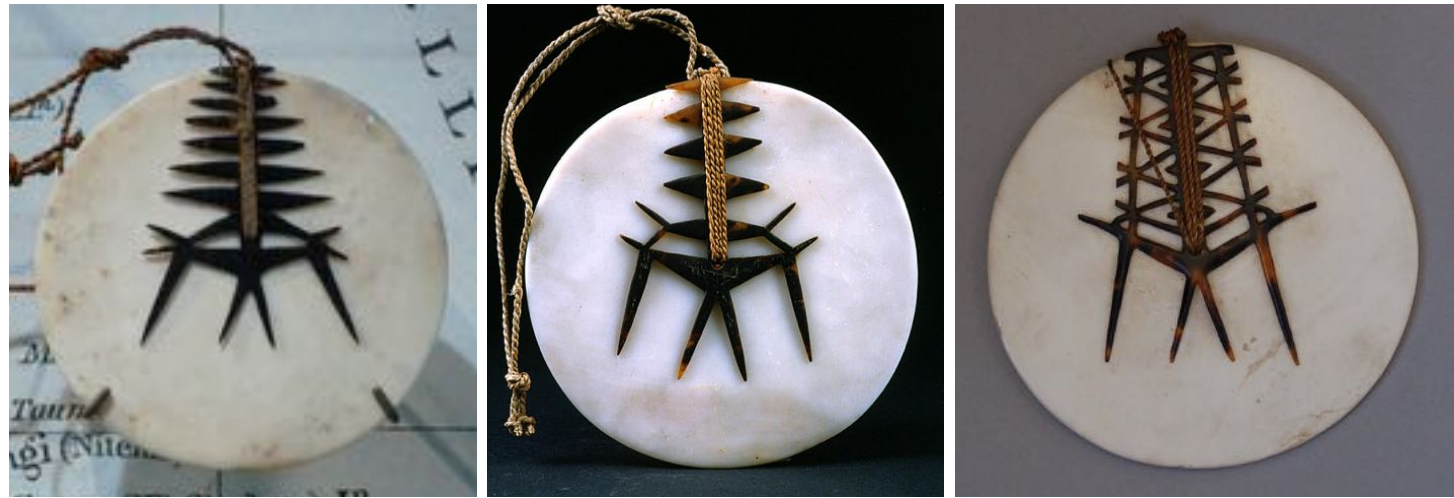

Abb. 90: Tema des nou nienda, 1897; Rautenstrauch-Joest-Museum 4372.

Abb. 91: Tema des nou bebla, 1897; Rautenstrauch-Joest-Museum 4373. C RJM

Abb. 92: Tema des nou nümbï, vor 1901; The British Museum Oc1944,02.1186. C) BM

Meine Informanten kannten drei Clans und deren Totems, da sie entweder zu einem der nou gehörten oder in Beziehungen zu Mitgliedern der beiden anderen standen: Das Totem des nou nienda war ein großer, schwarz-silbern gestreifter Fisch, der alleine jagte und ein gefürchteter Jäger war. Er wurde durch viele lange Zähne symbolisiert (vgl. Abb. 90). Den nou bebla zeichnete ein Fisch aus, der in großen Schulen lebt, ein festes Revier hat und größtenteils dunkelrot bis schwarz gefärbt ist. Er wurde im Vergleich zum nienda mit weniger Zähnen und großen Zahnlücken dargestellt (vgl. Abb. 91). Das dritte Totem stand für den nou nümbü, den Mdewöt als den „head of the tribes“ bezeichnete, und dem er selber angehörte. Das Totem - ebenfalls ein Fisch - galt als schneller, cleverer Jäger, der meist paarweise jagt, indem das Paar größere Fischschwärme teilt und so den Schutzmechanismus des Schwarms aushebelt. Die mabu-Darstellung des nou nümbü ist zusätzlich im oberen Teil mit einer sichelförmigen Linie sowie mit senkrecht verlaufenden Linien ausgestattet, was Mdewöt als Dach oder Schirm über alle Clans beschrieb bzw. als Zeichen der Verbindung mit anderen Clans und Kontrolle über sie verstand (vgl. Abb. 92). Meinen Informanten zufolge stand ein Totem mit seinen spezifischen Eigenschaften - Schnelligkeit, Größe oder Revierverhalten - für die Fähigkeiten der Clanmitglieder und signalisierte zudem das Verbot (Tabu), die jeweiligen Fische weder zu jagen noch zu verzehren. Sofern dies bekannt war, galt dies weiterhin. Mit diesem ,Identitätszeichen` konnte ein Krieger zudem im gesamten Archipel bei jedem anderen Mitglied des entsprechenden Clans in Notzeiten Unterschlupf finden, hatte jedoch keinen Anspruch auf das kastom-Land der Gastfamilien, auch wenn man demselben Clan angehörte. (Elisabeth I'nale, Ena Yamöli und Steven Mdewöt, 4.8. und 25.10.2011; Simon Meambö, 24.10.2011)

mir einen Überblick über die Clananzahl und die Beziehungen untereinander darstellen konnte. Die Aussagen unterschiedlicher Personen variierten erheblich. Auch DAVENPORT (2005: 63-65) verweist auf die variable Darstellung der Anzahl der Deszendenzgruppen. Joest (BAESSLER 1900: 386-387) berichtet von zwölf nou, deren Totems Fische, Pflanzen, Hunde und Vögel waren, und den mit ihnen verbundenen Nahrungstabus, vgl. Kap. I. 
Neben Reproduktionen dieser traditionellen Darstellungen entwickelte John Namiade seit etwa dem Jahr 2010 zusätzlich eigene Motive mit Delphin- und Haidarstellungen - Meerestieren, die er nach eigenen Aussagen mit seiner Heimat verband. Auf einem Foto, das einen nelo-Tanzanführer im Jahr 2014 auf dem Rückweg vom $5^{\text {th }}$ Melanesian Festival of Arts and Culture (Port Moresby, Papua-Neuguinea) in Honiara zeigt, trägt dieser ein solches neues tema, auf dem neben traditionell anmutenden Motiven wie dem Fregattvogel gleich zwei Haie dargestellt sind, die in ihrer Form der Darstellung an das Wappen der Solomon Islands erinnern (vgl. Abb. 93 und Abb. 94).
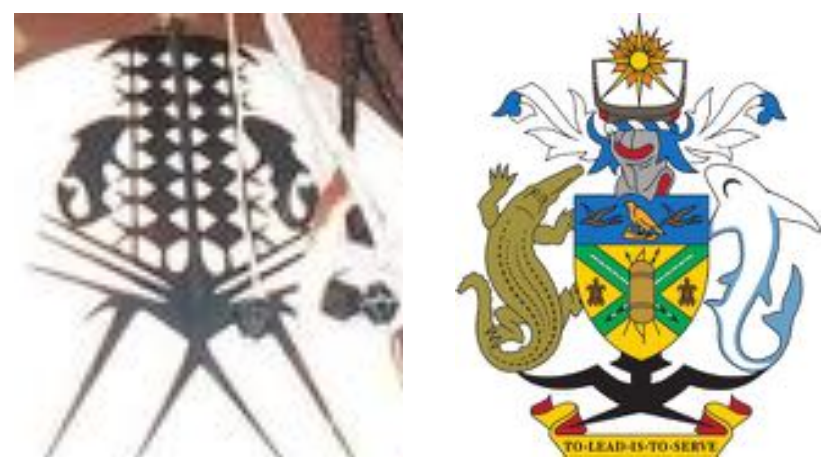

Abb. 93: Tema mit Haidarstellung; John Namiade, 2014, Bildausschnitt. (C) GNBA

Abb. 94: Wappen der Solomon Islands mit Haidarstellung (http://www.quickiwiki.com, letzter Zugriff am 12.9.2015).

\section{$\bigcirc$ Perspektiven auf Größen und Verwendung}

Bei den traditionellen tema bewerteten die Tänzer die großen Tridacnascheiben höher als kleinere. Namiade begründete dies mit der ursprünglichen Größe einer Tridacna als limitierenden Faktor des Endproduktes sowie der Schwierigkeit der Herstellung. Für große tema benötigte er große fossile Tridacnablöcke, die seltener waren. Häufig splitterten im Laufe der Fertigung Stücke ab, so dass das tema immer mehr an Größe verlor. Die Dimension eines mabu war wiederum durch den Durchmesser der Tridacnascheibe bedingt, auf der sie anschließend befestigt werden. John Namiade fertigte die Schildpattauflagen sehr filigran und möglichst groß, wobei es ihm sehr wichtig war, etwa die Schwingen der Fregattvögel möglichst lang und schlank auslaufend auszusägen und zu feilen (vgl. Abb. 21 und Abb. 93). Darin lag nach seinen eigenen Worten seine künstlerische Fähigkeit, die seine Kunden schätzen - inner- und außerhalb Ndendös. Das Größenverhältnis zwischen Tridacnascheibe und Schildpattauflage scheint für alle mir bekannten historischen tema weitestgehend flexibel bzw. abhängig von dem darzustellenden Totem gewesen zu sein. In der Regel bedeckte das mabu ein Viertel bis ein Drittel der Tridacnascheibe und war im Vergleich zu den neuen Arbeiten eher kompakt.

Auch im Kriegsfall wird ein möglichst großer Brustschmuck als Schutz gegen Pfeile wirkungsvoller gewesen sein als kleinere tema. Ob in der Vergangenheit die Größe eines tema Ausdruck der besonderen Position seines Trägers war, kann ich aufgrund fehlender Quellen nicht beurteilen. 
Ein Augenmerk möchte ich auf die Verkleinerung der tema legen. Die Größe war, so Namiade, dem Umstand geschuldet, möglichst schnell viele tema anbieten zu können. Er vermutete, dass der in seinen Augen niedrige Preis ein Grund für die zunehmende Popularität der kleinen tema war. Die Gestaltung variierte nur leicht zwischen den verschiedenen Produzenten: Ein Fregattvogel war angedeutet und einige kleine Haifischzähne zierten den oberen Teil. Namiade wie auch die anderen Hersteller schrieben ihnen, soweit mir bekannt, keine spezifischen Totem-Bedeutungen zu. Wichtig war ihm eher der dekorative Gesamteindruck mit einer möglichst glänzenden Schildpattauflage, um sie so besser an Personen aus Santa Cruz oder an Touristen auf Ndendö verkaufen zu können.

Einige Informanten drückten ihren Unmut über die Praxis der zur Zeit meiner Aufenthalte tema-produzierenden Männer in der Graciosa Bay aus, da sie diese weder mit traditionellen Werkzeugen herstellten, noch die Bedeutungen der Gestaltungen kannten und würdigten. Sie bezeichneten deren tema als „reine Dekoration“ (Elisabeth I'nale, Ena Yamöli und Steven Mdewöt, 4.8. und 25.10.2011).

Ein Kritiker der steigenden tema-Produktion in der Graciosa Bay stellte insbesondere den Umstand heraus, dass das Tragen des Brustschmucks in der Vergangenheit ausschließlich Kriegern oder Chiefs vorbehalten war und heute jeder Mann, in jüngster Zeit sogar Frauen und Mädchen, die verkleinerte tema-Variante ,einfach' als Alltagsschmuck tragen konnten (Tom Olu, 8.11.2011).

Auch in den Gruppendiskussionen thematisierten einige Schülerinnen und Schüler der Gruppe der 17- bis 21-Jährigen die Verkleinerung der tema. Wenngleich ein Teil sie abwertend als Modeerscheinung betrachtete, sprach sich die Mehrheit für das Tragen der verkleinerten tema aus. Lediglich der Preis, der in der Graciosa Bay dafür erhoben wurde, war einigen jungen Frauen zu hoch. Ihren Aussagen zufolge drückten die Trägerinnen und Träger mit dem Schmuck ihre genealogische Abstammung von Ndendö bzw. aus der Provinz Temotu aus. Für sie war er gleichbedeutend mit dem Piercing beider Ohrläppchen bei Jungen und Mädchen.

\section{○ Verkörperung von Beziehungen}

Wie gezeigt, traten und treten tema als Aktanten in vielen weiteren Akteur-Netzwerken neben dem nelo-Tanz in Erscheinung: Als Abbild des Mondes stellen die matt-weißen Muschelscheiben eine Beziehung zum Kosmos her. Durch die Herkunft der fossilen Tridacna verbinden die Männer sie mit ihrem kastom-Land. Die mit Schildpatt versehenen tema zeichneten früher fähige Krieger oder Chiefs aus. Die mabu drücken konkrete Zugehörigkeiten aus und stellen Verbindungen her: Als Clanzeichen vermitteln sie soziale Zugehörigkeit, bilden Brücken zu den Genealogien, zu Vorfahren und Ahnen der Träger, sichern Landnutzungsrechte und boten früher zudem im Kriegsfall Schutz. Mit den Verkörperungen der Totems verweisen tema direkt auf die lokale Umwelt und signalisieren gleichzeitig Nahrungsmitteltabus für einen regenerativen Umgang mit ihr. Für die Gestaltung der rezenten tema orientiert sich der heute mengenmäßig betrachtet größte Produzent nicht ausschließlich an traditio- 
nellen mabu, sondern entwickelt zusätzlich neue Formen und zieht dabei Erwartungshaltungen internationaler Abnehmer wie Touristen und Sammler in seine Überlegungen mit ein (vgl. Kap. 6.1). Auch wenn die verkleinerten tema heute keinen Bezug zu einem spezifischen nou darstellen, gelten sie als Ausdruck der Abstammung und Zugehörigkeit zu der Provinz Temotu, wenngleich ihr Tragen aktuell auf Ndendö Fragen zu status- und genderspezifischem Umgang mit ihnen nach sich zieht. ${ }^{175}$

Die vielen vorgestellten Attribute versetzen das Artefakt tema in die Position, vielfältige soziokosmische Beziehungen auszudrücken bzw. diese für ihre Träger herzuleiten.

\subsubsection{Nasenschmuck nelo}

Der Nasenschmuck trat meiner Beobachtung nach nahezu ausschließlich als Schmuck der Tänzer im Akteur-Netzwerk, nelo-Tanz‘ in Erscheinung. Weder in historischen Quellen noch in Gesprächen stieß ich abgesehen von sehr wenigen Verkäufen an Sammler auf weitere Verwendungen. Im Jahr 2011 gab es einen einzigen aktiven Produzenten, der neben anderem traditionellen Schmuck auch nelo reproduzierte. Nach eigener Aussage hatte dieser Hersteller Mitte bis Ende der 2000er-Jahre für einen Auftraggeber ein nelo mit einer neuartigen Tragetechnik entwickelt, die es fortan auch nicht vollständig initiierten Männern erlaubte, als nelo-Tänzer aufzutreten (vgl. Kap. 4.3.2). ${ }^{176}$

\section{○ Rezentes Wissen über Bedeutungszuschreibungen}

Das Wissen über nelo beschränkte sich zur Zeit meiner Aufenthalte auf Personen, die direkt mit dem nelo-Tanz in Verbindung standen. Inhaltlich umfasste es die Geschichte, die die Herkunft des Nasenschmucks von dem dukna Opla erzählte (vgl. S. 59-60). Gemäß dieser Überlieferung galten alle nelo als Kopien dieses einen ,Originals' (vgl. Abb. 6 und Abb. 37), das von allen Tänzern - und wie mir schien auch von anderen Männern in der Graciosa Bay - erkannt wurde. Auch wenn jeder wusste, dass es sich um eine Kopie handelte, wurde es als ,Oplas nelo bezeichnet. Da ich nur Kontakt mit Männern hatte, konnte ich nicht in Erfahrung bringen, ob auch die Ehefrauen, Schwestern und Töchter von Tänzern die Geschichte kannten. Auch bei den von mir durchgeführten Gruppendiskussionen mit Schülerinnen und Schülern erhielt ich keine einzige Information über den Nasenschmuck. Zur Herstellung konnte mir nur der heutige Produzent Auskunft geben.

\footnotetext{
175 WeRE (2005: 165) kommt bei der Untersuchung von kapkap - ebenfalls aus Tridacna und Schildpatt gefertigten Schmuckstücken von der Insel Neuirland im Bismarck-Archipel in Papua-Neuguinea - hinsichtlich ihrer sozialen Bedeutung zu einer ähnlichen Einschätzung: „In New Ireland, these kapkap pattems become material ways in which to conceive of genealogies that interlink clans from the region through a complex network of social relations while at the same time creating social distance."

176 Neben dem üblichen Pearcing der Ohrläppchen konnten männliche Jugendliche und junge Männer auch ihre Nasenflügel und ihr Septum durchstechen lassen. Dies erfolgte in der Regel in mehreren Stufen. Die mit der jeweiligen Initiation verbundenen Tauschhandlungen und Feierlichkeiten waren sehr ressourcenintensiv, weshalb nur ein geringer Teil der Männer auf Ndendö über Piercings in der Nase verfügten. Zum anderen entsprachen einigen Gewährsleuten zufolge gepiercte Nasenflügel im Gegensatz zu gepiercten Ohrläppchen auch nicht mehr unbedingt dem allgemeinen aktuellen ästhetischen Empfinden.
} 


\section{○ Begrifflichkeit}

Eine über die reine Benennung nelo hinausgehende Erläuterung der Bezeichnung konnte ich nicht in Erfahrung bringen. Der Nasenschmuck war Teil der Tanzausstattung der dukna und hatte daher seinen Namen.

\section{- Bewertung der Rohstoffe}

Der Produzent Malu tauchte selber in der Graciosa Bay nach den Austern. Die Nylonschnur erhielt er aus Honiara, die Glasperlen hatte er vor rund 15 Jahren von Mick Pendergrast geschenkt bekommen. Das Schildpatt für die kleinen Anhänger nutzte er auch für die Herstellung andere Schmuckstücke. Wo er es erworben hatte, konnte ich nicht in Erfahrung bringen, er hatte es ,,irgendwo gekauft“ (Philipp Malu, 25.5.2010).

\section{- Bewertung der Farbigkeit}

Die Färbung eines nelo hängt von der Perlausterart und die Größe von deren Alter ab. Goldlippige Perlaustern kamen gemäß Malus Aussage weniger häufig in der Graciosa Bay vor und galten daher als wertvoller, schwarzlippige zerbrachen relativ schnell (vgl. Anm. 124). In der späteren Verwendung durch die Tänzer sah Malu keinen Unterschied hinsichtlich der Bewertung der Farbigkeit. Die Farben der aufgezogenen Glasperlen variierte er nach Belieben und schrieb ihnen ebenfalls keine Bedeutung zu. Meist waren es drei Farben pro Schnur, von denen oftmals eine dominierte. (Philipp Malu, 25.5.2010 und 10.11.2011)

\section{○ Ikonografie}

Neben vier alten auf Ndendö überlieferten Designs, von denen eines die besagte Kopie des ,Originals ${ }^{6}$ und die übrigen Variationen von Letzterem waren, fertigte Malu ein nelo mit neuem Design, das er nach einem Traum angefertigt und bisher einmal verkauft hatte. Seines Wissens hatten die einzelnen Gestaltungen keine Bedeutungen. ${ }^{177}$ Die Fertigung des Querstegs am oberen Teil des nelo legt fest, ob der linke oder der rechte Teil durch das Septum gezogen wird, so dass jeder Nasenschmuck ausschließlich von links oder von rechts getragen werden kann. Die Entscheidung, wie die spätere Trageweise sein würde, hing weder von Malu noch von der Präferenz des Auftraggebers ab, sondern ergab sich aus der natürlichen Beschaffenheit der Auster nach dem Abschleifen ihrer äußeren Schale. Malu sah eigenen Aussagen zufolge in der Gestaltung der nelo keine eigentliche Bedeutung.

\section{○ Perspektiven auf die Verwendung}

Zum Tragen müssen die Tänzer den Steg des traditionellen Nasenschmucks durch das durchstoßene Septum führen, weshalb der Nutzerkreis auf entsprechend initiierte Männer beschränkt ist. Der Durchmesser der Öffnung in der Nasenscheidewand begrenzt die Dicke des einführbaren Stegs. Da die nelo über unterschiedlich starke Stege verfügen, kann längst nicht jeder initiierte Mann grundsätzlich jedes nelo tragen. ${ }^{178}$ Männer, die in nicht ausreichendem Grade initiiert worden waren, konnten kein nelo tragen - ihnen blieb das Tragen des traditionellen Nasenschmucks aufgrund des fehlenden Piercings im wahrsten Sinne des

\footnotetext{
177 Nach meinem Dafürhalten ähneln die grafischen Muster denen der napa-Tanzkeulen, und des Steckschmucks. Chief Ambros Me'naa (7.10.20II) erläuterte die Designs als Zeichen für bestimmte dukna.

$178 \mathrm{Vgl}$. hierzu das Ankleiden von Jerry Me'ioko S. I40-141.
} 
Wortes ,verschlossen`. Dieser Umstand hatte in den 2000er-Jahren Patteson Oti dazu veranlasst, Philipp Malu zu beauftragen, für ihn ein nelo zu entwickeln, das er auch ohne durchstoßenes Septum tragen könne. Durch Malus Innovation beschränkte sich das Tragen eines Nasenschmucks, der wie ein nelo aussah, nicht mehr nur auf initiierte Männer. Während meines Aufenthaltes im Jahr 2011 fertigte er auf Bestellung ein zweites derartiges nelo (vgl. Abb. 39 und Abb. 40) und hatte einen weiteren Auftrag von Bartholomew Me'esa für dessen Sohn vorliegen. (Philipp Malu, 25.5.2010 und 10.11.2011)

Ich stelle diese Neuerung besonders heraus, da es nicht wenige Tänzer gab, die ohne Nasenschmuck am nelo-Tanz teilnahmen. Ein nelo war folglich nicht zwangsläufig notwendig, um am Tanz teilnehmen zu können. Umso interessanter scheint mir der Umstand, dass die beiden besagten Männer ein modifiziertes nelo beauftragt hatten. Leider erfuhr ich erst in den letzten Tagen meines Aufenthalts davon und konnte weder deren Beweggründe erfragen noch - mit der Ausnahme von Selwyn Balu, der es als ,Trick ${ }^{6}$ ansah - herausfinden, wie andere Personen diese Modifikation bewerteten.

\section{○ Verkörperung von Beziehungen}

Das erste ,Original'-nelo stammte der Überlieferung nach von einem dukna und war in Form einer Kopie erhalten. Dieses nelo genoss im Netzwerk ,nelo-Tanz eine gewisse Position. Zum einen verkörperte es eine direkte Verbindung zur Vergangenheit im Sinne einer historischen Kontinuität, bei der die Besitzer der vergangenen Jahre namentlich erinnert wurden. Zum anderen war es auch der physische Beweis für die Existenz der dukna - denn diesen Nasenschmuck hatte einer von ihnen vor nur wenigen Generationen in der Graciosa Bay verloren. Aufgrund seiner Herkunft standen die Menschen in direkter Beziehung zu den dukna. Diese Erstkopie verfügte über eine unangefochten exklusive ,Authentizität ${ }^{6}$ - alle anderen nelo wurden von diesem ersten Nasenschmuck später kopiert und/oder leicht modifiziert. Die Originalkopie ,bedeutete über seine ehemaligen Besitzer hinausgehend, seine Handlungs- und Wirkmacht reichte weiter: Das Artefakt vergegenwärtigte die Vergangenheit, war eine physische Beziehung zu den dukna in der Gegenwart und evozierte genau diese Verbindung im Netzwerk ,nelo-Tanz'. Ohne das nelo wäre der Bezug zu den dukna weniger sichtbar und nur mittelbar erlebbar.

Der größte Materialanteil des nelo stammt aus dem Meer, wo es auch der Geschichte nach von einem Menschen gefunden worden war. Beide Aspekte stellen eine Verbindung zur Entität ,Umwelt‘ dar.

Getragen werden konnte ein nelo in der Vergangenheit ausschließlich von Männern, deren Nasenscheidewand im Rahmen ihrer Initiation durchstoßen worden war. Somit vergegenwärtigte ein getragenes nelo auch den erfolgreichen Abschluss eines Initiationsprozesses und die erfolgreichen, sozial produktiven Verbindungen des Trägers zu seiner Familie bzw. seinem namesake. Zugleich begrenzten die notwendigen Initiationen aber auch den Kreis möglicher Aktanten. Das Akteur-Netzwerk ,nelo-Tänzer` war nicht allen Männern zugänglich. Die Neuentwicklung der Tragetechnik, nelo als Nasenring' veränderte dies von Grund auf. Nunmehr konnte jeder Mann zu einem oberflächlich betrachtet voll ausgestatteten nelo- 
Tänzer transformieren, sofern er über ausreichende (finanzielle) Mittel für den Erwerb eines solchen nelo verfügte. Er benötigte die zuvor aufgeführten Initiationen nicht mehr, wurde diesbezüglich unabhängig von den dazu früher notwendigen sozialen Beziehungen. Das neue Artefakt ,ermächtigte‘ die Männer zu unabhängigen, selbstbestimmten Transformationen.

Aus diesen Überlegungen heraus kann ich sagen, dass auch der nicht menschliche Aktant nelo in verschiedenen Verbindungen wie etwa Nachfahren-Vorfahren, Mensch-Umwelt und Mensch-dukna agiert. Nelo können so betrachtet vielfältige soziokosmische Beziehungen ausdrücken und anderen Aktanten ermöglichen, diese in den jeweiligen Netzwerken einzugehen.

\subsubsection{Tanzschurz der Männer lepanesa}

Während meiner Aufenthalte habe ich Schurze aus Bananenbast ausschließlich bei Aufführungen des nelo-Tanzes gesehen. Es schien, dass die Männer sie exklusiv zu diesem Tanz trugen. Die Materialien der Gewebe variierten in der Vergangenheit, so dass neben Bananenbast auch andere Materialien vorkamen (vgl. Kap. 4.3.3). Ich habe nur einen einzigen nelo-Tänzer mit einem nicht gewebten Tanzschurz gesehen. Dieser bestand aus einer Bahn Tapa, war mit Mustern der lepanesa bemalt, mit Kurkuma bestrichen und wie gewebte lepanesa mit Applikationen aus Pandanusblatt versehen (vgl. Abb. 44 b). Zu allen anderen Tänzen trugen Männer und Frauen Tanzkleidung aus unterschiedlich bemalter oder nicht bemalter Tapa bzw. Alltagskleidung kombiniert mit Grasröcken, aber nie Schurze aus Bananenbast.

\section{$\bigcirc$ Rezentes Wissen über Bedeutungszuschreibungen}

Alle Personen, die ich zu lepanesa befragte, verwiesen mich an den Weber Selwyn Balu, so dass alle nachfolgenden Informationen zu den gewebten Tanzschurzen der Männer auf ihn zurückgehen.

\section{○ Begrifflichkeit}

Das Wort lempe bezeichnet Selwyn Balu zufolge in Natügu einen Schurz, und Weben hieß nesa (17.10.2011), so dass die Bezeichnung lepanesa deskriptiv ist und mit ,gewebter Schurz übersetzt werden kann. KOCH (1971: 98) führt als Begriffe napanesa oder nesa für die Graciosa Bay auf.

\section{- Bewertung der Rohstoffe}

In den 1980er-Jahren benutzte Balus Vater Jonas Kepule aus Honiara eingeführte, nicht traditionelle Materialien wie Baumwolle und Kunstfasern zum Weben der lepanesa, sofern ihn seine Auftraggeber darum baten und ihm entsprechendes Material überließen. Wie Balu darstellte, schätzten die Tänzer zu der Zeit die ,modernen' Materialien aufgrund ihrer Eigenschaften (vgl. Kap. 4.3.3). Selwyn Balu hingegen sah sich nach eigenen Aussagen seit jeher weit mehr der Tradition verpflichtet und unterstützte von Beginn an die seit den späten 1990er-Jahren aufgekommene Rückbesinnung auf ,traditionelle ${ }^{6}$ Materialien (vgl. Kap. 3.3.2). Da sowohl die Tänzer als auch der heutige Hersteller eigenen Aussagen zufolge seit der kastom-Rückbesinnung natürliche Materialien präferierten, beschränke ich mich in 
der weiteren Betrachtung auf die Bedeutungszuschreibungen zu diesen ,neuen alten` Rohstoffen.

Selwyn Balu gewann den Bananenbast ausschließlich selber aus dem Anbau in seinen eigenen Gärten. Die schwarzstämmigen Bananen wuchsen nur auf einem weiter entlegenen Stück Clanland, zu dem er lange Kanufahrten in Kauf nahm. (Selwyn Balu, 17.10. und $3.11 .2011)$

Auch wenn Bananenbast nicht so robust wie Kunstfasern war, galt er als wesentlich stabiler und langlebiger als andere natürliche Materialen, etwa Hibiskusbast oder Pandanus. So waren Bananenbasttaschen auf Ndendö und in Honiara wesentlich teurer als solche aus anderen Fasern. Schwarzer Bananenbast wurde auch zum Flechten von höherwertig eingestuften Taschen genutzt, die etwa zur traditionellen Ausstattung einer Braut gehörten. Mit ihm verzierte Taschen kosteten ein Vielfaches (Rhoda I'none, 21.7.2011 und Ena Yamöli, 26.10.2011).

\section{$\circ$ Wirkung der Farbigkeit}

Die Farben der lepanesa aus Bananenbast variierten abhängig vom Alter von Hellbeige über Gold bis Braun - je älter die Tanzschurze waren desto dunkler wurde ihre Farbe. Eine umgekehrte Entwicklung der Farbintensität zeigte sich bei dem schwarzen Bananenbast - hier blich das Schwarz im Alter aus. Die Faserbüschel und Pandanusblätter veränderten hingegen ihre Farben kaum. Die altersabhängigen Farbkontraste sind auf den Abbildungen 44 a und $44 \mathrm{~b}$ gut ersichtlich.

\section{○ Ikonografie}

Selwyn Balu produzierte zwei von seinem Vater bereits verwendete Designs, die auch KOCH (1971: Abb. 71) schon dokumentierte: ningi te'nipo (Abb. 71 a) und nina te'ba (Abb. 71 i). Diese Dekore finden sich auch auf den in den Sammlungen erhaltenen, ältesten Tanzschurzen aus der Zeit um 1900 (vgl. Anhang). Zu dem ersten Muster erläuterte Balu, dass es aus zwei Teilen bestehe. Zum einen aus einer Abfolge von Paaren gespiegelter, senkrecht stehender länglicher Dreiecke, die jeweils von mehreren dünnen Linien bzw. Schichten umhüllt werden (vgl. Abb. 95, obere und mittlere Dekorreihen). Jedes Paar zeigt den doppelten Kern einer Nalinuss (Canarium, Solomon Pijin: Nali nut, Natügu: nina oder ningi). Der andere Teil des Musters besteht aus einer oberen und unteren Reihe kleiner gleichschenkeliger Dreiecke, die Haifischzähne (Natügu: ningi bua) darstellen und die Reihe Nalinüsse am oberen und unteren Rand des Musters begrenzen müssen. Grundsätzlich symbolisiere eine Raute (als Einheit von zwei gespiegelten Dreiecken) eine Nalinuss, die entweder gefüllt (eine leere Nussschale) oder innen ausgespart (eine Nuss befindet sich in ihrer Schale) dargestellt werde. Der Umstand, dass die Raute in Form von zwei Dreiecken gezeigt werde, trage der Eigenart der Nalinuss Rechnung, die meist zwei Nusskerne in einer Schale enthalte. Das zweite Muster, das er herstellte, nina te'ba, zeige eine leere Nussschale (vgl. Abb. 95). Beide Muster können in der Vertikale betrachtet als Ganzes oder auch nur zur Hälfte vorkommen (vgl. Abb. 95, untere Dekorreihe). Auf der Vorderseite eines lepanesa finden sich drei, auf der Rückseite vier Reihen mit Mustern. (Selwyn Balu, 3.11.2011) 


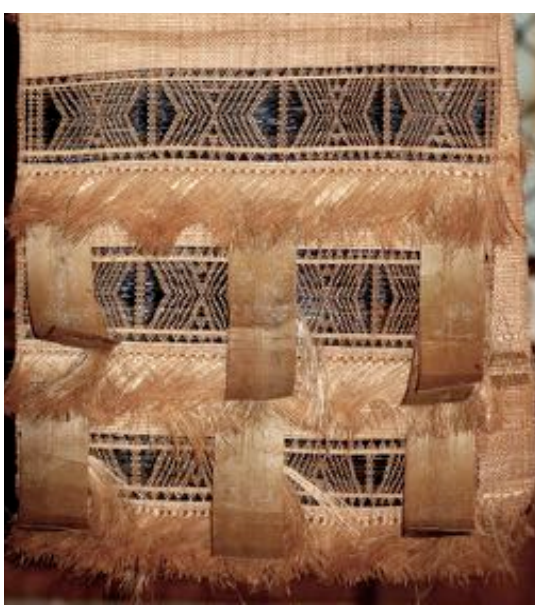

Abb. 95: Vorderseite eines lepanesa mit dem Nalinuss-Muster ningi te'ba (leere Nussschalen); Selwyn Balu, vor 2011. Die beiden oberen Reihen zeigen das ganze, die untere Reihe ein halbes Muster.

Der in meinen Augen zunächst schwer verständliche Umstand, dass eine gefüllte Raute eine leere Nuss darstellen soll, wird nachvollziehbar, wenn man die Nalinuss nicht geschlossen, sondern in zwei Hälften durchschnitten betrachtet. Enthält die Schale eine Nuss, ist die Mitte hell, was am besten eine nicht ausgefüllte Raute visualisiert. Nur wenn sie keinen oder nur einen winzig kleinen Kern enthält, ist die Schale dunkel sichtbar und daher für die Darstellung vollflächig dunkel. Bei der Betrachtung der Nusshälften zeigen sich auch die ,Haut` der Nuss und die verschiedenen Lagen der Schale als im Anschnitt unterschiedlich gefärbte bzw. hell- und dunkel schattierte Linien, womit nachzuvollziehen wäre, warum die Rauten respektive deren Hälften mit Linien umgeben dargestellt sind:
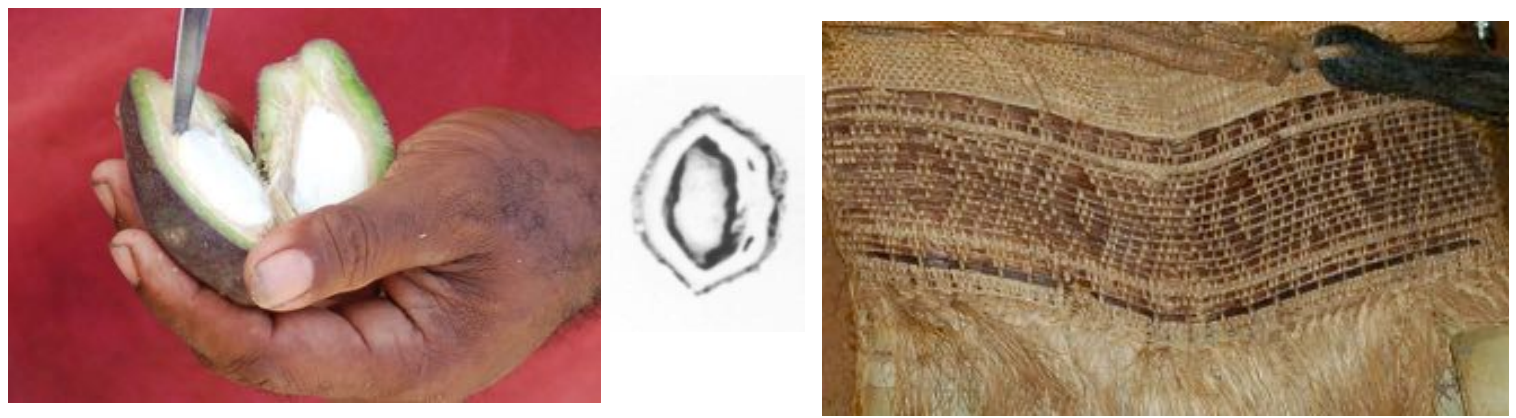

Abb. 96: Eine geöffnete Nalinuss.

Abb. 97: Querschnitt einer getrockneten Nalinusshälfte (YEN 1974: Fig. 3, Bildausschnitt).

Abb. 98: Lepanesa-Muster ningi te'nipo (gefüllte Nuss); Venga, 2010.

Nach YEN (1974: 264) kann Canarium vielleicht als die wirtschaftlich wichtigste Baumspezies in Santa Cruz bewertet werden. Auf Ndendö ist die Nalinuss ein sehr beliebtes Nahrungsmittel, das ganzjährig wächst und als Zwischenmahlzeit die Nahrung ergänzt. In der Hochsaison können die Nüsse im Rahmen einer Hauptmahlzeit sogar andere stärkehaltige Nahrungsmittel ersetzen (1974: 261-264). Zu Festessen werden sie meist zerstoßen in Yams- oder Bananenpudding eingearbeitet. In der Vergangenheit konnten sie sogar Anlass für das ,Stehlen eines Tanzzirkels' sein, wenn etwa ein Dorf bzw. eine madai-Organisation besonders viele 
Nalinüsse geerntet und mehr als die Nachbarn hatte (vgl. Kap. 3.3.1). Nalinüsse galten auch als Möglichkeit, Einkommen zu generieren (Ena Yamöli, 26.10.2011). Ich selber wurde mehrfach darauf hingewiesen, dass Früchte und Nüsse auf Santa Cruz größer als sonst irgendwo waren, was ich persönlich nicht für Bananen und Zitrusfrüchte, wohl aber für Papayas bestätigen kann. ${ }^{179}$ Nach Selwyn Balu steht die Nalinuss als anerkanntes Zeichen für Wohlstand, Essen und den sozialen Aspekt des Teilens von Essen. Die Rahmung des Nalinussmusters durch die symbolisierten Haifischzähne steht ihm zufolge für Stärke und Sicherheit, so dass das Gesamtmuster in der Vergangenheit, wie Balu es schilderte, für die Fähigkeiten (und die Verantwortung) von bonie oder Chiefs stand, Wohlstand und Sicherheit in den Dörfern sicherzustellen. Daher war ihnen das Tragen dieses Musters vorbehalten. (Selwyn Balu, 3.11.2011)

\section{○ Perspektiven auf Größen und Verwendung}

Nach eigener Aussage konnte Selwyn Balu mit der Webtechnik am Trennstab-Webgerät die Länge und Breite des Gewebes beliebig variieren und gleichermaßen Taschen, Schurze und Matten produzieren. Alle Produkte waren zeitaufwendige Handarbeiten und wurden Balu zufolge als sehr wertvolle Kleidungsstücke betrachtet. Anhand der Breite ließe sich erkennen, für wen das Kleidungsstück ursprünglich hergestellt wurde: Männerschurze waren eher schmal und länglich (ca. 22 bis $30 \mathrm{~cm}$ breit und zwischen 1,50 m und $2 \mathrm{~m} \mathrm{lang}$ ). In der Vergangenheit wickelten hochrangige Frauen Gewebe aus Bananenbast um ihre Körper. Diese ,Matten' waren vom Format her wesentlich breiter als die Schurze der Männer.

Selwyn Balu stellte v. a. Tanzschurze für Männer und Taschen her. Im Oktober 2010 hatte er zuletzt eine große ,Matte bzw., wie er sagte, einen sehr breiten lepanesa für die damals amtierende Miss Solomon Islands gewebt, die in ihrer kastom-Kleidung das Land bei einem offiziellen Anlass in Papua-Neuguinea präsentierte. (Selwyn Balu, 3.11.2011)

\section{○ Verkörperung von Beziehungen}

Das Tragen von aus Bananenbast gewebten ,Stoffen' war gemäß meinen Gewährsleuten in der Vergangenheit Männern und Frauen mit höherem sozialen Status vorbehalten. Rezent trugen ausschließlich nelo-Tänzer Schurze aus Bananenbast. Das Material zeichnete - auch in der Verwendung für Taschen im Rahmen von Heiratszeremonien - etwas Besonderes aus, d. h. bestimmte Personenkreise oder Anlässe bzw. Lebenszykluspassagen.

Die grafischen Darstellungen auf den Tanzschurzen symbolisieren zwei weitere, besonders geschätzte Materialien: Nalinüsse und Haizähne. Mit der Aufnahme dieser beiden Sujets in die Oberfläche des Tanzschurzes - der Weber zieht die Baststreifen der schwarzen Banane mit einer Nadel in das Gewebe ein - drückt der Tanzschurz nicht nur seine herausragende Wertigkeit aus. Vielmehr laden die Bedeutungen der Symbole den Schurz weiter auf: Die Nalinuss steht für Wohlstand, Fülle, die Bereitschaft, diese zu teilen, und so für die Absicht, mit anderen in Beziehung zu treten. Zwei Reihen von Haifischzähnen säumen das Muster und geben Stärke und Sicherheit. Teilen (Nalinuss) und Sicherheit geben (Haifischzähne)

\footnotetext{
179 Auch YEN (1974: 262) berichtet, dass ihm gegenüber derartige Aussagen geäußert wurden.
} 
gelten auf Ndendö, laut Selwyn Balu, auch heute noch als vorbildliche Eigenschaften sozial anerkannter Personen.

So vermitteln, ,übersetzen' die lepanesa in und mit dem Akteur-Netzwerk ,nelo-Tänzer' zum einen die erhoffte Qualität der Beziehungen der Auftraggeber des Festes zu deren Gästen: Die Beziehungen sollten Wohlstand und Sicherheit geben. Zum anderen visualisieren die Tanzschurze die erfolgreichen Beziehungen, die das Fest erst ermöglichten, den Wohlstand der Auftraggeber.

\subsubsection{Tapa}

Tapa habe ich als Material für Kleidungsstücke im Rahmen des nelo-Tanzes in vier Formen beobachten können: unbemalt und bemalt als Wickeltücher für Frauen bei touristischen Aufführungen in Malo oder einem Empfang nationaler Politiker in Venga, bemalt als Kopfbedeckung abe der gleichnamigen Tanzanführer und als Schurze für drei Jungen auf dem Fest in Ne'ele (vgl. Kap. 4.3.4). In der folgenden Beschreibung und Analyse werde ich mich auf die mit Mustern dekorierten Tapa-Varianten konzentrieren. Die für den Verkauf an Touristen hergestellten Tapa nehme ich an dieser Stelle nicht mit auf, da ich hier die Tanzkleidung untersuche. Dieses Erscheinungsbild von Tapa betrachte ich gesondert in Kapitel 6.

\section{○ Rezentes Wissen über Bedeutungszuschreibungen}

Im Alltagsleben der Menschen auf Ndendö spielte Tapa anscheinend kaum eine Rolle mehr, weil sie die Rindenbaststoffe durch andere Materialien ersetzt hatten. Dennoch war Tapa allen Personen, mit denen ich darüber sprach, bekannt - im Unterschied etwa zu den nelo oder auch den lepanesa. In den Gruppendiskussionen wurde sie im Zusammenhang mit Hochzeitsfeierlichkeiten, kastom-Tänzen und als Kleidung ,alter Frauen' genannt. Über Wissen zu Herstellung und Dekoration verfügten aber nur noch die wenigen Personenkreise, die sich aktiv damit auseinandersetzten.

\section{○ Begrifflichkeit}

Die Begriffe tapa oder tapa cloth waren auf Ndendö neben bark cloth die pijin-englische, umgangssprachliche Bezeichnung für bemalte und unbemalte Rindenbaststoffe gleichermaßen (vgl. Anm. 134). Obwohl meiner Beobachtung nach weitestgehend nur die Familie YamöliMdewöt im Süden Ndendös Tapa für die nelo-Tänze produzierte und den Rindenbaststoff neben tapa auch mit dem Begriff mokali aus ihrer Sprache Nalögo bezeichnete, konnte sich letzterer inselweit nicht durchsetzen. ${ }^{180}$

\section{○ Bewertung der Rohstoffe}

Die Familie Yamöli-Mdewöt nutzte ausschließlich auf ihrem kastom-Land wachsende Baumschösslinge. Die Ehefrau stellte die schwarze Farbe, mit der ihr Ehemann die Tapa bemalte, ausschließlich aus natürlichen Materialien her. Die von ihnen hergestellten Tapa wurden als

\footnotetext{
180 Zur Familie Yamöli-Mdewöt und ihrer Tapaproduktion vgl. Kap. 4.3.4 und Kap. 6.4.
} 
,echte' Santa-Cruz-Tapa u. a. im Museumsshop in Honiara wertgeschätzt und verkauft (Patricia I'tae, 29.11.2011). Mitunter verkaufte das Ehepaar sowohl unbemalte Tapa als auch Farbe an Männer aus der Graciosa Bay, etwa an Ben Banie oder John Namiade, die damit selber Tapa bemalten.

\section{○ Ikonografie}

Hinsichtlich ihrer Gestaltung weisen rezente Tapa nur sehr bedingt Ähnlichkeiten zu den früh erworbenen Tapa in den Museumssammlungen auf. Die Gestaltungen der historischen Artefakte sind hingegen relativ homogen: Die Gesamtfläche ist in mehrere Reihen mit gleichgroßen Rechtecken aufgeteilt, die jeweils mit wechselnden abstrakten Mustern aus Linien, Rauten und Dreiecken gefüllt sind. Abhängig von Länge und Breite variiert die Anzahl der Rechtecke (vgl. Anhang). Die Muster sind mit schwarzer Farbe aufgetragen. Zur Illustration beschränke ich mich an dieser Stelle auf die Darstellung nur eines Beispiels (vgl. Abb. 99). Zu den Bedeutungen der Muster erhielt ich keine Informationen.

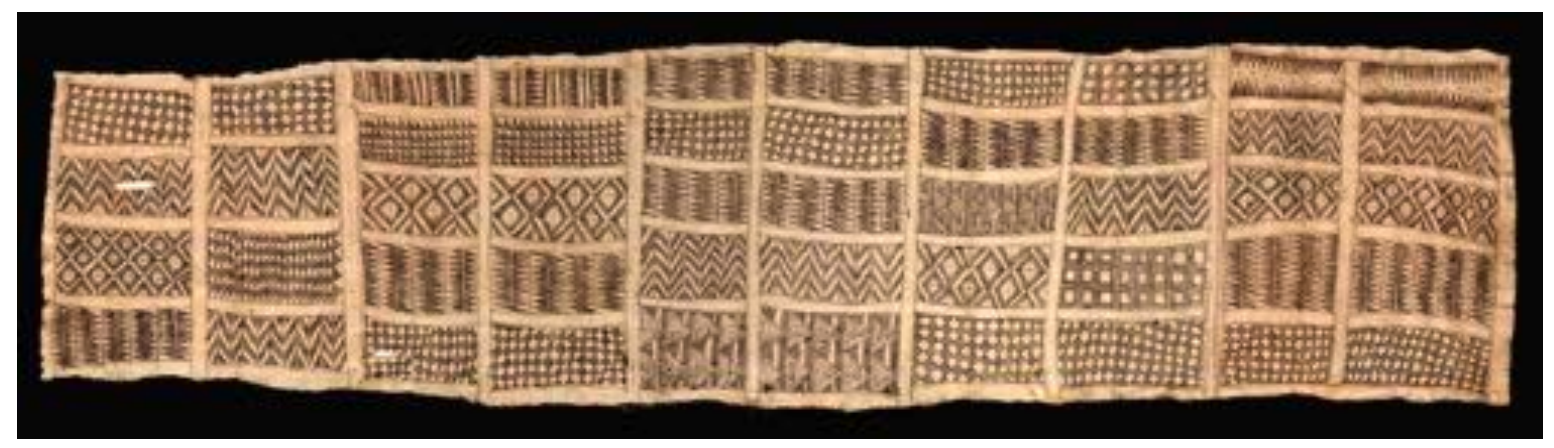

Abb. 99: Tapa, L.: 219 cm; Santa Cruz, 1897; Rautenstrauch-Joest-Museum 3986. (C) RBA, Fotograf: Wolfgang F. Meier

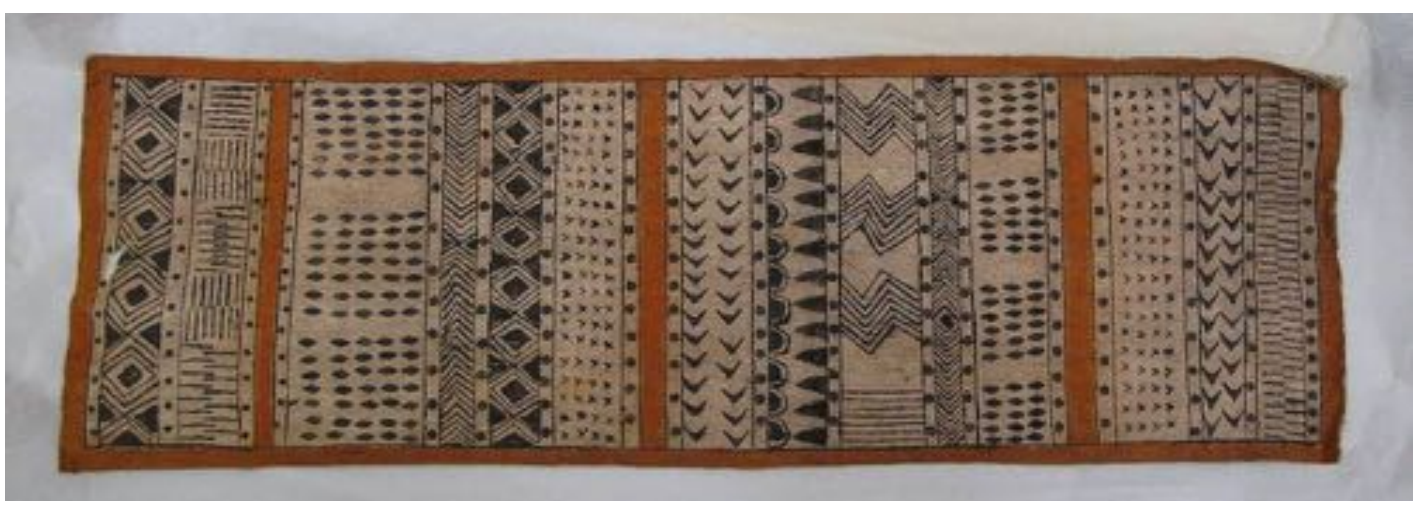

Abb. 100: Tapa, L.: 125 cm; Santa Cruz, 1996; Auckland War Memorial Museum 55128. 1996.48.2. (C) AM. Am linken Ende der Tapa ist eine Reihe mit Rauten zu sehen. Rechts der Mitte sind flächig ausgefüllte kleine Dreiecke in einer Reihe nebeneinandergestellt. Beide Muster finden sich auch auf den gewebten lepanesa (vgl. Abb. 95).

Aus den wenigen aus den 1990er-Jahren erhaltenen Tapa lassen sich keine Verbindungen zu den historischen Objekten erkennen (vgl. Abb. 46 und Abb. 100). 
Nach meinen Erkenntnissen lassen sich für die rezenten Arbeiten in den Jahren 2010 und 2011 zwei unterschiedliche Quellen ausmachen, denen die Produzenten ihre Tapa-Motive entnahmen und weiterentwickelten. Schon SPEISER hatte bei seiner Untersuchung Die Ornamentik von Santa Cruz (1915) zwei grundlegend unterschiedliche Mustergruppen ausgemacht. Zum einen ein Repertoire, das ausschließlich auf Tapa, zum anderen eines, das exklusiv auf anderen Artefakten eingesetzt wurde. ${ }^{181}$ Auch in den Jahren 2010/11 gab es nach meiner Beobachtung Muster, die nur Tapa schmückten und solche, die auf anderen Artefakten anzutreffen waren. Allerdings zeigte sich, dass letztere auch auf Tapa gemalt wurden. Sie hatten einen ,Sprung' von den Artefakten ,auf Tapa gemacht. Den ersten Bereich möchte ich aus Analysegründen als ,traditionelle Tapa-Rapporte' von dem zweiten als ,traditionelle Designs' abgrenzen.

1. Traditionelle Tapa-Rapporte

Unter einem Rapport verstehe ich hier ein flächenfüllendes Muster, das durch die ständige Wiederholung eines Motivs oder seiner Abfolge entsteht und in sich geschlossen ist. Diese Gestaltungsart entspricht der der ältesten in den Museumssammlungen erhaltenen Tapa (vgl. Abb. 99 und Anhang) und den wenigen historischen abe-Abbildungen (vgl. Abb. 2, 17 und 56). Während meiner Aufenthalte setzte meiner Beobachtung nach nur Steven Mdewöt diese Muster ein. Im Unterschied zu den historischen Freihandzeichnungen erstellte er seine Arbeiten jedoch mit einer selbstentwickelten Stempeltechnik, um seiner Aussagen nach möglichst akkurat zu arbeiten (vgl. Abb. 101 und Kap. 6.4). Allerdings nutzte er nicht ausschließlich diese überlieferten Muster, die er nach seiner Darstellung aus der Erinnerung reproduzierte, sondern ,spielte' mit den Mustern der traditionellen Designs und kombinierte sie mit den traditionellen Rapporten. ${ }^{182} \mathrm{Zu}$ den Bedeutungen der Tapa-Rapporte konnte das Ehepaar nichts sagen - im Gegensatz zu den traditionellen Designs der tema (vgl. oben Absatz 5.2.1 zur Ikonografie der tema).

2. Traditionelle Designs

Im Unterschied zu der ersten Gruppe subsumiere ich hierunter alle Muster, die nicht ausschließlich auf Tapa, sondern - in der Vergangenheit sogar vorrangig - auf anderen Artefakten oder auch auf menschlicher Haut Verwendung fanden und deren Bedeutungen teilweise überliefert wurden (GRAEBNER 1909; SPEISER 1915 und 1916; FOY 1916).

Neben dem bereits erwähnten Ehepaar Yamöli-Mdewöt arbeiteten weitere Personen mit den traditionellen Designs, etwa Matthias Me’lekaiva (Ena Yamölis Bruder), Ben Banie oder John Namiade - alle Mitglieder der Graciosa Bay Nelo Association. Me'lekaiva und Banie etwa hatten von Yamöli Tapa erworben und mit der ebenfalls von ihr erhaltenen Farbe

\footnotetext{
181 Von Speisers sonstigen Analyseergebnissen zur Stilistik möchte ich mich ausdrücklich distanzieren, da er sie nach meinem Dafürhalten zu sehr aus einer von den Produzenten losgelösten, westlich kunstgeschichtlich geprägten Perspektive durchgeführt und die Kreativität der Hersteller zu kurz auf ,Kopieren' und ,Vereinfachen des Vogelmotivs' reduziert hat.

182 Zu einem Beispiel für sein ,Vermischen' ursprünglich getrennter Musterrepertoires vgl. Kap. 6.4.
} 
freihändig die Muster auf die Kopfbedeckung abe für die beiden Anführer des nelo-Tanzes im August 2011 in Ne'ele gemalt (vgl. Abb. 102 und Abb. 103).

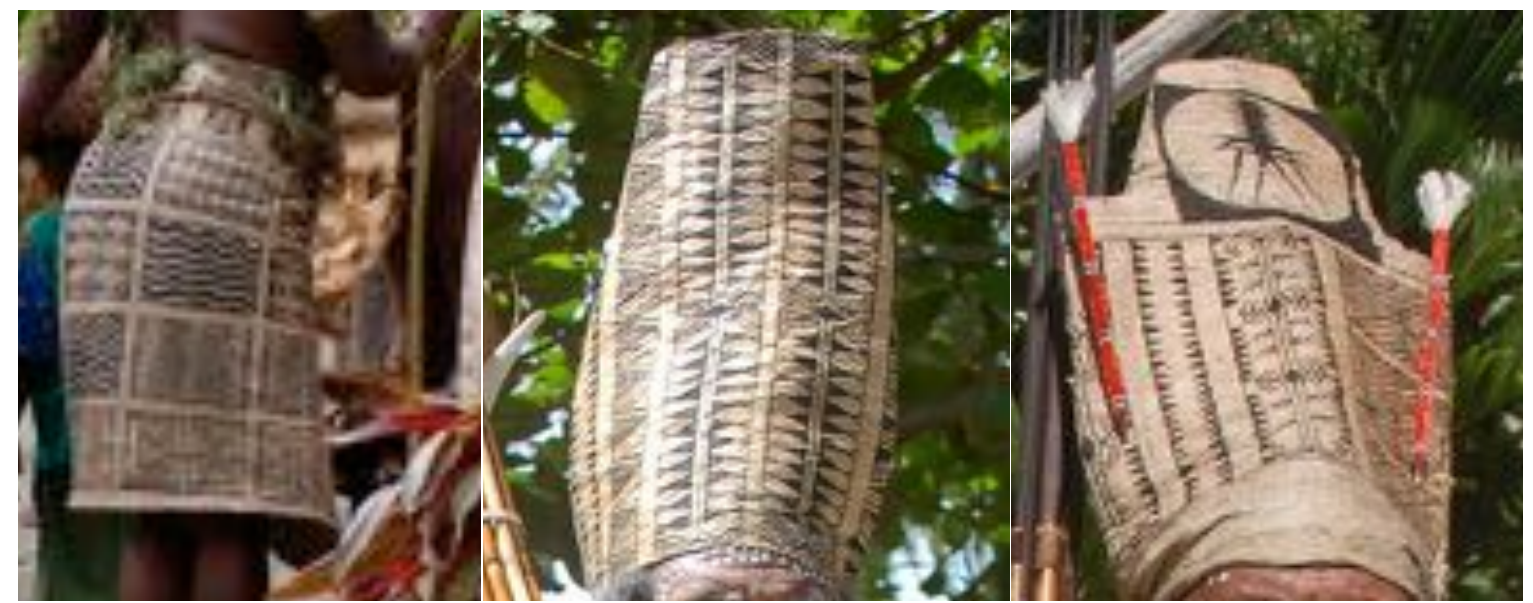

Abb. 101: Tapa als Hüfttuch mit, traditionellen Rapporten`; Steven Mdewöt, 2010.

Abb. 102: Kopfbedeckung abe mit dem traditionellen Muster , halbe Thunfische' in der mittleren und rechten Reihe; Matthias Me'lekaiva, 2011.

Abb. 103: Kopfbedeckung abe mit dem traditionellen Muster ,Haifischzähne“ und ,Sagopalme oder Nalinussbaum'; Ben Banie, 2011.

Me'lekaiva beanspruchte für sich das exklusive Verwendungsrecht an den von ihm verwendeten Designs, die gemäß seiner Aussage, einem Mythos zufolge, ausschließlich seiner Familie ,gehörten', etwa die langen doppelten Reihen von schwarzen Dreiecken, von denen jedes an der Spitze mit zwei kurzen schwarzen Linien verlängert war (vgl. Abb. 102). Me’lekaiva bezeichnete das Muster als nokaimawi (Nalögo) und erläuterte es als ,Reihen mit vielen Thunfischhinterleibern', was den Reichtum seines Trägers vermittelte. Hierin sehe ich eine Analogie zu Balus lepanesa-Mustern der Nalinuss. Me’lekaiva berichtete mir erst kurz vor Ende meiner Feldforschung von seinem Anspruch auf das Muster, so dass ich dem Thema ,Nutzungsrechte von Mustern' nicht weiter nachgehen konnte. ${ }^{183}$ Das von ihm beschriebene Muster findet sich zwar auf einigen historischen Tanzkeulen, nicht aber auf alten Tapa. Meines Wissens nach war Me'lekaiva auch nicht mit dem Träger des abe verwandt. (Matthias Me’lekaiva, 16.11.2011, und Ambros Me'naa, 7.10.2011)

Ben Banie kombinierte in seiner Arbeit traditionelle Designs mit einer tema-Darstellung in der oberen Spitze, die er zusätzlich, fast einer Krone gleich, ausgeschnitten hatte. Tema kamen historisch als Gestaltungsmittel nie auf Tapa vor. Da sie historisch betrachtet nur von Kriegern und Chiefs getragen wurden, unterstrich sie seiner Aussage nach die besondere Position seines Trägers. Des Weiteren stelle das linke Muster mit zwei Reihen schwarzer Dreiecke Haifischzähne dar, die für Stärke und Sicherheit stünden. Dieses Muster verwendete Selwyn mit derselben Bedeutung auch für seine lepanesa. Das zentral unter dem tema

183 Zur Auseinandersetzung um die Rechte zwischen dem Bruder und dem Ehemann Yamölis vgl. Kap. I und 6.4. 
verlaufende Muster symbolisierte Aussagen anderer Informanten zufolge Bäume, die als Nahrungsgrundlage für sehr wertvoll erachtet wurden, wie etwa die Sagopalme oder der Nalinussbaum (vgl. Abb. 103; Bolon Brown, 3.11.2011 und Isaac Me'satu, 9.11.2011). Teile dieses Musters wurden in der Vergangenheit auch für Tatauierungen genutzt (vgl. SPEISER 1916: 168). Zum rechten Muster liegen mir keine Informationen vor.

Beide Kopfbedeckungen unterstrichen mit ihren Mustern den herausragenden ökonomischen und sozialen Status der Träger. Denn nur Männer, die wirtschaftlich dazu in der Lage waren, und Andere davon überzeugen konnten, sie bei den Vorbereitungen zu unterstützen, konnten notwendige Tauschhandlungen einleiten und ein Fest zu einem erfolgreichen Abschluss führen. Der Police Commissioner Walter Kola war einer der Gastgeber und verkörperte seine Position auch als Tanzführer über seinen abe.

\section{Neue Gestaltungselemente}

Unter Nutzung traditioneller Designelemente gestaltete John Namiade für das besagte Fest in Ne'ele drei Tapa-Schurze für Jungen - wie er sagte erstmals. Mit Filzstiften bemalte er freihändig die Tapa und kombinierte Teile der zuvor erwähnten Muster (vgl. Abb. 104). Namiade reduzierte den Reihencharakter der traditionellen Muster, isolierte Einzelaspekte, vergrößerte diese und rückte sie so visuell in den Fokus, wie auf der Abbildung gut zu erkennen ist. Zudem hatte er die traditionell eher eckigen Linienformen des Motivs der Sagopalme abgerundet, so dass sie fast floral wirkten.

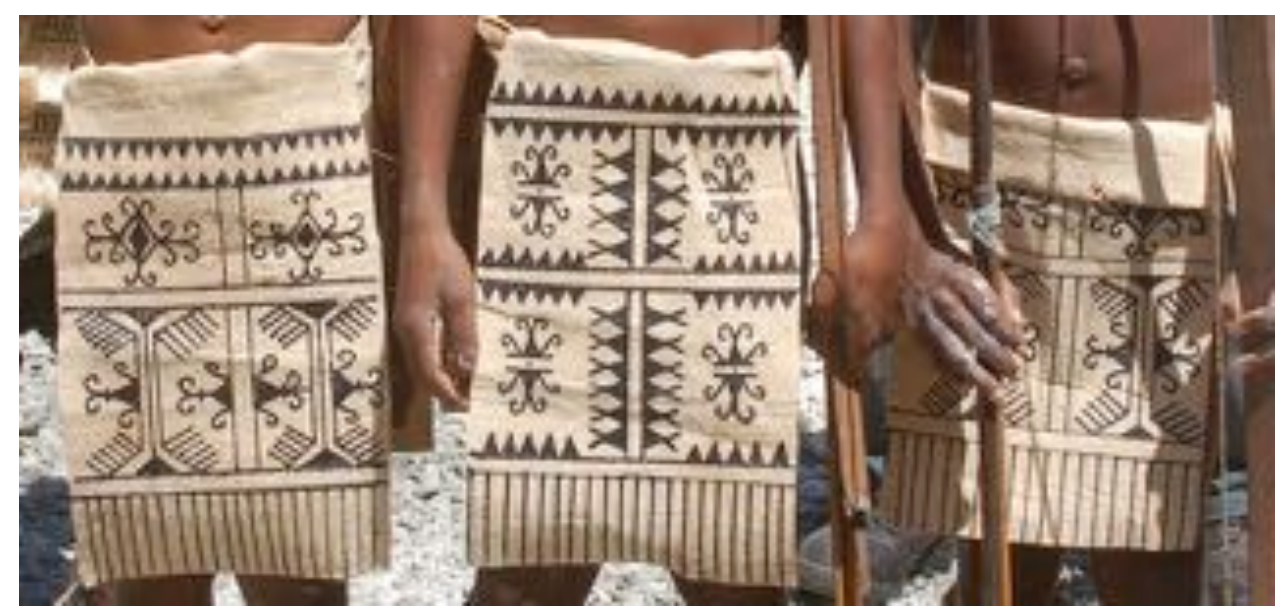

Abb. 104: Tapaschurze; John Namiade, 2011. V. 1. n. r.: John Namiades Sohn Don Boiken Kabi, Freddy Me'esas Sohn Randi Me'mua und David Me'nivis Sohn Alolo auf dem Fest in Ne'ele.

\section{○ Perspektiven auf Größen und Verwendung}

Die Größen der rezent hergestellten Tapa entsprachen den jeweiligen Verwendungszwecken. Als Schurze für Kinder waren sie schmal und lang, als Wickeltücher für Frauen wesentlich breiter. Für die abe war die Höhe des Rindenbasts so gewählt, dass die Kopfbedeckung von sich aus gerade noch aufrecht stehen konnte. 


\section{○ Verkörperung von Beziehungen}

In der Vergangenheit wurde Tapa auf Ndendö zu einem Großteil unbemalt im Alltag genutzt, etwa als Kleidung, als Laken zum Schutz vor Kälte oder Mücken, zur Beisetzung von Verstorbenen oder als Tanzkleidung der Frauen, bis das Material im Laufe des 20. Jh. weitestgehend von Baumwolle verdrängt wurde (vgl. Kap. 4.3.4). ${ }^{184}$ Mit Rapportmustern versehen, nutzten Männer und Frauen Tapa als (Tanz-)Kleidung in Form von Wickeltüchern und Schurzen, und manche Männer verwendeten bemalte Tapa für ihren abe. Damit wurde Rindenbast als ,Kleidungsstoff häufiger genutzt als Bananenbast. Auch wenn ich zu den traditionellen Rapporten keinerlei Informationen erhielt, wurde anderen traditionellen Mustern eine Bedeutung zugeschrieben. Alle verwiesen auf die Beziehungen der Träger zu ihrem Umfeld - ich gehe davon aus, dass in der Vergangenheit auch Frauen mit derselben Intention bemalte Tapa trugen, wie es für gewobene ,Matten' überliefert ist. Konkret drückten Männer einst und heute wieder - DAVENPORT (1990: 100) zufolge wurde diese Praxis um das Jahr 1958 eingestellt - mit dem Tragen der Tapa/Kopfbedeckung abe eine höhere soziale oder wirtschaftliche Stellung aus. ${ }^{185}$

So liegt es nahe, Tapa als Medium zu verstehen, auf das die Produzenten auftragen, was ihnen in der Beziehung zu und Kommunikation mit Anderen wichtig ist, wie etwa Verbindungen zu/mit Familienmitgliedern, Freunden, Nachbarn, Politikern, Touristen und mitunter auch dukna. Die auf den abe im Jahr 2011 dargestellten Muster drücken Wohlstand und Sicherheit aus - die Anführer generieren und ihrem Umfeld geben können, wozu sie nach Aussagen meiner Gewährsleute aber auch die Unterstützung der dukna benötigten. Nachdem die Bewohner Ndendös viele andere bemalte Artefakte wie Tanzkeulen, Kalkkalebassen, Ösfässer oder Kopfbänke nicht mehr herstellten und weniger Tatauierungen durchführten, bot Tapa die Möglichkeit, die Muster weiterhin zu überliefern. Dies könnte meiner Meinung nach auch erklären, warum die Produzenten heute auf Tapa Muster einsetzen, die ehemals nicht auf diesem Material verwendet wurden. In diesem Sinne würde Tapa als Vermittler eine Verbindung der Menschen zu ihrer Vergangenheit ermöglichen. Als kastom-Artefakt erschien Tapa in verschiedenen kastom-Konfigurationen und verkörperte genau diese Beziehungen zu den Vorfahren und einer eigenen Geschichte. Im Falle von Matthias Me'lekaiva verkörperte seiner Aussage zufolge das exklusive Verwendungsrecht bestimmter Muster die direkte Verbindung zu seinem Clanbegründer. Im Umfeld einer Touristendarbietung mit nelo-Tanz traf ich auf einen Mann, der eine Tapa als Wickeltuch um den Körper gehüllt trug und auf der diese Kontinuität in der Beziehung zu der Vergangenheit zu lesen war (vgl. Abb. 105).

\footnotetext{
${ }^{184}$ Auf anderen Inseln im Santa-Cruz-Archipel, insbesondere auf den polynesisch geprägten, mag sich die Situation anders darstellen.

${ }^{185}$ Das Einstellen des abe-Tragens in den 1960er-Jahren würde auch erklären, warum KOCH (197I) keine derartige Kopfbedeckung aufführt.
} 


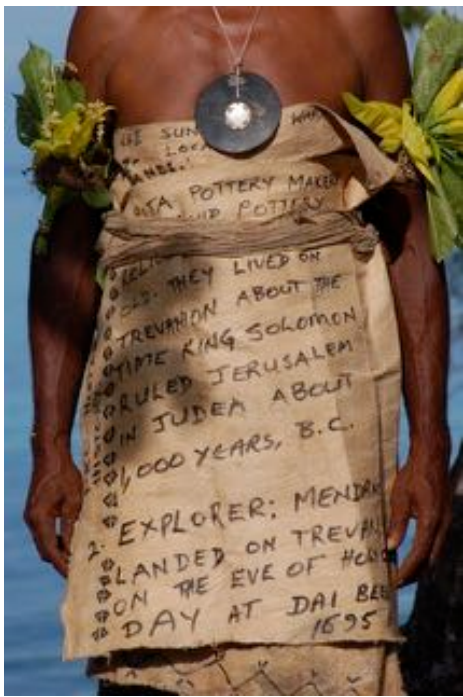

Abb. 105: Beschriebene Tapa; Hersteller unbekannt; Malo, 2012. Auf der Tapa sind Details der lokalen Geschichte aufgeführt, u. a.: Lapita-Keramik-Produzenten lebten zu Zeiten König Salomons um 1.000 vor Chr. auf Trevanion (Temotu Neo), der Entdecker Medaña landete am Heiligen Abend des Jahres 1595 vor Dai (heute unbewohnt, im Süden Temotu Neos).

\subsubsection{Schmuck aus Blättern, Blüten und Wurzeln}

Sowohl frische, kurz vor dem Ankleiden gepflückte Blätter und Blüten ausgewählter Pflanzen als auch die aus Kurkuma gewonnene Farbe Gelb machten, wie oben gezeigt, einen nicht unwesentlichen Teil des Schmucks der nelo-Tänzer aus. Das aus Korallen hergestellte Weiß stelle ich in Kapitel 5.2.6 gesondert vor, da es aus Tieren gewonnen wird. In der Literatur sind die pflanzlichen Aktanten bezüglich dieser zeremoniellen Nutzung kaum beschrieben und in den Museumssammlungen weitestgehend nicht vertreten.

\section{$\bigcirc$ Rezentes Wissen über Bedeutungszuschreibungen}

Pflanzen waren in vielerlei Hinsicht auch außerhalb des nelo-Tanzes in verschiedensten Momenten als Teil des alltäglichen Lebens gegenwärtig, wirkten in vielen weiteren Akteur-Netzwerken: ob bei der Zubereitung und Aufbewahrung von Speisen, beim Fischfang, zur Fütterung von Nutztieren, in der traditionellen Heilkunde, zur Körperpflege, zum Schutz vor Ungeziefer und Insekten, zum Schmücken des Gartens oder Hauses oder zur Begrüßung von Gästen - um nur einige Beispiele aufzuführen, die mir meine Gewährsleute demonstrierten. Yen (1974) schreibt Sträuchern und Bäumen im Santa-Cruz-Archipel eine im Vergleich zu anderen Inseln der Region überdurchschnittliche Bedeutung zu, sieht sie als eine wesentliche Form der Subsistenzwirtschaftsform auf den Inseln und bezeichnet sie als ,Arboriculture'.

\section{○ Begrifflichkeit}

Die zur Kleidung bzw. zum Schmuck der nelo-Tänzer zugehörigen Blätter und Blütenstände bezeichneten die Tänzer umgangssprachlich als parfium (Pijin) und differenzierten hinsichtlich der dekorativen Funktion nicht weiter zwischen ihnen. Das Kurkumapulver stellten sie mir als turmeric (engl., Pijin) vor.

\section{○ Bewertung der Rohstoffe}

Während des Ankleidens der nelo-Tänzer konnte ich vor allem folgende Pflanzen ausmachen: Blätter der Ti-Pflanze (no nüngü in Natügu, Cordyline fruticosa), des Crotons (Codiaeum 
variegatum), von verschiedenen Ingwergewächsen (Alpinia-Arten) sowie Blätter mit Blütenständen der Euodia hortensis (YEN 1974: 256). Dabei handelte es sich um Pflanzen, die überall wuchsen und an sich nicht als wertvoll beurteilt wurden. Allerdings wurden sie teilweise auch im Alltag zu bestimmten Zwecken genutzt, wie ich weiter unten aufführe.

Wie beim Ankleiden der Tänzer beschrieben, rieben sich einige nelo-Tänzer mit Kurkuma ein. Obwohl er auf allen Santa-Cruz-Inseln natürlich vorkommt, ist er traditionell wesentlicher Bestandteil des Handels mit den Reef Islands. Nach Aussagen einer Produzentin von verschiedenen Formen lokaler Taschen stellte im Jahr 2011 als einzige auf Ndendö die aus den Reef Islands stammende und in Neo-Nemba lebende I'nuni das Pulver her. Ansonsten tauschte man es von den Reef Islands in Form getrockneter Rollen ein. (Betsi I'nep, 21.7.2011)

\section{○ Wirkung der Farbigkeit und des Geruchs}

Allen gemeinsam war ihr intensiver Duft, der die Träger wohlriechend parfümieren sollte, und demzufolge die Pflanzen als Tanzschmuck für die nelo-Tänzer wohl auch als parfium bezeichnet wurden. Abhängig von der jeweiligen Pflanze waren die Blätter grün oder rötlich, grün-gelb oder rot-grün gesprenkelt oder gestreift; nur die Blütenstände waren eher weißlich.

\section{○ Herstellung}

Wie für das Ankleiden der nelo-Tänzer beschrieben, banden die Tänzer selber und auch andere Männer für sie Blätter respektive Blütenstände zu Büscheln, damit die Tänzer diese in die Oberarmreifen (Croton und Euodia hortensis) oder in die Gürtel am Rücken (Ti-Pflanze) einstecken konnten. Zusätzlich rollten sie große Blätter der Ingwergewächse solange zwischen ihren Händen, bis das Blattgrün fransenförmig an der Blattrippe hing. Sie banden die Enden zusammen und erhielten so eine Art Girlande oder Kette. Diese trugen später die Krieger und die mit den Tänzern in Beziehung stehenden Männer und Frauen.

\section{- Perspektiven auf die Verwendung}

$\mathrm{Zu}$ einer möglichen, über die reine Funktion als Duftspender hinausgehenden Bedeutung führt BOERGER (2009: 106) zu der Ti-Pflanze aus, dass der Pflanzenschmuck als Bündel am Rücken der Tänzer einen Hahnenschweif verkörpere. Die Angriffslust der Hähne verbinden die Männer ihr zufolge mit der Eigenschaft, einen Kampf anführen zu können. Man könne den Büschel herausnehmen, damit wedeln oder ihn an einen Stock binden und so Kämpfer anführen. Nach YEN (1974: 256) symbolisierte die Ti-Pflanze außerhalb des Tanzes Eigentums- oder Landnutzungsrechte und wurde zudem an Gräbern auf dem Friedhof gepflanzt. Auch ich habe sie während meiner Aufenthalte neben weiteren Pflanzen häufig als Markierungen von Wohneinheiten und Dörfern sowie als Einfriedung von Gräbern gesehen. Euodia hortensis sprachen meine Gewährsleute eine mücken- und termitenabweisende Wirkung zu, weshalb sie diese oft an tragende Pfähle ihrer Häuser pflanzten.

Kurkuma wurde (historisch betrachtet) vielfältig genutzt: Schon CODRINGTON (1891: 330) berichtet von der Verwendung von Kurkuma in Santa Cruz für das Färben von Taschen, worin er eine Verbindung zu polynesischen Gruppen sah. Bis in die 1960er-Jahre wurde der Leichnam höher angesehener Personen gehäutet, um den Verwesungsprozess zu 
beschleunigen und möglichst schnell die gereinigten Knochen in Höhlen beisetzen zu können. Zur Neutralisierung des Verwesungsgeruchs wurde der Leichnam mit Kurkuma eingerieben. Nach der Beisetzung konnte der Schädel von Zeit zu Zeit zur Ehrung hervorgeholt werden, wobei er erneut mit Kurkuma eingerieben wurde. (Yamöli und Mdewöt, 27.8.2011)

DAVENPORT (2005) beschreibt das Einreiben von Schädeln noch für das Jahr 1973 anlässlich einer closing ceremony in Neo. Seiner Meinung nach ermöglichte das Ausstellen der Schädel eine direkte Kommunikation mit den Ahnen (2005: 38). Wurden dukna-Darstellungen (die es zur Zeit meiner Feldforschung nicht mehr gab) mit Kurkuma eingerieben, verkörperte dies ihm zufolge einen ,_...] interstitial place of the figure: an object that exists between the human domain (as a representation) and the supernatural domain (in which the deity it represents is located)“ (2005: 101). Seiner Beobachtung nach war das Pulver ,[...] a substance Nendö people regarded as containing some supernatural properties and which was often smeared on sacred objects in order to sacralize them" (ebd.). Er führt dies auf die physikalische Reaktion bei der Zusammensetzung des Pulvers mit Kokosöl zurück: Wenn der pH-Wert des Pulvers durch das Vermischen mit Kokosöl alkalisch wird, wechselt die Farbe des zunächst gelblich-orangefarbenen Pulvers zu Lilatönen. Diese Veränderung interpretierten die Bewohner Santa Cruz' ihm zufolge als Ausdruck magischer Eigenschaften (ebd.).

Während meines Aufenthaltes beobachtete ich neben dem Einsatz bei den Tänzern auf der Feier in Neo-Nemba das Einreiben von Haaren und Oberkörpern der zu initiierenden Personen, ferner in Luepe das Einreiben der Haare von Braut und Brautmutter sowie der geflochtenen Hochzeitstaschen der Braut mit Kurkuma auf einer Hochzeitszeremonie.

Meines Erachtens leitet Kurkuma eine Transformation, einen Übergang in einen anderen Zustand ein und vermittelt diesen: vom nicht Initiierten zum vollwertigen Mitglied der Gruppe und vom Verstorbenen zum Ahnen. Mit der Hochzeit löst die Tochter die Bindung zu ihrer Mutter, so dass sie frei wird für eine neue, die zu ihrem Bräutigam. Sie wechselt ihren Status von Tochter zu Braut. Im Umkehrschluss gibt die Mutter ihre Verantwortung für die Tochter an den Bräutigam ab und wird ihrerseits wieder unabhängig. Im Ankleiden der Tänzer unterstützt das Kurkuma den Wandel vom gewöhnlichen Mann zum ,nelo-Tänzer'.

\section{$\bigcirc$ Verkörperung von Beziehungen}

Wie gezeigt, erscheinen die Pflanzen neben dem nelo-Tanz als Aktanten auch in anderen Akteur-Netzwerken. Indem sie zwischen ihnen wechseln (driften), können sie diese verbinden. Mit ihren natürlichen Attributen bzw. Inhaltsstoffen schützen sie die Menschen und sprechen deren Sinne an. Sie ermöglichen, dass Andere bestimmte konzeptionelle Überlegungen wahrnehmen können. So verkörpert etwa die Form zusammengebundener Blätter der Ti-Pflanze einen Hahnenschweif und ,überträgt' die Stärke zu Führen - eine Eigenschaft, die nach Sicht einiger Informanten den wilden Hähnen nachgesagt wird - auf die Tänzer, weil sie das Bild kämpfender Hähne evozieren und dadurch die direkte Verbindung zu dieser Eigenschaft der Tiere schaffen. 
Kurkuma leitet Passageriten ein und zeichnet diese aus. Das Pulver gilt grundsätzlich als wirkmächtige Substanz und besitzt neben medizinischen Eigenschaften auch ,übernatürliche' Kräfte. In der Vergangenheit leitete es nach dem Tod den Wandel vom Verstorbenen zum Ahnen ein. Das Einreiben eines Ahnenschädels mit frischem Pulver , aktivierte' den Ahnen und brachte ihn in die Welt der Menschen, so dass sie miteinander kommunizieren konnten. Aktuell begleitet es bei Hochzeitszeremonien Veränderungen der Beziehungen zwischen Braut und Brautmutter oder unterstützt Kinder und Jugendliche während ihrer ersten Initiation. Kurkuma löst Grenzen auf bzw. verbindet, verschiedene' Welten.

Meines Erachtens heben die Tänzer mit dem Einreiben ihres Körpers und der Ausstattung mit weiteren wirkungsvollen Pflanzen eine Grenze zu den dukna auf. Psychisch belastbar, ausgestattet mit einem virilen Köper, ,immun' gegen Schädlinge und körperlich gestärkt durch die Führungs- und Kampfeslust der Hähne, sind die nelo-Tänzer den dukna ebenbürtig und können mit ihnen im Namen der Gemeinschaft kommunizieren. Nun können die Menschen durch die nelo-Tänzer im ursprünglichen Sinn des Festes agieren, ihre Anliegen vorbringen und die dukna um Unterstützung oder Vergebung bitten. Die Pflanzen verbinden die diesseitige Welt der Menschen mit der jenseitigen der dukna. In diesem Sinne ,öffnen` die Pflanzen als Aktanten den nelo-Tänzern ein neues Akteur-Netzwerk, in dem die Tänzer mit den dukna in Kontakt treten können.

\subsubsection{Korallenkalk}

Wie ich bei Festvorbereitungen in Neo-Nemba beobachten konnte, gewannen die Dorfbewohner lime (Pijin) aus versteinerten Korallen, indem sie diese beim Heizen von Erdöfen zwischen die oberste Abdeckschicht Kochsteine mischten und nach dem Erlöschen des Ofens den reinweißen Staub der dann zerfallenen Korallen zwischen den Steinen sammelten und in Gefäße füllten. Lime schien daher auf Ndendö unbegrenzt verfügbar bzw. herstellbar zu sein. Oftmals sah ich, wie das Pulver an Personen weitergereicht wurde, wenn diese keines dabeihatten. Nur im urbanen Umfeld von Honiara konnte ich beobachten, dass es in kleinen Plastikgefäßen verkauft wurde.

Die Menschen auf Ndendö benutzen lime im Alltag, um ihn zusammen mit Betelnuss und -pfeffer zu kauen. Ich bin sehr wenigen Erwachsenen begegnet, die nicht Betel konsumierten, nicht wenige Kinder ab etwa zehn Jahren waren schon mit dem ,Genussmittel ${ }^{6}$ vertraut, noch jüngere kauten Teile der Betelnuss ohne lime. ${ }^{186}$ Der Korallenkalk dient der Freisetzung der in der Nuss enthaltenden Alkaloide. Bereits nach kurzer Zeit entfaltet die Mischung im Mund ihre gewünschte Wirkung: Meine Gesprächspartner betonten, dass Betelkauen erfri-

\footnotetext{
${ }^{186}$ Bereits de Quirós berichtete über den Genuss von Betel (Clemens Robert MARKHAM I 904: 5 I).
} 
schend schmecke und das Durst- und Hungergefühl reduziere. Ihm wird eine leicht stimulierende und stimmungsaufhellende Wirkung zugeschrieben. ${ }^{187}$ Zudem regt das Kauen den Speichelfluss an und färbt den Speichel blutrot.

Für den nelo-Tanz wurden die Haare der Tänzer mit dem feinen Pulver geweißt. In der aufgebürsteten und durch den lime gestärkten Frisur trugen die nelo-Tänzer Hahnenschweiffedern. ${ }^{188}$ In der Vergangenheit wurde er auch für Gesichtsbemalungen genutzt, wovon man Abstand genommen hatte, da die Farbe schweißbedingt nur kurze Zeit hielt und durch industriell gefertigte Farbe ersetzt worden war.

Darüber hinaus nutzen auf Ndendö einige Hersteller von kastom-Artefakten Korallenkalk für ihre Arbeiten: zum Polieren von Kokosnuss- oder Schildpattoberflächen, zum Weißen von Schnitzereien, bei denen sie die Vertiefungen mit dem weißen Kalk ausrieben, sodass sich die Muster deutlich vom dunkleren Holz abhoben, oder zum Grundieren anderer Arbeiten, etwa von Tanzkeulen.

\section{$\bigcirc$ Rezentes Wissen über Bedeutungszuschreibungen}

Einem Paramount Chief zufolge galt die Farbe Weiß - wie auch Schwarz und Rot - als Farbe der dukna, (Chief Ambros, 7.10.2011). Ob die Farbe Weiß, wie in vielen anderen melanesischen Kulturen, grundsätzlich als Farbe des Totenreichs und der Ahnen und/oder einer lebenspendenden Kraft verstanden wurde und folglich mit den Ahnen oder einer übernatürlichen Kraft in Beziehung stand, konnte ich nicht abschließend beurteilen. Bekannt hingegen war der Umstand, dass Betelnusskonsum erst durch den Einsatz von lime zu den erwünschten Veränderungen der Wahrnehmung führte und den Speichel rot färbte.

\section{$\circ$ Verkörperung von Beziehungen}

In keinem anderen Zusammenhang färbten sich die Menschen auf Ndendö ihre Haare weiß, nur die nelo-Tänzer traten derart in Erscheinung. Wäre es möglich, dass das Färben der Haare mit dieser Substanz analog zu Kurkuma ein Mittel ist, um die Transformation vom gewöhnlichen Mann zu einem dukna ebenbürtigen nelo-Tänzer zu unterstützen? Meines Erachtens liegt dieser Schluss nahe, da Korallenkalk wie auch Kurkuma physische Reaktionen hervorrufen kann: Der Kalk färbt den Speichel rot, und sein Genuss hat wahrnehmbare Auswirkungen auf den menschlichen Körper. Meiner Ansicht nach agiert auch Korallenkalk als Aktant in dem Akteur-Netzwerk nelo-Tänzer und ermächtigt die Menschen zu Handlungen, etwa zu einer Kommunikation mit den dukna.

\subsubsection{Wirkmacht der Tanzkleidung und des -schmucks für die Tänzer}

Nach meiner Erkenntnis können die nelo-Tanzartefakte wie die menschlichen Aktanten aus unterschiedlichen Perspektiven betrachtet werden: Man kann sie sowohl als heterogene AkteurNetzwerke, in denen nicht menschlichen Aktanten soziale Beziehungen mit den Menschen

\footnotetext{
$187 \mathrm{Vgl}$. http://www.dr-bernhard-peter.de/Apotheke/seite 179.htm, letzter Zugriff am 9.9.20 I 5. Ich habe beobachtet, wie der überhöhte Genuss zu einem so starken Verwirrungszustand führte, dass ein PKW-Fahrer abrupt anhalten und ein Gegenmittel nehmen musste.

188 Zur Bedeutung der Metapher ,Hahnenschweiffedern' vgl. Kap. 5.2.5, ,Ti-Pflanze'.
} 
eingehen, als auch als deren Effekte verstehen. Beim vorliegenden Fall verdeckten sogenannte Punktualisierungen (Entitäten wie etwa tanzende und singende nelo-Tänzer) die hinter den vermeintlichen Einheiten liegenden Akteur-Netzwerke (,nelo-Tänzer` als Geflecht von heterogenen Beziehungen und als Transformationsprozess) mit ihren Figurationen und ,Übersetzungen` und ließen sie als deren Effekte erscheinen.

Bei der Betrachtung der ,nelo-Tänzer ${ }^{6}$ als heterogene Akteur-Netzwerke konnte ich aufzeigen, dass die nicht menschlichen Aktanten Tanzkleidung und -schmuck spezifische ,Essenzen' einbrachten. In der Analyse der physischen Attribute und Eigenschaften der eingesetzten Materialien zeigten sich diese Essenzen und ihre Bedeutungen für die Menschen.

Meines Erachtens verfügen die Artefakte über eine eigene Wirkmacht. Sie unterstützen den Wandel der Männer von Alltagspersonen zu Tanzpersonen innerhalb des Akteur-Netzwerks ,nelo-Tänzer‘. Möglicherweise leiten sie ihn sogar erst ein und sind daher zwingend notwendig. Die Wirkkraft der Tanzkleidung und des -schmucks resultiert aus den Materialeigenschaften, den Essenzen der Rohstoffe. Diese Eigenschaften der Artefakte unterscheiden sich stark von denen der Menschen. Aufgrund ihrer Langlebigkeit etwa ermöglichen die Tanzkleidung und der -schmuck das über ein Menschenleben hinausgehende Fortbestehen von Beziehungen in Zeit und Raum. Die ,Essenzen` der genutzten Materialien eröffnen vielfältige Beziehungen und legen damit die Basis für die aus ihnen geschaffenen Kleidungs- und Schmuckstücke, zwischen verschiedenen Akteur-Netzwerken zu ,driften'.

Die in dieser Arbeit fokussierten Artefakte ermöglichten und verkörperten erfolgreiche soziokosmische Beziehungen, ohne die sich das Akteur-Netzwerk ,nelo-Tänzer' nicht hätte entwickeln können: Beziehungen zu den Clans, Vorfahren und Ahnen, zur Umwelt (Nahrungsmitteltabus und der dadurch sichergestellte regenerative Umgang mit den Ressourcen oder kastom-Land mit seinen verteilten Landnutzungsrechten) und letztlich zu den dukna. Darüber hinaus luden die Artefakte und der pflanzliche Schmuck mit ihren eigenen bzw. ihnen zugeschriebenen Kompetenzen die Tänzer auf und verliehen ihnen wichtige Fähigkeiten wie Führungsstärke, Kampfeskraft, Langlebigkeit oder Widerstandsfähigkeit. Die Tanzkleidung und der -schmuck übersetzten, transformierten die gewöhnlichen Männer auf eine neue Ebene in neue Wesen, eben die nelo-Tänzer. Die Artefakte schützten und ermächtigten sie, den dukna auf Augenhöhe gegenüber zu treten und stellvertretend die Anliegen der Auftraggeber vorzutragen, etwa eine auf die Zukunft gerichtete Sicherung von Wohlstand und Schutz aller.

John Me'alue (15.10.2011) bezeichnete diese soziokosmischen Verbindungen als „holistisch“, womit er den Menschen als einen Teil - und nicht als Mittelpunkt - einer beseelten Umwelt sah, zu der er sowohl Flora und Fauna, Land, Meer und Himmel als auch den christlichen Gott, die dukna und andere spirituelle Wesen, die Lebenden, Verstorbenen und Ahnen aber auch die Feste zählte. Letztere waren gemäß seiner Aussage relevant, da sie diese Beziehungen im gemeinschaftlichen Essen und in nelo-Tanzaufführungen auf vielen Ebenen erst real erlebbar machten. Diesen unterschiedlichen ,Berührungs- oder Beziehungsebenen` der Artefakte und Menschen im heterogenen Akteur-Netzwerk ,nelo-Tanz ${ }^{6}$ werde 
ich im nächsten Kapitel aus zwei Perspektiven, der der Tänzer und der des Publikums, näher beleuchten.

\subsection{Effekte von Tanzkleidung und -schmuck im Akteur-Netzwerk ,nelo-Tanz ${ }^{6}$}

Im vorangegangenen Kapitel bin ich den Wirkweisen und der Relevanz der Tanzkleidung und des -schmucks innerhalb des Akteur-Netzwerks ,nelo-Tänzer` im Rahmen der Transformationen nachgegangen. Ausgehend vom Ankleideprozess eines einzelnen Tänzers habe ich aufgezeigt, welche Rollen dabei einzelnen Artefakten zukamen, welche spezifischen ,Essenzen` sie in die werdende neue Entität, nelo-Tänzer' einbrachten und dadurch andere Aktanten veranlassten, miteinander in Beziehungen zu treten und so den Menschen soziokosmische Beziehungen ermöglichten. Es zeigte sich, dass ohne die Tanzkleidung und den -schmuck die Transformationen von Alltagspersonen zu Tanzpersonen unmöglich gewesen wären und die Tänzer ihrer originären Aufgabe, nämlich für die Auftraggeber mit den dukna in Kontakt zu treten, nicht hätten gerecht werden können, da die menschlichen Aktanten alleine nur unzureichend über die dafür notwendigen Fähigkeiten verfügten, unzureichend ,mächtig waren. In diesem Kapitel werde ich möglicher Handlungs- und Wirkmacht der Artefakte im Akteur-Netzwerk ,nelo-Tanz für Jonas Kepule‘ als Effekte auf Andere nachgehen. Die Wirkweisen der Tanzkleidung und des -schmucks stellen sich in den Bewegungen des Tanzes anders dar, als im ,ruhenden' Zustand beim Ankleiden. Daher werde ich nun untersuchen, was die Artefakte im nelo-Tanz bei den teilnehmenden Menschen - Tänzern und Publikum - auslösten, welche Effekte die Entitäten auf sie hatten, soweit dies die Aussagen meiner Gewährsleute und meine Beobachtungen zulassen.

\subsection{Artefakte und Tänzer}

Nelo-Tänzer konnte meinen Gewährsleuten zufolge nur derjenige werden, der dem männlichen Schönheitsideal auf Ndendö entsprach, als jung, viril, physisch und mental stark galt. Laut ihrer Aussagen konnte man nicht selber den Anstoß geben, sondern musste von Anderen gefragt und von ihnen ,ermächtigt' werden, Tänzer zu werden - d. h., als Aktant in ein Akteur-Netzwerk ,nelo-Tanz' berufen zu werden. Der zukünftige Tänzer musste dazu zudem über die für das Tragen eines nelo oder der Schmuckstäbe neiapo notwendigen Piercings der Nasenscheidewand respektive Nasenflügel verfügen. Im übertragenen Sinne ,zwangen“ die Nasenschmuckstücke die Eltern oder den namesake schon viele Jahre vor dem Tanzdebüt zu komplexen Handlungssträngen. So mussten sie etwa, um einen Jungen initiieren zu lassen, lange vor der eigentlichen Handlung, Akteur-Netzwerke aufbauen, um notwendige Ressourcen zu generieren. Ebenso veranlassten die Schmuckstücke den Initianden, seine Ohrläppchen und Nase durchstechen zu lassen und die damit verbundenen Schmerzen zu ertragen. Eine vollständige Initiation, mit sichtbaren Löchern bzw. Öffnungen in Ohrläppchen, Nasenflügeln und Nasescheidewand konnte ein junger Mann in der Vergangenheit ausschließ- 
lich im Rahmen mehrerer, oftmals im Abstand vieler Jahre stattfindender, kostspieliger Initiationsfeiern erlangen. ${ }^{189}$ So verfügten etwa Selwyn Balu erst im Alter von 20 Jahren und Jerry Me'ioko erst mit 22 Jahren über die Nasen-Piercings. Die bis zu meinen Aufenthalten auf Ndendö durchgeführten Initiationsfeiern wurden nach Aussage meiner Gewährsleute von einem oder mehreren Gastgebern als eigenständiges Fest oder im Anschluss an eine Schließung eines Tanzplatzes veranlasst. ${ }^{190}$ Die Ausrichter des Festes kamen dazu bereits über ein Jahr vorher zusammen und stießen frühzeitig reziproke Tauschsysteme (neue Akteur-Netzwerke) um Schweinefleisch und Arbeitsleistungen an, mittels derer (neben Geld) die notwendigen Transferleistungen ausgeglichen wurden. ${ }^{191}$ In der Regel trugen der Vater oder der namesake eines Initianten die mit der Initiation verbundenen Kosten des Festes sowie das Entgelt der Person, die die Piercings vornahm. Trug ein nelo-Tänzer später im Tanz ein nelo und/oder die Nasenstäbe naiapo, so verkörperten die Artefakte im Getragenwerden gleichermaßen den wirtschaftlichen Erfolg des Vaters oder die erfolgreichen namesake-Beziehungen des Tänzers selber und die noch längeren seiner Eltern zu seinem namesake.

Den Aussagen meiner Informanten zufolge erbte ein Tänzer seine Tanzausstattung meist von nelo-Tänzern aus seiner Familie (mütterlicher- oder väterlicherseits) oder von seinem namesake. Der Tänzer trat die direkte Nachfolge eines Vorfahren an, lebte und indizierte diese Beziehung mit dem Tragen der ererbten Kleidungs- und Schmuckstücke bei jedem Auftritt als nelo-Tänzer aufs Neue. So wussten die meisten Teilnehmer des vorgestellten Tanzes in Ne'ele, dass der Debütant Steward Bice Me'tu die Nachfolge seines Vaters antrat. Für Chief Peter Lawrence Dewa verkörperten das Tragen seines lepanesa in der dritten und des tema in der vierten Generation seine Verbindung zu den Vorfahren väterlicherseits und das Tragen des Ziergürtels lemkalo die Beziehung zu der Linie seiner Mutter. Ben Banie trug zu dem Tanz in Ne'ele die noch erhaltene erste Kopie des ,Original-nelo', das der dukna Opla der Überlieferung nach vor vier Generationen in der Graciosa Bay verloren hatte - es verkörperte die kontinuierliche Verbindung mit der Vergangenheit sowie die direkte Beziehung zur Herkunft des Schmucks und der Welt der dukna. ${ }^{192}$ Konnten die Tänzer auf keine Erbstücke zurückgreifen, mussten sie sich fehlende Tanzkleidungs- und -schmuckstücke ausleihen. Die Kosten trug der Auftraggeber des Tänzers; die Auswahl der Stücke traf der Tänzer meist selber (eine weiteres Akteur-Netzwerk). So stellten die Artefakte bzw. ihr Verleih eine Einnahmequelle für ihre Eigentümer dar, sie verkörperten einen bestimmten ökonomischen Wert, der in der jüngeren Zeit in der Regel eine Geldzahlung war. Ob als Erbstück oder als

\footnotetext{
189 Steward Bice Me'tu sprach im Jahr 20। I über die (neue) Möglichkeit, diese Piercings unabhängig von den Initiationsfeiern ambulant von Ärzten neu erlangen bzw. wieder öffnen zu können (vgl. Anm. I58). Gegen Ende der 2000er-Jahre war der nelo-Produzent Philipp Malu erstmals beauftragt worden, ein nelo mit einer neuen Tragetechnik zu entwickeln, die einem Mann auch ohne durchstoßenes Septum das Tragen eines nelo ermöglichen sollte (vgl. Kap. 4.3.I insb. Abb. 39 und Abb. 40). Diese Beziehungsebene befand im Wandel.

190 Letzteres war der Anlass der Initiationen in Neo-Nemba.

191 Zu den Ausprägungen reziproker Tauschsysteme auf Ndendö vgl. Anm. 8I.

192 Zum Entstehungsmythos vgl. S. 59-60.
} 
Leihgabe, die Tanzkleidung und der Schmuck waren für die Tänzer ,wertvolle', nicht alltägliche Artefakte, die als Mediatoren die besondere Position ihrer Träger herstellten und durch die Beziehung zu der Vergangenheit und der spirituellen Welt gleichermaßen begründeten.

Auch als Verkörperungen von Transformationen sozialer Beziehungen im Rahmen des Tanzes traten Artefakte in Erscheinung: Für alle ersichtlich, zerriss die am Rand des Tanzplatzes stehende Mutter des Debütanten genau in dem Augenblick einen kaleko, als ihr Sohn an ihr vorbeitanzte. ${ }^{193}$ Wie mir erklärt wurde, folgte sie damit kastom. Die Mutter anerkannte mit diesem Akt dessen Transformation vom jugendlichen Mann zum erwachsenen nelo-Tänzer. Denn nun trug dieser einen gewebten Schurz aus Bananenbast und keinen kaleko mehr, ein Kleidungsstück, das er bei seiner ersten Initiation als Kleinkind erhalten hatte. Die Handlung der Mutter vollzog und verkörperte die nun gewandelte Beziehung zu ihrem Sohn in aller Öffentlichkeit. ${ }^{194}$

Bei Betrachtung der Beziehung der Artefakte und Tänzer im Tanz stellten sich diese als vielfältig dar: Teile des Schmucks konnten nur von denjenigen getragen werden, die von Anderen als hierfür würdig erachtet und von ihnen dazu ,ermächtigt ${ }^{6}$ worden waren, indem etwa Andere die materiellen Ressourcen für die notwendigen Initiationen aufgebracht hatten. Der Schmuck veranlasste eine Reihe von Handlungen, die sich teilweise über Jahre hinweg erstreckten. In der Vergangenheit konnte ein Mann nicht von sich aus entscheiden, Tänzer zu werden, er war auf die Unterstützung anderer angewiesen, in der Regel die seines Vaters oder namesake. Die Artefakte konnten von Tänzern ererbt werden, so dass der Schmuck eine Form von ,Nachfolgeregelung“ anstieß. Die Tanzkleidung und der -schmuck konnten zudem verliehen werden und stellten so eine Einkommensmöglichkeit dar, man könnte sagen, der Schmuck regte den Geldkreislauf an. Am Beispiel des zerrissenen kaleko zeigte sich, dass ein weiteres Artefakt beim nelo-Tanz auch eine Trennung von Beziehungen vollführte und so den Status der betroffenen Personen transformierte. Die Artefakte standen in sehr engen Beziehungen zu den Tänzern und ermöglichten (nicht nur) ihnen, bestehende soziale Beziehungen aufrechtzuerhalten, neue zu begründen und existierende aufzulösen, die jeweiligen Beziehungsmodi zu vermitteln und zu verkörpern - mitunter waren es die Artefakte selber, die konkrete menschliche Handlungen als Effekte nach sich zogen.

\subsubsection{Artefakte und Publikum}

Neben den Tänzern traten weitere menschliche Aktanten im Akteur-Netzwerk ,nelo-Tanz für Jonas Kepule‘ in unterschiedlichen Handlungen in Erscheinung. Manche waren an den Essensausgaben während des Tanzfestes (eigene Akteur-Netzwerke) beteiligt, manche tanzten mit - nahezu alle schauten zu. Alle feierten gemeinsam, wurden Teil der Aufführung,

\footnotetext{
193 Zur Bedeutung des kaleko als erstem offiziellen Kleidungsstück eines Heranwachsenden vgl. S. 56-66.

194 Auf ein weiteres Beispiel für die enge und identitätsbestimmende Beziehung von Artefakten und Menschen auf Ndendö bin ich in Erzählungen zur Herkunft der ersten Menschen auf Ndendö gestoßen. Die Geschichten variierten zwar von Ort zu Ort, aber ein zentrales Element konnte ich bei allen ausmachen: Die beiden ersten Menschengruppen auf Ndendö wurden als , die mit Pfeil und Bogen' und ,die mit Keulen' bezeichnet.
} 
gaben mit ihrer Anwesenheit der Darbietung den von den Veranstaltern gewünschten Rahmen und trugen mit dazu bei, die Aufgaben des Festes zu erfüllen - nämlich dem Verstorbenen zu gedenken, dem dukna für das begangene Unrecht Kompensation zu leisten und im Gegenzug wieder von ihm unterstützt zu werden, soziale Verbindungen aufzubauen, zu pflegen und zu lösen und Spaß zu haben.

Die Gruppe der Anwesenden setzten sich auf dem Fest am 12./13. August 2011 in Ne'ele sehr heterogen zusammen - von jung bis alt, aus Männern und Frauen. Soweit ich beobachten konnte, bestand sie aus Mitgliedern der auftraggebenden Familien, d. h. Personen, die an den Vorbereitungen des Festes beteiligt gewesen waren, sowie deren Familien, Gästen und Mitgliedern anderer Dörfer und Männerhausgruppen, geladenen Vertretern der Provinzregierung und der internationalen Friedenstruppe RAMSI, Schülern anderer Inseln des Santa-Cruz-Archipels, die in Lata auf verschiedene (u. a. theologische) Schulen gingen und dort von dem Fest erfahren hatten, geladenen Angestellten ausländischer Entwicklungsorganisationen und mir. Am späten Abend des 12. Augusts 2011 trafen zusätzlich Besatzungsmitglieder eines Segelbootes ein, die tagsüber zufälligerweise bei Einkäufen in Lata von dem Fest gehört hatten. ${ }^{195}$ Zum Abschluss des nelo-Tanzes im Morgengrauen des nächsten Tages trat der in Malo lebende Katechet der Anglican Church of Melanesia Simon Peter Dewa in Erscheinung. Nachdem die nelo-Tänzer den Schlusstanz ausgeführt hatten, dankte er dem christlichen Gott für das gelungene Fest und das gute Wetter.

Aufgrund ihrer Heterogenität verfügten die Teilnehmenden in Ne'ele sicherlich über unterschiedliches Wissen über das Fest und seine Hintergründe. Aus zahlreichen, später von mir mit verschiedenen Personen(-Gruppen) geführten Gesprächen ergaben sich teilweise divergierende Perspektiven auf die Aufführung des nelo-Tanzes (und damit auch auf die Artefakte), aus denen sich weitere Aussagen über die Beziehungen von Menschen zu den Artefakten und im Umkehrschluss über die Handlungs- und Wirkmacht der Tanzkleidung und des -schmucks ableiten lassen.

Die nelo-Tänzer traten zu dem Fest wie gewöhnlich in einer Gruppe, paarweise aufgestellt und von ,Kriegern“ unterstützt, auf dem nir auf. Nach eigenen Aussagen führten die Tänzer die Notwendigkeit, in Paarformationen tanzen zu müssen, auf die virulente Gefahr zurück, ein dukna könne sich unerkannt unter sie mischen und sie gefährden (vgl. Anm. 150). Der Schutz eines jeden Einzelnen erfolgte zudem durch die (Zusammenarbeit der) Gruppe. In den synchronen Tanzbewegungen mit dem lauten, durch die Beinrasseln untermalten parallelen Aufstampfen und den gemeinschaftlichen Gesängen lenkten die Tänzer den Blick auf die gesamte Gruppe. Der visuelle Fokus verlagerte sich weg von der einzelnen Person hin zur Gruppe als einem einheitlich agierendem Ganzen. Dieser Eindruck wurde zusätzlich durch die Uniformität der Tanzkleidung und des -schmucks unterstrichen: Die Gesichter

\footnotetext{
195 Das Segelboot war am Morgen zur Abwicklung von Einreiseformalitäten in der Graciosa Bay eingelaufen und hatte gleichzeitig Proviant für die Weiterfahrt in Lata eingekauft. Die Besatzung arbeitete für ein Naturschutzprojekt einer australisch-neuseeländischen Nichtregierungsorganisation und stammte aus verschiedenen Industrienationen.
} 
aller Tänzer waren durch Nasen- und Ohrschmuck und die Bemalung zu einem Großteil bedeckt. Die fast einheitliche Kleidung und der Schmuck könnte man fast mit einer Uniform vergleichen. Der Glanz des Perlmutts und die sich bewegenden Anhänger des nelo lenkten die Blicke weg vom eigentlichen Gesichtsausdruck des Tänzers. Die wippenden Hahnenschweife zogen die Blicke auf die geweißten Haare der Tänzer. Die Oberarme der Tanzenden waren mit Artefakten sowie Duft verbreitenden Blättern und Blüten geschmückt. Alles bewegte sich synchron im Takt und lenkte so vom einzelnen Tänzer ab. Der einzelne neloTänzer trat durch die mit den anderen synchron ausgeführten Bewegungen augenscheinlich in den Hintergrund, wurde Teil eines einheitlichen Effektes. Der Fokus verschob sich vom Einzelnen auf die Gruppe, von der Person auf ihre Kleidung und ihren Schmuck, von zunächst einzelnen Attributen auf ein gemeinsames Ganzes.

In der Aufführung des nelo-Tanzes stimulierten die Einheiten von Tänzern und ihrer Ausstattung die Betrachter und riefen bei ihnen gewünschte - und sicherlich auch unerwünschte - Reaktionen hervor. Indem die Zuschauenden auf die Tänzer reagierten, lachten, mitsangen und -tanzten, sich im Vorfeld auf das Fest freuten und nach Abschluss über die Darbietungen sprachen, wertschätzten sie die Anstrengungen der Tänzer und letztlich deren Auftraggeber. Sie bekundeten die Aufführung als relevant und ,bezeugten“ durch Handlungen ihrerseits die Inhalte. Die Zuschauer bestätigten die nelo-Tänzer und Artefakte als konstituierende Teile der Aufführungen und wurden dadurch selber zu aktiven Aktanten der Aufführung. Ohne die Ergriffenheit und Zustimmung des Publikums wäre der nelo-Tanz ,unwirksam', redundant gewesen.

Im nelo-Tanz erschienen die nelo-Tänzer mit Kleidung und Schmuck, die der Überlieferung nach von den dukna entlehnt waren und für den Tanz über Generationen weitergegeben oder nach historischen Vorlagen reproduziert wurden. Die ererbten wie auch die nach historischen Vorbildern wieder hergestellten Kleidungs- und Schmuckstücke wurden vom Publikum als kastom, tradition und Santa-Cruz-kalsa eingeordnet. Die Tänzer verwendeten in ihren Gesängen teilweise Wörter und Redewendungen, die nur noch wenige alte Menschen spezifisch, die meisten anderen aber emotional-inhaltlich verstanden, so einer der Liedertexter, Alfred Dawi. Das Tragen historischer Kleidung sowie die Verwendung ,alter Sprache stellten eine zeitliche Kontinuität und eine Verbindung zu den Vorfahren oder Ahnen her.

Ich meine, dass das Erscheinen der Artefakte und der Sprache den kastom-Gehalt des Tanzes unterstrich, wenn nicht sogar begründete. Beide waren zum jeweiligen Zeitpunkt real wahrnehmbare physische „Beweise' der Erzählungen, man konnte sie sehen, hören und sogar teilweise anfassen. In den öffentlichen Auftritten vergegenwärtigten die Tanzkleidung und der -schmuck die Vergangenheit, und zwar so, wie sie von den Auftraggebern verstanden wurde und durch die Tänzer als ausführende Akteur-Netzwerke vermittelt werden sollte. Die Aufführung schuf kastom, transformierte ein eher abstraktes Akteur-Netzwerk ins reale Leben, in den wahrnehmbaren nelo-Tanz - quasi als Punktualisierung von kastom. Gleichzeitig legitimierte der Tanz das Erscheinen der Einheit von Mensch und Artefakten und damit deren Echtheit. Ich denke, man kann in diesem Fall von einer substantiellen Beziehung 
sprechen: Die kastom-Artefakte sind im nelo-Tänzer/-Tanz verankert; die Tänzer und der Tanz schließen die Kleidung und den Schmuck ein - das eine kann ohne das andere weder werden noch sein. Durch die Vergegenwärtigung der Vergangenheit in der Gegenwart legen sie die Basis für zukünftige kastom-Handlungen.

Diese Verbindung von einer auf der Vergangenheit basierenden und auf die Zukunft gerichteten Perspektive von Artefakten führt das in meinen Augen bestehende grundsätzliche Verständnis des Tanzes respektive Festes auf Ndendö fort: John Me'alue (15.11.2011) umschrieb das Fest u. a. als „,a kind of healing of an association“, worunter er das Erbringen einer reziproken Leistung verstand, bei der die Veranstalter eine aus der Vergangenheit bestehende kastom-Pflicht erfüllten, etwa ein Fest für (einen) dukna oder eine Gegeneinladung für ein Fest eines anderen Dorfes in der Vergangenheit auszurichten. Damit schlossen sie die Vergangenheit ab und brachten teilweise über Generationen bestehende Beziehungen zum erfolgreichen Abschluss. ${ }^{196}$ Die Partner wurden frei, um zukünftig neue Assoziationen eingehen zu können. Damit legten sie die Basis für neue, auf die Zukunft gerichtete Beziehungen bzw. Vereinbarungen: Mit einem gut besuchten Fest mit reichlich Essen eröffneten die Auftraggeber positive Beziehungen u. a. zu den dukna und Ahnen und sicherten so, auf die Zukunft gerichtet, die Prosperität für die eigene Familie oder das Dorf: „You [living people, O. L.] do this [feast] for me [dukna] and I will give you wealth." (John Me'alue, 15.11.2011)

Meines Erachtens ergibt sich insbesondere durch die Rolle des Publikums eine weitere Handlungs- und Wirkmacht der nelo-Tanzkleidung- und des -schmucks:

Die neuen oder erneuerten Verbindungen von Menschen, Kleidung/Schmuck und Aufführung evozierten bei den meisten aus Santa Cruz stammenden Teilnehmenden eine für den Moment reale, mit allen Sinnen wahrgenommene Zugehörigkeit zu Santa Cruz. Diese kastom-Konfiguration verkörperte bzw. repräsentierte für sie nicht nur die vielfältigen Beziehungen, sondern sie bestätigte, erneuerte oder rief diese als Effekte erst hervor - und zwar immer wieder, bei jeder einzelnen Aufführung aufs Neue.

Die Artefakte nehmen im nelo-Tanz eine aktive und unentbehrliche Rolle im Aufrechterhalten und Fortschreiben unterschiedlichster Beziehungen ein. Ihr Erscheinen im neloTanz evoziert kastom. Sie machen etwas Abstraktes physisch erlebbar, mit allen Sinnen. Insbesondere für das junge Publikum werden Geschichten der ,Alten` sowie die Operatoren (soziokosmischer) Beziehungen allgegenwärtig. Die Artefakte verorten die Anwesenden in Raum und Zeit und konstituieren als Effekt kastom. Sie sind Teil einer dialektischen, substantiellen Beziehung: ohne Artefakte kein kastom - ohne kastom keine Artefakte. Durch diese Beziehung legitimieren die Artefakte ihre Daseinsberechtigung auch außerhalb des nelo-Tanzes, etwa als kastom-Objekt zu Repräsentationszwecken oder als ,typisches' Kunsthandwerk aus Santa Cruz.

\footnotetext{
${ }^{196} \mathrm{Vgl}$. etwa Selwyn Balus Beziehung zu der Schwester seiner Ehefrau und seinem tabu, S. 128.
} 


\subsection{Zwischenfazit}

„Dinge wandern nicht nur durch Netzwerke oder repräsentieren diese nicht nur, sondern können als ihr Bestandteil und als von sich selbst aus vernetzend wahrgenommen werden.“ (Susanne KÜCHLER 2015: 132)

Die Dinge können ,[...] nicht nur als Hüllen oder Träger von Netzwerken verstanden, sondern selbst als Netzwerk aufgefasst werden“ (2015: 135).

Mittels einer an der Akteur-Netzwerk-Theorie orientierten Beschreibung der Genese eines Tanzfestes sowie des Ankleidens eines Tänzers für dieses Tanzfest am 12./13. August 2011 in Ne'ele zeigte sich zunächst, wie aus einem ursprünglich privaten Anliegen eines einzigen Mannes - nämlich eine Gedenkfeier für seinen verstorbenen Vater mit einer aus seinem kastom-Verständnis resultierenden Kompensationsverpflichtung gegenüber eines dukna zu verbinden - zahlreiche menschliche und nicht menschliche Aktanten in Beziehung traten und neue Assoziationen schufen, u. a. den ,nelo-Tanz ${ }^{6}$ und mit ihm die ,nelo-Tänzer'. Beide stellten sich dabei als heterogene Akteur-Netzwerke dar. Beteiligte Aktanten - menschliche wie nicht menschliche - waren ihrerseits weitere Akteur-Netzwerke.

Bei deren Analyse zeigte sich, dass neben den Menschen insbesondere die Tanzkleidungsund -schmuckstücke konstituierende Bestandteile von nelo-Tanz und -Tänzern waren und in vielfältigen soziokosmischen Beziehungen standen, diese vermittelten, verkörperten und,waren`. Die Fähigkeit dazu lag in ihren ,Essenzen` begründet, von Menschen zugeschriebenen und bewerteten Eigenschaften, die sie meist aus den jeweiligen spezifischen körperlichen Beschaffenheiten herleiteten. Die Artefakte luden die Konfiguration des ,nelo-Tänzers' mit Eigenschaften oder Attributen auf, über die die Menschen selber nicht verfügten, und hoben die nelo-Tänzer als neue Entität auf eine neue Wirkungsebene. Als Effekte/Punktualisierungen ihre Akteur-Netzwerke vergegenwärtigten bzw. bewirkten die Tänzer im Tanz lebendige Verbindungen von Raum und Zeit und ermöglichten den Menschen bzw. ermächtigten sie lebensnotwendige soziokosmische Beziehungen einzugehen, zu pflegen oder abzuschließen.

Eine über die Betrachtung einzelner Beziehungen hinausgehende Analyse, nämlich des Auftritts der nelo-Tänzer in der Gruppe als Gesamtheit, brachte weitere Erkenntnisse. Es zeigte sich, dass etwa der aufwendige Schmuck eines Tänzers die Aufmerksamkeit nicht einer einzelnen Person herausheben, sondern im Gegenteil dabei helfen sollte, gerade die individuellen äußeren Erscheinungsmerkmale zu verhüllen, um ein geschlossenes Bild einer solidarischen und starken Gruppe zu schaffen. Die Artefakte trugen maßgeblich dazu bei, den Blick vom Einzelnen auf die Gruppe zu lenken und die Tänzer zu vereinheitlichen.

Viele am Fest Teilnehmende ließen sich dazu hinreißen zu tanzen und zu singen, die ganze Nacht wachzubleiben und aktiv teilzunehmen. Sie bezeugten durch ihre aktive Teilnahme das Geschehen, bekundeten seine Relevanz und legten damit die Grundlage für eine Art Legitimation des nelo-Tanzes, der -Tänzer und der mit ihnen im Zusammenhang stehenden Artefakte. Die heterogenen Netzwerke ,nelo-Tänzer ermöglichten im Zusammenführen von gestalteten Artefakten und singenden bzw. tanzenden Männern die lebendige 
und beeindruckende Darstellung einer überlieferten, vermeintlich kontinuierlichen gemeinsamen lokalen Geschichte sowie idealisierter homogener Vorstellungen und Ziele - letztlich kastom. Kastom legitimierte die Artefakte, den Tanz und das Fest, und diese vergegenwärtigten im Gegenzug kastom, sowohl im Sinne von Verkörpern und Repräsentieren, als auch im Sinne von Bestätigen, Erneuern und Werden lassen. Die Tanzkleidung und der -schmuck waren Operatoren, ,übersetzten' mit Blick auf das Publikum bestimmte Inhalte und veranlassten andere Menschen zu Reaktionen bzw. Handlungen. Die Artefakte machten kastom (erlebbar). Insbesondere in der Rückbesinnung auf traditionelle Materialien drückten die Auftraggeber der Tänze und Tänzer m. E. ihre eigene Wertschätzung von lokalen Verbindungen und lokalem Wissen, Nachhaltigkeit, kultureller Zugehörigkeit und Einzigartigkeit aus. Durch das bewusste Nichtaufnehmen von industriell hergestellten Fasern und Materialien verkörperten und vermittelten die Artefakte den Wunsch nach Abgrenzung und Auflösung einiger Beziehungen, etwa die Abhängigkeit vom Ausland. Dadurch, dass die neloTanzkleidung und der-schmuck essentieller Bestandteil der kastom-Aufführung waren, konnten sie auch außerhalb der eigentlichen Aufführung Inhalte verkörpern, in andere Akteur-Netzwerke ,driften' und Vorstellungen und Handlungen ,übersetzen'. So konnte etwa der Brustschmuck tema - ursprünglich Ausdruck einer Clanzugehörigkeit und Männern von höherem sozialen Status vorbehalten - in verkleinerter Form, quasi als auf das Wesentliche reduzierte Abbild seines Vorbildes, eine kulturelle Zugehörigkeit zu Santa Cruz ausdrücken bzw. im Gegenüber hervorrufen und (nicht unumstritten) von jeder Person getragen werden, die sich ein solches ,Schmuckstück ${ }^{6}$ leisten konnte. Ich behaupte, dass weder die Verbreitung und Beliebtheit der kleinen tema noch die Debatten um die Verfügbarkeit, gerade auch für Frauen, ohne die nach wie vor aufgeführten nelo-Tänze und den darin lebendig vermittelten kastom-Bezug so anhaltend wären, wie sie sich im Jahre 2011 darstellten.

Diese Erkenntnisse erlauben, die Tanzkleidung und den -schmuck nicht länger als den Menschen nachgelagerte Objekte zu betrachten, sondern sie hinsichtlich ihrer Handlungsund Wirkmacht als gleichwertige Aktanten in den heterogenen Netzwerken ,nelo-Tanz und Tänzer zu verstehen. Eine Unterteilung in Subjekte und Objekte wird zunehmend schwieriger: In den Netzwerken vergegenständlichen sich Personen mittels Kleidung und Schmuck als einheitliche, ,anonyme ' Tanzfiguren, werden so betrachtet, objektgleich'. Die Artefakte nehmen ihrerseits eine Handlungs- und Wirkmacht in den und auf die Beziehungen innerhalb der Netzwerke ein, werden in dem Sinne ,subjektgleich`. Personen und Artefakte sind gleichermaßen sowohl Aktanten in Akteur-Netzwerken wie ,nelo-Tänzer ${ }^{6}$, ,nelo-Tanz' als auch eigene Akteur-Netzwerke von Handlungen/Ereignissen, Beziehungen und Substanzen, die fortwährend weitere Events, Beziehungen und Substanzen im Sinne der ursprünglichen Intention (kastom) absorbieren und damit kastom permanent in Raum und Zeit bestätigen und 
ausbauen. ${ }^{197}$ Ich behaupte, dass die Artefakte vermeintlich abstrakte und heterogene Vorstellungen von kastom in erlebbare Realitäten ,übersetzen'.

Nachdem das Fest in Ne'ele am frühen Morgen des 13. Augusts 2011 mit einem Gebet des Katecheten Simon Peter Dewa abgeschlossen war, lösten sich das Akteur-Netzwerk ,neloTanz für Jonas Kepule' und viele seiner Aktanten in ihrer Vergegenwärtigung auf. Die physischen Entitäten der nelo-Tänzer waren nicht mehr vorhanden - im Gegensatz zu dem Potential vor allem der Alltagsbeziehungen, die nun bestärkt waren oder jederzeit wieder reaktiviert und für neue ,Problematisierungen' aufgenommen werden konnten. Manche Beziehungen waren vollkommen aufgelöst worden und die Aktanten frei für zukünftige Beziehungen. Manche Tanzkleidungs- und -schmuckstücke ,verschwanden': Die duftenden Pflanzenketten, Blätterbüschel und Blütendolden etwa wurden entsorgt, wohingegen andere Kleidungs- und Schmuckstücke sorgfältig verpackt, ggf. an die Leihgeber zurückgegeben und bis zum nächsten Einsatz eingelagert wurden. Man sprach noch lange über das Fest, insbesondere über Geschehnisse, die sich im Umfeld des Festes ereignet hatten, wie z. B. ob jemand betrunken gewesen war, ob neue Freundschaften/Liebesbeziehungen entstanden waren, welche Gäste auf dem Fest anwesend gewesen waren, wer warum gefehlt hatte etc. Im Zusammenhang mit diesem Fest sprachen einige Personen insbesondere über das erfolgreiche Debüt von Steward Bice Me'tu, den Auftritt des Police Commissioner Walter Kola, Selwyn Balus Leistung, das Fest so erfolgreich (im Sinne von gut besucht, reichhaltigem Essen und vielen Tänzern) und dem kastom entsprechend gestaltet zu haben. Ebenso war mein ,Vorfall' in aller Munde, und viele mir fremde Personen würden sich noch bis zum Ende meines Aufenthaltes hierfür entschuldigen (vgl. Kap. 1). Später sollten sogar zwei neue kastom-Lieder dazu gedichtet werden (vgl. Anm. 32 und Anm. 146).

Andere Artefakte blieben als traditionelle Tanzkleidung und -schmuck präsent und erhielten sogar weitere Attribute zugeschrieben, die über den Tanzplatz und das Fest hinaus galten. Welche Zuschreibungen nach dem Tanz stattfanden und welche Handlungs- und Wirkmacht der Artefakte sich daraus wiederum ergaben, werde ich anhand der Hersteller der vier Artefaktegruppen nachgehen. Da sie meist nicht direkt im Zusammenhang mit der Umsetzung eines konkreten nelo-Tanzes standen, konnte ich sie bisher noch nicht gebührend darstellen, was ich im folgenden Kapitel 6 nachholen werde, um die ,Macher ${ }^{6}$ der Artefakte und deren Wirkmacht außerhalb der bisher besprochenen Akteur-Netzwerke zu berücksichtigen.

\footnotetext{
197 In seiner Analyse materieller Ausstattung von Darhad-Schamanen in der Nordmongolei kommt Morten Axel PEDERSEN zu einem ähnlichen Ergebnis und beschreibt das fortwährende Zusammenfügen und Absorbieren, ihre Kombinationen als ,fluid world", in der die multiplen Formen schamanischer Spirits den heterogenen materiellen Objektivationen entsprechen (2007: 155-156).
} 


\section{Tanzkleidung und -schmuck und ihre Hersteller}

„[M] ultiple expressions of agency might be discerned as dynamically interacting across several encompasssing spheres of engagement $[\ldots]$ or otherwise strategically situated expressions of intention." (MORGAIN \& TAYLOR 2015: 5, 6)

Im vorangegangenen Kapitel habe ich, ausgehend von dem konkreten Fall ,nelo-Tanz für Jonas Kepule', die Tanzkleidung und den -schmuck als nicht menschliche Aktanten in den miteinander verwobenen Akteur-Netzwerken ,nelo-Tanz' und ,nelo-Tänzer' betrachtet. In ihren Beziehungen sowohl zu den Tänzern als auch zum Publikum zeigte sich für die Artefakte, dass sie wie menschliche Aktanten über eine Handlungs- und Wirkmacht verfügten. Die Tänzer erhielten die Tanzkleidung und den Schmuck entweder als Erbe von einem älteren Tänzer, als entgeltliche Leihgaben oder indem sie den Tanzschmuck in der Vergangenheit selber herstellten bzw. heute dessen Produktion beauftragten. Nach dem Rückgang der Nachfrage hatte sich die Herstellung im Laufe der späteren Revitalisierung auf wenige Produzenten konzentriert. Den Aussagen meiner Gewährsleute zufolge waren es in der Regel die Tänzer, die die Materialien und Gestaltungen festlegten, nicht die Hersteller. Daher traten die Produzenten hinsichtlich der Analyse von Handlungs- und Wirkmacht der Tanzkleidungs- und -schmuckstücke in den beiden Akteur-Netzwerken ,nelo-Tanz‘ und ,nelo-Tänzer ${ }^{6}$ bisher weniger auf.

Auch außerhalb des nelo-Tanzes erschienen die Tanzkleidung und der -schmuck, nämlich als ,kastom- oder traditionelle Artefakte' etwa als Auftragsarbeiten (z. B. vom Bischof der Anglican Church of Melanesia für die Diözese Temotu oder von der Provinzregierung) sowie als ,Kunsthandwerk aus Santa Cruz' für den Museumsshop in Honiara oder für private/institutionelle Sammler, als Souvenirs für Touristen oder als persönliche Geschenke. In diesen Fällen kamen die Hersteller - nicht eine nelo-Tanzaufführung - als originäre ,Anlässe' der Artefakte zum Vorschein und sind daher für eine weitergehende Betrachtung der Handlungs- und Wirkmacht der Tanzkleidung und des -schmucks unerlässlich. 
Aus diesem Grund werde ich in diesem Kapitel in einem ersten Schritt die Biografien der Hauptproduzenten der vier in dieser Arbeit untersuchten Artefaktegruppen hinsichtlich ihrer persönlichen Beweggründe für die selbstgewählte Beschäftigung mit der Herstellung der Tanzkleidung und des -schmucks vorstellen. Hierbei werde ich auch die Graciosa Bay Nelo Association (GNBA) berücksichtigen, weil sich in ihr einige Produzentinnen und Produzenten von ,kastom-Artefakten' zu einer staatlich geförderten Organisation zusammengeschlossen hatten.

In einem zweiten Schritt werde ich konkret die Beziehungen der Hersteller zu ihren Artefakten auf die Fragestellungen hin untersuchen, ob letztere auch außerhalb von mit neloTanzaufführungen in Verbindung stehenden Akteur-Netzwerken als nicht menschliche Aktanten agierten, und ob sich darin weitere Ansätze für eine Handlungs- und Wirkmacht der Tanzkleidungs- und des -schmucks ausmachen lassen. Für eine Betrachtung sozialer Beziehungen zwischen den Auftraggebern, Herstellern, ihren Arbeiten und Abnehmern bzw. Empfängern bietet ALFRED GELLS (1998: 1),,anthropology of art/anthropological theory of art" hilfreiche analytische Perspektiven an (vgl. Kap.1.2). So diskutiert er u. a. in seinem Konzept des ,Art Nexus' Artefakte als Verbindungsglieder sozialer Beziehungen - insbesondere der zwischen Herstellern und Rezipienten - und untersucht, welche Effekte - hier im Sinne von Intentionen - die Artefakte haben und diese verkörpern, in dieser Perspektive über Agency verfügen und so in den sozialen Beziehungen Resultate erzielen, in denen sie eingebettet sind (LEACH 2007: 171). Daher werde ich Gells ,Art Nexus'-Konzept am Ende dieses Kapitels nutzen, um die Verbindungen der Produzenten zu ihren und über ihre Arbeiten zu anderen untersuchen, die verschiedenen Intentionen zusammenführen und aus den möglichen Verbindungen und Nicht-Verbindungen Rückschlüsse auf die Handlungsund Wirkmacht der Artefakte ziehen.

\section{I Tema und John Namiade ${ }^{198}$}

John Namiade wurde im Jahr 1975 im Krankenhaus in Lata geboren und wuchs in Luepe in der Graciosa Bay auf. Sein Vater Wilson Kabi war Chief und ein lokal bekannter neloTänzer, der sich seit den 1980er-Jahren autodidaktisch u. a. mit der Herstellung verschiedener nelo-Tanzschmuckstücke beschäftigte, um sie selber zu nutzen und zu verkaufen. ${ }^{199}$

Namiade hatte die Primary School in Mona und die National Secondary School in Luesalemba, beide auf Ndendö, bis zum Form-5-Abschluss besucht und anschließend im Fernstudium am Solomon Islands College of Higher Education in Honiara Kurse zu ,Development and Change' und ,Business' belegt. Nach einem Jahr als Rezeptionist im Luelta Resort, einem kleinen, privat geführten Gästehaus in der Graciosa Bay, wechselte er Anfang der

\footnotetext{
198 Das für die Darstellung seines beruflichen Werdegangs aufgenommene biografische Interview führten John Namiade und ich am 9. November 201 I in meiner Unterkunft in Lata. In zahlreichen weiteren persönlichen Gesprächen und während gemeinsam besuchter Feste und Versammlungen erläuterte John Namiade mir seine Sichtweisen und Vorstellungen zu Tanzkleidung und -schmuck.

199 Vgl. zu Wilson Kabi Kap. 5.2.l.
} 
1990er-Jahre für ein halbes Jahr als nicht ausgebildeter Lehrer nach Utupua, bevor er sich bei der Royal Solomon Island Police für eine Ausbildung zum Polizisten qualifizierte. Da alle Ausbildungsplätze in Honiara belegt waren, wartete er ein Jahr lang in der Landeshauptstadt, bis er sich entschied, nach Ndendö zurückzukehren, um die folgenden drei Jahre als Manager im Geschäft des späteren Parlamentsmitglieds Patteson Oti zu arbeiten. Einen in dem Zeitraum freigewordenen Ausbildungsplatz als Polizist lehnte er ab. Während dieser Zeit wuchs in ihm der Wunsch, nicht länger als Angestellter zu arbeiten, sondern eigenverantwortlich Einkünfte zu generieren. Namiade erinnerte die Zeit seiner Secondary School, während der er Bambus für den Verkauf angebaut hatte, griff die Idee des Anbaus von Nutzpflanzen wieder auf und bepflanzte in den Folgejahren rund vier Hektar kastom-Land seiner Familie mit Mahagonibäumen. Während seiner beruflichen Entscheidungsphase beobachtete er, wie sein Vater mit der Herstellung von ,traditionellen' Artefakten Einkünfte generierte - insbesondere dann, wenn dieser seine Arbeiten an Besucher, etwa Touristen, Sammler oder Forscher, verkaufte. Anfang der 2000er-Jahre begann Namiade seinen Vater bei der Herstellung verschiedener Schmuckstücke zu unterstützen. ${ }^{200}$

Im Jahr 2005 besuchten drei Deutsche die Graciosa Bay: der Ethnologe Frank Reiter mit seinem Sohn Amu und dem befreundeten Lehrer Klaus Maaz. ${ }^{201}$ John Namiade erinnerte insbesondere die offizielle Abschiedsfeier, die er mit seinem Vater für die drei ausgerichtet hatte, da ihm an diesem Abend die Bedeutung und das Potential von ,traditionellen' Artefakten vollends bewusst wurde. Reiter hatte angeregt, ein kleines Museum für die Artefakte in Luepe zu errichten. Namiade beeindruckte nachhaltig, dass Fremde nach nur zwei Wochen Aufenthalt auf Ndendö die Wichtigkeit gerade seines Heimatdorfes für die Produktion ,traditioneller ${ }^{6}$ Artefakte erkannt hatten. „That [Franks, O. L.] statement touched me, to think more seriously about it. [...] So, I now wanted to make something more looking like a museum“", so Namiade. Nur eine Woche nach Reiters Abreise gründeten mehrere Personen in der Graciosa Bay die Graciosa Bay Eco and Cultural Tourism Association, um den Tourismus auf Ndendö anzukurbeln. Unter dem Dach dieser Assoziation sollten sich weitere zusammenfinden, etwa die der Gartenbauer oder Fischer, die gemeinsame Ziele einte, etwa traditionelles Wissen und entsprechende Fähigkeiten zu erhalten und in das Zentrum ihrer Arbeit zu rücken. ${ }^{202}$ Zwei Jahre später, im Jahr 2007, besuchte eine Delegation des Kulturund Tourismusministeriums der Solomon Islands Ndendö und überreichte in der Graciosa

\footnotetext{
200 Wilson Kabi stellte mir im Mai des Jahres 2010 die Situation als sehr schwierig für ihn selber da, weil er befürchtete, sein Sohn würde ihm alles „,wegnehmen“. Laut Kabis Darstellung wollte sein Sohn Kabis kastom-Haus abreißen, um stattdessen eine Kochhütte zu errichten. Kabi hatte daraufhin nach eigenen Aussagen seinen Sohn bei RAMSI-Soldaten angezeigt und wollte nichts mehr mit ihm zu tun haben. Als ich im Folgejahr zurückkehrte, hatte sich die Lage entspannt und Kabi seine Anzeige zurückgezogen. Er hatte gesehen, dass sich sein Sohn nachhaltig mit der Herstellung traditioneller Artefakte beschäftigte, diese mit seinen eigenen Fähigkeiten vorantrieb und ihn letztlich unterstützte.

201 Gemäß ihrer Aussage wohnten sie zwei Wochen lang in der Graciosa Bay und besuchten ein Tanzfest in Neo mit 18 Tänzern. Sie übergaben eine Ausgabe von KoCH ( I97I) an Wilson Kabi (Klaus Maaz, 30. I I.20I 5).

202 Dazu wird auch später die zu Beginn des Jahres 201 I gegründete Graciosa Bay Nelo Association (GBNA) gehören; vgl. nachfolgend Kap. 6.5.
} 
Bay (laut Namiades ihm) einen Dieselgenerator und 10.000 SBD (entsprach im Jahr 2011 rund 1.100 Euro) in bar. Für Namiade war dies, ihm zufolge, der ausschlaggebende Anlass, unter Leitung seines Verwandten Freddy Me'esa, der zu dieser Zeit Sekretär der Provinzregierung war, einen Förderantrag für ein „Santa Cruz (Nende) Traditional Artifacts Museum“ zu erarbeiten, den letztlich Me'esa im Jahr 2009 bei der Provinzregierung einreichte. ${ }^{203}$ Namiade sah eine enge Beziehung zwischen der Revitalisierung der Artefakte und dem Wiedererstärken ,seiner Kultur' insgesamt, weil es in seinen Augen gerade die historischen Artefakte waren, die bei der Bevölkerung ein grundsätzliches Interesse für dieses Thema weckten. ${ }^{204}$ Den von ihm hergestellten kleinen tema räumte er eine besondere Stellung ein, da die Nachfrage nach ihnen in seinen Augen stetig stieg. ${ }^{205}$ Namiade betrachtete sie als ,special gift $[\ldots]$ in Temotu Province, $[\ldots]$ as a nice gift $[\ldots]$ to friends, or as a souvenir [...]“ und bezeichnete sie in der Regel als „traditional artefacts“ und nicht als ,kastom artefacts'. Er sah in ihrer Herstellung im Vergleich zu anderen Erwerbstätigkeiten sehr gute Einkommensmöglichkeiten für sich selber. Erhielt ein Angestellter ihm zufolge rund 30 SBD am Tag, konnte Namiade täglich bis zu drei kleine tema im Wert von 150 SBD herstellen. Sofern er Abnehmer fand, stellte die Produktion für ihn ein regelmäßiges Einkommen dar: „And now it's for me [...] my income, my salary, fortnightly or monthly or weekly. "Ebenso schätze er die Möglichkeit, jederzeit persönlich entscheiden zu können, wann er arbeitete und wann nicht.

Für die Gestaltung der Schildpattauflagen der verkleinerten „special gifts“ verwendete Namiade nur ein einziges Design, das er als Darstellung eines Fregattvogels in Kombination mit Haizähnen erläuterte. Für die Schildpattauflagen der großen tema hingegen, die er in erster Linie für die nelo-Tänzer produzierte, nutzte er verschiedene Motive. Entweder reproduzierte er auf Ndendö vorhandene historische Originale oder er stellte auf Basis von Abbildungen von sich im Ausland befindenden alten tema Repliken her. Letztere stammten etwa aus KoCH (1971) oder es handelte sich um Kopien anderer Publikationen, die Namiade von Bekannten (auch von mir) erhielt. Sein erklärtes persönliches Ziel war es, alle auf Ndendö nur in Abbildungen vorhandenen tema zu reproduzieren und sie so lokal wieder verfügbar zu machen. Im Jahr 2010 hatte er begonnen, bei der Gestaltung der Schildpattauflagen eigene Motive zu entwerfen, wobei er Hai- und Delphin-Darstellungen in die historischen Abbildungen integrierte (vgl. Abb. 93, 94 und 106). ${ }^{206}$ Namiade betrachtete die tema (und

\footnotetext{
203 Dem Antrag war bis zu meiner Abreise im Dezember 20II nicht stattgegeben worden. Dennoch wollte Namiade nach eigener Aussage dieses Ziel weiterverfolgen. Bei meinem Survey ein Jahr zuvor hatte bereits der in Noipe geborene George Malirbaal mit der Unterstützung für die Pläne eines lokalen Museums in der Graciosa Bay um Stimmen für sich bei der nationalen Parlamentswahl geworben. Der zu dem Zeitpunkt in Honiara lebende Politiker war mit Patricia l'tae verheiratet, der aus Mbanua nach Honiara gezogenen Schwester von Tom Olu und Leiterin des Shops des Nationalmuseums.

204 „When we started reviving the artefacts, we saw people generating interest in reviving some of the old artefacts. Then we started to revive our culture." (John Namiade, 9.1 I.20। I)

205 Zur Entstehung der verkleinerten tema-Variante vgl. Kap. 4.3.I.

206 Eines dieser neuen Motive trug Freddy Me'esa beim Auftritt der Graciosa Bay Nelo Association auf dem $5^{\text {th }}$ Festival of Melanesian Arts and Culture im Juli 2014 in Port Moresby, Papua-Neuguinea; vgl. Abb. 125.
} 
nicht die nelo) als die herausragenden Artefakte sowohl für die Graciosa Bay Nelo Association als auch für das erhoffte Museum (16.7.2011). Seine Wertzuschreibung der tema vermittelte Namiade eindrucksvoll an seinem Haus, wie Abb. 107 zeigt. Über dem Eingang zu seiner Werkstatt, die er bedarfsabhängig auch als Verkaufs- und Versammlungsraum nutzte, hingen als Werbeschilder jeweils eine rund $70 \mathrm{~cm}$ große nelo- und tema-Nachbildung sowie zwei Texttafeln: „NELO and TEMA PRODUCERS, LUEPE, GRACIOSA BAY, Contact: 54244“ und „PRODUCTS: NELO (Nose Ornament), TEMA (Shield Disc), Other Nende Traditional Artifacts. REVIVING OUR CULTURE, OUR HERITAGE, OUR DESTINY“ (Hervorhebung im Orig.). Den letztgenannten Claim hatte John Namiade von der Agricultural \& Cultural Trade Show im Jahr 2008 übernommen. ${ }^{207}$

$\mathrm{Zu}$ den Bedeutungen der Schildpattauflagen der historischen tema konnte Namiade nichts über die Vorstellungen zu den Motiven auf den kleinen tema Hinausgehendes sagen. Mögliche Eigentumsrechte an einzelnen Darstellungen, von der etwa die Familie Yamöli-Mdewöt sprach, erwähnte Namiade nicht. Auch sah er kein Problem darin, dass ich in Geschäften in Honiara nachgemachte tema aus Malaita gesehen hatte, oder dass gar T-Shirts mit tema-Designs in der Landeshauptstadt angeboten wurden (19. und 26.7.2011, vgl. Abb. 32 und Abb. 33). Im Gegenteil: Zu vielen öffentlichen Veranstaltungen während meines Aufenthaltes im Jahr 2011 trug er das T-Shirt, das ich ihm als ,Beweismaterial für den Verstoß gegen Urheberrechte' mitgebracht hatte. Seine Ehefrau Eli trug es zur Abschiedsfeier, die Namiade mit seiner Familie für mich ausrichtete.
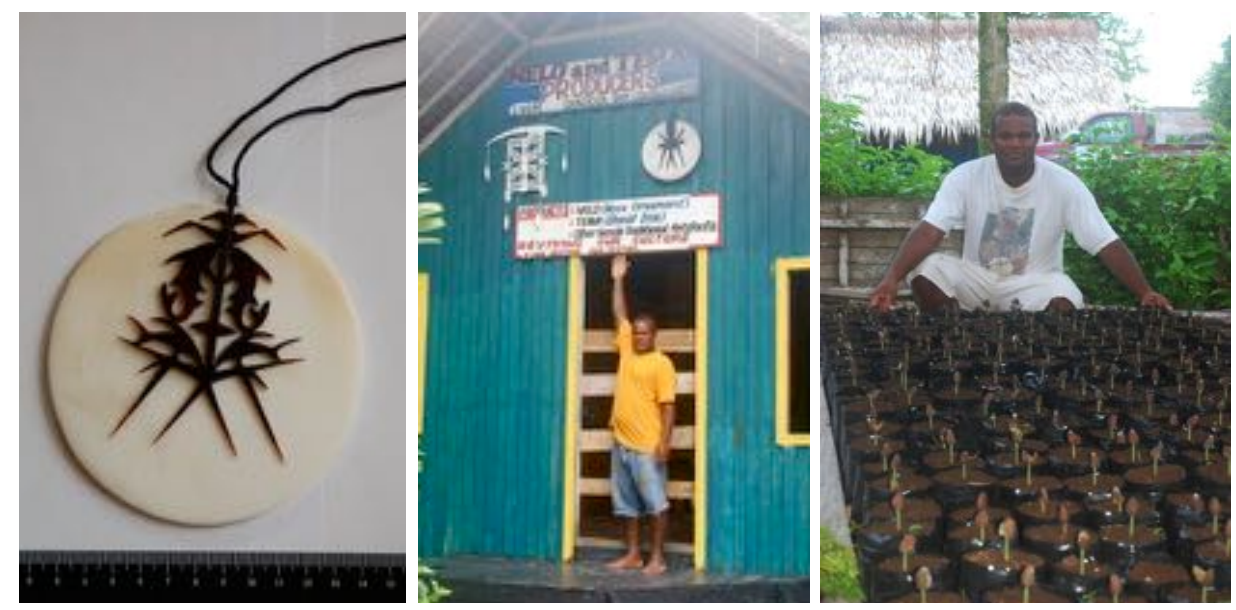

Abb. 106: Tema mit neu entworfener Schildpattauflage; John Namiade, 2011.

Abb. 107: John Namiade vor seiner Werkstatt/seinem Verkaufsraum; Luepe, 2010.

Abb. 108: John Namiade mit jungen Kakaopflanzen vor seinem Haus; Luepe, 2011.

\footnotetext{
${ }^{207}$ Nach eigenen Aussagen war es auch seine Idee, T-Shirts mit einer tema-Abbildung für die Agricultural \& Cultural Trade Show im Jahr 2008 zu verkaufen (vgl. Abb. 9). Im August 201 I plante Namiade mit dem Surplus-Geld der Beerdigung seines Vaters eine Neuauflage der T-Shirts für das Festival of Pacific Arts im Jahr 2012 in Honiara, um mit deren Verkauf Gewinn zu erzielen und die Kreuzerrichtung auf dem Grab seines Vaters im nachfolgenden Jahr bezahlen zu können.
} 
Neben dem ,langfristigen“ Anbau von Tropenholz betrachtete John Namiade nach eigenen Worten die Herstellung von ,traditionellem“ Schmuck als „kurzfristige“ Möglichkeit, Einkünfte zu generieren. Nach einem Workshop des Ministeriums für Landwirtschaft und -entwicklung im Oktober 2011 begann John Namiade zudem, im Schatten seiner Mahagonibäume Kakao anzupflanzen (vgl. Abb. 108). Damit verfolgte er laut eigenen Worten „mittelfristige“ Einkommensmöglichkeiten. In den Kursen am College hatte er gelernt, in „long term, medium and short term investments“ zu denken. Mit dem Abdecken unterschiedlich terminierter Einkünfte wollte er laut eigener Aussage das finanzielle Auskommen für sich und seine Familie beständig sichern und seinen Kindern möglichst gute Schulausbildungen garantieren.

Als ich im April 2012 im Rahmen einer Kreuzfahrtbegleitung nach Ndendö kam und John Namiade wiedersah, teilte er mir mit, dass er nur wenige Wochen nach meiner Abreise im Vorjahr als Nachfolger seines verstorbenen Vaters zum Chief gewählt worden war. Namiade berichtete weiter, dass er einen Prototyp eines neuen Brustschmucks angefertigt hatte, den er mir für das Museum in Köln überlassen wollte (vgl. Abb. 109). Diesen neuen Schmuck sollten Tänzer der Graciosa Bay Nelo Association (GBNA) zum sogenannten lirle-Tanz tragen und erstmalig auf dem Festival of Pacific Arts in Honiara im Juli 2012 vorstellen. ${ }^{208}$ Nur eine Stunde zuvor hatte mir Selwyn Balu einen Entwurf dieses Schmucks aus Keramik überlassen und dazu gesagt, dass die Form der Scheibe von den Mitgliedern der GBNA aus mehreren Vorschlägen ausgewählt und Namiade mit der Herstellung beauftragt worden war (vgl. Abb. 110).
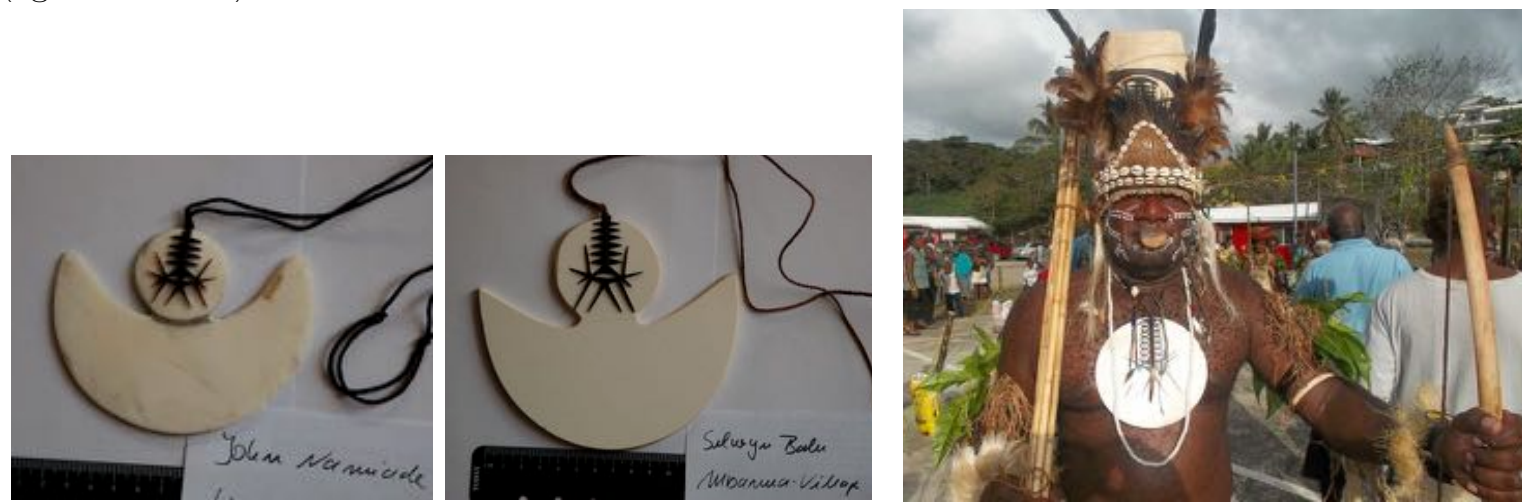

Abb. 109: Lirle-Prototyp aus Tridacna, Schildpatt und Synthetikschnur; John Namiade, 2012.

Abb. 110: Lirle-Entwurf aus Keramik, Kunststoff und Naturfaser; Hersteller unbekannt, 2012.

Abb. 111: John Namiade nach einer nelo-Tanzaufführung; Honiara, 2014. C GBNA

\footnotetext{
208 Diesen Tanz hatte ich bereits im Frühjahr 20। I bei einer Aufführung für Touristen in Malo auf der Ndendö vorgelagerten Inseln Temotu Neo gesehen. Damals erläuterte mir John Me'alue, dass es sich dabei um die Darstellung einer Mythe handeln würde, nach der ein Verstorbener durch den Tanz von Spirits, die seine Schwester gerufen hatten, wieder zum Leben erweckt worden wäre. In der Vergangenheit wäre ein lirle-Tanz oft zu Trauerfeiern aufgeführt worden. Diese Praxis war Me'alue zufolge aber seit langem nicht mehr ausgeübt worden. Damit die Touristen neben dem nelo- und dem napa-Tanz noch andere Vorführungen sehen konnten, hatten einige Bewohner Malos den lirle-Tanz neu choreografiert (John Me'alue, I6.4.20 I I).
} 
Im Juli 2014 war John Namiade einer der Vertreter der GBNA, die neben weiteren Gruppen die Solomon Islands auf dem $5^{\text {th }}$ Festival of Melanesian Arts and Culture in Port Moresby, Papua-Neuguinea, repräsentierten. Dort trat Namiade als nelo-Tänzer auf (vgl. Abb. 111). Dies hätte er sich bis zu meiner Abreise Ende 2011 nicht vorstellen können. Damals sah er sich ausschließlich als Hersteller des Schmucks, nicht als nelo-Tänzer.

Während der Rückreise vom Festival in Port Moresby trat er zusammen mit anderen Tänzern auf einem Fundraising-Event in Honiara auf und trug gleich zwei Kopfbekleidungsstücke. ${ }^{209}$ Beide kamen historisch betrachtet nicht auf Ndendö vor: ein aus Bananenbast gewebter (traditionell Tapa) und mit einem tema bemalter abe und darüber gestülpt eine geknüpfte Kopfbedeckung mit Nassaschnecken, Kasuaren- und anderen Federn (typisch für Papua-Neuguinea). ${ }^{210}$ Des Weiteren trug Namiade einen Nasenring aus Schildpatt, einen außergewöhnlich großen Brustschmuck sowie Pfeile und Bogen. Der Kopfschmuck abe vermittelte Namiades Position als Anführer, Pfeil und Bogen wiesen ihn als Krieger aus, der die nelo-Tänzer ,beschützte‘. Namiades Vater war ein regional bekannter nelo-Tänzer gewesen. Nun trat sein Sohn - wenn auch nicht als nelo-Tänzer, sondern als Anführer und ,Beschützer der nelo-Tänzer - das Erbe seines Vaters als aktiv Beteiligter im nelo-Tanz an.

John Namiade hatte sich in seinem Erwerbsleben auf eigene Initiative vom nicht ausgebildeten Lehrer, Rezeptionisten eines Gästehauses und Shop Manager zum maßgeblichen tema-Produzenten auf Ndendö gewandelt und war im Juli 2014 auf dem $5^{\text {th }}$ Melanesian Festival of Arts and Culture in Port Moresby, Papua-Neuguinea, erstmalig als Tänzer aufgetreten. Neben der Reproduktion historischer tema hatte er im Jahr 2010 begonnen, eigene Gestaltungen der tema-Auflagen mabu zu entwerfen, von denen Freddy Me'esa eine auf dem Festival in Port Moresby getragen hatte (vgl. Abb. 125). Zu den ursprünglichen Bedeutungen der unterschiedlichen mabu-Darstellungen konnte Namiade kaum Auskunft geben, verfolgte aber persönlich das Ziel, alle ihm verfügbaren Vorlagen zu reproduzieren, da sie in seinen Augen grundsätzlich eine Zugehörigkeit zu und Abstammung von Santa Cruz vermittelten. Dies taten auch die von ihm hergestellten verkleinerten tema, in deren Produktion er eine kurzfristige, flexible, lukrative und wachsende Einkommensmöglichkeit sah. Ihm zufolge verkaufte Namiade seine tema zwar nahezu ausschließlich auf Ndendö, dort aber an die lokale Bevölkerung, die Provinzregierung sowie an Besucher aus dem In- und Ausland.

Unabhängig vom Verkauf weitete Namiade mittels der Artefakte seinen Wirkungskreis weit über Ndendö hinaus aus: Das Schildpatt für die Auflagen erwarb er aus Vanikoro. Den Antrag auf Förderung eines lokalen Museums hatte er über die Provinzregierung an das entsprechende Ministerium in der Landeshauptstadt gerichtet und infolgedessen einen Dieselgenerator erhalten. Wissenschaftler aus dem Ausland suchten ihn auf, um ihn zu seiner Arbeit zu befragen. Namiade hatte an dem Workshop in der Kati School in der Graciosa Bay teilgenommen, den die Ethnologin Liz Bonshek im Rahmen des Melanesian Project für

209 Zum Anlass dieses Auftrittes vgl. Kap. 6.5, Spendenaufruf.

210 Zur Materialgeschichte der abe auf Ndendö vgl. Kap. 4.3.4. 
das British Museum im Jahr 2010 durchgeführt hatte. Im Nachgang hatte er über dessen Internet-Datenbank ein altes - für ihn aber neues - mabu-Design heruntergeladen. Die Artefakte ermöglichten Namiade, in neue Netzwerke einzutreten. In diesem Zusammenhang möchte ich die These formulieren, dass sie ihm andere Identitäten ermöglichten, z. B. als Einkäufer, Kreativer, Verkäufer, Projektleiter, Informant und Forscher.

Durch die auf der Herstellung von tema basierenden Mitgliedschaft in der GBNA reiste er im Jahr 2014 sogar von Ndendö nach Port Moresby und trat dort als Repräsentant seines Landes auf. Die von ihm hergestellten Artefakte gaben ihm auch dort eine neue Identität. Er wurde vom Produzenten von Tanzschmuck außerhalb des nelo-Tanzes zum Tänzer des Akteur-Netzwerkes ,nelo-Tanz'. John Namiade ,driftete' in ein neues Akteur-Netzwerk, eine Bewegung, die er m. E. aufgrund der Artefakte vorgenommen hatte und die ohne sie nicht möglich gewesen wäre; sie hatten ihn dazu motiviert und ermächtigt. Als Teil der Aufführung produzierten er und die Artefakte Bilder. Diese regten die Zuschauer im Sinne einer ästhetischen Evokation zum aktiven Sehen an und bildeten die Basis für die Zuschreibung und das Erleben von kastom/tradition/kalsa. Daher wurde der von Namiade produzierte Schmuck kastom - obwohl Namiade ihn selber nicht so benannte. Durch Namiades öffentliches Zeigen seiner Zugehörigkeit zum nelo-Tanz erhielten die von im hergestellten Artefakte im Gegenzug eine ,authentische ${ }^{6}$ Provenienz. Ich würde behaupten, Namiade und tema bedingten sich gegenseitig, sie unterhielten eine substantielle Beziehung. Die Artefakte legitimierten Namiades Auftritt im nelo-Tanz, der wiederum die ,Originalität' der Artefakte begründete. Die tema und John Namiade konnten anschließend vom nelo-Tanz weg in andere Netzwerke ,driften` und vielfältige Identitäten einnehmen und Intentionen verfolgen.

\subsection{Nelo und Philipp Malu'2II}

Philipp Malu wurde 1969 im damaligen Krankenhaus in Lueva geboren und wuchs in Monou in der Graciosa Bay auf. Sein Vater, David Käeluwio, war nelo-Tänzer, und Malu begleitete ihn schon früh auf die Feste. Nach eigener Aussage war Malu von Anfang an vom nelo-Tanz begeistert. Statt jedoch selber nelo-Tänzer werden zu wollen, interessierte er sich mehr für den Schmuck. Malu hatte in den Jahren 1992/93 als Bäcker und Verkäufer für Patteson Otis Bäckerei in Lata gearbeitet, sich anschließend gegen ein derartiges Arbeitsverhältnis entschieden und die Herstellung von Schmuck aufgenommen. Im Folgejahr 1994 fertigte er mit von Wilson Kabi geliehenem Werkzeug erstmals selber ein tema. Der Erfolg motivierte ihn, sich daraufhin auch der Herstellung von nelo zuzuwenden. Dazu bestellte er in Honiara Feilen aus Eisen, tauchte in der Graciosa Bay nach passenden Austern und versuchte mehrfach, die filigranen Perlmuttarbeiten zu produzieren. Als Vorlage diente ihm das nelo seines Vaters. Das erste von ihm hergestellte nelo verkaufte Malu - eigener Schätzung

\footnotetext{
211 Das Interview führten wir am I0. November 201 I in Malus Haus in Monou. Ergänzt ist der nachfolgende Inhalt um Informationen aus unserem Erstgespräch am 25. Mai 2010 sowie weiteren im Umfeld der Tänze in Ne'ele und in Neo-Nemba.
} 
zufolge - im Jahr 1998 an Mick Pendergrast bei dessen erstem Besuch auf Ndendö. ${ }^{212}$ Pendergrast bestellte zwei weitere nelo für seinen zwei Jahre später geplanten Besuch, bei dem er Malu so viele bunte Glasperlen mitbrachte, dass diese für die Dekoration der nelo bis ins Jahr 2011 ausreichten. Im Jahr 1998 träumte Malu eine andere nelo-Gestaltung, die er in den darauffolgenden Tagen aus dem Gedächtnis rekonstruierte und bisher einmal verkauft hatte. In den anschließenden gut zehn Jahren stellte Malu rund 50 bis 60 nelo her, wobei ihm als Vorlagen insgesamt vier historische Schmuckstücke, die er von unterschiedlichen Tänzern auslieh, sowie eine Abbildung auf einer Telefonkarte (vgl. Abb. 113), die ihm Chief Peter Lawrence Dewa zeitweise überlies, dienten. Unter den historischen Vorlagen befanden sich auch die erste Kopie des ,Originals', das der dukna Opla in der Graciosa Bay verloren hatte, sowie ein Nasenschmuck, den der Großvater von Malus Ehefrau selbst hergestellt und als nelo-Tänzer getragen hatte.

Malu zufolge entwickelte er Ende der 2000er-Jahre auf Anfrage seines früheren Vorgesetzten Patteson Oti einen völlig neuen nelo-Typ. Da Otis Septum nicht durchstoßen war, konnte er kein traditionelles nelo tragen. Er bat Malu, für ihn eine neue Trageart zu entwickeln, die es auch ihm erlauben würde, ein nelo zu tragen. Dazu montierte Malu einen Ring aus Schildpatt an das nelo, mit dem der Nasenschmuck an die Nase gehängt werden konnte. Von weitem betrachtet war dieser, Trick' kaum zu sehen, wie Selwyn Balu später attestierte. Nach Oti bestellte Duddley Dopwe im Jahr 2010 ein nelo gleichen Typs (vgl. Abb. 39 und Abb. 40). Einen derartigen Nasenschmuck trug auch ein Tänzer der Delegation für das $5^{\text {th }}$ Melanesian Festival of Arts and Culture (vgl. Abb. 114).
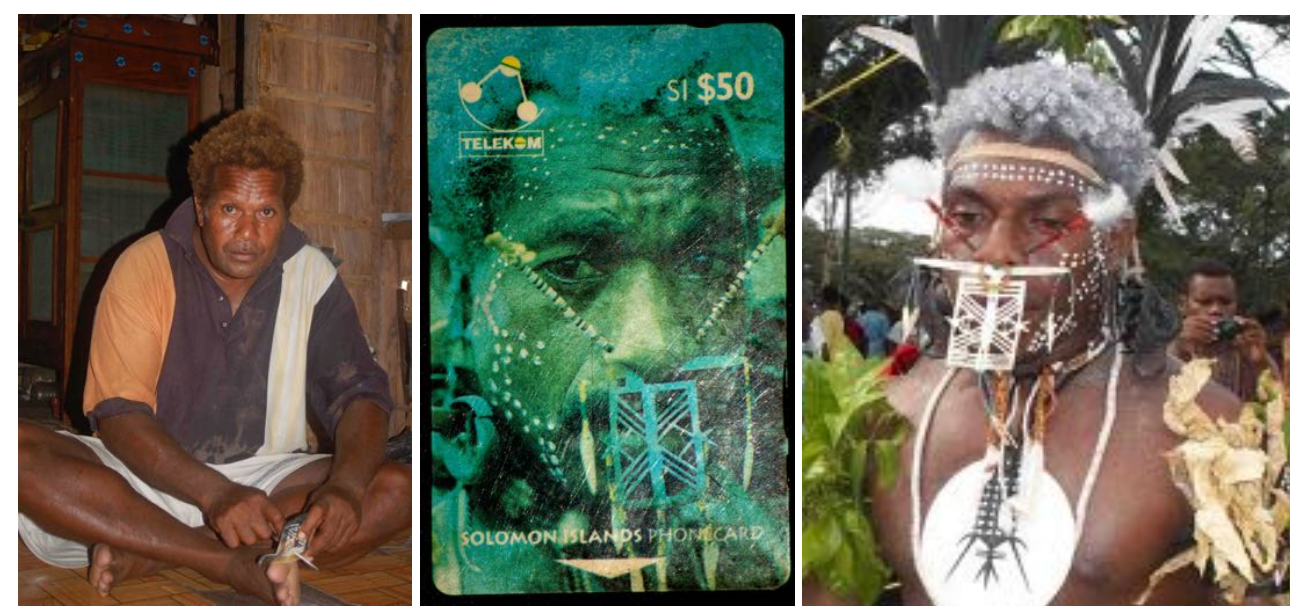

Abb. 112: Philipp Malu demonstriert das Ausfeilen eines nelo-Motivs; Monou, 2010.

Abb. 113: Telefonkarte „People of the Solomon Islands. Man of Santa Cruz, Temotu Province“; Solomon Telekom, vor 2010. Die Abbildung zeigt Chief Peter Lawrence Dewas Vater aus Malo. Abb. 114: Bartholomew Me'esas Neffe Philix mit neu entwickelter Tragetechnik des nelo (an die Nase und nicht in sie eingehangen) nach einer nelo-Tanzaufführung; Honiara, 2014. (C) GBNA

\footnotetext{
212 Nach Aussagen von Selwyn Balu suchte Pendergrast bereits zu Beginn der 1990er-Jahre Balus Vater in der Graciosa Bay auf (Selwyn Balu, 17.1 0.201 I).
} 
Im Laufe der Jahre widmete sich Malu der Fertigung weiterer Schmuckstücke der nelo-Tänzer, etwa der Ohrringe telengi oder der Halskette bo. Zudem wurde er von Zeit zu Zeit für die Herstellung kleiner tema angefragt (vgl. Kap. 4.3.2). Nur wenige Wochen vor unserem Gespräch hatte er etwa eine Bestellung über 90 kleine tema für eine Synode der Mothers Union fertiggestellt. ${ }^{213}$ Die Gestaltung des Schmucks oblag ihm dabei selber. Der Auftraggeber, Bischof George Takeli, hatte ihn lediglich gebeten, das offizielle Logo der Mothers Union in einer für die Provinz Temotu typischen Art und Weise darzustellen. Malu streckte aus diesem Grund den Buchstaben U ein wenig und fügte an dessen untere Ende Schwingen des Fregattvogels hinzu. In die beiden Außenschenkel des Buchstaben M integrierte er die von ihm entwickelte Abstraktion eines Vogelkopfes, die er bereits im Jahr 2008 als Abwandlung der Fregattvogelschwingen kreiert hatte, wie er erläuterte. In den folgenden Darstellungen sind diese Bezüge deutlich erkennbar:
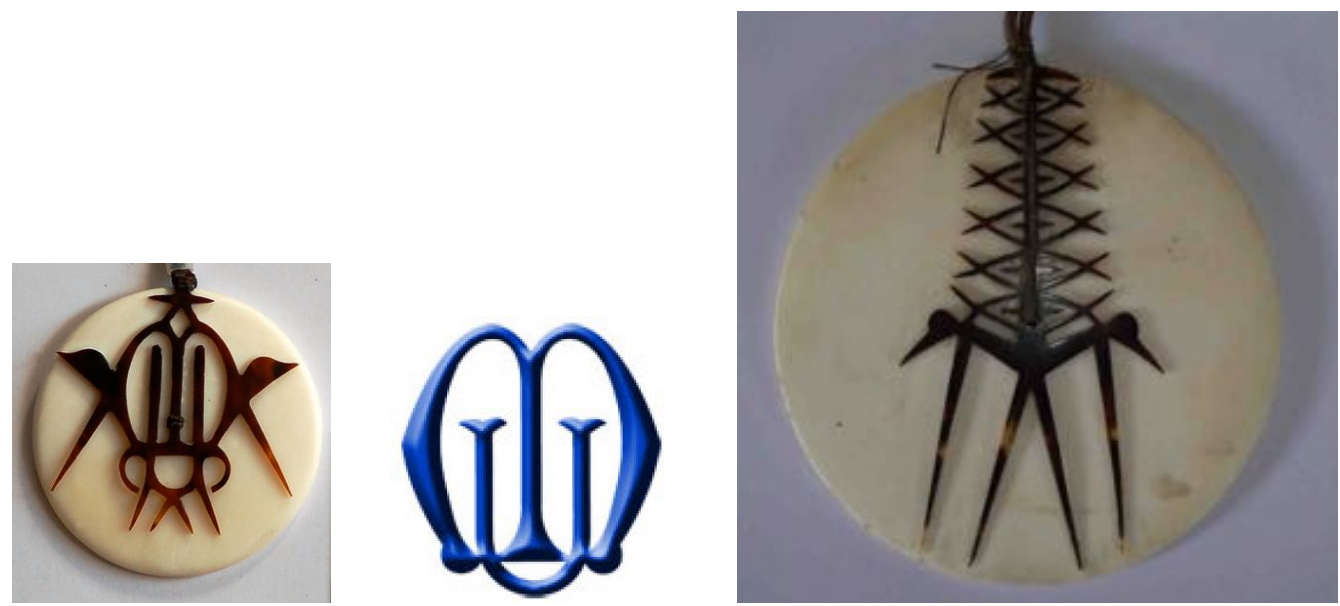

Abb. 115: Tema, Ø ca. $5 \mathrm{~cm}$; Auftragsarbeit für die Mothers Union der Anglican Church of Melanesia; Philipp Malu, 2011.

Abb. 116: Logo der Mothers Union, 2015.

Abb. 117: Tema mit Vogelkopfdarstellungen, Ø ca. 15 cm; Philipp Malu, 2011.

Neben der Annahme von Auftragsarbeiten bestritt Philipp Malu seinen Lebensunterhalt und den seiner Familie u. a. mit dem Verleih der von ihm gefertigten Schmuckstücke an die Tänzer gegen Gebühr oder mit dem Verkauf der Artefakte an die Tänzer, die lokale Bevölkerung, den Museumsshop in Honiara oder an Besucher, die ihn aufsuchten. Ich habe ihn auf keiner Veranstaltung für Kreuzfahrttouristen Artefakte an die Touristen verkaufen sehen. Er hatte als einer der wenigen Hersteller von ,traditionellem' Schmuck nicht an dem Workshop zum Melanesia Project des British Museum im Jahr 2010 teilgenommen. Ebenso war er kein Mitglied der Delegation, die zum $5^{\text {th }}$ Melanesian Festival of Arts and Culture nach

213 Diese Frauenorganisation der Anglican Church of Melanesia richtet in den unterschiedlichen Provinzen der Solomon Islands jährlich Synoden aus, sofern die budgetären Mittel zur Verfügung stehen. Im Jahr 20। I wollte Bisch of George Takeli allen Teilnehmerinnen ein Geschenk machen, das für die ,Kultur von Santa Cruz' stand; vgl. Abb. II5. 
Papua-Neuguinea reiste, obwohl er der GBNA angehörte. Aber er war derjenige, welcher die Gesichtsbemalungen der Tänzer sowohl in Ne'ele als auch in Neo-Nemba durchführte und in Ne'ele einen Teil des Steckschmuck ausbesserte (vgl. Kap. 5.1 und Abb. 67).

Philipp Malu hatte sich nach einer kurzen Zeit als Bäcker gegen eine Festanstellung entschieden und war gegen Ende der 1990er-Jahre seinem Interesse am Schmuck der nelo-Tänzer auch erwerbsmäßig gefolgt. Neben Reproduktionen von auf Ndendö noch existierenden nelo entwickelte er diese - wie auch kleine tema als Auftragsarbeiten - formalästhetisch weiter. Auf einen konkreten Auftrag hin hatte er sogar eine völlig neue Tragweise für ein nelo entwickelt, die den Auftraggebern ermöglichte, fortan ein nelo tragen zu können, ohne über das ehemals dafür notwendige Pearcing des Septums verfügen zu müssen, bzw. dem kastom entsprechend initiiert zu sein. Malu stellte eine Vielzahl des Tanzschmucks her und wurde zu Tanzfesten eingeladen und gebeten, die nelo-Tänzer zu bemalen und vor Ort noch Schmuck auszubessern. Selten verkaufte er seine Schmuckstücke an Ausländer, die ihn zu einem Kauf aufsuchen mussten. Sowohl die Artefakte als auch deren Herstellung ermöglichten Malu, in unterschiedlichen Akteur-Netzwerken zu agieren. Malu war über den von ihm gefertigten Schmuck besonders eng mit den nelo-Tänzern verbunden, indem er ihn für sie herstellte, verlieh und als einer von wenigen ihre Gesichter ,bemalen' durfte. Im letztgenannten Fall war er bedingt auch Aktant in beiden Akteur-Netzwerken ,nelo-Tänzer' und ,nelo-Tanz' und reproduzierte damit kastom. Zugleich modifizierte Malu das nelo und versetzte Männer in die Lage, diesen zu umgehen und als nelo-Tänzer auftreten zu können, ohne zuvor alle früher notwendigen Initiationen durchlaufen haben zu müssen. Das ,neue ${ }^{6}$ nelo stellte daher nicht nur eine formelle Variante dar, sondern ermöglichte eine Modifikation von kastom, da Männer zukünftig ohne Pearcing des Septums ein nelo tragen können. Malu, das neue nelo und dessen Träger setzten sich m. E. über kastom-Regeln hinweg. So reproduzierten und modifizierten kastom gleichermaßen. Letztlich diente kastom auch Philipp Malu zur Generierung von Einkünften. So erhielt Malu etwa während meines Aufenthaltes im Jahr 2011 von einer Firma aus Papua-Neuguinea eine Anfrage, gleich 300 Schmuckstücke zu produzieren.

\subsection{Lepanesa und Selwyn Balu'14}

Selwyn Balu wurde im Jahr 1960 in Ne'ele geboren. Nach seiner Schulausbildung arbeitete er im Jahr 1976 für ein Jahr im Forstdienst auf Vanikoro. Die folgenden drei Jahre lebte er ohne ein festes Beschäftigungsverhältnis wieder bei seinen Eltern in der Graciosa Bay. In dieser Zeit begann er, von seinem Vater Jonas Kepule sowie von zwei dessen Brüdern das Weben von Taschen aus Bananenbast zu erlernen. Balus Aussage zufolge gehörten sie zu

\footnotetext{
${ }^{214}$ Das biografische Interview für dieses Kapitel führten Selwyn Balu und ich am 17. Oktober 20 I in der Rotary Lodge in Lata. Ergänzt ist der nachfolgende Inhalt um Informationen aus zahlreichen Gesprächen, die wir während meines Surveys 2010 und meiner Feldforschung im Jahr 201 I immer wieder führten. Balu war mein Hauptinformant und verhalf mir sowohl zur Teilnahme an dem von ihm organisierten Fest in Ne'ele als auch an der großen Abschlussfeier eines Festzyklus in Neo-Nemba. Ohne seine Hilfe wären mir viele Kontakte verschlossen geblieben.
} 
den letzten Webern von Matten, Schurzen und Taschen aus Bananenbast im Santa-CruzArchipel. Alle drei hatten das Weben von ihrem Vater erlernt und waren über die Grenzen der Inselgruppe bekannt. So findet sich etwa die Abbildung eines lepanesa von einem der Brüder, dem namesake von Selwyn Balu, bei Harry BERAN(1998: 66).215 Laut Balus Aussagen hatte sein Vater Kepule als einziger von den dreien Tanzschurzen und Gewebe für Frauen produziert, sein namesake Taschen; zu dem dritten Bruder machte Balu keine Angaben. In den Jahren 1980 bis 1982 war Selwyn Balu in der Planungsabteilung für die Provinzregierung in Lata tätig. Während dieser Zeit lebte er bei seinen Eltern und unterstützte seinen Vater und dessen Brüder bedarfsweise bei deren Vorbereitungsarbeiten zum Weben, insbesondere bei der Aufbereitung der Materialien sowie dem Einrichten der Webgeräte (vgl. Kap. 4.3.3). Im Jahr 1984 heiratete Balu und baute sein eigenes Haus in Ne'ele. Ihm zufolge gefiel manchen Bewohnern der Graciosa Bay die Art und Weise, wie er sein Haus gebaut hatte, so dass er seitdem immer wieder für den Hausbau engagiert wurde und damit Einkünfte generierte. Balu unterstützte parallel zu dieser Tätigkeit weiterhin seinen Vater und dessen Brüdern beim Weben. Balu wies darauf hin, dass für ihn das Lernen zu der Zeit aus reinem Zuschauen bestand - er sei nicht unterwiesen worden. Bei seinem Vater etwa beobachtete Balu, wie dieser die Tanzschurze lepanesa wob und die Muster aus schwarzem Bananenbast einzog; bei seinem namesake richtete er sein Augenmerk auf die Herstellung der traditionellen Taschen. Seinem Vater gegenüber zeigte er nie offen sein tatsächliches Interesse am Weben, so dass Kepule immer wieder geäußert haben muss, dass mit seinem Tod das Wissen um das traditionelle Handwerk verloren ginge. Wie Selwyn Balu es darstellte, unterhielt er zeitlebens eine sehr enge und respektvolle Beziehung zu seinem Vater Jonas Kepule. Balu stellte ihn als Mann dar, für den kastom wichtig war, und zu dem fortwährend Personen kamen, um ihn um Rat zu fragen. ${ }^{216} \mathrm{Zu}$ ihnen zählte später auch Mick Pendergrast. Er hatte 1992 Jonas Kepule in Ne'ele aufgesucht, um ihn und seine Arbeit kennenzulernen. Dies war die Basis für die spätere Freundschaft zwischen ihm und Kepules Sohn Balu, in dessen Verlauf Pendergrast Balu viermal besuchte, viele Briefe mit Informationen über lepanesa bzw. Bananenbastmatten schickte und Balu mit der internationalen Außenwelt

\footnotetext{
215 Lt. der schriftlichen Zusammenfassung eines Gesprächs zwischen meinem Gewährsmann Selwyn Balu (jun.) und Mick Pendergrast im August 1998, die mir Selwyn Balu jun. zum Scannen überließ, hatte sein namesake Selwyn Balu (sen.) jedoch nie einen Tanzschurz gewoben, sondern sich auf die Herstellung von Taschen konzentriert, zu deren Fertigung er auch eine Nähmaschine benutzte. Gemäß dieser Aufzeichnung gab sich Balu sen. in den 1970er-Jahren gegenüber Besuchern in der Graciosa-Bay sehr offen, indem er sich befragen und fotografieren ließ. Zudem war er sogar einmal zu einer Demonstration seines Handwerks nach Queensland, Australien, eingeladen gewesen. Balu jun. äußerte mir gegenüber, dass sein namesake auch Tischsets aus Bananenbast als Souvenirs für den Verkauf in Honiara fertigte, was er für sich selber strikt ablehnte.

216 Jonas Kepule war, seinem Sohn zufolge, auch ein bekannter nelo-Tänzer gewesen. Selwyn Balu war derjenige Sohn, der von ihm das nelo-Tanzen übernommen hatte. Dazu hatte er im Jahr $1980 \mathrm{im}$ Alter von 20 Jahren seine Nasenpiercings im Rahmen der Schließungsfeierlichkeiten des Tanzplatzes in Neo erhalten, da sein Vater mit dem Gastgeber und Ausrichter des Festes verwandt war. Nachdem Balu seinen Vater über viele Jahre hinweg zu Festen auf Ndendö begleitet hatte, gab er im Jahr 1984 während der Eröffnung des Tanzplatzes in Luepe sein Debüt. Bis zum Jahr 20 I I hatte Selwyn Balu rund I 5 Mal getanzt; vgl. Abb. I I 9 und I 20.
} 
verband. ${ }^{217}$ Balu zufolge ermunterten Pendergrast und andere Ausländer Kepule fortwährend, das Wissen um das Weben vom Vater an den Sohn weiterzugeben. Balu hatte zur Erinnerung an seinen Vater ein gerahmtes Foto von ihm im öffentlichen Bereich seines Hauses aufgehängt (s. Abb. 118).

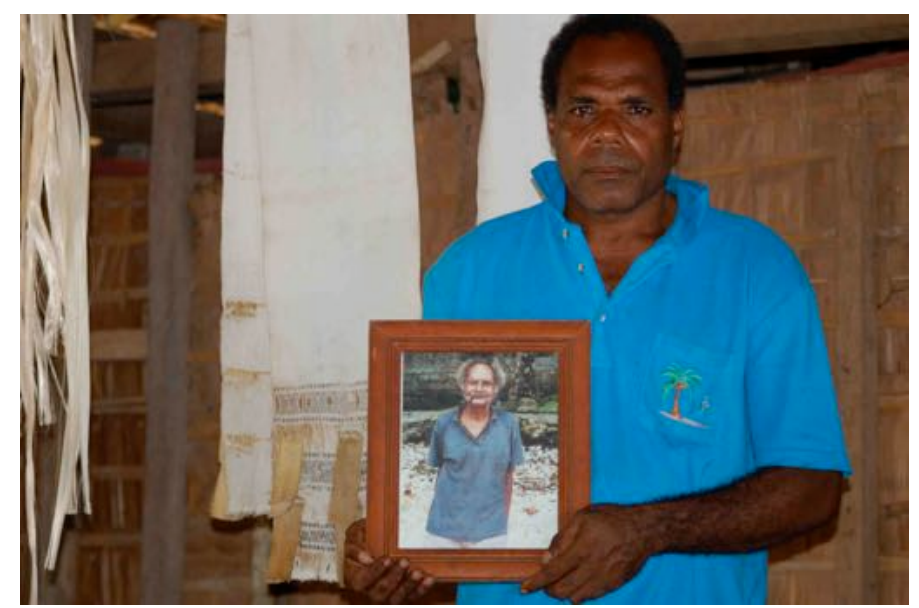

Abb. 118: Selwyn Balu mit einem Foto seines Vaters Jonas Kepule; Ne'ele, 2010. Im Hintergrund hängen lepanesa aus Baumwolle sowie Streifen von getrocknetem Bananenbast.

Im Jahr 1995 begann Selwyn Balu unter Barry Skudder, einem neuseeländischen ehrenamtlichen Manager, der die im Jahr 1993 gegründete Temotu Development Autorithy (TDA) leitete, erneut für die Provinzregierung zu arbeiten. ${ }^{218}$ Nach eigener Aussage half Balu dort zunächst beim Bau einer Kopramühle in Lata, und nach deren Einrichtung leitete er als einer von zwei Supervisoren ein kleines Schichtteam. Parallel zu dieser Arbeit beschäftigte er sich zunehmend mit dem Weben und experimentierte zusammen mit seinem Vater beim Weben der lepanesa den Einsatz anderer Materialien antelle des Bananenbasts (vgl. Kap. 4.3.3). Zu Lebzeiten seines Vaters fertigte Balu - mit zwei Ausnahmen für den Eigenbedarf als nelo-Tänzer - selbständig nur Bananenbasttaschen und keine lepanesa. In der Kopramühle arbeitete er bis zum Tod seines Vaters im Jahr 2006, der bereits ein Jahr zuvor altersbedingt das Weben einstellen musste. Selwyn Balu übernahm zu der Zeit sukzessive die Herstellung der Bananenbasttaschen und -schurze. Wie Balu sagte, hatte sein Vater es ihm zwar nicht explizit gezeigt und gedacht, sein Sohn wäre noch nicht dazu bereit, aber Balu hatte sich die Herstellung genauestens abgeschaut und eingeprägt, so dass er umgehend nach dem Tod seines Vaters mit der Herstellung der Tanzschurze beginnen konnte. Gemäß eigener Darstellung war Balu seitdem der einzige lepanesa-Produzent auf der Insel - wenn nicht gar im Archipel. Fortan kamen alle nelo-Tänzer der Insel zu ihm, um ihre Tanzschurze vor

\footnotetext{
217 Wie Selwyn Balu berichtete, hatte Mick Pendergrast ihn auf dem Weg von Lata nach Mbanua angesprochen und gefragt, ob er wisse, wo Jonas Kepule lebte. Balu hatte ihm zwar den Weg beschrieben, ihm aber verschwiegen, dass er dessen Sohn war. Erst als Balu später zum Haus seines Vaters zurückkehrte, stellte er sich Pendergrast vor.

${ }^{218}$ Einen Überblick über die verschiedenen Aufgabengebiete und die Historie der TDA gibt WILSON (2009), der im Jahr 1997 Skudders Nachfolge antrat. Wilson erwähnt auch Selwyn Balus Tätigkeit im Rahmen des Aufbaus einer Kopramühle der TDA und zeigt ihn auf zwei Abbildungen (2009: I5-34, 7I, I55).
} 
einem Einsatz ausbessern zu lassen oder um neue in Auftrag zu geben. ${ }^{219}$ Selwyn Balu hatte nach eigener Darstellung direkt nach dem Tod seines Vaters nur einen lepanesa aus Baumwolle gewebt und seitdem ausschließlich mit Bananenbast gearbeitet. Ihm war sehr daran gelegen, lepanesa möglichst genau dem kastom entsprechend zu reproduzieren. ${ }^{220} \mathrm{Ihm}$ zufolge waren die Taschen auch kastom, aber in einer anderen Weise als lepanesa. Bei beiden Webarbeiten nutzte er ausschließlich Muster, die er von seinem Vater übernommen hatte. Bei den Taschen aber entwickelte er zusätzlich zu den alten Mustern auch neue und kombinierte diese. In dieser unterschiedlichen Vorgehensweise zeigt sich, dass Balu kastom als altes Wissen, überlieferte Praktiken und Werte betrachtete, die möglichst unverändert weitergegeben werden sollten. Damit erklärt sich auch, warum Balu von der Provinzregierung in Lata für seine Webarbeiten geschätzt und von Zeit zu Zeit von ihr beauftragt wurde, Taschen aus Bananenbast als Geschenke für offizielle Gäste herzustellen.221

Bis zum Zeitpunkt meiner Feldforschung hatte Balu zwei seiner drei Söhne (Walter Kola und Paul Menata) in das Weben von Taschen eingewiesen. ${ }^{222}$ Ersterer hatte wiederum auf Wunsch seines Vaters sein Wissen an zwei jüngere Brüder seines Vaters (David Yanepia und Paul Me’plü) weitergegeben. Die beiden hatten beobachtet, wie gut ihr Bruder Balu nach dem Tod ihres Vaters mit der Herstellung von Taschen Geld verdiente und Balu gebeten, sie anzulernen. Da Balu sich Ende der 2000er-Jahre aufgrund eines Arbeitsverhältnisses eine

\footnotetext{
219 Zu Balus Webarbeiten vgl. Kap. 5.2.3. Liz Bonshek hatte im Jahr 2009 zu ihrem Workshop im Rahmen des ,Melanesia Project' des British Museum auch Selwyn Balu eingeladen.

220 Zur Relevanz von kastom für Selwyn Balu vgl. Kap. 5.I .

221 Auch mir überreichte Selwyn Balu im April 2012 eine Tasche aus Bananenbast mit ,neuen' Mustern und eingezogenem Schriftzug „AWITAPE NIMLA 'Oliver" (Vielen Dank, auf Wiedersehen Oliver, O. L.). Wie er mir sagte, war es nicht das erste Mal, dass er eine Tasche mit einem Namensschriftzug versehen hatte.

222 Balus Sohn Walter Kola lebte im Jahr 20I I bei Jos Suku, einem jüngeren Bruder seines Vaters, in Honiara, besuchte dort Form-7-Kurse am University of South Pacific (USP) Solomon Island Campus und hoffte, später an der USP in Fiji Accounting und Management studieren zu können. Er wollte nicht nach Ndendö zurückkehren, um dort ein Leben wie sein Vater zu führen. In seinen Augen war hingegen sein jüngerer Bruder Menata dafür prädestiniert, da dieser nicht so gerne zur Schule ging und stattdessen lieber mit den Eltern arbeitete. Kola war sehr froh, mit dem Weben der Umhängetaschen eigenständig Geld verdienen zu können. So bestritt er nach eigener Aussage selber einen Teil seines Aufenthaltes in Honiara (in erster Linie Kosten für Kleidung, Mobiltelefon und Fahrten zur Schule), während seine Eltern das Schuldgeld für ihn aufbrachten. Kolas Arbeiten waren in der Landeshauptstadt als zwar teure, aber ,originale' Taschen aus Santa Cruz beliebt. Dem Wunsch einiger Schulfeunde, sie ebenfalls anzulernen, verneinte er stets mit ",no, that is our kastom“. Er hatte noch zu Lebzeiten seines Großvaters mit dem Weben von Taschen begonnen, beherrschte die vier Designs seiner Vorfahren und hatte zusätzlich eigene entworfen. Besonders stolz war er darauf, Schriftzüge einweben und nicht wie sein Vater, nur' einziehen zu können. Bisher gab es ihm zufolge noch keine Nachahmer der typischen Santa-Cruz-Muster in Honiara. Mittlerweile hatte er über 40 Taschen hergestellt, die er meist in den Schulferien produzierte und zu einem Festpreis von je 250 SBD (entsprach 201 I ca. 25 Euro) an den Nautilus Shop, die bjs-Gallerie oder an den Museumsshop in Honiara verkaufte, falls er keine Bestellungen vorliegen hatte. Die einzige Herausforderung sah er in der Versorgung mit ausreichend Rohstoffen. Den naturfarbenen Bast gewann er selber aus Bananen aus dem Garten seinen Onkels Suku. Den schwarzen Bananenbast musste ihm sein Vater in unregelmäßigen Abständen per Frachtschiff von Ndendö nach Honiara schicken. Zur einfacheren Kommunikation hatte Balu seinem Sohn Kola sein eigenes Mobiltelefon überlassen und musste selber infolgedessen das Telefon seines bei ihm lebenden Sohnes Menata oder das anderer Personen benutzen. Balu hatte Kola noch nicht in das Weben der lepanesa eingewiesen und würde dieses Wissen wahrscheinlich eher an seinen jüngsten Sohn Menata weitergeben, vermutete Kola. (Walter Kola, 27. I I.20 I I)
} 
Zeit lang in Honiara aufhielt, hatte er seinen Sohn Kola beauftragt, Balus Brüder mit dem Weben von Bananenbasttaschen vertraut zu machen. Balus Aussagen zufolge waren gewebte Matten nicht mehr gefragt, und lepanesa wurden selten und fast ausschließlich von den nelo-Tänzern nachgefragt, so dass sich die Brüder und Söhne ausschließlich dem Weben von Taschen widmeten.
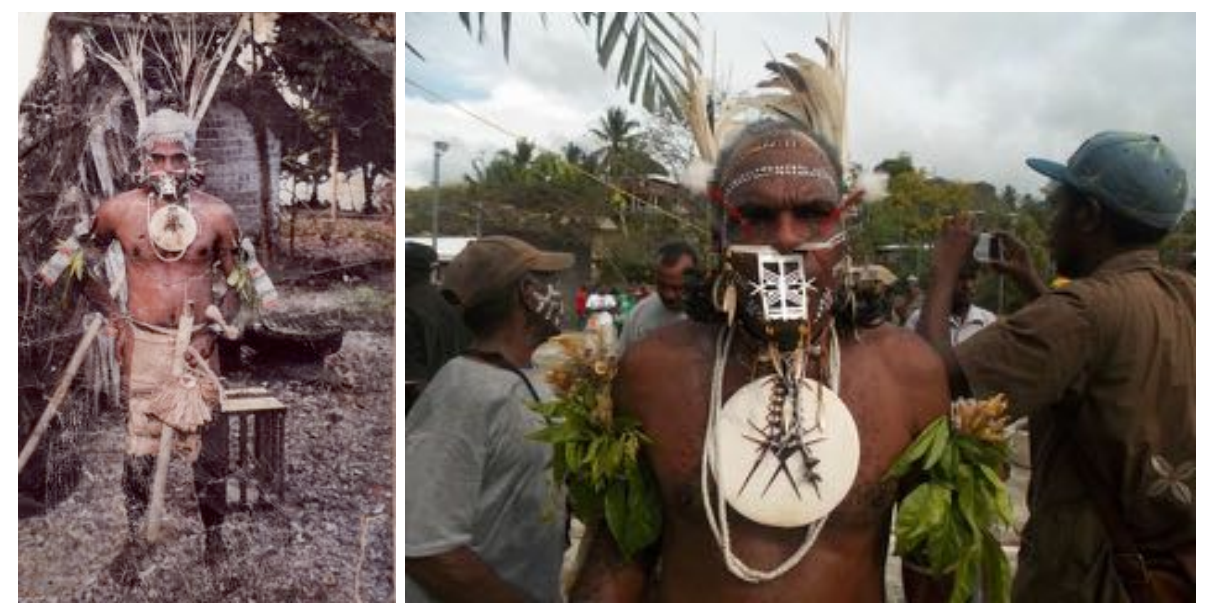

Abb. 119: Selwyn Balu als nelo-Tänzer in den 1990er-Jahren, Selwyn Balu.

Abb. 120: Selwyn Balu nach einer nelo-Tanzaufführung; Honiara, 2014. C GBNA

Selwyn Balu war im Jahr 2010 Gründungsmitglied und seitdem stellvertretender Vorsitzender der Graciosa Nelo Bay Association. Im Jahr 2014 war er auch Teil deren Delegation für das $5^{\text {th }}$ Melanesian Festival of Arts and Culture (vgl. Abb. 120).

Zwei Frauen der Delegation trugen aus Bananenbast gewebte Wickelröcke und -oberteile und zwei Tanzanführer ebenfalls gewebte abe (vgl. Abb. 129 und Abb. 130). Da Selwyn Balu im Jahr 2011 der vermeintlich letzte Weber Ndendös war, gehe ich davon davon aus, dass er diese hergestellt hatte. Einen Wickelrock für Frauen hatte er bereits im Jahr 2010 produziert, wohingegen die Oberteile Neuentwicklungen zu sein schienen. ${ }^{223}$ Bei meinen Besuchen als Touristenbegleiter in Malo trugen die Federgeld präsentierenden Frauen unbemalte Tapa-Tücher als Wickelröcke und keine Oberteile. In unterschiedlichen nicht lokalen kastomFigurationen (Melanesian Festival of Arts and Culture und Touristenaufführung) übersetzten unterschiedliche Artefakte (Bananenbastgewebe und Tapa) dieselben Inhalte (Frauen präsentieren Federgeldrollen). Welche Diskussionen und Motivationen der Modifikation zugrunde lagen und ob Selwyn Balu der Initiator gewesen war, konnte ich drei Jahre nach meiner Abreise von Deutschland aus nicht in Erfahrung bringen.

Selwyn Balu hatte - im Gegensatz zu den in den Kapiteln 6.2 und 6.3 dargestellten Produzenten John Namiade und Philipp Malu - seine Fähigkeiten und sein kastom-Wissen direkt

\footnotetext{
${ }^{223} \mathrm{Vgl}$. Kap. 5.2.3 Den Oberteilen vergleichbare Objekte habe ich während meiner Aufenthalten, nicht gesehen. In den Museumssammlungen befinden sich einige als Matten bezeichnete Formate, die auch aus Bast gewoben sind.
} 
von seinem Vater und dessen Brüdern in einem langen, eher kontinuierlichen Prozess des Zu- und Mitarbeitens gelernt. Auch wenn er nicht direkt von ihnen unterwiesen worden war, hatte er die Möglichkeit gehabt, fast 30 Jahre lang seinen Vater beim Weben und als neloTänzer zu begleiten. Da Balus Vater ein örtlich bekannter und respektierter Mann war, der sein Leben am kastom orientierte, und Balus namesake sogar international für sein Kunsthandwerk bekannt war, kam Selwyn Balu von Jugend an mit den entsprechenden Akteur-Netzwerken in Kontakt. Balu übernahm zunehmend die Rolle seines Vaters als Weber und neloTänzer und avancierte dadurch zu einer ebenfalls lokal (meist) respektierten Person. ${ }^{224}$

Die Artefakte ermöglichten ihm ein lokal weit überdurchschnittliches Einkommen und Zugänge zu sehr unterschiedlichen Akteur-Netzwerken. Auf lokaler Ebene verhalfen ihm die Weberzeugnisse dazu, maßgeblich an der Ausstattung von Festen beteiligt zu werden, in direktem Kontakt mit der Provinzregierung zu stehen und sich als Vorstandsmitglied der GBNA platzieren zu können. Insbesondere die beiden letzten Punkte sowie die Tatsache, dass ihn immer wieder Personen aus dem Ausland aufsuchten, um sein Kunsthandwerk kennenzulernen, ermöglichten Balu vor Ort internationale Kontakte, etwa zu Mick Pendergrast, Liz Bonshek oder auch zu mir. Ähnlich wie Philipp Malu suchte Selwyn Balu touristische Veranstaltungen kaum auf, um seine Artefakte direkt an Touristen zu verkaufen. Kamen jedoch Besucher zu ihm, investierte er seine Zeit und war offen für jeglichen Austausch - ihm zufolge wie sein namesake eine Generation zuvor. Ebenso fertigte er Taschen für Geschenke der Provinzregierung, wobei er bei diesen sehr viel freier mit den Mustern umging. Bei den lepanesa reproduzierte er die Muster, die er bei seinem Vater gesehen hatte. Daher sehe ich seinen Umgang mit dem Weben durchaus mehrschichtig. Die Taschen boten ihm eine Möglichkeit, mit seinem Handwerk über die Grenzen Ndendös hinweg Einkommen zu generieren, so wie Balu auch sporadische Kontakte ins Ausland unterhielt. Im Gegensatz zu den Schurzen, die nach seiner Aussage nur einen geringen Abnehmerkreis fanden und deren zeitlicher Arbeitsaufwand sehr hoch war, konnte er die Taschen schneller und für ein gröBeres Publikum herstellen. Hierbei verfolgte er die von der Generation seines Vaters überlieferten Techniken und Materialien. Bei den lepanesa waren ihm zudem die überlieferten Muster wichtig. Durch deren Geschichte wirkten sie ,traditionell'. Die ,alten` Materialien und Muster übersetzten Balus Intention, lokalem kastom zu folgen und sie vermittelten in ihrer Ästhetik eine Kontinuität von Balu zu seinen Vorfahren, von der Gegenwart zur Vergangenheit. Laut seiner Aussage versuchte Selwyn Balu nicht nur in Bezug auf sein Handwerk den Traditionen der Generation seines Vaters zu folgen. Bei der Organisation der Gedenkfeier für diesen etwa hatte er in mehreren Versammlungen und Gesprächstreffen herauszufinden versucht, wie die Feste zur Zeit der ältesten noch Lebenden organisiert worden waren.225

\footnotetext{
${ }^{224}$ Diese Wertschätzung erfuhr Selwyn Balu zwar von den meisten, aber nicht allen Mitgliedern seiner erweiterten Familie. Zwei männliche Verwandte arbeiteten gegen ihn; vgl. Kap. I.

225 Als neueste Ergebnisse hatte Selwyn Balu für die Gedenkfeier etwa zum ersten Mal seit vielen Jahren wieder einen kastom-Kalender aufgehängt, an dem jeder Besucher sehen konnte, wie viele Tage es noch bis zum Fest
} 
Meines Erachtens untermauerten die Artefakte Balus Streben, Aspekte seiner Weltsicht - und in letzter Konsequenz auch die seiner Vorfahren - weiterzugeben. Ebenso verkörperten die von ihm hergestellten lepanesa mit ihrer physischen Präsenz und ständigen Erneuerung seine Bemühungen, lokalen kastom zu erhalten und weiterzugeben. Seine Artefakte legten eine Basis für lokale kulturelle Identifikationsmöglichkeiten. Im Gegenzug wurde Selwyn Balu von vielen älteren Bewohnern der Graciosa Bay als kastom-leader bezeichnet und anerkannt. Sein Mitwirken in der Graciosa Bay Nelo Association als Produzent der lepanesa und als aktiver nelo-Tänzer ,versetzten' auch Selwyn Balu nach Port Moresby und ließen ihn dort aufzutreten. Auch Balu konnte seinen Wirkungskreis mit den von ihm hergestellten Artefakten ausweiten und seine Position in Ne'ele ausbauen.

\subsection{Tapa und Ena Yamöli \& Steven Mdewöt 226}

Ena Yamöli wurde im Jahr 1961 in Nea, ihr Ehemann Steven Mdewöt im Jahr 1954 im Nachbarort No'ole geboren. Beide hatten sechs Jahre lang eine Primary School besucht. Während Yamöli fortan im elterlichen Haushalt half, arbeitete Mdewöt in den Jahren 1971 bis 1972 für die australische Firma Allardyce Lumber auf Nddendö und später von 1978 bis 1993 für die Landwirtschaftsplanungsabteilung der Provinzregierung. Die Heirat der beiden im Jahr 1980 war ihnen zufolge eine zu der Zeit wenig übliche Liebesheirat. Mdewöt hatte sieben Jahre lang auf die Heirat warten und in der Zeit einen außergewöhnlich hohen Brautpreis zusammentragen müssen, um die Tochter eines Chiefs aus Liebe ehelichen zu können. Das Ehepaar hatte im Jahr 2011 sieben Kinder, von denen die beiden ältesten (geb. 1983 und 1985) in Honiara und die übrigen fünf bei ihnen in Nea lebten. Ihr Zuhause bildete seit der völligen Zerstörung ihres Wohnhauses durch einen Zyklon im Jahr 2008 ihre ursprüngliche Kochhütte. Tagsüber nutzten sie parallel dazu zusammen mit Yamölis Schwestern und deren Kindern das frühere Haus ihres Vaters, der erst im Juli des Jahres 2011 verstorben war.

Seit Mdewöts Kündigung des Verwaltungspostens in der Provinzregierung arbeitete das Ehepaar gemeinsam als Tapa-Produzent und versuchte damit in erster Linie - zusätzlich zu der üblichen Subsistenzwirtschaft - Einkünfte für den Lebensunterhalt ihrer Familie zu generieren. ${ }^{27}$ Nach eigener Darstellung waren sie seit dieser Zeit immer wieder durch verschiedene Personen aus dem Ausland zu einer Intensivierung ihrer Tapa-Produktion motiviert worden, etwa durch ein amerikanisch-mexikanisches Ehepaar, das für die Entwicklung ländlicher Gebiete der Solomon Islands arbeitete, oder das neuseeländische Ärzteehepaar

\footnotetext{
waren; vgl. Abb. 64. Auch hatte er einen Schießwettbewerb für den Beginn des Festes organisiert. Ebenso folgte seine Beziehung zur Schwester seiner Ehefrau kastom-Vorstellungen; vgl. Kap. 5. I .

${ }^{226}$ Ende Oktober 20I I beherbergten und verköstigten mich Ena Yamöli und ihr Ehemann Steven Mdewöt für eine knappe Woche bei sich in Nea. In der Zeit zeigten sie mir, wie sie Tapa und die schwarze Farbe für deren Dekoration gewannen und damit den Rindenbast bemalten. Am 25. Oktober führten wir zusammen mit Yamölis Schwester l'nale sowie deren Tochter Wendy Mena das diesem Kapitel zugrunde liegende Gespräch. Ergänzt werden die Informationen durch weitere Gespräche während meiner diversen Aufenthalte von 2009 bis 2014.

227 Zu ihrer Tapa-Herstellung vgl. Kap. 4.3.4.
} 
Arathoon, das in den späten 1990er-Jahren das Anti-Malaria-Programm der Nationalregierung am Krankenhaus in Lata leitete und deren Sohn im Jahr 2012 das Ehepaar YamöliMdewöt besuchen kommen wollte. ${ }^{228}$ Ebenso war Mick Pendergrast in den Jahren 1998 und 2001 bei ihnen zu Gast gewesen und hatte auch ihnen im Laufe der Jahre viele Unterlagen zu verschiedenen historischen Artefakten mitgebracht. ${ }^{229}$

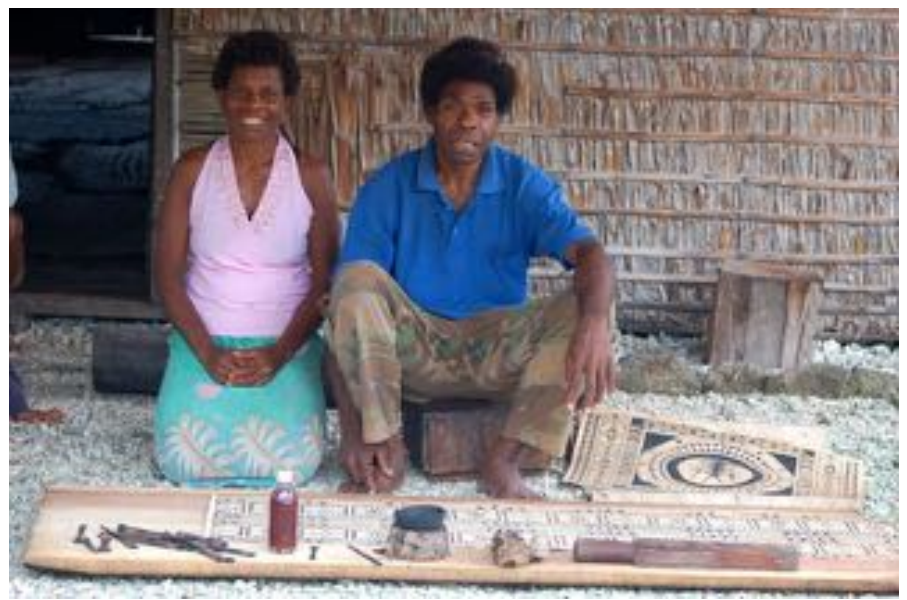

Abb. 121: Ena Yamöli und Steven Mdewöt mit von ihnen für einen späteren Verkauf an Touristen hergestellten Tapa vor dem Eingang des Hauses von Yamölis Vater; Nea, 2011.

Yamöli und Mdewöt verkauften bemalte oder unbemalte Tapa an lokale Tänzerinnen und unbemalte an lokale Tänzer, die diese dann selber dekorierten. ${ }^{230}$ Yamöli hatte auch die Tapa der beiden Kopfbedeckungen abe für den Tanzauftritt in Ne'ele hergestellt, die anschließend ihr Bruder Matthias Me'lekaiva bzw. Ben Banie bemalt hatten (vgl. Abb. 102 und Abb. 103). Ebenso verkauften sie bemalte Tapa an Kreuzfahrttouristen, wenn diese zu Tanzaufführungen auf die Insel kamen. ${ }^{231}$ Bis zu dem Erdbeben und dem darauffolgenden Tsunami mit Überschwemmung und Versalzung des Waldgebietes um Nea am 6. Februar

\footnotetext{
${ }^{228}$ Eine Fotografie des Ehepaares Sarah und David Arathoon mit ihren Kindern Megan, Barney und Rosamund findet sich in Wilson (2009: 80).

229 Mick Pendergrast informierte insbesondere Ena Yamöli über verschiedene Dekore von Hochzeitstaschen (Pijin: marriage baskets, Nalögo: putë und putë nawö, erstere wird über der Schulter, letztere auf dem Kopf getragen), die Yamölis eigenen Aussagen zufolge als einzige auf Ndendö aus Hibiskusfaser flocht, im Gegensatz zu den weiter verbreiteten Pandanus- oder Kokosnusspalmblatt-Taschen. Ihre Taschen kosteten im Jahr 20I I 450 SBD (entsprach im Jahr 20 I I ca. 45 Euro), die der Anderen lediglich 50 SBD (entsprach im Jahr 20 I I ca. fünf Euro). Nach eigener Aussage hatte Pendergrast ihr damals gesagt, sie sei auch die einzige Person auf Ndendö, die viereckigen Hochzeitstaschen (Nalögo: nölü) herstelle.

$230 \mathrm{Zu}$ den bemalten Tapa für Frauen bei Aufführungen zu politischen Empfängen vgl. Kap. 3.3.4 und Kap. 4.3.4 sowie Abb. I0I.

23I Ich traf das Ehepaar bei jeder meiner Anlandungen in den Jahren 2009, 20II, 2012 und 2014 an. Im März 2014 wurde ich Zeuge, wie Yamöli und Mdewöt von einem Sprecher des Dorfes Malo aufgefordert wurden, ihre Tapa und Hibiskustaschen wegzuräumen und deren Verkauf zu beenden. Laut dieses Sprechers hatte das Ehepaar erneut keine ,Standgebühr' an das Dorf entrichtet und durfte dem kastom entsprechend ohne diese Zahlung in Malo nicht verkaufen. Neben dem Ehepaar bot an dem Tag niemand weiteres Tapa oder Taschen an.
} 
2013 verkaufte das Ehepaar monatlich zwischen zehn und 30 Tapa an den Shop des Nationalmuseums in Honiara. Abhängig von der Größe und dem Abnehmer (lokale oder andere) kostete eine Tapa im Jahr 2010 200-600 SBD.

Die Tapa-Herstellung teilte sich das Ehepaar auf: Mdewöt fällte den Schössling, seine Frau gewann den Bast aus der Rinde des Baumes und stellte die Farbe zur Dekoration her, mit der ihr Mann wiederum die Tapa dekorierte. ${ }^{232}$ Mdewöt übernahm für die Bemalung Muster von Vorlagen historischer Arbeiten, die er u. a. von Mick Pendergrast erhalten hatte, Designs der Familie seiner Ehefrau oder Dekorationen anderer von ihm als wertvoll erachteter Artefakte. Bei der Gestaltung orientierte er sich nach eigenen Worten an den Zielgruppen, für die er die Tapa herstellte: Historische Gestaltungen und traditionelle Formate fertigte er für lokale Tänzerinnen. Für Touristen und andere Kunden kombinierte er verschiedene Ornamente auf unüblichen Formaten, die nicht mehr der herkömmlichen Funktion ,Bekleidung $^{6}$ dienten, sondern neue Kontexte indizierten, etwa rein ästhetische Rezeptionen. ${ }^{233}$ Dazu griff er seit dem Jahr 2010 auf die Abbildung eines tema zurück, rückte es in das Zentrum seiner Darstellung und füllte die freien Flächen mit Ornamenten anderer Artefakte aus, wie Abbildung 122 eindrücklich wiedergibt: ${ }^{234}$

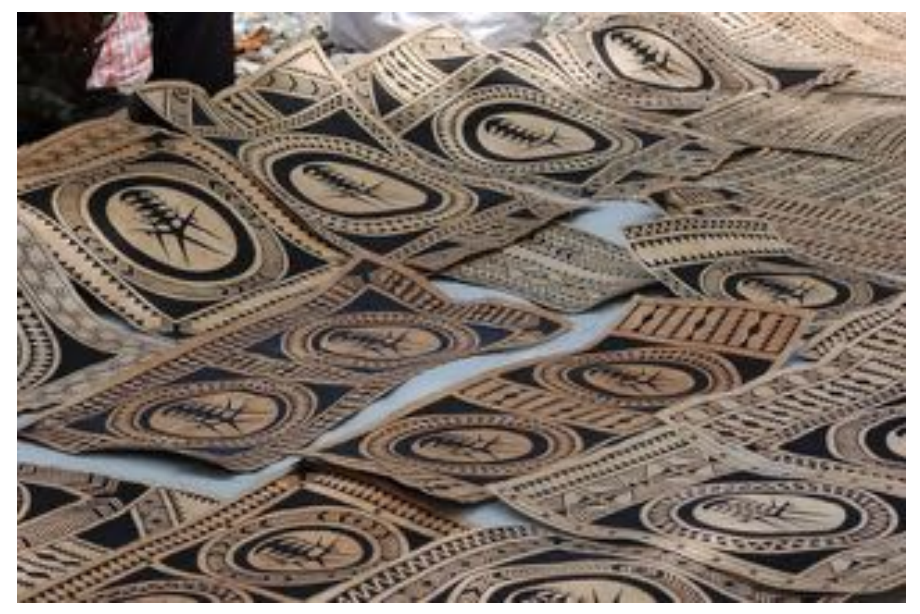

Abb. 122: Tapa mit zentralem temaMotiv; Steven Mdewöt, 2014. Kurze Zeit nach der Aufnahme wurde das Ehepaar aufgefordert, seinen Verkauf einzustellen (vgl. Anm. 231).

Wie Mdewöt erklärte, hatte er bei den Verkäufen an Touristen und an den Museumsshop festgestellt, dass sauber und gleichmäßig bemalte Tapa schneller verkauft wurden als unregelmäßige Freihandzeichnungen. Aus diesem Grund hatte er eine Stempeltechnik entwickelt, mit der er ein sehr akkurates Auftragen der Farbe sicherstellte (vgl. Abb. 123 und Abb. 124).

\footnotetext{
232 Zu den einzelnen Arbeitsschritten bei der Gewinnung der Tapa sowie der Herstellung der Farbe siehe Kap. 4.3.4.

233 Zu Reproduktionen ,traditioneller Taparapporte' vgl. Abb. IOI.

${ }^{234} \mathrm{Vgl}$. Kap. 4.3.4 und 5.2.4 und weiter LUEB (20I3).
} 

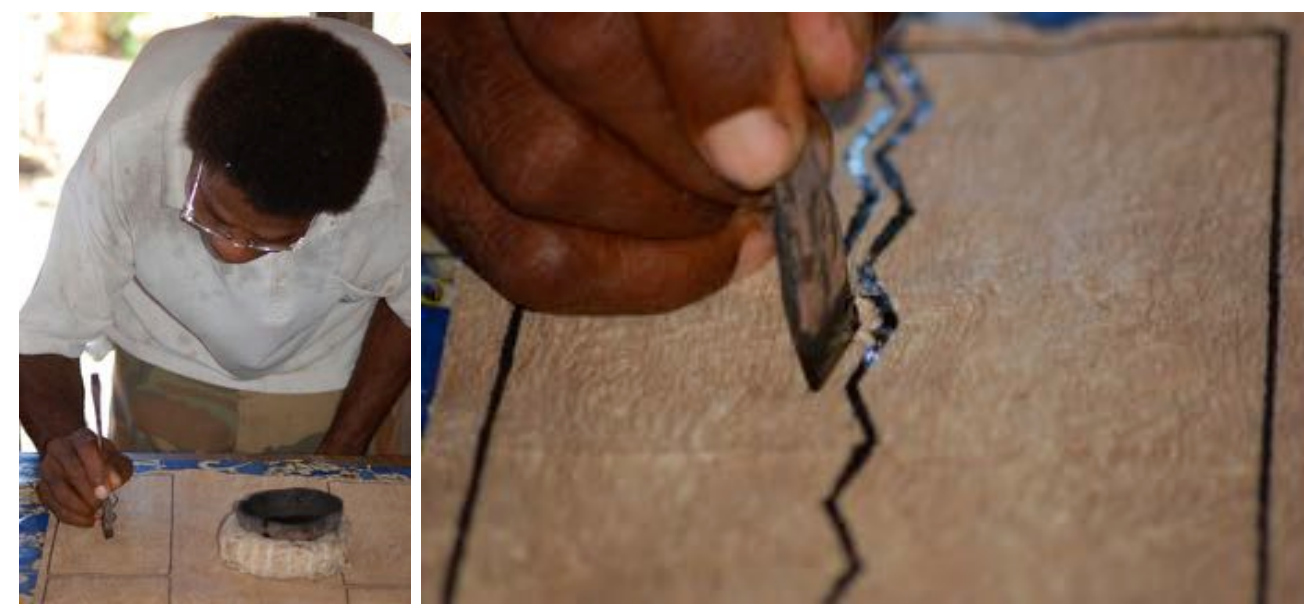

Abb. 123 und 124: Steven Mdewöt nutzt eine eigens von ihm entwickelte Stempeltechnik für den Farbauftrag auf Tapa; Nea, 2010.

Manche der von Mdewöt genutzten ,traditionellen Muster ${ }^{6}$ besaß die Familie seiner Ehefrau. Yamölis Aussage zufolge hatte ihr Ehemann das Recht für den Gebrauch der Muster durch die gemeinsame Heirat erworben. Ihr Bruder Matthias Me'lekaiva, Mdewöts tabu, schätzte die Situation gegenteilig ein, missbilligte die Tätigkeit seines Schwagers und distanzierte sich von ihm. ${ }^{235}$ Me'lekaiva war im Gegensatz zu seiner Schwester und deren Ehemann als TapaProduzent Mitglied der Graciosa Bay Nelo Association, wobei er die Tapa nicht selber fertigte, sondern ausschließlich bemalte. Yamöli und Mdewöt sprachen sich gegen die ,Geschäftstätigkeit' der in der Assoziation organisierten Hersteller der Artefakte in der Graciosa Bay aus, und Mdewöt überlegte, eine eigene Assoziation für ,traditionelle` Artefakte in seinem Dorf zu gründen. Bei einem früheren Gespräch hatte ich dem Ehepaar verschiedene Kurzdokumentationen über die Herstellung von Artefakten, u. a. Tapa, zu Ende der 1960erJahre (KOCH 1972 a-e) gezeigt, wobei Ena Yamöli ihren Großvater Harry Me'niepoi beim Binden des roten Federgeldes und John Me'napa bei der Herstellung der Federplättchen im Nachbardorf Nemboi wiedererkannt hatte. Bei meinem Aufenthalt in Nea baten sie mich, diese Kurzdokumentationen den Dorfbewohnern im Elternhaus Yamölis zu zeigen und später Kopien für Demonstrationen und Unterweisungen der Heranwachsenden in den entsprechenden Arbeiten zu hinterlassen.236 Die Dokumentationen eines ausländischen Wissenschaftlers aus den 1960er-Jahren und das öffentliche Aufführen der Filme 45 Jahre später in ihrem Dorf durch mich (einem weiteren Wissenschaftler aus dem Ausland) vermittelten

\footnotetext{
235 Wie mir Me'lekaiva später erkärte, war dies auch der Grund dafür, dass er während meines Aufenthaltes bei der Familie nicht für ein Gespräch zu den Mustern zur Verfügung stand. Nach seinen sowie Yamölis Aussagen stammten die Designs (Nalögu: nembualaiö, was so viel wie Schreiben bedeutet) von dem dukna Melake, der diese vor zehn bis zwölf Generationen an ihren Vorfahren Dangga gegeben hatte, die dieser wiederum in einer Höhle in Nanggu im Westen Ndendös an die Decken und Wände gemalt hatte. Die Geschichte der Überlieferung erzählte mir Me'lekaiva kurz vor meiner Abreise, so dass ich nicht herausfinden konnte, ob die Höhle zugänglich war; vgl. Kap. I und Kap. 5.2.4.

236 Dazu baten sie mich, bei meinem für das Folgejahr geplanten Besuch mit einem Kreuzfahrtschiff ein entsprechendes DVD-Abspielgerät mitzubringen und gegen Tapa zu tauschen.
} 
eine direkte Verbindung des Ehepaares Yamöli-Mdewöt zur internationalen Wissenschaftswelt oder zumindest eine Zugangsmöglichkeit zu ihr und untermauerten somit ihre Position als (international) beachtete Hersteller ,traditioneller Artefakte aus Santa Cruz'. Seit den 1990er-Jahren standen sie in regem Kontakt zu Ausländern. Manche von ihnen besuchten aufgrund der Artefakte immer wieder das Ehepaar. Yamöli und Mdewöt betrachteten die direkten, persönlichen Verbindungen über die Artefakte als relevanter als eine Mitgliedschaft in der GBNA. Indem mich das Ehepaar am Abend vor meiner Abreise aus Nea in Gegenwart der meisten Familien des Dorfes zudem ,adoptierte', untermauerten sie nachhaltig und auf die Zukunft gerichtet ihre internationale Beziehungsmöglichkeit als Zugang zu neuen Akteur-Netzwerken, die letztlich durch ihre Tapa entstanden waren. So verbanden auch hier die Artefakte die Vergangenheit mit der Gegenwart und Zukunft, frühere Generationen mit den aktuellen sowie Ndendö mit dem Rest der Welt. Unabhängig davon, ob die Artefakte Reproduktionen oder Innovationen waren, die lokal und/oder über die Grenzen Ndendös hinweg genutzt und geschätzt wurden, waren sie es, die die Basis für diese Beziehungen legten. Sie ermöglichten ihren Produzenten, über Raum und Zeit hinweg zu agieren.

\subsection{Nelo-Tanzkleidung und die Graciosa Bay Nelo Association (GBNA)}

Im Februar 2011 gründeten „traditional elders and artifacts producers“ (ME’ESA 2011: 1) der Graciosa Bay, Ndendö, die Graciosa Bay Nelo Association. Laut Antrag zur Teilnahme am Festival of Pacific Arts 2012 in Honiara, den Freddy Me'esa als Technical Advisor der Assoziation (vgl. Abb. 125) am 24. Juni 2011 an das Organisationskomitee des Kultur- und Tourismusministeriums in Honiara schickte, vertrat die GBNA die Philiosophie „,...] to revive our cultural dances and chants, produce our traditional artifacts, train our young generations and exhibit to the world our rich cultural heritage" (2011: 1, Hervorhebung O. L.). Als daraus abgeleitete Ziele verfolgte die Gruppe u. a. ,,[to] [p]roduce traditional artifacts for dances and chants with local materials in Temotu Province“, ,[to] [c]oordinate and promote traditional activities as part of building the Tourism Industry" und „,[to] [p] articipate in building up the Tourism Industry in Solomon Islands by doing traditional dances around Temotu, Solomon Islands and abroad" (ebd., Hervorhebungen O. L.).

Im Jahr 2011 hatte die Assoziation gemäß eigener Aussage bereits über 50 aktive, größtenteils aus der Graciosa Bay stammende Mitglieder - Tänzer, Kultur- oder Geschichtsreferenten (cultural or history orators) sowie Produzenten der Tanzkleidung und des -schmucks. ${ }^{237}$ Gegen Ende meiner Feldforschung lud mich die GBNA ein, an einer Mitgliederversammlung teilzunehmen (vgl. Abb. 126 und Abb. 127). Wie sich in deren Verlauf herausstellte,

\footnotetext{
${ }^{237}$ In Gesprächen mit napa-Tänzern aus dem Dorf Malo vernahm ich des Öfteren, dass auch sie eine Assoziation gründen wollten, um die Provinz Temotu auf Festivals zu repräsentieren. Im Gegensatz zu den auf der Hauptinsel Ndendö gegenüberliegenden Dörfern der Graciosa Bay war Malo derjenige Ort, den Touristen von Kreuzfahrtschiffen in den Jahren 2009 bis 2014 besuchten. Aus Malo wurde aber keine Gruppe zu den Festivals in Honiara oder Port Moresby entsandt.
} 
diente das Treffen dazu, ein Abkommen mit mir vorzubereiten, das nach meiner Abreise beide Seiten fortan binden sollte, Informationen zu ,traditionellen` Artefakten und Tänzen auszutauschen.

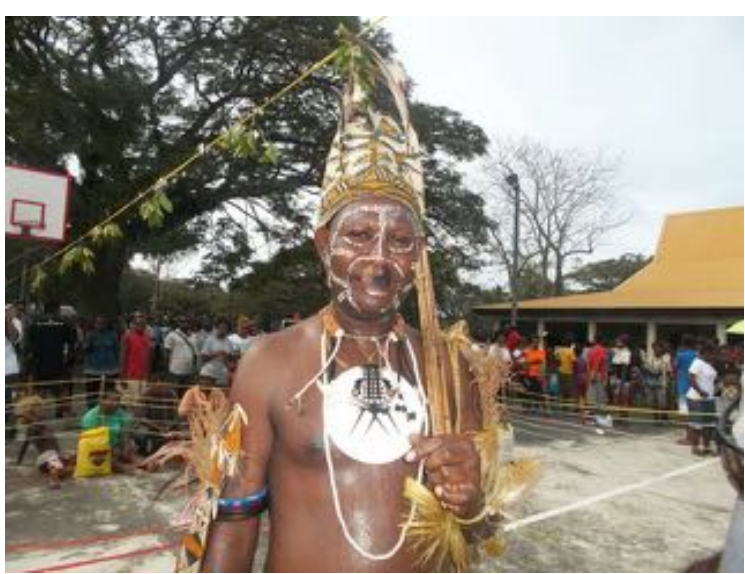

Abb. 125: Der Technical Advisor der GBNA, Freddy Me'esa, bei einer nelo-Tanzaufführung während des $5^{\text {th }}$ Melanesian Festivals of Arts and Culture in Port Moresby, Papua-Neuguinea, 2014. C GBNA

Im historischen Vergleich fallen die geänderte Form seiner Gesichtsbemalung wie auch die neuen Gestaltungen seines abe und tema auf.
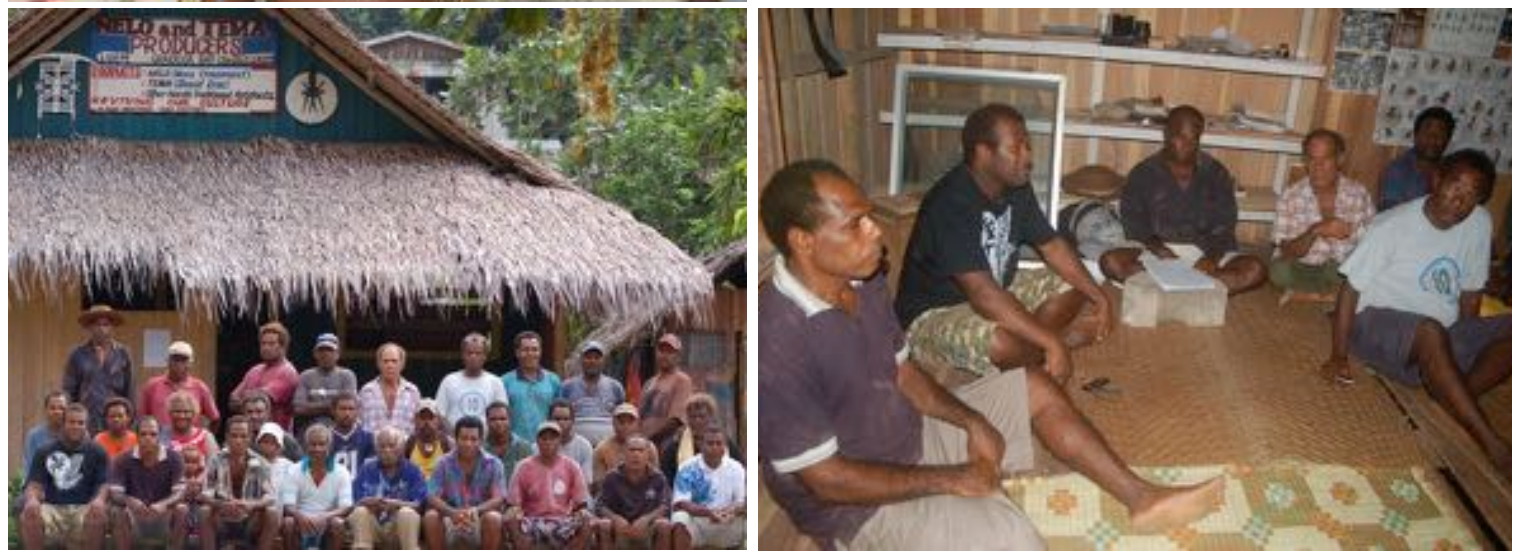

Abb. 126: GBNA-Mitglieder anlässlich der Mitgliederversammlung; Luepe, 2011.

Abb. 127: Vorstandsmitglieder der GBNA während der Mitgliederversammlung.

Zur selben Zeit wurde eine erste Facebook ${ }^{\circledR}$-Gruppe gegründet, das eher gesellschaftspolitisch-kritisch ausgerichtete „Temotu Public Forum“, in dem u. a. Postings über nelo-Tänzer zu finden sind. ${ }^{238}$ Im September 2013 folgte eine weitere Gruppe: „Kalenesian in Pictures...“ (der Natügu-Begriff kale bedeutet Freund). ${ }^{239}$ Im Juli 2014 erschien ein Facebook ${ }^{\circledR}$-Profil der nelo-Tanz-Delegation des $5^{\text {th }}$ Festival of Melanesian Arts and Culture in Port Moresby (letztlich die GBNA-Vertreter), das sich ausschließlich auf einen besonderen Umstand während der Rückreise der GBNA von den Auftritten bezog: Die Delegation hatte unerwartet in Honiara ausharren müssen, da zu der Zeit keine Fähren nach Ndendö verkehrten und die Festival-Ausrichter keine Flugtickets für die Teilnehmer bezahlten. Mit einem öffentlichen Auftritt sammelten die Tänzer Geld für ihre Flugtickets nach Hause:

\footnotetext{
${ }^{238} \mathrm{Vgl}$. etwa am I. Juli 2014 https://www.facebook.com/groups/temotu.pf/, letzter Zugriff am 6. I.20 I6.

239 Die Kalenesian-Gruppe postete zu größeren Anlässen, zu denen nelo-Tänzer auftraten, etwa zum Festival of Pacific Arts 20 12. Vgl. https://www.facebook.com/groups/6662600600533 I9/, letzter Zugriff am 6.1.2016.
} 

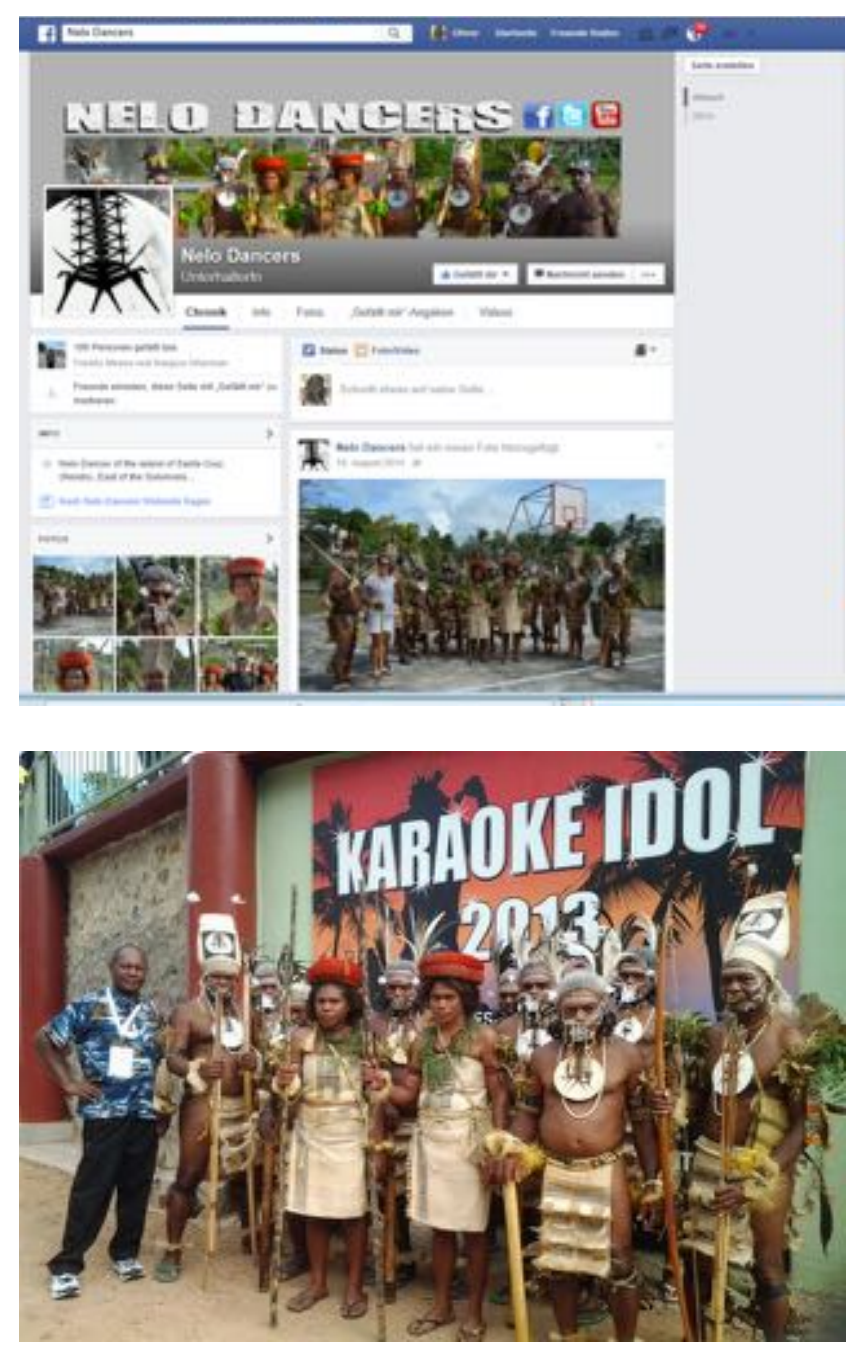

Abb. 128: Facebook $^{\circledR}$-Auftritt anlässlich der Rückreise der GBNA vom $5^{\text {th }}$ Melanesian Festival of Arts and Culture in Port Moresby, Papua-Neuguinea, Juli 2014. ${ }^{240}$

Abb. 129: Delegation der GBNA nach einer nelo-Tanzaufführung in Honiara auf dem Hinweg nach Port Moresby, PapuaNeuguinea, Juni 2014. C GBNA
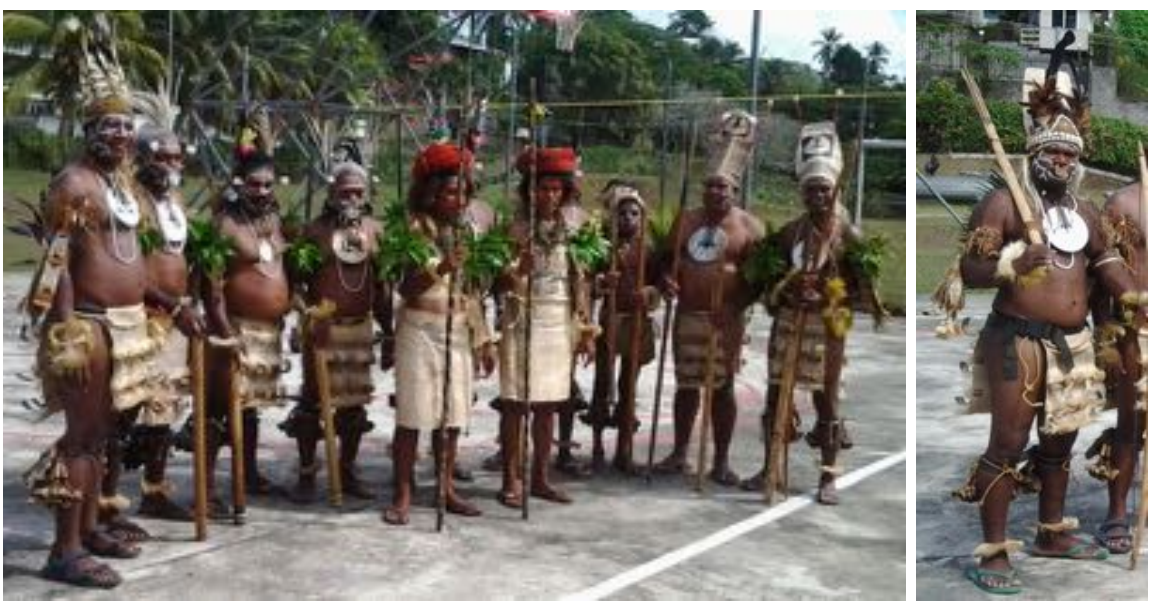

Abb. 130: Die Gruppe auf dem Rückweg vom Festival während des Spendenaufrufs in Honiara im Juli 2014. John Namiade fehlt auf dem Bild. C GBNA

Abb. 131: John Namiade bei dem Event. (C) GBNA

\footnotetext{
${ }^{240}$ Vgl. https://www.facebook.com/Nelo-Dancers-1529508740604385/, letzter Zugriff am 6. I.20 I6.
} 
Wie sich rückblickend zeigt, war das Jahr 2011 der Zeitraum, in dem sich die zunächst auf die Insel Ndendö beschränkte Revitalisierung des nelo-Tanzes und der mit ihm verbundenen Kleidungs- und Schmuckstücke geografisch ausweitete bzw. einen weiter gefassten Rezipientenkreis erreichte. Die ersten Ergebnisse der lokalen Bewegung vor Ort - etwa in Form einer steigenden Wertschätzung und zunehmenden Präsenz der neuen, alten' Artefakte nicht nur auf lokalen Festen - wurden mit der Annahme der GBNA-Bewerbung für die Teilnahme am Festival of Pacific Arts 2012 durch die Regierung ,offiziell‘ bestätigt und die zunächst auf wenige Personen in Santa Cruz beschränkte Bewegung auf eine nationale Ebene gehoben. Es war ein Moment, in dem die Mitglieder der GBNA ihre Arbeiten ,zum Leben erwecken und einem internationalen Zuschauerkreis ihr, eigenständiges und lebendiges kulturelles Erbe' demonstrieren konnten, so wie es in der Satzung der Assoziation verankert war. Im Vordergrund standen dabei die ,Übersetzungen` in Form von nach ihrer Aussage einzigartigen Artefakten und Tanzdarbietungen, die die Delegation der GBNA von anderen Festivalgruppen unterschied - sie machten den Unterschied. Ihr Auftritt muss erfolgreich gewesen sein, denn im nachfolgenden Jahr reiste sie als eine Gruppe der nationalen Repräsentanten zum $5^{\text {th }}$ Festival of Melanesian Arts and Culture nach Papua-Neuguinea (vgl. Abb. 128130).

Ein Vergleich der Tanzkleidung und des -schmucks während des Festivals im Jahr 2014 mit den von mir begleiteten Auftritten in den Jahren 2010 und 2011 zeigt einige Unterschiede: Alle Tänzer der Gruppe trugen im Jahr 2014 aus Bananenbast gewobene lepanesa auf den Darbietungen auf Ndendö traten auch Tanzschurze aus anderen Materialien in Erscheinung. Einer der Tänzer trug eines der ,neuen` nelo, die nicht mehr durch das Septum gezogen, sondern an die Nase gehängt wurden (vgl. Abb. 39, 40 und Abb. 114). Die beiden abe waren nicht aus Tapa hergestellt, sondern gewoben und mit einem tema bemalt (vgl. Abb. 129 und Abb. 130). Der dritte bestand zwar aus Tapa, war aber ebenfalls mit Mustern bemalt, die im historischen Vergleich in der Art auf Ndendö nicht vorkamen (vgl. Abb. 125). Die tema der Tänzer waren von beachtlicher Größe, und mindestens zwei hatten neue Darstellungsformen der Schildpattauflagen (vgl. Kap. 114). Ebenso wich die Gesichtsbemalung einiger Tänzer von den von mir auf den Festen auf Ndendö dokumentierten ab (vgl. Abb. 125). Zu der Tanzgruppe gehörten zwei Frauen, die Federgeld präsentierten. Im Unterschied zu den Federgeldpräsentationen auf dem alue-Fest in Nea und den Touristenaufführungen in Malo waren diese beiden Frauen mit Wickelröcken und mit Oberteilen aus gewobenem Bananenbast bekleidet. In Nea und Malo trugen die Frauen keine Oberteile. Sie hatten ihren Oberkörper mit Kurkuma eingerieben, und ihre Röcke bestanden aus unbemalter Tapa (vgl. Abb. 132-134). Die Federgeldrollen waren allem Anschein nach neu, denn die sichtbaren Federn waren im Gegensatz zu den verblassten, eher bräunlichen Federn in Neo und Malo von intensiver roter Farbe. Dass die Frauen und die Kleidung als eine Einheit jeweils unterschiedliche Bilder kreierten, ist in den nachfolgenden Abbildungen klar ersichtlich: 


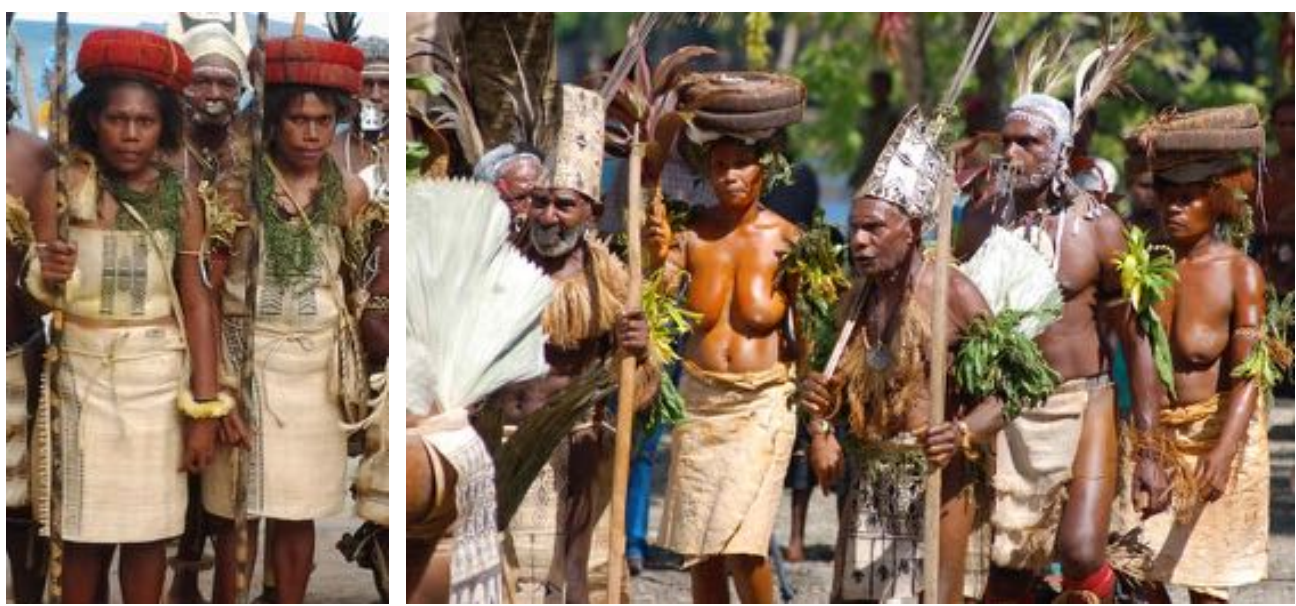

Abb. 132: Frauen der GBNA präsentieren Federgeldrollen auf dem $5^{\text {th }}$ Melanesian Festival of Arts and Culture in Port Moresby, Papua-Neuguinea, 2014. (C) GBNA

Abb. 133: Präsentation von Federgeld auf einer Tanzaufführung für Touristen; Malo, 2011.

Meines Erachtens vermittelten die von der GBNA für den Auftritt im Jahr 2014 hergestellten und getragenen Tanzkleidungs- und -schmuckstücke ein eher homogenes, in sich geschlossenes Bild und stellten die Gruppe als Einheit dar. Sie verkörperten ein Ergebnis der Revitalisierungsbemühungen um kastom auf Ndendö, hier den nelo-Tanz als einen Aspekt von kastom aus Sicht der GBNA-Vertreter. Bei einem Vergleich zu anderen, ebenfalls nicht lokalen Anlässen zeigen sich in der Darstellungsweise und in den Artefakten Unterschiede. Diese werden noch größer bei einem Vergleich mit dem in Kapitel 5 dargestellten lokalen Anlass, zu dem manche Tänzer (noch) Tanzschurze und Brustschmuck aus nichtnatürlichen Materialien oder sehr stark gebrauchte, fast verschlissene trugen. Seit meinem Feldforschungsaufenthalt hatten die Produzenten ihre Werke umgestaltet und erneuert, immer mit der Intention, ,traditionelle Artefakte und Tänze' wiederzubeleben. Die Artefakte hatten ihren Herstellern und Nutzern im Rahmen der kulturellen Revitalisierung einen völlig neuen Wirkverbund (ein neues Akteur-Netzwerk) eröffnet: eine organisierte und seitens der Regierung unterstützte Kooperationsmöglichkeit, die Graciosa Bay Nelo Association. Dieser Verbund erschloss den Aktanten wiederum neue Einkommensmöglichkeiten und ermöglichte vielen von ihnen, ihren Wirkungskreis geografisch zu erweitern, d. h. zunächst in Honiara und im folgenden Jahr in Port Moresby aufzutreten. Über die Auftritte waren die Delegationsmitglieder und ihre Kleidung (die menschlichen wie nicht menschlichen Aktanten) sogar Teil der virtuell globalisierten Welt im World Wide Web (einem neuen Akteur-Netzwerk) und dort Ausgangspunkt für weitere Diskussionen um kulturelle Zugehörigkeiten geworden. ${ }^{241}$

\footnotetext{
${ }^{241}$ Insbesondere im sozialen Netzwerk Facebook ${ }^{\circledR}$ waren im Verlauf von drei Jahren mehrere Auftritte entstanden (vgl. S. 204-205), auf denen Nutzer miteinander diskutierten, wie sie kastom, tradition und kalsa verstanden. Auf Youtube ${ }^{\circledR}$ sind nur wenige Videos zu nelo-Tänzen veröffentlicht und werden kaum besprochen; vgl. etwa https://www.youtube.com/watch?v=CV2s4ZzfOfg oder https:/www.youtube. com/watch?v=-FJ_dxJ-3iY, beide letzter Zugriff jeweils am 8.1.2016.
} 


\subsection{Art Nexus ${ }^{6}$ - Artefakte als Intentionen}

Gells erklärtes Ziel ist es, Kunst/-Handwerk als Domäne zu untersuchen, „in which ,objects merge with ,people by virtue of the existence of social relations between persons and things, and persons and persons via things" (1998: 12, Hervorhebungen im Orig.; vgl. Kap. 1.2). Um dies zu ermöglichen entwickelt er als theoretisches Konstrukt den ,Art Nexus', demzufolge Artefakte als Verbindungsglieder sozialer Beziehungen zwischen Handlungsbestimmenden (agents: A) und Handlungsempfangenden (patients: P) zu sehen sind. Als Verbindungsglieder zwischen diesen beiden Seiten stehen zentral die indices, unter denen Gell materielle Entitäten (etwa Kunstwerke/Artefakte) versteht, die meist für Repräsentationen von Referenzen (prototypes) gehalten werden. Diese motivieren jedoch die Betrachter (recipients) durch die kognitive Operation der Abduktion (abductive inference), Folgerungen hinsichtlich der Fähigkeiten und Intentionen ihrer Erzeuger oder anderer Urheber (artists) zu schließen, wobei letztere als kausal verantwortlich für die Existenz oder Charakteristika der indices gesehen werden (GELL 1998: 12-27; CHUA \& ELLIOT 2013: 5).242 Nach Gell können artists, indices, prototypes und recipients sowohl als agents als auch als patients agieren. ${ }^{243}$ „To be an ,agent ${ }^{6}$ one must act with respect to the ,patient'; the patient is the object which is causally affected by the agent's action. [...] [1]n any given transaction in which agency is manifested, there is a ,patient', who or which is another ,potential agent, capable of acting as an agent or being a locus of agency“ (GELL 1998: 22, Hervorhebungen im Orig.). Für eine Klassifizierung aller möglichen Beziehungen stellt Gell eine Matrix auf, aus der sich 16 Beziehungsmuster ergeben (1998: 29). In der bisherigen Analyse der Tanzkleidung und des -schmucks habe ich in Kapitel 4 die Materialien und in Kapitel 5 die Referenzen und das Publikum in ihren Akteur-Netzwerken berücksichtigt. Diese entsprechen den Indices, Prototypen und Rezipienten Gells ,Art Nexus'. Daher fokussiere ich in der weiteren Ausführung auf die Beziehungen der artists (hier im Sinne von Urheber bzw. Hersteller der Artefakte) zu den indices, prototypes und recipients - und zwar in beiden Ausprägungen, als agents und patients. ${ }^{244}$

Aus den zuvor dargestellten Lebensläufen und Überlegungen der Produzentin und der vier Produzenten geht hervor, dass sich alle Personen freiwillig für ihre Tätigkeiten entschieden und - mit Ausnahme von Stephen Mdewöt, der in eine Produzentenfamilie eingeheiratet hatte - diese von ihren Eltern übernommen und sich im Laufe der Revitalisierungsbemühungen darauf spezialisiert hatten. ${ }^{245}$ Zudem sahen alle in der Herstellung ihrer Artefakte

242 Zu seiner Herleitung des aus der Logik und Semiotik entlehnten Begriffs der Abduktion vgl. GELL 1998: I3-16.

243 Zur Verdeutlichung der unterschiedlichen Statusmöglichkeiten führt Gell folgendes Beispiel auf: Wenn ein Auto während der Fahrt seinen Betrieb einstellt, ist der Wagen in der Position des Agenten und der Fahrer in der des Patienten. Beschimpft der Fahrer daraufhin das Auto und tritt es möglicherweise, so ist er der Agent und der PKW der Patient.

244 Zur Verdeutlichung der jeweiligen Position übernehme ich Gells Verwendung der Suffixe -A und -P, um auf den agent- resp. patient-Status aufmerksam zu machen.

${ }^{245} \mathrm{Vgl}$. Kap. 6. I-6.4. Zu einem Zusammenhang von rituellen Festen und einer Spezialisierung von (Kunst-)Handwerk in ,small-scale societies', zu denen ich Ndendö zähle, vgl. SPIELMANN (2002). In ihrer Darstellung zeigt die 
eine wichtige Einkommensquelle und verfolgten individuelle Intentionen. Die Entscheidung, grundsätzlich/freiwillig ,traditionelle ${ }^{6}$ Artefakte zu produzieren, entspricht dem ,Idealfall ${ }^{6}$ von Gells Agency-Verständnis, bei dem der Künstler/Hersteller frei in der Wahl der Materialien/Form und Intention/Inhalte sowie des Publikums ist und aus sich heraus ein Artefakt herstellt (Artist-A $\rightarrow$ Index-P). Anschließend waren die Hersteller aber nicht mehr völlig frei bei der Auswahl der Materialien und der Formen, da die historischen Vorlagen (indices) maßgeblich die Materialität bestimmten (Index-A $\rightarrow$ Artist-P).

John Namiade verfolgte mit der tema-Produktion taktisch eine „Business-Strategie“, wie er es formulierte. Aus den vielen Tätigkeiten, die er zu Beginn seines Berufslebens ausgeübt hatte, entschied er sich aktuell für die Produktion von ,traditionellen` Artefakten (Artist-A $\rightarrow$ Index-P). Für die Herstellung nutzte er einen Generator sowie Werkzeuge aus dem Ausland und wollte alle historisch belegten tema-Darstellungen reproduzieren (Index-A $\rightarrow$ Artist-P). Zudem hatte er begonnen, Eigenkreationen zu entwickeln, deren Ikonografie er im Gegensatz zu der der historischen tema erklären konnte (Artist-A $\rightarrow$ Index-P sowie im Falle der Entlehnung von Haidarstellungen aus dem Wappen der Salomonen Prototype-A $\rightarrow$ ArtistP). Er sah in dem Brustschmuck das Artefakt Ndendös, einen Mittler der lokalen Historie und ,Tradition'. Auf lokaler Ebene indizierten tema - nicht nur in seinen Augen - eine kulturelle Zugehörigkeit zu Santa Cruz oder eine Abstammung aus der Region. Seine Intention bestand in erster Linie darin, die Artefakte Ndendös über die Grenzen der Insel bekannt zu machen und dadurch möglichst viele zu verkaufen. Dazu plante er über die tema-Herstellung hinaus einen eigenen Präsentationsraum (ein Museum) für viele ,traditionelle ${ }^{6}$ Artefakte zu schaffen. Ebenso verkaufte er tema und T-Shirts mit tema-Darstellungen vor Ort an die lokale Bevölkerung und Besucher (als Indices für eine kulturelle Zugehörigkeit oder für eine Erinnerung, eine Zugehörigkeit und Nicht-Zugehörigkeit für den Moment des Besuchs). Zur weiteren Steigerung des Bekanntheitsgrades hatte er maßgeblich an Förderanträgen an die Landesregierung mitgearbeitet und war Mitbegründer der GBNA. An dieser Stelle möchte ich die These formulieren, dass er im Sinne Gells eine ,distributed person ‘ ist, da er über die von ihm hergestellten Artefakte seinen Einflussbereich ausweitete, was sein Dorf mit seiner Wahl zum Chief als Nachfolger seines verstorbenen Vaters annahm.

Auch Philipp Malu und Selwyn Balu gehörten dieser Assoziation an. Malu bewunderte von Kindheit an den nelo-Tanz und fertigte Nasen- und anderen Schmuck in erster Linie für die wenigen verbliebenen nelo-Tänzer. Dazu reproduzierte er historische Vorlagen (Index-A $\rightarrow$ Artist-P) und hatte einmal von einer neuen nelo-Gestaltung geträumt und diese realisiert $\left(\right.$ Artist-A $\rightarrow$ Index-P). ${ }^{246}$ Zudem fertigte Philipp Malu für externe Auftraggeber von Zeit zu

Autorin mehrere mögliche Gründe für eine Intensivierung lokaler Produktionen: Relevanz der geografischen Herkunft der Materialien, des lokalen Wissens um und Fähigkeiten zur Herstellung, der ästhetischen Qualitäten und Historien der Objekte.

246 Unter Malus Vorlagen befand sich auch die erste Kopie des, Original'-nelo von Opla, das dieser der Überlieferung nach in der Graciosa-Bay verloren hatte. Da es sich dabei also um den ,Urtyp' oder die Referenz eines nelo handelt, entspricht dieses nicht mehr vorhandene Artefakt dem prototype und die erste Kopie einem Index. 
Zeit verkleinerte tema in größerer Stückzahl, für deren Gestaltung ihm die Kunden eigene Vorstellungen vorgaben (Recipient-A $\rightarrow$ Artist-P). Die Artefakte vermittelten in dem Fall nicht mehr eine kulturelle Zugehörigkeit zu Santa Cruz, sondern waren eher eine Art Souvenir des Auftraggebers, teilweise in einer vermeintlichen Santa-Cruz-Stilistik.

Selwyn Balu war nach eigener Darstellung der einzige Produzent von Tanzschurzen aus Bananenbast auf Ndendö. Er hatte sich dazu entschieden, im Falle der lepanesa ausschließlich die von seinem Vater tradierten Muster zu nutzen und nur mit traditionellen Materialien zu arbeiten (Index-A $\rightarrow$ Artist-P). Er stellte die lepanesa nahezu ausschließlich für die Tänzer her. Balu war von seinem Vater auch zu einem nelo-Tänzer erzogen worden, so dass Balu nicht nur die Tanzschurze herstellen konnte, sondern auch viel über den nelo-Tanz wusste. Er versuchte, möglichst umfassend Wissen der Generation seines Vaters zu erhalten und zu teilen. Die Kombination der von ihm hergestellten lepanesa mit seinem kastom-Wissen und seinem Engagement für die Dorfgemeinschaft versetzten ihn in die Lage, in der GBNA eine Vorstandsposition zu besetzen. Mittels seiner Unterstützung ,traditioneller' Artefakte intendierte er u. a. die Revitalisierung des lokalen kastom sowie eine damit einhergehende soziale Reproduktion (etwa in Form der politischen Stärkung lokaler Chiefs und der Stützung reziproker Beziehungen). Balu wob zudem Taschen aus Bananenbast, wobei er sein Wissen darüber mit zwei seiner Kinder und zwei seiner Brüder geteilt hatte. Die Taschen produzierte er auf Bestellung und griff hier auf überlieferte Muster zurück (Index-A $\rightarrow$ Artist-P) oder entwickelte eigene Designs (Artist-A $\rightarrow$ Index-P). Ihm zufolge vermittelten die gewebten Bananenbastschurze und -taschen als gemeinsame Erinnerung und Herleitung der eigenen (kulturellen) Zugehörigkeit diese Revitalisierungsbemühungen (Artist-A $\rightarrow$ Recipient-P).

Das Ehepaar Ena Yamöli und Steven Mdewöt stellte auf traditionelle Weise Tapa her und konzentrierte sich bei der Produktion für den lokalen Markt auf Reproduktionen historischer Vorlagen (Index-A $\rightarrow$ Artist-P). Ebenso produzierte es für den Verkauf an Besucher und für den Museumsshop in Honiara, wobei der Ehemann die Dekore frei und wechselnd kombinierte, auf den Einsatz natürlicher Farbe zurückgriff und neue Nutzungsformate schuf (Artist-A $\rightarrow$ Index-P). Mdewöt hatte dabei in beiden Fällen die Maltechnik in eine Stempeltechnik überführt, da mittels dieses seiner Aussage nach gleich starke und akkurate Linien entstanden, was die Abnehmer schätzten (Recipient-A $\rightarrow$ Artist-P). Das Ehepaar war nicht Mitglied der GBNA und sprach sich gegen deren Geschäftstätigkeit aus, da die Assoziation ihnen zufolge zu wenig kastom berücksichtigte und die Hersteller die Bedeutungen der Motive oftmals nur unzureichend oder gar nicht kannten.

Die Mitglieder der GBNA hatten sich zusammengeschlossen, um satzungsgemäß,traditionelle' Artefakte herzustellen, das Wissen darüber festzuhalten und beides zu propagieren (Index-A $\rightarrow$ Artist-P). Dabei thematisierten sie die traditionellen lokalen Materialien der Artefakte als Sinnbilder für die Revitalisierung des lokalen kastom. Ihre Intention war letztlich die Aufrechterhaltung lokaler kultureller und sozialer Wissensformationen und Praktiken. Dabei verkörperten die Artefakte eine kulturelle Eigenständigkeit (Prototype-A $\rightarrow$ Artist$\mathrm{P} /$ Artist-A $\rightarrow$ Index-P). In den Augen der Beobachter konnte diese entweder ein Gefühl der 
Zugehörigkeit, d. h. eine Beziehung auslösen, deren Grenzen oder Nichtvorhandensein aufzeigen (Index-A $\rightarrow$ Recipient-P).

\subsection{Zwischenfazit}

Gell zufolge entsteht die Handlungs- und Wirkmacht von Artefakten in einem kognitiven Prozess, der aus den Artefakten die Intentionen ihrer Hersteller in den Augen der Betrachter folgert. Gells ,Art Nexus ${ }^{6}$ - ein Konzept bzw. eine Klassifizierung grundsätzlicher möglicher Beziehungen zwischen Auftraggeber, Hersteller, Artefakt, Referenz und Betrachter - ermöglichte es, die Beziehungsmuster auf Santa Cruz zu systematisieren. Dabei zeigte sich, dass die Beziehungsfolgen Index-A $\rightarrow$ Artist-P und Artist-A $\rightarrow$ Recipient-P am häufigsten auftraten. Bei ihnen stellte sich die Handlungs- und Wirkmacht der Artefakte dadurch ein, dass die Hersteller auf historische Vorlagen zurückgriffen, diese reproduzierten und durch deren ,Wiedererweckung ${ }^{6}$ und physische Gegenwart zur Revitalisierung traditioneller Werte- oder Überzeugungssysteme (kastom) bei den Rezipienten beitrugen. Eine weitere häufigere Beziehung war die Artist-A $\rightarrow$ Index-P. Eine Handlungs- und Wirkmacht bildete sich hier in der künstlerischen Umsetzung von eigenen ästhetischen ,kastom-Artefakte' betreffenden Vorstellungen der Hersteller zu Zugehörigkeit und Eigenständigkeit einer ,Santa-Cruz-Kultur`. Bei der Beziehung Recipient-A $\rightarrow$ Artist-P ergab sich die Handlungs- und Wirkmacht der Artefakte durch die Berücksichtigung der Vorstellungen der Auftraggeber bei der Gestaltung von ,kastom-Artefakten' durch die Hersteller. Denn Letztere verfolgten die Intention, Einkommen zu generieren, wobei sie sich an den Vorstellungen oder antizipierten Wünschen der Auftraggeber orientierten, um möglichst viele Artefakte zu veräußern.

Es zeigte sich, dass die Artefakte parallel (wenn auch nicht zeitgleich) in verschiedenen Beziehungsstrukturen als indices auftraten und unterschiedlich wirken konnten: Sie vermittelten die Aktualität/Relevanz von lokalen bis internationalen kastom-Konfigurationen (vgl. Kap. 3). Sie kreierten vor Ort Effekte und bestärkten Zugehörigkeitsgefühle zu Santa Cruz oder schufen Grenzen und ermöglichten eine Verbreitung von Santa-Cruz-Artefakten über die Grenzen Ndendös hinweg, wodurch sie nicht zuletzt lukrative Einkommensmöglichkeiten für ihre Hersteller darstellten.

Die Hersteller der Tanzkleidung und des -schmucks auf Ndendö waren ihrerseits in diverse Beziehungen eingebunden und unterlagen - abhängig von der jeweiligen Zugehörigkeit - unterschiedlichen Bedeutungszuschreibungen. Dafür schufen die Produzenten mit ihren Artefakten immer wieder neue Beziehungen. Sie setzten die Artefakte strategisch oder situationsabhängig für ihre vielfältigen gemeinsamen und/oder persönlichen Bedürfnisse und Ziele ein. Die Handlungs- und Wirkmacht der Tanzkleidung des Schmucks zeigte sich vielfältig strategisch platziert und als greifbare Ausdrucksform unterschiedlicher Intentionen (vor allem soziale und kulturelle Reproduktion sowie Einkommen) der Hersteller, Empfänger oder Auftraggeber. Alle Handlungen und Bezugssysteme referierten dabei auf die jeweiligen kastom-Vorstellungen der Beteiligten. 



\section{Zusammenfassung und Schlussfolgerungen}

In der vorliegenden Arbeit habe ich verschiedene Gruppen von Kleidungs- und Schmuckstücken des nelo-Tanzes auf Ndendö untersucht. Ausgehend von aktuellen Anlässen, zu denen die Artefakte auftraten, stellten sich mir zunächst die Fragen, warum sie in ihrem ästhetischen Erscheinungsbild gegenüber historischen Vergleichsobjekten nahezu unverändert schienen und zum überwiegenden Teil noch oder wieder aus natürlichen Materialien bestanden - was für die Region außergewöhnlich war.

Zur Beantwortung der Fragen verglich ich in einem ersten Schritt früheste schriftliche Quellen, Abbildungen und historische Objekte aus dem späten 19. und frühen 20. Jh. mit Darstellungen und Objekten aus den 1960er- und 1970er-Jahren sowie mit rezenten Artefakten hinsichtlich deren Materialität und wenn möglich deren Herstellung. Die Vergleiche brachten in allen Artefaktegruppen einen Wandel ihrer Materialitäten zutage. Nach einem frühen, gescheiterten Versuch, zum Ende des 16. Jh. auf Ndendö eine spanische Kolonie zu errichten, setzte die Kolonialisierung und Christianisierung in den Santa-Cruz-Inseln vergleichsweise spät in der Mitte des 19. Jh. ein. Von 1898 bis 1978 hatte England den Archipel als Teil des British Solomon Islands Protectorates annektiert. Aufgrund der geografischen Lage der Inseln und der lange Zeit erfolgreichen Gegenwehr der lokalen Bevölkerung erfolgte der europäische Zugriff nur langsam und kam bis nach dem Zweiten Weltkrieg immer wieder zum Erliegen. Ab den 1950er-Jahren importierten die Bewohner der Santa-CruzInseln neue Materialien und nutzten diese u. a. für die Tanzkleidung und den -schmuck. Die beiden Ethnologen William Davenport und Gerd Koch führten unabhängig voneinander in den 1960er- und 1970er-Jahren mit unterschiedlichen Schwerpunkten Forschungen in dem Archipel durch, und insbesondere ersterer beschrieb einen starken kulturellen Wandel. Für die folgenden 20 Jahre liegen meines Wissens keine gesicherten Informationen vor, so dass ich versuchte, diesen Zeitraum mit besonderem Fokus auf Tanzkleidung und -schmuck im Rahmen meiner ethnografischen Forschung zu rekonstruieren. 
Während verschiedener Aufenthalte arbeitete ich in Gesprächen und durch Beobachtungen das Zusammenwirken diverser Personenkreise - Tänzer, Hersteller und Publikum - mit den Artefakten sowie die Sichtweisen einzelner Personen/-gruppen auf die Kleidung und den Schmuck heraus. Die Zusammenführung der Daten zeigte, dass sich verschiedene Personen - ausgehend von einer zunächst politisch landesweit angetriebenen kulturellen Revitalisierung Mitte der 1990er-Jahre - intensiv mit der Herstellung und Nutzung einiger Artefaktegruppen beschäftigten, und die Tanzkleidungs- und -schmuckstücke zu unterschiedlichen Anlässen in Erscheinung traten. Diese konnten etwa sakral, rituell und profan sowie gemeinschaftsstiftend und abgrenzend sein und stellten sich auf lokaler bis internationaler Ebene als vielseitige und mitunter divergierende kastom-Konfigurationen dar. Im Jahr 2011 etwa hatte eine Gruppe von Frauen und Männern sogar eigens für die Vermarktung ,traditioneller Artefakte und Tänze eine Assoziation gebildet und war als Repräsentantin zunächst der Provinz Temotu und später auch des Nationalstaates der Salomonen auf (inter-)nationalen Festivals im Pazifik aufgetreten. So unterschiedlich die individuellen Intentionen waren, gemeinsam war allen Beteiligten der Rückgriff auf weitestgehend natürliche Materialien sowie die Wiederauflage ,traditioneller ${ }^{6}$ Designs. Hatten die wenigen verbliebenen Produzenten bis in die 1980er-Jahre mit zu der Zeit ,neuen` Materialien wie Keramikkacheln und Kunststoffen experimentiert, betrachteten sie bzw. die nachwachsende Generation seit den 2000erJahren diese nun als, fremde‘ Materialien und sahen von einer weiteren Verwendung ab.

So stellten sich die Fragen, warum die Produzenten die Materialitäten der Artefakte thematisierten, über welche Eigenschaften (,Essenzen $\left.{ }^{\circ}\right)$ Letztere verfügten, die für manche Personen auf Ndendö anscheinend relevant waren und ihr Handeln beeinflussten. Letztlich wollte ich untersuchen, was die Tanzkleidung und der -schmuck auf Ndendö bewirkten, wie sie (zusammen mit den Menschen) agierten .

Eine Möglichkeit, ,aus den Dingen heraus, durch sie zu denken‘ (HENARE et al. 2007a), erforderte, die Artefakte als den Menschen gegenüber gleichwertige bzw. gleichberechtigte ,Wesen`zu begreifen (LATOUR 2008). Die handlungsorientierte Akteur-Netzwerk-Theorie (LAW 1992; LATOUR 2005; CALLON 2006; LATOUR 2014) erwies sich für meine Arbeit als geeignetes Gerüst, die Beziehungen zwischen den Artefakten und Menschen, die ich, dem Ansatz entsprechend, beide gleichermaßen als heterogene Aktanten bezeichne, symmetrisch $^{`} \mathrm{zu}$ analysieren. Die Erkenntnis, dass die Tanzkleidung und der -schmuck im Sinne dieses Ansatzes gleichzeitig Aktanten in Netzwerken und eigene Akteur-Netzwerke waren, bereicherte und erschwerte zugleich die Analyse. Die Artefakte erschienen in diversen Konfigurationen von ,kastom ${ }^{6}$ - meist als zentrale Aktanten der heterogenen Entität ,nelo-Tänzer ${ }^{6}$ im ,nelo-Tanz', aber eben nicht ausschließlich - und moderierten, operationalisierten und ,waren' selber komplexe Beziehungen. Um die Artefakte zu verstehen, musste ich untersuchen, was sie taten bzw. was sie bewirkten (LATOUR 2014: 16, 21). Zu Analysezwecken trennte ich ein konkretes Akteur-Netzwerk aus den miteinander verwobenen und endlos ineinander verschachtelten Netzwerkverbünden heraus und beschrieb es im Sinne der ANT 
(LATOUR 2004: 69-70) möglichst dicht. Dadurch ergaben sich verschiedene Zugangsmöglichkeiten zu den Artefakten. Auf der Ebene der Akteur-Netzwerke ,nelo-Tänzer ,übersetzten' die Kleidung und der Schmuck gemeinsam mit den Menschen und anderen Aktanten die Inhalte, für die diese Netzwerke ursprünglich gebildet worden war (CALLON 2006: 135170; LAW 2006: 438-441). Mit Blick auf die Aufführung betrachtete ich, welche Effekte die im ANT-Sinne als Punktualisierungen wahrgenommenen Einheiten - bestehend aus Tänzern, Kleidung und Schmuck - hervorriefen. Da die Hersteller mit ihren Handlungen weder in den herausgelösten konkreten Akteur-Netzwerken noch in den Aufführungen selber als relevante Aktanten erschienen, habe ich ihre Beziehungen zu den Artefakten anschließend erörtert. Hierbei nutzte ich aufgrund unzureichender Informationen und zu hoher Komplexität der vielen neuen Akteur-Netzwerke einen anderen, ebenfalls handlungsorientierten Erklärungsansatz zur Beantwortung der Frage, wie sich das Wirken der Artefakte in sozialen Handlungen darstellt. Bei der Untersuchung orientierte ich mich an dem von Alfred Gell entwickelten ,Art Nexus'-Konzept, mit dessen Hilfe ich die Beziehungen zwischen den Herstellern, den Artefakten und den jeweiligen Auftraggebern/Abnehmern/Betrachtenden systematisch analysieren und verdichten konnte (GELL 1998; 2009). Dabei ermittelte ich verschiedene, durch die Artefakte hergestellte Beziehungsmuster, aus denen die jeweiligen Intentionen bzw. Absichten, etwas zu bewirken, sichtbar wurden und die Tanzkleidung und der -schmuck auch als Ausweitungen der Handlungsräume der Hersteller gesehen werden sollten.

Dieses vielseitige Vorgehen ermöglichte letztlich ein komplementäres Verständnis der Artefakte: Zum einen traten sie als substantielle Entitäten - mit ihren Fähigkeiten, Anderen Handlungsmöglichkeiten zu eröffnen, durchaus ihren menschlichen ,Komplizen` gleichwertig - in verschiedenen heterogenen, miteinander verbundenen Akteur-Netzwerken auf und trugen maßgeblich zu der Transformation der nelo-Tänzer bei. Zum anderen waren sie gleichzeitig selber heterogene Akteur-Netzwerke und moderierten und operationalisierten soziokosmische Beziehungen. Dazu zählte in besonderem Maße die nach meinem Dafürhalten wachsende Relevanz von kastom, aus dem sich wiederum ein Handlungsspielraum ergab, den die Hersteller der Artefakte mit deren Produktion taktisch und strategisch für ihre ganz eigenen Ziele nutzten.

- Tanzkleidung und -schmuck in Akteur-Netzwerken

Aufgrund des unrechtmäßigen, dem Besitzer nicht kompensierten Verzehrs eines Schweins in den 1970er-Jahren bestand für einige Familien in Ne'ele, Manao und Luepe eine Art Erbschuld gegenüber ihrem dukna. Als Sühne hatte dieser einen Festzyklus alue eingefordert. Seit dem Jahr 2000 hatten die Familien ihrem dukna zu Ehren mehrere Feste ausgerichtet. Dazu zählte auch das von mir begleitete Fest im Jahr 2011. Ausgehend von der Entstehung des heterogenen Akteur-Netzwerkes, Gedenkfeier für Jonas Kepule‘ initiierte der Sohn des Verstorbenen u. a. einen nelo-Tanz. Für dessen Umsetzung musste der Initiator viele Menschen und nicht menschliche Aktanten zusammenführen, motivieren, koordinieren und verpflichten, um zum Gelingen des Festes beizutragen. Dazu gehörten zunächst die Tänzer. 
Dies waren Männer mit bestimmten Attributen und Fähigkeiten, aufgrund derer sie lange Zeit vor dem Ereignis von anderen ausgewählt und initiiert worden waren. Neben den Männern waren insbesondere bestimmte Tanzkleidung und bestimmter -schmuck notwendig, um aus den Alltagspersonen nelo-Tänzer zu machen. Während eines mehr oder weniger festgelegten Ankleideprozesses entstanden neue Entitäten, die ,nelo-Tänzer‘. Die Untersuchung der ,Essenzen“ von den eingesetzten Materialien der Artefakte zeigte, wie substantiell diese für die neuen Einheiten waren. Die Qualitäten der genutzten Materialien ermöglichten es erst, einen gewöhnlichen Mann für die und in der Aufführung in einen nelo-Tänzer zu überführen, ihn auf dieselbe Wirkmacht wie einen dukna zu bringen, damit die Menschen unbeschadet mit diesen in Kontakt treten konnten. Dabei brachte jedes Kleidungs- und jedes Schmuckstück Attribute der eigenen Materialien ein, um diese Wandlung herbeizuführen, etwa die physische Stärke und Menschengenerationen überdauernde Langlebigkeit der fossilen Tridacna, das Schutzvermögen des Crotons, das Heilungs- und Transformationsvermögen der Gelbwurz oder des Korallenkalks, die Ästhetik aller Materialien. Nicht zuletzt ermöglichten die Stofflichkeiten (auch auf metaphorischer Ebene) Beziehungen herbeizuführen, was eigene Netzwerke bedingte. Diese den Artefakte ureigensten innewohnenden „Essenzen“ waren substantiell für das ,Werk' des Akteur-Netzwerks ,nelo-Tänzer', seiner transformativen Leistung, da die Menschen eben nicht über diese Fähigkeiten verfügten.

- Tanzkleidung und -schmuck als Akteur-Netzwerke

Die Artefakte standen aber auch für sich alleine und stellten als Aktanten wiederum eigene Akteur-Netzwerke dar. Sie verkörperten und vermittelten soziokosmische Beziehungen, aus denen sie entstanden waren bzw. die sie im Augenblick ihres Erscheinens herstellten. Manche dieser Beziehungen verbanden die Gegenwart mit der Vergangenheit, wie im Falle der tema, die, mit einem mabu versehen, Verbindungen zum Clan und den Vorfahren verkörperten. Der Nasenschmuck nelo galt als Kopie eines Schmuckstücks, das ein dukna verloren hatte, so dass es eine Verbindung zur übernatürlichen Welt herstellte. Die für die Tapa notwendigen Baumschösslinge sowie die fossilen Tridacna verbanden die Träger mit ihrem kastomLand. Die Ti-Pflanze als Steckschmuck am Rücken der Tänzer wurde als Hahnenschweif gesehen und stand für die Fähigkeit, andere anzuführen. Nelo konnten nur vollständig initiierte Männer tragen, die damit ihre erfolgreichen sozialen Beziehungen verkörperten, ohne die sie den Schmuck nicht hätten tragen können. In diesem Sinne verkörperten die Tanzkleidung und der -schmuck vielseitige Aspekte soziokosmischer Beziehungen. Die von den Tänzern im nelo-Tanz geschaffenen Effekte wären ohne die Artefakte so nicht möglich gewesen. Insbesondere ihre Langlebigkeit, ihre multiplen - weil nicht konkreten - Inhalte und die mit ihnen verbundenen Übersetzungsprozesse ermöglichten durch die fortwährenden Aufführungen eine Kontinuität soziokosmischer Beziehungen, trotz Wandels im zeitlichen Verlauf und über den lokalen Raum hinweg. 
- Revitalisierung der Artefakte und traditionellen Materialien

Die Hersteller der Tanzkleidung und des -schmucks wie auch die Tänzer, durch die die Artefakte seit jeher immer wieder aufs Neue ihre Legitimation als mehr oder weniger relevanten kastom erhielten, nutzen die unterschiedlichen Attribute der Objekte für ihre eigenen Intentionen, nicht zuletzt - wie ein Informant es sehr eindrücklich schilderte - als kurz-, mittel- und langfristige Business-Strategie. Indem die Produzenten die Artefakte immer wieder neu schufen und nutzten, führten sie kastom in seinen vielen Konfigurationen fort und passten ihn den jeweiligen Umständen an. Kastom wurde in den und mit den Artefakten verbundenen Tänzen und Festen für die lokale Bevölkerung in unterschiedlichen Aufführungen vergegenwärtigt und erneuert, ob in ,traditionellen' Glaubensvorstellungen und als Teil komplexer ,traditioneller' Sozialstrukturen, in christlichen Liturgien, auf aktuellen Festivals oder für den Tourismus. Auch wenn viele Akteure auf Ndendö kastom als eine kontinuierliche Beziehung zurück in die Vergangenheit deuteten, zeigten sich in der Realität Brüche, da die meisten Akteure in ihren jeweiligen Einflusssphären Modifizierungen vornahmen und Neuerungen einführten. Kastom wurde als sich wandelnder und durchaus nicht unumstrittener Aushandlungsraum physisch erlebbar Die Revitalisierung der Artefakte verband die Vergangenheit auf die Zukunft gerichtet mit der Gegenwart und stellte so eine weitere Neukonfiguration von kastom dar.

Als Ergebnis der vorliegenden Arbeit verstehe ich die Tanzkleidung und den -schmuck auf Ndendö als konstituierende Aktanten und Praktiken verschiedenster Akteur-Netzwerke. Im Falle der traditionellen alue-Feste sind es gerade die Artefakte, die Alltagspersonen in ,neloTänzer transformieren und den Menschen soziokosmische Beziehungen zur Vergangenheit, in der Gegenwart und für die Zukunft ermöglichen. Die Fähigkeiten der Artefakte dazu entstammen den natürlichen Materialien, aus denen sie zusammengesetzt sind - ,Essenzen“, über die Menschen nicht verfügen. Bei anderen Aufführungen bewirken die Kleidung und der Schmuck Effekte, die je nach Zusammensetzung bzw. Sichtweise des Publikums unterschiedliche, sich fortwährend wandelnde Inhalte hervorrufen. Die Artefakte ermöglichen für die einen Zugehörigkeiten zu einer ,Santa-Cruz-Kultur und -Geschichte', setzen anderen Grenzen zu dieser, sind diskursiver Raum. Für ihre Produzenten erweitern die Artefakte deren Handlungsräume, sowohl sozial als auch geografisch. Auf Ndendö sind die wenigen Hersteller vielen Personen bekannt und werden nach meinem Dafürhalten seit der kulturellen Revitalisierung von den meisten besonders wertgeschätzt. Seit dem ausgehenden 19. Jh. kommen Sammler und Wissenschaftler nach Ndendö und suchen die Hersteller auf. Mitunter beauftragen Vertreter der Provinzregierung, der Kirche oder jüngst sogar eines Unternehmens aus Papua-Neuguinea die Produzenten, Schmuck- bzw. Kleidungsstücke in größerem Umfang zu fertigen. Zudem ermöglichen die Artefakte den Mitgliedern der Graciosa Bay Nelo Association, auf Festivals zu reisen, international tätig zu werden und in die virtuelle Realität einzutreten.

Nach meinem Verständnis treten die Tanzkleidung und der -schmuck auf Ndendö aktiv in Erscheinung, nicht mit einer eigenen Intention, aber ihr Auftreten veranlasst andere zu 
Handlungen. Die Artefakte verfügen in diesem Sinne über eine eigene Handlungs- und Wirkmacht. Daher plädiere ich dafür, sie nicht als losgelöstes Konzept ,materielle oder materialisierte Kultur' einer wie auch immer anders gearteten und genannten ,Kultur' gegenübergestellt oder dem menschlichen Denken nachgelagert zu sehen. Meines Erachtens stehen die in dieser Arbeit fokussierten Artefakte in substantiellen Beziehungen zu den Menschen, sind konstituierende Praktiken und eine kulturelle Wissens- und Seinsform. Sie unterliegen kontinuierlichem Wandel und reproduzieren sich in immer wieder neuen Konfigurationen, die vielfältige, oftmals divergierende Sichtweisen nach sich ziehen und damit Ausgangspunkte, Medien und Aushandlungsfelder für lokale Diskurse darstellen.

Ich schlage daher vor, die Tanzkleidung und den -schmuck als Teil lokaler Ontologien zu verstehen und sie relational im Umfeld ihrer Akteur-Netzwerke und in ihren Beziehungen (und Nicht-Beziehungen) zueinander zu betrachten. Neben einer Verortung in Raum und Zeit konstituieren die Artefakte auf Ndendö soziokosmische Beziehungen - sie zeigen, sprechen und sind soziokosmische Realitäten. Nach meinem Verständnis verkörpert insbesondere die Rückbesinnung auf natürliche Materialien bei der Tanzkleidung und dem -schmuck, bzw. deren „Essenzen', eine Renaissance gerade dieser durch Kolonisierung und Missionierung lange Zeit unterbundenen Beziehungen und lässt die ,Subjekte' in den ,Objekten“ wieder sichtbar werden, hebt ihren vermeintlichen Gegensatz auf und zeigt die Macht der Artefakte. 


\section{Verzeichnis der Quellen}

\section{Literatur}

AKRICH, Madeleine \& Bruno LATOUR 2006: Zusammenfassung einer zweckmäßigen Terminologie für die Semiotik menschlicher und nicht menschlicher Konstellationen. In: Andréa Belliger \& David J. Krieger (Hg.): Anthology. Ein einführendes Handbuch zur Akteur-Netzwerk-Theorie. Bielefeld: transcript, 399-405.

Alasia, Sam 1989: Politics. In: Hugh Laracy (Hg.): Ples Blong Iumi. Solomon Islands, the Past Four Thousand Years. Suva, Honiara: Institute of Pacific Studies, University of the South Pacific, 137-151.

ALDRICH, Robert 2003: Colonialism and Homosexuality. New York: Routledge.

Amnesty InTERnational 2000: Solomon Islands. A Forgotten Conflict. London: Amnesty International.

APPADurai, Arjun (Hg.) 1986: The Social Life of Things. Commodities in Cultural Perspective. Cambridge: Cambridge University Press.

BAEssLer, Arthur 1900: Neue Südsee-Bilder. Berlin: A. Asher \& Co.

BANKS, Marcus 2001: Visual Methods in Social Research. London: SAGE.

Beasley, Harry Geoffrey 1936: Notes on Red Feather Money from Santa Cruz Group New Hebrides. The Fournal of the Royal Anthropological Institute of Great Britain and Ireland 66: 379-391.

- 1939: The Tamar of Santa Cruz. Ethnologia Cranmorensis 4: 27-32.

BeatTie, John Watt 1906: Fournal of a Voyage to the Western Pacific in the Melanesian Mission Yacht Southern Cross - 25. August - 10 November 1906. Hobart: Royal Society of Tasmania MSS RS.29/3 (http://anglicanhistory.org/oceania/beattie_journal1906.html, letzter Zugriff am 12.1.2014).

- o. J.: Catalogue of a Series of Photographs Illustrating the Scenery and Peoples of the Islands in the South and Western Pacific. Hobart: Beattie. 
BEgG, Neil Colquhoun 1983: Foreword. In: Ruth M. Ross Melanesians at Mission Bay. A History of the Melanesian Mission in Auckland. Historic Places Trust Publication, 18: IX-X.

BeImers, Gerry 2008: Wei Fo Raetem Olketa Wod Long Pïin. Official Pïin Spelling Guide as approved by Solomon Islands Government. Ministery of Education \& Human Resource Development. Honiara: Solomon Islands Translation Advisory Group.

BeLL, Joshua \& Haidy GeISMAR 2009: Materialising Oceania. New Ethnographies of Things in Melanesia and Polynesia. The Australian Fournal of Anthropology 20 (1): 3-27.

BeLliger, Andréa \& David J. KRIEgER 2006: Einführung in die Akteur-Netzwerk-Theorie. In: Dies. (Hg.): Anthology. Ein einführendes Handbuch zur Akteur-Netzwerk-Theorie. Bielefeld: transcript, $13-50$.

BennetT, Judith A. 1987: Wealth of the Solomons. A History of a Pacific Archipelago. 1800-1978. Pacific Islands Monograph Series, 3. Honolulu: University of Hawai'i Press.

Beran, Harry (Hg.) 1998: Oceanic and Indonesian Art. Collector's Choice. Bathurst: Crawford House Publishing in association with Oceanic Art Society.

Boerger, Brenda H. 2007: Natügu Literacy. Capturing Three Domains for Written Language Use. Language Documentation and Conservation 1(2): 126-153.

- 2009: Trees of Santa Cruz Islands and their Metaphors. Texas Linguistic Forum 53: 100-109.

Boerger, Brenda H. \& Gabrielle ZimmermanN 2012: Recognizing Nalögo and Natügu as Separate Languages. Code-Splitting in ISO 639-3. Language \& Linguistics in Melanesia 30 (1): 95-132.

Bolton, Lissant, Nicholas Thomas, Elizabeth Bonshek, Julie AdAms \& Ben BurT (Hg.) 2013: Melanesia. Art and Encounter. London: The British Museum Press.

BONSHEK, Liz 2009: A Personal Narrative of Particular Things. Feather Money from Santa Cruz. The Australian Fournal of Anthropology 20: 74-92.

BORN, Georgina 2013: Music. Ontology, Agency, Creativity. In: Liana Chua \& Mark Elliot (Hg.): Distributed Objects. Meaning and Mattering after Alfred Gell. New York u. a.: Berghahn Books, 130-154.

Bounoure, Gilles 2004: Les Bâtons de Danse des Îles de Santa Gruz et la Collection du Musée de Leipzig. Fahrbuch des Museums für Völkerkunde zu Leipzig 62: 137-154.

BRIgGS, Charles L. 1996: The Politics of Discursive Authority in Research on The ,Invention of Tradition'. Cultural Anthropology 11(4): 435-469.

BRITiSH Solomon IsLANDS 1931: British Solomon Islands Protectorate. Colonial Reports. Annual. London: H. M. S. O.

BuRT, Ben 2013: Solomon Islands. Introduction. In: Lissant Bolton et al. (Hg.): Melanesia. Art and Encounter. London: The British Museum Press, 191-195.

Gallon, Michel 2006: Einige Elemente einer Soziologie der Übersetzung. Die Domestikation der Kammmuscheln und der Fischer der St. Brieuc-Bucht. In: Andréa Belliger \& David J. Krieger (Hg.): Anthology. Ein einführendes Handbuch zur Akteur-Netzwerk-Theorie. Bielefeld: transcript, 135-174. 
ChuA, Liana \& Mark ElLiot 2013: Introduction. Adventures in the Art Nexus. In: Dies. (Hg.): Distributed Objects. Meaning and Mattering after Alfred Gell. New York u. a.: Berghahn Books, 1-24.

ChuA, Liana \& Amiria SALmond 2012 : Artefacts in Anthropology. In: Richard Fardon (Hg.): The SAGE Handbook of Social Anthropology. Bd.2. London: SAGE Publishing, $130-141$.

Cisikszentmihalyi, Mihali und Eugène Rochberg-Holton 1981: The Meaning of Things. Domestic Symbols and the Self. Cambridge u. a.: Cambridge University Press.

Codrington, Robert Henry 1891: The Melanesians. Studies in their Anthropology and Folk-Lore. Oxford: Clarendon Press.

CoIfFIER, Christian 2014: À bord de La Korrigane. Carnet de Voyage de Régine van den Broek d'Obrenan aux Nouvelles-Hébrides, aux Îles Salomon et aux Îles de l'Amirauté en 1935. Paris: Somogy éditions d'art.

CoOmBE, Florence E. 1911: Islands of Enchantment. Many-Sided Melanesia. London: Macmillan and Co.

Coote, Walter 1882: Wanderings, South and East. London: Sampson Low, Marston, Searle \& Rivington.

Constitutional ReForm Unit (o. J.): Brief Information and Update for Provincial Executives and HODs. Abridged Document. Honiara: Solomon Island Islands Government, Office of the Prime Minister \& Cabinet.

DalRymple, Alexander 1770: Historical Collection of the Several Voyages and Discoveries in the South Pacific Ocean, vol. I. Being Chiefly a Literal Translation from the Spanish Writers. London: Printed for the Author.

DALsGaARD, Steffen \& Ton OтTO 2011: From Kastom to Kalsa? Leadership, Gultural Heritage and Modernization in Manus Province, Papua New Guinea. In: Edvard Hviding \& Knut M. Rio (Hg.): Made in Oceania. Social Movements, Cultural Heritage and the State in the Pacific. Wantage: Sean Kingston, 141-160.

DavenPORT, William 1962: Red Feather Money. Scientific American 206 (3): 94-104.

— 1964a: Notes on Santa Cruz Voyaging. Polynesian Society fournal 72 (3): 134-142.

— 1964b: Social Structure of Santa Cruz Island. In: Ward H. Goodenough (Hg.): Explorations in Cultural Anthropology. New York: McGraw-Hill Book, 57-93.

- 1968a: Social Organisation Notes on the Southern Santa Cruz Islands: Utupua and Vanikoro. Baessler-Archiv NF 16: 207-275.

- 1968b: Social Organisation Notes on the Northern Santa Cruz Islands: The Duff Islands (Taumako). Baessler-Archiv NF 16: 137-205.

- 1969: Social Organisation Notes on the Northern Santa Cruz Islands: The Main Reef Islands. Baessler-Archiv NF 17: 151-243.

- 1975: Lyric Verse and Ritual in the Santa Cruz Islands. Expedition 18 (1): 39-47.

- 1990: The Figurative Sculpture of Santa Cruz Island. In: Alan Hanson \& Louise Hanson (Hg.): Art and Identity in Oceania. Honolulu: University of Hawai'i Press, 98-110. 
- 2005: Santa Cruz Island Figure Sculpture and its Social and Ritual Contexts. Philadelphia: University of Pennsylvania Museum of Archaeology and Anthropology.

De Labillardière, Jacques Julien Houtou 1800: Relation du Voyage à la Recherche de La Perouse vol. II. Paris: Jansen.

De Tolna, Rodolphe Festetics 1903: Chez les Cannibales. Huit Ans De Croisière Dans L' Océan Pacifique à Bord Du Yacht, Le Tolna'. Paris: Plon-Nourrit.

DevesI, Sir Baddeley 1992: Independence or Dependence. In: Ron Crocombe \& Esau Tuza (Hg.): Independence, Dependence, Interdependence. The First 10 Tears of Solomon Islands Independence. Honiara: Government Printing Press, 1-6.

Dewar, James Cumming 1892: Voyage of the Nyanza R. N. Y. C. Edinburgh: William Blackwood and Sons.

Dillon, Peter 1829: Narrative and Successful Result of a Voyage in the South Seas, vol II. London: Hurst, Chance \& Co.

Dinnen, Sinclair \& Stewart FIRTH (Hg.) 2008: Politics and State Building in Solomon Islands. Canberra: ANU E Press and Asia Pacific Press.

Doherty, Moira Winifrid 2007: Post-Lapita Developments in the Reef-Santa Cruz Islands, Southeast Solomon Islands. PhD Thesis, University of Auckland (https://researchspace.auckland. ac.nz/handle/2292/4240, letzter Zugriff am 21.7.2012).

D’URville, Jules Sébastian César Dumont 1833: Voyage de la Corvette L'Astrolabe. Exécuté par Ordre du Roi. Pendant les Années 1826-1827-1828-1829, vol. V. Paris: Tastu.

East, Roger \& Richard J. ThOmas 2003: Profiles of People in Power. The World's Government Leaders. London: Europa Publications Limited.

Edge-Partington, James \& Charles Heape 1890: An Album of the Weapons, Tools, Ornaments, Articles of Dress of the Natives of the Pacific Islands. Herausgegeben als Privatausgabe von J. Edge-Partington und C. Heape.

FoAnAOTA, Lawrence 1989: Social Change. In: Hugh Laracy (Hg.): Ples Blong Iumi. Solomon Islands, the Past Four Thousand Years. Suva, Honiara: Institute of Pacific Studies, University of the South Pacific, 68-72.

ForRest, Actaeon Edward C. 1894: Particulars Concerning Santa Cruz District. In: Inwards Correspondence 1877-1908. Record No. 4137, File No. 17/1895. 1877-1978 MSS \& Archives 2003/1. Western Pacific Archives, Special Collections, University of Auckland Library.

Foster, Robert John 1992: Commoditization and the Emergence of Kastom as a Cultural Category. A New Ireland Case in Comparative Perspective. Oceania (Special Issue) 62 (4): 284-294.

- 1995: Social Reproduction and History in Melanesia. Mortuary Ritual, Gift Exchange, and Custom in the Tanga Islands. Cambridge: Cambridge University Press.

Foy, Wilhelm 1916: Zur Geschichte der Tanzkeulen von den Santa-Cruz-Inseln. Ethnologica 2: 215-238. 
FraenKeL, Jon 2004: The Manipulation of Custom. From Uprising to Intervention in the Solomon Islands. Wellington: Victoria University Press.

Fugui, Leslie \& Simeon Butu 1989: Religion. In: Hugh Laracy (Hg.): Ples Blong Iumi. Solomon Islands, the Past Four Thousand Years. Suva, Honiara: Institute of Pacific Studies, University of the South Pacific, 73-93.

GeISMAR, Haidy 2011: ,Material Culture Studies` and Other Ways to Theorize Objects. A Primer to Regional Debate. Comparative Studies in Society and History 53 (1): 210-218.

GELL, Alfred [1992] 2009: The Technology of Enchantment and the Enchantment of Technology. In: Fiona Candlin \& Raiford Guins (Hg.): The Object Reader. London u. a.: Routledge, 208-228.

- 1998: Art and Agency. An Anthropological Theory. Oxford: Oxford University Press.

GiLLETT, Joyce 1939: ,Dukas' of Santa Cruz. MAN (39): 153-154.

Girieud, J. \& H. Herrensahmidt 1898: La Nouvelle-Calédonie, Suivie d'un Aperçu sur les Nouvelles-Hébrides, les Iles Santa-Cruz et les Swallow. Rouen: J. Girieud et Cie.

Glaser, Barney G. \& Anselm STRAuss (Hg.) 2008: Grounded Theory. Strategien qualitativer Forschung. 1. Nachdr. der 2. korrigierten Aufl. Bern: Huber.

GraebNER, Fritz Robert 1909: Völkerkunde der Santa-Cruz-Inseln. Ethnologica 1: 71-184.

Great Britain. Foreign AND COMMONWEALTH OFFICE 1974: BSI Protectorate 1974. London: H. M. S. O.

Green, Roger 1991: Near and Remote Oceania. Disestablishing,Melanesia' in Culture History. In: A. Pawley (Hg.): Man and a Half. Essays in Pacific Anthropology and Ethnobiology in Honour of Ralph Bulmer. Auckland: The Polynesian Society, 491-502.

GuPPY, Henry B. 1887: The Solomon Islands and Their Natives. London: Swan Sonnenschein, Lowrey \& Co.

HaHN, Hans Peter 2005: Materielle Kultur. Eine Einfuihrung. Berlin: Dietrich Reimer.

- 2015 (Hg.): Vom Eigensinn der Dinge. Berlin: Noefelis Verlag.

HANDLER, Richard \& Jocelyn LinNEKIN 1984: Tradition, Genuine or Spurious. Fournal of American Folklore 97: 273-290.

HARPER, Douglas 2000: Fotografien als sozialwissenschaftliche Daten. In: Uwe Flick, Ernst von Kardorff \& Ines Steinke (Hg.): Qualitative Forschung. Ein Handbuch. Rowohlts Enzyklopädie, Rowolth, 402-416.

- 2002: Talking about Pictures. A Case for Photo Elicitation. Visual Studies 17 (1): 13-26.

Harris, Clare \& Michael O'Hanlon 2013: The Future of the Ethnographic Museum. Anthropology Today 29 (1): 8-12.

HAUSER-SCHÄUBLIN, Brigitta 2002: Gender. Verkörperte Feldforschung. In: Hans Fischer (Hg.): Feldforschungen: Erfahrungsberichte zur Einführung, 2. Aufl., Neufassung. Berlin: Dietrich Reimer, 73-100.

- 2012: The Diversion of the Village Gods. A Criminal Turn in the Biography of Balinese Copperplate Inscriptions. Bijdragen tot de Taal-, Land- en Volkenkunde (BKI) 168-1: 74-99. 
Henare [Salmond], Amiria, Martin HolbraAd \& Sari WAStell (Hg.) 2007a: Thinking Through Things. Theorising Artefacts Ethnographically. London, New York: Routledge.

Henare [Salmond], Amiria, Martin HolbraAd \& Sari Wastell 2007b: Introduction. Thinking Through Things. In: Dies. (Hg.): Thinking Through Things. Theorising Artefacts Ethnographically. London, New York: Routledge, 1-31.

Hicks, Dan 2010: The Material-Cultural Turn. Event and Effect. In: Dan Hicks \& Mary C. Beaudry (Hg.): The Oxford Handbook of Material Culture. Oxford: Oxford University Press, 25-98.

High Commission fOr Western PaGific Islands 1886: Australian Station. New Guinea and Solomon Islands, 1886. WPHC 8/III/15. 1877-1978 MSS \& Archives 2003/1. Western Pacific Archives, Special Collections, University of Auckland Library.

- 1898-1903: Despatches from the High Commissioner for the Western Pacific to the Resident Commissioner, British Solomon Islands Protectorate. WPHC 27/X/1. 1877-1978 MSS \& Archives 2003/1. Western Pacific Archives, Special Collections, University of Auckland Library.

Hobsbawm, Eric \& Terence Ranger 1983: The Invention of Tradition. Cambridge: Cambridge University Press.

HodDer, Ian (Hg.) 1989: The Meaning of Things. Material Culture and Symbolic Expression. One World Archaelogy 6. London u. a.: Unwin Hyman.

HÖRNING, Karl H. 2015: Was fremde Dinge tun. Sozialtheoretische Herausforderungen. In: Hans Peter Hahn (Hg.): Vom Eigensinn der Dinge. Berlin: Noefelis, 163-176.

IRvine, Lucy 2000: Faraway. London: Doubleday a Devision of Transworld Publishers.

Joest, Wilhelm 1897: Tagebuch XXIV. MS, Köln: Privatbesitz Ludwig von Rautenstrauch.

Johansen, Ulla 1992: Materielle oder materialisierte Kultur. Zeitschrift für Ethnologie 117: $1-15$.

Jolly, Margaret \& Nicholas Thomas (Hg.) 1992: The Politics of Tradition in the Pacific. Oceania (Special Issue) 62 (4): 241-354.

KeEsING, Roger M. 1993: Kastom Re-examined. Anthropological Forum 6 (4): 587-596.

KeEsing, Roger M. \& Robert Tonkinson (Hg.) 1982: Reinventing Traditional Culture. The Politics of Kastom in Island Melanesia. Mankind (special issue) 13 (4): 297-399.

KocH, Gerd 1971: Materielle Kultur der Santa-Cruz-Inseln unter besonderer Berücksichtigung der RiffInseln. Berlin: Museum für Völkerkunde.

Kolshus, Thorgeir 2013: Codrington, Keesing, and Central Melanesian mana. Two Historic Trajectories of Polynesian Cultural Dissemination. Oceania 83 (3): 316-327.

KÜCHLER, Susanne 2015: Wenn Dinge Netzwerke sind. In: Hans Peter Hahn (Hg.): Vom Eigensinn der Dinge. Für eine neue Perspektive auf die Welt des Materiellen. Berlin: Neofelis, 127-145.

LATOUR, Bruno [1991] 2008: Wir sind nie modern gewesen. Versuch einer symmetrischen Anthropologie. Frankfurt a. M.: Suhrkamp. (Original: Nous n'avons pas jamais été modernes. Essai d'anthroplogie symétrique. Paris). 
- 2004: On using ANT for studying Information Systems. A (somewhat) Socratic Dialogue. In: Chrisanthi Avgerou, Claudio Ciborra \& Frank Land (Hg.): The Social Study of Information and Communication Technology. Innovation, Actors, and Contexts. Oxford: Oxford University Press, 62-76.

- 2005: Reassembling the Social. An Introduction to Actor-Network-Theory. Oxford, New York: Oxford University Press.

— 2006: Die Macht der Assoziation. In: Andréa Belliger \& David J. Krieger (Hg.): Anthology. Ein einführendes Handbuch zur Akteur-Netzwerk-Theorie. Bielefeld: transcript, 195-212.

- 2010: Networks, Societies, Spheres. Reflections of an Actor-Network Theorist (http://www.brunolatour.fr/sites/default/files/121-CASTELLS-GB.pdf, letzter Zugriff am 18.5.2016).

- 2014: How Better to Register the Agency of Things. Tanner Lectures, Yale (http://www.brunolatour.fr/sites/default/files/137-YALE-TANNER.pdf, letzter Zugriff am 16.2.2015).

LAW, John 1992: Notes on the Theory of the Actor-Network. Ordering, Strategy, and Heterogeneity. Systems Practise 5 (4): 379-393.

LEACH, James 2007: Differentiation and Encompassemnt. A Critique of Alfred Gell's Theory of the Abduction of Creativity. In: Henare [Salmond] et al. (Hg.): Thinking Through Things. Theorising Artefacts Ethnographically. London, New York: Routledge, 167-188.

LE RoY, Katy 2011: Public Participation in Constitution-Making. The Pacific Islands. Genf: Interpeace.

Lindstrom, Lamont \& Geoffrey M. White 1993: Introduction. Custom Today. Anthropological Forum 6 (4): 467-473.

- 1994: Cultural Policy. An Introduction. In: Lamont Lindstrom \& Geoffrey M. White (Hg.): Culture, Kastom, Tradition. Developing Cultural Policy in Melanesia. Suva: Institute of Pacific Studies, University of The South Pacific, 1-18.

LuEB, Oliver 2008: Materielle Kultur und Symbolik. Transformation von Ahnenpfählen in Asmat, Westpapua. Köln: Unveröffentlichte Magisterarbeit.

- 2013: Tapa auf Santa Cruz. Kastom und Bisnis, Wir und die Anderen (deutsch/englisch). In: Peter Mesenhöller \& Oliver Lueb (Hg.): Made in Oceania. Tapa. Kunst und Lebenswelten. Ethnologica NF 29: 160-175.

Mamaloni, Solomon 1992: The Road to Independence. In: Ron Crocombe \& Esau Tuza (Hg.): Independence, Dependence, Interdependence. The First 10 Years of Solomon Islands Independence. Honiara: Government Printing Press, 7-18.

MARKHAM, Albert Hastings 1872: The New Hebrides and Santa Cruz Groups. Fournal of the Royal Geographical Society of London 42: 213-243.

- 1873: The Cruise of the ,Rosario'. London: Sampson Low, Marston, Low, and Searle.

Markham, Clements Robert (Hg.) 1904: The Voyages of Pedro Fernandez de Quirós. 1595 to 1606, 2. Serie, vol I. London: Haklyut Society.

Ma COY, Michael 2006: Solomon Islands: A South Seas fourney. Munda: Zipolo Habu.

ME'ESA, Freddy (Hg.) 2009: Santa Cruz [Nende] Traditional Artifacts Museum. MS, Ndendö: Privatbesitz. 
- 2011: Graciosa Bay Nelo Association. Submission to Participate in the South Pacific Arts Festival in Honiara 2012. MS, Ndendö: Privatbesitz.

Miller, Daniel 1987: Material Culture and Mass Consumption. Oxford: Blackwell.

- 1998: Material Cultures. Why some Things Matter. London: Routledge.

- 2005: Materiality. An Introduction. In: Daniel Miller (Hg.): Materiality. Durham und London: Duke University Press, 1-50.

- 2008: The Comfort of Things. London: Polity Press.

— 2009: Stuff. London: Polity Press.

MiLLER, Daniel \& Christopher TILLEY (Hg.) 1996: Introduction. Fournal of Material Culture 1 (1): 5-14.

Montgomery, Charles [2004] 2006: The Shark God. Encounters with Ghost and Ancestors in the South Pacific. Harper Collins e-books. (Original: The Last Heathen. Vancouver, BC: Douglas \& McIntyre.)

MoOre, Glive 2004: Happy Isles in Crisis: The Historical Causes for a Failing State in Solomon Islands, 1998-2004. Canberra: Asia Pacific Press.

- 2009: Pacific Islanders in Australia. A Visual History, 1860s-1930s. Solomon Islands National Museum Occasional Paper No. 1. Brisbane: The University of Queensland.

MoskO, Mark S. 2002: The Objectivation of Tradition among North Mekeo. Oceania 73 (2): 89-109.

MORGain, Rachel \& John P. TAYLOR 2015: Transforming Relations of Gender, Person, and Agency in Oceania. Oceania 85 (1): 1-9.

NEICH, Roger 2009: James Edge-Partington (1854-1930). An Ethnologist of Independent Means. Records of the Auckland Museum 46: 57-110.

NeIch, Roger \& Mick Pendergrast (Hg.) 1997: Traditional Tapa. Textiles of the Pacific. London: Thames and Hudson.

O'Ferrall, Rev. W. C. 1908: Melanesia. Santa Cruz and the Reef Islands. Westminster, S. W.: The Melanesian Mission, The Church House. In: Project Canterbury, transkribiert von Terry Brown (http://anglicanhistory.org/oceania/oferrall_santacruz1908/, letzter Zugriff am 11.10.2009).

- 1922: The Depopulation of Santa Cruz and the Reef Islands. In: W. H. R. Rivers (Hg.): Essays on the Depopulation of Melanesia. Cambridge: Cambridge Universiy Press, 67-68.

OfFice of THE High COMmissioner FOR THE Western PACIFIC 1898a: British Protectorate over the Bellona, Stewart, and Renell Islands, the Santa Cruz and Reef Groups, and the Island of Tucopia. Suva: Government Printer.

- 1898b: British Protectorate over the Anuda or Cherry Island, Fataka or Mitre Island, Trevannion or Temotu Island, and over the Duff or Wilson Group. Suva: Government Printer.

OTTO, Ton 1992: The Ways of Kastam. Tradition as Category and Practise in a Manus Village. Oceania (Special Issue) 62 (4): 264-283. 
- 2011: Inventing Traditions and Remembering the Past in Manus. In: Elfriede Hermann (Hg.): Changing Contexts, Shifting Meanings. Transformations of Cultural Traditions in Oceania. Honolulu: University of Hawai'i Press, 157-173.

Otto, Ton \& Poul Pedersen 2005: Disentangling Traditions. Culture, Agency and Power. In: Dies. (Hg.): Tradition and Agency. Tracing Cultural Continuity and Invention. Aarhus: Aarhus University Press, 11-49.

Pedersen, Morten Axel 2007: Talismans of Thought. Shamanist Ontologies and Extended Cognition in Northern Mongolia. In: Henare [Salmond] et al. (Hg.): Thinking Through Things. Theorising Artefacts Ethnographically. London, New York: Routledge, 141-166.

PRICE, Charles \& Elizabeth BAKER, 1976: Origins of Pacific Island Labourers in Queensland, 1863-1904. A Research Note. Fournal of Pacific History 11 (1-2): 106-121.

QueEnsLand 1895: Enclosure in No. 26. Supplement to the Queensland Government Gazette, Friday, 13th October 1893. In: Queensland. Further Correspondence Relating to Polynesian Labour in the Colony of Queensland, 62-3.

RAnger, Terence 2005: Postscript. In: Ton Otto \& Poul Pedersen (Hg.): Tradition and Agency. Tracing Cultural Continuity and Invention. Aarhus: Aarhus University Press, 327-338.

RAnNIE, Douglas 1912: My Adventures Among South Sea Cannibals. London: Seeley, Service \& Co.

RICHARDS, Rhys 2013: Headhunters Black and White. Three Collectors in the Western Solomon Islands 1893 to 1914. Wellington: Paremata Press.

RIO, Knut M. \& Edvard Hviding 2011 : Introduction. Pacific Made. In: Edvard Hviding \& Knut M. Rio (Hg.): Made in Oceania. Social Movements, Cultural Heritage and the State in the Pacific. Wantage: Sean Kingston, 5-29.

RIVERs, William Halse Rivers 1914: The History of the Melanesian Society, vol. I. Cambridge: Cambridge University Press.

Robson, Robert William (Hg.) 1950: The Pacific Islands Yearbook 1950. Sydney, Suva: Pacific Publications.

Ross, Ruth Miriam 1983: Melanesians at Mission Bay. A History of the Melanesian Mission in Auckland. Historic Places Trust Publication, 18. Wellington: Historic Places Trust.

RukiA, Alec 1989: Digging. In: Hugh Laracy (Hg.): Ples Blong Iumi. Solomon Islands, the Past Four Thousand Years. Suva, Honiara: Institute of Pacific Studies, University of the South Pacific, 1-15.

Samida, Stefanie, Manfred K. H. EgGert \& Hans Peter Hahn (Hg.) 2014: Handbuch Materielle Kultur. Bedeutungen, Konzepte, Disziplinen. Stuttgart, Weimar: J. B. Metzler.

SAMOU, Salome 2014: Santa Cruz Feather-Money. In: Ben Burt \& Lissant Bolton (Hg.): The Things We Value. Culture and History in Solomon Islands. Canon Pyon: Sean Kingston Publishing, 15-24.

SchmelTZ, Johannes Dietrich Eberhard \& Rudolph KRAUSE (Hg.) 1881: Die ethnographischanthropologische Abtheilung des Museum Godeffroy in Hamburg. Ein Beitrag zur Kunde der SüdseeVölker. Hamburg: L. Friederichsen \& Co. 
SHEPPARD, Peter J. \& RiChARD Walter 2006: A Revised Model of Solomon Islands Culture History. The Journal of the Polynesian Society 115: 47-76.

Solomon Island Government 2011: Census 2009. Basic Tables and Census Description. Statistical Bulletin 06/2011.

Solomon Islands Constitutional Reform Projects 2003: Workshop Paper 5. MS, Ndendö: Privatbesitz.

Solomon Times 2011: Investigation Continues over Grueling Death. Solomon Times Online (http://www.solomontimes.com/news.aspx?nwID=6451, letzter Zugriff am 16.9.2012).

- 2012: Vanuatu and Temotu Trade Agreement Signed. Solomon Times Online, (http://www.solomontimes.com/news.aspx?nwID=6383, letzter Zugriff am 16.9.2012).

SPEISER, Felix [1913] 1924: Südsee, Urwald, Kannibalen, 2. Auflage. Stuttgart: Strecker und Schröder. (Original: Leipzig).

- 1915: Die Ornamentik von Santa Cruz. In: Johannes Ranke \& Georg Thilenius (Hg.): Archiv für Anthropologie NF 13: 323-334.

- 1916: Völkerkundliches von den Santa-Cruz-Inseln. Ethnologica 2: 153-213.

SpIElmann, Katherine A. 2002: Feasting, Craft Specialization, and the Ritual Mode of Production in Small-Scale Societies. American Anthropologist 104 (1): 195-207.

StePhen, Ann (Hg.) 1993: Pirating the Pacific. Images of Trade, Travel \& Tourism. Haymarket, NSW, Australia: Powerhouse.

Strathern, Marilyn 1979: The Self in Self-Decoration. Oceania 49 (4): 241-257.

- 1988: The Gender of the Gift. Problems with Women and Problems with Society in Melanesia. Berkeley: University of California Press.

- 1990: Artifacts of History. Events and the Interpretation of Images. In: Jukka Siikala (Hg.): Culture and History in the Pacific. Transactions of the Finnish Anthropological Society 27: $25-44$.

- 1996: Cutting the Network. The Journal of the Royal Anthropological Institute of Great Britain and Ireland NF 2 (3): 517-535.

- 2013: Learning to see in Melanesia. Lectures Given in the Department of Social Anthropology, Cambridge University, 1993-2008. HAU Masterclass series 2. HAU-N. E. T. Network of Ethnographic Theory (http://haubooks.org/ viewbook/masterclass2/, letzter Zugriff am 16.3.2015).

STRAuss, Anselm \& Juliet CORBIN 1996: Grounded Theory. Grundlagen Qualitativer Sozialforschung. Weinheim: Psychologie Verlags Union.

Temotu Provincial Submission 2003. MS, Ndendö: Privatbesitz.

The Melanesian Mission 1880: Reports and Other Papers of the Melanesian Mission in New Zealand. Auckland: The Melanesian Mission.

ThileniUs, Georg Christian 1902: Ethnographische Pseudomorphosen in der Südsee. Teil 2. Globus 81 (9): 133-140.

Thomas, Nicholas 1998: Foreword. In: Alfred Gell: Art and Agency. An Anthropological Theory. Oxford: Oxford University Press, i-xiii. 
- 2012: Introduction. In: Peter Brunt \& Nicholas Thomas (Hg.): Art in Oceania. A New History. London: Thames \& Hudson Ltd., 11-23.

Tilley, Christopher Y. (Hg.) 1990: Reading Material Culture. Structuralism, Hermeneutics and PostStructuralism. Oxford u. a.: Blackwell.

Tilley, Christopher Y., Webb Keane, Susanne KÜChler, Michael Rowlands \& Patricia SPYER 2006: Introduction. In: Dies. (Hg.): Handbook of Material Culture. London: SAGE Publications, 1-6.

Timmer, Jaap 2008: Kastom and Theocracy. A Reflection on Governance from the Uttermost Part of the World. In: Sinclair Dinnen \& Stewart Firth (Hg.): Politics and State Building in Solomon Islands. Canberra: ANU E Press and Asia Pacific Press, 194-212.

Tonkinson, Robert 1993: Understanding, Tradition` - Ten Years After. Anthropological Forum 6 (4): 597-606.

- 2000: ,Tradition“ in Oceania and Its Relevance in a Fourth World Context (Australia). FOLK 42: 169-195.

Tropa, Ataban M. (Hg.) 2009: Part A. Nendr Region Report. MS, Ndendö: Privatbesitz.

VOIROL, Beatrice 2011: Sich windende Wege. Ethnografie der Melo-Schnecke in Papua, Indonesien. Göttinger Beiträge zur Ethnologie 4. Göttingen: Universitätsverlag.

VON Rautenstrauch, Ludwig Theodor 2010: Grußwort. In: Jutta Engelhard \& Klaus Schneider (Hg.): Der Mensch in seinen Welten. Das neue Rautenstrauch-foest-Museum - Kulturen der Welt. Ethnologica NF 28: 6-7.

Wagner, Roy 1991: The Fractal Person. In: Marilyn Strathern \& Maurice Godelier (Hg.): Big Men and Great Men. Personifications of Power in Melanesia. Cambridge: Camebridge University Press, 159-173.

WAite, Deborah B. 1983: Art of the Solomon Islands. Geneva: Musée Barbier-Mueller.

- 1987: Artefacts from the Solomon Islands in the Julius L. Brenchley Collection. London: The British Museum Publications Limited.

Were, Graeme 2005: Pattern, Efficacy and Enterprise: On the Fabrication of Connections in Melanesia. In: Susanne Küchler \& Daniel Miller (Hg.): Clothing as Material Culture. Oxford, New York: Berg Publishers, 159-174.

- 2015: Coming together. Kastom, Religiosity and Scale-Making in New Ireland, Papua New Guinea. In: Edvard Hviding \& Geoffrey White (Hg.): Pacific Alternatives. Cultural Politics in Contemporary Oceania. Canon Pyon: Sean Kingston Publishing, 200-217.

White, Geoffrey M. 1993: Three Discourses of Custom. Anthropological Forum 6 (4): 475-494.

- 2015: Feasts, Festivals and Phantoms. The Predicament of Cultural Policy in a Solomon Islands Society. In: Edvard Hviding \& Geoffrey White (Hg.): Pacific Alternatives. Cultural Politics in Contemporary Oceania. Canon Pyon: Sean Kingston Publishing, 70-92.

White, Geoffrey \& Edvard Hviding 2015: Introduction. Pacific Alternatives in a Global Context. In: Edvard Hviding \& Geoffrey White (Hg.): Pacific Alternatives. Cultural Politics in Contemporary Oceania. Canon Pyon: Sean Kingston Publishing, 1-23. 
WILSON, Ashley 2009: Solomon Islands Sojourn. A Volunteer's Story of Life and Development on Remote Pacific Islands. New Zealand: Alliance.

WoODFORD, Charles Morris 1898: Santa Cruz and Reef Islands: Incorporation in the British Protectorate. In: Inwards Correspondence 1877-1908. Record No. 5902, File No. 233/1898. 1877-1978 MSS \& Archives 2003/1. Western Pacific Archives, Special Collections, University of Auckland Library.

WOODWARD, Ian 2007: Understanding Material Culture. London u. a.: SAGE Publishing.

Yen, Douglas Ernest 1974: Arboriculture in the Subsistence of Santa Cruz. Solomon Islands. Economic Botany 28 (3): 247-284.

- 1976: Inland Settlement on Santa Cruz. The Royal Society of New Zealand Bulletin 11: 203-224.

Zeitschrift für Ethnologie 1993118 (1) Diskussion zu Ulla Johansens Aufsatz 1992: Materielle oder materialisierte Kultur. Zeitschrift für Ethnologie 117: 1-15.

\section{Bibliografien}

EDRIDGE, Sally 1985: Solomon Islands Bibliography to 1980. Suva u.a: Institute of Pacific Studies. The University of the South Pacific.

Krauss, N. L. H. 1969: Bibliography of the Santa Cruz Islands, Western Pacific. MS, Honolulu.

\section{Filme}

KOCH, Gerd 1972a: Melanesier (Santa-Cruz-Inseln, Ndende) Herstellen von Rindenbaststoff. Länge: 9 min. In: G. Wolf (Produzent/Hg.) Encyclopedia Cinematographica E 1400/1971. Göttingen: Institut für den wissenschaftlichen Film.

— 1972b: Melanesier (Santa-Cruz-Inseln, Ndende) Herstellen von Federgeld. Länge: 10 1⁄2 min. In: G. Wolf (Produzent/Hg.) Encyclopedia Cinematographica E 1400/1971. Göttingen: Institut für den wissenschaftlichen Film.

— 1972c: Melanesier (Santa-Cruz-Inseln, Ndende) Sago-Gewinnung. Länge: 12 1/2 min. In: G. Wolf (Produzent/Hg.) Encyclopedia Cinematographica E 1402/1971. Göttingen: Institut für den wissenschaftlichen Film.

- 1972d: Melanesier (Santa-Cruz-Inseln, Riff-Inseln) Weben. Länge: 13 min. In: G. Wolf (Produzent/Hg.) Encyclopedia Cinematographica E 1429/1971. Göttingen: Institut für den wissenschaftlichen Film.

— 1972e: Melanesier (Santa-Cruz-Inseln, Ndende) Anlegen des Tanzschmuckes und Tänze. Länge: 13 min. In: G. Wolf (Produzent/Hg.) Encyclopedia Cinematographica E 1450/1971. Göttingen: Institut für den wissenschaftlichen Film.

\section{Internetquellen}

http://anglicanhistory.org/oceania/cwilson/report1902.html, letzter Zugriff am 23.4.2016. http://collections.quaibranly.fr/\#eca06085-14af-4564-b984-918faa393472, letzter Zugriff am 1.9.2014. 
http://collections.tepapa.govt.nz/search?searchTerm=Pacific $\% 20$ Cultures $\% 20$ collection \&scope=all, letzter Zugriff am 3.4.2016

http://collections.tepapa.govt.nz/Topic/1330, letzter Zugriff am 3.4.2016

http://www.alienor.org/collections-des-musees/fiche-personne-27586-festetics-de-tolnarodolphe, letzter Zugriff am 22.4.2016.

http://www.aucklandmuseum.com/collections-research/collections/about-our-collections, letzter Zugriff am 17.4.2016.

http://www.austlii.edu.au/au/journals/AltLawJl/2002/78.html, letzter Zugriff am 23.9.2012.

http://www.britishmuseum.org/about_us/the_museums_story/general_history.aspx, letzter Zugriff am 22.4.2016.

http://www.britishmuseum.org/research/collection_online/collection_object_details.

aspx?objectId=484450\&partId=1\&searchText=Oc1991,08.1\&page=1, letzter Zugriff am 26.7.2014.

http://www.britishmuseum.org/research/collection_online/search.aspx?place=9022,

Sucsbegriff: Santa Cruz Islands Oceania Melanesia Solomon Islands, Zugriff am 2.8.2014.

http://www.britishmuseum.org/research/projects/melanesia_project.aspx, letzter Zugriff am 30.9.2012.

http://www.dr-bernhard-peter.de/Apotheke/seite179.htm, letzter Zugriff am 9.9.2015.

http://www.ethnologue.com/language/pis, letzter Zugriff am 16.2.2013.

http://www.pacificarts.org/node/382, letzter Zugriff am 30.9.2012.

http://www.ramsi.org/about-ramsi/, letzter Zugriff am 30.5.2016

http://www.spektrum.de/lexikon/physik/welle-teilchen-dualismus/15525, letzter Zugriff am 18.5.2016.

http://www.tepapa.govt.nz/AboutUs/history/Pages/default.aspx, letzter Zugriff am 26.10.2014.

http://www.un.org/Depts/OHRM/salaries_allowances/salaries/solomon.htm, letzter Zugriff am 16.5.2016.

http://www.usp.ac.fj/index.php?id=salary_scales, letzter Zugriff am 16.5.2016.

http://www.uss-hornet.org/history/wwii/santa_cruz. shtml, letzter Zugriff am 5.9.2014.

http://www.vatican.va/archive/hist_councils/ii_vatican_council/documents/vat-ii_de-

cree_19651207_ad-gentes_ge.html, letzter Zugriff am 18.07.2014.

http://www.visitsolomons.com.sb/about-solomons/people-and-culture, letzter Zugriff am 22.12.2015.

http://pidp.org/archive/2003/May/05-02-17.htm, letzter Zugriff am 17.7.14.

https://en.wikipedia.org/wiki/Santa_Cruz_Islands\#/media/File:Map_of_the_Santa_

Cruz_Islands_(Solomon_Islands).png, letzter Zugriff am 26.5.2016.

https://www.facebook.com/groups/666260060053319/, letzter Zugriff am 6.1.2016.

https://www.facebook.com/groups/temotu.pf/, letzter Zugriff am 6.1.2016.

https://www.facebook.com/Nelo-Dancers-1529508740604385/, letzter Zugriff am 6.1.2016. 
https://www.youtube.com/watch?v=-FJ_dxJ-3iY, letzter Zugriff am 8.1.2016.

https://www.youtube.com/watch?v=CV2s4ZzfOfg, letzter Zugriff am 8.1.2016.

https://www.youtube.com/watch?v=Tj5ciY4Njic, letzter Zugriff am 17.7.2014. 


\begin{tabular}{|c|c|c|c|c|c|}
\hline Inv.Nr. & Abb. & Erwerb & Sammler & Anmerkung & Maße \\
\hline \multicolumn{6}{|c|}{ Rautenstrauch-Joest-Museum } \\
\hline 3949 & & 1897 & Wilhelm Joest & & $\begin{array}{l}\text { L: } 279 \\
\mathrm{~cm}, \\
\text { B: } 20 \mathrm{~cm}\end{array}$ \\
\hline 3957 & & & Wilhelm Joest & $\begin{array}{l}\text { Grundsätzlich verfügt der Schurz wie alle lepanesa über vier bzw. } \\
\text { drei Reihen mit Mustern aus eingezogenem schwarzen Bananenbast } \\
\text { und eingewobenen Pflanzenfasern. Dieser Schurz enthält jedoch } \\
\text { keine eingearbeiteten Pandanusstreifen (vgl. etwa RJM 3949), statt- } \\
\text { dessen längere Büschel mit weiteren Pflanzenfasern. In dieser Mach- } \\
\text { art gleicht er den Objekten RJM } 3982 \text { und British Museum Oc1906,- } \\
\text {.51.Wie bei Objekt RJM } 3982 \text { besteht das Muster am unteren Ende } \\
\text { aus einer Reihe geometrischer Figuren, wie sie auf keinem anderen } \\
\text { Schurz zu finden sind. Auch bei Koch (1971) ist diese Darstellung } \\
\text { nicht aufgeführt. }\end{array}$ & $\begin{array}{l}\text { L: } 310 \\
\mathrm{~cm}, \\
\text { B: } 22 \mathrm{~cm}\end{array}$ \\
\hline
\end{tabular}




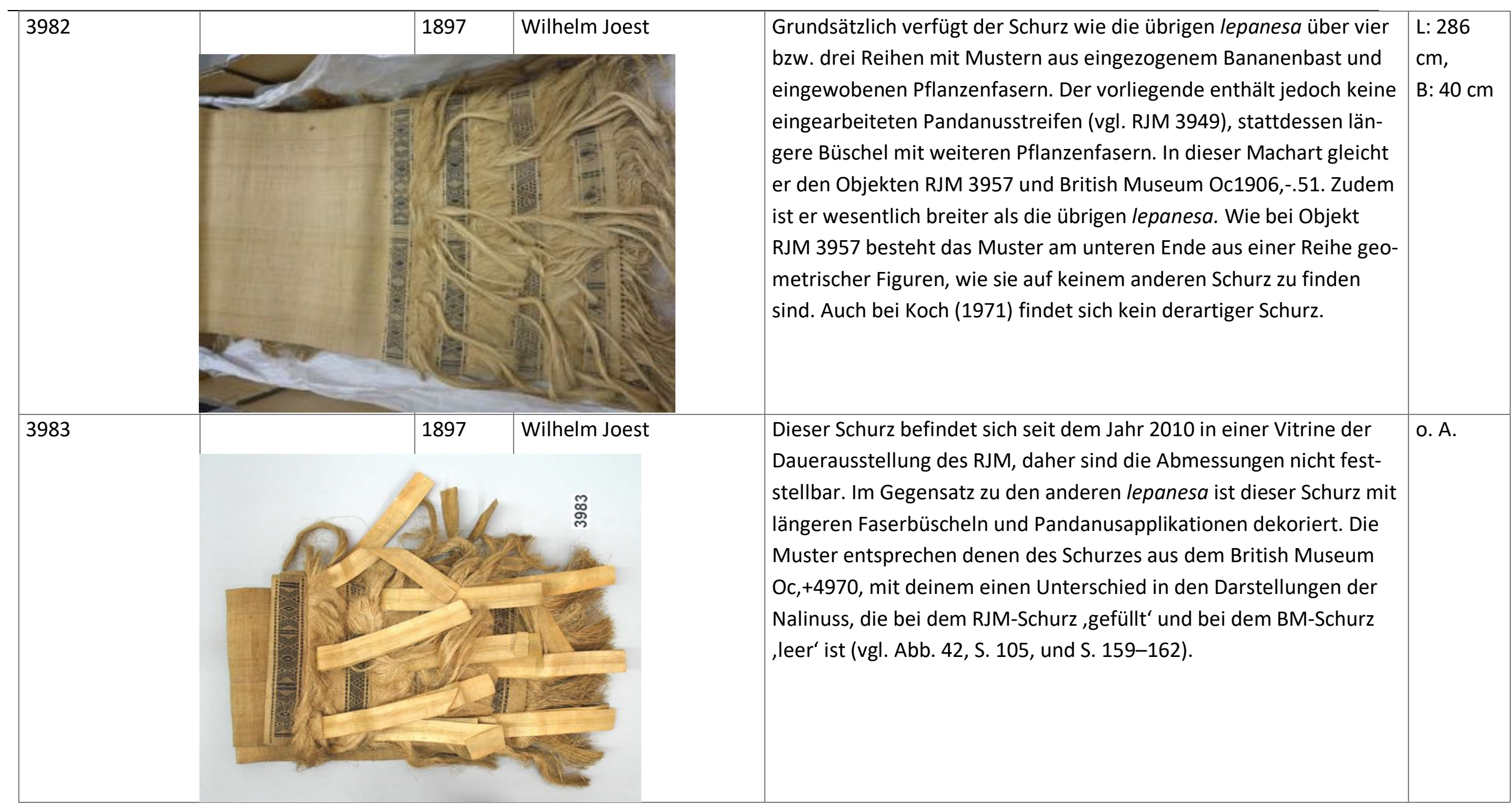




\begin{tabular}{|c|c|c|c|c|c|}
\hline$\underline{\text { Inv.Nr. }}$ & $\underline{A b b}$. & Erwerb & $\underline{\text { Sammler }}$ & Anmerkung & Maße \\
\hline \multicolumn{6}{|c|}{ The British Museum } \\
\hline Oc, +4970 & & 1891 & Alan Lister-Kaye & $\begin{array}{l}\text { "Christy collection registration slip description, written in } 1891 \text { ?: } \\
\text { Santa Cruz, grass cloth band, with bands of pattern in black at the } \\
\text { two ends, fringes and leaf tabs. Mat, man's dress; Oc1891C2.4970 } \\
\text { (old CDMS no.)." (Vgl. S. } 82 \text { und Abb. 43, S. 105) }\end{array}$ & o. A. \\
\hline Oc, $+4965 b$ & o. A. & 1891 & Alan Lister-Kaye & "Unfinished textile, woven; Oc1891C2.4965b (old CDMS no.).“ & o. A. \\
\hline Oc, $+4966 b$ & o. A. & 1891 & Alan Lister-Kaye & „Unfinished textile, woven; Oc1891C2.4966b (old CDMS no.).“ & o. A. \\
\hline
\end{tabular}




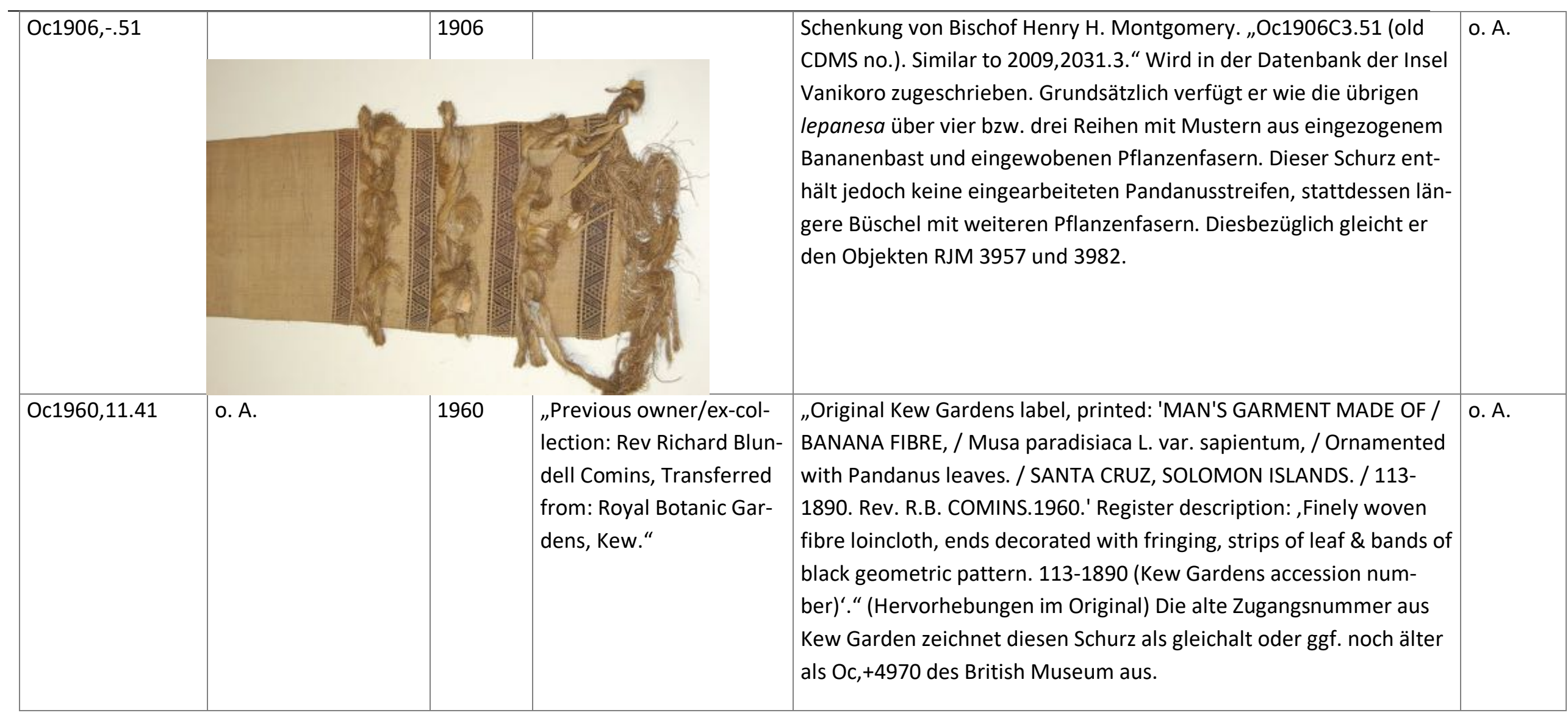




\begin{tabular}{|c|c|c|c|c|c|}
\hline $2009,2031.3$ & o. A. & 2009 & Elizabeth Bonshek & $\begin{array}{l}\text { „Apron or loin cloth (lapanesa) made of black banana fibre (birpiba), } \\
\text { banana leaf and pandanus fibre. One continious piece of woven fi- } \\
\text { bre, at each end is a panel that is decorated. The design of the two } \\
\text { end panels is three sections of horizontal black banana fibre in rows } \\
\text { that form triangular and diamond shapes, followed by a row of plain } \\
\text { fibre tassles (dirlap). The tassles are followed by three sections of } \\
\text { two flat ribbons of leaf, which is follwed by three more plain fibre } \\
\text { tassles. It comes rolled up with a wooden pole and a piece of fibre } \\
\text { for rolling. Information from Elizabeth Bonshek 2009: This is a nelo } \\
\text { apron, worn by men during the nelo dance. It is made on a back } \\
\text { strap loom. Selwyn Balu, his son Walter Kola and Selwyn's brother } \\
\text { David Yanepia are the only known surviving male weavers who know } \\
\text { how to make this type of apron. This piece was commissioned in by } \\
\text { Liz Bonshek in November 2009, Research Fellow of the Melanesia } \\
\text { Project (2005-2010). This fieldwork trip was carried out as part of } \\
\text { the project, funded by the Arts and Humanities Research Council, a } \\
\text { collaboration between the British Museum and the Museum of Ar- } \\
\text { chaeology and Anthropology in Cambridge." (Hervorhebungen im } \\
\text { Original) }\end{array}$ & $\begin{array}{l}\text { L: } 222 \\
\mathrm{~cm}, \\
\text { B: } 26 \mathrm{~cm}\end{array}$ \\
\hline
\end{tabular}




\begin{tabular}{|c|c|c|c|c|c|}
\hline Inv.Nr. & Abb. & Erwerb & $\underline{\text { Sammler }}$ & Anmerkung & Maße \\
\hline \multicolumn{6}{|c|}{ Museum of New Zealand Te Papa Tongarewa } \\
\hline FE000811 & & 1913 & Gift of Alexander Turnbull & $\begin{array}{l}\text { "Cloth, textile." Verfügt wie RJM } 3957 \text { und } 3982 \text { sowie BM Oc1906,- } \\
.51 \text { über keine Pandanusapplikationen. }\end{array}$ & o. A. \\
\hline FE005055 & o. A. & o. A. & & $\begin{array}{l}\text { "Banana fibre. Six bands of black and natural design. Fringed and } \\
\text { decorated with tufts - decorative at ends. Woven. 1.3.1968.“ ", ha- } \\
\text { ven't managed to locate it yet but will search in the new year." } \\
\text { (pers. Kommentar Grace Hutton, 23.12.15) }\end{array}$ & o. A. \\
\hline FE005741 & o. A. & o. A. & & $\begin{array}{l}\text { "Loincloth. Banana fibre, black fibre designs. Fringes at ends. Fibre } \\
\text { and leaf tassels, 1.11.1970.“ }\end{array}$ & o. A. \\
\hline FE005742 & o. A. & o. A. & & $\begin{array}{l}\text { "Loincloth. Banana fibre, black fibre designs. Fringes at ends. Fibre } \\
\text { and leaf tassels, 1.11.1970.“ }\end{array}$ & o. A. \\
\hline FE005743 & o. A. & o. A. & & $\begin{array}{l}\text { "Loincloth. Banana fibre, black fibre designs. Fringes at ends. Fibre } \\
\text { and leaf tassels, 1.11.1970.“ }\end{array}$ & o. A. \\
\hline FE005746 & liegt vor & o. A. & & Kein lepanesa. & $\begin{array}{l}\text { L: } 108, \\
\text { B: } 22 \mathrm{~cm}\end{array}$ \\
\hline
\end{tabular}




\begin{tabular}{|c|c|c|c|c|}
\hline FE005747 & o. A. & o. A. & $\begin{array}{l}\text { "Loom woven long and narrow mat, made of banana fibre, incorpo- } \\
\text { rates a black fibre to form a geometric design on both ends. One end } \\
\text { has two black designs and two layers of fringes while the other end } \\
\text { has four stripes of black designs and four layers of fringes. Fringes at } \\
\text { ends. Fibre and leaf, 1.11.1970.“ ",l haven't managed to locate it yet } \\
\text { but will search in the new year.“ (pers. Kommentar Grace Hutton, } \\
\text { 23.12.15) }\end{array}$ & $\begin{array}{l}\text { L: } 280, \\
\text { B: } 22 \mathrm{~cm}\end{array}$ \\
\hline FE005748 & o. A. & o. A. & $\begin{array}{l}\text { „Loincloth. Banana fibre, black fibre designs. Fringes at ends. Fibre } \\
\text { and leaf tassels, 1.11.1970.“ }\end{array}$ & o. A. \\
\hline FE005758 & o. A. & o. A. & "Loincloth." & $\begin{array}{l}\text { L: } 218, \\
\text { B: } 74 \mathrm{~cm}\end{array}$ \\
\hline FE005761 & o. A. & o. A. & „Loincloth.“ & $\begin{array}{l}\text { L: } 133, \\
\text { B: } 37 \mathrm{~cm}\end{array}$ \\
\hline FE005764 & o. A. & o. A. & „Loincloth large loom woven textile.“ & $\begin{array}{l}\text { L: } 145, \\
\text { B: } 60 \mathrm{~cm}\end{array}$ \\
\hline FE005765 & o. A. & o. A. & Kein Dekor, „Weaving in progress, 1.11.1970.“ & $\begin{array}{l}\text { L: } 240, \\
\text { B: } 21 \mathrm{~cm}\end{array}$ \\
\hline FE005772 & o. A. & o. A. & $\begin{array}{l}\text { "They are loom weaving in progress i.e. not completed yet." (pers. } \\
\text { Kommentar Grace Hutton, 23.12.15) "Neich note reads Durrad } \\
\text { Coll?" }\end{array}$ & L: $53 \mathrm{~cm}$ \\
\hline FE005773 & o. A. & o. A. & $\begin{array}{l}\text { „They are loom weaving in progress i.e. not completed yet.“ (pers. } \\
\text { Kommentar Grace Hutton, 23.12.15) }\end{array}$ & o. A. \\
\hline
\end{tabular}




\begin{tabular}{|c|c|c|c|c|c|}
\hline$\underline{\text { Inv.Nr. }}$ & $\underline{A b b}$. & Erwerb & Sammler & Anmerkung & Maße \\
\hline \multicolumn{6}{|c|}{ Auckland War Memorial Museum Tāmaki Paenga Hira } \\
\hline 17444 & & 1932 & $\begin{array}{l}\text { Captain Hector MacQuar- } \\
\text { rie }\end{array}$ & „Band woven on loom.“ & $\begin{array}{l}\text { L: } 240, \\
\text { cm, } \\
\text { B: } 17 \mathrm{~cm}\end{array}$ \\
\hline 56242 & & 2004 & $\begin{array}{l}\text { Mrs A F Kramer-Walter } \\
\text { (Te Puke), Melanesian } \\
\text { Mission }\end{array}$ & $\begin{array}{l}\text { „Napanesa. Fine loom weaving. Warp fibres left to form fringe at } \\
\text { both ends. One end has two bands of black decorative elements, the } \\
\text { other has four." }\end{array}$ & $\begin{array}{l}\text { L: } 276 \\
\mathrm{~cm}, \\
\text { B: } 22 \mathrm{~cm}\end{array}$ \\
\hline
\end{tabular}




\begin{tabular}{|c|c|c|c|c|c|}
\hline Inv.Nr. & Abb. & Erwerb & $\underline{\text { Sammler }}$ & Anmerkung & Maße \\
\hline \multicolumn{6}{|c|}{ Rautenstrauch-Joest-Museum } \\
\hline 30562 & $\frac{\vec{N}}{\sqrt{2}} \frac{1}{\sqrt{2}}$ & 1914 & Felix Speiser & $\begin{array}{l}\text { „Schmuckstück (Nasenschmuck) aus Perlmutter mit europ. Perlen } \\
\text { rot, weiß grün verziert.“ Die beiden Stege rechts und links sind abge- } \\
\text { brochen und fehlen. Auf der Inventarkarte ist das nelo noch kom- } \\
\text { plett abgebildet (vgl. Abb. 38). }\end{array}$ & o. A. \\
\hline \multicolumn{6}{|c|}{ The British Museum } \\
\hline Oc1944,02.1234 & & 1944 & $\begin{array}{l}\text { „Purchased by Harry } \\
\text { Beasley from Rev. H Nind } \\
\text { of the Melanesian Mis- } \\
\text { sion in 1924. Biography } \\
\text { Rev. Hubert S. Nind: } \\
\text { Born 1877, joined the } \\
\text { Melanesian Mission } \\
\text { 1899, ordained in the An- } \\
\text { glican church 1906. Post- } \\
\text { ings with the Melanesian } \\
\text { Mission included: } \\
\text { Santa Cruz 1900-1907“ }\end{array}$ & $\begin{array}{l}\text { "1497 (Beasley catalogue). Beasley register reads: Santa Cruz. N. } \\
\text { Hebrides: - A facial ornament, worn at certain dances before the } \\
\text { nose and mouth, being attached by the fine strip passing behind the } \\
\text { ears....... Collected on Santa Cruz by the Rev. Herbert J. Nind \& pur- } \\
\text { chased of him. Blurton, 1997. Rectangular openwork plaques made } \\
\text { of pearl shell functioned as nose ornaments, ,nelo', in Santa Cruz, } \\
\text { the southeasternmost group of islands in the Solomon archipelago. } \\
\text { They were the most highly valued of all ornaments there and were } \\
\text { worn by men during ceremonial dance known as nelo. Exhibited: } \\
199713 \text { Oct-1998 } 5 \text { Jan, India, New Delhi, National Museum, The En- } \\
\text { during Image; } 19989 \text { Feb-3 May, India, Mumbai, Sir Caswasjee Ja- } \\
\text { hangir Hall, The Enduring Image." }\end{array}$ & $\begin{array}{l}11 \mathrm{~cm} \\
\text { breit }\end{array}$ \\
\hline \multicolumn{6}{|c|}{ Museum of New Zealand Te Papa Tongarewa } \\
\hline FE001281 & o. A. & 1916 & & „Nose ornament, purchased from Bethunes. Not able to locate." & o. A. \\
\hline
\end{tabular}




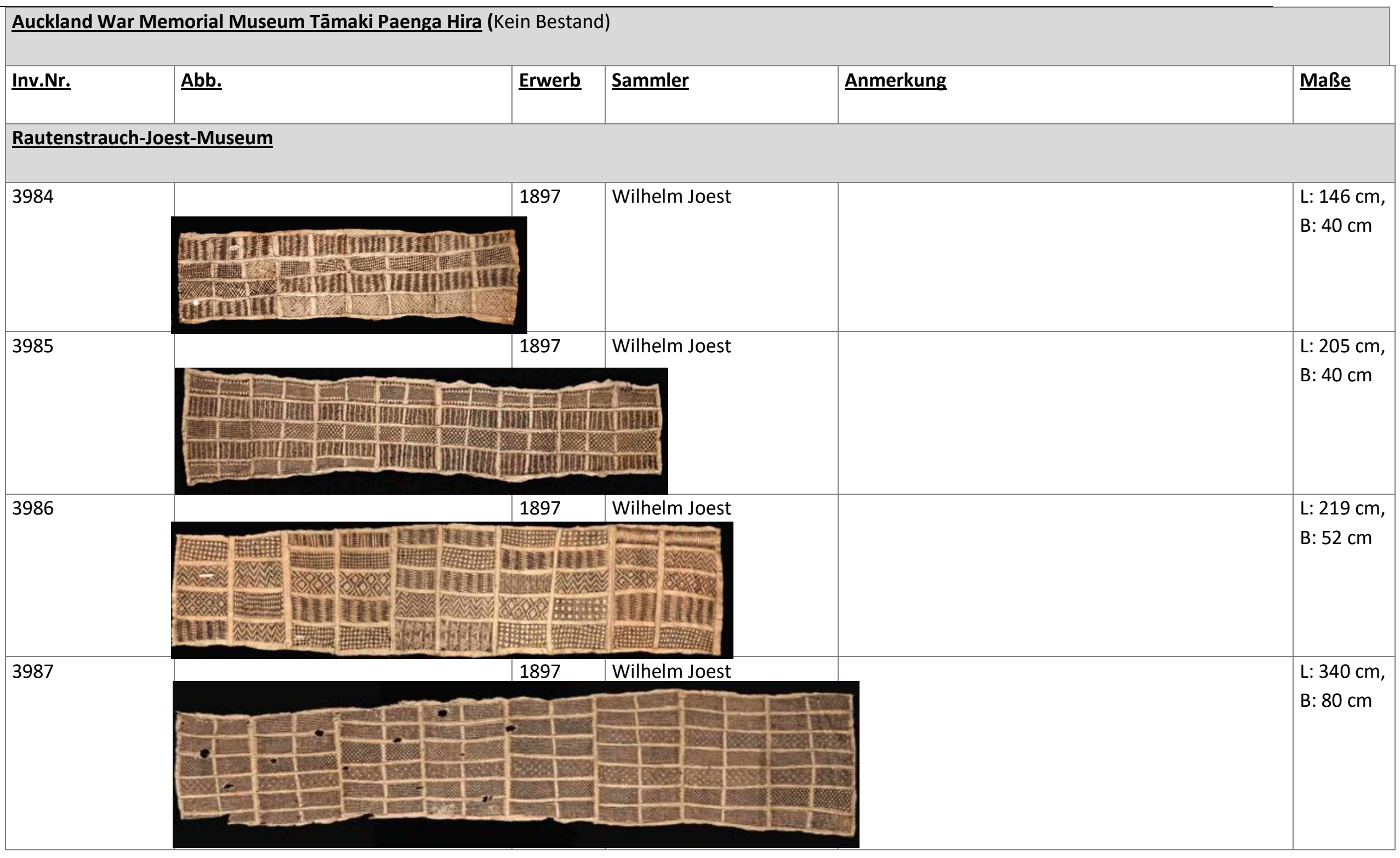




\begin{tabular}{|c|c|c|c|c|}
\hline 4094 & 1897 & Wilhelm Joest & nicht bemalt & o. A. \\
\hline 4095 & 1897 & Wilhelm Joest & nicht bemalt & o. A. \\
\hline 30583 & 1911 & Felix Speiser & Santa Cruz, Solomon Islands, ca. 1910 & $\begin{array}{l}\text { L: } 131 \mathrm{~cm} \text {, } \\
\text { B: } 42 \mathrm{~cm}\end{array}$ \\
\hline 64823 & 2011 & Oliver Lueb & $\begin{array}{l}\text { Abe, Matthias Me'lekaiva; Nea, Santa Cruz, Solo- } \\
\text { mon Islands, 2011. Diese Kopfbedeckung wurde im } \\
\text { August desselben Jahres von Duddley Dopue auf ei- } \\
\text { nem Tanzfest in Ne'ele Village, Graciosa Bay, Santa } \\
\text { Cruz getragen (vgl. Abb. 59, S. 115). }\end{array}$ & $\begin{array}{l}\mathrm{H}: 45 \mathrm{~cm}, \\
28 \mathrm{~cm} \\
\text { Durchm. }\end{array}$ \\
\hline
\end{tabular}




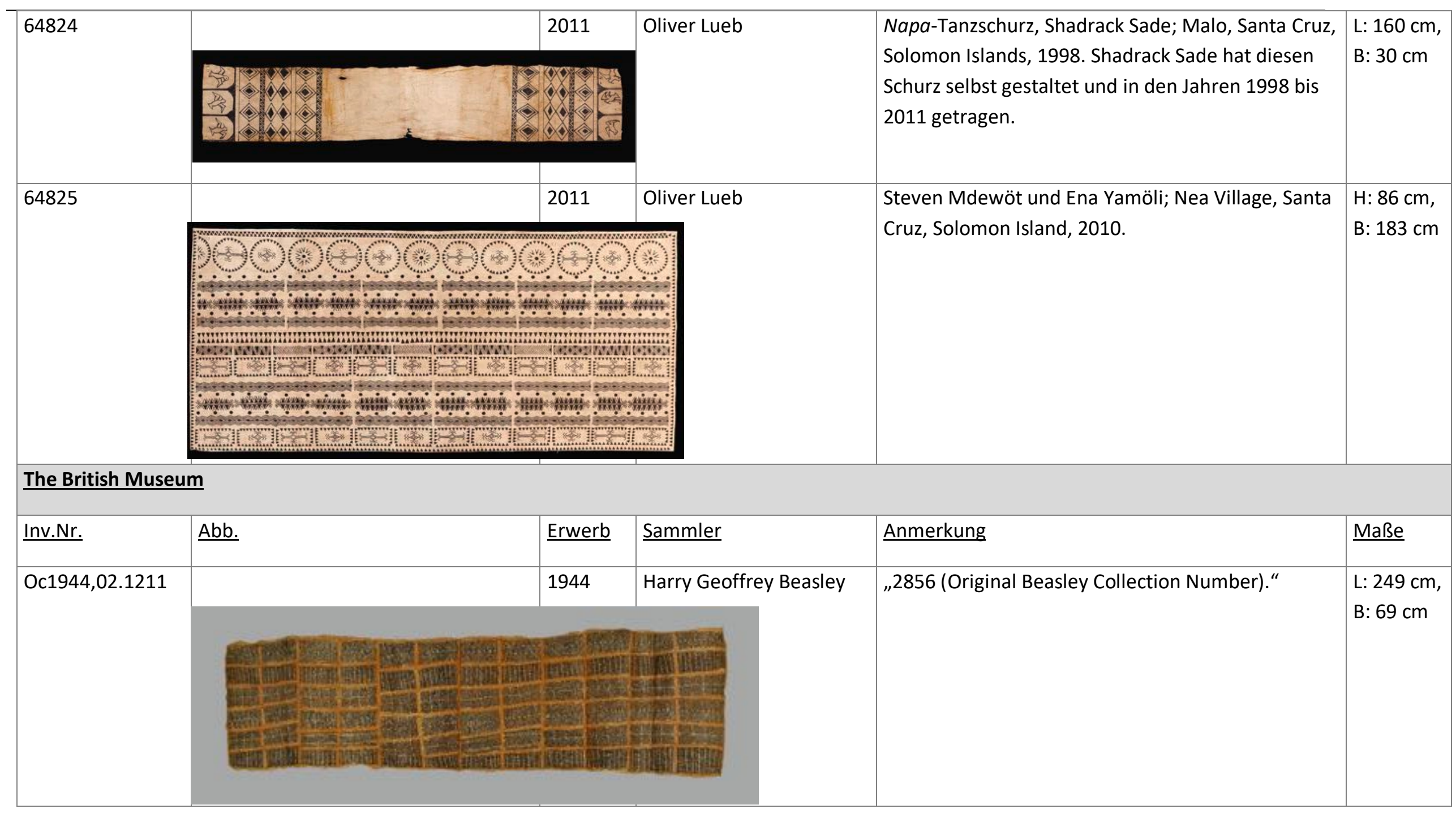




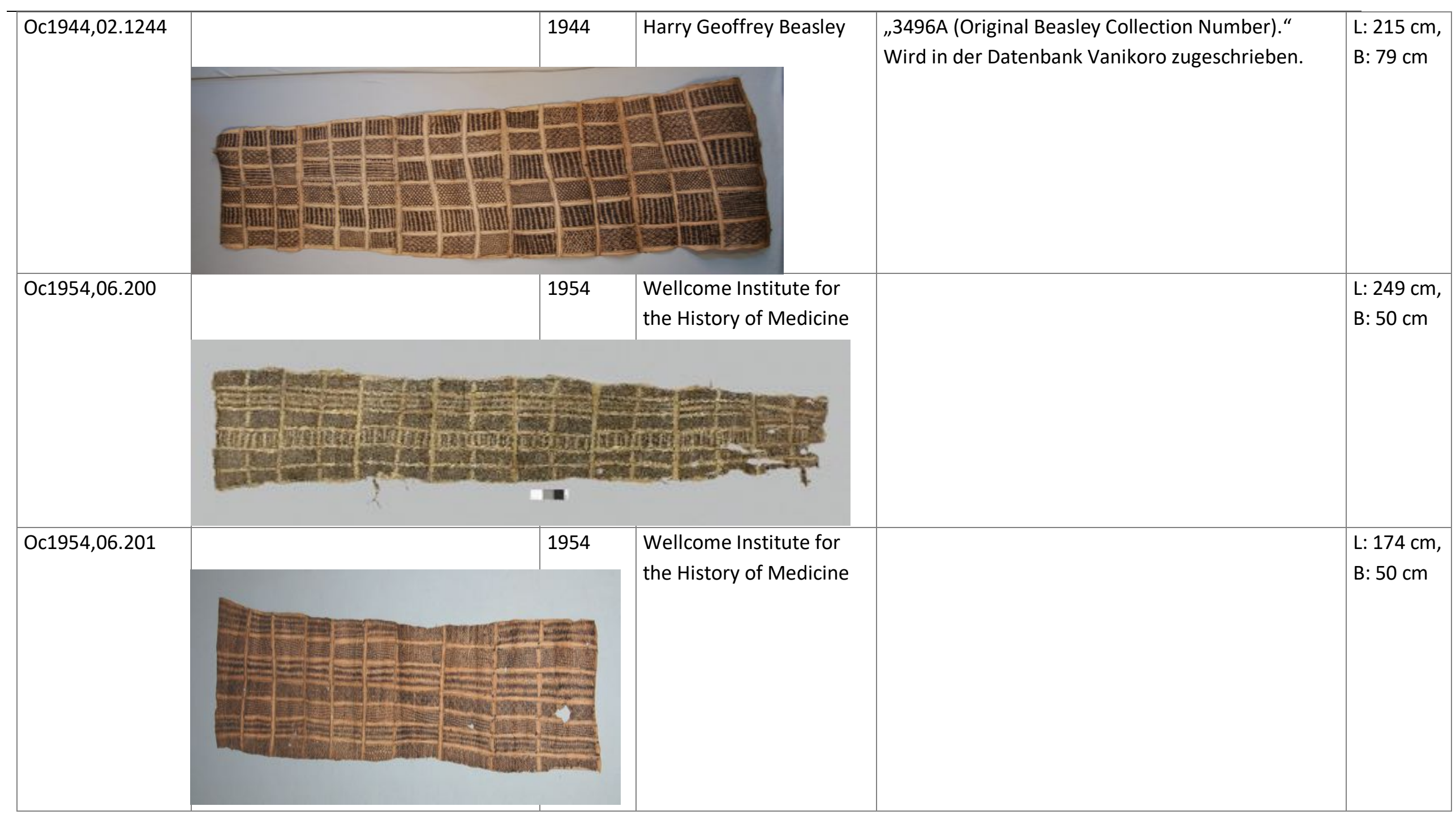




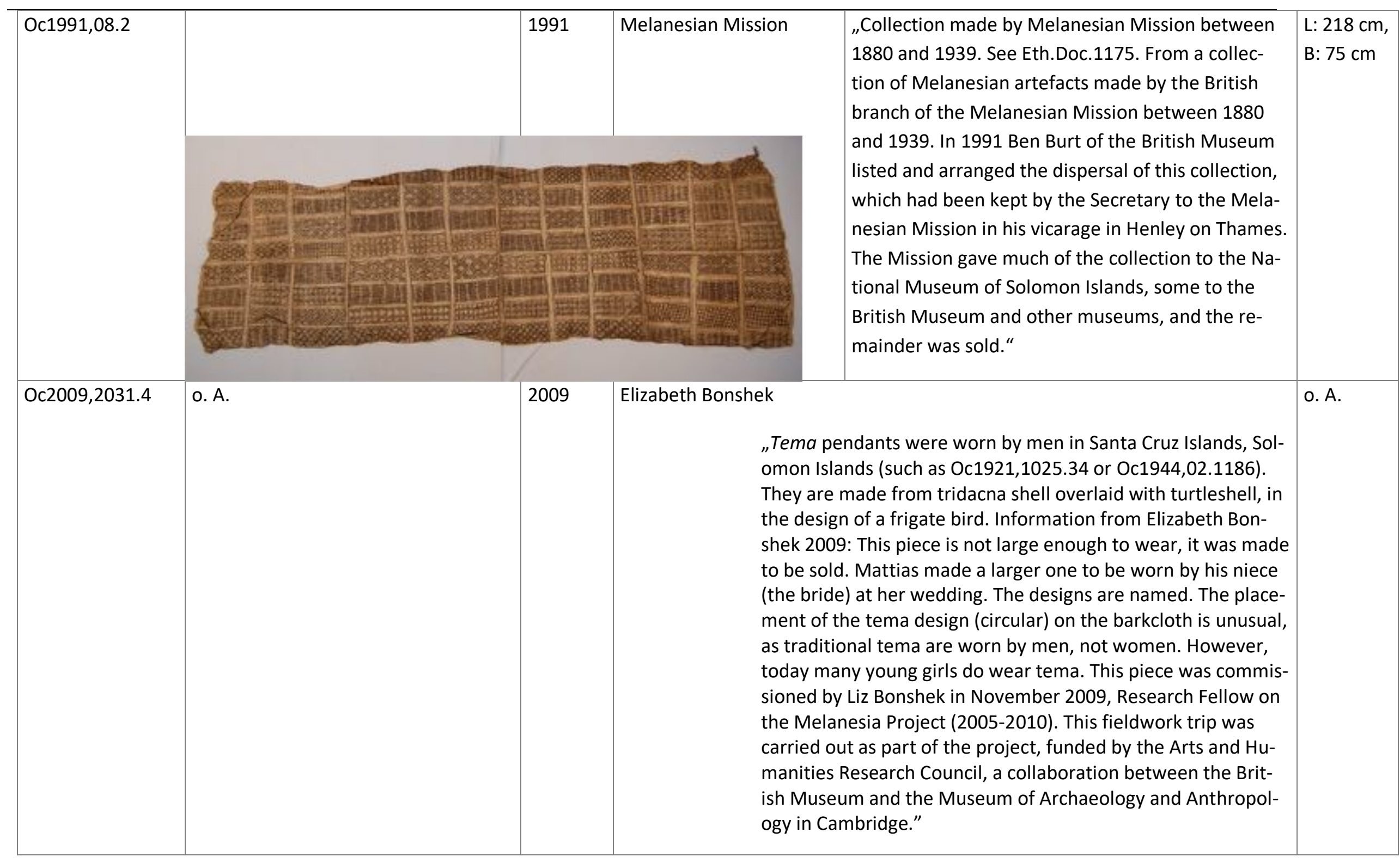




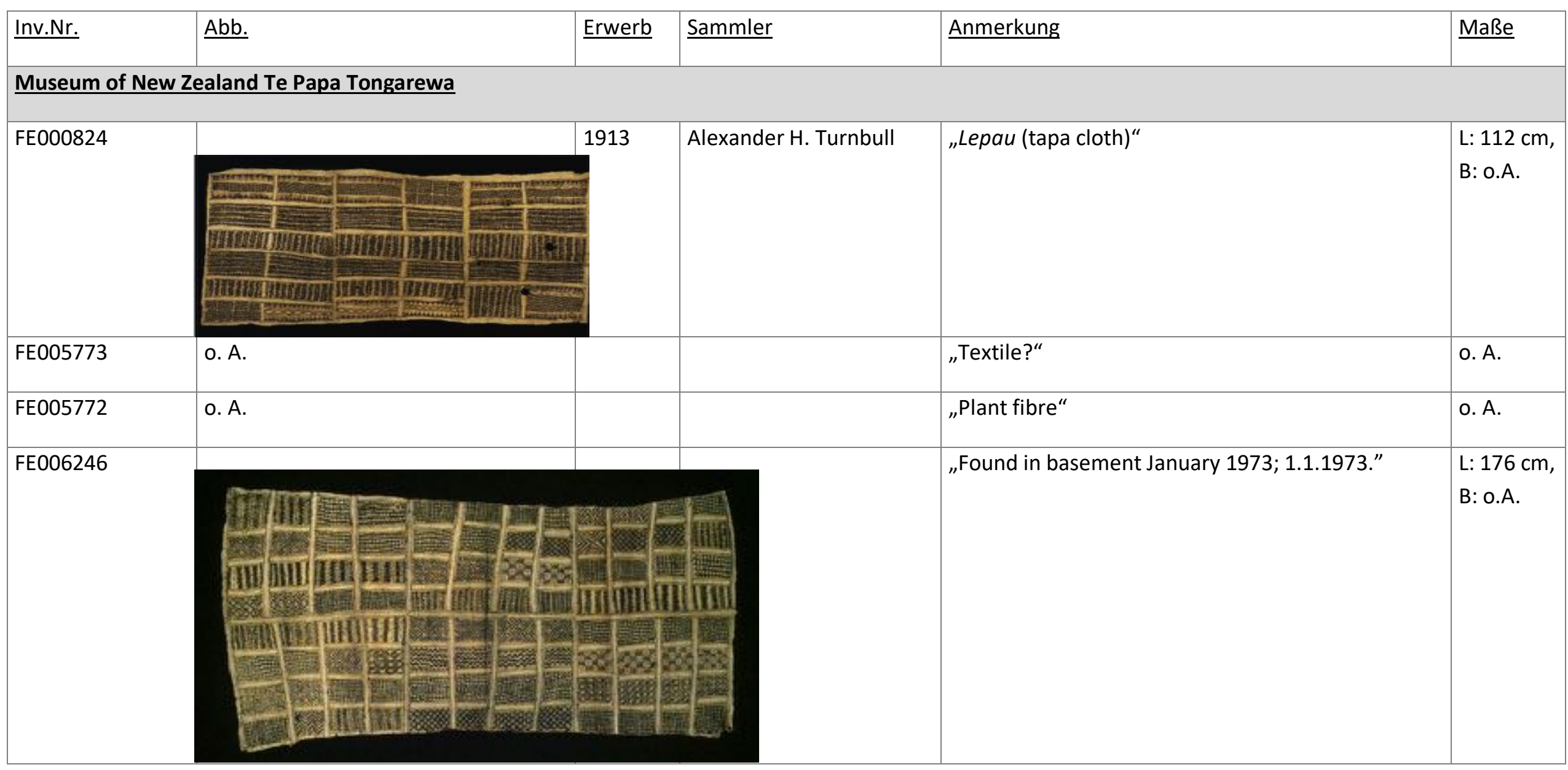




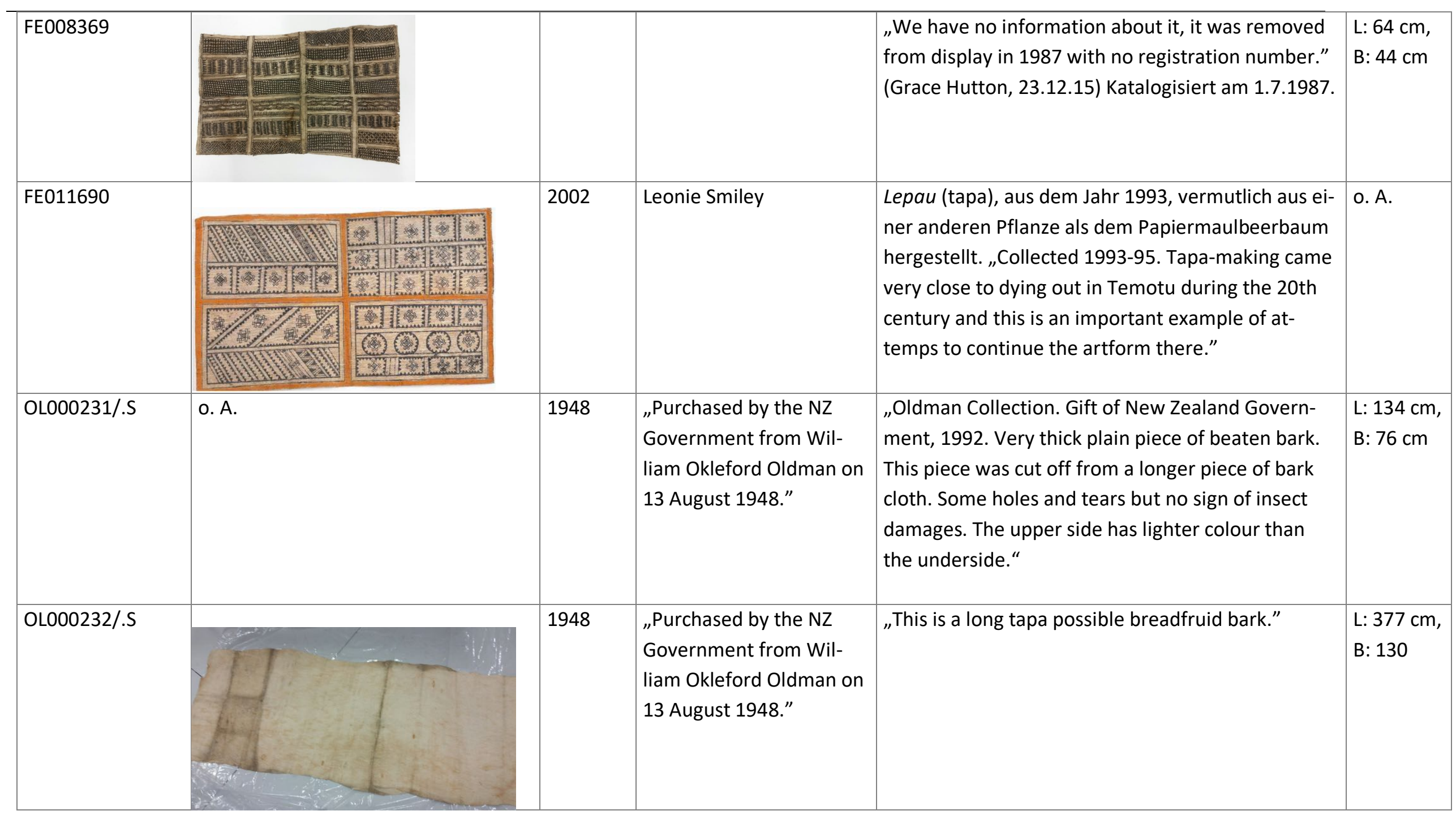




\begin{tabular}{|c|c|c|c|c|c|}
\hline OL002254 & o. A. & 1948 & $\begin{array}{l}\text { „Purchased by the NZ } \\
\text { Government from Wil- } \\
\text { liam Okleford Oldman on } \\
13 \text { August 1948.” }\end{array}$ & $\begin{array}{l}\text { „A thick, stiff, plain piece of tapa. It is a small piece } \\
\text { cut off from a bigger tapa cloth. Another small } \\
\text { piece was cutt off at one end measured } 170 \mathrm{~mm}(\mathrm{I}) \\
\text { x } 90 \mathrm{~mm}(\mathrm{w}) \text {. An attached sticker lable says, Reef } \\
\text { Is."“ }\end{array}$ & o. A. \\
\hline OL002270 & 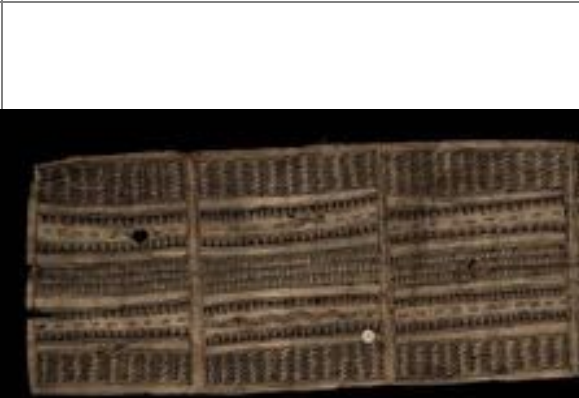 & 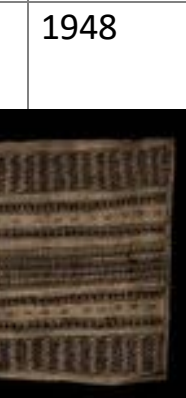 & $\begin{array}{l}\text { "Purchased by the NZ } \\
\text { Government from Wil- } \\
\text { liam Okleford Oldman on } \\
13 \text { August 1948." }\end{array}$ & $\begin{array}{l}\text { "A small rectanguar tapa with intricate geometrical } \\
\text { black designs. It has four panels. It looks very old } \\
\text { and thin." }\end{array}$ & $\begin{array}{l}\mathrm{L}: 129 \mathrm{~cm}, \\
\text { B: } 43 \mathrm{~cm}\end{array}$ \\
\hline$\underline{\text { Inv.Nr. }}$ & $\underline{A b b}$. & Erwerb & $\underline{\text { Sammler }}$ & Anmerkung & Maße \\
\hline \multicolumn{6}{|c|}{ Auckland War Memorial Museum Tāmaki Paenga Hira } \\
\hline 9603.21924 .113 & & 1924 & Dr. A. C. Purchas & „Piece of barkcloth, undecorated.“ & $\begin{array}{l}\text { L: } 207 \mathrm{~cm} \text {, } \\
\text { B: } 54 \mathrm{~cm}\end{array}$ \\
\hline
\end{tabular}




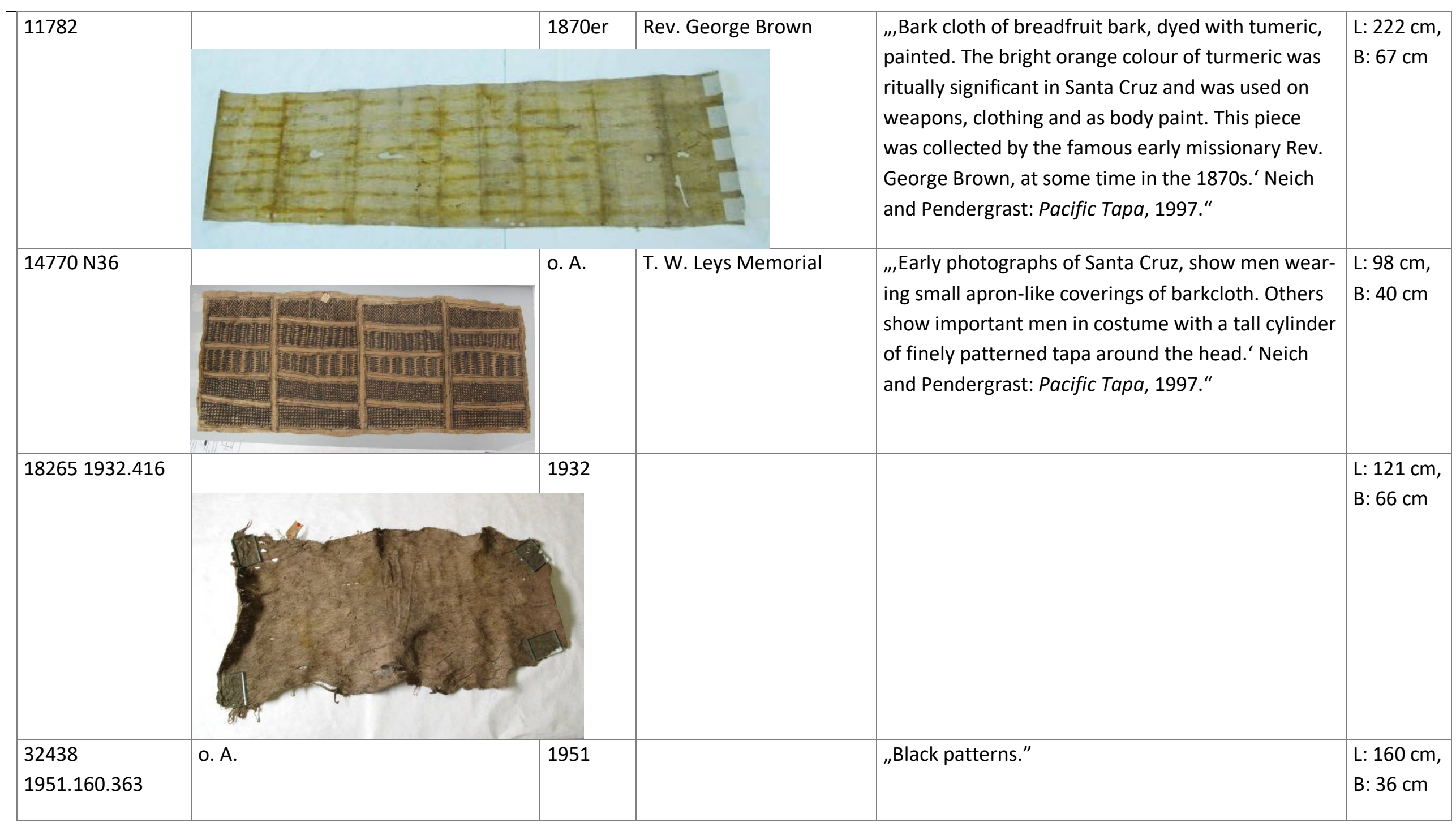




\begin{tabular}{|c|c|c|c|c|c|}
\hline 329421952.93 .17 & 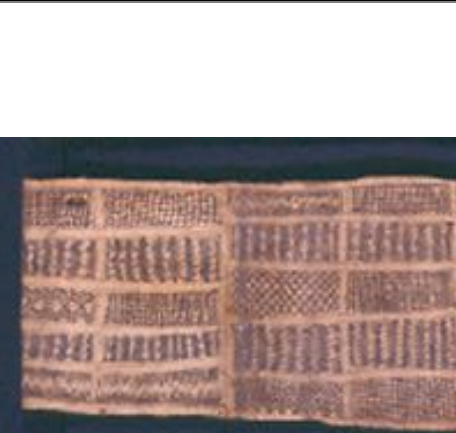 & andition & 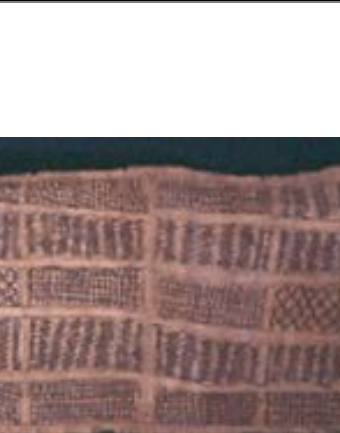 & $\begin{array}{l}\text { "'Santa Cruz tapa is divided into rectangles which } \\
\text { are decorated with fine black hatching. Old photo- } \\
\text { graphs show these cloths being worn as a cylindri- } \\
\text { cal head-dress by important men. Tapa was also } \\
\text { worn as a male breechclout, but for this purpose it } \\
\text { was usually left undecorated.' Neich and Pender- } \\
\text { grast: Pacific Tapa, 1997." }\end{array}$ & $\begin{array}{l}\text { L: } 292 \mathrm{~cm} \text {, } \\
\text { B: } 48 \mathrm{~cm}\end{array}$ \\
\hline 335041953.44 .26 & IIUIII & 1953 & & $\begin{array}{l}\text { ",The tree used in the manufacture of tapa in Santa } \\
\text { Cruz is Antiaris toxicaria, known locally in the area } \\
\text { around Graciosa Bay as nokali. By the late 1980s a } \\
\text { few pieces were reaching the commercial market in } \\
\text { Honiara, the capital of the Solomons, and are still } \\
\text { being produced today, but only intermittently.' } \\
\text { Neich and Pendergrast: Pacific Tapa, 1997." }\end{array}$ & $\begin{array}{l}\text { L: } 61 \mathrm{~cm}, \\
\text { B: } 35 \mathrm{~cm}\end{array}$ \\
\hline 336361953.95 .1 & & 1953 & $\begin{array}{l}\text { Mr F. Harvey-Wright } \\
\text { (Raglan) }\end{array}$ & „Tapa-decorated with design in panels." & $\begin{array}{l}\text { L: } 88 \mathrm{~cm}, \\
\text { B: } 38 \mathrm{~cm}\end{array}$ \\
\hline 490911981.56 & o. A. & 1981 & & o. A. & $\begin{array}{l}15 \mathrm{~cm}, 25 \\
\mathrm{~cm}\end{array}$ \\
\hline
\end{tabular}




\begin{tabular}{|c|c|c|c|c|c|}
\hline $5512719,96.48 .1$ & 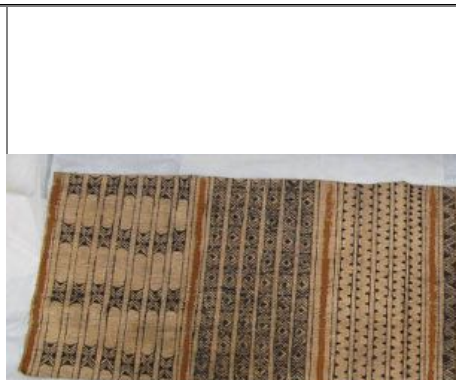 & 1996 & Pendergrast & $\begin{array}{l}\text { ",'Closely patterned with bands of black pattern. } \\
\text { Seven bands of turmeric. The Santa Cruz group con- } \\
\text { sists of a small number of islands including Ndende, } \\
\text { the central and largest islands. Ndende is one of } \\
\text { the few areas in the Pacific where both weaving } \\
\text { and tapa manufacture were practised.' Neich and } \\
\text { Pendergrast: Pacific Tapa, 1997.“ }\end{array}$ & $\begin{array}{l}\mathrm{L}: 85 \mathrm{~cm}, \\
\text { B: } 26 \mathrm{~cm}\end{array}$ \\
\hline 551281996.48 .2 & (4) & 1996 & Pendergrast & $\begin{array}{l}\text { „,'Bands of black pattern. Three bands and border } \\
\text { of turmeric. Tapa had not been made in Santa Cruz } \\
\text { since about the 1930s until the early 1970s, when a } \\
\text { few school teachers were experimenting with its } \\
\text { production in the hope of introducing the craft into } \\
\text { school art programmes which were starved for art } \\
\text { materials.' Neich and Pendergrast: Pacific Tapa, } \\
\text { 1997.“ }\end{array}$ & $\begin{array}{l}\text { L: } 25 \mathrm{~cm}, \\
\text { B: } 8 \mathrm{~cm}\end{array}$ \\
\hline 551301996.48 .4 & 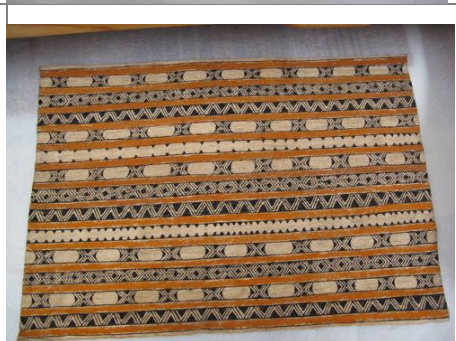 & 1996 & Pendergrast & $\begin{array}{l}\text { „,'Bands of black patterning separated by bands of } \\
\text { turmeric. Early photographs show men wearing } \\
\text { small apron-like coverings of barkcloth. Others } \\
\text { show important men in costume with a tall cylinder } \\
\text { of finely patterned tapa around the head. 'Neich } \\
\text { and Pendergrast: Pacific Tapa, 1997." }\end{array}$ & o. A. \\
\hline 560512003.76 .4 & & 2003 & & $\begin{array}{l}\text { "Surface drawn up into grid of ten rows of four } \\
\text { boxes, each hand patterned in black with geometric } \\
\text { patterning." }\end{array}$ & $\begin{array}{l}\text { L: } 159 \mathrm{~cm} \text {, } \\
\text { B: } 48 \mathrm{~cm}\end{array}$ \\
\hline
\end{tabular}




\begin{tabular}{|c|c|c|c|c|c|}
\hline Inv.Nr. & Abb. & Erwerb & $\underline{\text { Sammler }}$ & Anmerkung & Maße \\
\hline \multicolumn{6}{|c|}{ Rautenstrauch-Joest-Museum } \\
\hline 4372 & & 1897 & Wilhelm Joest & & D: $14 \mathrm{~cm}$ \\
\hline 4373 & & 1897 & Wilhelm Joest & & D: $13 \mathrm{~cm}$ \\
\hline 51551 & & 1988 & Volker Schneider & $\begin{array}{l}\text { Dr. Volker Schneider, Heidelberg, Naturwissenschaftler, unterhielt in } \\
\text { den 1980er-Jahren eine Schmetterlingsfarm in Papua-Neuguinea. } \\
\text { Während der Zeit bereiste er mehrfach Melanesien, so auch die Sa- } \\
\text { lomonen und erwarb zahlreiche Artefakte. Volker Schneider teilte } \\
\text { am } 26.08 .2014 \text { mit, dass er nicht persönlich auf Santa Cruz gewesen } \\
\text { war und nicht mehr sagen konnte, wo er das tema erworben hatte. } \\
\text { Die Gestaltung ähnelt der von tema } 53221 \text { vom Auckland Memorial } \\
\text { Museum, das zurselben Zeit in das Museum gelangte wie dieses } \\
\text { Stück. (Vgl. Abb. } 32 \text { und 33, S. 96) }\end{array}$ & D: $18 \mathrm{~cm}$ \\
\hline 4374 & o. A. & 1897 & Wilhelm Joest & $\begin{array}{l}\text { "Getauscht mit Rijks Ethnographisch Museum, Leiden, (22.10.1913 } \\
(1913 / 26) . “\end{array}$ & o. A. \\
\hline
\end{tabular}




\begin{tabular}{|c|c|c|c|c|c|}
\hline 4375 & o. A. & 1897 & Wilhelm Joest & $\begin{array}{l}\text { „Getauscht mit Städtisches Völker-Museum, Frankfurt a.M., } \\
\text { 01.08.1937 (1937/06).“ }\end{array}$ & o. A. \\
\hline 4376 & o. A. & 1897 & Wilhelm Joest & „Getauscht mit Zürich.“ & o. A. \\
\hline 6679 & o. A. & 1897 & Wilhelm Joest & $\begin{array}{l}\text { "Getauscht mit dem Deutschen Kolonial- und Überseemuseum Bre- } \\
\text { men, 24.09.1937 (1937/09-10).“ }\end{array}$ & o. A. \\
\hline
\end{tabular}

\begin{tabular}{|c|c|c|c|c|c|}
\hline Inv.Nr. & Abb. & Erwerb & Sammler & Anmerkung & Maße \\
\hline \multicolumn{6}{|c|}{ The British Museum } \\
\hline Oc.6376 & o. A. & 1870 & Julius Lucius Brenchley & $\begin{array}{l}\text { "Shell-disk of tridacna with central hole and suspension cord } \\
\text { resembling a Santa Cruz tema. Register slip reads: } \\
\text { Large discoidal Neck Ornament / From San Cristoval, Sept. } 1865 . \\
\text { "Santa Cruz' has been added in another hand, and the shell disk does } \\
\text { indeed resemble a Santa Cruz tema pendant. From a collection of } \\
\text { more than 1,000 artefacts made by Julius Brenchley in } 1865 \text { on a } \\
\text { cruise of HMS Curacoa in Solomon Islands, which was divided among } \\
\text { Maidstone Museum, the British Museum, the Pitt Rivers Museum } \\
\text { and Exeter Museum. Register slip reads: Presd. by Julius L. Brenchley } \\
\text { Esq 24.3.1870 (M.)” }\end{array}$ & D: $20 \mathrm{~cm}$ \\
\hline Oc. 7622 & & 1872 & $\begin{array}{l}\text { „Collected by: Rev. Dr } \\
\text { Robert Henry Codrington; } \\
\text { Donated by: William } \\
\text { Henry Blackmore." }\end{array}$ & $\begin{array}{l}\text { "Oc1872C0202.5, Oc1872C1.7622 (old CDMS no.). Rev. R. H. Cod- } \\
\text { rington was affiliated with the Melanesian Mission." }\end{array}$ & o. A. \\
\hline
\end{tabular}




\begin{tabular}{|c|c|c|c|c|}
\hline Oc, +5665 & 1891 & $\begin{array}{l}\text { „Donated by: Sir Augus- } \\
\text { tus Wollaston Franks; } \\
\text { Previous owner/ex-col- } \\
\text { lection: Government of } \\
\text { Victoria." }\end{array}$ & $\begin{array}{l}\text { "See Christy Correspondence (File V); ,Ethnographic Collection for Sir } \\
\text { John Lubbock' (from the Government of Victoria). There are two } \\
\text { copies of the list which gives further information about the objects. } \\
\text { One of these is annotated to show how the collection was divided } \\
\text { between the BM (+5586-5677), J. Edge Partington and the Natural } \\
\text { History Museum. Christy collection registration slip description, writ- } \\
\text { ten in } 1891 \text { ?: Santa Cruz Group, Breast ornament formed of a circu- } \\
\text { lar disc of tridacna shell, pierced near the centre from which a cord } \\
\text { proceeds to the edge \& is attached to a rope for suspension. } 101 \\
\text {,Breast plate of shell New Ireland'; Oc1891C2.5665 (old CDMS no.)." }\end{array}$ & \\
\hline Oc1910,1106.7 & 1910 & $\begin{array}{l}\text { „Collected by: Guildhall } \\
\text { Museum; Donated by: } \\
\text { City of London Library } \\
\text { Committee.” }\end{array}$ & $\begin{array}{l}\text { "Original data entry reads, New Guinea'. However, object label has } \\
\text { 'New Guinea' crossed out, and replaced with ,Melanesia, Santa } \\
\text { Cruz'." }\end{array}$ & o. A. \\
\hline Oc1913,1115.45 & 1913 & Louis-Joseph Bouge & „Breast ornament made of tridacna shell.” & o. A. \\
\hline Oc1913,1115.46 & 1913 & Louis-Joseph Bouge & „Breast ornament made of tridacna shell, turtle-shell, fibre cord.” & o. A. \\
\hline
\end{tabular}




\begin{tabular}{|c|c|c|c|c|}
\hline Oc1921,1025.34 & 1921 & Col. F. H. Ward & $\begin{array}{l}\text { „Neck ornament, tema disk of tridacna shell overlaid with a frigate- } \\
\text { bird motif of turtleshell. Tema is a characteristic neck-pendant of } \\
\text { Santa Cruz, worn by senior men (not a kapkap, as commonly de- } \\
\text { scribed) (See G. Koch } 1971 \text { Materielle Kultur der Santa Cruz-Inseln } \\
\text { pp114-115).” }\end{array}$ & o. A. \\
\hline Oc1929,0304.6 & 1929 & $\begin{array}{l}\text { „Donated by: William } \\
\text { Hesketh Lever, 1st Vis- } \\
\text { count Leverhulme.” }\end{array}$ & $\begin{array}{l}\text { „Breast ornament made of tridacna shell, tortoise-shell. Acquisition } \\
\text { name: Donated by William Hesketh Lever, 1st Viscount Leverhulme.” }\end{array}$ & o. A. \\
\hline Oc1944,02.1183 & 1944 & Harry Geoffrey Beasley & $\begin{array}{l}\text { „From a collection made by Rev. Nind of the Melanesian Mission in } \\
1901 \text { which he sold to Harry Beasley in 1924, } 2400 \text { (Beasley cata- } \\
\text { logue). Tema is a characteristic neck-pendant of Santa Cruz, worn by } \\
\text { senior men (not a kapkap, as commonly described) (See G. Koch } \\
1971 \text { Materielle Kultur der Santa Cruz-Inseln pp114-115).” }\end{array}$ & o. A. \\
\hline Oc1944,02.1184 & 1944 & Harry Geoffrey Beasley & $\begin{array}{l}\text { „From a collection made by Rev. Nind of the Melanesian Mission in } \\
1901 \text { which he sold to Harry Beasley in 1924, } 2401 \text { (Beasley cata- } \\
\text { logue). Tema is a characteristic neck-pendant of Santa Cruz, worn by } \\
\text { senior men (not a kapkap, as commonly described) (See G. Koch } \\
1971 \text { Materielle Kultur der Santa Cruz-Inseln pp114-115).” }\end{array}$ & o. A. \\
\hline
\end{tabular}




\begin{tabular}{|c|c|c|c|c|c|}
\hline Oc1944,02.1185 & o. A. & 1944 & Harry Geoffrey Beasley & $\begin{array}{l}\text { „From a collection made by Rev. Nind of the Melanesian Mission in } \\
1901 \text { which he sold to Harry Beasley in 1924, } 3225 \text { (Beasley cata- } \\
\text { logue). Tema is a characteristic neck-pendant of Santa Cruz, worn by } \\
\text { senior men (not a kapkap, as commonly described) (See G. Koch } \\
1971 \text { Materielle Kultur der Santa Cruz-Inseln pp114-115).” }\end{array}$ & o. A. \\
\hline Oc1944,02.1186 & & 1944 & Harry Geoffrey Beasley & $\begin{array}{l}\text { „From a collection made by Rev. Nind of the Melanesian Mission in } \\
1901 \text { which he sold to Harry Beasley in 1924, } 4792 \text { (Beasley cata- } \\
\text { logue).” }\end{array}$ & D: $13 \mathrm{~cm}$ \\
\hline Oc1944,02.1187 & o. A. & 1944 & Harry Geoffrey Beasley & $\begin{array}{l}\text { "Tema pendant: a disk of tridacna shell overlaid with a frigate-bird } \\
\text { motif of turtleshell. From a collection made by Rev. Nind of the } \\
\text { Melanesian Mission in } 1901 \text { which he sold to Harry Beasley in 1924, } \\
1120 \text { (Beasley catalogue)." }\end{array}$ & D: $13 \mathrm{~cm}$ \\
\hline Oc1944,02.1189 & & 1944 & Harry Geoffrey Beasley & $\begin{array}{l}\text { „From a collection made by Rev. Nind of the Melanesian Mission in } \\
1901 \text { which he sold to Harry Beasley in 1924, } 1501 \text { (Beasley cata- } \\
\text { logue).” }\end{array}$ & D: $11 \mathrm{~cm}$ \\
\hline
\end{tabular}




\begin{tabular}{|c|c|c|c|c|c|}
\hline Oc1944,02.1190 & o. A. & 1944 & Harry Geoffrey Beasley & $\begin{array}{l}\text { "Tema pendant: a disk of tridacna shell overlaid with a motif of } \\
\text { turtleshell. From a collection made by Rev. Nind of the Melanesian } \\
\text { Mission in } 1901 \text { which he sold to Harry Beasley in 1924, } 2432 \\
\text { (Beasley catalogue)." }\end{array}$ & D: $5 \mathrm{~cm}$ \\
\hline Oc1944,02.1191 & & 1944 & Harry Geoffrey Beasley & $\begin{array}{l}\text { „From a collection made by Rev. Nind of the Melanesian Mission in } \\
1901 \text { which he sold to Harry Beasley in 1924, } 4332 \text { (Beasley cata- } \\
\text { logue).” }\end{array}$ & o. A. \\
\hline Oc1944,02.1192 & & 1944 & Harry Geoffrey Beasley & $\begin{array}{l}\text { „From a collection made by Rev. Nind of the Melanesian Mission in } \\
1901 \text { which he sold to Harry Beasley in 1924, } 619 \text { (Beasley cata- } \\
\text { logue).” }\end{array}$ & o. A. \\
\hline Oc1944,02.1193 & & 1944 & Harry Geoffrey Beasley & $\begin{array}{l}\text { „From a collection made by Rev. Nind of the Melanesian Mission in } \\
1901 \text { which he sold to Harry Beasley in 1924, } 764 \text { (Beasley cata- } \\
\text { logue).” }\end{array}$ & o. A. \\
\hline
\end{tabular}




\begin{tabular}{|c|c|c|c|c|c|}
\hline Inv.Nr. & $\underline{A b b}$. & Erwerb & Sammler & Anmerkung & Maße \\
\hline \multicolumn{6}{|c|}{ Museum of New Zealand Te Papa Tongarewa } \\
\hline FE000734 & & 1913 & Alexander H. Turnbull & $\begin{array}{l}\text { Circa 1870, Santa Cruz Islands. Geschenk v. Alexander Turnbull, } \\
\text { 1913. Gesammelt von M. Huggins auf der MV Southern Cross als } \\
\text { Agent von Turnbull. }\end{array}$ & $\begin{array}{l}\text { H: } 18,5 \\
\mathrm{~cm} \\
\text { B: } 17,5 \\
\mathrm{~cm}\end{array}$ \\
\hline FE000735 & o. A. & 1913 & Alexander H. Turnbull & Geschenk v. Alexander Turnbull, 1913. & o. A. \\
\hline FE001249 & & 1916 & & $\begin{array}{l}\text { "A thin circular shell disc with a hole in the centre. [The] cord ap- } \\
\text { pears to be twisted sennit wound five times through the hole and } \\
\text { around the circumference of the disc. There is a lenght of cord at- } \\
\text { tached to the shell. Purchased from Bethunes." }\end{array}$ & D: $22 \mathrm{~cm}$ \\
\hline FE001227 & & 1916 & & „Purchased from Bethunes for $2 / 6 . "$ & $\begin{array}{l}\text { D: } 34 \mathrm{~cm} \\
\text { [???, OL] }\end{array}$ \\
\hline FE001275 & o. A. & 1916 & & „Ornament, shell." & o. A. \\
\hline
\end{tabular}




\begin{tabular}{|c|c|c|c|c|}
\hline FE001276 & & 1916 & „Tema (Breast Ornament)." & o. A. \\
\hline FE001279 & o. A. & 1916 & „Ornament, shell.“ & o. A. \\
\hline FE001281 & o. A. & 1916 & „Purchased from Bethunes.” & o. A. \\
\hline FE001442 & & o. A. & „Tema (Breast Ornament)." & o. A. \\
\hline FE001919 & & o. A. & „Tema (Breast Ornament).“ & o. A. \\
\hline
\end{tabular}




\begin{tabular}{|c|c|c|c|}
\hline FE003829 & 1943 & „Tema (Breast Ornament)." & o. A. \\
\hline FE003830 & 1943 & „Tema (Breast Ornament).” & o. A. \\
\hline FE003831 & o. A. & „Tema (Breast Ornament)." & o. A. \\
\hline FE003834 & o. A. & „Tema (Breast Ornament)." & o. A. \\
\hline
\end{tabular}




\begin{tabular}{|c|c|c|c|}
\hline FE006575 & o. A. & $\begin{array}{l}\text { "Gift of Tairawhiti Museum, Te Whare Taonga Tairawhiti 1975, } \\
\text { 1.11.1975." }\end{array}$ & o. A. \\
\hline FE006576 & o. A. & $\begin{array}{l}\text { "A thin circular shell disc with a hole in the centre. [The] cord ap- } \\
\text { pears to be twisted sennit wound twice through the hole and around } \\
\text { the circumference of the disc. There is a short length of cord at- } \\
\text { tached to the shell. Gift of Tairawhiti Museum, Te Whare Taonga } \\
\text { Tairawhiti 1975, 1.11.1975." }\end{array}$ & D: $19 \mathrm{~cm}$ \\
\hline FE006682 & o. A. & $\begin{array}{l}\text { "This is a flat circular clam shell disc with a turtle shell fretwork over- } \\
\text { lay secured to the clam shell through the top and the centre of the } \\
\text { turtle shell. The cord extending from the clam shell and the cord } \\
\text { around the turtle shell appear to be thinly twisted sennit, } \\
\text { 1.11.1975." }\end{array}$ & D: $8 \mathrm{~cm}$ \\
\hline FE007579 & o. A. & „Tema (Breast Ornament)." & o. A. \\
\hline
\end{tabular}




\begin{tabular}{|c|c|c|c|c|c|}
\hline$\underline{\text { Inv.Nr. }}$ & Abb. & Erwerb & $\underline{\text { Sammler }}$ & Anmerkung & Maße \\
\hline \multicolumn{6}{|c|}{ Auckland War Memorial Museum Tāmaki Paenga Hira } \\
\hline 1901 & & 1928 & Reverend Jasper Calder & $\begin{array}{l}\text { "Breast ornament; clam shell disc with turtle shell fish and bird motif } \\
\text { attached by rolled firbe cord. Written in pencil on the back of the or- } \\
\text { nament is ,Rev'd Arthur Hopkins Menetela. Nan Brian Menetela. } \\
\text { Santa Cruz'." }\end{array}$ & o. A. \\
\hline 3652 & & 1929 & Mrs Porter & „Disc pendant." & D: $20 \mathrm{~cm}$ \\
\hline 3873; N.50 & & o. A. & $\begin{array}{l}\text { T. W. Leys Memorial Col- } \\
\text { lection: J. Edge Parting- } \\
\text { ton }\end{array}$ & „Clam shell breast ornament.” & D: $11 \mathrm{~cm}$ \\
\hline
\end{tabular}




\begin{tabular}{|c|c|c|c|c|}
\hline 4319 & 1929 & Mrs Frank Quayle & $\begin{array}{l}\text { „Chest ornament; clam shell disc, cut turtle shell, fibre suspension } \\
\text { cord." }\end{array}$ & D: $11 \mathrm{~cm}$ \\
\hline 7309 & 1925 & Dr Marsack & $\begin{array}{l}\text { "Chest ornament; Tridacna shell disc with turtle shell bird and fish } \\
\text { motif section attached by rolled fibre cord." }\end{array}$ & D: $10 \mathrm{~cm}$ \\
\hline 7317 & 1925 & $\begin{array}{l}\text { Sir Frank Mappin (Auck- } \\
\text { land) }\end{array}$ & $\begin{array}{l}\text { „Breast ornament; Tridacna shell disc, turtle shell fish and bird motif } \\
\text { fretwork attached, shell currency discs, two small white cowrie } \\
\text { shells and blue glass beads threaded on the rolled fibre suspension } \\
\text { cord; worn by high ranking men; ,Coll: by Capt Bongard'.” }\end{array}$ & D: $15 \mathrm{~cm}$ \\
\hline 7318 & 1925 & $\begin{array}{l}\text { Sir Frank Mappin (Auck- } \\
\text { land) }\end{array}$ & $\begin{array}{l}\text { „Tridacna and turtle shell breast ornament collected in Santa Cruz, } \\
\text { Solomons Islands, by Captain James Bongard, SS Southern Cross, } \\
\text { Melanesian Mission [1871-1896].” }\end{array}$ & D: $18 \mathrm{~cm}$ \\
\hline
\end{tabular}




\begin{tabular}{|c|c|c|c|c|}
\hline 7319 & 1925 & $\begin{array}{l}\text { Sir Frank Mappin (Auck- } \\
\text { land) }\end{array}$ & „Breast ornament; Tridacna and turtle shell; ,Coll: by Capt Bon'.” & D: $14 \mathrm{~cm}$ \\
\hline 9011 & 1921 & $\begin{array}{l}\text { Mr George Graham } \\
\text { (Auckland) }\end{array}$ & $\begin{array}{l}\text { „Breast ornament; Tridacna clam shell disc; turtle shell bird and fish } \\
\text { motif overlay; portion of rolled fibre cord still attached." }\end{array}$ & D: $13 \mathrm{~cm}$ \\
\hline 9028 & 1918 & Archdeacon Comins & $\begin{array}{l}\text { „Breast ornament; Tridacna clam shell disc; turtle shell bird and fish } \\
\text { motif overlay; portion of rolled fibre cord still attached.” }\end{array}$ & D: $19 \mathrm{~cm}$ \\
\hline 10130 & 1926 & Miss White & $\begin{array}{l}\text { „Breast ornament; Tridacna clam shell disc; turtle shell bird and fish } \\
\text { motif overlay; portion of rolled fibre cord still attached." }\end{array}$ & D: $11 \mathrm{~cm}$ \\
\hline
\end{tabular}




\begin{tabular}{|c|c|c|c|c|c|}
\hline 12266 & & o. A. & Sigvard Jacob Dannefaerd & $\begin{array}{l}\text { "Breast ornament. cut and ground from Tridacna shell. Tortoise shell } \\
\text { overlay has fish and bird motifs, some of the finer pierced fretwork } \\
\text { segments have broken away." }\end{array}$ & D: $16 \mathrm{~cm}$ \\
\hline 14754; N46 & & o. A. & $\begin{array}{l}\text { T. W. Leys Memorial Col- } \\
\text { lection: J. Edge Parting- } \\
\text { ton }\end{array}$ & „Chest ornament; clam shell disc on suspension cord." & o. A. \\
\hline 14755; N47 & & o. A. & $\begin{array}{l}\text { T. W. Leys Memorial Col- } \\
\text { lection: J. Edge Parting- } \\
\text { ton }\end{array}$ & „Chest ornament; clam shell disc on suspension cord." & o. A. \\
\hline 14755a; N47a & o. A. & o. A. & $\begin{array}{l}\text { T. W. Leys Memorial Col- } \\
\text { lection: J. Edge Parting- } \\
\text { ton }\end{array}$ & "Chest ornament; clam shell disc on suspension cord." & o. A. \\
\hline 14756; N54 & & o. A. & $\begin{array}{l}\text { T. W. Leys Memorial Col- } \\
\text { lection: J. Edge Parting- } \\
\text { ton }\end{array}$ & $\begin{array}{l}\text { "Chest ornament; Tridacna clam shell disc with turtle shell overlay; } \\
\text { white shell beads are incoporated into the plaited fibre suspension } \\
\text { cord." }\end{array}$ & D: $11 \mathrm{~cm}$ \\
\hline
\end{tabular}




\begin{tabular}{|c|c|c|c|c|c|}
\hline 14757; N55 & o. A. & o. A. & $\begin{array}{l}\text { T. W. Leys Memorial Col- } \\
\text { lection: J. Edge Parting- } \\
\text { ton }\end{array}$ & „Chest ornament; Clam shell disc with turtle shell front." & o. A. \\
\hline 18131 & & 1932 & $\begin{array}{l}\text { Miss E Burgess, Mrs J. } \\
\text { Ford Wilson }\end{array}$ & „Breast ornament of clam shell, turtle shell and fibre cord.” & D: $13 \mathrm{~cm}$ \\
\hline 18565 & & 1932 & A. T. Pycroft (Auckland) & „Breast ornament of clam shell, turtle shell, fibre cord." & D: $15 \mathrm{~cm}$ \\
\hline 19469.1 & & 1933 & Mr O. E. Nielson & $\begin{array}{l}\text { „Breast ornament made of Tridacna clam shell, turtle shell overlay, } \\
\text { rolled fibre cord attached.” }\end{array}$ & D: $10 \mathrm{~cm}$ \\
\hline
\end{tabular}




\begin{tabular}{|c|c|c|c|c|}
\hline 19469.2 & 1933 & Mr O. E. Nielson & $\begin{array}{l}\text { „Breast ornament made of Tridacna clam shell, with turtle shell bird } \\
\text { and fish motif overlay, rolled fibre cord attached." }\end{array}$ & D: $11 \mathrm{~cm}$ \\
\hline 19469.3 & 1933 & Mr O. E. Nielson & $\begin{array}{l}\text { „Breast ornament made of Tridacna clam shell disc, with turtle shell } \\
\text { bird and fish motif overlay, rolled fribe cord.” }\end{array}$ & D: $16 \mathrm{~cm}$ \\
\hline 20292.1 & 1934 & Mr J. O'Neill (Auckland) & o. A. & D: $15 \mathrm{~cm}$ \\
\hline 20292.2 & 1934 & Mr J. O'Neill (Auckland) & $\begin{array}{l}\text { „Breast ornament; Tridacna clam shell disc, turtle shell bird and fish } \\
\text { motif overlay, length of red fabric as suspension cord.” }\end{array}$ & D: $17 \mathrm{~cm}$ \\
\hline
\end{tabular}




\begin{tabular}{|c|c|c|c|c|}
\hline 24893 & 1930 & W. Cole (Auckland) & $\begin{array}{l}\text { "Chest ornament of Tridacna shell disc with turtle shell overlay. } \\
\text { Remnant of fibre suspension cord still attached." }\end{array}$ & D: $11 \mathrm{~cm}$ \\
\hline 24894.1 & 1930 & W. Cole (Auckland) & „Chest ornament of Tridacna shell; turtle shell overlay missing." & D: $13 \mathrm{~cm}$ \\
\hline 24894.2 & 1930 & W. Cole (Auckland) & „Chest ornament of Tridacna shell; turtle shell overlay missing." & D: $11 \mathrm{~cm}$ \\
\hline 24894.3 & 1930 & W. Cole (Auckland) & „Chest ornament of Tridacna shell; turtle shell overlay missing." & D: $10 \mathrm{~cm}$ \\
\hline
\end{tabular}




\begin{tabular}{|c|c|c|c|c|}
\hline 24894.4 & 1930 & W. Cole (Auckland) & „Chest ornament of Tridacna shell; turtle shell overlay missing." & D: $9 \mathrm{~cm}$ \\
\hline 24894.5 & 1930 & W. Cole (Auckland) & „Chest ornament of Tridacna shell; turtle shell overlay missing." & D: $6 \mathrm{~cm}$ \\
\hline 26073.1 & 1940 & Hickson Family & „Tridacna shell breast ornament.“ & D: $9 \mathrm{~cm}$ \\
\hline 26073.2 & 1940 & Hickson Family & $\begin{array}{l}\text { "Chest ornament of Tridacna shell disc with overlay of turtle shell. } \\
\text { Remnant of fibre suspension cord still attached." }\end{array}$ & D: $6 \mathrm{~cm}$ \\
\hline
\end{tabular}




\begin{tabular}{|c|c|c|c|c|}
\hline 26691 & 1943 & Mr T. Murrell & $\begin{array}{l}\text { „Breast ornament of Tridacna clam shell disc, overlaid with bird and } \\
\text { fish motif in tortoise shell. Rolled fibre suspension cord attached.” }\end{array}$ & D: $9 \mathrm{~cm}$ \\
\hline 26778 & 1940 & Vaile Collection & $\begin{array}{l}\text { „Tridacna shell disc. Hole drilled in centre as for dala type ornament- } \\
\text { but turtle shell frets missing." }\end{array}$ & D: $11 \mathrm{~cm}$ \\
\hline 28127 & 1946 & $\begin{array}{l}\text { Miss Minniw Duder } \\
\text { (North Shore City) }\end{array}$ & $\begin{array}{l}\text { „Clam shell disc ornament attached to bark fibre. Disc perforated in } \\
\text { centre." }\end{array}$ & D: $10 \mathrm{~cm}$ \\
\hline 30986.1 & 1949 & $\begin{array}{l}\text { Mr W. H. O. Johnston } \\
\text { (Ruatoria) }\end{array}$ & $\begin{array}{l}\text { „Breast ornament; Tridacna shell disc; cracked. Portion of turtle shell } \\
\text { overlay missing." }\end{array}$ & D: $13 \mathrm{~cm}$ \\
\hline
\end{tabular}




\begin{tabular}{|c|c|c|c|c|}
\hline 30986.2 & 1949 & $\begin{array}{l}\text { Mr W. H. O. Johnston } \\
\text { (Ruatoria) }\end{array}$ & $\begin{array}{l}\text { "Chest ornament made of Tridacna shell disc with pearl shell fret- } \\
\text { work overlay. Shell currency discs and one blue bead are threaded } \\
\text { onto rolled fibre suspension cord." (Hervorhebung O. L.) }\end{array}$ & D: $13 \mathrm{~cm}$ \\
\hline 30986.3 & 1949 & $\begin{array}{l}\text { Mr W. H. O. Johnston } \\
\text { (Ruatoria) }\end{array}$ & $\begin{array}{l}\text { "Chest ornament, of Tridacna shell disc with turtleshell overlay; } \\
\text { there is a crack to the Tridacna shell." }\end{array}$ & D: $8 \mathrm{~cm}$ \\
\hline 31594 & 1950 & $\begin{array}{l}\text { Department of Internal } \\
\text { Affairs }\end{array}$ & $\begin{array}{l}\text { "Chest orament of Tridacna clam shell disc overlaid with turtle shell } \\
\text { frigate bird and bonito pattern. Portion of fibre suspension cord still } \\
\text { attached; NOT illustrated in 'Polynesian Artifacts'." }\end{array}$ & D: $9 \mathrm{~cm}$ \\
\hline 32281.1 & 1951 & $\begin{array}{l}\text { Reverend C. Palmer } \\
\text { (Manukau Heads) }\end{array}$ & $\begin{array}{l}\text { "Breast ornament; base disc of clam shell; turtle shell frigate bird de- } \\
\text { sign; rolled fibre cord attached." }\end{array}$ & D: $14 \mathrm{~cm}$ \\
\hline
\end{tabular}




\begin{tabular}{|c|c|c|c|c|}
\hline 32281.2 & 1951 & $\begin{array}{l}\text { Reverend C. Palmer } \\
\text { (Manukau Heads) }\end{array}$ & $\begin{array}{l}\text { „Breast ornament - base is disc of clam shell; turtle shell frigate bird } \\
\text { design, shell currency discs attached to fibre suspension cord, pink, } \\
\text { blue and red ,trade beads' attached.” }\end{array}$ & D: $12 \mathrm{~cm}$ \\
\hline 32281.3 & 1951 & $\begin{array}{l}\text { Reverend C. Palmer } \\
\text { (Manukau Heads) }\end{array}$ & $\begin{array}{l}\text { „Breast ornament - base is disc of clam shell; turtle shell frigate bird } \\
\text { design, fibre cord.” }\end{array}$ & D: $17 \mathrm{~cm}$ \\
\hline 32281.4 & 1951 & $\begin{array}{l}\text { Reverend C. Palmer } \\
\text { (Manukau Heads) }\end{array}$ & $\begin{array}{l}\text { „Breast ornament - base is disc of clam shell; turtle shell frigate bird } \\
\text { design, fibre cord.” }\end{array}$ & D: $8 \mathrm{~cm}$ \\
\hline 32282 & 1951 & $\begin{array}{l}\text { Reverend C. Palmer } \\
\text { (Manukau Heads) }\end{array}$ & „Breast ornament.” & D: $8 \mathrm{~cm}$ \\
\hline
\end{tabular}




\begin{tabular}{|c|c|c|c|c|}
\hline 34365 & 1955 & Mrs R. H. Gibbons & "Clam shell disc with fibre." & D: $15 \mathrm{~cm}$ \\
\hline 34366 & 1955 & Mrs R. H. Gibbons & „Breast ornament.“ & D: $14 \mathrm{~cm}$ \\
\hline 34367 & 1955 & Mrs R. H. Gibbons & $\begin{array}{l}\text { "Clam shell breast ornament overlaid with turtle shell which is at- } \\
\text { tached with fibre cord; portion of turtle shell appears to have broken } \\
\text { away." }\end{array}$ & D: $14 \mathrm{~cm}$ \\
\hline
\end{tabular}




\begin{tabular}{|c|c|c|c|c|}
\hline 34368 & 1955 & Mrs R. H. Gibbons & „Clam shell disc with fibre.” & D: $7 \mathrm{~cm}$ \\
\hline 34588 & 1955 & Mrs R. H. Gibbons & „Clam shell disc pendant. Toggle of fish jaw." & D: $5 \mathrm{~cm}$ \\
\hline 36359 & 1961 & Rev Canon Godfrey & $\begin{array}{l}\text { „Breast ornament, Tridacna shell disc, with cut turtle shell } \\
\text { decoration, fibre suspension cord.” }\end{array}$ & D: $11 \mathrm{~cm}$ \\
\hline 45737 & 1972 & $\begin{array}{l}\text { Judge M. Brook (Auck- } \\
\text { land) }\end{array}$ & $\begin{array}{l}\text { "Breast ornament; Tridacna shell disc, tortoiseshell overlay, } \\
\text { fragment of rolled fibre cord attached." }\end{array}$ & D: $8 \mathrm{~cm}$ \\
\hline
\end{tabular}




\begin{tabular}{|c|c|c|c|c|c|}
\hline 49074 & & 1981 & & „Breast ornament, two. Clam shell." & $\begin{array}{l}\text { D: } 8 \mathrm{~cm}, \\
4 \mathrm{~cm}\end{array}$ \\
\hline 52442,122 & o. A. & 1987 & $\begin{array}{l}\text { Melanesian Mission Trust } \\
\text { Board (loan) }\end{array}$ & „Breast plate.“ & o. A. \\
\hline 52513 & & 1987 & & $\begin{array}{l}\text { „Breast ornament, clam shell, turtle shell overlay, fibre suspension } \\
\text { cord.” }\end{array}$ & D: $12 \mathrm{~cm}$ \\
\hline 53221 & & 1989 & $\begin{array}{l}\text { Mr Mariano Kelesi (Gua- } \\
\text { dalcanal) }\end{array}$ & $\begin{array}{l}\text { "Clam shell with turtle shell overlaid; slightly convex clam shell; tur- } \\
\text { tle shell attached with rolled fibre cord." }\end{array}$ & D: $9 \mathrm{~cm}$ \\
\hline
\end{tabular}




\begin{tabular}{|c|c|c|c|c|}
\hline 53638 & 1990 & Mr E. B. Kirk (Auckland) & „Ornament, clamshell disc - collected Santa Cruz." & D: $14 \mathrm{~cm}$ \\
\hline 54063 & 1992 & $\begin{array}{l}\text { Mrs Margaret Stockford } \\
\text { (Waitakere City) }\end{array}$ & $\begin{array}{l}\text { „Breast ornament; Tridacna shell disc with overlaid shape in turtle } \\
\text { shell; shell currency discs on rolled fibre suspension cord; ,Bought } \\
\text { for Mabel at Santa Cruz, this day 13th July, 1869' written on in pen- } \\
\text { cil. Great-grandfather of vendor was Robert Capel Tilly, Captain of } \\
\text { the 'Southern Cross' mission ship. Mabel was his wife's sister." }\end{array}$ & D: $9 \mathrm{~cm}$ \\
\hline 55156 & 1996 & John Cordy Ltd & $\begin{array}{l}\text { „Breast ornament; clam shell disc, bird and fish motif turtle shell } \\
\text { overlay attached. Currency shell discs are threaded onto a double } \\
\text { ply rolled fibre cord which is in turn attached to the thicker rolled fi- } \\
\text { bre suspension cord and the Tridacna shell disc at the other end. } \\
\text { There is a tuft of red fabric attached at the termination of a span of } \\
\text { threaded croix seed halves.” }\end{array}$ & $\mathrm{D}: 11 \mathrm{~cm}$ \\
\hline 56229 & 2004 & $\begin{array}{l}\text { Mrs A. F. Kramer-Walter } \\
\text { (Te Puke) }\end{array}$ & $\begin{array}{l}\text { "Circular clamshell disc, turtle shell fish and bord motif overlay at- } \\
\text { tached by rolled fibre cord, the suspension cord has broken away." }\end{array}$ & D: $12 \mathrm{~cm}$ \\
\hline
\end{tabular}




\begin{tabular}{|l|l|l|l|l|}
\hline 56230 & 2004 & $\begin{array}{l}\text { Mrs A. F. Kramer-Walter } \\
\text { (Te Puke) }\end{array}$ & $\begin{array}{l}\text { "Circular clamshell disc with turtle shell overlay, lower figure right } \\
\text {,leg' proper broken away, rolled fibre cord." }\end{array}$ & \begin{tabular}{l} 
D: $11 \mathrm{~cm}$ \\
\hline 56231
\end{tabular} \\
\hline
\end{tabular}

